\title{
FIRST COURSE IN GENERAL SCIENCE
}
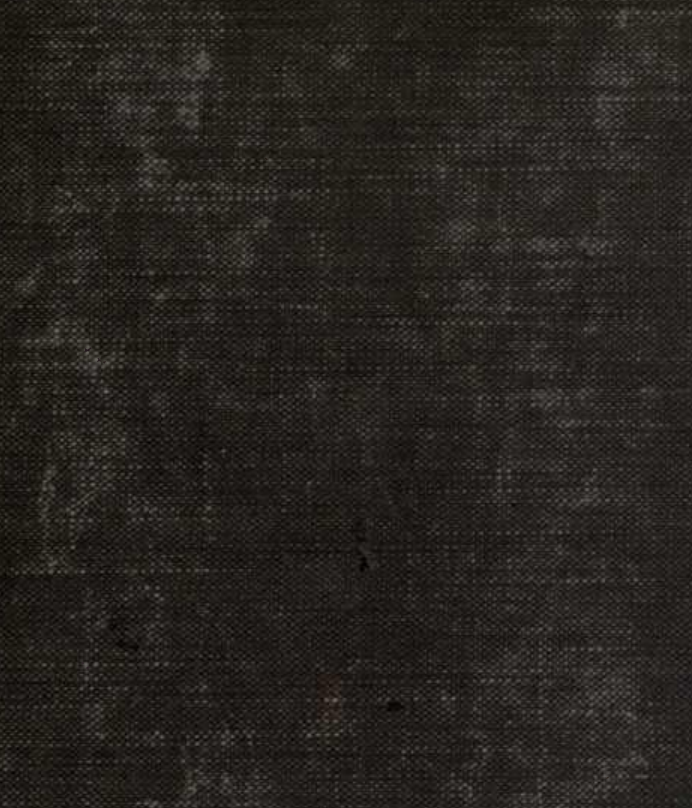

30
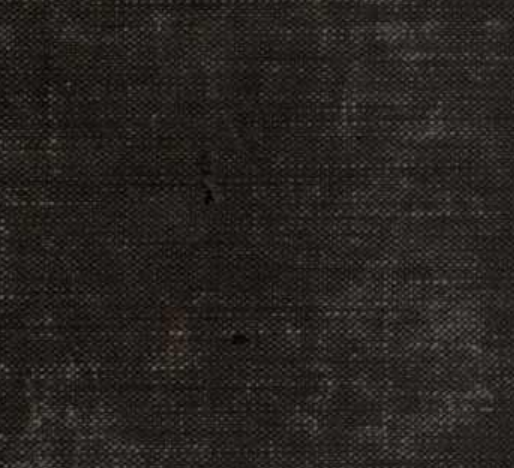

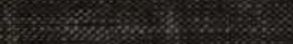

(5)
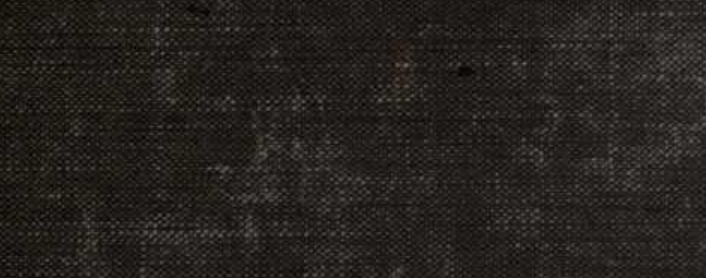

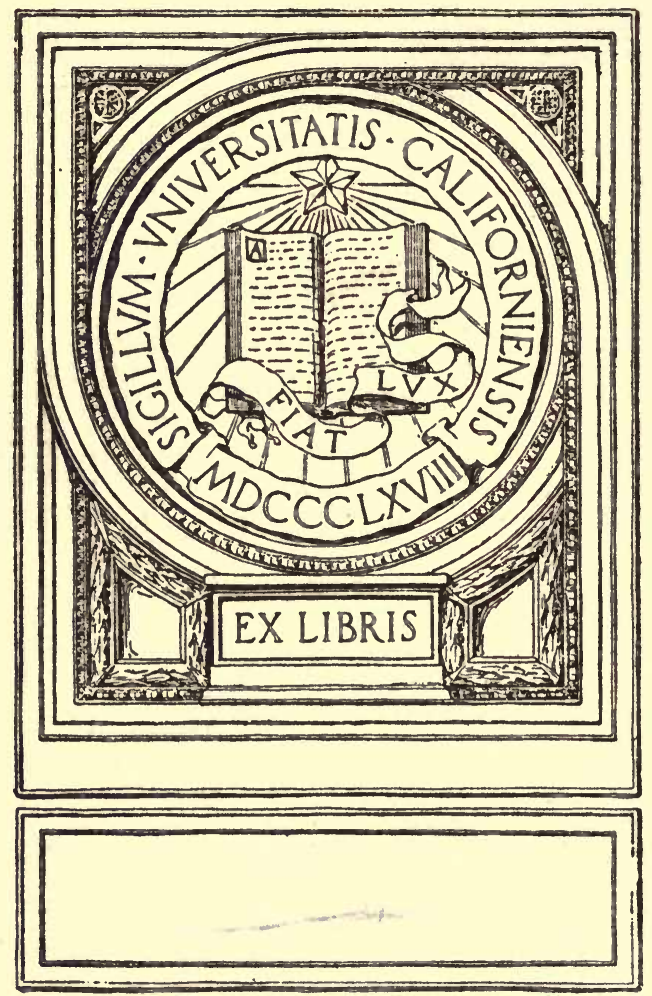





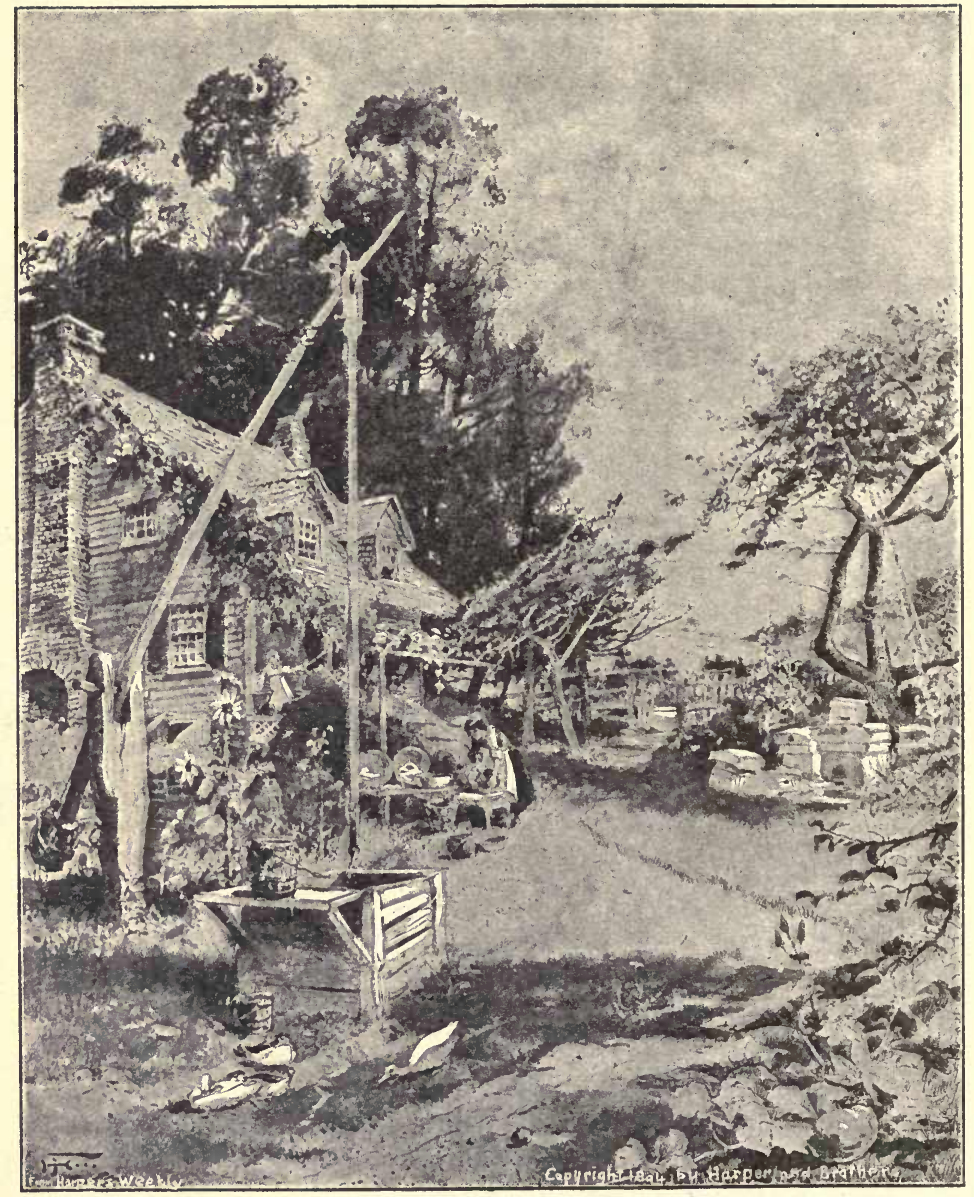

FIG. 289.-New England well-sweep and oaken bucket.-(Frontispiece.) 


\title{
FIRST COURSE
}

IN

\section{GENERAL SCIENCE}

BY

FREDERIC DELOS B.ARBER, A. M.

PROFESSOR OF PHYSICS, ILLINOIS STATE NORMAL UNIVERSITY

MERTON LEONARD FULLER, M. DI., M. A. LOCAL FORECASTER, 『. S. WEATHER BCREAU; LECTURER ON METEOROLOGY, BRADLEY POLYTECHNIC INSTITUTE

JOHN LOSSEN PRICER, A. M.

PROFESSOR OF BIOLOGY, ILLINOIS STATE NORMAL UNIVERSITY AND

HOWARD WILLIAM ADAMS, B. S. PROFESSOR OF CHEMISTRY, ILLINOIS STATE NORMAL CNIVERSITY

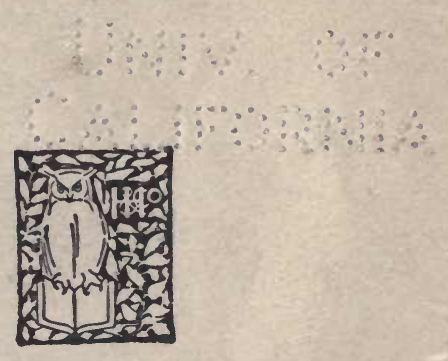

\author{
NEW YORK \\ HENRY HOLT AND COMPANY \\ 1917
}




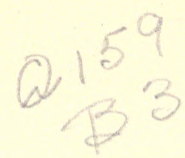

Copyright, 1916

BY

HENRY HOIT AND COMPANY

2

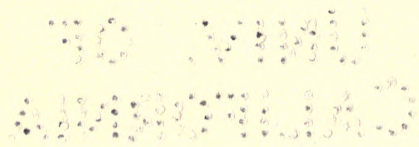




\section{PREFACE}

This book is written in the belief that science instruction in the first high-school year should not aim primarily to survey the entire field of nature and present scattered bits and choice morsels from every special science in order that the pupil may decide which of the special sciences he likes best and which he will omit. Nor should first-year general science be regarded primarily as an introduction to, or a foundation for, the special science he may later study. While it should, in a large measure, accomplish both these results it has a vastly more important function to perform. The primary function of firstyear general science is to give, as far as possible, a rational, orderly, scientific understanding of the pupil's environment to the end that he may, to some extent, correctly interpret that environment and be master of it. It must oe justified by its own intrinsic value as a training for life's work.

- General science has been accused of being a hodgepodge, an incoherent mass of science materials without form, or continuity, or order of development. In this course a conscious effort has been made to select a straight and solid track and to proceed in a well-ordered, common sense manner along it. The train of thought, as it were, runs upon, and is guided by two parallel rails, the one physical, ENERGY, the other sociological, HUMAN WELFARE. These two supporting and guiding rails are everywhere strongly bound together.

The topics presented have chiefly to do with the school life and home life of the pupil; they are essentially projects to be solved. Being topics with which the pupil is already more or less familiar, they have real significance and meaning to him. Only such matters as have vital relation to our experiences can have real significance to any of us. In dealing with home and school environment the laws and principles of the physical 
sciences are of primary importance, moreover, physical laws and principles are fundamental to all science, therefore they form the major portion of this course. Microörganisms, however, play so large a part in the daily life of all people that the principal facts concerning them are also presented. The main study of animal and plant life has been left to be developed as a course in general biology, or as special courses in botany and zoölogy.

The approach to each new topic is made from a historical point of view, thus developing a real interest in the subject. The course is progressive; the earlier chapters are relatively easy; as the ability of the pupil grows, the course becomes correspondingly more difficult. Numerous cross references are given to stimulate frequent review. The teacher is urged to insist upon the pupil's utilizing these references to past work. It is not expected, nor is it desirable, that every school, or every class in any school, shall study all the topics presented in this text. Topics not essentially important in the environment of any class, or in the environment of the community, may easily be omitted without seriously breaking the continuity of the course. It is expected that the teacher will exercise some judgment and discretion in omitting material from this course which is least essential to the welfare of his particular class.

Experience has shown that many of the exercises are best conducted as class demonstrations while a sufficient number of them are well adapted to individual work. The apparatus is, we believe, unusually inexpensive and is such as is to be found in any fairly well-equipped laboratory, or it is of a commercial type easily procured. The authors strongly advise, however, that a few standard pieces of equipment, such as a good barometer, a reliable air pump, a set of chemical thermometers, a good microscope, etc., be purchased if not already at hand.

This text is a revision and enlargement of the Elements of Physical Science published by the senior author in 1906 . The 
earlier text was written primarily for use in the Illinois State Normal University and was the outgrowth of a course which had already been taught for several years. At that time no similar material was available; the demand for general science in the high school had not yet risen. The earlier book was prepared with the definite purpose of getting away from the abstract and impractical science of the day. It is the belief of the authors of this text that the present strong demand for general science in the high school is a demand for the accomplishment of the same end.

We wish to express our appreciation of the painstaking and efficient reading of proof by Laura Hayes Pricer. We also appreciate highly the aid rendered by those who have assisted in the preparation of the illustrations or who have granted us permission to use illustrations from their publications.* The

* In the preparation of the illustrations for this text the authors wish to acknowledge valuable assistance from the following sources. Some of these illustrations appear unmodified; some have been adapted to the special needs of a text-book; some have been prepared especially for this text.

The Century Company, Figs. 2, 64, 86, 352, 355, 361. Detroit Heating \& Lighting Company, Figs. 19, 20. J. B. Colt \& Co., Figs. 31, 32. Prestolite Company, Fig. 34. Westinghouse, Church, Kerr \& Co., Figs. 41, 42. American Home Magazine Co., Figs. 43, 44, 45. General Electric Co., Figs. 46, 47. Central Electric Co., Figs. 37, 38, 50, 52, 53, 54. Welsbach Company, Figs. 56, 57, 58, 59, 60, 61. Curtis Publishing Co., Fig. 65. Kalamazoo Stove Co., Figs. 73, 114. Patric Furnace Co., Figs. 74, 75. Williamson Heating \& Ventilating Co., Figs. 76, 77, 78, 92, 93, 94. American Radiator Co., Figs. 103, 233, 234, 237. Edwin J. Jackson \& Bro., Figs. 104, 105, 106. Durham Manufacturing Co., Fig. 116. Mechanical Refrigerator Co., Fig. 123. Encyclopedia Americana, Fig. 127. Monthly Weather Review, Figs. 192, 193 and others. Dr. S. Adolphus Knopf and Moffat, Yard \& Co., Figs. 228, 229, 230. Waterbury-Waterman Co., Figs. 235, 236. Municipal Magazine, Fig. 242. Standard Sanitary Manufacturing Co., Figs. 277, 297, 298, 311, 312. R. D. Wood \& Co., Figs. 295, 301, 372, 373. Bishop \& Babcock Company, Fig. 300. Rensselaer Manufacturing Co., Fig. 302. Thompson Meter Co., Fig. 304. National Meter Co., Figs. 305, 306. F. J. Drake \& Co., Fig. 316. Chas. Brossman, Indianapolis, Figs. $317,318,319,320,321$. International Harvester Co., Figs. 322, 364, 366, 368,370 . Singer Sewing Machine Co., Figs. 323, 324, 325, 326, 327, 328, 329. Mississippi Power Co., Figs. 345, 346, 349, 351. DeLaval Manufacturing Co., Figs. 331, 332, 333. American Book Co., Fig. 353. James Leffel \& Co., Figs. 358, 359, 360 . Westinghouse Manufacturing Co., Figs. 62, 63. Parrett Tractor Co., Fig. 339. Swift \& Co., 252, 253, 254. Creamery Package Co., 251. U. S. Weather Bureau, Figs. 147, 148, 154, 155, 166, 172, $173,174,175,176,177,178,189,190$. Perfection Vacuum Cleaner Co., Fig. 241. 
hearty coöperation of manufacturers and business men and the interest they have manifested in our efforts to present faithfully the application of science to the actual affairs of life have been most helpful. Chapter IV, The Weather, is published with the approval of the Central Office of the United States Weather Bureau.

The Authors.

Normal, Illinois.

May 20, 1916. 


\section{CONTENTS}

Chapter $\quad$ Page

I. The Production and Use of Light . . . . . . . . 1

II. The Proddction and Use of Heat. . . . . . . . . 71

III. Refrigeration and Its Uses. . . . . . . . . . . . 154

IV. The Weather. . . . . . . . . . . . . . . 176

V. The Seasons-Climate and Health . . . . . . . 281

VI. Ventilation. . . . . . . . . . . . . . 311

VII. Food AND Nutrition. . . . . . . . . . . . 343

VIII. MICroörgantsms . . . . . . . . . . . . . . 380

IX. Soil Physics, Water Sopply, and Sewage Disposal. . 450

X. Machines, Work, And Energy . . . . . . . . . . 518 Appendix. Weights and Measures . . . . . . . . . . 585 Glossary . . . . . . . . . . . . . . . . 589 INDEX . . . . . . . . . . . . . . . 599 



\section{GENERAL SCIENCE}

\section{CHAPTER I \\ THE PRODUCTION AND USE OF LIGHT}

\section{PRIMITIVE LIGHTING}

1. The Discovery of Fire.-There probably was a time when primitive man was without fire. In those days he had no artificial heat or light, and he ate his food uncooked. Perhaps man first obtained fire from dead trees ignited by lightning, perhaps from oil wells which are known to have been

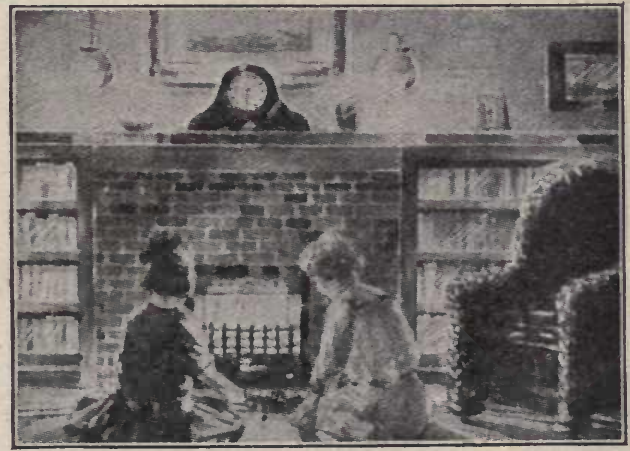

Fig. 1.-The oper fire is the center of the home.

burning for centuries. With fire came warmth, light, and cooked food. The light from the camp fire also furnished protection from wild animals. Gradually the fire came to be the center of the home. It is probable that we owe more than we realize to fire for what it has done toward building up and strengthening family ties. 
2. The Primitive Lamp.-Perhaps a pine knot snatched from the fire constituted the first portable light. How recently pine knots have been in common use is shown by the fact that Abraham Lincoln learned to read by the light of them. Perhaps by collecting the grease obtained from cooking and placing it in a rude vessel with a bit of bark or a thread

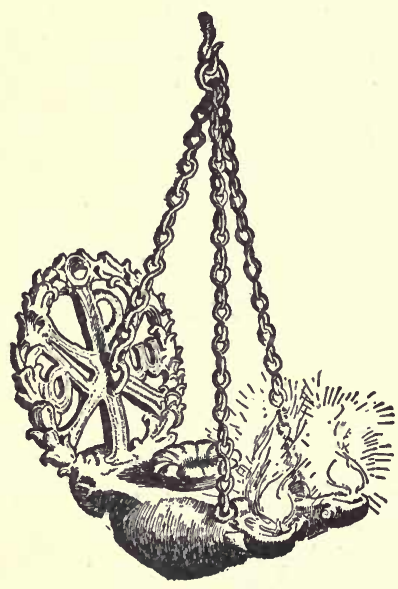

Fig. 2.-A Roman lamp. From Stories of Useful Inventions. (By courtesy of The Century Company.) of twisted moss for a wick, man made the first lamp. We would consider the light produced by such a lamp a poor one indeed, but the Eskimos still use such primitive lamps. The bowl is hollowed out from soapstone; the fat comes from the animals they slay. The Eskimo lamp serves also as a stove. By its heat all their cooking is done and their snow huts are warmed.

3. Greek and Roman Lamps.The lamps of Greece and Rome were no better than the Eskimo lamps of today, but the lamp bowls were often very costly and elaborately ornamented (Fig. 2). The rich used lamps of bronze or silver; the middle classes, lamps made of terra-cotta; the poor, cheap iron lamps.

4. The Early Candle.-The earliest lamps could not conveniently be moved about. The oil or fat, especially when warm, spilled out of the bowl. It was noticed, probably, that when some fats were cold they became quite stiff and solid. Tallow is much more solid than lard. Someone concluded, therefore, that it would not be necessary to use a lamp bowl at all if tallow were used and a small wick imbedded in it. The tallow prepares its own bowl during the process of burning. Like lamps, candles have been used from prehistoric times.

5. Modern Candles.-While the candles our grandfathers 
and grandmothers made were of tallow, the modern candle is made of paraffin which is obtained from petroleum. Over $300,000,000$ paraffin candles were sold in the United States in 1913 , about two dozen candles for each family.

\section{Exercise 1.-How the Candle Burns}

Place a piece of candle upright on a square of pasteboard after melting a little of the paraffin at the bottom of the candle to make it stick. Light the candle. After it has burned three or four minutes notice what is happening to the paraffin near the wick. This cup corresponds to the bowl of the primitive lamp. To have a perfect cup three things are necessary: (1) There must be no draft in the room; (2) the wick must not be too large for the candle; (3) the wick must be in the center of the candle. Is it desirable to have the cup perfect? Why?

Hold one of the strands of candle wicking in a vertical position and light its upper end. Does it burn readily? Does it continue to burn? Is its flame like that of the candle flame? Is it the burning of the candle wick that is the chief cause of the candle flame? If not, what is it?

Blow out the candle flame and examine the wick. Is it wet? With what is it wet? Does it remain wet all the time that the candle is burning? Re-light the candle and, using two iron nails, squeeze the wick; then examine the nails to see whether or not there is any paraffin on them. The wick is constantly soaked in melted paraffin while the candle burns. But is it the liquid paraffin which burns?

Re-light the candle and blow out the flame again. Notice the smoke which rises from the wick. How

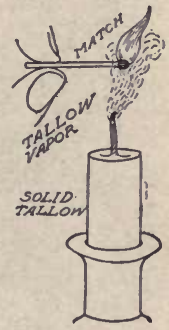

Frg. 3. Lighting the candle vapor. long does it continue to rise? Re-light the candle. Hold the lighted match in one hand. Blow out the candle and quickly thrust the lighted match into the column of rising smoke about 1 in. above the candle. What happens? (Fig. 3.) Try the same again. Make several trials to see how far above the tip of the wick you can hold the match and still have the candle re-light. Does it make any difference how long you wait after blowing out the flame before applying the match? Do drafts through the room make a difference? What do you now think it is that burns?

Have you ever seen a frying pan in which meat or eggs were frying become so hot that the smoke rising from the fat caught 
on fire? This sometimes happens. The fat, however, begins to smoke some time before it gets hot enough to catch on fire.

The Explanation.-All kinds of greases, fats, and oils when heated sufficiently hot give off vapons in large quantities. This simply means that these fats and oils are changed by heat from liquids into vapors, or gases, exactly as water is changed by heat from its form as liquid water into steam, or water vapor. It is paraffin vapor which burns in the candle flame.

\section{Exercise 2.-The Flashing Point and the Burning Point}

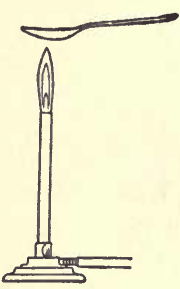

FIG. 4.Flashing point of paraffin.

Put a little paraffin in a large iron spoon and slowly heat it until it begins to smoke, VAPORIzE, (Fig. 4). Then test the smoke, vapor, frequently with a burning match to see when it will ignite. At a certain temperature of the liquid paraffin in the spoon the vapor becomes dense enough to produce a momentary flash over the surface. The paraffin is then at the FLASHING POINT. Continue to heat the paraffin in the spoon slowly, testing the vapor as before. When the vapor becomes dense enough to burn continuously, the paraffin has reached the BURNING POINT.

Definitions.-The flashing point of paraffin, lard, tallow, or oil is that temperature at which the vapor arising and mixing with air produce a momentary flash when ignited.

The burning point is that temperature of the substance at which the vapor arising and mixing with air produces a continuous flame when once ignited.

It is now evident that in lighting a candle the burning match must be held against the wick long enough to melt and then to vaporize the paraffin in it in such quantities that the vapor is ignited by the match and burns with a continuous flame. The heat from the candle flame continues to melt and to vaporize the paraffin fast enough to produce a steady flame.

6. Fresh Air is Necessary.-We have seen that the vapor from the heated tallow or paraffin rises and mixes with the air. Is the air really necessary that the vapor may burn? We can answer the question best by trying an experiment. 


\section{Exercise 3.- Shutting the Fresh Air Away from the Candle}

Light a piece of candle 1 or 2 in. in length and stand it on the table before you. Watch it for a minute to see that it burns properly. Now invert a tumbler and place it over the candle. Does the candle continue to burn? Remove the tumbler. Re-light the candle. Try the experiment again, using a 2-qt. fruit jar instead of the tumbler. Does the candle continue to burn longer this time? Why? Re-light the candle. Again place the fruit jar over the burning candle. Watch carefully to see what happens just as the flame goes out. Is there much smoke given off for a moment after the flame dies out? What is this smoke? If it is paraffin vapor, why does it not burn? (Fig. 5.)

Now carefully raise the jar and set it aside while you re-light the candle, letting just as little fresh air into it as possible. Again place the jar over the candle and

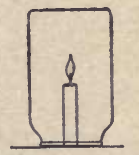

Fig. 5.-Excluding fresh air from the candle. notice carefully how long the flame continues this time. Raise the jar, blow all the smoke out of it; re-light the candle and again place the jar over the candle. Does the flame burn longer than it did before? Explain.

Explanation.-As long as the wick is hot there will be plenty of paraffin vapor. But this vapor cannot possibly burn alone. The flame is the result of the uniting of the vapor with one of the gases, OXYGEN, in the fresh air. The air is not fresh when the vapor has burned out the oxygen. No matter how much of the burned air and vapor you may have in the tumbler, or how well mixed they may be, you can not get a flame till you have some of the fresh, unburnt air mixed with the vapor.

\section{THE KEROSENE LAMP}

7. The First Kerosene Lamp.-The kerosene lamp has been in use only about 50 years. The lamps which had previously been used usually burned heavy oils and fats, which gave only low, flickering, smoky flames. During the first half of the last century WHALE OIL was in common use along the seacoast. Whale oil lamps were less smoky and disagreeable than most lamps of the period. A few lamps had been made which burned so-called BURNING FLUIDS. But these fluids were very inflam- 
mable and dangerous. Up to about 1860 candles were by far the safest and best sources of artificial light which the world had ever used.

It was in August, 1858, that the first successful oil well was sunk in Pennsylvania. Petroleum had been known for a long time, but it had never before been found in commercial quantities and littie use had been made of it except as medicine. Soon after it was obtained in large quantities, the discovery was made that an oil could be obtained from crude petroleum which would burn freely and still be safe to handle. This new oil was called Kerosene, though some people, supposing that it came from coal, called it COAL oIL. We still sometimes hear it called by that name. Inventors soon made lamps well suited for the burning of this oil. The common kerosene lamp of today is, in principle, exactly like those earliest lamps.

8. Parts of the Kerosene Lamp.-The ordinary kerosene lamp really consists of three parts: (1) The BowL for containing the oils; (2) the WICK; (3) the BURNER AND CHIMNEY. The wick is usually made of soft, loosely woven cotton cloth. What is its purpose? What does it do?

Burners vary much in construction, but all have certain necessary parts, namely: (1) The CAP, OR CROwN; (2) the PERFORATED BASE; (3) the TUBE FOR THE WICK.

\section{Exercise 4.-The Use of the Burner and Chimney}

Examine a burner carefully and discover these parts. Make a sketch in your notebook of your burner showing clearly each of these parts. Label all parts of your sketch somewhat as the sketch, Fig. 6, is labeled. Do not copy the sketch from the book but sketch your lamp.

Study carefully the device for regulating the height of the wick.

Light the lamp, place the chimney in position, and observe the steadiness of the flame. If there is not much draft through the room there should be very little flickering of the flame. It should burn with a steady flame.

Wave your book past the bowl of the lamp so as to produce a strong gust of air against the under side of the burner. What is the effect upon the flame? Can you tell why it becomes smoky? Did 
you increase or decrease the amount of air which was passing through the chimney and past the flame? Hold the lamp up before you and blow strongly into the bottom of the burner. What is the effect upon the flame? Is it a case of too much air or not enough?

Wrap a towel about the base of the burner so as to prevent air's

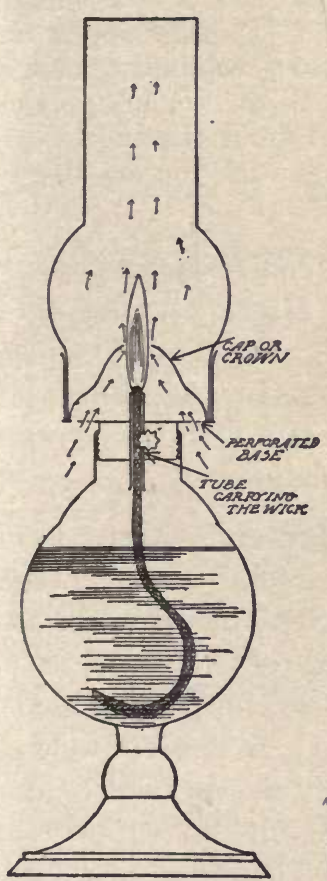

Fia. 6.-Parts of the burner. entering through the perforated base. What is the effect upon the flame? If you could see only the upper portions of the chimney could you be certain from the bèhavior of the flame whether too much or too little air was entering the burner?

Place a piece of cardboard or window glass for an instant on the top of the chimney so as to close it. What is the result? What is the effect upon the flame of having too little air? What is the effect of having too much air? What do you think is the chief purpose of the burner and chimney?

Kerosene burns just as freely without the use of a burner or chimney. This can be easily shown by placing some, kerosene in a tumbler and covering the tumbler with a sheet of tin in which a slit has been cut by means of a cold chisel. An ordinary lamp wick is drawn into the slit as shown in Fig. 7. In this case, however, the flame will be smoky and unsteady

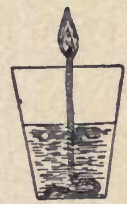

Frg. 7. Burning kerosene without a burner.

no matter how still the air in the room may be.

Evidently, the chief purpose of the burner and chimney is to regulate the air supply. If the air supply be either too abundant or too scarce the flame will be unsteady and smoky. We shall see later why this is so. We shall also study later the principle by which the burner and chimney regulate the air supply.

9. How Kerosene Burns.--Just as we proved that it was not the liquid paraffin which burned in the case of the candle, 
so we can show that it is not the liquid kerosene which burns in the case of the kerosene lamp.

\section{Exercise 5.-It is Kerosene Vapor that Burns}

Remove the chimney from the lamp. Light it. Hold the lighted match ready to apply. Blow out the flame. Quickly apply the

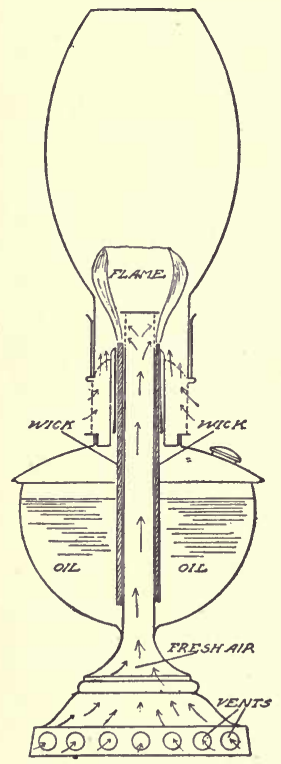

FIg. 8.-Center-draft lamp.

lighted match to the rising column of smoke. Does it ignite? If not, be quicker in applying the match next time. Repeat the experiment to see how far above the wick you are able to ignite the vapor.

Have you ever noticed a strong odor of kerosene in the room after "blowing out" a lamp? (Art. 103.) Explain. Can this be prevented by first turning the wick down so as.to produce a low flame before blowing it out? Explain.

10. Center Draft Burners.-Many large kerosene lamps use circular wicks. They have an open tube extending from the top of the burner down through the center of the bowl to the open central portion of the base. The rim of the base is perforated so that a current of fresh air can readily pass upward through the tube to supply the inside of the flame. There are, of course, perforations through the sides and bottoms of the burner to supply fresh air to the outside of the flame. Such lamps are known as CENTER DRAFT lamps (Fig. 8).

\section{EVAPORATION, BOILING TEMPERATURE, AND DISTILLATION}

\section{Evaporation}

11. Need of New Terms.-We have thus far been studying the burning of paraffin in the candle and of kerosene in the ordinary lamp. Gasoline has often been used for producing 
artificial light where gas or electricity is unobtainable. Gasoline lamps of many different kinds have been made and in many homes gasoline is used both for lighting and cooking. With this increase in its use people have discovered that gasoline is also one of man's most dangerous servants if not carefully and properly handled. Many accidents have resulted from its use. Most people who use gasoline know that it is more dangerous than is kerosene. But many people are using gasoline every day who do not know just why it is dangerous, what to do with it, or how to handle it to make it a safe and obedient servant.

We should like to study gasoline; we hope to learn its nature and how to handle it. Before we can do so, however, we must know the meaning of certain terms and how to use them correctly. We must know where gasoline comes from and its relation to kerosene. These topics will be studied next.

12. Evaporation.-We are all aware that damp clothes hung upon the line at any time except when it is raining soon lose the water they contain and become dry. We wash our porches and floors and soon they are dry. We place a basin of water in an exposed place and the water soon disappears.

The explanation is that the water changes from a liquid to a gas, or vapor, and escapes into the air. This process by which water changes from its liquid form into a gas, or vapor, we call EVAPORATION.

The washerwoman is also aware that on some days the clothes will dry much more rapidly than on others. We know that the freshly washed floors will dry more quickly if we open the doors and windows or build a fire in the furnace or stove. The farmer has learned to tell very accurately, by watching the weather, whether or not the fields and roads are drying rapidly. The question naturally arises: What are the conditions under which evaporation takes place most rapidly? This question can best be answered by experiment. 


\section{Exercise 6. -Effect of Extent of Surface on Rate of Evaporation}

Fill a small drinking cup about half full of water, measuring exactly the amount used. Again measure the same amount of water, and place it in a large, shallow pan or basin. Set the cup beside the pan in a safe place where it will not be disturbed. The two vessels should have the same temperature and be exposed to the same air currents. Examine them daily and note the rate of evaporation in each, till one is dry. Measure the amount of water remaining in the other.

Which is dry first? What conclusion do you draw regarding the effect of extent of surface on evaporation?

\section{Exercise 7.-Effect of Temperature on Rate of Evaporation}

Place one drinking cup containing a measured quantity of water on or near the stove or radiator. The water should not boil, but be kept warm. Place another cup of the same size and shape containing the same amount of water in a cooler place. Watch these two cups till one is dry. Draw a conclusion regarding the effect of temperature on the rate of evaporation.

\section{Exercise 8.-Effect of Air Currents on Rate of Evaporation}

Place two drinking cups of the same size and shape, each about one-half full of water (measuring amounts accurately), side by side in an open window or in some other position where the wind can sweep past them. Turn a large, 2-qt., cup or a small pail over one of the cups of water. Examine the cups of water daily and note which suffers the greater evaporation. What is your conclusion?

\section{Exercise 9.-Rate of Evaporation Varies with Different Liquids}

Place two drinking cups of the same size and shape side by side in some safe place. Fill one about half full of water, and place in the other the same amount of alcohol or gasoline. (Caution.-It is dangerous to leave gasoline in a closed room. It should be in the open air and no flames should be brought near it.) Note which evaporates more rapidly. Draw your conclusion.

\section{Exercise 10.-Effect of Evaporation on Temperature}

Let a few drops of alcohol or gasoline fall upon the back of your hand. Does it produce the sensation of heat or cold? Wrap a small piece of cotton cloth around the bulb of the thermometer and tie with a cord or thread. Take the reading of the temperature. 
Drop a few drops of alcohol or gasoline upon the cloth. Watch for a change in temperature. Repeat the experiment. Does the thermometer record the lowest temperature when the liquid is first dropped upon it or a little later? How do you account for this fact? Draw a conclusion regarding the effect of evaporation upon temperature.

Wet your hand and hold it out of the window where the wind can strike it. What is the sensation?

Hunters usually wish to approach their game from the leeward side, that is, so that the wind will blow from the game toward the hunter. Why do they wish to do so? In order to tell the direction of the wind when it is too light to be observed readily by ordinary means the hunter often wets one finger at his mouth and then holds it high above his head where the wind can strike it. Try the experiment when you are out of doors and decide how it is that this tells the direction of the wind.

Why do we often feel chilly if we sit down with damp clothing on? Why does fanning one's self produce the cooling effect that it does? Is the cooling effect of fanning increased or decreased by the fact that one has been perspiring freely?

In regions having a dry, hot, windy climate like Arizona and New Mexico, it is found that butter can be kept hard and sweet for long periods simply by setting the dish containing the butter into a larger dish containing water and then spreading over the butter a piece of soft absorbent cloth, such as a clean towel, so that its corners and edges dip down into the water. Explain.

In the same regions drinking water is generally kept during the summer months in a large, porous, earthen vessel called an OLLA (ō-ya), which is hung out of doors, usually under a porch or tree. The olla being porous, its outer surface is constantly covered with a film of water. Evaporation taking place over so large a surface cools the water within the vessel far below the temperature of the surrounding air.

13. Laws of Evaporation.-From these and similar experiences we draw the following conclusions: 
I. The rate of evaporation from any given amount of liquid increases when the exposed surface is increased.

II. Increasing the temperature of a liquid increases the rate of its evaporation.

III. The rate of evaporation is increased by the continual removal of vapor above the surface of the liquid.

IV. Some liquids evaporate much more rapidly than do others.

V. Evaporation of a liquid always produces a cooling effect upon surrounding bodies.

\section{Temperature AND the Thermometer}

14. Temperature.-We are all familiar with the common use of the term temperature. By it we mean the hotness or the coldness of a body. On a cold day we say that the temperature is low; on a warm day we say it is high. We can generally tell when one body is warmer than another if we feel of the two bodies at the same time. We cannot, however, be certain of our judgment. Different substances feel to be of different temperature when they are in fact of the same temperature. The bare-footed boy knows this to be true. A piece of iron and a piece of wood lying side by side on a hot day will be of the same temperature. Will they feel so? Which feels the warmer? What would be the case on a cold day? Which would then feel the colder?

If at the close of a long ride on a very cold, windy day we were to step into an unheated room we would at once say that the room was warm. If we were to remove our wraps and sit down we should soon find, however, that the room was really cold.

The truth is we cannot depend upon the appearance of objects, or upon our sensations of heat and cold, to tell us the temperature of surrounding bodies. In all our work we shall be obliged to use an instrument especially constructed for this purpose, the THERMOMETER. 


\section{Exercise 11.-How Heat Affects the Thermometer}

Fill a small flask with water. Fit a glass tube, 12 or 15 in. long, into a one-hole rubber stopper. Press the stopper down tightly into the flask. This should force the water well up into the tube.

Light an alcohol lamp or Bunsen burner. Hold the flask for about one second in the flame. Notice carefully the first movement of the surface of the water. Does it rise or fall at first? What does it do later? Repeat the experiment till you feel certain that you see that the second motion is opposite to the first motion.

The first motion is due to the fact that the heat first strikes the glass and expands it. This makes the flask larger-increases its volume. If the volume of the flask grows suddenly larger, what would you expect to see happening to the surface of the water? The second movement is due to the fact that, when heated, the water increases in volume much more rapidly than the glass vessel does.

The common thermometer consists of a very small glass tube ending in a glass bulb at its lower end. This bulb and the tube are partly filled with mercury or alcohol. The air is nearly all removed from the upper portion of the tube. The tube is then closed by heating the glass till it softens and closes together. The principle of the thermometer may be summed up thus: When heated, the glass in the thermometer expands, increasing the capacity of the bulb and tube, but the heat soon penetrates to the liquid which then expands to a still greater extent. Alcohol expands more than 40 times as much as does the glass vessel, and mercury expands about 7 times as much as does the glass vessel for a given change in temperature.

16. The Fixed Points of Temperature in Nature.-The ther, mometer just described is still without any scale. In placing a scale upon it, the position of the surface of mercury or alcohol is marked when the thermometer is cooled or heated to some certain FIXED TEMPERATURES IN NATURE. The distance between the lower and higher temperature marks is then divided into a certain number of equal parts called DEGREES.

1. It has been long known that water always freezes and 
ice always melts at a certain temperature. For pure water this temperature is called the FREEZING POINT OF WATER.

2. It has also been known that at the average atmospheric pressure at sea level. water always boils at a certain temperature. The temperature of the steam arising from water boiling under the atmospheric pressure which exists at the sea level is, therefore, called the BOILING POINT OF WATER.

3. About two hundred years ago Fahrenheit found that a mixture consisting of 1 part common salt and $2 \frac{1}{2}$ parts snow or crushed ice always melted at a certain temperature considerably below the temperature of freezing water. This third temperature is known as the MELTING POINT OF A MIXTURE OF SALT AND ICE.

There are a great many other fixed points of temperature in nature. For example, pure iron always melts at exactly the same temperature; so does lead, and so does zinc. Both pure mercury and pure alcohol have certain temperatures at which they boil and others at which they freeze. When in good health the human blood always has the same temperature. But in marking the common thermometer the three temperatures first mentioned, namely, the freezing point of water, the boiling point of water, and the melting point of a mixture of ice and salt, are the only temperatures which we use.

17. Fahrenheit's Thermometer.-In making the thermometer which bears his name, Fahrenheit marked the position of the mercury " $0^{\circ}$ " when the thermometer was cooled down to the temperature of the mixture of ice and salt. It is believed that he was induced to call this temperature $0^{\circ}$ partly because it was the unusually low temperature reached by the weather in Holland in the winter of 1709 . He called the temperature of freezing water " $32^{\circ}$ " and the temperature of boiling water " $212^{\circ}$."

18. Centigrade Thermometer.-Much later Celsius made his so-called CENTIGRADE THERMOMETER. On this thermometer the freezing point of water is marked as " $0^{\circ}$ " and the boiling point of water as " $100^{\circ}$." 
Often both scales are placed upon the same thermometer stem. It is also true that the scale may extend far above the boiling point of water and far below the melting point of the mixture of ice and salt.

\section{Determining the Freezing Point on a Thermometer.-}

\section{Exercise 12.-Testing a Thermometer for the Freezing Point}

Suspend a funnel in the ring of an iron support. Clamp a thermometer by means of the burette clamp at such a height that the bulb hangs well down in the throat of the funnel. Pack the funnel full of finely broken ice or snow, heaping it well up around the stem of the thermometer. The stem should be surrounded with ice or snow up as nearly as possible to the point marked $0^{\circ} \mathrm{C}$., or $32^{\circ} \mathrm{F}$. Keep plenty of ice or snow in the funnel and see that it remains tightly packed around the thermometer for some minutes. Does your thermometer record correctly the freezing point of water? If not, what is the amount of the error? (Fig. 9.)

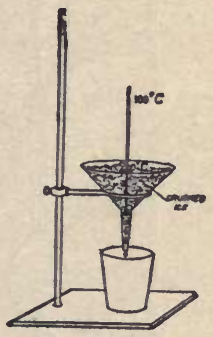

Fig. 9.-Freezing point of water.

Even very good thermometers are often slightly incorrect.

\section{Boiling Point}

\section{The Temperature of Boiling Water.-}

Definitions. - A liquid is said to EVAPORATE when it changes from the liquid form to the vapor form at the surface only.

$A$ liquid is said to BoIL when it changes to the vapor form beneath the surface and the bubbles of vapor rise to and escape from the surface.

A liquid is said to be VAPORIZED whenever it changes to vapor. A liquid is vaporized when it evaporates or boils.

\section{Exercise 13.-To Determine the Temperature of Boiling Water}

Fill a 4-oz distilling flask half full of water. Slip a chemical thermometer into the hole in a rubber stopper. Push the thermometer far enough through the stopper so that the bulb will dip into the water when the stopper is fitted into the mouth of the flask. Before inserting the stopper and thermometer it is well to place a 
few small nails or some common glass beads in the flask. The presence of something of this kind in the flask will cause water to boil more steadily and prevent "bumping." (Fig. 10.)

Clamp the iron ring to the stand at a point about 2 in. above the flame. Place a wire gauze upon the ring and set the flask on the gauze. Steady its top by clamping it loosely with the burette clamp. Adjust the flame so that it will not be

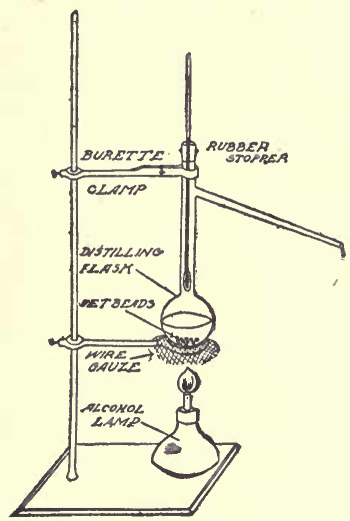

FIG. 10.-Boiling point of water. too high. Slip it under the flask and watch for results.

The first small bubbles which you see rising through the water are bubbles of air, not of steam. Keep watch of the reading of the thermometer. Do you see any evidence of steam, or water vapor, before the water actually boils? Does the steam rise from a pan of hot water on the stove before the water really begins to boil? At what temperature by your thermometer does the water finally boil? Continue to heat the water to see if it is possible to raise the temperature higher. Can you see steam in the upper portion of the flask? Can you see it immediately after it escapes from the side tube? (Caution.-Do not permit the flame to reach higher than the surface of the water in the flask, else the flask will probably crack.)

If you are not careful you may be led to give incorrect answers to the last two questions. Steam, or water vapor, is invisible. But something escaped from the side tube. What do you now think that it was? What happens to steam when it is again cooled after escaping from the flask? We sometimes say that we see steam escaping from an engine or locomotive. This is not strictly true. We see only the small particles of water which have been formed again from the steam and which are floating in the air.

Unless you are living at or very near the sea level you have probably found that the temperature of the boiling water according to your thermometer is somewhat below $212^{\circ} \mathrm{F}$., or $100^{\circ} \mathrm{C}$. 


\section{The Temperature of the Steam Arising from Boiling} Water.-In the last experiment the bulb of the thermometer was in the water, therefore the thermometer recorded the temperature of the water itself. Would it record a different temperature if it were raised above the surface of the water, high enough so that no water could touch it, but still be surrounded by steam?

\section{Exercise 14.-Temperature of Steam Arising from Boiling Water}

Raise the thermometer higher in the rubber stopper used in Ex. 13. The bulb of the thermometer should be up in the neck of the distilling flask but below the side tube. Replace the lamp and bring the water to a boil. What temperature does the thermometer record now? See if the temperature can be raised by causing the water to boil more rapidly. (Caution. - Do not permit the flame to reach higher than the surface of water in the flask.)

The temperature of the steam which escapes from boiling water is always a little lower than the temperature of the boiling water itself. This is exactly what we should expect, for the heat is being applied to the glass vessel and then transferred to the water. The water is constantly in contact with glass which is slightly above the temperature of boiling water. Moreover, if there are impurities in the water their presence will tend to change the boiling temperature; generally they raise the temperature, although certain dissolved gases lower it.

Definition.-The temperature marked $100^{\circ} \mathrm{C}$, or $212^{\circ} \mathrm{F}$., and called "boiling point" is the temperature of steam arising from boiling water when the pressure is equal to that of the atmosphere at the sea level.

In the experiment did your thermometer indicate a temperature of $100^{\circ} \mathrm{C}$, or $212^{\circ} \mathrm{F}$.? Can you explain why it did not?

22. To Change the Temperature Reading from One Scale to the Other.-We have seen that there are 100 degrees on the centigrade scale between the freezing point of water and the boiling point of water; on the Fahrenheit scale there are 
180 degrees. It is, therefore, evident that 100 degrees on the centigrade scale equal 180 degrees on the Fahrenheit scale, or $1^{\circ} \mathrm{C}$. equals $1.8^{\circ} \mathrm{F}$. But we must always remember that the $0^{\circ} \mathrm{C}$. is at the freezing point of water while $0^{\circ} \mathrm{F}$. is at the freezing point of the mixture of ice and salt, and that the freezing point of water is $32^{\circ} \mathrm{F}$. (Fig. 11).

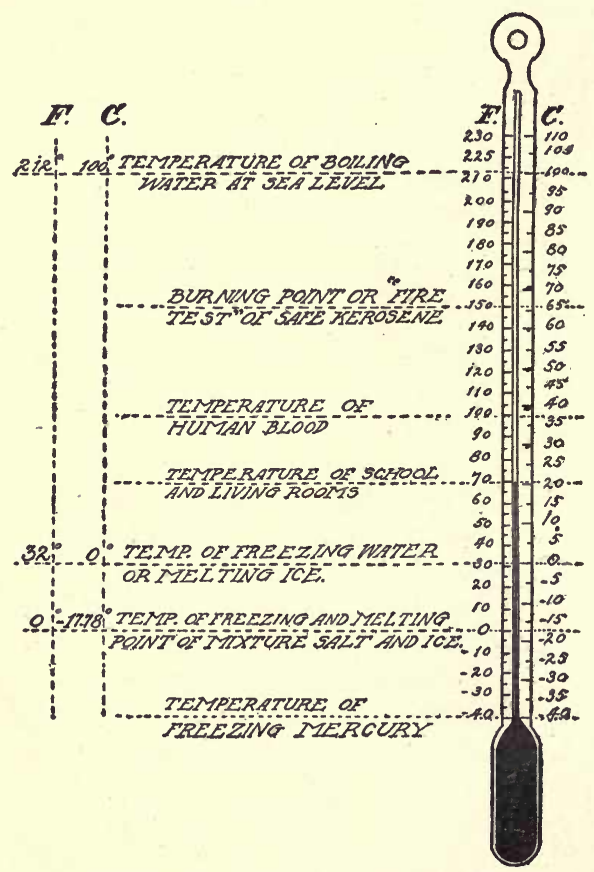

Fig. 11.-Thermometer scales.

Example.-Change $70^{\circ} \mathrm{F}$. to C. Solution: $70^{\circ} \mathrm{F}$. means 70 Fahrenheit degrees above the melting temperature of the mixture of salt and ice. $70^{\circ}-32^{\circ}=38^{\circ}$. This temperature is, therefore, 38 Fahrenheit degrees above the freezing point of water. But each centigrade degree equals 1.8 Fahrenheit derrees. Therefore, it is as many centigrade degrees above the freezing point of water as 1.8 is contained times in 38 which is $21 \frac{1}{9}$. Therefore, $70^{\circ} \mathrm{F}$. $=21 \frac{1}{9} 9^{\circ} \mathrm{C}$.

Example.-Change $-10^{\circ} \mathrm{C}$. (10 degrees below zero, centigrade) to $\mathrm{F}^{\circ}$. Solution: $-10^{\circ} \mathrm{C}$. means 10 degrees below the freezing point 
of water. But 10 centigrade degrees equal 1.8 times 10 Fahrenheit degrees, or 18 Fahrenheit degrees. Therefore, the temperature referred to is 18 Fahrenheit degrees below the melting point of ice. But the melting point of ice is 32 Fahrenheit degrees above the melting point of the mixture of ice and salt, or the zero point on the Fahrenheit scale. Hence the temperature is $32^{\circ}-18^{\circ}$ or $14^{\circ} \mathrm{F}$.

\section{The Boiling Point of Alcohol.}

Exercise 15.-To Determine the Boiling Point of Wood or Grain Alcohol

Fill a distilling flask half full of alcohol. Put in some glass beads or nails. Insert the stopper and thermometer, adjusting the thermometer in height so that the bulb will extend somewhat below the side tube and still be above the base of the neck of the flask. Clamp the flask in the ring stand at the proper height above the alcohol lamp or burner. Set the stand in a metal tray such as a large dripping pan. Place a clean vessel close under the side delivery tube to catch the condensed vapor as it drips from the tube. Since alcohol is inflammable it should be handled with care. Before lighting the lamp, place a piece of cardboard between the flask and the delivery tube to avoid any possibility of the escaping alcohol vapor being set on fire by the flame (Fig. 12).

Light the lamp or burner and notice all that takes place as the alcohol is brought slowly to a boil. Record the temperature of the alcohol vapor when the condensed vapor begins to drip from the delivery tube. Should much alcohol vapor escape from the tube

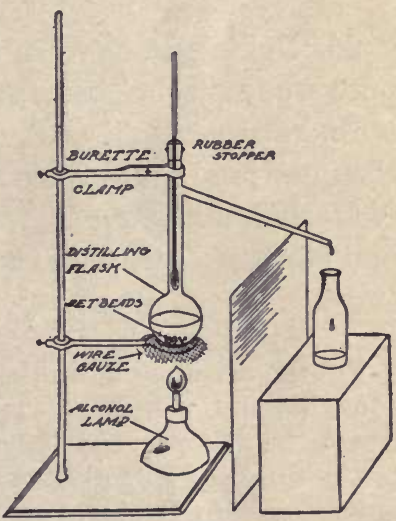

FIG. 12.-Distillation of Alcohol. before it condenses, moisten a small cloth in cold water and lay it over the delivery tube to keep it cool. Is alcohol vapor visible or invisible? What is the "boiling point" of alcohol? Does it remain constant as the alcohol continues to boil? Does rapid boiling raise the "boiling point?"

Should the "boiling point" of your sample of alcohol not remain constant but rise with continued boiling your alcohol probably contains water. The simplest test for pure alcohol is the test of the boiling point. Wood alcohol, as pure as can be obtained by distillation, has a constant boiling point of $66^{\circ} \mathrm{C}$., 
or $1504 / 5{ }^{\circ} \mathrm{F}$. Ordinary grain alcohol has a constant boiling point of $78^{\circ} \mathrm{C}$., or $17225^{\circ} \mathrm{F}$. These are the boiling points at the sea level. In our school rooms these temperatures will be slightly lower. Then, too, our thermometers may not be exactly correct. But in any case the boiling point of pure alcohol will not change with continued boiling. All pure substances in the liquid state have certain constant boiling points. Some are much higher than that of water, for example, the boiling point of mercury is $357^{\circ} \mathrm{C}$.; some are much lower, as oxygen, $-182^{\circ} \mathrm{C}$., or hydrogen, $-252^{\circ} \mathrm{C}$.

\section{Distillation}

\section{Boiling Point of a Mixture of Alcohol and Water.-If} pure wood alcohol boils at $66^{\circ} \mathrm{C}$. and continues to boil at that temperature till all of the alcohol has been turned into vapor the question arises: What would take place if we had a mixture of alcohol and water? With our distilling flask, thermometer, and lamp or burner we can soon answer the question.

\section{Exercise 16.-Distillation of Alcohol}

Fill the distilling flask about one-fourth full of alcohol and add an equal amount of water. Place some beads or small nails in the flask, insert the stopper and thermometer, and place the cardboard between the flask and the side tube. Light the lamp or burner and notice carefully the temperature at which boiling first takes place, i.e., when the first drops of liquid fall from the side tube. Catch this liquid in a beaker or small bottle. Watch the temperature carefully as the boiling continues. As soon as a little liquid has been caught as it drips from the side tube, perhaps a teaspoonful, remove the vessel and set another in its place. Probably some vapor will be escaping from the side tube. Light this vapor to see if it burns. Continue to watch the temperature at which the liquid in the flask boils. Does the temperature finally reach that of boiling water? How do you account for this fact? About what portion of the entire quantity of liquid has boiled over when the temperature reaches this point? Try to light the vapor now coming over. How do you explain the fact that this vapor will not burn? Remove the lamp. The portion of liquid which DISTILLED over and condensed is called DistiLlate. 
Pour the small portion of distillate first eaught into a shallow tin dish and see if it will burn. Pour some of the liquid remaining in the flask into another dish and see if it will burn.

Definition.-This process of changing a liquid into vapor by means of heat and then of changing the vapor back into a liquid by cooling it is called DistiLlation.

Because different liquids have different boiling points we are often able to separate the liquids in a mixture as we have just separated the alcohol from the water. It is not true, however, that the alcohol has been entirely separated from the water by this one distillation. The first portion of alcohol which passed over and which we burned contained some water; the water which remained in the flask at the close of the experiment likewise contained some alcohol. To get the alcohol nearly free from water it is necessary to re-distil several times. The factories where alcohol is made in large quantities are called DISTILLERIES because the alcohol when first made is mixed with water and must be separated from it by means of distillation (see Art. 447, page 394). We shall soon see that all the kerosene and gasoline which we use have been separated from petroleum by this same process of distillation.

\section{PROBLEMS}

Note.-In solving the following problems always draw the three horizontal lines to represent the three fixed temperatures and the two vertical lines to represent the two scales as in Fig. 11.

1. What reading on the centigrade scale corresponds to $100^{\circ} \mathrm{F}$.? Ans. $377 / 9^{\circ} \mathrm{C}$.

(2.) Lead melts at $326^{\circ} \mathrm{C}$. What is its melting point on the Fahrenheit scale?

Ans. $61845^{\circ} \mathrm{F}$.

(3. Cast iron melts at $1200^{\circ} \mathrm{C}$. What is the melting point on the Fahrenheit scale?

4. If a certain sample of paraffin melts at $50^{\circ} \mathrm{C}$., what is its melting point on the Fahrenheit scale? 122

5. If a liquid boils at $140^{\circ} \mathrm{F}$, what is its boiling point on the centigrade scale?

6. Which is the higher temperature: $-10^{\circ} \mathrm{C}$. or $10^{\circ} \mathrm{F}$, and what is the difference (1) in Fahrenheit degrees, and (2) in centigrade degrees? Ans. $-10^{\circ} \mathrm{C}$.; (1) $4^{\circ} \mathrm{F}$; (2) $2 \% 9^{\circ} \mathrm{C}$. 
7. Zero F. is what temperature on the centigrade scale? Ans. $-177 / 9^{\circ} \mathrm{C}$.

8. Prove that if mercury freezes at $-40^{\circ} \mathrm{C}$. that it also freezes at $-40^{\circ} \mathrm{F}$.

9. $-10^{\circ} \mathrm{F}$. is what temperature on the centigrade scale?

10. The temperature of the human body is $98.4^{\circ} \mathrm{F}$. What is it on the centigrade scale?

11. The temperature of a living room should be about $70^{\circ} \mathrm{F}$. What should it be on the centigrade scale?

12. What is the boiling point of mercury on the Fahrenheit scale?

13. What is the boiling point of oxygen on the Fahrenheit scale? Of hydrogen?

14. Gold melts at $1080^{\circ} \mathrm{C}$. What is this temperature on the Fahrenheit scale?

15. If the lowest temperature reached in the winter is $-25^{\circ} \mathrm{F}$. and the highest temperature of the summer is $100^{\circ} \mathrm{F}$., what is the total range of temperature (1) in Fahrenheit degrees, (2) in centigrade degrees?

16. Common salt melts at $1320^{\circ} \mathrm{F}$. and aluminum melts at $625^{\circ} \mathrm{C}$. Which is the higher melting point? Could salt be melted in an aluminum dish?

17. Under the pressure of $15 \mathrm{lb}$. per sq. in. water boils at $213^{\circ} \mathrm{F}$.; under the pressure of $30 \mathrm{lb}$. it boils at $250^{\circ} \mathrm{F}$.; under the pressure of $100 \mathrm{lb}$. it boils at $328^{\circ} \mathrm{F}$; under the pressure of $200 \mathrm{lb}$. it boils at $382^{\circ} \mathrm{F}$. What is each of these temperatures on the centigrade scale?

18. The electric furnace produces the highest artificial temperature known. It is usually estimated at about $4000^{\circ} \mathrm{C}$. Ball estimates the temperature of the sun to be about $14,000^{\circ} \mathrm{F}$. Compare these two temperatures.

19. Solder is made of a mixture of tin and lead. Lead melts at $326^{\circ} \mathrm{C}$. and tin melts at $230^{\circ} \mathrm{C}$. A certain sample of solder melted at $390^{\circ} \mathrm{F}$. Compare these temperatures and state the peculiar fact you notice.

20. A person with a fever has a temperature of $105^{\circ}$. A steam radiator has a temperature of $110^{\circ}$. Many people cook eggs at a temperature of $180^{\circ}$. The temperature of the schoolroom should be kept at about $70^{\circ}$. On a certain day a rain-storm suddenly turned into a snow-storm; the thermometer then indicated a temperature of $-5^{\circ}$. Which scale is referred to in each of these cases?

\section{PETROLEUM AND ITS PRODUCTS}

25. Petroleum.-When petroleum first comes from the well it is usually of a dirty, dark, bluish-brown color; usually 
it gives off a strong odor which is disagreeable to most people. In the region of oil wells the whole atmosphere is charged with this odor for miles around. This simply means that as the petroleum comes from the well some of it immediately evaporates, or passes off into the air in the form of vapor, or gas, NATURAL GAS.

We are not greatly surprised to find that this is so, for we have seen that water left uncovered is constantly evaporating. We have also seen that alcohol left uncovered evaporates even more rapidly. It is the same with all other liquids, though some evaporate very rapidly and others very slowly.

We have also seen that heating water or alcohol, or a mixture of the two, increases the rate of evaporation. If we heat either liquid hot enough, it boils and vaporizes with great rapidity.

26. The Distillation of Petroleum.-Remove the stopper from the bottle of petroleum. Notice carefully the color and odor. If we were to place a little in a vessel and heat it, we should see that it boils quickly. Hence, petroleum would seem to behave very much as water or alcohol does so far as evaporation and boiling are concerned. To understand the real nature of petroleum, however, it will be necessary to keep constantly. in mind all the facts we observed when we distilled the mixture of alcohol and water. What did we notice in regard to the boiling point of the mixture? Did it remain constant? At what temperature did it begin to boil? What was its boiling point when we stopped the experiment? What was our conclusion? We must keep these things in mind while we perform the following experiment:

\section{Exercise 17.-To Distil Petroleum}

Fill a 4-oz. distilling flask half full of petroleum, using a funnel so that no petroleum enters the delivery tube. Put some small nails or beads into the flask. Clamp the flask to the stand as in Ex. 15 and insert the stopper and the thermometer, which must have a scale which reads to about $360^{\circ} \mathrm{C}$. or $680^{\circ} \mathrm{F}$. The lower end of the bulb of the thermometer should reach about $1 / 2$ in. below the side tube. 
As the experiment proceeds the thermometer may have to be raised or lowered in the stopper in order that its reading may be taken. Place the piece of cardboard between the distilling flask and the vessel into which the distillate will drip. Guard against possible accident, such as the cracking of the flask. While it is extremely improbable that the flask will crack, it is well to set the entire apparatus in an ordinary dripping pan or some flat-bottomed vessel and to keep a wet towel near with which to smother the flames in case of accident (See Fig. 12).

Place the lamp under the flask and gently heat the petroleum. Notice that it begins to boil very soon. As soon as you see the vapor pass over into the delivery tube and there condense, read the thermometer. Catch the distillate in a small, clean bottle. Notice the color and appearance of the distillate. Watch the thermometer carefully. Is the temperature rising steadily? When it reaches $70^{\circ} \mathrm{C}$., or $158^{\circ} \mathrm{F}$., remove the bottle in which you have been catching the distillate and place another in position. Label this first bottle "Distillate No. 1." Does the temperature still continue to rise? When it reaches $80^{\circ} \mathrm{C}$., or $176^{\circ} \mathrm{F}$., again remove the bottle in which you have been catching the distillate and label it "Distillate No. 2." In the next bottle catch the distillate till the temperature has risen to $120^{\circ} \mathrm{C}$., or $248^{\circ} \mathrm{F}$. Label this "Distillate No. 3." Catch in a fourth bottle the distillate which passes over between $120^{\circ} \mathrm{C}$. and $150^{\circ} \mathrm{C}$. and label it "Distillate No. 4." Finally in a fifth bottle catch the distillate which passes over between $150^{\circ} \mathrm{C}$. and $300^{\circ} \mathrm{C}$. It will be found necessary to heat more strongly now and possibly to enclose the flask partly in a shield of tin or asbestos paper in order to raise the temperature to $300^{\circ} \mathrm{C}$. This last portion of the distillate will probably contain about one-half of the entire distillate. Remove the lamp and pour as much of the residue as possible out of the flask while it is still hot. When it cools it will be solid and cannot be removed readily from the flask. Wash the flask out clean with gasoline so that it will be ready for future use.

Caution.-Gasoline should be used for this purpose out of doors, or, if in the house, the doors and windows should be left open so that the wind may quickly remove the vapor from the room. Never use gasoline when there is a flame near.

27. The Products of Petroleum.-In this last experiment we have separated the crude petroleum into six different portions. The process is FRACTIONAL DIsTILLATION, and the products are practically the products of petroleum as they are sold on the 
market. We shall be able to remember these products better if we put them in a table thus:

\section{Table I.-Products of Petroleum}

\section{Boiling points}

1. Distillate No. 1 - "Petroleum Ether," $40^{\circ}-70^{\circ} \mathrm{C}$. or $104^{\circ}-158^{\circ} \mathrm{F}$.

2. Distillate No. 2- "Light Gasoline".. $70^{\circ}-80^{\circ} \mathrm{C}$. or $158^{\circ}-176^{\circ} \mathrm{F}$.

3. Distillate No. 3- "Heavy Gasoline," $80^{\circ}-120^{\circ} \mathrm{C}$. or $176^{\circ}-248^{\circ} \mathrm{F}$.

4. Distillate No. 4 "Naphtha"...... $120^{\circ}-150^{\circ} \mathrm{C}$. or $248^{\circ}-302^{\circ} \mathrm{F}$.

5. Distillate No. 5-"Illuminating Oil" or "Kerosene"...........

$150^{\circ}-300^{\circ} \mathrm{C}$. or $302^{\circ}-576^{\circ} \mathrm{F}$.

6. The Residue - The thick, tarry substance remaining in the flask.

28. Purifying the Petroleum Products.-These products of petroleum obtained by distillation will have a strong odor, and the kerosene will probably show considerable color. Formerly all illuminating oil was highly colored and had this same strong odor. Nowadays all of the products of petroleum are carefully cleansed and purified before they are put on the market. The purifying removes nearly all of the color and most of the offensive odor. The process of purifying kerosene is much too difficult for us to undertake.

\section{The Uses of These Petroleum Products.-}

Petroleum Ether is subdivided into several portions to each of which a special name is given. It is used chiefly in surgery and in dissolving substances like resin and heavy oils.

Light Gasoline is chiefly used in gasoline gas machines (see Art. 45).

Heavy Gasoline is often known as "stove gasoline" and is the common gasoline sold at the grocery store. It is used in gasoline stoves, in gasoline lamps, in automobiles and gasoline engines. It is also sometimes used in paints.

NAPHTHA, often called "heavy naphtha," is used as a substitute for turpentine in making paints and varnishes, and also for cleaning heavy oils from machinery.

On account of their evaporating so rapidly when exposed to the air or, as we say, being so very volatile, these first four products of petroleum are called the LIGHT OILS or SPIRITS. 
Kerosene or Illuminating Oil is chiefly used to furnish light when burned in the ordinary kerosene lamp. It is also frequently burned in stoves of special construction for heating purposes.

The Residue is manufactured into LUBRICATING oIL, PARAFFIN OIL, and SOLID PARAFFIN. A small amount of coKE still remains after these are removed.

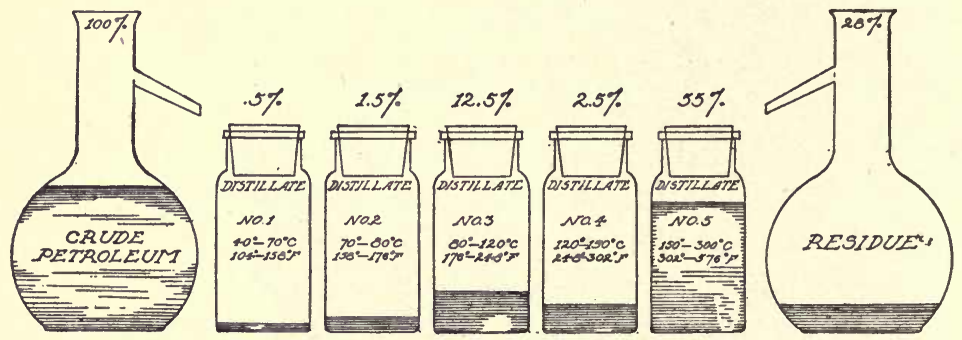

Frg. 13. - The products of petroleum.

SugGestion.- It would be well for you to catch the different distillates which you obtained in Ex. 17 in small bottles, cork them air tight, label each with its correct name and boiling points, then set them away for future reference. Your parents and friends will be glad to see samples of the crude petroleum and these products (Fig. 13).

\section{PROPERTIES OF GASOLINE-SOURCES OF DANGER}

Density, Flashing Point and Burning Point

\section{The Grades of Gasoline as the Merchant Knows Them.} -We have seen that gasoline is a name applied to some of the lighter, more volatile products of petroleum. We have also seen that it is separated both from the lighter petroleum ether and the heavier naphtha and kerosene by means of fractional distillation. We have further seen that there are two grades, at least, of gasoline-light gasoline and heavy gasoline. When you buy gasoline at the grocery store you will receive what the grocer calls stove Gasoline. This is the heavy gasoline. 
The oil manufacturer and dealer, however, know it as $62^{\circ}$ to $68^{\circ}$ GASOLINE, and they know the lighter gasoline as $86^{\circ}$ to $88^{\circ}$ GASOLINE. This speaking of gasoline as being such or such a degree gasoline refers to the grading of it by means of a little instrument called a 'BAUMÉ HYDROMETER (Bō-mā).

31. Baumé's Hydrometer.-This instrument (Fig. 14) consists of a glass tube 8 or $10 \mathrm{in}$. in length. Near its lower end this tube has been blown into a large bulb, and still farther down, at its very end, it has been blown into a small bulb and sealed. Some mercury or small shot is dropped down the tube into the lower, small bulb. Some melted sealing wax is then dropped down inside the tube and made to close the opening between the two bulbs. Care is taken to have the instrument so weighted that it floats with the stem above the large bulb above the surface when placed in water. The instrument is then GRADUATED by floating it in lighter liquids and marking the scale on a strip of paper which is slipped down inside the stem. The stem is then sealed and the instrument is complete.

The instrument is called a Baumé hydrometer (hydro - water, and metron - measure), because Baumé invented the scale used upon it. Oils of all kinds including the products of petroleum, also syrups, vinegars, and many other liquids are regularly bought and sold on the market at prices which vary according to the density of the liquids as determined by this

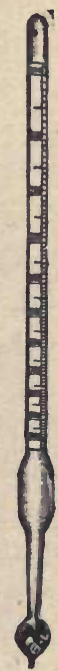

FIG. 14.

Baumé hydrometer. hydrometer. It must be remembered that the light gasoline has a lower boiling point and is a lighter liquid per gallon than the heavy gasoline. But it must also be remembered that the grading of the lighter oil by the Baumé hydrometer is $86^{\circ}$ or $88^{\circ}$, while the heavy oil grades $62^{\circ}$ to $68^{\circ}$. That is, it is always true that the lighter the oil, the higher it will grade in Baume degrees; the heavier the oil, the lower it will grade in Baumé degrees. Kerosene grades about $45^{\circ}$ Baumé, and is written " $45^{\circ} \mathrm{B}$." 
32. The Inspection of Oil.-If the different grades of gasoline, naphtha, and kerosene have been properly distilled and purified we are able to tell fairly closely the range of boiling points of the different oils, simply by testing their DENsITY, by means of this hydrometer. The different states have passed laws governing the manufacture and sale of the products of petroleum. These laws have been passed for the protection of the purchaser and user. There are oil inspectors in nearly all cities and in many of the smaller towns whose duty it is to inspect the products of petroleum offered for sale and to see that they are really what they are said to be. In most, if not all, of the states the products of petroleum must be thus inspected before they are offered for sale. This test for density by means of the Baumé hydrometer is one of the tests.

33. Flashing Point.-The most important test, however, which can be given the products of petroleum is to test their FLASHING POINT (Art. 5, page 4). This consists in determining the temperature of the oil at which the vapor arising from it will flash when a flame is brought near it. It is this test which determines whether an oil is safe or unsafe to have about a building or to be put to certain uses. A good, legal quality of kerosene is not to be considered dangerous to have in a room. Any quality of gasoline, on the other hand, is always to be considered dangerous, and must be cared for accordingly. A very simple experiment will show us that this is so, and will help us to understand why it is so.

\section{Exercise 18.-Flashing Point of Gasoline and Kerosene}

Put four or five tablespoonfuls of kerosene in a tin cup. Place the bulb of the thermometer in the oil and take its temperature. Record this. Light a match and try to set the kerosene on fire. Are you successful? Try again. Make a sufficient number of trials to satisfy yourself whether or not you are able to set the kerosene on fire. It is not probable that you will succeed, but if you should finally get it to burn, smother the flames quickly by placing a piece of glass over the dish so as to exclude all air. Take the temperature of the oil again and record all that happened. 
Now place two tablespoonfuls of gasoline in another cup. Take its temperature. Remove the thermometer. Try lighting the gasoline as you did the kerosene. Be sure that the glass is close by so that you can cover the dish quickly in case the oil catches on fire. Also be sure that the can of gasoline has been removed from the room, or tightly corked. When the flame has been extinguished, remove the glass from the dish, light another match and bring it slowly down above the dish to see at what height above the surface of the gasoline the flash does take place. Try again. Is it the liquid gasoline which burns?

Set the gasoline to one side, and make a further study of the kerosene. If you have a good quality of oil, you have probably not yet succeeded in making it burn. Fit the wire gauze on the ring of the stand. Set the cup of kerosene on the gauze and heat very gently (Fig. 15). Test the oil frequently with the lighted match to see if it will catch on fire. When it is hot enough it will suddenly flash when the lighted match is applied. Take its temperature. This temperature is somewhat, perhaps slightly, above the FLASHING POINT. If the flame continues to burn above the surface of the oil, you have heated it several degrees above the flashing point. It is, indeed, above

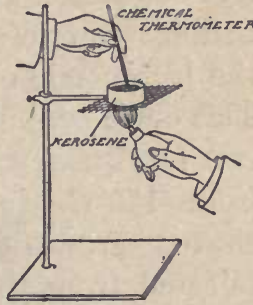

Fia. 15.-Flashing point of kerosene. the BURNING POINT. Let the oil cool. But to do so you must put out the flame. Take the temperature each minute or two, as it cools, and after each reading of the thermometer test the oil with a lighted match to see if it still burns. When it no longer burns, you have passed the BURNING POINT. It may still flash, however, but the flame immediately goes out. It is still above the FLASHING PoINT if this is the case. When the oil no longer flashes you have passed the flashing point.

Definitions.-The flashing point of an oil is the lowest temperature of that oil at which it will give off enough vapor so that when mixed with the air above, it produces a momentary flash when a flame is brought near the surface of the oil.

The burning point, or fire test, of an oil is the lowest temperature of that oil at which it will give off enough vapor to maintain a continuous flame when once ignited.

The burning point of kerosene may be from $20^{\circ}$ to $60^{\circ} \mathrm{F}$. higher than its flashing point. In ordinary kerosene it is usually froin $40^{\circ}$ to $50^{\circ} \mathrm{F}$. higher. Most of the states have 
laws which forbid the sale of oil as illuminating oil, or kerosene, which has a flashing point lower than about $110^{\circ} \mathrm{F}$. or a burning point lower than about $150^{\circ} \mathrm{F}$. This is the most important of all of the tests which the inspector applies to kerosene.

The better qualities of kerosene have a flashing point of $120^{\circ} \mathrm{F}$. to $140^{\circ} \mathrm{F}$. If a lighted match be dropped into it, the flame is extinguished. It has no unpleasant odor and burns up completely without charring the wick of the lamp. Such an oil is obtained by rejecting the first of the distillate after the boiling point of the petroleum has reached $150^{\circ} \mathrm{C}$. and also the last portion just before the boiling point reaches $300^{\circ} \mathrm{C}$. This choice distillate is then carefully purified.

A fair quality of oil is obtained by using all of the distillate from $150^{\circ} \mathrm{C}$. to $300^{\circ} \mathrm{C}$. and carefully purifying it. The cheaper grades of oil contain larger amounts of the portions rejected from the higher grades. They therefore have low flashing and burning points, and char the wicks.

34. Use of Kerosene in Kindling a Fire.-If instead of catching on fire itself a good quality of kerosene will put out a burning mat.ch, how is it that kerosene may be used as a kindling in starting a fire? It is a common thing for people to dash a little kerosene upon the fuel in a stove when starting a fire. Can you readily start a coal fire by the use of kerosene alone as kindling? Why does kerosene ignite so much more readily when poured upon wood or paper than when poured upon coal? Is it ever safe to use kerosene as kindling when starting a fire? These and other questions which may arise are easily answered by remembering that kerosene vapor burns only when the kerosene is heated to its burning point.

When the oil is poured upon wood, especially if the wood is splintered or in the form of shavings, it becomes an easy matter to heat small portions of the oil which saturate the smaller splinters or shavings to the burning point. When the oil lies spread as a thin coat over the chunks of coal it is difficult to raise any portion of the oil to its burning point, unless the ooal 
is very finely divided, because the heat applied to the oil passes on into the coal and it becomes necessary to raise the temperature of the whole chunk of coal to the burning point of kerosene. The match does not furnish a sufficient amount of heat to do this.

Danger of an explosion from the use of kerosene arises only when the oil is heated above its flashing or burning point. Evidently if the oil is poured upon unheated fuel and is then ignited, the flame will consume the vaporized oil as rapidly as it is vaporized. If, however, the oil is poured upon heated fuel or live coals, or even upon fuel in a heated stove, there is then danger that the oil will be vaporized in large quantities and mixing with the air will produce an explosive mixture. If the flame be then applied a violent explosion is certain to occur. Therefore, kerosene should never be used as kindling if there are live coals in the stove or if the stove is itself still hot.

\section{Danger in Using Cheap Kerosene and Gasoline}

35. Danger in Using Cheap Kerosene.-Many experiments with lamps of different shapes and materials show clearly the danger which comes with the use of inferior qualities of kerosene. With the temperature of the room $73^{\circ}$ or $74^{\circ} \mathrm{F}$. the temperature of the oil in the lamp bowl has been found to vary from $76^{\circ}$ to $100^{\circ} \mathrm{F}$. With the temperature of the room $82^{\circ}$ to $84^{\circ} \mathrm{F}$. the temperature of the oil is from $84^{\circ}$ to $120^{\circ} \mathrm{F}$. With the temperature of the room $90^{\circ}$ to $92^{\circ} \mathrm{F}$. the temperature of the oil in the lamps in some cases ran as high as $129^{\circ} \mathrm{F}$., though these were exceptional.

From these facts it is evident that the oil within the lamp is likely to be heated to a temperature considerably above the temperature of the room. It is also evident that no oil should be used which does not have a flashing point considerably above the highest temperature ever reached by the air of the room. Explosions occur because the oil has been heated to a temperature above the flashing point. 
36. Oil May be Dangerous when Standing in the Can.-The following facts must be kept constantly in mind by all users of petroleum products:

1. Any oil is a dangerous oil and must be kept away from all fires or open flames if it has a flashing point which is at or below the highest temperature ever attained by the room or building in which it is stored.

2. In fact, merely removing the can of oil from the room does not remove all of the danger. If the room has been closed for some time, the vapor which has escaped may have saturated the air in the closets, cupboards, or even trunks, and this saturated air will explode when ignited.

3. Gasoline has a flashing point far below the temperature of any living room. If the can is not air tight, the vapor of the gasoline is certain to escape into the room. Unless the room is very well ventilated, the air in it may become so saturated with the vapor of the gasoline that it will burn with an explosion when ignited. In its low flashing point lies the danger of using yasoline.

4. The flashing point of legal kerosene is sufficiently above the ordinary temperatures so that no corresponding danger exists in its use.

37. May Gasoline be Used with Comparative Safety?Yes, by observing the following precautions:

1. Keep the main can of gasoline in some well-ventilated outbuilding.

2. If the can must be kept in the living rooms, see that it is corked as tight as possible, that it is in as cool a place as possible, and that the room is well ventilated.

3. Never take a flame of any kind near the can, nor near any large quantity of gasoline.

4. Never attempt to fill a gasoline stove or lamp by lamp light.

5. In case gasoline is spilled by accident, or has leaked from the receptacle, open wide the doors and windows of the room to change the air completely before bringing a flame into the room. Also thoroughly ventilate all cupboards and closets in which 
there is a possible chance of the air having become saturated with the gasoline vapor.

If these precautions are observed there will be but little danger in handling gasoline.

\section{GASOLINE LAMPS AND GASOLINE GAS MACHINES}

\section{Gasoline Lamps}

38. Reviewing the Kerosene Lamp.-When we studied the kerosene lamp we saw that it was the vapor arising from the heated kerosene in the wick which burned. We also saw that this vapor had to be mixed with just the right amount of fresh air before it burned properly.

When the kerosene burned in the lamp we noticed that this changing of the liquid kerosene into vapor and the mixing of the vapor with the air, both processes, took place in the upper portion of the burner. The oil in the bowl of the lamp was not heated much by the flame. If a good quality of kerosene is used, it will never be heated to the flashing point except at the tip of the wick where the flame is burning. Therefore in constructing an ordinary kerosene lamp no attempt is made to have the bowl of the lamp air tight or to remove the oil far from the flame. There is no need of doing so. The ordinary kerosene stove is constructed on precisely the same principles as the lamp.

39. Dangerous to Burn Gasoline in a Kerosene Lamp.-To burn gasoline in an ordinary kerosene lamp would be a very dangerous undertaking. We have seen that gasoline is always at a temperature far above its flashing point when in the ordinary heated or unheated room. This means that if gasoline were placed in a kerosene lamp it would constantly be vaporizing from the wick exactly as it would from an open can. Such a condition would be dangerous when the lamp was lighted. The lamp bowl would contain a mixture of air and gasoline vapor which would be ready to explode as soon as the flame should reach it. 
40. Construction of the Gasoline Lamp.-We shall first look at the construction of an ordinary hanging gasoline lamp

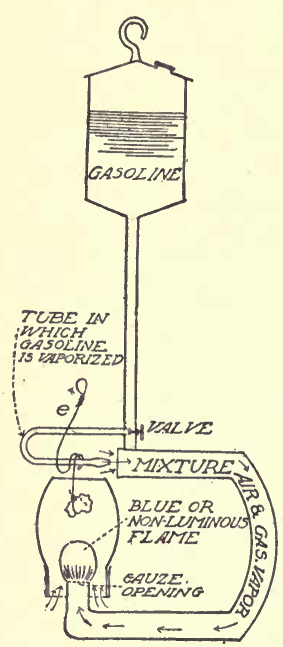

FIg. 16.-Gasoline lamp. (Fig. 16). At the top we notice the holder containing the gasoline. From its bottom a small tube extends downward, $2 \mathrm{ft}$. or more. Connected with this tube and extending sidewise from it is a small U-shaped tube. The lower arm of this U-tube is somewhat shorter than the upper arm. This lower, shorter arm has a small opening about the size of a pin hole in its end. There is a valve in the lower end of the upright tube just opposite the small Utube. This valve completely closes the opening into the small U-tube when the lamp is not burning.

Supported below the upright tube and extending out on the side opposite the small U-tube is another and much larger U-tube. The upper end of this second large U-tube is entirely open and is directly in front of the opening in the end of the small U-tube. The lower end of this large U-tube is bent upward directly below the small U-tube and carries all there is of a burner. But the burner is very simple. The only really necessary thing about the burner is a piece of fine wire gauze which must be slipped over the bent-up end of the large U-tube. Sometimes there is a perforated framework to support the chimney. The chimney must extend upward nearly to the small U-tube.

41. Lighting and Burning the Gasoline Lamp. -The lamp bowl is filled with $62^{\circ} \mathrm{B}$. oil. A small

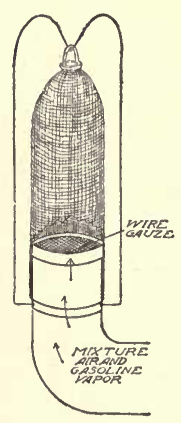

Fig. 17. Mantle for gasoline lamp. wire 10 or $12 \mathrm{in}$. in length is bent as shown by e, Fig. 16. The lower end of this wire has been wrapped around some 
asbestos wool. This asbestos wool is saturated with alcohol just before being placed upon the small U-tube. This alcohol is lighted. The flame heats the small U-tube quite hot. The valve is now cautiously opened so that gasoline may flow. As the gasoline flows through the heated U-tube it is vaporized. This gasoline vapor mixes with air as it passes into the MIXER. This mixture of gasoline vapor and air, or GASOLINE GAS as it is called, is lighted as it escapes through the burner.

As soon as the lamp is lighted the asbestos is removed. The heat from the burning gasoline keeps the small U-tube hot, thus vaporizing the gasoline as long as the lamp burns.

The purpose of the small U-tube is to heat the gasoline and vaporize it; it is the VAPORIzER. The purpose of the large U-tube is to mix the gasoline vapor with air; it is the MIXER.

42. The Need of a Mantle.-The flame is, however, a disappointment to those who expect much light. But by holding your hand above the chimney, you will see that a great deal of heat is being produced. Before much light can be obtained from this lamp we must place a MANTLE over the burner as shown in Fig. 17. This mantle consists of a small inverted sack about 1 in. in diameter and 4 in. long. It is suspended from a metal frame which sits over the burner and holds the mantle in place.

The mixture of gasoline vapor and air is burning within the mantle. The mantle does not burn but glows, because it is heated white hot, exactly as a piece of iron glows when heated to white heat in a blacksmith's forge. The material out of which the mantle is made is now said to be heated to INCANDESCENCE. Such lamps as this consequently are said to be INCANDESCENT lamps. The word incandescence comes from two Latin words: in, meaning in; and candesco, meaning to grow hot.

This lamp involves principles employed in the burning of gasoline in all gasoline lamps, stoves, and gasoline engines. It is capable of giving as much light as 100 or 150 candles or 10 
common kerosene lamps. When understood, it is easily handled and has found wide use, especially in lighting stores and large public rooms where electricity or gas is not available.

43. Modified Forms of the Gasoline Lamp. - In the form of lamp just studied, the gasoline is contained in a reservoir above

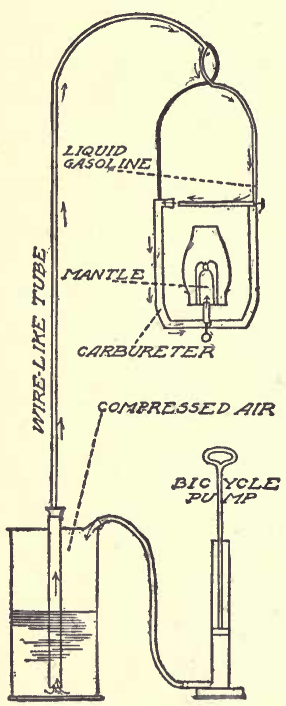

FIG. 18.-Gasoline lamp tube system. the lamp. The gasoline flows down the tube by the force of its own weight. In many gasoline lamps the oil is stored in a bowl below the burner and is forced up into the burner by means of compressed air.

A slightly modified form of this lamp is often used when a complete lighting system is to be installed in a store or building (Fig. 18). In this case any number of lamps may be joined in one system. The gasoline is stored in a stout iron cylinder which may be placed in the basement or at any distance desired from the lamps. Leading from this tank is a wire-like tube. This tube connects with the lamp which is in all respects similar to the lamp studied. By means of a bicycle pump, air is compressed in the top of the cylinder. The pressure of this compressed air forces the gasoline up through the tube to the lamp, where it is heated and turned into vapor and then burned exactly as in any other gasoline lamp.

The advantages of this system are: (1) The gasoline may be removed to any safe and convenient place; (2) any number of lamps may be attached to the tube leading from a single tank; therefore an entire building can be supplied from one tank; (3) the whole apparatus is very light and is easily moved from place to place.

While this system has been used extensively in lighting stores, and other public and private buildings, it has been found to be 
especially adapted to the lighting of tents and temporary buildings for public meetings.

\section{Gasoline Gas Machines}

44. Gasoline Easily Vaporizes.-We have seen that gasoline exposed to the air vaporizes rapidly. We have also seen that if any considerable quantity of gasoline remains exposed to the air of a room for a short time that the air becomes so charged with the vapor of gasoline that it burns readily. In fact, the mixture frequently explodes violently when a flame is brought near. This is the cause of most accidents which occur from the careless use of gasoline.

Since, in the lamp, the gasoline is exposed to the air for an instant only it is necessary to heaf it so as to completely vaporize it before mixing with the air. The heat produces complete vaporization, as we might suppose from the second law of evaporation (Art. 13). In the gasoline machine the gasoline is exposed to the air for a sufficient time so that all of the gasoline is vaporized without the use of artificial heat.

45. Gasoline Gas Machines.-There are many different types of gasoline gas machines. Every machine must, however, consist of two distinct and different parts and usually possesses a third. The essential parts are a BLOWER or PUMP, and a CARBURETER. The third part is called a MIXER.

THE BLower is simply a device for forcing a current of air out through the carbureter and back into the pipes of the building. It maintains the pressure on the gas. Fig. 19 shows a common form of blower. It consists of a large fan operated by means of a heavy weight. The weight is wound up at intervals as required. It exerts a constant pressure upon the pump. As long as lights are burning, the pressure is being reduced and the pump works to maintain the pressure.

Tire Carbureter is a large tank capable of holding several barrels of gasoline. It is buried in the ground usually some distance from the wall of the basement of the building. There are, of course, different styles of carbureters. The 
cuts (Figs. 19 and 20) show one form made of heavy sheet steel. It is shaped much like a cheese tub, but is divided into
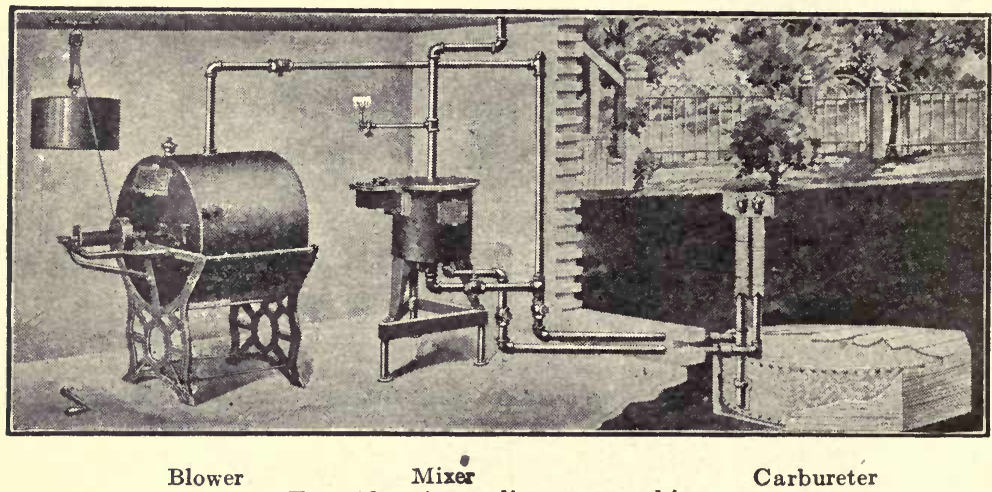

FIG. 19.-A gasoline gas machine.

four cells by the three false bottoms. Upon each of these shelves, or bottoms, stands a spiral coil of absorbent material

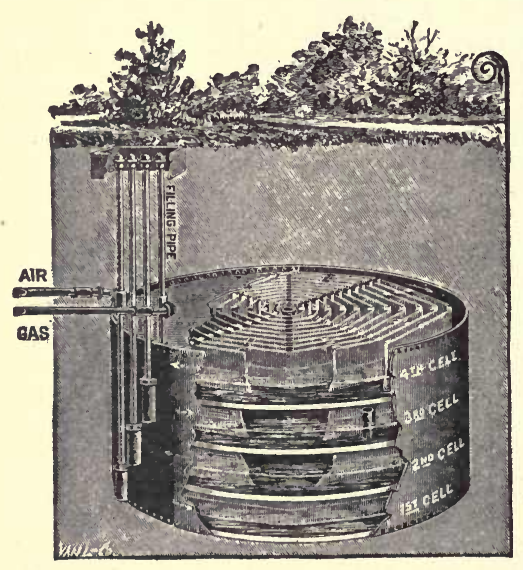

FIG. 20-Sectional view of the carbureter. like lamp wicking. This absorbent material is intended to form a coil-like partition extending from top to bottom of each cell so that the air must, in passing through one cell, pass through the long coillike passage. The bottom of the passage is gasoline; each side is the absorbent material saturated with gasoline. The cells are so connected that air in passing through the carbureter must pass through all four of these passages. If straightened out the passage would be 2 in. high, 3 in. wide and $300 \mathrm{ft}$. long. The purpose of the carbureter is to expose the 
gasoline to the air as much as-possible so that the air will become fully saturated with the gasoline vapor producing gasoline gas.

THe Mixer is a device for maintaining the proper mixture of gasoline vapor and air. Gasoline consists of many different compounds (See Ar.t. 88). Each compound has a certain rate of evaporation, at a given temperature. The lighter portions of the gasoline evaporate more quickly than the heavier portions. This means that for some time after each refilling of the carbureter the air is more completely charged with vapor than is the case later when the lighter portions of the gasoline have evaporated and only the heavier portions remain in the carbureter. The purpose of the mixer is to keep the gasoline gas, i.e., the mixture of air and gasoline vapor, the same at all times.

The gasoline gas machine is used successfully, not only to furnish gas for lighting purposes, but also for cooking in a gas range exactly as city illuminating gas is used. It is found in many country residences. Only $88^{\circ} \mathrm{B}$. gasoline can be used in these machines.

\section{MANUFACTURED GASOLINE AND MOTOR SPIRIT}

46. Importance of Gasoline.-Up to about the year 1900 kerosene, or illuminating oil, was by far the most important product of petroleum. Only a certain percentage of the crude oil-generally from 30 to 50 per cent.-could be refined as illuminating oil and about 20 per cent., as gasoline. There was a good market for the kerosene but only a light demand for the gasoline. As a consequencé, kerosene sold for a higher price than did gasoline. With the general introduction of electric lighting in towns and cities the demand for kerosene fell off; while, at the same time, with the perfecting of the automobile and the gasoline engine's coming into general use, the demand for gasoline increased greatly. About 1910 the demand for gasoline became greater than the supply, and the price became higher than that of kerosene. This increased demand for gasoline has led oil refiners to adopt the plan of putting nearly 
all of the distillates of petroleum up to illuminating oil together and selling them as gasoline. While the common grade of gasoline, heavy gasoline, or stove gasoline, as it was called, used to have a density of about $72^{\circ}$ to $74^{\circ} \mathrm{B}$., it now commonly has a density considerably greater, about $62^{\circ}$ to $64^{\circ} \mathrm{B}$. (see Art. 31). This heavier gasoline does not work so well in automobiles during cold weather and manufacturers have been obliged to modify their engines so that they could burn the grade of gasoline obtainable.

47. Manufacture of Gasoline from Natural Gas.-In the vicinity of petroleum wells the atmosphere is charged with the odor of escaping gases. A considerable portion of the flow from an oil well evaporates immediately at the temperature of the atmosphere. This is natural gas. Recently it has been found possible to change this escaping gas into an oil closely resembling gasoline. This is done by placing the gas under very high pressure and at the same time cooling it to a very low temperature. In 1912 there were 250 plants in the United States for changing natural gas from petroleum wells into gasoline and over 12,000,000 gal. were produced.

48. Manufacture of Motor Spirit, or Motor Oil.-During recent years oil refiners have been constantly searching for some method by which they could profitably produce more gasoline from a barrel of petroleum. In 1911 W. M. Burton, a chemist in the employ of the Standard Oil Company of Indiana, perfected a process of producing a good substitute for gasoline from the residue of petroleum after the illuminating oil has been removed. This new oil is called MOTOR sPIRIT or MOTOR OIL. By a special method of "destructive" distillation a large amount of this motor spirit is obtained. In general, this "destructive" distillation is accomplished by distilling the residue containing the lubricating oils, the paraffin and the tar and coke, under high pressure and therefore at high temperature (see Arts. 154 to 160).

49. Properties of Motor Spirit.-Motor spirit is somewhat lighter than gasoline and has somewhat different properties, 
but it has been found to be a very good substitute for gasoline when used as a fuel for gasoline engines. It is said to produce more power per gallon than does gasoline. However, it has an unpleasant odor and is more inclined to produce a deposit of carbon in the cylinder of the engine. At the present time it is being used extensively only in heavy auto trucks and in automobiles used in business. Figure 21 shows the relative amounts of the products obtained from crude petroleum when distilled by the old methods and by the new method.

\section{OUR SUPPLY OF PETROLEUM}

\section{The Rise of the Petroleum} Industry.-Petroleum was first produced in commercial quantities in the United States in 1858 . In 1860 about $2,000,000 \mathrm{bbl}$. were produced; in 1913 about $240,000,000 \mathrm{bbl}$. were produced. On the average the
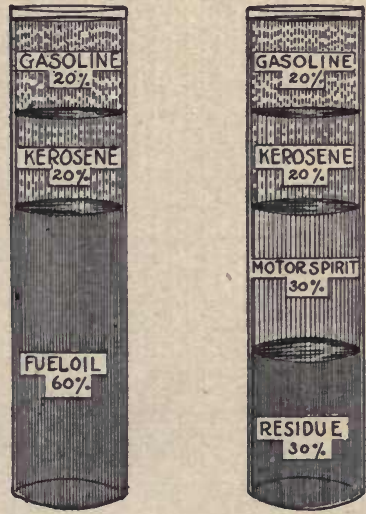

FIG. 21.-Products of petroleum when distilled by the old and by the new methods. production of petroleum in the United States has doubled about every eight years. Figure 22 shows the growth of the petroleum industry and also shows the date at which each new field was discovered.

51. The Oil Fields of the United States.-The Pennsylvania fields produced all of the petroleum up to 1886 , when the Lima, Ohio, field was discovered. The Indiana field was discovered in 1897; the Texas field, in 1901; the California field, in 1903; the Oklahoma field, in 1905, and the Illinois field, in 1906. Figure 23 shows the known fields of the United States.

52. How Long Will Our Supply of Petroleum Last?-Experience has shown that the supply of oil in each field is limited. The Pennsylvania field is now nearly exhausted. All of the older fields are rapidly falling off in the amount of oil produced 


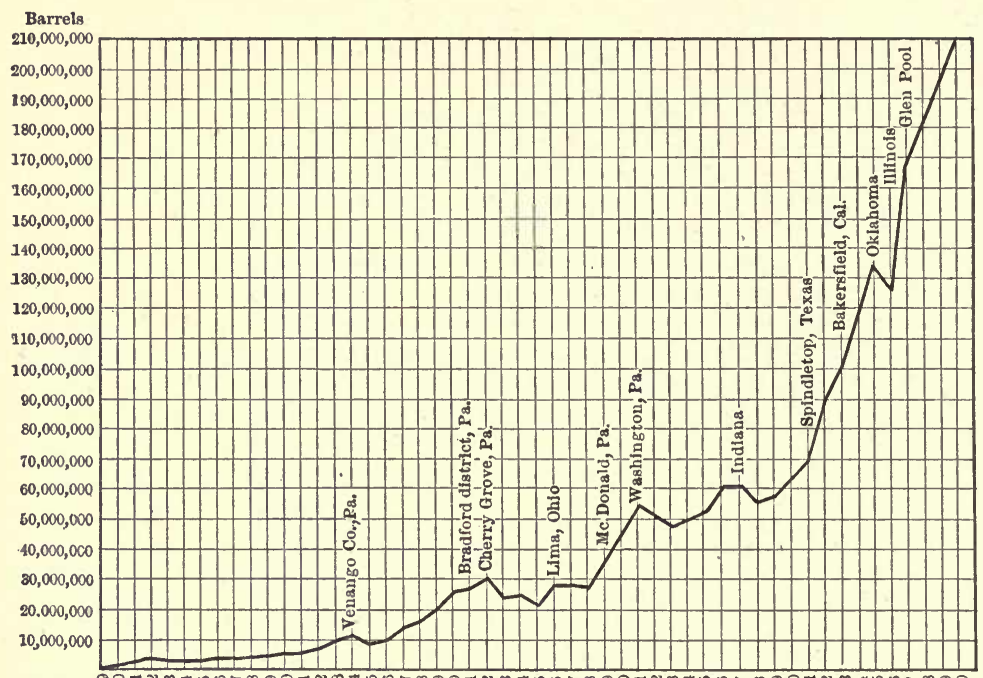

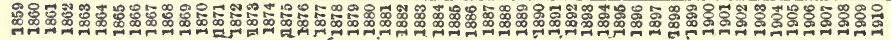

FIG. 22.-Annual production of petroleum, 1859 to 1910 .

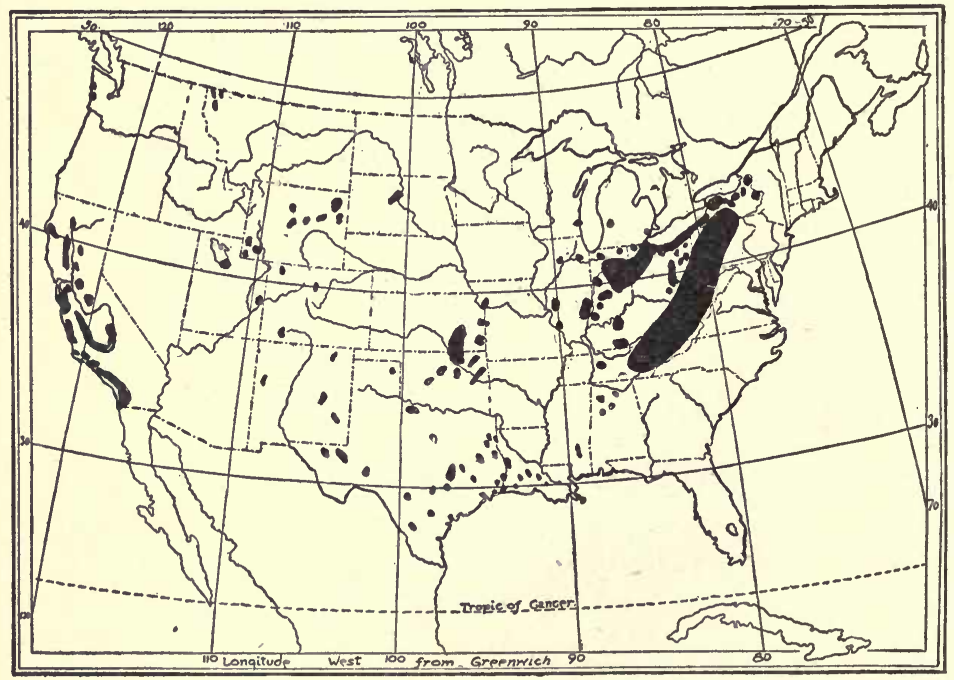

FIG. 23.-The oil fields of the United States. 
annually. Fortunately, up to the present time, as the older fields began to fail new fields have been discovered. It is thought, however, that most of the oil fields of the United States are now known. It seems nearly certain that before many years the supply of petroleum in the United States will be declining. Oil fields of undetermined productiveness are known to exist in Mexico and South America and so it may be possible that we shall be importing much oil from these countries before many years.

\section{ILLUMINATING GAS LIGHTING}

53. Illuminating Gas.-By illuminating gas we usually mean either manufactured coal gas or water-gas saturated with oil vapors (Arts. 115 and 116), although gasoline gas, as we have just seen, and acetylene, as we shall see in the next section, are also used for illuminating purposes. Whatever the source of illuminating gas, it usually is piped into the house and passes through a meter where its volume is measured. The price paid for it is usually set at a certain sum per $1000 \mathrm{cu}$. ft.

54. The Gas Meter.-The common gas meter consists of an air-tight, and therefore gas-tight, metal ease, Fig. 24, which is divided into two compartments by a metal partition. Each of these compartments is again divided into two compartments, $A$ and $B$, Fig. 25 , by a metal disk, 2 , and a leather diaphragm, 4, Fig. 24. The leather diaphragm permits the metal disk, $D$, Fig. 25 , to move freely from left to right and from right to left under the pressure of the gas. The gas enters through the inlet pipe, 9, Fig. 24, into the valve chamber. It then passes past the valves, 8 , into the chambers $A$ and $A$, Fig. 25. Both disks, $D$ and $D$, are, then, being forced to the right by the gas pressure. Whenever an outlet is opened, i.e., a gas jet or gas stove is lighted, the gas escapes through the valves as indicated into the house pipes. As the disks move, the flags, 3 , twist the flag rods, 5 . This rotating motion of the flag rods is transmitted by the flag arms, $7,7,7$, to the valves and the dial pointers. When the disks have moved to the 
right till the compartments $B$ and $B$ are quite small and the compartments $A$ and $A$ are quite large, the valves are shifted to the left so that the gas then enters the compartments $B$ and $B$ and escapes from $A$ and $A$. The two are so attached that one shifts one-fourth of a complete vibration before the other does.

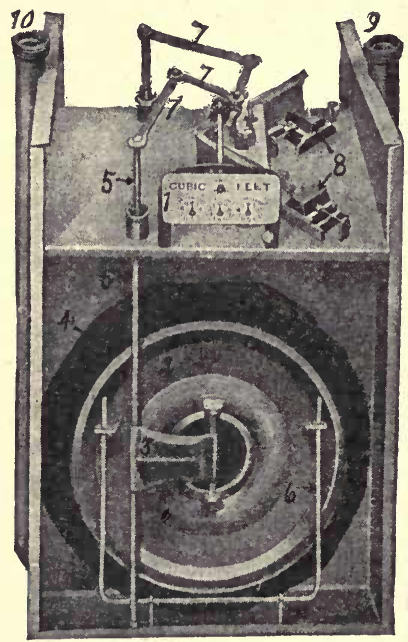

FIG. 24.-A dry gas meter, the front and top casings removed.

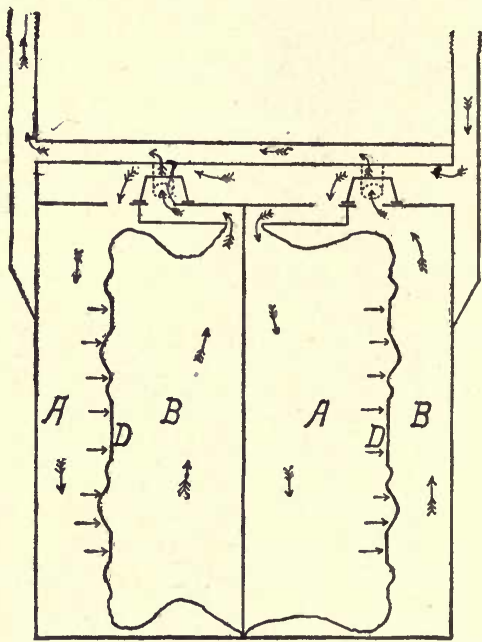

Fig. 25.-Ideal diagram showing the operation of the gas meter.

The gas pressure is then exerted upon the right side of the disks and they move to the left whenever gas is being used. Thus, so long as gas is being consumed the disks keep moving back and forth. This to-and-fro movement of the disks operates the valves and the dial pointers.

\section{Exercise 19.-To Study the Construction and Operation of a Gas Meter}

Stand at one end of a meter from which the casing has been removed as shown in Fig. 24. ${ }^{1}$ Grasp the two flags, one in each hand. By pressing the disks to right and left alternately you will soon learn so to operate them as to cause the crank always to revolve in the right direction. Watch carefully the movement of the valves and the pointers.

1 A worn-out meter can usually be obtained from the local gas company. 
55. Reading a Gas Meter.-The small upper dial on a gas meter is the TEST DIAL. It is generally used only in testing the accuracy of a meter. The other dials are the ones ordinarily used in reading the amount of gas consumed.

Exercise 20.-To Study the Recording Mechanism of the Gas Meter

Notice that the right-hand pointer revolves in a clockwise direction, that the second pointer revolves in a counter-clockwise direction and the third revolves in a clockwise direction. Study the gear wheels to see why this is so. Notice that a small $\operatorname{cog}$ wheel on the shaft which carries the TEST POINTER engages a large cog wheel on the shaft which carries the right-hand pointer. By counting the cogs on each of the wheels determine how many turns the test pointer makes to one turn of the right-hand pointer.

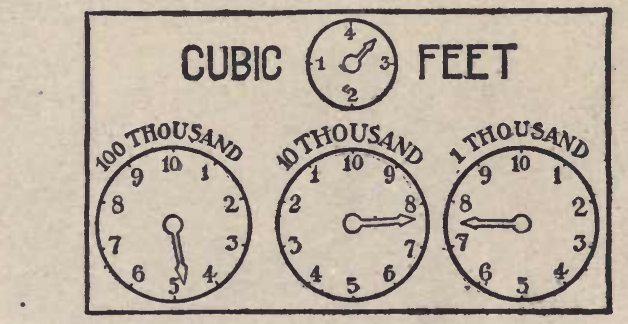

FIG. 26.-This meter reads 47,750 cubic feet.

The right-hand pointer makes one complete revolution while 1000 cu. $\mathrm{ft}$. of gas is passing through the meter; the second pointer makes one revolution while $10,000 \mathrm{cu}$. $\mathrm{ft}$. of gas is passing through the meter. See that the number of cogs in the gear wheels indicates this relation (Fig. 26).

What is the reading of the gas meter you have been studying?

Read the gas meter at the school, or at home, every day for a week, keeping a careful record of the readings in your permanent notebook. You will need these readings later.

\section{6.-Determining the Pressure of Gas.-}

\section{Exercise 21.-To Measure the Pressure of Gas}

Connect a U-tube with the gas jet as shown in Fig. 27. Fill the U-tube half full of water. Support the apparatus in an upright position. Such a piece of apparatus is called a MANOMETER. Carefully 
open the gas cock, letting the gas pressure into the manometer. With the ruler read accurately the difference in the level of the water in the two arms of the manometer. If convenient, permit the manometer to remain in position so that you can quickly determine the pressure several times each day for several days. Read often and record the reading together with the data and the hour. If the pressure varies considerably at different hours of the day, how do you account for it?

57. Gas Burners.-Illuminating gas may be burned in open jets or in incandescent burners, that is, within mantles. The incandescent gas lamp is constructed on exactly the same principles as the incandescent gasoline lamp. The gas is

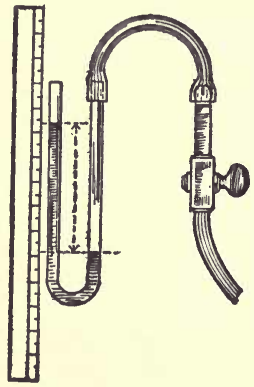

FIG. 27.-Device for determining gas pressure.

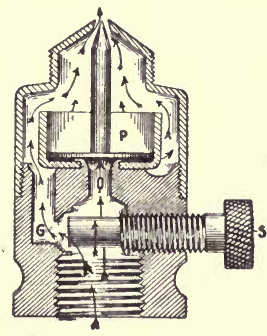

FIG. 28.-Automatic device for regulating gas pressure.

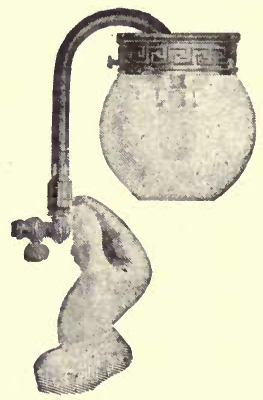

Fig. 29.-An inverted illuminating gas lamp.

mixed with air in a tube below the burner. This tube is therefore the MIXER. The mixture of gas and air passes through a wire gauze at the top of the mixer and is burned within the mantle, there producing a blue, or non-luminous, flame but much heat. What, then, is the source of the light? All burners are supplied with some device for regulating the gas and air supply. Some burners are also supplied with an automatic device for regulating the gas pressure (Fig. 28). Recently several forms of inverted mantle gas lamps have come into common use (Fig. 29). 


\section{ACETYLENE LIGHTING}

58. The Nature and Preparation of Acetylene.-Acetylene is a combustible gas burning, under proper conditions, with a white light which is the nearest approach to sunlight of any of the artificial illuminants. As commonly prepared it has a strong, disagreeable odor. It produces an extremely high temperature when burned. It is easily prepared when wanted and it may be stored in metal tanks and used when desired.

The gas is commonly prepared by allowing CALCIUM CARBIDE to react with water. Calcium carbide is a gray rocklike solid that is prepared in the electric furnace by the action of coke and lime. The calcium carbide may be shipped any distance and stored any length of time so long as it is kept in air-tight, moisture-proof containers. When acetylene is desired, the carbide is allowed to react with water in a device called a GENERATOR.

\section{Exercise 22.-Generating Acetylene}

Select a narrow baking powder can or a tin cup and fill it half full of water. Drop a piece of calcium carbide as large as a small marble into the water and notice the bubbling due to the escape of the gas from the water. Notice the odor of the gas. Hold a lighted match, at arm's length, over the top of the can and ignite the gas. Notice the appearance of the flame.

59. Acetylene Generators. -Figure 30 shows a simple generator. It consists of a GENERATING TANK and a GAS HOLDER. As the carbide

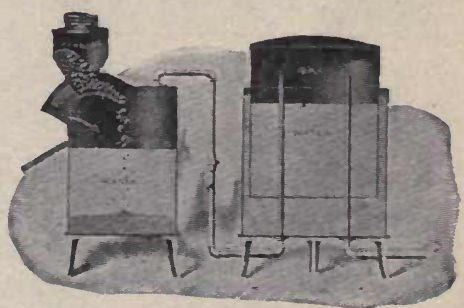

Fig. 30.-A simple acetylene generator.

feeds into the water, acetylene is generated which is delivered through a pipe to the gas holder. From the gas holder it is conveyed by pipes to the place where it is to be consumed. The gas holder is much like two cans, the larger standing upright and containing water; the other, the smaller, 
inverted and floating upon the water within the first. The gas confined within the smaller can supports it. As the gas is used, the smaller can falls.

60. Automatic Feed Generators.-These generators are arranged so as to feed the carbide into the generator tank as fast as the gas is consumed, Figs. 31 and 32 . When the gasholder can has fallen because of the removal of gas from the

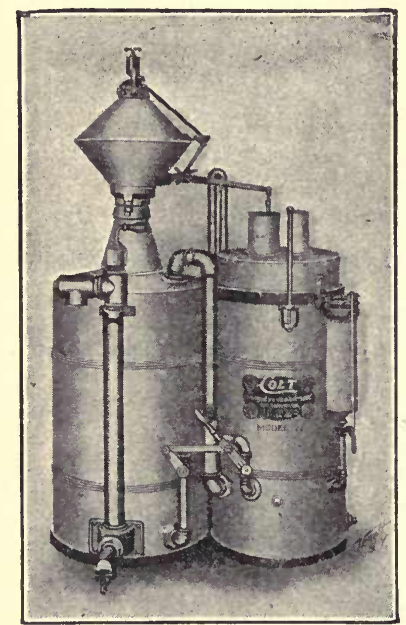

Fig. 31.-Acetylene generator. holder, a lever which is attached to the can opens a valve at the bottom of the carbide holder, thus allowing carbide to drop

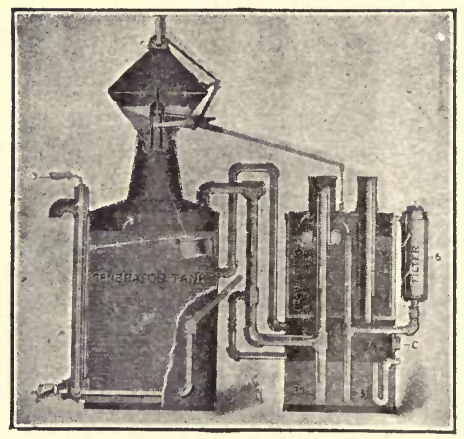

FIG. 32.-Sectional view of acetylene generator.

into the water and generate gas. As the gas accumulates in the gas holder the can rises, and the lever closes the valve at the bottom of the carbide holder and the generation of gas stops.

61. The Cost of Acetylene.-One pound of calcium carbide will produce from 4.25 to $4.85 \mathrm{cu}$. $\mathrm{ft}$. of acetylene, depending upon the size of the carbide lumps, the larger lumps producirg more gas than the smaller ones. In 100-lb. drums the carbide may be purchased for about $\$ 4.50$, so that the cost of the acetylene is very nearly 1 ct. per cu. ft. Ordinary illuminating gas sells for about $1 / 10$ ct. per cu. ft. However, a cubic foot of acetylene will produce about twice as much light as 
a cubic foot of ordinary illuminating gas when burned in an open flame, and about six times as much when burned in a mantle burner. Acetylene will produce about 2.6 times as much heat per cubic foot as ordinary illuminating gas. When these facts are considered the difference in cost of acetylene and ordinary illuminating gas is not so great as it would seem at first thought. Its use, however, is limited to those places where illuminating gas cannot be procured. It is extensively used as an illuminant in country homes and institu-

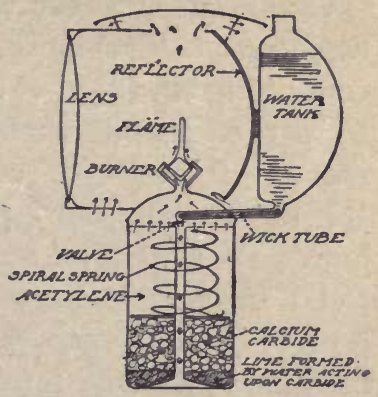

FIG. 33.-Acetylene bicycle lamp. tions, on automobiles, and in the United States lighthouses.

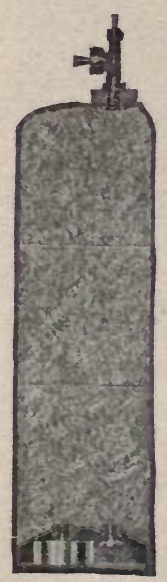

FIG. 34 . Prest-O-Lite tank, showing the internal construction.

62. Acetylene as an Illuminant for Vehicles. -With the coming of the automobile, some reliable, powerful illuminant was demanded. Acetylene seems to be satisfactory. Small acetylene generators are sometimes carried on the machine, which produce the gas as rapidly as it is used (Fig. 33). However, the constant jarring of the vehicle is likely to disarrange the parts of the generator, thus leading to unsatisfactory service. The care of such a small generator is more or less troublesome. For these reasons acetylene is now stored in strong metal tanks which may be carried on the machine. The tanks (Prest-O-Lite, Fig. 34) are filled with some absorbent material, as asbestos or cotton, which is saturated with a liquid called ACETONE. Acetone has the property of dissolving large quantities of acetylene when under high pressure. When the gas is allowed to pass from the tank to the burner, the acetylene passes out of solution. A tank such as used on 
automobiles holds $40 \mathrm{cu}$. ft. of gas which sells at about $6 \frac{1}{4}$ cts. per cu. ft.

63. Danger of Acetylene Explosions.-The gas is highly explosive. Its explosive limit with air is very wide. Air containing over $2 \frac{1}{2}$ per cent. of acetylene by volume and under 55 per cent. will explode. With gasoline gas the limit is narrow, from 2 per cent. to 5 per cent. Since acetylene generators are usually placed in the cellar or basement of the house, the danger of acetylene accumulating in the air of the cellar through leakage from the generator is rather great, especially with poorly constructed machines and careless handling. If such a mixture should be ignited by striking a match in the cellar or by other means, the result would be disastrous. Generators that stand outside the house and in the open air are now on the market. They are protected against freezing in the winter.

\section{ELECTRIC LIGHTING}

64. Heating Effects of the Electric Current.-Whenever an electric current passes along a wire, the wire becomes more or less heated. It may not become very hot, but it would if it were not sufficiently large or made of the right kind of material to carry that amount of current. A copper wire will carry, without becoming perceptibly heated, a current of electricity which would heat to a high temperature a wire of iron or German silver of the same size.

\section{Exercise 23.-Heating a Wire by Means of an Electric Current}

Scrape the insulation off the ends of some No. 32 German silver wire. Loosen the burr, or nut, on one of the binding posts of a fresh dry cell. Slip one end of the wire under the burr and turn the burr down tight upon it. Be certain that none of the insulation comes between the wire and the binding post and burr. Now loosen the burr on the other binding post. Grasp the loose end of the wire and draw the bared portion under the burr of the second binding post and turn the burr down tight. If the cell is fresh, the wire will become hot; the insulation will begin to smoke and char, and probably will actually burn. The shorter the wire, the hotter it will become (Fig. 35). 
The over-heating of electric wires sometimes causes fires. If the wires in a building should be too small to carry the current which is sent over them, they may become very hot

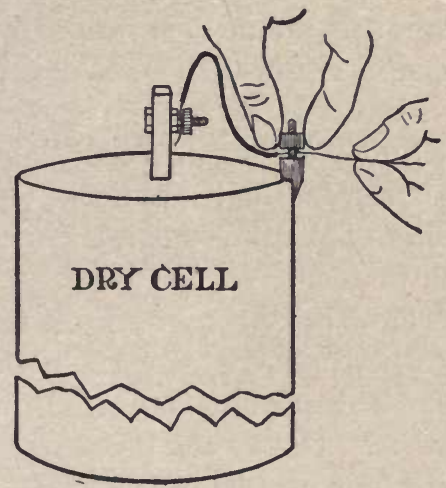

Fig. 35.-Electric current heating a wire.

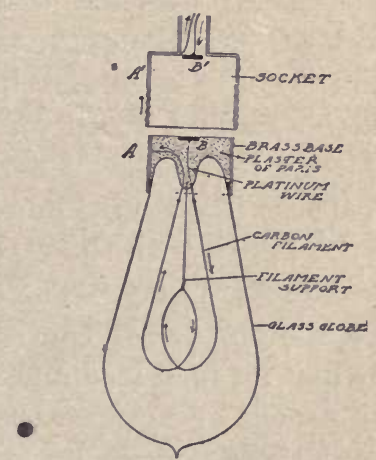

Fig. 36.-Incandescent lamp and socket.

and set on fire the wood or other burnable material with which they come in contact. For this reason all cities have very strict rules and ordinances governing the wiring of buildings for electric lighting.

\section{The Incandescent Lamp.-} The incandescent lamp is very simple in principle. It consists of a glass bulb from which practically all of the air has been removed. Sealed into the base of the globe are two pieces of platinum wire. The base, or top, of the bulb is set by means of plaster of Paris in a brass base which can be screwed into a socket (Fig.

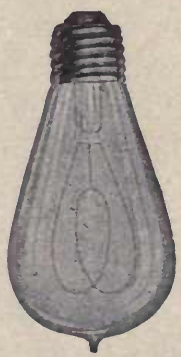

FIG. 37.-Carbon lamp.

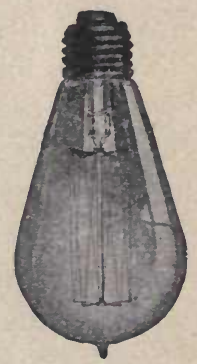

Fig. 38.-Tungsten lamp. 36). One of the platinum wires is soldered to the brass base at $A$, the other is soldered to the plate at the center of the base at $B$. When the lamp is screwed into the socket, $B$ 
comes in contact with $B^{\prime}$ and $A$ is in contact with $A^{\prime}$, completing the circuit. Connecting the two platinum wires within the bulb is a filament sometimes composed of specially prepared carbon. It is really a long thread of carbon. When the current passes through, this filament is heated to a white heat, or becomes INCANDESCENT (Fig. 37). There being no air present, it cannot burn out. If air were present it would be burned up in an instant. In most recent lamps the filament is made of a rare metal called Tungsten (Fig. 38). These lamps give much more light with far less current than the lamps with the carbon filament.

66. The Arc Lamp.-The are light is still more simple than the incandescent. It consists of two pencils of carbon, each about half an inch in diameter. The current flows in on one of the pencils and out on the other. Unlike the incandescent filament these pencils are usually not protected from the air, consequently they are consumed quite rapidly. At first the carbons are permitted to rest against each other. A very strong current of electricity is then sent through them. They quickly become very hot at the points where they touch. They are then separated about one-quarter of an inch. They still continue to carry the current and glow, for the space between them is now filled with glowing-hot carbon vapor. This glowing vapor is called the ELECTRIC ARC.

Within this electric are is the highest temperature ever obtained by artificial means. It is the high temperature of this arc which is used in the electric furnace to produce calcium carbide from the lime and coke (Art. 58). It is estimated at about $4000^{\circ} \mathrm{C}$.

It is evident that, as the pencils are consumed, the space between them will widen. This difficulty is overcome in most lamps by an artificial feeding device which always keeps the pencils at about the proper distance from each other. In the ordinary open are lamp the pencils are consumed at the rate of about 1 inch per hour.

The arc lamp is the most powerful of all artificial lighting 
devices. The common street open arc lamp may give as high as 2000 candlepower of light. Lamps having still greater power are sometimes used for special purposes.

67. The Enclosed Arc Lamp.- Some years ago it was discovered that, if the carbons of an arc light were enclosed in a small glass globe nearly air-tight, the light produced was different from that produced by the open arc. For most purposes the light from the enclosed are is preferred to that from the open arc. Since the small globe is almost air-tight it is readily seen that the burning carbons will soon consume all of the oxygen in the globe, and after that will merely glow and not burn. The carbons on the enclosed arc lamp last about ten times as long as those on the open arc. This means a great saving of time in taking care of the lamps. During recent years the enclosed arc lamp largely displaced the open arc, not only for indoor lighting, but also for street lighting.

At the present time, the incandescent tungsten lamp is rapidly displacing the enclosed arc lamp both for indoor and for street lighting.

68. Electric Wiring.-Electric wiring of buildings must be carefully done by competent electricians. As we have already seen, Art. 64, Exp. 23, electric wires become very hot if they are too small to carry the amount of current sent over them. It is also true that, if two wires carrying currents come directly into contact with each other, a spark passes between them. Occasionally fires are started by this "crossing" of "live" wires. Most electric wires are of copper and are covered with insulation. This insulation is a thick covering of material through which very little electricity passes. If the wires are not sufficiently large to carry the current required they become so hot as to destroy this insulation. Two of the wires upon which the insulation has been destroyed may come in contact, producing a spark which may set fire to the building.

In the better modern buildings all electric wires are run in conduits. These conduits are simply iron tubes. They are 
easily bent and are placed in the walls and ceilings of the building when it is being constructed. When it is necessary to turn a corner with a conduit, as in passing from the wall of a room into the ceiling, care is taken to make the turn a curve instead of a sharp angle. When the building is nearly completed a long, flexible steel, resembling somewhat a long, straight clock spring, called a "fishing wire," is pushed through the conduit; the insulated copper wire is attached to the end of the fishing wire and pulled into place in the conduit. The placing of electric wires in conduits, not only safeguards the building against fire, but also makes it possible to remove, to repair, or to replace the wiring of the building without injury to the walls or the decorations.

In wiring an old building in which no conduits were placed when the building was constructed, the wires are "fished" through the walls and ceilings, the electricians working through small openings made in the walls, floors, or ceilings. Flexible insulating tubing called цоом is slipped over the wire till it is completely encased before the wire is drawn into place.

\section{NATURAL AND ARTIFICIAL LIGHTING}

69. Importance of Studying the Lighting Question.Thinking people are rapidly coming to recognize the fact that more attention must be given to the lighting of our houses, our stores, our factories, and especially our libraries and schoolrooms. All who have given this matter special attention agree that too careful consideration can not be given this lighting problem in this day when we spend so large a portion of our lives in reading and studying or in other occupations requiring close and almost constant use of the eye. Factory superintendents and school officials are especially active in endeavoring to secure better light for employees and studerits. Factory superintendents find that it pays financially to provide the best lighting conditions possible for their employees. School officials and parents should give careful attention to securing the best of light in the school and the home. 
70. Light Should Come from Above.-Through ages of out-of-door life the eye has become adapted to receiving light from above. The human eye is not adapted to receiving strong light from below or even from a source on a level with the eye. By far the strongest light is received from the sun at midday. But at that hour the sunlight comes from overhead, and even its great intensity is not particularly painful. On the other hand, we are all familiar with the blinding effect of the far less intense rays of the setting sun. When boating, the rays reflected from the water come from below the eye; the effect is blinding and extremely unpleasant. Snow blindness is common in the polar regions, and even uncivilized races have invented devices to protect the eyes against the ill effects of the sun's rays reflected from the snow. Even the reflected light from concrete walks and from light-colored soils is very trying to the eyes because it comes from below.

71. Direct Light and Diffused Light.- The most comfortable light, and therefore the best, is DIFFUSED LIGHT from above.

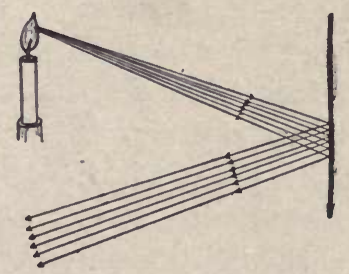

Fig. 39.-Direct light reflected from a polished surface.

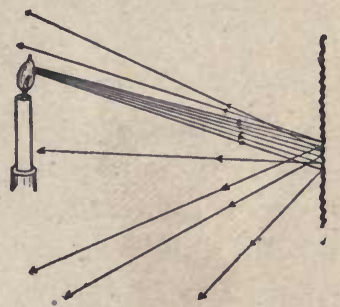

FIG. 40.-Diffused light reflected from a rough surface.

When light comes directly from a luminous body it is said to be DIRECT LIGHT; when such rays are reflected from a smooth surface, such as a mirror or any highly polished surface, they still have the properties of the direct rays. All such rays are parallel to each other or nearly so (Fig. 39). All such direct light, i.e., light with parallel rays, is unpleasant and more or less injurious to the eye. Light is said to be diffused when its rays are not parallel. 
Diffused light is usually obtained by one or the other of the following methods:

First, by causing direct light to be reflected from some uneven or unpolished surface. Examples: (1) Light reflected from a common plastered, or a "white finish" wall; (2) light reflected from a light-colored papered or painted wall (Fig. 40); (3) light reflected from the sky, especially from the portion of the sky opposite the sun, in general, from the northern sky.

Second, by causing the direct light to pass through some semi-transparent substance or ribbed or fluted glass. Examples: (1) Light which passes through the common white or opalescent globes such as we used on gas mantle burners; (2) light which passes through the frosted tips, or "frosted bowl," of the common tungsten lamps; (3) light which passes through thin cloth such as is commonly used for curtains or light window shades; (4) light which passes through ribbed or frosted glass commonly used in skylights.

72. Obtaining Diffused Natural Light.-Photographers have long recognized the value of diffused light in their work. Most photograph galleries are lighted by means of windows placed in a slanting position and facing the northern sky. Only diffused light from the northern sky can enter these windows. Further to diffuse the light, the windows are often. fitted with ribbed glass or glass coated with a thin coat of white paint. Still further to control the light, muslin curtains or light, semi-transparent shades are hung before these windows.

It is becoming common practice for factories to be constructed with what are known as SAW-Tоотн Roofs (Figs. 41 and 42). The windows are placed in a slanting position on the north slope of the "saw-tooth" roof, thus admitting only diffused light from the northern sky. By this method of lighting, even large rooms may be evenly and effectively lighted with a soft, mellow light. It is found in factories thus lighted, not only that the employees can do more and better work on ac- 


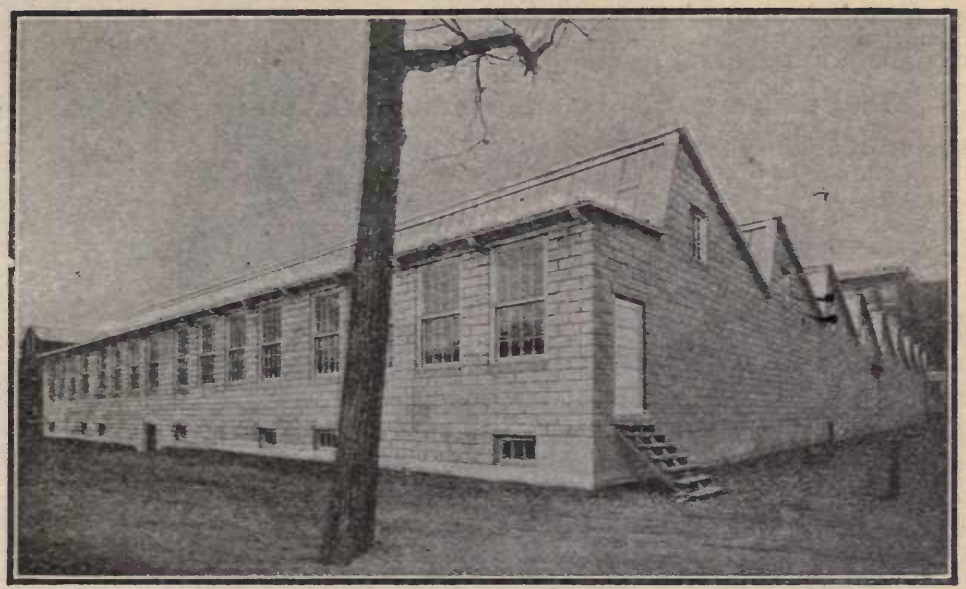

Fig. 41.-Weave shed at a cotton mill, showing the saw-tooth roof. We are looking at the northwest corner of the building; the roof windows face the north.

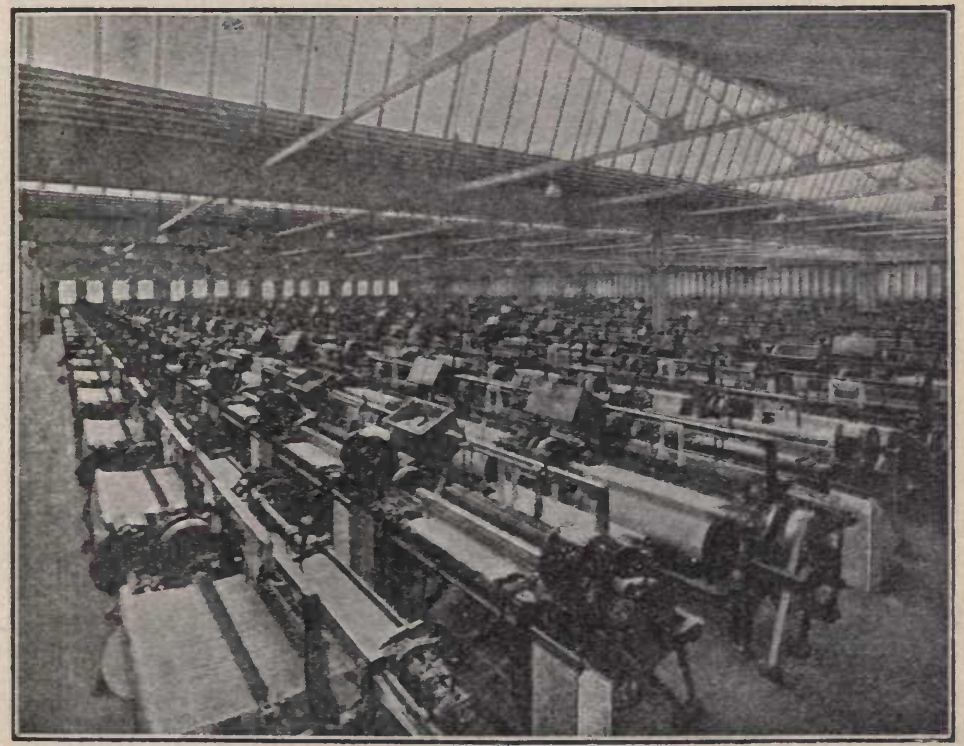

Fig. 42.- Interior view of the weave shed. The camera stood in the southwest corner of the room. Note the evenness of the lighting throughout the room. This room is $253 \mathrm{ft}$. by $140 \mathrm{ft}$. and contains 648 looms. 
count of the better light and lack of shadows, but also that the expense of artificial lighting is greatly reduced.

School officials and schoolhouse architects are beginning to recognize the great value of this method of lighting. Figures

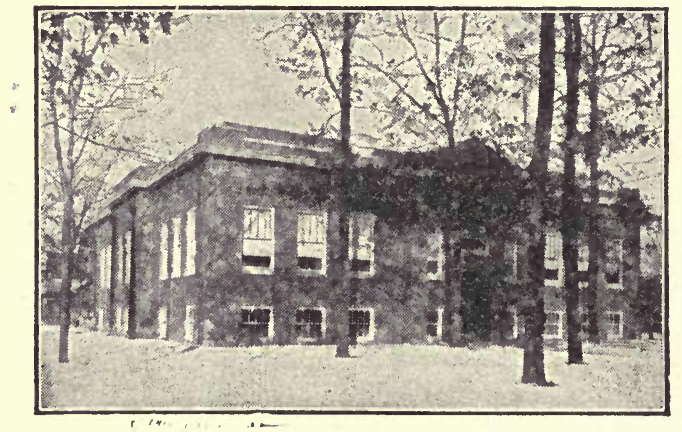

Fig. 43.-Exterior of an overhead lighted schoolhouse. (Copyright, 1911, by American Home Magazine Company.

By courtesy of Good Housekeeping Magazine.)

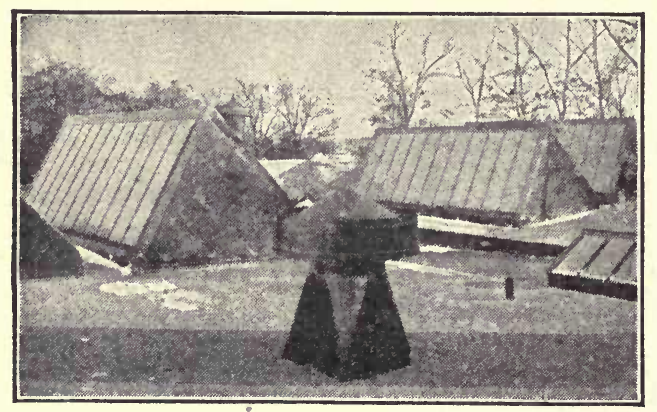

Frg. 44.-A portion of the roof of the schoolhouse.

(Copyright, 1911, by American Home Magazine Company.

By courtesy of Good Housekeeping Magazine.)

43,44 , and 45 give three views of a schoolhouse thus lighted. Notice that in Fig. 45 all shades are drawn and that most of the light comes from above. Nearly all of the ceiling of the room is fitted with ribbed glass so that none but diffused light from 
above can enter. It has been found that no artificial lighting is needed in this schoolroom during school hours at any time during the year, although this particular schoolhouse is located in northern Illinois.

It should always be remembered that direct light produces a glaring effect which is unpleasant and trying to the eye, while

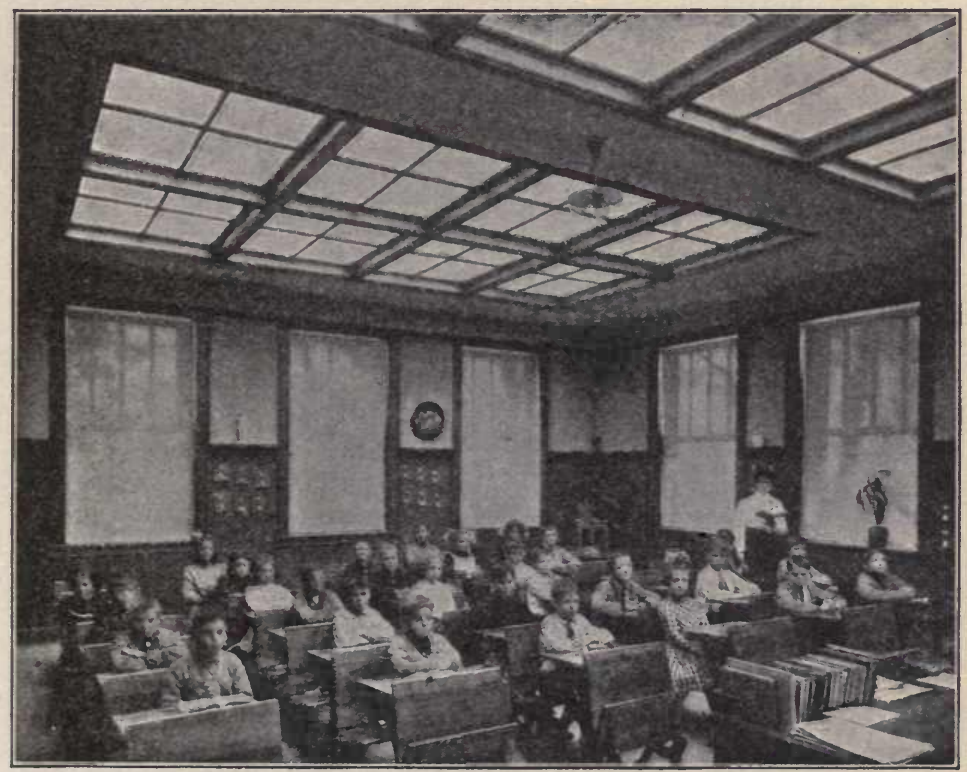

FIG. 45.-Interior view of an overhead lighted schoolroom. (Copyright, 1911, by American Home Magazine Company. By courtesy of Good Housekeeping Magazine.)

diffused light produces a soft, mellow, comfortable effect which is not injurious. It should also be remembered that light should be admitted through the upper portion of the windows if it is impossible to admit it through skylights directly above. The common practice of controlling the amount of light by drawing down heavy shades from the top of the windows is bad practice. Much better light can be obtained by providing 
each window with two light shades, one for the upper and one for the lower sash of the window.

73. Obtaining Diffused Artificial Light.-The first requirement in all modern lighting is that the light for the room shall come from several sources, each of moderate intensity, rather

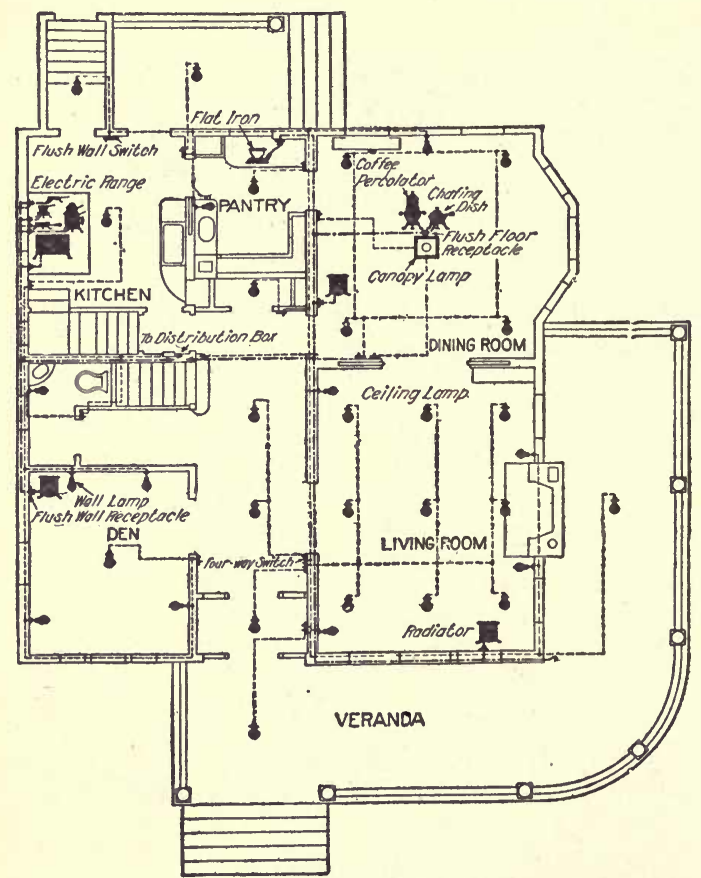

FIG. 46.-Plan of first floor of a modern residence showing system of electric lighting; also other electric appliances.

than from a single source of great intensity. Figures 46 and 47 are the floor plans of a modern residence, lighted by electricity. These plans indicate clearly the number and location of the lights as placed by an expert lighting engineer. Notice that in the living room there are nine ceiling lights, and four wall lights - thirteen in all. In the dining room there are four 
ceiling lights and one wall light, besides the central canopy light.

It is readily seen that, if the light for a room is thus obtained from many sources, much the same effect is produced as by strictly diffused light. The rays from the several different

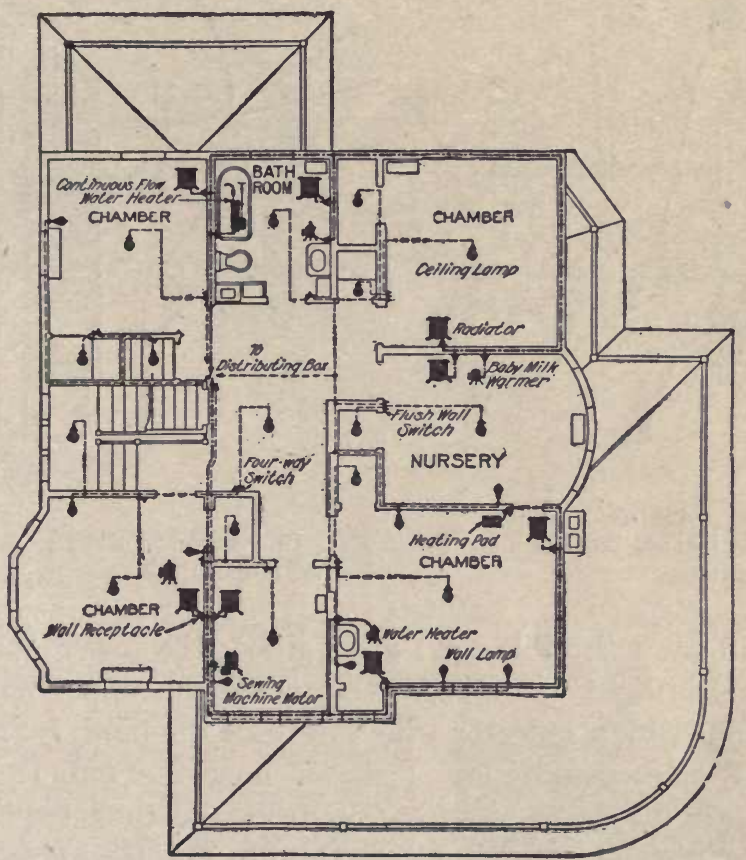

FIG. 47.-Second floor plan of a modern residence showing system of electric lighting; also other electric appliances.

sources are not parallel to each other; moreover, shadows are practically eliminated. The expense of operating the many small lamps to furnish a certain amount of illumination is not materially different from that of operating a small number of large lamps giving the same amount of illumination.

The second requirement of modern lighting is that the light shall be diffused. Lamps for use in residences, in schoolrooms, 
in libraries, and even in factories, are very generally so constructed as to give only diffused light. This is especially true of gas and electric lighting. The gas mantle is often sur-

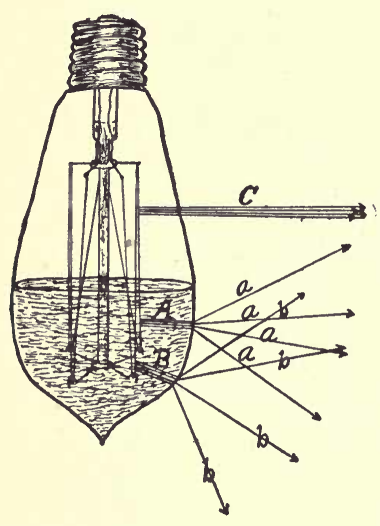

FIG. 48.-Diffused light from the frosted bowl of a tungsten lamp.

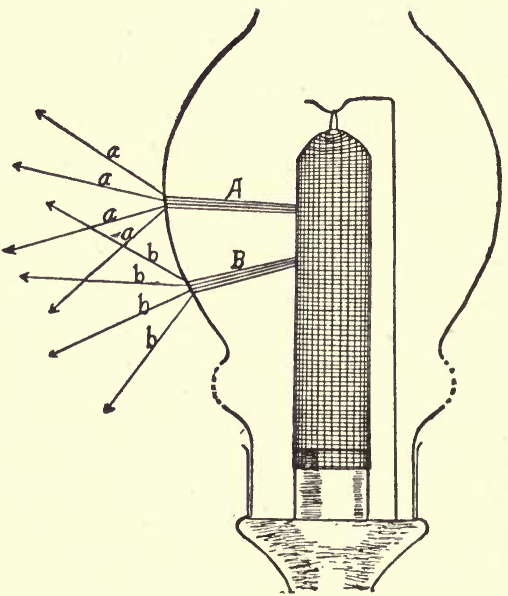

Fra. 49.-Diffused light from the opal glass globe of the gas mantle lamp.

rounded by a suitable opal glass globe; the lower portion of the electric light globe is frosted, while the upper portion is surrounded by a reflector which diffuses the light. Figure 48

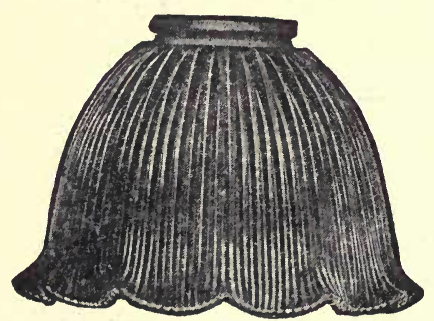

FIG. 50.-A fluted glass reflector.

Used on gas and electric lamps.

shows how the direct, parallel rays from the tungsten light are diffused by the frosted bowl, and Fig. 49 shows how the direct rays from the gas mantle are diffused by the white glass globe. In each case, the pencil of parallel rays $A$ is broken up into the diffused rays, $a, a, a$, and $a$, while the pencil of parallel rays $B$ is broken up into the diffused rays $b, b, b$, and $b$. On the other hand the direct rays $C$ pass through the clear glass of the 
upper portion of the tungsten lamp without being diffused. This direct light from the upper portion of the tungsten lamp

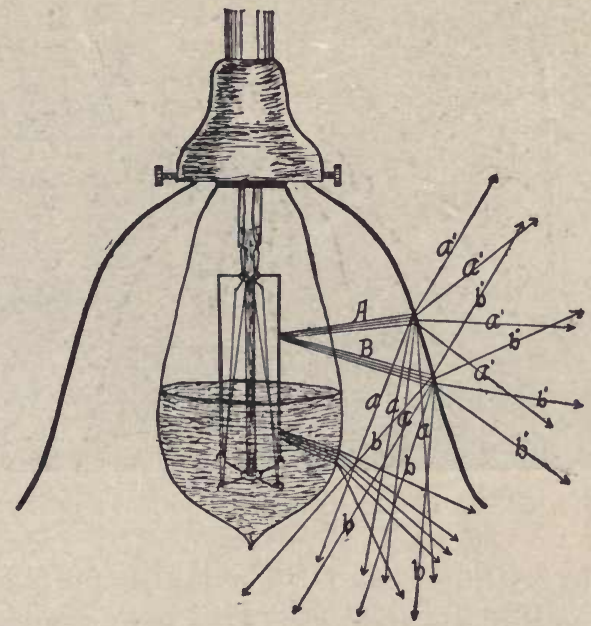

Fia. 51.-Diffused light from tungsten lamp with frosted bowl and fluted glass reflector.

is not permitted, however, to escape into the room. The lamp is surrounded by a fluted glass reflector (Fig. 50). This reflector reflects the larger portion of the rays as diffused light, mixing it with the diffused light which passes through the frosted bowl (Fig. 51 rays $a, a, a, a$, and $b$, $b, b, b)$. A sufficient amount of light to illuminate the ceiling of the room passes through the fluted glass reflector. This light is also diffused, $a^{\prime}, a^{\prime}, a^{\prime}, a^{\prime}$, and $b^{\prime}, b^{\prime}, b^{\prime}, b^{\prime}$, Fig. 51 .

74. Indirect Lighting.-The best artificial lighting is INDIRECT LIGHTING. In the indirect system none

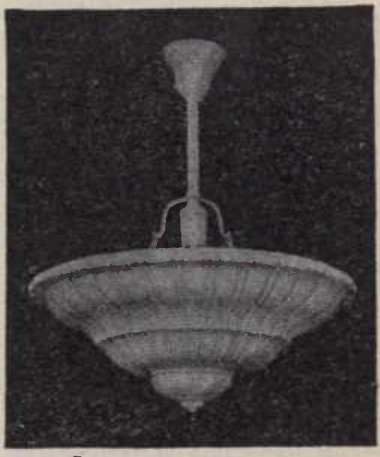

FIG. 52.-Indirect light bowl. of the rays from the light source is permitted to fall directly upon 


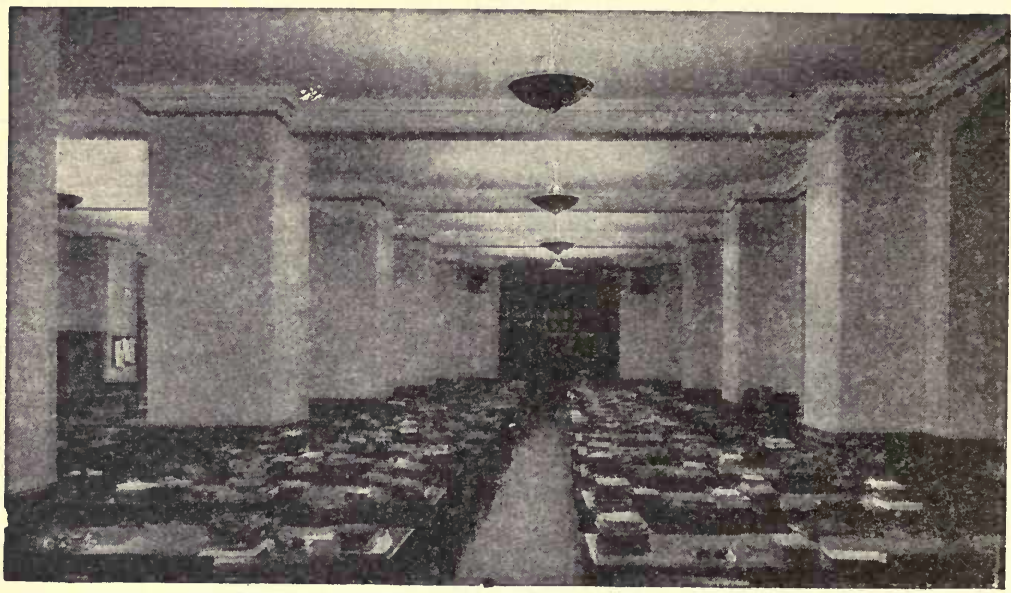

FIG. 53.-A library lighted by indirect lighting,

the surface to be illuminated. The lamps are placed within a reflector which diffuses and-reflects the light against the ceiling

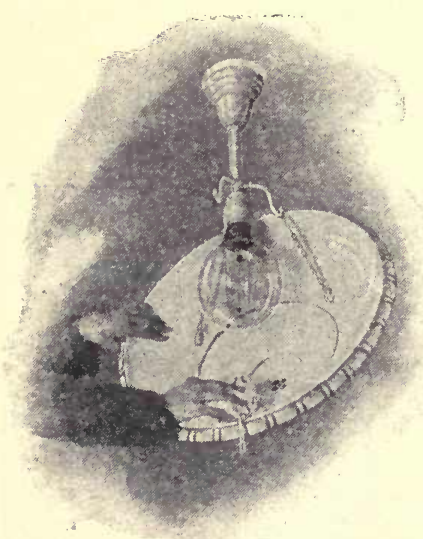

FIG. 54.-Removing the dust from the indirect lighting bowl.

(Figs. 52 and 53), which in turn reflects the light downward to the surfaces which are to be illuminated. The efficiency of such lighting depends largely upon keeping the reflector free of dust (Fig. 54) and upon the character and color of the ceiling finish. At best, however, not more than about 70 per cent. of the light is reflected by the ceiling; generally the efficiency of the indirect systems of lighting is much lower than this. Owing to its low efficiency, indirect lighting is frequently regarded as a luxury although its superior quality is recognized by everyone. Bright spots, such as bright, exposed, unshaded 
lights, have a strong tendency to cause the pupils of the eye to close, thus, in a measure, shutting out the light and producing the same effect as that due to poor illumination. With indirect lighting all bright spots and glaring effects are avoided and shadows are few; the diffused light coming from all parts of the ceiling makes this an ideal system of artificial lighting.

75. Amount of Light Which Should be Provided.-It is impossible to give any but very general rules governing the amount of light which should be provided for a room, and therefore the number and size of the lamps which should be installed. The color and the nature of the wall coverings and the character of the furniture and the decorations, as well as the use to which the room is to be put, all have important bearings upon the lighting. A white wall paper or a "white finish" wall will reflect 80 per cent. of the light; a red, dark brown, or dark green wall will reflect only about 15 per cent. A light buff or yellow wall will reflect 45 per cent. of the light; a light apple green will reflect about 40 per cent. The decorations of a room determine largely the illumination of the room with a given amount of lighting.

Intensity of illumination is measured in FOOT-CANDLES. $A$ FOоT-CANDLE is the amount of light, or illumination, received by a plane surface $1 \mathrm{ft}$. from a 1-candlepower light. The illumination varies inversely with the square of the distance from source of the light to the surface illuminated, i.e., if the distance from the lamp be doubled, the illumination will be but one-fourth as great; if the distance be made three times as great, the illumination will be but one-ninth as great, etc. A 16-candlepower lamp illuminates a surface $1 \mathrm{ft}$. distant with an intensity of 16 foot-candles, but it illuminates a surface $4 \mathrm{ft}$. distant with only 1 foot-candle intensity; a 32-candlepower lamp illuminates a surface $1 \mathrm{ft}$. distant with an intensity of 32 foot-candles, but it illuminates a surface $4 \mathrm{ft}$. distant with an intensity of only 2 foot-candles. 
Table II.-Accepted Light Intensities for Different Service Auditoriums, Churches-General Illumination. 1 to 3 foot-candles Reading Rooms-General Illumination....... 2 to 3 foot-candles Residences-General Illumination.......... 1 to 2 foot-candles Desk Illumination................... 3 to 5 foot-candles Bookkeeping........................ 3 to 5 foot-candles Drafting and Engraving............... 5 to 10 foot-candles

If desk illumination is to have an intensity of 4 foot-candles and the light is to be hung $4 \mathrm{ft}$. above the desk, it is necessary to provide for one 64-candlepower light, or two 32-candlepower lights, or four 16-candlepower lights. While reading and studying, the student should not hold his book more than 2 or $3 \mathrm{ft}$. from a 16- or 20-candlepower lamp nor more than about $5 \mathrm{ft}$. from a 60 - or 80-candlepower lamp, such as an ordinary

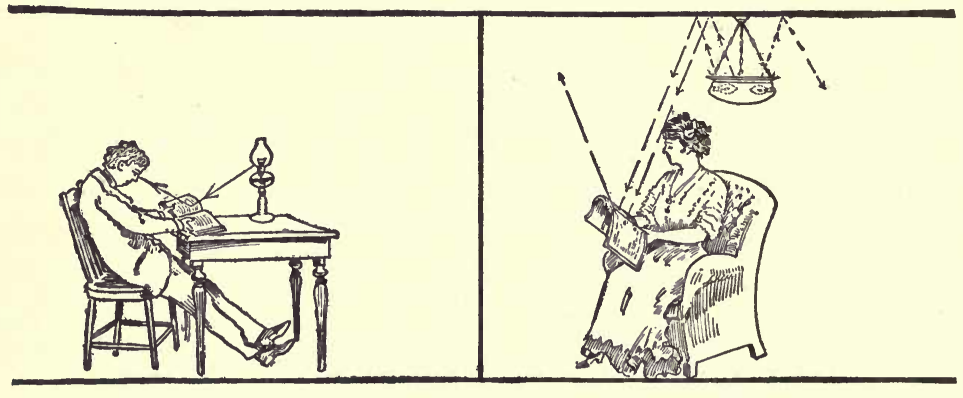

$A$

$B$

FIG. 55.-A. A bad position and poor light. There is a bright spot before the eye and the light is reflected from the book to the eye. $B$. A good position and good light. The light reflected from the ceiling is diffused light.

Welsbach gas mantle lamp. Moreover, the book should be held in such a position that the reflected light from the page will not fall upon the eye. The best position for the light is above and behind the reader (Fig. 55).

76. Controlling the Distribution of Light.- $\mathrm{It}^{-}$is probable that fully 50 per cent. of the light produced in ordinary residence lighting is wasted. Light is wasted unless it is used to illuminate the surfaces which need to be illuminated. When reading a book or paper, a person needs to have that page 
illuminated with an intensity of about 3 to 5 foot-candles; it is of no benefit to the reader, however, to have the walls and ceiling of the room illuminated to the same extent. In fact, if all other objects in the room were illuminated to the same intensity as the book, they would tend to draw the attention of the reader from the page. We all know that the attention

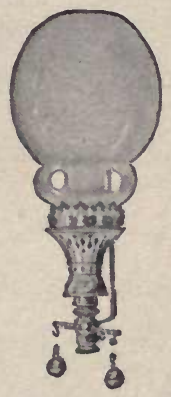

FiG. 56.-Upright gas mantle lamp.

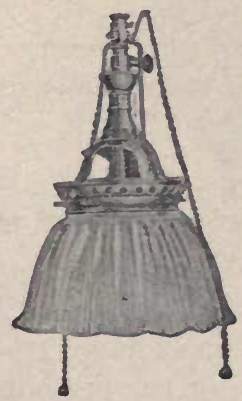

Fig. 58. - A reflex or inverted gas mantle lamp with prismatic glass reflector.

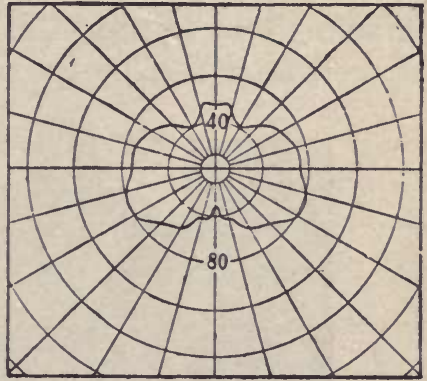

FIG. 57.-The distribution curve for the lamp.

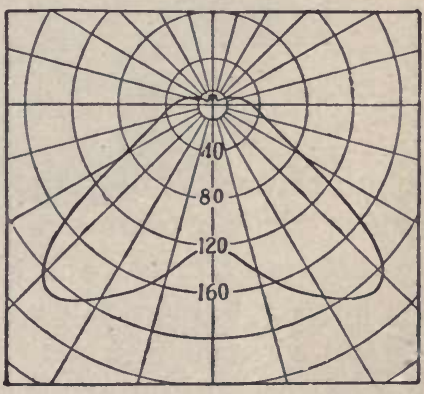

Fig. 59.-The distribution curve for the lamp.

of the audience in a theater is directed to the players by subduing the light in the body of the house and increasing the light on the stage.

In modern lighting, the choice of fixtures and shades is determined by the use to be made of the light. If the purpose is to supply light for the general illumination of the room, the 
fixtures and shades will be chosen which will distribute the light with approximately equal intensity in all directions, Figs. 56 and 57. If, on the other hand, it is desired to illuminate a desk or table standing directly beneath the lamp, another style of fixture and shade should be used, Figs. 58 and 59.

77. Relative Cost of Operating Gas and Electric Lights.Illuminating gas is furnished to the consumer under very slight pressure. Usually gas pressure is sufficient to support

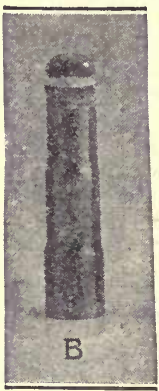

FiG. 60.-The open jet burner.

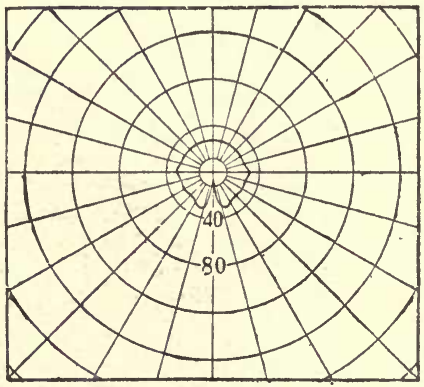

FIG. 61.-The distribution curv? for the burner.

a column of water only from 1.8 to $2.8 \mathrm{in}$. in height, Art. 56 . The price charged varies in different localities but usually ranges between 80 cents and $\$ 1.25$ per $1000 \mathrm{cu}$. ft.

Gas may be burned either in the opEN FLAME jet or in the welsbach mantle (see Art. 57). The open flame jet (Figs. 60 and 61 ) usually burns about $5 \mathrm{cu}$. ft. of gas per hour and gives about 20 candlepower of light. Therefore, the cost of this light at $\$ 1.00$ per $1000 \mathrm{cu}$. ft. for gas is about .025 of a cent per candlepower-hour. (The student should verify these computations.)

When gas is burned in a Welsbach mantle it is generally consumed at the rate of about $31 / 2 \mathrm{cu}$. ft. per hour and the mantle gives about 60 to 80 candlepower of light. Therefore at $\$ 1.00$ per $1000 \mathrm{cu}$. ft. the cost of this light is not more than 
.005 or .006 of a cent per candlepower-hour. This is approximately $1 / 5$ the cost of the open flame gas light per candlepower-hour.

Electricity is sold by the WATT-HOUR or KILOWATT-HOUR. The kilowatt-hour is equal to 1000 watt-hours. The ordinary house meter reads off directly the number of kilowatt-hours of current used. This WATT HOUR-METER, or "WATT-METER," as it is usually but erroneously called, is really little more than a very small and easy running motor (Fig. 62). A very small

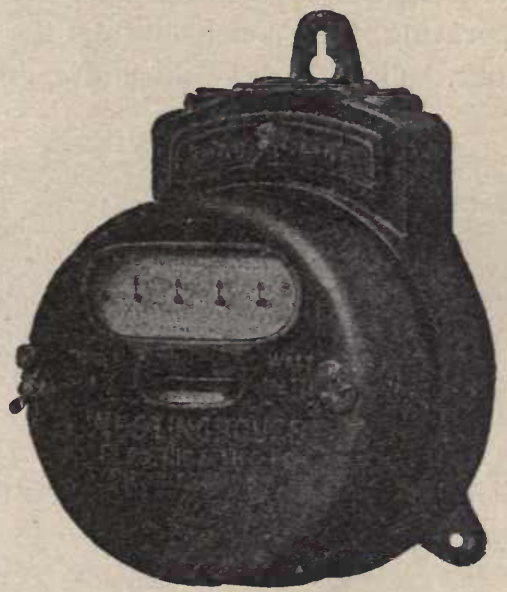

Fig. 62.-A watt-hour meter.

portion of the current passing through this meter runs the motor which, in turn, operates a chain of gear wheels which turn the hands before the dials (Fig. 63). The usual cost of electric current for lighting purposes is from 8 to 15 cents per kilowatt-hour.

The common CARBON FILAMENT lamps are made in several sizes; the sizes most commonly used are the 50-watt lamps giving about 16 candlepower of light and the 100-watt lamp giving about 32 candlepower of light. Therefore, at 10 cents per kilowatt-hour for current, these carbon lamps cost about 
.03 of a cent per candlepower-hour, or about the same as the open flame gas jet. (Verify these computations.)

The TUNGSTEN FILAMENT lamp is also made in several sizes; the sizes most commonly used for resident lighting are the 25-watt lamp giving about 20 candlepower of light, the 40 -watt lamp giving about 32 candlepower of light, and the 60 -watt lamp giving about 50 candlepower of light. Therefore, at 10 cents per kilowatt-hour for current, these lamps cost about .012 of a cent per candlepower-hour. This is about $2 / 5$ the cost of operating the carbon lamps and about.two times the cost of operating the Welsbach mantle gas lamps per candlepower-hour. (Verify these calculations.)

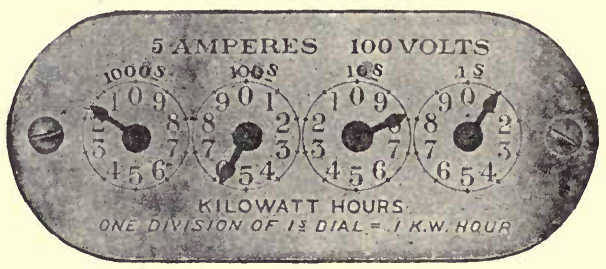

Fig. 63.-Dial of the watt-hour meter. The reading is 1581 kilowatt-hours.

Although modern electric lighting using tungsten lamps is as yet generally more expensive than gas lighting using Welsbach mantles, still electric lighting affords so many advantages that it is rapidly displacing gas where both are available. Some of these advantages are: (1) Greater convenience; (2) smaller and more numerous units are easily provided - a very desirable feature; (3) to a certain extent gas lights consume the oxygen in the air and give off carbon dioxide; electric lights do not; (4) to a certain extent gas lights tend to blacken the ceiling and walls of the room; electric lights do not; (5) while gas may be put to many uses other than lighting in the home, notably cooking and heating, modern invention makes it possible to use the electric current in the home in a multitude of ways (Figs. 46 and 47). 


\section{CHAPTER II}

\section{THE PRODUCTION AND USE OF HEAT}

\section{THE BEGINNING OF WARMTH AND COMFORT}

78. Importance of Fire.-Wood has been burned by man ever since the beginning of history. It is impossible even to guess at the time when it was first used as fuel by our ancestors, although there undoubtedly was a time when man did not know the use of fire.

We are so accustomed to fire that we can scarcely realize how much we are indebted to it for the necessities and comforts of life. We forget that, if all the fires in the land should go out, nearly all of the work we see being done about us would cease; that all travel would stop; that, with the coming of darkness all play and pleasure, reading and work would come to an end. We forget that, if we had no fires, we could have no houses to live in, no school buildings to study in; that there would be no street cars, no railroads, no clocks, no watches, no pocket knives-indeed we can hardly mention anything which we enjoy today that we could then have except the fruits, the grains, and the vegetables that grow from the soil. Even then, we should have no tools with which to cultivate the land except such as could be shaped from limbs of trees or from rocks. We should soon all be savages and again live in the woods, sheltered only by rude huts. Our food would be raw meat and such roots, berries, and fruits as we could find.

79. Fires 100 Years Ago. - At the beginning of the 19th century, wood was cheap and labor scarce, and the big fireplace commonly served for both cooking and heating. Hinged to the jamb of the fireplace was an iron crane filled with dangling pot-hooks. It was pulled out so that pots and kettles might be hung upon the hooks, and the crane was then hung back over the blazing fire. Potatoes were baked in the 
hot ashes. In the wall beside the fireplace was built the brick oven, with its flat bottom and arched top, having an iron door in front (Fig. 64). On baking day, a wood fire was built in the oven, and, when it had burned to coals and thoroughly heated the oven, the fire was neatly removed and the bread placed on the oven bottom. In those days, there was

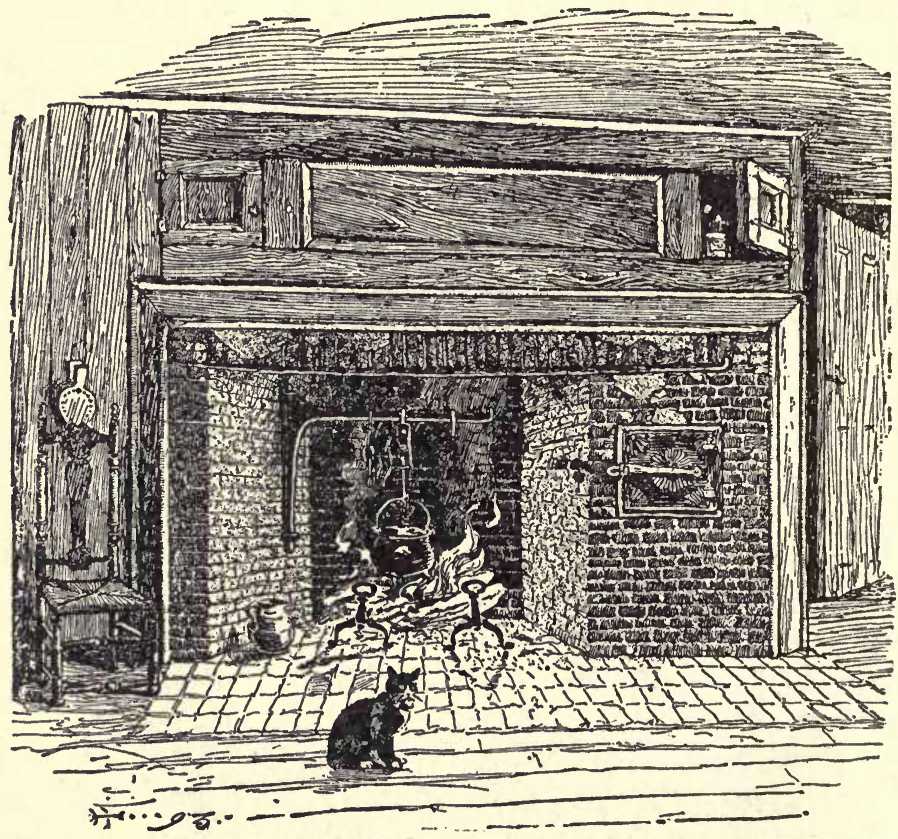

Fig. 64.-An old-fashioned fireplace and oven. (From Stories of Useful Inventions. By permission of The Century Company.)

usually no attempt to heat other than the living room of the house. The sleeping rooms, in the winter, were damp and bitter cold. The bedstead was surrounded by thick, heavy, bed curtains that hung from the bed frame which reached nearly to the ceiling. Before retiring, the sheets were warmed by means of a warming pan. This consisted of a metal pan 
mounted on a handle and having a cover. Live coals were placed in the pan and it was then moved about between the sheets till the chill and the dampness were removed.

In the living room in Whittier's old home, at Haverhill, Massachusetts, can be seen today the fireplace and its old andirons upon which once rested the blazing logs. The crane fastened to the left-hand jamb supports numerous pot-hooks and pots. Two pairs of tongs lean against the jambs. In the wall at the right is the oven with its iron door. Hanging at the left of the fireplace is the warming pan and the lantern. The latter consists merely of a tin can with many small holes punched in its sides and a socket within to hold the candle upright. On the floor beneath them is the foot-warmer. Beyond the door is the flax wheel and the desk at which Whittier wrote all of his earlier poems. The candlesticks and candles are on the desk.

"And for the winter fireside meet,

Between the andiron's straddling feet,

The mug of cider simmered slow,

The apples sputtered in a row."

This old living room has been restored till it accurately represents the home conditions in which the Quaker poet lived and wrote his earlier poems.

For two centuries after the landing of the Pilgrims the people of New England shivered throughout the long, bleak New England winters. Most of the colonists had come from much milder climates and the icy blasts which met them were most trying. In many instances the suffering was intense. In the first place, many of the houses were not well constructed and the cold wind would creep in. In the second place, the huge fireplaces but poorly heated the one room which was supposed to be warmed. Even though Whittier wrote:

"What matter how the night behaved!

What matter how the north wind raved!

Blow high, blow low, not all its snow

Could quench our hearth-fire's ruddy glow," 
it still was true that a short distance from the fireplace the room was so cold as to be quite unendurable to us today. There are plenty of records to show that it was not uncommon for ink to freeze upon the pen even as the recorder wrote his diary at the chimney side. "One noted, that when a great fire was built upon the hearth, the sap which was forced out of the wood by the flames froze into ice at the ends of the logs." "President John Adams so dreaded the bleak New England

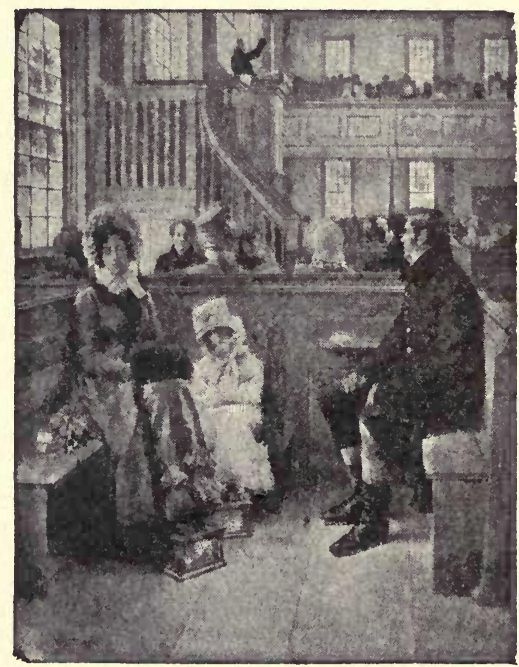

FIG. 65.-A winter's service at church.

(Copyright, 1900, by Curtis Publishing Company, and reproduced by courtesy of the Ladies' Home Journal.)

winter and the ill-warmed houses that he longed to sleep like a dormouse every year, from autumn to spring." Colonial Days, Earle.)

(Home Life in

All through the days of the colonies and for a half century following the Revolutionary War, the churches of New England were entirely without heat. The men sat throughout the long forenoon and afternoon services wrapped in overcoats and wearing their warmest mittens and footwear. The women 
and children were provided with foot warmers, sheet-iron boxes containing live coals (Fig. 65).

80. The First Stove.-The first stoves ever used by our American forefathers were made about 40 or 50 years before the Revolutionary War. The stove was merely a castiron box with a door in one end and an opening in the upper side through which the smoke could escape. 'The back or side of the fireplace was removed and this box was slipped into the space beneath the chimney. A very peculiar thing about this stove, as it seems to us, is the fact that the end containing the door was left on the outside of the house. What we should call the back of the stove projected into the room and the operator was obliged to go out of the room into the wood house to feed it. It was, however, a great improvement over the open fireplace because it overcame the strong draft, which, in the open fireplace, sent most of the heat up and out of the chimney.

81. Franklin's Stove.-In 1742 Benjamin Franklin invented his "Pennsylvania Fireplace" (Fig. 66). $\mathrm{He}$ called it "an open stove for the

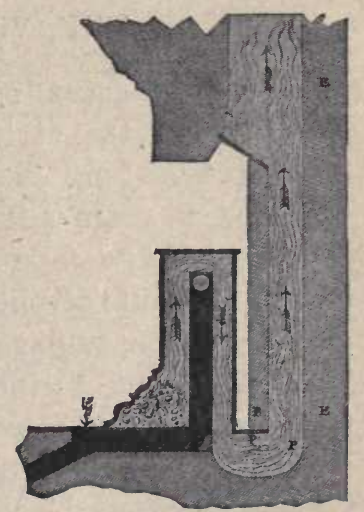

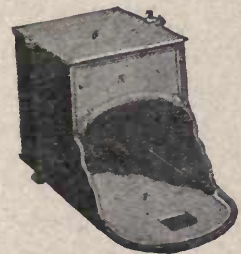

Front view.

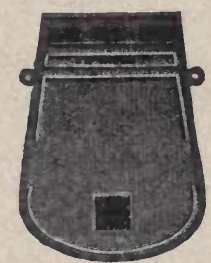

The bottom plate. Side view showing the smoke flue. FIG. 66.-Franklin stove.

better warming of a room." It was really an open stove which was placed within the old fireplace. The air of the room became heated when it came in contact with any portion of the stove. Franklin said: "The use of these fireplaces in very many houses, both in this and neighboring colonies, has been 
and is a great saving of wood to the inhabitants. Some say it saves five-sixths, some say three-fourths, others much less. I suppose two-thirds or one-half is saved; my room is twice as warm with one-fourth the wood formerly used."

As a means of securing comfort, Franklin's invention, without doubt, was the greatest single step ever made in perfecting heating devices. With this stove it became possible to heat most of the rooms of a house so that they were fairly comfortable. Such stoves would hardly be considered of great value today for heating purposes, but at the time of the Revolutionary War they were the king of heaters. In fact, there was no very great improvement over the Franklin stove for a century. In this line of advancement, as well as in many other lines, the world must ever recognize in Benjamin Franklin one of its greatest benefactors.

\section{THE CHEMISTRY OF COMBUSTION}

82. The Classes of Fuels.-The wood, coal, kerosene, gasoline, and the various kinds of gases burned for the production of heat or light are called Fuels. They are commonly classified as SOLID FUELS, LIQUID FUELS, and GASEOUS FUELS. Wood, coal, and coke are common solid fuels; petroleum and its products and alcohol are common liquid fuels, illuminating gas, acetylene, and gasoline gas are common gaseous fuels.

83. The Fuel Elements. - While there are many kinds of fuels, it has been found that they all contain and are made chiefly of two kinds of matter, namely, CARBON and HYDROGEN. Carbon is a solid, black in color, as ordinarly met in CHARCOAL and in the GRAPHITE of the lead pencil, but colorless and sparkling as found in the DIAMOND. Hydrogen is a colorless gas. It is the lightest known substance. Carbon and hydrogen are called the FUEL ELEMENTS.

84. Chemical Elements.-Carbon and hydrogen are also two of the CHEMICAL ELEMENTS because no other kind of matter has ever yet been obtained from either of them alone. 
That is, carbon alone, can produce only carbon. No other kind of matter has ever yet been prepared from it alone. Similarly, hydrogen alone can produce only hydrogen. Substances that have, so far, defied all attempts on the part of man to change them into simpler substances are called CHEMICAL ELEMENTS. About 80 chemical elements are known. The following is a list of the common chemical elements.

$\begin{array}{llll}\text { Aluminum } & \text { Gold } & \text { Mercury } & \text { Silicon } \\ \text { Calcium } & \text { Hydrogen } & \text { Nickel } & \text { Silver } \\ \text { Carbon } & \text { Iron } & \text { Nitrogen } & \text { Sodium } \\ \text { Chlorine } & \text { Iodine } & \text { Oxygen } & \text { Sulphur } \\ \text { Copper } & \text { Lead } & \text { Phosphorus } & \text { Tin } \\ \text { Fluorine } & \text { Magnesium } & \text { Potassium } & \text { Zinc }\end{array}$

85. Energy.-If one lifts a weight, work is done. In climbing the stairs, work is done. The locomotive works when it pulls the train. The engine at the electric station did work in running the dynamo which supplies the electricity used in lighting (Chap. I, Sec. XI). Electricity may be made to do work by running the electric motor. The engine at the electric station was able to do work because of the heat produced by burning coal. Likewise, any of the fuels studied in the previous chapter may be made to do work by the use of proper machinery. A person is able to do work because of the food eaten. Bodies that are able, by proper means, to do work are said to possess ENERGY.

Definition.- "Energy is work and every other thing which can arise from work and be converted into work" (Ostwald).

Heat, light, electricity, and the energy of a moving body (KINETIC ENERGY) are different forms of energy. When a body is lifted above the surface of the earth, it possesses energy due to its position Such energy is known as energy of position (POTENTIAL ENERGY). The different forms of energy may be converted into one another. Thus electrical energy may be converted into heat energy or into light energy by means of an electric lamp. Electrical energy, by means of a motor, 
may be converted into the energy of the moving parts of the machine. The working steam-engine at the electric station drives the dynamo which generates electricity. Physicists tell us that there is no gain nor loss of energy when it is converted from one kind into another. This principle is known as the Conservation of Energy.

86. Chemical Energy.-It is evident that, since the coal produces heat which causes the steam-engine to do work, and since the food eaten keeps the body warm and enables it to do work, and since kerosene, gasoline, and acetylene produce light and heat, each of these substances possesses energy of a different kind from that of heat, light, electricity, kinetic energy, or potential energy. It is also to be remembered that the coal, the kerosene, and the other fuels must be burned in order to liberate their energy as light and heat. The food must be eaten, digested, and assimilated in order to liberate its energy to the body. The kind of energy possessed by such materials is called chemical ENERGY. This kind of energy, of course, may be transformed into other kinds. The principle of conservation of energy holds for this kind of energy as it does for other kinds. In fact, chemical energy is one of the fundamental kinds of energy. From it most of our other kinds are produced.

87. Chemical Change.-When coal burns and liberates its chemical energy, it undergoes what is called a CHEMICAL CHANGE. The coal and the oxygen of the air with which it unites produce new substances. Gasoline, kerosene, and acetylene undergo chemical changes as they liberate light and heat. Food undergoes many complex chemical changes as it liberates its chemical energy to the body. All of the substances just mentioned give out energy as they undergo chemical change. But some substances must take in energy as they undergo chemical change. Thus the compound, calcium carbide, which was used in making acetylene, took in a large amount of energy in the electric furnace when it was made from lime and coke (Chap. I, Sec. X). Many other com- 
pounds are known which, like calcium carbide, take in energy during the process of their formation. Every chemical change is accompanied by either the liberation or the absorption of energy as well as the formation of one or more new substances.

Definition.-Chemical changes are those changes in matter in which one or more new substances are formed and in which energy is produced or absorbed.

88. Chemical Compounds. - Two or more chemical elements may unite to form a new substance with the accompanying chemical change. Thus the elements, copper and sulphur, will unite to form a new substance, a COMPOUND, COPPER SULPHIDE, which is black in color. Heat energy is liberated at the same time.

\section{Exercise 24. - Union of Elements to Form Compounds}

Clean a piece of copper foil with emery or sand paper until the surface of the metal is bright. What is the color of the copper? Now hold the cleaned foil with a pair of tongs and sprinkle a thin layer of powdered sulphur on the surface of the copper. What is the color of the sulphur? Are the substances copper and sulphur elements or compounds? (See Art. 84, list of chemical elements.) The copper and sulphur are undergoing chemical change at ordinary temperatures, but very slowly. The rate of union may be increased by heating them. By means of the tongs hold the copper and sulphur in the flame of the burner and watch changes. If too much sulphur has been used, it may be burned off from the surface of the metal. Remove the foil from the flame and examine the surface of the copper. What is its color now? This is a new substance produced by the union of the copper and the sulphur. It is known as COPPER SULPHIDE. Not all of the copper was used in the change. Only that portion on the outside, and next to the sulphur really underwent chemical change. Heat was liberated as the elements united but it was not noticeable in the flame.

Discussion of the Exercise.-This experiment illustrates a number of chemical combinations that may be made by the union of different chemical elements. Copper and oxygen, a gas, may be united to form COPPER OXIDE. Sodium and chlorine may be united to form SODIUM CHLORIDE, common table 
salt. Carbon and oxygen may be united to form CARBON DIOXIDE, a gas. In other proportions carbon and oxygen may be united to form a different compound, known as CARBON MONOXIDE. Hydrogen and oxygen unite to form HYDROGEN OXIDE (WATER). In other proportions hydrogen and oyxgen unite to form HYDROGEN DIOXIDE (HYDROGEN PEROXIDE) commonly called "peroxide."

89. Chemical Compounds do not Vary in Composition.Chemical elements, not only unite to form compounds with the accompanying chemical change, but, moreover, the elements are found in the compound in certain fixed and definite proportions by weight. Thus it is found that the compound copper sulphide is very nearly $1 / 3$ sulphur and $2 / 3$ copper by weight. Common salt (sodium chloride) is composed of nearly $3 / 5$ chlorine and $2 / 5$ sodium. Carbon dioxide is composed of just $3 / 11$ carbon and $8 / 11$ oxygen while carbon monoxide is composed of just $3 / 7$ carbon and $4 / 7$ oxygen. Water is nearly 1/9 hydrogen and 8/9 oxygen while hydrogen peroxide is 1/17 hydrogen and 16/17 oxygen. Each chemical compound has unvarying composition.

90. Oxygen and Getting Energy from Fuels.-Oxygen combines with nearly every other element, but with some more readily than with others. When it combines with the fuel elements, carbon and hydrogen, it liberates energy and forms carbon monoxide or carbon dioxide with the carbon, and water with the hydrogen. These compounds are the common products arising from the burning of fuels. Oxygen is necessary for burning all fuels. In a certain sense, it is the element which liberates the chemical energy bound up in fuels, thus making the fuel useful to man. The oxygen for burning fuels comes from the air.

91. Constituents of the Air.-Air is a mixture of gases, consisting of the elementary gases, oxygen and nitrogen, and the chemical compounds, water vapor and carbon dioxide. Besides these there are several other gaseous èlements and compounds in the air but they are unimportant for our purpose. The air usually contains tiny particles of solids as dust and germs. 
The following table gives the constituents of the air out of doors.

Oxygen, 21 volumes in 100 volumes of dry air.

Nitrogen, 78 volumes in 100 volumes of dry air.

Water vapor, variable within wide limits.

Carbon dioxide, 3 volumes in 10,000 volumes of dry air.

Since the burning of fuels requires oxygen and produces carbon dioxide and water vapor, it is evident that combustion will tend to change the proportions of the constituents of the air. Why the oxygen is not all used up and why the volume of the carbon dioxide does not largely increase in amount will be explained in Art. 381.

92. Study of Oxygen. - Since oxygen plays so important a part in all burning and the liberation of energy from fuels, it is well for us to study it. We want it unmixed with other gases. There are many compounds of oxygen which may be made to give up a part or all of their oxygen by heating or by other means. One such compound is potassium chlorate, a white crystalline compound composed of potassium, chlorine, and oxygen. When it is heated, it liberates its oxygen. If it is mixed with manganese dioxide, it liberates oxygen at a much lower temperature.

\section{Exercise 25. - The Preparation and Properties of Oxygen}

Set up the apparatus as shown in Fig. 67. Remove the test tube, fill it about one-third full of potassium chlorate; then place about an equal amount of manganese dioxide in the tube. Close the tube with the hand and shake it until the chlorate and the dioxide are well mixed. Replace the stopper in the apparatus, making sure that the stopper fits tightly. Apply gentle heat to the mixture in the tube, beginning at the end which has the stopper, but do not heat the stopper, for it may catch fire and make serious trouble. As the oxygen is given off, gradually and carefully extend the heat toward the closed end of the tube. At no time should so much heat be applied that the escaping gas carries the oxygen-producing mixture along with it bodily, thus tending to clog the delivery tube and to prevent the escape of the gas. Fill as many bottles as possible from the gas produced. To do this, submerge the bottle in the water in the pan, 
seeing that all of the air is expelled from the bottle by the water; then, keeping the mouth of the bottle beneath the surface of the water, invert the bottle and place it over the end of the delivery tube. As the oxygen escapes from the delivery tube, it bubbles into the bottle of water and crowds the water out. When the first bottle is full, place another bottle over the end of the delivery tube just as the first one was placed. Set the full bottles on the top of the table, keeping them inverted. The water around the mouth of the bottle will keep the oxygen from getting out. When you have driven as much oxygen

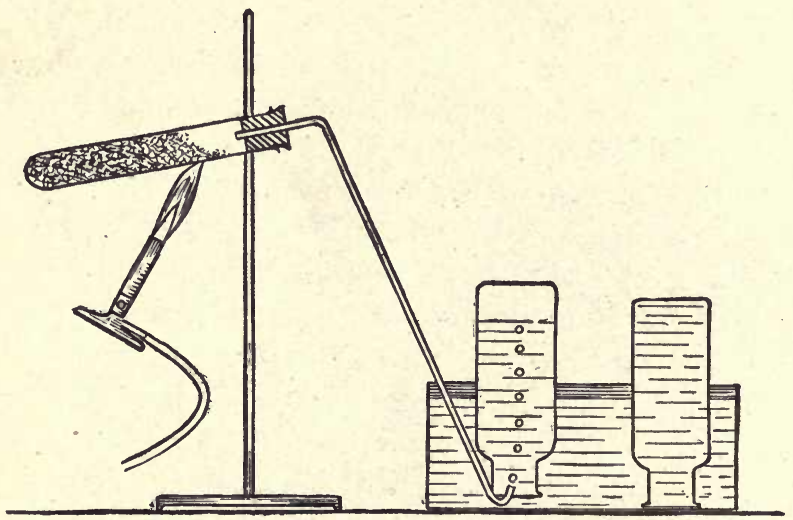

FIg. 67.-The preparation of oxygen. Potassium chlorate and manganese dioxide are placed in the test-tube and heated and the oxygen is collected in bottles. Be careful to see that the delivery tube extends entirely through the rubber stopper. Do not allow the delivery tube to become clogged.

as possible from the mixture in the tube, remove the end of the delivery tube from the water; then remove the flame from the test tube.

Study the oxygen obtained as follows:

(a) Effect of Pure Oxygen on a Burning Splinter.-Place a splinter of wood in a bottle of oxygen to see that the wood does not burn in oxygen at ordinary temperatures. Now heat the splinter, that is, "set it on fire," and thrust it into a bottle of oxygen. What is the result? In which, gas, oxygen or air, does the wood burn more rapidly? Why? Ignite another splinter and blow out the flame leaving the splinter merely glowing. Hold it in the air for a moment to see whether it will again burst into a flame. If it does not, place the glowing splinter in a fresh bottle of oxygen and observe the result. How do you explain it?

(b) Effect of Pure Oxygen on Smoldering Substances.-Repeat the 
latter part of $(a)$ using a piece of smoldering candle wicking or a piece of burning punk and a fresh bottle of oxygen.

(c) Effect of Pure Oxygen on Glowing Charcoal. - Wrap a small wire around a piece of charcoal the size of a lead pencil and an inch in length. Heat the charcoal in the flame until it glows. Quickly lower it into another bottle of oxygen and notice what takes place. When the charcoal ceases to burn, remove it from the bottle and close the mouth of the bottle. Compare the rate at which the charcoal burns in the oxygen with that in the air. Charcoal is chiefly carbon, and the compound resulting is carbon dioxide, a gas, which remains in the bottle. Caution.-Quench the charcoal by putting it into water.

(d) Effect of Pure Oxygen on a Burning Candle.-Twist a small wire around a short piece of candle or taper, light the candle and observe the rate at which it burns in the air; then plunge it into a fresh bottle of oxygen. Observe the rate of burning in the oxygen.

(e) Burning Iron in Oxygen.- Slightly unravel the end of a piece of iron picture wire. Heat the unraveled end in the flame; then quickly dip it into a little powdered sulphur and at once plunge it into a bottle of oxygen. Does the iron burn? It may be necessary to make several trials before the iron burns brilliantly. Do not use too much sulphur, just enough to kindle the iron. Can you make iron burn in the air?

(f) The Limewater Test for Carbon Dioxide.-Place a tablespoonful of fresh, clear limewater in each of the bottles used above. Place the palm of the hand over the mouth of each bottle in turn and shake well. In which cases does the limewater become milky in color and in which does it not? There may be several dark-colored specks in some of the bottles, but disregard them. The milky color of the limewater is a test for carbon dioxide.

\section{Discussion of the Experiment.-The union of oxygen} with the substances burned in this experiment is termed OXIDATION. The products arising from the union of the oxygen with the elements burned are called oxides. Thus the carbon in the wood, candle wicking, charcoal, and candle united with the oxygen to form carbon dioxide. The hydrogen in the wood, the candle wicking, and the candle united with the oxygen to form water. This was in the form of steam when made. The iron of the picture wire formed iron oxide.

Carbon dioxide causes limewater to become milky. Oxygen does not change limewater. 
In each part of the experiment, probably a part of the combustible substance was left unburned. One might infer that burning ceased because the oxygen was all used up, but it is not likely that such was the case in any part of the experiment. The reason for this will be apparent in the discussion which follows.

94. Concentration of the Oxygen.-It was observed that the burning was much more vigorous in the bottle of oxygen than in the air. This is because the air is but $21 \%$ oxygen while the gas in the bottle was $100 \%$ oxygen. Therefore, the burning particles would meet oxygen particles much oftener in the bottle of oxygen than in the air, and hence the union of the combustible material with oxygen was more rapid in the pure oxygen. This factor which influences the rate of oxidation is known as CONCENTRATION. If our atmosphere contained 100 per cent. oxygen or even 80 per cent. oxygen, iron would be a poor metal of which to make stoves, because the iron would burn in such an atmosphere just as soon as it became hot enough. Iron will burn in the air but not with sufficient rapidity to injure it much when used for stoves. When fuels containing carbon are burned, they, of course, produce carbon monoxide or carbon dioxide. These substances, being gases, mix with the unused oxygen and thus dilute it or decrease its concentration. The effect is the same as if the fuel were burning in an atmosphere containing less oxygen. It becomes necessary, then, to remove these gases of combustion as fast as formed so as to keep them from decreasing the concentration of the oxygen. This is exactly what is done in a stove or furnace by means of the draft (Arts. 136 and 137). The draft serves to remove, from the stove or furnace, the gases produced by combustion, and also to introduce fresh air into the fire. Both of these ends serve to maintain the concentration of the oxygen about the fire.

95. Temperature and Oxidation.-Another factor which influences the rate of oxidation is TEMPERATURE. At ordinary temperatures the rate of oxidation is very slow for most 
materials. Wood and many other fuel materials decay at ordinary temperatures. They are really undergoing what is called sLow oxidation. At higher temperatures the rate is much more rapid. For each substance that burns, there is a temperature at which it burns rapidly in the air. This temperature is called the KINDLING TEMPERATURE. When a fire is kindled, the aim is to heat the fuel to be burned by burning the kindling, the kindling having a lower kindling temperature than the fuel. Thus sulphur is used to kindle the iron; kerosene, paper, or shavings are used to kindle the coal or wood because these kindling agents have lower kindling temperatures than the fuel which is to be burned. When the fuel is once ignited, it then liberates heat fast enough to keep itself at the kindling temperature and so the fire continues as long as the concentration of the oxygen is sufficient. Wet fuels often require so much heat to dry them that the burning portion can not supply heat enough to dry the unburned portion and to raise it to the kindling temperature. Hence the fire goes out. Water is thrown on a fire to cool the burning material below its kindling temperature. Also the steam arising from the water serves to dilute the air and thus to lower the concentration of the oxygen so that the fire goes out.

96. Study of Hydrogen.-Hydrogen is the second of the fuel elements. It is to be prepared and studied.

\section{Exercise 26. - The Preparation and Properties of Hydrogen}

Set up the apparatus as shown in Fig. 68. Cover the bottom of the flask with granular zinc, replace the stopper and see that all joints of the apparatus are tight. Prepare to collect the gas, hydrogen, just as oxygen was collected. Do not have any flames closer than $4 \mathrm{ft}$. from the hydrogen generator. Pour water down the thistle tube until the bottom of the flask is well covered and the lower end of the thistle tube is submerged; then pour in concentrated hydrochloric acid slowly until the action between the zinc and the acid is rapid. Do not spill the acid on the hands, clothing, or desk. Allow the hydrogen to escape from the delivery tube for about one minute; then collect the gas in bottles as in the last exercise. Fill one bottle half full of the gas. Finally remove the delivery tube from the water, 
wipe it dry, and allow the gas to flow into a dry bottle containing air. Cover this bottle as well as possible. Take the hydrogen generator apart, fill the flask with water to dilute the acid and stop the action. Pour the dilute acid into the sink, rinse the unused zinc with fresh water and save the metal for future use.

Study the hydrogen as follows:

(a) The Burning of Hydrogen.-Light a splinter of wood. Lift one of the full bottles of hydrogen from the water, and, keeping the mouth of the bottle down, bring the flame of the splinter to the mouth

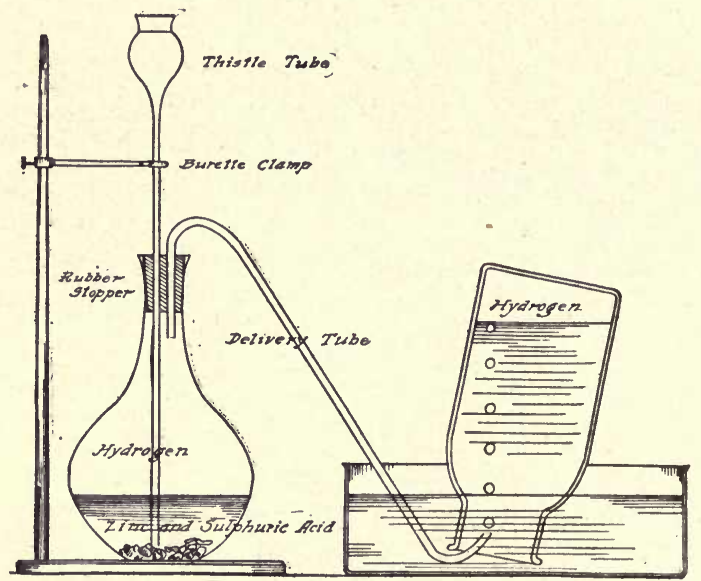

FIG. 68.-Apparatus for generating hydrogen.

of the bottle. Pay no attention to the noise, but look for the flame of burning hydrogen playing about the mouth of the bottle where it is uniting with the oxygen of the air. The experiment may be repeated with other bottles of the gas.

(b) The Burning of a Mixture of Hydrogen and Air.-Prepare another burning splinter. Lift from the water the bottle which was filled half full of hydrogen, keeping the mouth of the bottle down. What enters the bottle as the water runs out? Allow the air and hydrogen a few seconds in which to mix; then ignite them by means of the flame. The result illustrates the burning of a mixture of hydrogen and air. The noise is due to the sudden rush of the products of the burning from the bottle. The outrush is due to the heat generated by the combustion. Such a mixture is said to be Explosive. Such mixtures should be ignited only in bottles having wide mouths to allow the easy escape of the products of the burning. 
(c) The Product Formed When Hydrogen Burns in Air.-Prepare another burning splinter of wood. Take the $d r y$ bottle containing the mixture of air and hydrogen, and keeping it mouth downward, ignite the mixture. After the combustion is over carefully examine the inside of the bottle. Do you find any moisture on the walls? Where did this come from? What then is the product arising from the burning of hydrogen in air? Why was it necessary to use a dry bottle for this part of the experiment?

97. Discussion of the Exercise.-When hydrogen burns, it unites with oxygen, liberating much heat and producing water, in the form of vapor, as a product. This vapor condenses to water when it is cooled. Hydrogen is the lightest known substance. It is much lighter than air, and hence the bottles containing hydrogen are kept inverted so that the hydrogen will not run out. Mixtures of hydrogen and air containing more than 5 per cent. by volume of hydrogen and less than 72 per cent. are explosive. That is to say, a mixture of 95 cu. ft. of air and $5 \mathrm{cu}$. ft. of hydrogen will explode; so will other mixtures containing relatively less air and more hydrogen until a mixture of $28 \mathrm{cu}$. ft. of air and $72 \mathrm{cu}$. ft. of hydrogen is obtained, beyond which the mixture is no longer explosive. This means that, within the limits named, the concentration of hydrogen and oxygen is sufficient to maintain rapid combustion. In the experiment (b) the mixture was probably about 50 per cent. of each.

98. Hydrocarbons. -

\section{Exercise 27.-Burning Compounds of Hydrogen and Carbon}

(a) Light the Bunsen burner and hold over the flame an inverted, dry, cold tumbler. What substance appears on the inside of the glass? Pour a tablespoonful of limewater into the tumbler, cover it and shake it. Notice the change in the limewater. What two substances were formed by burning the gas?

(b) Repeat (a) but use a candle flame instead of the gas flame. Study the products arising from the burning of the candle.

(c) Repeat $(a)$ using a kerosene lamp flame, studying the products of the combustion.

What products of combustion may we expect when fuels containing hydrogen and carbon are burned? 
HydRocarbons are compounds of hydrogen and carbón. Petroleum is a very complex mixture of hydrocarbons. Some of the hydrocarbons of petroleum are gases at ordinary temperature, some are liquids, and some are solids (Chap. I, Sec. IV). The liquids predominate. By distillation, the gaseous, liquid, and solid hydrocarbons are separated. Gasoline and kerosene are common liquid hydrocarbons, while the paraffin of which the candle is made is a solid hydrocarbon. There are not large amounts of uncombined hydrogen in nature, but the compounds of hydrogen and carbon known as hydrocarbons are abundant, and in these the hydrogen and carbon are combustible. Acetylene is a gaseous hydrocarbon. It is one of the few manufactured hydrocarbons.

\section{Summary of Section II. The Chemistry of Combus-} tion.-(1) Fuels may be classified as solid, liquid, or gaseous. (2) Carbon and hydrogen are fuel elements. (3) Carbon and hydrogen are also chemical elements. Chemical elements are substances that, so far, have defied all attempts on the part of man to change them into simpler substances. There are about 80 chemical elements. (4) "Energy is work and everything that can arise from work and be converted into - work." Heat, light, electricity, kinetic energy, potential energy, and chemical energy are different forms of energy which may be converted, the one into another. During such changes there is no gain nor loss of energy. Chemical energy is the cause of the heat and the light produced when substances burn. (5) A chemical change is that kind of change in matter in which one or more new substances are formed and in which some kind of energy is produced or absorbed. (6) Chemical compounds result from the union of two or more chemical elements with the accompanying energy change. (7) The proportion of the elements in a compound is fixed. (8) Oxygen is the element commonly used to liberate the chemical energy of fuels as heat or light or both. (9) Oxygen constitutes more than $1 / 5$ of the air. (10) Oxygen may be prepared from a number of compounds, potassium 
chlorate among others. It causes many substances to burn. Oxidation is the union of oxygen with the material burned. (11) The rate at which the substance burns is determined, in part, by the concentration of the oxygen, and, in part, by the temperature of the material burning. All substances must be heated to a certain temperature before they will burn in air. This temperature is called the kindling temperature. (12) When the fuel element, carbon, burns in oxygen it forms carbon monoxide, or carbon dioxide. When the fuel element, hydrogen, burns in oxygen it forms water. (13) The hydrocarbons are compounds of hydrogen and carbon. They represent man's chief supply of fuel hydrogen. Petroleum is a complex mixture of hydrocarbons.

\section{THE BURNING OF WOOD AND COAL}

100. The Burning of Wood.-Wood is composed chiefly of carbon, hydrogen, and oxygen. These elements are present in various compounds which make up the wood. When the wood is heated to the kindling temperature in the presence of the air containing oxygen, a complicated series of changes take place which may be understood in part at least, by means of Exs. 28 and 29.

\section{Exercise 28.-Heating Wood in the Air}

Place two or three thicknesses of wire gauze on a ring attached to a ring stand and lay a piece of wood about $1 / 2$ by $1 / 2$ by 1 in. in size on the gauze. By means of a flame apply heat to the wood from beneath the gauze. If the flame from the burner passes through the gauze, more thicknesses of the gauze must be used. While the wood is smoking strongly, remove the flame and apply a lighted match to the escaping smoke. Does the smoke catch on fire? (Fig. 69.) How high above the wood can you cause the smoke to ignite?

This smoke consists of VOLATILE MATTER produced by the action of the heat on the wood. The volatile matter consists in part of hydrocarbons, and in part of water, acids, and wood alcohol. It is the burning of the volatile matter which causes the flame when wood is burned.

The black material, left on the gauze after the volatile matter is 
removed, is called wood charcoal. Place it on the edge of the gauze so that the end of the stick of charcoal extends beyond the gauze and heat the charcoal strongly by means of a flame. Does the charcoal get red hot?. Does it burn after the flame is removed? Does the charcoal burn with a flame? Does it give off much heat? Do you find any ash remaining after the charcoal has burned? The glowing embers of a wood fire are due to the burning of the wood charcoal after the volatile matter has been removed and burned.

Caution.-Be sure to quench the glowing charcoal lying on the gauze by throwing it into water. If left, it might set fire to the building.

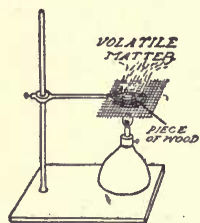

Frg. 69.-Burning wood on gauze.

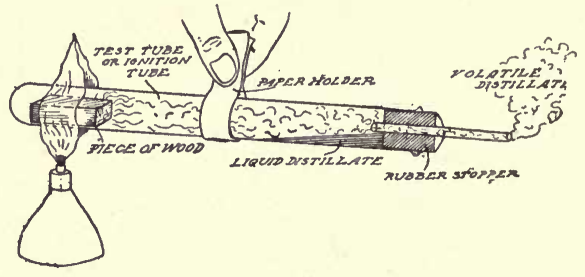

FIG. 70.-Distillation of wood.

\section{Exercise 29.-The Distillation of Wood}

Select a piece of wood about 1 in. long and of such a size as will slip into a test tube. Close the test tube with a one-hole stopper through which passes a short glass tube (Fig. 70). Heat the test tube as shown in the figure, carefully observing what takes place. Does smoke appear? Try lighting it as it comes from the small tube. Does liquid appear in the tube? Keep the tube inclined so that the liquid will stay near the stopper. If you allow it to run back and meet the hot glass it will probably break the tube. When the wood ceases to give off smoke, cool the tube, remove the stopper and pour the liquid into a shallow vessel. What is its color, odor, and appearance?

101. Discussion of the Exercise.-The liquid distilled from the wood is known as PYroligneous (pī-rō-lĭg'-nĕ-us) ACID (pyro meaning fire, and ligneous meaning woody). It is, therefore, acid obtained from woody substances by means of fire. It is composed largely of water but it also contains acetic acid (the acid of vinegar) and wood alcohol and other substances of commercial value. When wood is burned in a stove or grate these substances, except the water, together 
with the gases which escaped from the tube are all consumed in the flames, while the charcoal remains on the grate to be slowly oxidized to carbon dioxide, producing much heat but little or no flame.

102. A Study of Flame. - It has been seen that it is the vapor of the candle, of the gasoline, and of the kerosene that burns. The hydrogen has been seen to burn with a flame. The illuminating gas burns with a flame. The volatile matter from the wood burns with a flame. In every case a flame is produced by a burning vapor, or gas. Those fuels that are gases or that may be changed into vapors, or gases, by means of heat burn with a flame. Four conditions are necessary in order that a flame be produced: (1) The material must be in the form of a vapor or gas; (2) this vapor or gas must be mixed with oxygen; (3) the mixture of oxygen and vapor or gas must have concentration within certain limits; (4) the mixture must be heated to the kindling temperature. If one or more of these conditions are wanting there can be no flame.

103. Blowing Out a Flame.-A common expression is that of "blowing out" a flame. Candle flames, lamp flames, and even the flame of a fire just started may be blown out. However, if the fire is well started, it may be impossible to blow it out, but rather the blowing only serves to make the fire burn faster. From what has been given in Art. 102, on flames, it is evident that the effect of blowing into a candle flame or a lamp flame is to scatter the particles of vapor or gas and thus reduce their concentration (Art. 94) to such a point that there can be no flame. Moreover, the cold blast of air entering the flame serves to cool the burning materials below their kindling temperature (Art. 95). With a solid fuel such as charcoal, however, the case is different.

\section{Exercise 30.-Effect of Blowing upon Glowing Charcoal}

Place a piece of charcoal upon the gauze and heat it with a flame until it glows. Now blow gently upon the glowing portion. Does the blowing cause it to burn more or less rapidly? Can you blow it out? Caution.-Quench the charcoal in water. 
It is evident that one can not blow hard enough on the charcoal to scatter the particles as the gas particles are scattered and thus stop the burning. Rather, the blowing serves to bring in fresh oxygen and to remove the carbon dioxide resulting from the burning thus favoring the burning.

104. Luminous and Non-luminous Flames.-It will be recalled that the flames of the candle, of the kerosene lamp, of acetylene and of the burning wood are yellow or red in color and give much light. Such flames are said to be Luminous. The hydrogen flame, the gasoline flame as commonly used in stoves, and the illuminating gas flame as used in stoves are blue. Such flames are said to be Non-Luminous. It will be recalled that the non-luminous gasoline flame was made to give light by placing a mantle around it (Art. 42). The heat of the flame caused the mantle to become very hot and thus to give light. The light producing ability of the flames of the candle, of kerosene, of acetylene, and of wood is due to the presence of red- or white-hot particles of carbon. The carbon has been separated from the fuel burned by the action of the heat on certain compounds in the fuel. This carbon is heated by the burning of other elements in the fuel and thus gives light. The carbon finally meets oxygen and it too burns liberating heat. If anything interferes with the burning of the carbon, a black smoke composed of unburned carbon particles results.

\section{Incomplete Combustion.-}

\section{Exercise 31.-Causing a Flame to Smoke}

Light a candle flame. Can you see any unburned carbon escaping from the flame? Now introduce some cold object, as a glass tumbler, into the flame. What is the result? What do you find is being deposited upon the cold surface? Why did it not burn?

Light a kerosene lamp and replace the chimney. Turn the wick higher until the lamp smokes. What is the smoke? Why does not this smoke burn? Why does not the flame smoke when the wick is turned lower as it should be (Art. 8, Ex. 4)?

Discussion of Exercise 31.-The fuels burned in the above exercise were hydrocarbons. We have just seen that 
the fuel suffers decomposition or a breakdown into its elements, hydrogen and carbon, as it burns. These elements then burn separately. If there is a lack of sufficient oxygen, or if the fuel and oxygen are not properly mixed, or if the carbon is cooled below its kindling temperature before it has a chance to meet oxygen, then there will be more or less unburned carbon and the flame will smoke, due to the escape of this unburned carbon. Now it happens that the volatile matter from wood contains some oxygen in addition to what may mix with it from the air, and consequently wood ordinarily burns without black smoke. It is therefore said to be a cleaner fuel than soft coal which ordinarily burns with a black smoke.

106. Burning Coal.- Soft or BItuminous coal is the name applied to most of the coal mined in the United States except that which is mined in the eastern half of Pennsylvania. To this latter the name HARD or ANTHRACITE coal is applied.

\section{Exercise 32.-How Soft Coal Burns}

Place two or three thicknesses of wire gauze on a ring attached to a ring stand and lay a piece of soft coal about the size of a marble on the gauze. Heat the lump strongly by means of a flame. Does the coal produce any smoke? Remove the flame (Fig. 71). Can this smoke be ignited? How far above the coal are you able to ignite the smoke? The smoke, or volatile matter, consists of water and various hydrocarbons arising from changes in the coal, due to the heating. After all of the volatile matter of the coal has been driven off, remove the flame and examine the part which remains. It is called coke. What is the name of the corresponding material obtained by heating wood? See if you can ignite the coke as the charcoal from

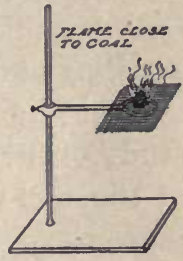

Fig. 71.Burning the volatile portion of coal in air. wood was ignited. Coke is much used as fuel, especially in obtaining metals from their ores.

\section{Exercise 33.-How Hard Coal Burns}

Repeat the preceding experiment using a lump of hard coal instead of the soft coal. Can you heat it hot enough to drive off enough 
volatile matter to support a flame? What can you say about the relative amounts of volatile matter in the two kinds of coal?

\section{Exercise 34.-Distillation of Soft Coal}

Arrange to distil soft coal just as wood was distilled (Ex. 29) except that the test tube is filled about one-third full of fine soft coal. The liquid which collects in the test tube is called COAL TAR, the gas which burned is the COAL GAS, while the solid portion left from the coal is the COKE.

107. Familiar Facts about the Burning of Wood and Coal.Wood and soft coal burn with long red flames because they contain so much volatile matter, while hard coal, because it contains so little volatile matter, does not produce such flames. Wood and hard coal make but little smoke because they are completely burned, including whatever volatile matter they contain, while soft coal, because it contains so much volatile matter, produces more or less black smoke. Hard coal and wood produce light fleecy ashes, while those from soft coal often melt together in the fire, causing clinkers. For starting a wood or a soft coal fire, a rather small amount of kindling is needed, since these fuels catch on fire easily because of their large amounts of volatile matter which easily ignites. Hard coal, because it contains so little volatile matter, requires more kindling and a hotter fire to start it.

108. The Composition of Common Solid Fuels.-In our study of fuels it is important that we understand the behavior of the fuel when heated. The following table gives: (1) The percentage of carbon that does not pass away as volatile matter, known as coke or fixed carbon; (2) the percentages of volatile matter which is produced by the fuel when it is heated; (3) the percentage of water; (4) the percentage of ash.

In the construction of stoves and furnaces in which the various fuels are to be burned, the manufacturer must keep in mind these facts of composition. The customer who buys a stove or furnace must know in general what kind of fuel is to be burned. Even with all of these conditions in mind, it is yet a difficult matter to burn soft coal, which produces much volatile matter, in such a way as to avoid serious loss. 
TABle III.-Composition of Solid Fuels

\begin{tabular}{|c|c|c|c|c|c|}
\hline & Substance. & $\begin{array}{l}\text { Coke or } \\
\text { fixed carbon, } \\
\text { per cent. }\end{array}$ & $\begin{array}{c}\text { Volatile } \\
\text { matter, } \\
\text { per cent. }\end{array}$ & $\begin{array}{l}\text { Moisture, } \\
\text { per cent. }\end{array}$ & $\begin{array}{l}\text { Ash, } \\
\text { per cent. }\end{array}$ \\
\hline \multicolumn{2}{|c|}{ Wood, dried............. } & 20 to 30 & 55 to 65 & 15 to 20 & 1 to 3 \\
\hline \multirow[t]{3}{*}{ Peat, } & dried. & 25 to 35 & 25 to 50 & 20 to 35 & 2 to 7 \\
\hline & Lignit & 40 to 70 & 23 to 48 & 4 to 40 & 3 to 20 \\
\hline & Cannel... & 30 to 40 & 45 to 55 & 1 to 4 & 6 to 12 \\
\hline \multirow[t]{4}{*}{ Coal } & Bituminous.. & 40 to 75 & 20 to 50 & 3 to 10 & 2 to 10 \\
\hline & Semi-bituminous. & 70 to 80 & 10 to 20 & 1 to 5 & 4 to 10 \\
\hline & Semi-anthracite...... & 80 to 90 & 5 to 10 & 1 to 3 & 3 to 7 \\
\hline & Anthracite & 85 to 93 & 3 to 6 & 1 to 3 & 3 to 5 \\
\hline \multicolumn{2}{|c|}{ Coke. } & 85 to 95 & none & 1 to 5 & 2 to 12 \\
\hline
\end{tabular}

\section{SMOKE; ITS CAUSE AND PREVENTION}

109. The Cause of Smoke.-Because of the high percentage of volatile matter in soft coal, it is likely to produce much black smoke unless precautions are used to prevent it. The principles concerned in smoke production are identical with those explained in connection with the smoking candle and the oil lamp. Hydrocarbons produced by the heated coal are decomposed more or less completely into hydrogen and carbon. Failure of the carbon to meet a sufficient supply of oxygen at or above the kindling temperature of the carbon, causes more or less of the carbon to be carried up the chimney unburned, making its appearance as black smoke. Even though the temperature of volatile matter is kept sufficiently high until it meets oxygen, if the supply of the latter is insufficient, the carbon will be incompletely burned at best. It may be burned to CARBON MONOXIDE instead of CARBON DIOxIDE. This means a loss of heat, since less than one-third of the energy of the carbon is liberated as heat if it is burned to carbon monoxide instead of carbon dioxide.

110. Some of the Evils of Smoke. The Smoke Nuisance.The production of black smoke means, not only poor combustion of the coal and hence a loss of heat, but also injury to health and property. People who are compelled to live and work 
in a'smoky atmosphere are liable to injury to their health. Moreover, the smoke and its accompanying dirt have a depressing effect on people. They are liable to become despondent and unhappy. This in turn may affect their health. Smoke makes necessary the more frequent painting of buildings. Stone buildings become dingy and the owners are sometimes put to the expense of washing the entire outside of the building. White clothing becomes soiled because of soot. Furnishings and draperies in houses are injured. Goods on the dealer's shelves are injured because of soot. Our waste due to poor combustion of soft coal runs into millions of dollars annually.

111. How Can This Waste be Prevented?-Of course, the prevention is by practising more perfect combustion of soft coal. Did you ever follow the changes that take place when fresh soft coal is thrown into a stove containing a bed of hot coals? When the coal first meets the hot bed of coals the volatile matter of the coal begins to distill off. If the temperature in the stove is fairly high, this volatile matter may undergo more or less complete decomposition into carbon and hydrogen. The hydrogen burns if the oxygen supply is somewhat limited, while the carbon, which requires a greater concentration of oxygen, is burned incompletely or not at all. Black smoke results. If the temperature in the stove is rather low, the volatile matter may not be decomposed so much. A bluish-gray smoke results. At all events the drafts of the stove are generally not able to supply enough oxygen and maintain at the same time a temperature high enough to burn the volatile matter immediately after throwing fresh coal into the fire. Consequently smoke issues from the chimney as long as there is much volatile matter being produced from the coal. After the volatile matter has been set free, smoke ceases to escape from the chimney until a fresh charge of coal is thrown into the stove. If smaller amounts of coal could be thrown in at shorter intervals of time, it might be that the drafts of the stove would be able to supply enough oxygen 
to burn the volatile matter as fast as it is produced by the coal. Since it is not convenient to place frequent small charges of coal in the stove, the other method commonly resorted to in smokeless combustion is the gradual and slow distillation of the volatile matter in the soft coal, so that the drafts can furnish oxygen fast enough to consume the volatile matter completely.

112. How Some Stoves and Furnaces are Constructed to Prevent Smoke.-A common device is the HоT BLAST stove.

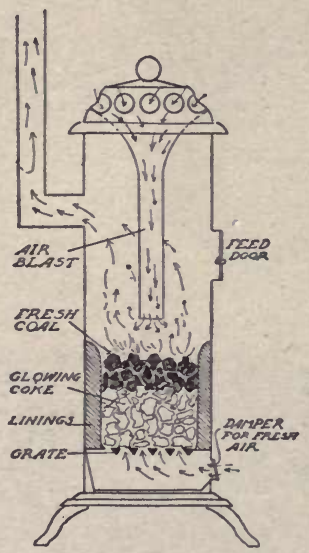

FIG. 72.-Stove with air blast.

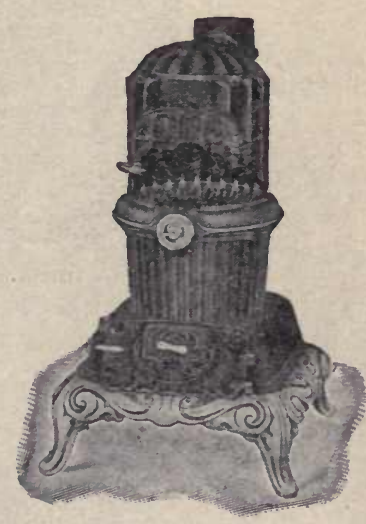

FIG. 73.-Another form of air blast.

In this stove the air for the oxygen supply is admitted from above instead of from beneath the grate as in most stoves. By the top-draft arrangement, the volatile matter has a better chance to meet oxygen and hence its complete combustion is more readily accomplished (Figs. 72 and 73 ).

In some furnaces the coal is first thrown into a cokING CHAMBER which is heated by the fire in the fire pot. Here slow distillation of the volatile matter takes place. By means of a damper in the coking chamber door, sufficient air can be admitted and a sufficiently high temperature may be main- 


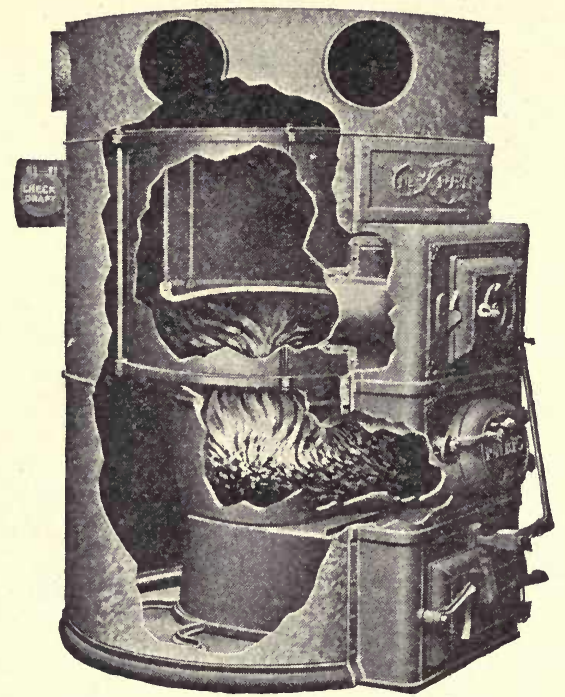

FrG. 74.-A furnace with a coking chamber.

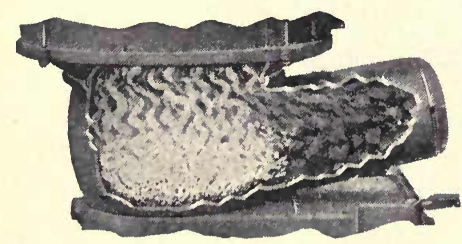

FIG. 75. - Coking chamber of a side.. feed furnace.

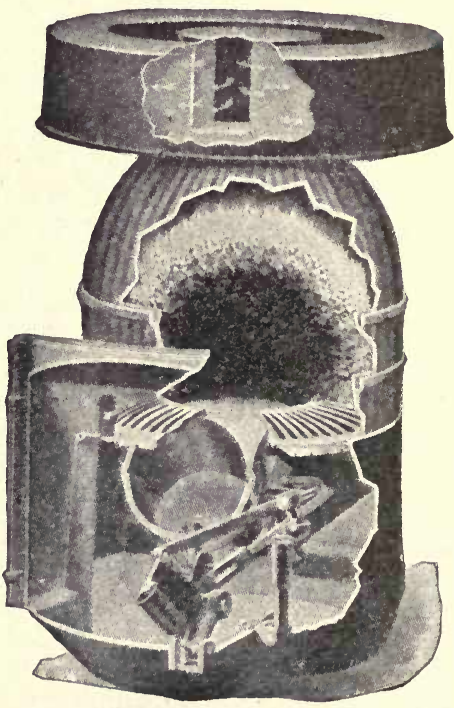

FIG. 76.-An underfeed furnace. 
tained in the combustion chamber to burn the volatile matter completely (Figs. 74 and 75 ).

In the UNDERFEED furnace, fresh coal is introduced at the bottom of the fire bed. Distillation of the volatile matter

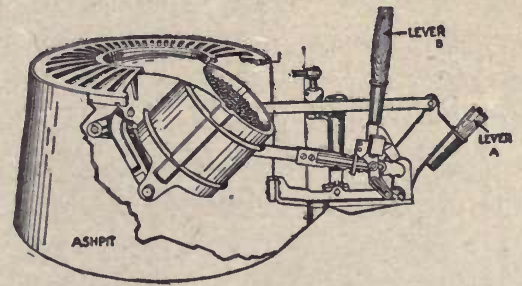

FIG. 77.-Showing the feed cylinder tilted forward and filled with coal. The apron closes the opening in the center of the grate through which the coal is forced upward into the fire box.

takes place therefore at the bottom of the fire, where the oxygen supply may be more abundant than on top of the fire, and hence it is more completely burned (Figs. 76, 77 and 78). Moreover, in passing through the glowing coke above, the volatile matter is sure to be heated to the kindling temperature.

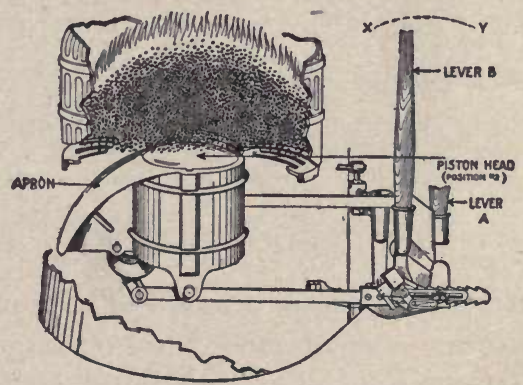

Fig 78.- Showing the fresh coal forced into the fire box and the burning coal resting on the top of the fresh coal.

In steam boiler plants MECHANICAL STOKERS are often employed. With the mechanical stokers, the aim is to feed the fuel to the fire gradually by some device. In the stoker shown (Fig. 79), which is a chain grate stoker, the coal is fed 
continually by being carried into the furnace on the grate. As the fresh coal approaches the zone of combustion, the volatile matter is gradually distilled from the coal. There is also provision for a supply of air ample to burn the volatile matter as well as the fixed carbon or coke.

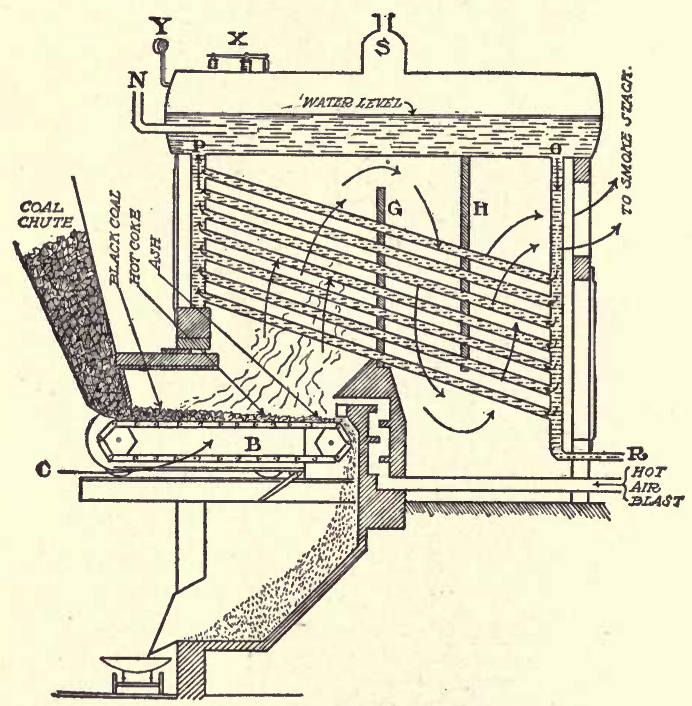

Fig. 79.-Mechanical stoker and a water-tube boiler. $B$, Chain grate. $C$, Fresh air. $G, H$, Baffle plates. $N$, Water feed pipe. $R$, Blow off. $\mathrm{S}$, Steam dome. $Y$, Pressure gage. $X$, Safety valve.

\section{LIQUID FUELS}

113. The Burning of Liquid Fuels.-The burning of kerosene and of gasoline has already been studied. It will be remembered that, in each case, the liquid is first converted into a vapor, and then the vapor is burned, using an adequate supply of air. The same principle is used in burning liquid fuels generally. Crude petroleum is burned by vaporizing it by means of a jet of air or steam, after which the vapors are burned in the proper supply of air. The gasoline in the automobile is vaporized and mixed with the proper amount 
of air in the carbureter, after which the mixture is drawn into the cylinder, compressed to increase the rate of combustion, and finally burned within the cylinder (see Gas Engines, Chap. X).

\section{GASEOUS FUELS}

114. Gaseous Fuels.-These have long been a favorite kind of fuel. Their use in the home and in various industries has gradually increased. Gaseous fuels are commonly transmitted from producer to consumer in pipes. The cost of pipes makes it unprofitable to transmit the fuel long distances. Some gases, as acetylene, are transmitted under pressure in metal tanks (Art. 62). The material for making acetylene, calcium carbide, may be transmitted long distances profitably.

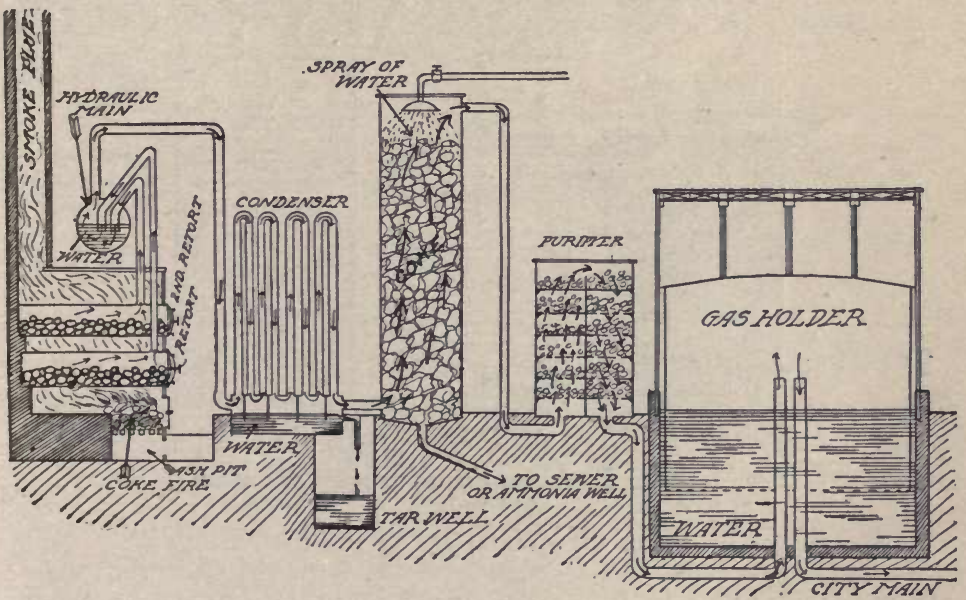

Fig. 80.-An illuminating coal gas plant.

115. Coal Gas.-CoAl gas was the first manufactured gas. It was used for lighting the streets of London and Paris more than 100 years ago. In 1817, the city of Baltimore began to use it for street lighting. The gas is made by distilling soft coal in air-tight retorts (Fig. 80). The coal contains many hydrocarbons which leave it when the coal is 
heated. The hydrocarbons at the same time are broken down into simpler compounds. The gas also contains hydrogen and carbon monoxide. Because of the hydrocarbons in coal gas it burns with a luminous flame. The manufacture of coal gas has gradually declined of late owing partly to the fact that but few kinds of coal are suitable for use in making it and these are becoming more expensive, and partly to the decrease in cost of electricity.

116. Water-Gas.-WATER-GAS has come to replace coal gas in many cities. When steam is passed over red-hot carbon, the former is decomposed into hydrogen and oxygen.

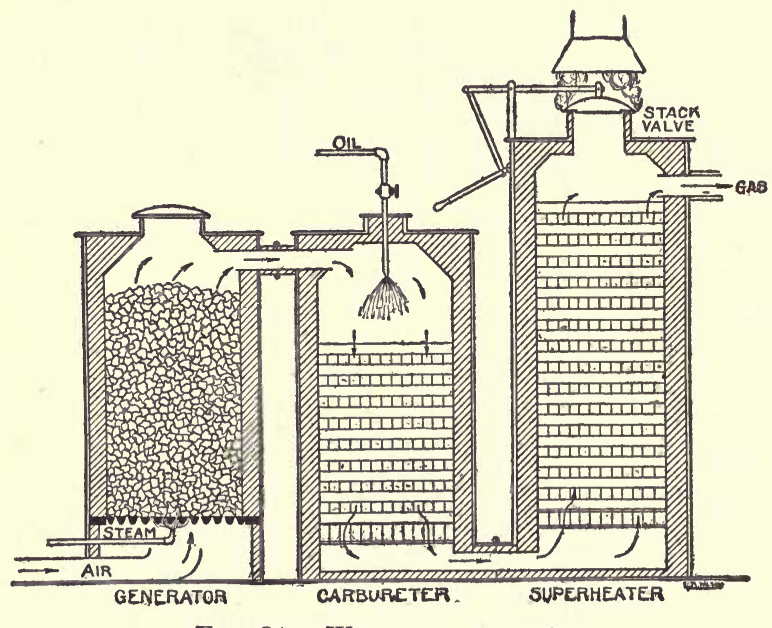

Fig. 81.-Water-gas apparatus.

The carbon then unites with the oxygen from the steam to form carbon monoxide or carbon dioxide depending upon conditions, while the hydrogen from the water is set free. By proper control of conditions, carbon monoxide rather than carbon dioxide may be formed, which, with the hydrogen set free, makes a mixture of highly combustible gases. The mixture is called WATER-GAS. During the chemical reaction of the steam and the hot carbon, heat is absorbed, and conse- 
quently the carbon soon cools to a temperature at which the reaction stops. The carbon is then heated again by blowing air through the furnace, called the GENERATOR (Fig. 81), in which it is contained. When the carbon again becomes hot enough, the air is shut off and steam is again admitted. Since the carbon monoxide and the hydrogen burn with a blue flame, it becomes necessary to introduce some substance that will render the flame of water-gas luminous. This is done by introducing into the gas vaporized, or gasified, hydrocarbons derived from crude petroleum. The petroleum is sprayed into a CARBURETER which is heated to a very high temperature. Here the petroleum hydrocarbons are broken down into simple hydrocarbons which remain as gases. These are mixed with the water-gas and the mixture is passed through the SUPERHEATER. Such a mixture is known as CARBURETTED WATER-GAS.

117. Gasoline Gas.-Gasoline gas is simply air and gasoline vapor mixed in such proportions as to be non-explosive. Air containing less than 1.5 per cent. and more than 6.4 per cent. of gasoline vapor, by volume, when $88^{\circ} \mathrm{B}$. gasoline is used, is non-explosive, while a mixture containing between 1.5 per cent. and 6.4 per cent. of gasoline is explosive. There are two general processes used for vaporizing the gasoline. One, known as the COLD PROCESS, is described in Art. 45. For this a light oil $\left(88^{\circ} \mathrm{B}\right.$.) must be used. The other process, known as the HOT PROCESS, uses heat to vaporize the gasoline. This makes possible the use of a heavier, and hence a cheaper, grade of gasoline. In each of these systems, it is expected that the air will carry from 12 to 20 per cent. of gasoline vapor. Gasoline gas is almost always used with a mantle when used to produce light. It may be used in ranges for cooking. The production of gasoline gas offers a convenient means of producing gas in small amounts for home or school use in places inaccessible to a city gas supply.

118. Acetylene.-The preparation and the use of this gas have been discussed in Chap. I, Sec. X. The gas is used to a limited 
extent in country homes for cooking. Gas stoves for burning acetylene require a special burner so that the acetylene flame will not smoke.

119. Producer Gas.-A gas that has come into extensive use of late as a fuel for gas engines and for certain kinds of heating is called PRODUCER GAS. Large quantities of producer gas are used in making steel and in making glass. In both of these cases it is used to produce heat in the furnace. The

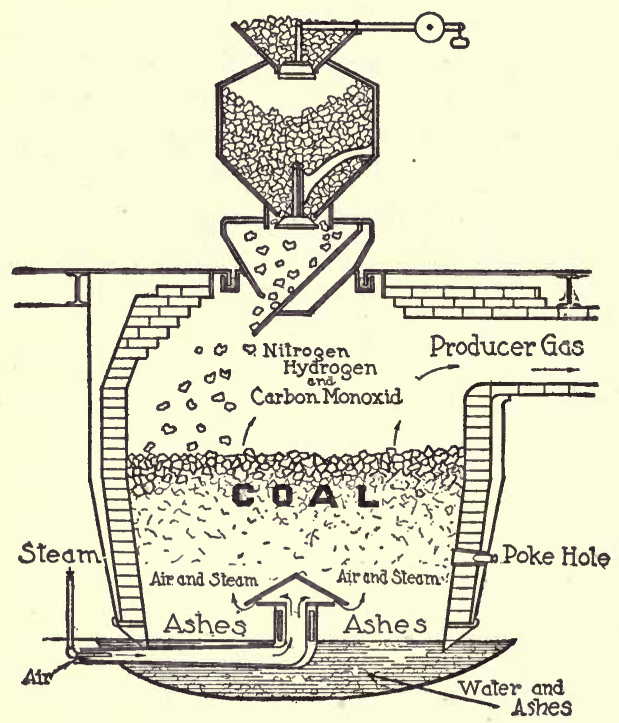

Fig. 82.-Producer gas plant.

principle employed in making producer gas is that of the incomplete combustion of carbon. The resulting carbon monoxide is then used as a fuel when it burns to carbon dioxide. When carbon burns to carbon monoxide, about 30.6 per cent. of the heat energy of the carbon is liberated, the remaining 69.4 per cent. being liberated when the resulting carbon monoxide is burned to carbon dioxide. The fuel (coal is usually used) is placed in the producer (Fig. 82). A 
current of air is then forced or drawn through the red-hot fuel. At the bottom of the producer, the oxygen of the air forms carbon dioxide. As this rises through the fuel bed, it gives up a part of its oxygen to carbon, thus forming the carbon monoxide which escapes through the exit to the engine or furnace.

Now since the carbon in the producer is burned to carbon monoxide only, it therefore liberates about 30 per cent. of its energy. This serves to keep the fuel bed hot. In fact, the temperature would soon rise too high for successful working. In order to keep the temperature down and yet not waste heat energy, a jet of steam is introduced into the producer. As it rises through the red-hot bed of coal, the steam is decomposed, liberating hydrogen, while the oxygen of the steam unites with carbon to form more carbon monoxide exactly as in the manufacture of water-gas. Heat is absorbed during this change. The hydrogen and the carbon monoxide resulting are also delivered through the exit pipe and are used as fuel.

Producer gas differs from water-gas in that it contains all of the nitrogen that was in the air used to feed the producer. Since the nitrogen neither burns nor supports combustion, the producer gas has a lower heat-producing ability than any of the other gases mentioned.

Table IV.-Composition of Gaseous Fuels (Approximate)

\begin{tabular}{|c|c|c|c|c|c|c|}
\hline \multirow[b]{2}{*}{ Kind of gas } & \multicolumn{3}{|c|}{ Combustible constituents } & \multicolumn{2}{|c|}{$\begin{array}{l}\text { Non-combustible } \\
\text { constituents }\end{array}$} & \multirow{2}{*}{$\begin{array}{c}\text { B.t.us. } \\
\text { per cubic } \\
\text { f oot } \\
\text { (see Art. } \\
\text { 122) }\end{array}$} \\
\hline & $\begin{array}{c}\text { Hydro- } \\
\text { gen, } \\
\text { per cent. }\end{array}$ & $\begin{array}{l}\text { Hydro- } \\
\text { carbons, } \\
\text { per cent. }\end{array}$ & $\begin{array}{c}\text { Carbon } \\
\text { monoxide, } \\
\text { per cent. }\end{array}$ & $\begin{array}{l}\text { Carbon } \\
\text { dioxide, } \\
\text { per cent. }\end{array}$ & $\begin{array}{l}\text { Nitrogen, } \\
\text { per cent. }\end{array}$ & \\
\hline Natural gas... & 0.0 & 99.0 & 0.4 & 0.3 & 0.2 & 900 \\
\hline Coal gas....... & 41.3 & 49.0 & 6.4 & 2.0 & 1.0 & 600 \\
\hline Water-gas....... & 38.0 & 19.0 & 33.0 & 4.0 & 5.0 & 600 \\
\hline Producer gas...... & 11.0 & 1.0 & 20.0 & 9.0 & 60.0 & 140 \\
\hline Gasoline gas...... & 0.0 & 15.0 & 0.0 & 0.0 & 68.0 & 570 \\
\hline Acetylene gas..... & 0.0 & 100.0 & 0.0 & 0.0 & 0.0 & 1440 \\
\hline
\end{tabular}


By means of the gas producer the coal is "gasified" and the resulting gas may be burned with all the advantages that belong to other gaseous fuels. By the producer gas method, a larger amount of the energy of the coal may be obtained than by the direct burning of coal beneath a boiler (see Chap. X, Sec. VII).

\section{THE MEASUREMENT OF HEAT}

Our fuels are burned for the production of heat or light. A fuel intended for the production of heat is more or less valuable depending on the amount of heat that can be obtained from it when it is burned.

120. Distinction Between Heat and Temperature.-We have learned that temperature refers to the hotness or coldness of a body (see Art. 14). Temperature is measured by means of a thermometer. Two bodies may have the same temperature but may contain vastly different amounts of heat. A pint of water may have the same temperature as the average temperature of a large body of water like Lake Michigan, yet it will possess very little heat compared with that in the lake. The lake influences the climate of the surrounding states, but the influence of the pint of water on the temperature of objects around it will amount to almost nothing. It is apparent that the weight of the body has a great deal to do with the heat it contains at a given time. Then, too, the amount of heat a body contains also depends upon the material of which it is made. Two objects of the same weight but of different materials may be changed in temperature an equal number of degrees, and yet the amounts of heat required to produce the change in temperature may differ greatly. One pound of water in being raised in temperature $10^{\circ} \mathrm{C}$. will require more than 32 times as much heat as will be required by $1 \mathrm{lb}$. of lead raised a like amount in temperature. Other substances require still different amounts of heat for a like temperature change.

Definition.-The heat capacity of 1 gram of a substance 
while being raised $1^{\circ} \mathrm{C}$. is called the SPECIFIC HEAT of that substance.

So it is evident that the heat an object possesses depends upon three factors: (1) Its weight; (2) its temperature; (3) the material or substance of which it is made.

\section{Units of Heat Quantity.-}

Definitions.-1. One unit is the amount of heat necessary to raise 1 gram of water $1^{\circ} \mathrm{C}$. It is called the LESSER CALORIE and this is usually abbreviated, thus: 1 cal.

2. A second heat unit is the amount of heat necessary to raise 1000 grams, or $1 \mathrm{Kg}$., of water $1^{\circ} \mathrm{C}$. It is called the GREATER CALORIE and is usually abbreviated, thus: $1 \mathrm{Cal}$. This is the unit generally used by European engineers in calculating all large quantities of heat, such as are required in heating buildings.

3. A third unit is the amount of heat required to raise the temperature of $1 \mathrm{lb}$. of water $1^{\circ} \mathrm{F}$. This is called the BRITIsH THERMAL UNIT. In writing it is usually abbreviated, thus: 1 B.t.u. This is the unit commonly used by British and American engineers.

\section{PROBLEMS}

1. How many lesser calories (cal.) of heat are absorbed when 20 grams of water are raised $5^{\circ} \mathrm{C}$.?

2. 500 cal. of heat will raise 25 grams of water from $20^{\circ} \mathrm{C}$. to what temperature?

3. How many greater calories (Cal.) are absorbed when $50 \mathrm{Kg}$. of water are raised from $15^{\circ} \mathrm{C}$. to $25^{\circ} \mathrm{C}$.?

$4.800 \mathrm{Kg}$. of water are to be heated from $15^{\circ} \mathrm{C}$. to $100^{\circ} \mathrm{C}$. How many Cal. of heat will be required?

5. If $40 \mathrm{lb}$. of water are raised from $18^{\circ} \mathrm{F}$. to $80^{\circ} \mathrm{F}$; how many B.t.us. are consumed?

6. How many B.t.us. of heat are required to raise $50 \mathrm{lb}$. of water from the freezing point to the boiling point?

7. How many B.t.us. are given off when $80 \mathrm{lb}$. of water are cooled from $180^{\circ} \mathrm{F}$. to the freezing point?

122. How Heat is Measured. Calorimetry.-Heat is measured by means of an instrument called a CALORIMETER. 
The principle of the calorimeter is that the heat produced by the body when burned is absorbed by water. As a consequence the temperature of the water rises, and by knowing the weight of the water and its rise in temperature the amount of heat which the water absorbed can be calculated. Of

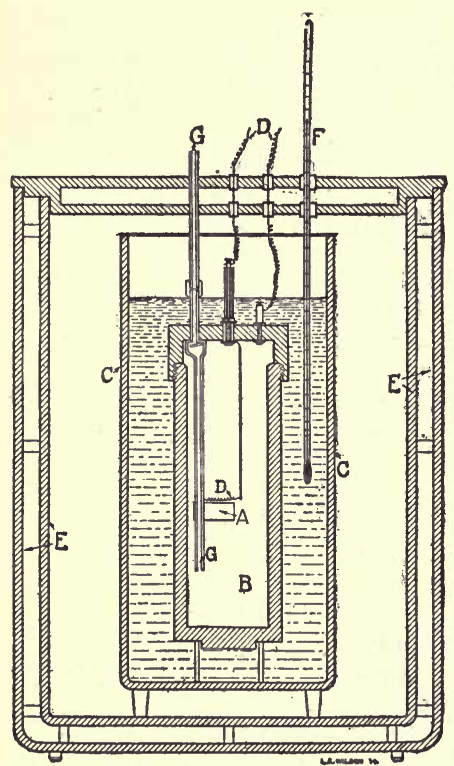

Fig. 83.-A calorimeter used to determine the heat of fuels.

course every possible means is used to prevent the escape of heat from the water during the determination.

Figure 83 represents a calorimeter used in determining the heat value of fuels. The fuel to be examined is carefully weighed and placed in the metal cup, $A$; placed inside the metal bomb, $B$. The bomb is water tight and is placed in the water contained in the vessel, $C$. The weight of the bomb and the weight of the vessel, $C$, are both known. Electric wires, $D$, carry a current of electricity into the bomb where a wire leads across the surface of the fuel to be burned. The bomb contains oxygen under pressure. The vessel containing the water and bomb is set in a doublewalled vessel, $E$, which prevents the escape of heat from the apparatus. The temperature of the water is taken by means of the thermometer, $F$. When all is ready, a current of electricity is passed through the wires. That portion of the wire over the fuel becomes red hot and ignites the charge in the cup. The fuel burns and produces heat which is absorbed by the bomb, the metal vessel, $C$, and the water. The rise in temperature is determined by means of the thermometer. By knowing the heat absorbed by the water and 
the different parts of the apparatus, the heat produced by the fuel may be determined.

\section{Table V.-Heat Value of Fuels (Approximate)}

Calories per pound

Carbon

Hydrogen . . .

Wood, Ash...............

Wood, Beech...............

Wood, Oak...............

Wood, Pine...............

Wood, Elm...............

Charcoal. . . . . .

Peat.

Lignite

Coal, Bituminous.

Coal, Semi-anthracite.

Coal, Anthracite.

Coke.

Petroleum
3,672

15,664

2,141

2,161

2,100

2,311

2,150

3,227

1,800 to 2,300

1,800 to 3,000

3,000 to 3,600

3,000 to 3,600

3,400 to 3,900

3,450 to 3,700

about 5,000
B.t.us. per pound

14,544

62,032

8,480

8,591

8,316

9,153

8,510

12,780

7,200 to 9,000

7,200 to 11,700

11,700 to 14,400

11,700 to 14,400

13,500 to 15,300

13,700 to 14,500

about 20,000

\section{OUR COAL SUPPLY}

123. Development of Coal Production.-The first coal produced in the United States was mined and marketed in 1820. The records show that 365 tons, an average of 1 ton per day, were produced that year. For many years the production of coal increased slowly. During recent years the increase in production of coal has been very rapid, till in 1910 about 500,000,000 tons were mined and used. The diagram, Fig. 84, shows that on the average the production of coal in the United States has doubled about every ten years. If this rate of increase in the use of coal continues in the future, we shall be consuming in 1920 about $1,000,000,000$ tons; in 1930 about 2,000,000,000 tons; in 1940 about 4,000,000,000 tons, and so on. At this rate of increase, how many tons will we require in the year 2000? How many tons in the year 2040?

124. Waste in Mining of Coal.- In mining coal, it has generally been found necessary to leave large columns of coal to support the roof of the mine. In the anthracite fields of 
Penusyivania more than one-half of the coal is thus left in the mine-only about 40 per cent. is removed. The remaining 60 per cent. of the coal is left in such shape that it can probably never be recovered. This means that for every ton of anthracite coal which has been mined, about $1 \frac{1}{2}$ tons have been forever lost to the use of mankind. In the bituminous, fields, there has been less waste. For every ton of bituminous coal mined about $1 / 2$ ton has been left in the mine.

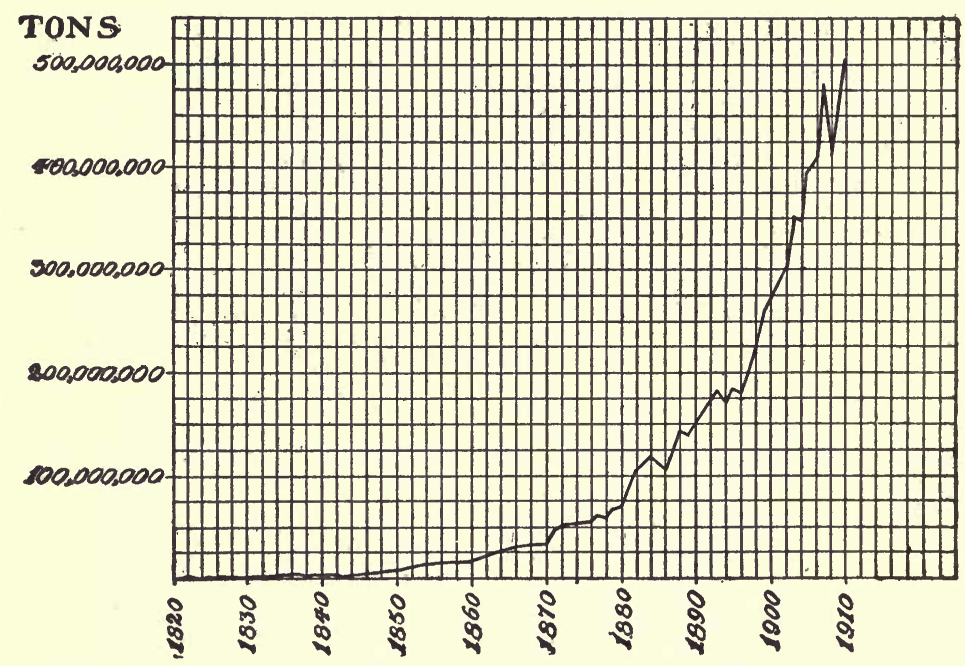

FIG. 84,-Annual production of coal in the United States, 1820-1910.

125. How Long Will Our Coal Supply Last?-Government officials have made careful estimates of the number of tons of coal in all known coal deposits of the United States. Accepting this estimate and supposing that the consumption of coal will continue to increase at the same rate in the future as it has in the past, it has been shown that our available coal supply will be exhausted in about 120 years, or about the year 2030. We therefore see how necessary it is that we avoid as far as possible all waste of coal.

At the present time a much larger portion of our coal is 
being wasted than is being used for the benefit of mankind. The two chief sources of loss are:

1. Only about one-half of the coal is being removed from the mine; the other half is being left in such a condition that it probably can never be recovered.

2. We have seen in the preceding pages of this chapter, and shall see still more clearly in Chap. X, that only a small portion of the energy in the coal burned is now being utilized.

126. The Coal Fields of the United States.-The map, Fig. 85, shows the location of the more important coal fields

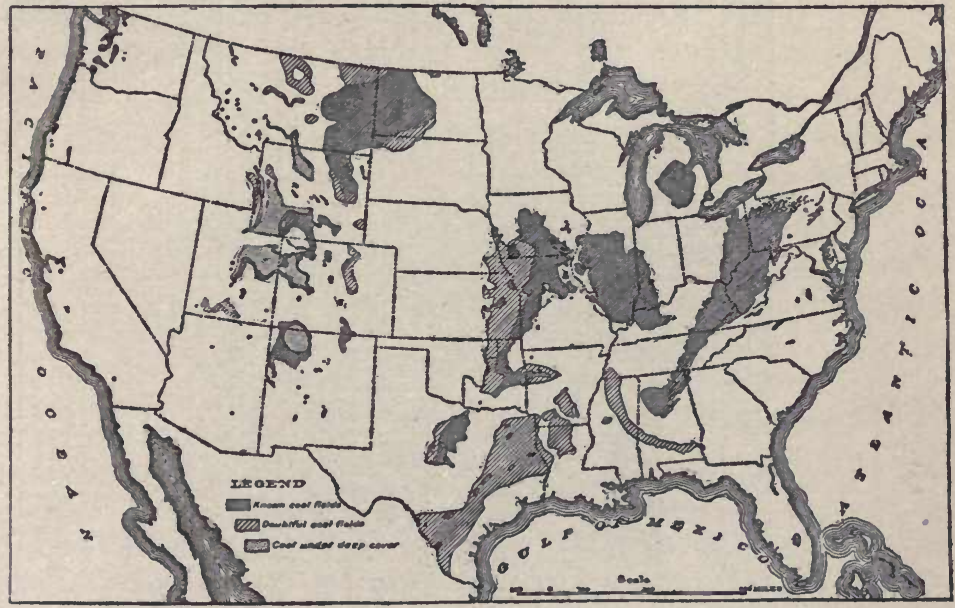

FIG. 85.-Distribution of coal fields in the United States.

of the United States. The large eastern field extending from Pennsylvania to Alabama yields chiefly anthracite, semianthracite and semi-bituminous coals. The central fields, consisting of the Illinois, Indiana, Kentucky, Iowa, and Missouri fields yield chiefly bituminous and cannel coals. The large northwestern field of the Dakotas, Montana, and Wyoming yields bituminous and lignite coals. The fields of Colorado yield bituminous and semi-anthracite coals (see Table III, page 95, Composition of Solid Fuels, for the distinction in different kinds of coals). 


\section{DEVELOPMENT OF HOUSE HEATING}

127. The Roman Hypocaust.-The houses of the Romans were heated by hypocausts. These were fire rooms constructed in the cellars (Fig. 86). From these rooms clay pipes led to various rooms of the house above. Through these pipes all of the smoke and heat from the burning wood passed to the rooms above. This method of heating would seem very disagreeable to us, especially when the volatile matter

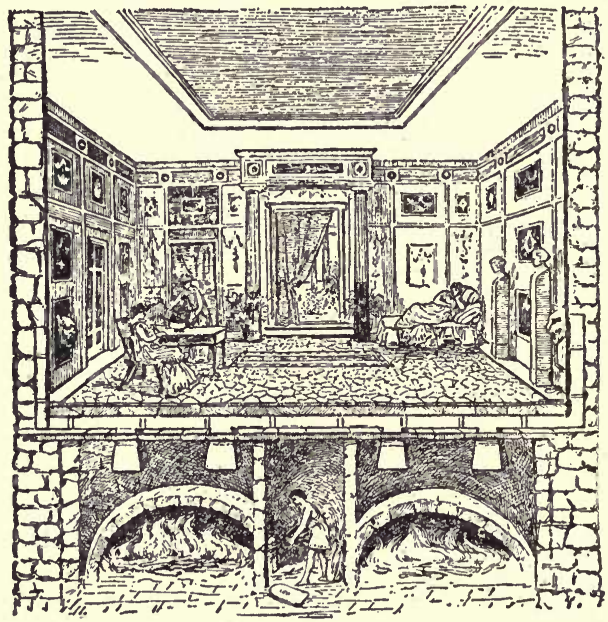

Fia. 86.-A Roman hypocaust. (From Stories of Useful Inventions. By permission of The Century Company.)

was distilling from the wood. Crude as this method of heating was, it was the best method known until comparatively recent times. The use of the hypocaust perished with the civilization of Rome.

128. The Fireplace and the Early Stoves.-Mention has already been made of the use of the fireplace in house heating and cooking, and of Franklin's invention of the stove. Stoves did not come into general use in the United States until after 
1825. Wood was used as the fuel and the stoves were but little more than open, iron fireplaces standing out in the room. Between 1825 and 1835, the first stoves for burning hard coal were made. Some of these were fairly successful but all have been greatly improved since that time.

129. The Invention of the Chimney.-It is recorded that the invention of the chimney was the result of war. At the time of the Norman conquest of England in 1066 the Britons heated their houses by means of fires built on the floor at the center of the house. The smoke was permitted to escape through a hole in the center of the roof. But the smoke so bothered the Britons as they fought from the house roofs that the custom arose of building a fire at one side of the room and providing for the escape of the smoke through an opening in the side wall. To cause the smoke to escape more readily through the opening, a hood was built into the room over the fire. From this crude beginning chimneys finally developed.

\section{Gauses of Convection Currents}

130. Some Common Observations.-You have very likely noticed many times that when a fire in the stove is first lighted the draft is not strong for a minute or so. As soon as the fire is really burning well, the draft becomes strong. When we first light a bonfire, the feeble flame is blown about in all directions by the breezes. When the fire gets to burning fiercely, all these conditions change. Instead of being carried off by the wind, the smoke and burning embers are swept swiftly upward, rising in a vertical, tapering column to the height of 20,30 or perhaps $50 \mathrm{ft}$. If we notice carefully now, we shall see that the wind blows into the fire at the ground from every direction. The rising column of air is called a coNVECTION CURRENT. We shall be able to understand this better if we learn what effect the heating of air has upon its volume. 


\section{Effect of Heat upon the Volume of Air.-}

\section{Exercise 35.-Air Expanded by Heat}

Fit a 10 - or 12-in. glass tube into the stopper and the stopper into the flask. Be sure that the apparatus is air-tight (Fig. 87). Invert the flask so that the end of the tube dips into the water in a vessel. Gently apply heat to the flask, constantly turning it so as to heat it evenly on all sides. Do bubbles of air escape from the tube? Heat the flask quite hot; then remove the flame and allow the flask to cool. What happens? What portion of the air was forced out of the flask?

When air is heated, it always expands. When a certain volume of air at the temperature of freezing water is heated

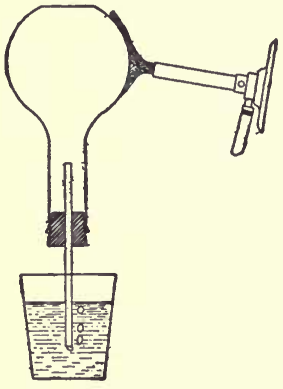

Fig. 87.-Effect of heat upon volume of air. to the temperature of boiling water, it increases nearly $1 / 3$ in volume. If it is heated but $1^{\circ} \mathrm{C}$., it increases exactly $1 / 273$ part of itself. This fact was discovered by a Frenchman named Charles in 1787. $\mathrm{He}$ discovered that this was the rate at which all gases expand when heated. This fact is called CharLes' LAw and is stated thus: Pressure remaining constant, the volume of a given portion of gas increases 1/273 part of its volume at zero centigrade for each rise of $1^{\circ} \mathrm{C}$. above that temperature, and it decreases $1 / 273$ of its volume for each fall of $1^{\circ}$ below that temperature. Were we to state the law in the Fahrenheit scale of temperature, we should use $32^{\circ} \mathrm{F}$. in the place of $0^{\circ} \mathrm{C}$. and the fraction $1 / 491$ in the place of 1/273. Explain why this is so (see Art. 22).

132. Application of Charles' Law.-It is not probable that in any two lamps we might examine we should find that the gases within the chimney are heated to exactly the same temperature. But we are probably not far from the truth if we say that the gases within the ordinary lamp chimney are so heated that they are expanded to twice the volume they had when they entered the bottom of the burner. Every cubic inch of air which enters the burner leaves the top of the chimney as $2 \mathrm{cu}$. in., if this be true. The same thing takes 
place in the bonfire. As soon as the fresh air reaches the heated portion of the fire it is greatly expanded. The coal in the stove or furnace produces a still higher temperature. The air passing up through the bed of glowing coke is so heated at that moment that it is increased to three or possibly five times its volume as it enters the damper. It is this heating of the air and the consequent expansion, or increase in volume, which produces CONVECTION CURRENTS. Just why and how this is so we must learn.

133. Floating Bodies and Buoyancy.-We all know that a cork or a piece of wood weighs less than a piece of iron of the same size. We also know, that if we place the cork or piece of wood in water, it will float, while if we place the iron in water, it sinks. What makes the cork float? Just why does the iron sink? Does the iron have any tendency to float? Answers to these questions will help us to understand coNVECTION CURRENTS.

\section{Exercise 36.-Floating Bodies and Buoyancy}

(a) Place a cork in a basin of water. Does it float entirely upon the surface? If any portion of the cork is below the surface of the water, about how much of it is so? Does "floating upon the water" mean that all of the body is above the level of the water? Does the cork have any tendency to sink?

(b) Set a small pail in an empty basin. See that the pail is exactly level. Fill it exactly full of water. Take care that no water runs over into the basin. Now tie a cord securely around a stone. Weigh the stone by means of a spring balance. While the stone is still suspended from the balance, lower it into the pail of water

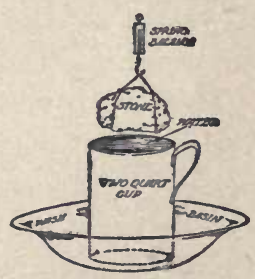

FIg. 88.-Buoyancy. till it is entirely covered by water. At the same time the stone must not touch the bottom of the pail. See how much the stone now seems to weigh (Fig. 88)? How much has it lost in weight?

(c) Carefully remove the stone from the water. Remove the pail from the basin. You now have in the basin the water which ran over when the stone was immersed in the pail. Empty the water out of the pail and pour the water from the basin into it. Weigh the pail and 
this water. Now empty out this water and weigh the pail. The difference in these last two weights gives you the weight of the water which ran over when the stone was immersed in the water. The difference between the two weights of the stone gives the loss of weight which the stone seemed to suffer upon being immersed. How does this loss of weight compare with the weight of the water which ran over? What is now your answer to the question: Does the stone have any tendency to float when immersed in water? To what extent does the water lift or hold up the stone? Repeat the experiment.

(d) Fill the pail partly full of water again. Now hold the cork down near the bottom of the water and release it. What happens? To what extent does the water lift, or force up, the cork? If you had a body exactly as dense as water, i.e., which weighs exactly the same per cubic inch, would it float or sink? What would it do?

134. Archimedes' Principle.-In performing part $(c)$ of the preceding experiment, a student got the following results:

Weight of the stone in air................ $46 \mathrm{oz}$.

Apparent weight of the stone immersed in water... $30 \mathrm{oz}$.

From which we get the loss in weight........ 16 oz.

Weight of pail and water which ran over....... $23 \mathrm{oz}$.

Weight of the pail empty.................. 7 oz.

From which we find the weight of water....... $16 \mathrm{oz}$.

From this experiment the student concluded that the loss of weight by the stone when immersed in water was equal to the weight of the water displaced.

This truth was first stated by a Greek philosopher named Archimedes who lived about 25 years before Christ in ancient Syracuse. He was a close friend of King Hiero; his life was spent in the study of mathematics and science. He was the most profound student of these subjects in his day. It is said that his friend, King Hiero, ordered from his goldsmith a crown of pure gold. When the crown was completed, however, the king suspected that it was not pure gold. $\mathrm{He}$ summoned Archimedes and instructed him to ascertain the truth without injuring the crown. Archimedes was pondering over this question as he went to his daily bath. Noticing, as he entered the full bath, that the water was lifted and ran over 
the edge of the tub just in proportion as his body was immersed, and also that his own weight was decreased at the same time, he leaped from the bath and ran to his home shouting, "Eureka, Eureka," which means "I have found it, I have found it." Pure gold is a little more than nineteen times as heavy as water, while silver is but ten and one-half times as heavy. If the crown had been pure gold it should have lost one-nineteenth of its weight when immersed in water. He found that it lost more than one-nineteenth of its weight in water, so he concluded that silver had been used in its construction.

ARCHIMEDES' PRINCIPLE may be thus stated: Whenever $a$ body is immersed in a fluid (liquid or gas) it is buoyed up with a force which exactly equals the weight of the fluid displaced.

When the cork was immersed in the water (d, Ex. 36), it was being pushed upward with a force equal to the weight of an equal volume of water. Since the weight of the cork was less than this force, it was pushed to the surface of the water and partly out of it. As it floated upon the surface of the water, it was displacing an amount of water which exactly equaled it in weight. The stone, on the other hand, sank to the bottom because it was heavier than an equal volume of water; its weight was therefore greater than the buoyancy of the water. That it was buoyed up to a considerable extent was shown by the balance.

135. Convection Currents Caused by the Buoyant Effects of the Air.-The solid portion of the earth is covered by an ocean of air many miles, probably some hundreds of miles, in depth. This air has weight just as water has weight. In fact, it is much heavier than we usually suspect until we have weighed some of it. A box $2 \mathrm{ft}$. by $2 \mathrm{ft}$. by $3 \mathrm{ft}$., or $12 \mathrm{cu}$. ft., holds $1 \mathrm{lb}$. of air. A common schoolroom $30 \mathrm{ft}$. by $30 \mathrm{ft}$. by $10 \mathrm{ft}$. therefore holds $750 \mathrm{lb}$. of air.

All bodies here on the earth's surface are being buoyed up by this air exactly as the stone and the cork were buoyed up by the water. A stone will fall through the air and rest at 
the bottom of the atmosphere exactly as it fell through the water and rested at the bottom of the pail. Even the cork is so much heavier than the air that it, too, sinks to the bottom of the atmosphere. There are some substances lighter than the air. Hydrogen weighs but about one-fifteenth as much as the air. A BALLOon is a bag filled with this very light hydrogen or some other light gas. Whenever the bag and the hydrogen which it contains weigh less than the air it displaces, the surrounding air buoys it up with a force greater than its weight and it floats. Instead of using hydrogen, heated air is often used in toy balloons. The toy Fourth of July balloon con-

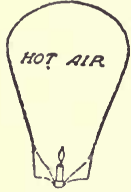

FIG. 89.

Hot-air

balloon. sists merely of a sack of light, nearly air-tight material, usually paper. The bag is inverted and its lower end is somewhat open (Fig. 89). A burning candle is suspended in the open mouth of the sack. The heat from the candle keeps the air in the balloon warm. As long as this air is sufficiently heated, the balloon continues to float. The important thing to notice is this: The heated air would be buoyed up, pushed upward, just the same if it were not enclosed in a sack. From this fact we see that convection currents are always produced when any fluid is heated more at one point than at surrounding points.

We shall find convection currents of great importance in the study of the weather, Chap. IV.

\section{Application of Convection Currents to Chimnets}

136. The Draft in the Chimney.-The current of air, or draft, in the chimney is caused by the column of air within the chimney becoming either warmer or cooler than the surrounding air. If the air within the chimney is warmer, the draft will be upward. Why? When there is a fire in the furnace or stove, the air within the chimney will be heated and the draft will be upward. It is now evident that the draft is not strong when we first light a fire in the stove because the air within the chimney has not yet been heated. 
ConcLusion.-There is nothing mysterious about the draft of a chimney. A chimney will "draw" if the laws of physics have been regarded in the construction of the chimney and in the operating of the stove. A column of heated air is lighter than a column of cold air and will, therefore, be pushed up through and out of the top of a chimney, unless there is some other force opposing its motion.

\section{PROBLEMS}

1. How much will a column of air $1 \mathrm{ft}$. square and $30 \mathrm{ft}$. high weigh if $12 \mathrm{cu}$. $\mathrm{ft}$. weigh $1 \mathrm{lb}$.?

2. If a chimney is $1 \mathrm{ft}$. square and $30 \mathrm{ft}$. in height and the air within it is heated to $273^{\circ} \mathrm{C}$., how much will the air within it weigh if $1 \mathrm{cu}$. ft. of air at $0^{\circ} \mathrm{C}$. weighs $1 / 12 \mathrm{lb}$.?

3. The ordinary residence chimney for a stove is $9 \mathrm{in}$. square and about $30 \mathrm{ft}$. in height. If the air out of doors is at $0^{\circ} \mathrm{C}$. and the air within the chimney heated to an average temperature of $250^{\circ} \mathrm{C}$., a similar column of air outside is how many times as heavy as that within the chimney? What will be the result?

137. Construction of the Chimney.-Certain rules should be followed in constructing a chimney, otherwise some interfering forces may prevent the chimney from "drawing" properly.

1. The chimney must be large enough to carry the volume of air and smoke which is to be turned into it.

2. The chimney must not be so large that the gases within it do not become heated to a temperature considerably higher than the surrounding air.

3. The chimney should be as straight as possible and as smooth as possible on its inside.

4. It is best not to place the chimney in or against the outside wall. Why?

5. The higher the chimney, the longer the column of heated air and hence the greater the difference in weight between this column and a similar column of outside air.

6. It is well to line the chimney inside, making it doublewalled to further protect it from the cold, just as our houses are double-walled. 
7. The chimney should extend higher than any other portion of the house or surrounding buildings. If this is not the case, the wind is likely to blow over the buildings and downward into the chimney with sufficient force to ruin its draft.

8. All openings into a chimney should be completely closed except those which are in actual use. Why?

It is rarely possible to comply with all of these rules. If many of them are disregarded, however, there should be no cause to regard the poor draft as mysterious. If the laws of physics have been understood and regarded in constructing the chimney, and if the chimney is kept reasonably free from soot, there will be a good draft upward whenever there is a fire in the stove, furnace, or fireplace. NATURE'S LAwS ARE INVARIABLE.

\section{Application of Convection Currents to Room Heating}

138. Convection Currents in a Room Heated by Means of a Stove.-Convection currents play an important part in all heating of rooms by means of stoves. The movements of air in a stove-heated room can easily be determined by experiment.

\section{Exercise 37.-Air Currents about a Stove}

Close all windows and doors. Light some punk or a piece of cotton cloth and test the currents of air by holding the torch in the following positions and observing the movement of the smoke: First, above the stove; on each side of the stove, level with the top of it; on each side of the stove and about 6 in. from the floor. Second, hold the torch 6 in. or $1 \mathrm{ft}$. from the ceiling and about half way from the stove to the window or outside wall; do this on each side of the room. Third, hold the torch about $3 \mathrm{ft}$. from the floor and about 6 in. or $1 \mathrm{ft}$. from the window or outside wall. Fourth, hold the torch 6 in. from the floor and half way from the outside walls to the stove. Show by means of a sketch the air currents as you found them. If some of the walls of the room are inside walls, the circulation will hardly be as perfect as it would be if they were all outside walls.

The general circulation about the stove in a room having all four of its walls outside walls is very simple. There is a rising column about and above the stove. As this column 
pours upward against the ceiling, it spreads out in every direction toward the outside walls. The outside walls, and especially the windows, are cold, consequently the air is here chilled. It therefore becomes heavy and drops to the floor. Across the floor from every side of the room the cold stream of air passes back to the stove. As a person sits facing the stove in such a room there is sure to be a stream of cold air blowing against his back and past his feet. This is especially true if the stove is not large enough to heat all the air in the room. These returning currents of air are often mistaken for cold, outside air which is supposed to have crept in through cracks and crevices about the windows and in the outside wall. If the walls of the room were air-tight these currents would still exist.

139. Radiant Heat. - Not all of the heat from the stove, however, is distributed through the room by means of these convection currents. Often from one-fourth to one-third is given off in what is called RADIANT HEAT.

\section{Exercise 38.-Radiant Heat}

Heat a poker red hot. While holding it with one hand, place the other hand about 2 in. above it. Can you feel the heat? Hold your hand about 2 in. from its side. Can you still feel the heat from it? Is the heat carried by the convection current? Place the hand about 2 in. below the poker. Can you still feel the heat? Certainly this heat is not carried by convection currents.

This experiment shows clearly that some heat is sent off from the poker to each side and downward, as well as upward. This heat is said to be RADIANT HEAT, and it is said to have passed from the poker by RADIATION. While it is difficult to explain radiation and radiant heat, it is very easy to show some of the results of radiation of heat from the ordinary stove. Before we study these applications we shall state the LAws of RADIATION as they have been determined by careful experiments:

1. Heat is radiated from a heated body in straight lines in all directions and in equal amounts in every direction. 
2. Radiation takes place through a vacuum as well as through air.

3. The rate of radiation varies with the temperature of the heated body.

It is known that the amount of heat given off from the stove by radiation as compared to that given off by convection currents is dependent upon the temperature of the stove. The higher the temperature, the greater the proportion of heat given off by radiation. It is probable, though, that in the case of the ordinary stove one-fourth to one-third of the heat is given off as radiant heat and the remainder in the convection currents.

140. Jacketing the Schoolroom Stove.-It is difficult to heat schoolrooms properly by means of stoves. The room is usually allowed to get cold at night. In severe weather the room is often uncomfortably cold when the opening hour arrives. In an endeavor to heat the room, the janitor has

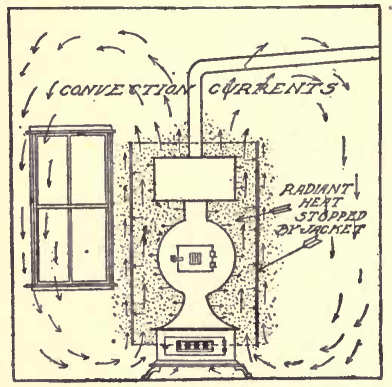

FIG. 90.-A jacketed stove. the stove heated to a high temperature. The result is that a much larger portion of the heat than usual is being given off as radiant heat. The pupils and furniture near the stove are consequently overheated, while the pupils at the outer edges of the room are suffering with the cold.

The remedy for this defect is found in placing a sheet-iron jacket around the stove (Fig. 90). The jacket should be 4 or $5 \mathrm{ft}$. in diameter and have a door in front through which the stove may be reached. It should be supported 6 or 8 in. from the floor and should reach to the top of the stove. This jacket catches most of the radiant heat. The cool air comes into contact with it and is heated as it is by the stove. The jacket not only prevents the overheating of the portion of the room nearest the stove by 
radiation, but it also greatly increases the convection currents which heat the outside edges and corners, and the floor of the room (see Art. 364).

\section{The Setting of Furnaces}

141. The Furnace.-The Furnace for house heating is little more than a large stove of simple construction inclosed within a sheet-iron jacket or surrounded by brick walls. When the iron jacket is used it is said to have a PORTABLE SETTING; when the brick walls are used it is said to be a BRICK SET FURNACE. In either case, the furnace with its jacket employs the same principles which are employed in the jacketed schoolroom stove, the principal difference being that the furnace is set in the basement or cellar. The air to be heated is led to the bottom of the space inclosed by the jacket by means of sheet-iron pipes running through the basement, or better still, by means of large tile or cemented brick passages beneath the basement floor. The heated air is led upward from the top of the jacket to the rooms above, which are to be heated.

142. Air Supply for the Furnace.-The cold air supplied to the furnace is often taken from within the house; a more sanitary method is to supply the furnace with pure, fresh air from without the basement wall. When the second plan is followed, the furnace becomes, not only a heating plant, but also an excellent means of furnishing ventilation as well. By this plan, a considerable stream of fresh air is coming into the house at all times. This is, of course, quite impossible unless some opening is provided to allow an equal amount of air to escape. The ordinary house is often too well built to permit this amount of air to escape through cracks and crevices. The exit may be provided by partly opening a window; it is better, however, to provide fireplaces with flues extending above the roof. Many people do not yet appreciate the great importance of proper ventilation for their homes and therefore they provide for taking the cold air supply only from within 
the house. This practice is a saving of fuel, for none of the air within the house is very cold at any time. A common practice, which can be made to meet the wishes of all, is so to construct the COLD AIR DUCT, as it is called, that the air may be taken either from within the house or from the outside as is desired 'Fig. 91).

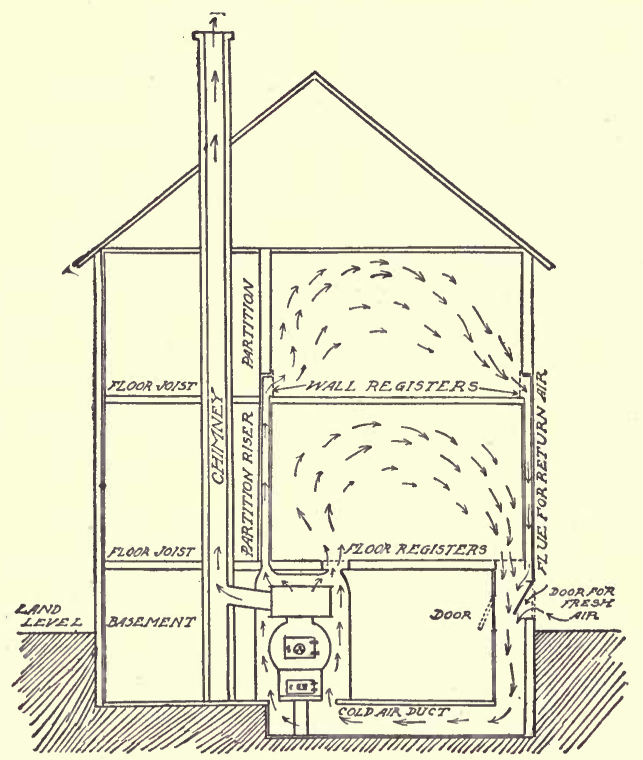

FIG. 91.-Furnace and air supply.

143. Placing the Registers and Risers.-The pipes which lead up from the furnace open into the rooms by means of REGISTERS, open frameworks of iron. The pipes leading from the furnace to the second floor or higher are made of tin, are rectangular in shape and usually about $3 \frac{1}{2}$ in. by $12 \mathrm{in}$. so as to be easily placed within a 4 -in. wall. These hot air pipes are called RISERS, or STACKS.

One general rule should be followed: All heating pipes should be as short as possible; all risers should be placed in inside walls; and all registers should be placed as far as possible 
in the warmest portion of the room. The reason for this rule is easily seen. Just as the tallest chimney produces the best draft because it contains the longest column of heated air, so the upward current of air through the furnace, through the riser which leads from it and into the room above will be strongest if the air is well heated throughout its

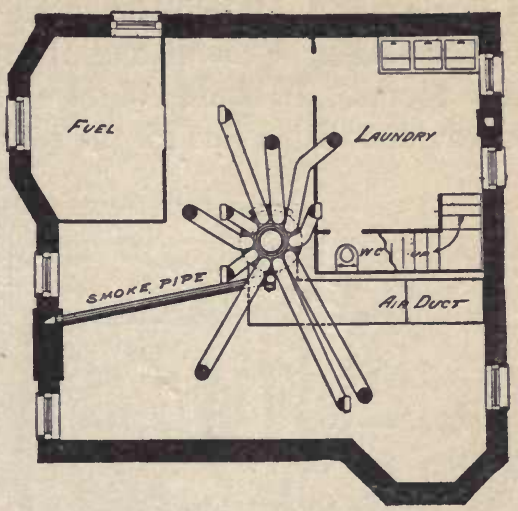

FIG. 92.-Basement plan for setting a furnace. entire course. By placing the riser in inside walls and the register in the warmest por-

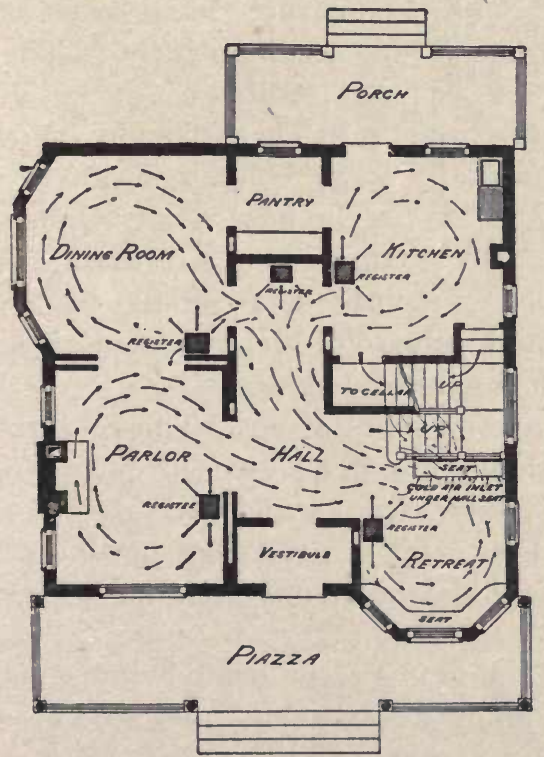

Fig. 93.-First floor plan for setting a furnace. tion of the room, which is usually also near an inside wall, a column of heated, and consequently light air, of the greatest possible length is assured. Were the register placed at the coldest point in the room, the upper portion of the column would be cold air, and consequently heavy air, and the movement of the air through the furnace and riser would be slow and sluggish. $A$ strong and reliable circulation of air is the keynote to success in furnace heating.

In Fig. 91 the circulation of air from a furnace 
is made clear. It will be noted that floor registers are used for the first floor rooms and all wall registers for the second floor rooms. In some houses each room on the second floor is provided with a flue for the return of cold air to the furnace,

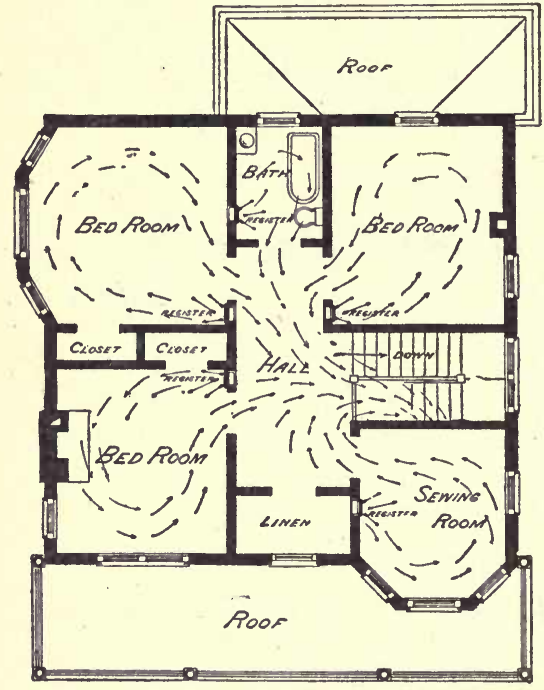

Fig. 94.-Second floor plan for setting a furnace.

if INSIDE CIRCULATION is the iystem to be used. These are not often provided, however. A good circulation is secured by permitting the cold air to return down the stairway (see plans, Figs. 92, 93 and 94).

144. A Successful Furnace.-To be a success, the furnace should be so constructed and so set as to accomplish the following results:

1. There should be a large volume of moderately heated air passing through the furnace and into the rooms to be

heated at all times. A small volume of highly heated air is not only uncomfortable but unhealthful as well.

2. There should be no cross-currents of air. The cold air from all parts of the house should join in a single current when returning to the furnace. (Study Figs. 93 and 94.)

3 . The heated air should enter at the warmest portion of the room and the cold air should be drawn out from the coldest portion.

4. All of the air in all of the rooms to be heated should be in constant circulation, and all of the air should be heated to a comfortable temperature.

5. A successful furnace does not overheat the basement. 
A furnace should have such a perfect circulation that the jacket never becomes very hot. The purpose of the furnace is to send heated air into the rooms above and not to heat the basement.

\section{Hot Water Heating}

145. Principles of Heating by Hot Water.-In heating houses by means of hot water, we depend largely upon the same principles as in furnace heating. In the furnace we depend upon the heating of the air and the consequent expansion of it to produce the circulation; so here also we depend

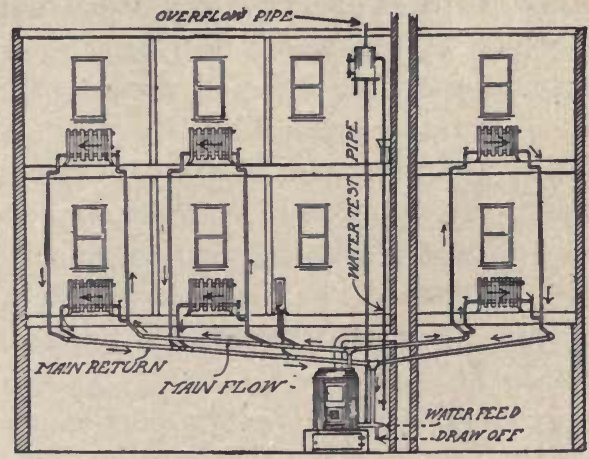

FIG. 95.-A hot water system.

upon the heating of the water and the consequent expansion of it to produce the necessary circulation.

The WATER HEATER is usually placed in the basement (Fig. 95). The hot water flows from the highest point of the heater through the MAIN FLOW PIPES to the radiators placed in the various rooms. From the radiators, the cold water returns through the RETURN FLOW PIPES to the bottom of the heater. In passing through the radiators, the water heats them and they in turn heat the air in the rooms, producing convection currents precisely as the stove does.

The water cannot be kept in circulation without some active force to keep it moving. It is easily seen that we have 
vertical pipes filled with hot water, and others filled with cold water. The cold water being the denser and therefore the heavier, and the pipes being connected both at the top and the bottom, the cold water is certain to fall to the bottom of the system and crowd the heated water to the top. This means that the cold water sinks into the heater and that the hot water is forced up into the radiators. The water in the radiators soon becomes cool and the water in the heater soon becomes heated, thus the circulation is maintained. Notice the slope, or PITCH, as it is called, in the case of the horizontal pipes. Why should these pipes slope as they do?

146. Essential Features of Any Hot Water Heating System. -1. In any system of hot water heating, the circulation of the water depends upon the unequal weight of two columns of water, one heated and one cold. The heater, the piping, and the radiators must be placed with this thought in mind.

2. Since water expands when heated and contracts when cooled, every hot water heating system must be provided with an ExPANSION TANK. This tank is to give the water a chance to expand when heated without bursting the pipes. (See Art. 15, Ex. 11.)

3. Care must be taken that every portion of the heater, the pipes, and the radiators can be drained completely when not in use; this will prevent freezing and bursting of pipes.

4. Care must be taken that the water in the expansion tank and in the pipe leading to it does not freeze when the heater is in use; otherwise a severe explosion may occur. Why is this so?

\section{Advantages of Hot Water Heating.-Many people} regard the hot water system of heating as superior to any other system. When well installed and properly operated, it doubtless is cheaper to operate and gives a milder, and more even heat than is usually obtained from other systems. It is also possible so to install this system of heating as to give ample ventilation, but in such a case it is doubtful if it is less expensive to operate than a good furnace system providing 
equal ventilation. This will be explained in Chap. VI. The first cost of a hot water system of heating is considerably greater than that of furnace heating and slightly greater than that of STEAM HEATING, which will soon be considered.

\section{Sensible and Insensible Heat}

148. The Factors of Heat Quantity.-We are all more or less familiar with heat changes. If we place a hot iron in a pail of cold water, the water becomes heated and the iron cooled. The temperature of both the iron and the water soon becomes the same. All of the heat which goes out of the iron goes into the water. The change in temperature in each case indicates the change in heat quantity. But we know that, if we use more of the water the change in temperature of the water will be less; or, if we use a larger piece of iron and heat it to the same temperature before placing it in the water, the water will be heated to a much higher temperature. The fact is that heat quantity is made up of three factors. Usually these factors are: (1) Change in temperature; (2) quantity of matter involved; (3) kind of matter (Art. 120). We shall see, however, that the three factors may be: (1) A change in the form or state of the matter; (2) quantity of matter; (3) kind of matter.

149. Sensible Heat.-When the three factors involved in the heat quantity are change in temperature, quantity of matter, and kind of matter we say the heat is SENSIBLE HEAT, because it may be perceived by the senses. The heat units are based upon the measurement of sensible heat. Define 1 B.t.u. and show that the last statement is true, likewise show that it is true by defining a Cal. and a cal. (Art. 121).

150. Heat Necessary to Turn a Liquid into a Vapor.-We have seen that by applying heat to the paraffin in the candle wick, to the kerosene in the lamp, to the alcohol and water in the distilling flask we changed these liquids into vapors. In each case we put heat, a certain number of calories, or B.t.us. of heat, into the liquid to turn it into vapor. It takes a large 
amount of heat to turn water into vapor after it has been heated to the boiling temperature. We can get a good idea of the amount required by performing an experiment.

\section{Exercise 39.-Amount of Heat Required to Vaporize Water}

Weigh a tin quart cup or small tin basin. Fill the cup half full of water and crusined ice or snow. Weigh again. Stir the water until the ice is just melted. The water should now be at $0^{\circ} \mathrm{C}$. Quickly place the cup over a flame and note the exact time by the watch. The height of the flame must not be changed during the experiment. Watch the water till it begins to boil. Note the exact time again. Record the number of minutes required to bring the water to the boiling point. Allow the water to continue boiling about twice as long as was required to bring it to the boiling point. Now remove the flame and record the exact time. Weigh the vessel and contents again.

Record your results as in the table below.

Discussion of Exercise 39.-A student performing this experiment got the following record:

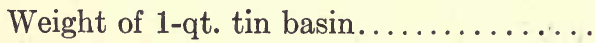

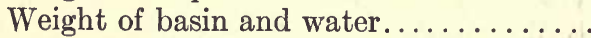

Weight of the water alone...........

Began heating the water at...........

Water began boiling at.............

Time required to boil the water

Let the water boil till..............

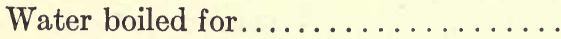
Weight of the basin and water after boiling

Therefore, weight of the water vaporized

86 grams

309 grams

223 grams

2-33-30

$2-42-40$

$9 \mathrm{~min} .10 \mathrm{sec}$. , or $550 \mathrm{sec}$. 3-1-40

19 min., or $1140 \mathrm{sec}$.

219 grams

90 grams

From this record we see that it required only 550 seconds to raise 223 grams of water from $0^{\circ} \mathrm{C}$. to $100^{\circ} \mathrm{C}$.; but that it required 1140 seconds, while applying the same heat, to vaporize 90 grams of water. Now 90 grams was but $9 \% 223$ of the whole amount of water or 0.403 of it. To have evaporated all of the water would have required 1140 seconds $\div 0.403$ or 2828 seconds. From this experiment we conclude that it requires $2828 / 550$ times, or 5.14 times, as much heat to vaporize a certain quantity of water as is required to raise that 
quantity of water from the freezing point to the boiling point.

Very careful experiments repeated many times have proved that these figures should be 5.36. Heat which is used thus to change the state of matter without changing its temperature is called INSENSIBLE HEAT. When used to change a liquid to a vapor, it is called HEAT of vaporization. When used to change a solid into a liquid, it is called HEAT OF FUSION. We now see that the heat of vaporization of water is 5.36 times the sensible heat of raising the same amount of water from the freezing point to the boiling point.

\section{Steam Heating}

151. Principles of Steam Heating.-We saw in Arts. 20 and 21 that the temperature of steam arising from boiling water is nearly the same as that of the water. It is also known

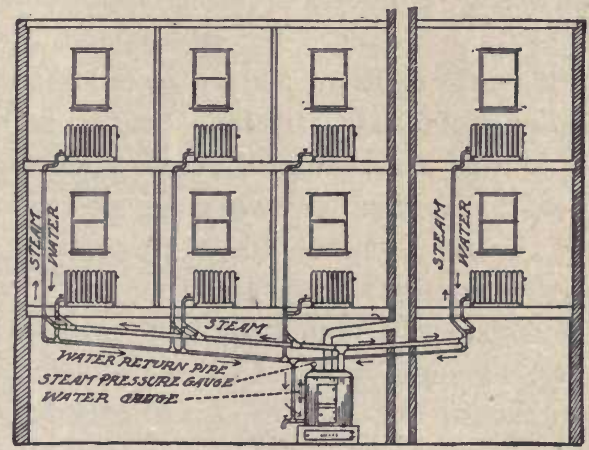

FIG. 96.-System of piping for steam heating system.

that as long as the pressure remains constant the temperature of the steam remains the same. In Art. 150 we saw that a large amount of heat must be put into water to turn it into steam. When the steam is again turned into liquid, i.e., liquefied, exactly the same amount of heat is given off as was absorbed in the vaporizing. Steam heating depends upon an application of these principles. 
152. Equipment for Steam Heating.-As in the case of hot water heating, the equipment consists of a HEATER, generally called BorLER, of connecting pipes, and radiators (Fig. 96). In fact, a plant for hot water heating may be, and sometimes is, used for steam heating with but slight modification. This is so, notwithstanding the fact that the two systems are very different in principle.

153. Hot Water and Steam Systems Contrasted.-The two systems may be contrasted as follows:

1. In the hot water system, the radiator is heated by receiving the SENSIBLE HEAT given off by the water as it is cooled in passing through the radiator.

In the steam system, water is turned into steam in the boiler. The steam then passes up through the pipes to the radiator and is there condensed, giving off its HEAT OF VAPORIzation. This is the source of the heat which keeps the radiator hot. The hot water, condensed steam, returns to the boiler, often at $100^{\circ} \mathrm{C}$.

2. In the hot water system, the water is kept in circulation by its own unequal density. The hot water, being lighter, is pushed upward into the radiator while the colder, heavier water sinks into the heater, crowding the hot water upward.

In the steam system, the steam is forced upward into the radiators by the unequal pressure upon it. In the boiler, more water is constantly being changed into steam, tending thereby to increase the pressure. In the radiator, the steam is constantly condensing into water, tending thereby to decrease the pressure. This means that there is always a lower pressure in the radiator than in the boiler and, consequently, steam is constantly being forced from the boiler into the radiator.

3 . In the hot water system, the heater, the pipes and the radiators are always completely filled with water.

In the steam system, the boiler is but partlly filled with water.

4. The ordinary hot water system is never closed but always open at the expansion tank. 
The steam system is always closed but the boiler must be provided with a safety valve (Art. 158).

5. Hot water heating and furnace heating are generally used in small or medium sized buildings where all of the rooms

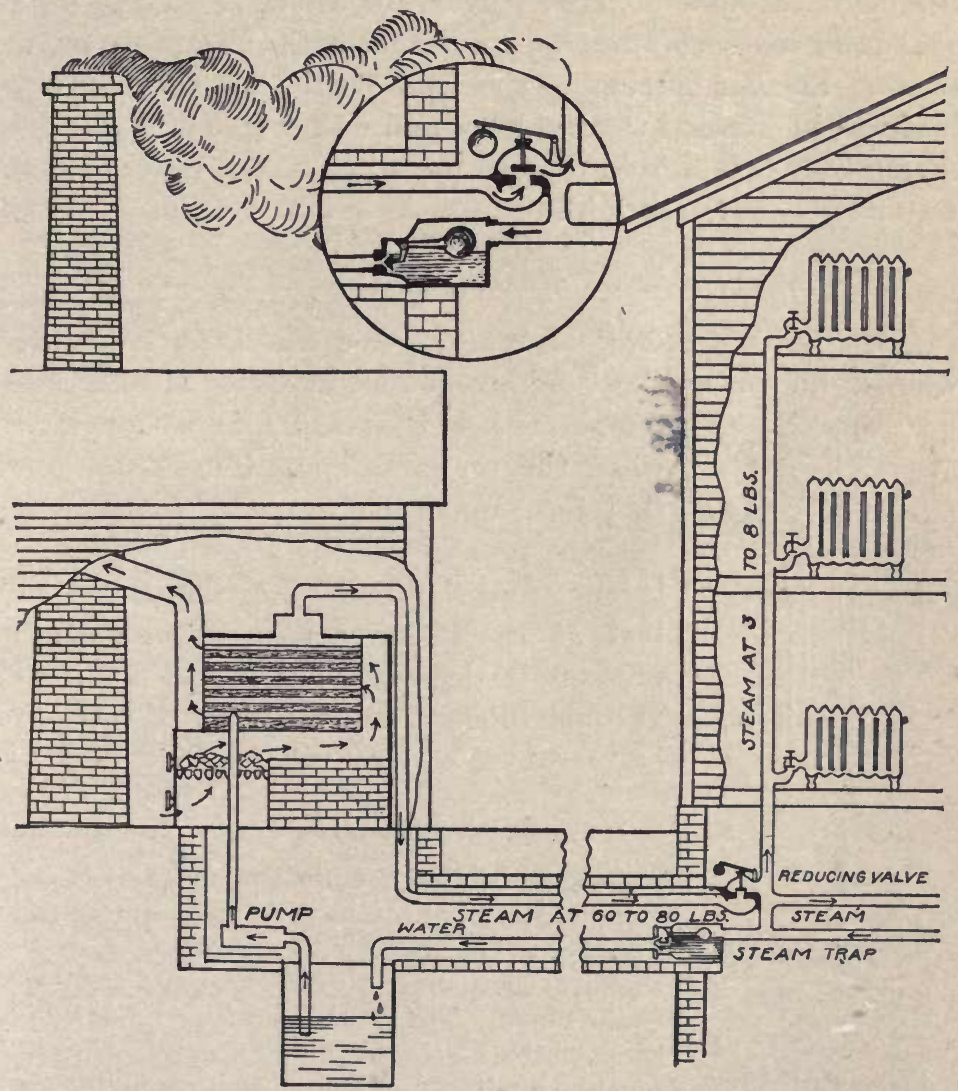

Fra. 97.-A steam heating plant. The steam trap and reducing valve are enlarged.

to be heated are above the heater or furnace and not far removed from it. They do not give good results when long horizontal pipes must be used. 
Steam heating is especially adapted to the heating of large buildings and rooms which are considerably removed from the boiler (Fig. 97). In many cities large, central steam heating plants are constructed. Steam pipes extend from the plant throughout large portions of the city. These pipes are supported within brick conduits beneath the surface of the street. Smaller SUPPLY PIPEs lead from the maIns to the business blocks and the residences. on either side of the street. Steam heat is then sold to customers just as gas (Art. 77) and water (Art. 564) are sold.

\section{Temperature of Steam Varies with Pressure}

154. "Boiling Point" of Water.-We saw in Art. 21 that what is known as the "boiling point" of water is really the

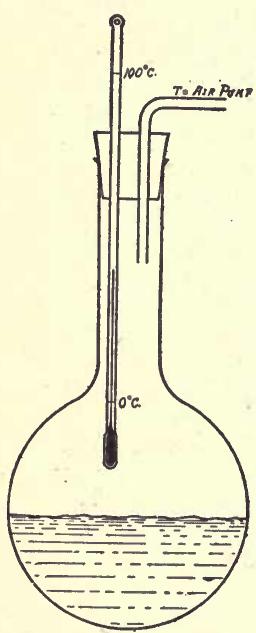

Fig. 98.-Boiling water at low temperatures. temperature of the steam arising from water when the pressure upon the steam, and, therefore, upon the water, is equal to the average pressure of the atmosphere at sea level. We shall now see that water will boil at much lower temperatures if the pressure be decreased below that point, and at much higher temperatures if the pressure be increased above that point.

\section{Exercise 40.-Boiling Water at Low Temperatures}

Arrange a round bottom flask using a two-hole stopper and connect it with an air pump as in Fig. 98. The stopper in the flask carries a chemical thermometer in one hole and an L-tube in the other. The L-tube and the rubber tubing connect the flask and the air pump. All joints must be air-tight. First, without applying heat to the flask remove all air possible from the flask by means of the pump. Does the water boil? If your pump is in good condition, the water will boil. If your pump is not in good condition, you may find it necessary to heat the water somewhat. Note and record the lowest temperature at which you are able to make the water boil. 
155. Relation of Pressure to the Temperature of Steam Arising from Boiling Water.-From many carefully performed experiments, the exact relation of the pressure of water vapor, or steam, to the temperature of boiling water has been. determined. We may speak of this relation in either of two ways: First, we may speak of the boiling point of water under varying pressures, or second, we may speak of the vapor pressure of water at varying temperatures. In either case we refer to exactly the same relation.

Table VI.-Boiling Point of Water at Different Pressures, or Vapor Pressure of Water at Different Temperatures

\begin{tabular}{|c|c|c|c|}
\hline Temp. of water & $\begin{array}{l}\text { Absolute pressure in } \\
\text { lb. per sq. in. }\end{array}$ & $\begin{array}{c}\text { Absolute pressure in } \\
\text { atmospheres }\end{array}$ & $\begin{array}{l}\text { Gauge pressure in } \\
\text { lb. per sq. in. }\end{array}$ \\
\hline $0^{\circ} \mathrm{C}$. or $32^{\circ} \mathrm{F}$. & 0.09 & 0.006 & $\begin{array}{cc}8 & 14.61\end{array}$ \\
\hline $10^{\circ} \mathrm{C}$. or $50^{\circ} \mathrm{F}$. & 0.18 & 0.012 & $\begin{array}{ll}\text { క్త్ } & 14.52\end{array}$ \\
\hline $20^{\circ} \mathrm{C}$. or $68^{\circ} \mathrm{F}$. & 0.34 & 0.023 & \& 14.36 \\
\hline $30^{\circ} \mathrm{C}$. or $86^{\circ} \mathrm{F}$. & 0.61 & 0.042 & 14.09 \\
\hline $40^{\circ} \mathrm{C}$. or $104^{\circ} \mathrm{F}$. & 1.06 & 0.072 & ల్డ 13.63 \\
\hline $50^{\circ} \mathrm{C}$. or $122^{\circ} \mathrm{F}$. & 1.78 & 0.121 & $>\quad 12.92$ \\
\hline $60^{\circ} \mathrm{C}$. or $140^{\circ} \mathrm{F}$. & 2.88 & 0.196 & 11.82 \\
\hline $70^{\circ} \mathrm{C}$. or $158^{\circ} \mathrm{F}$. & 4.51 & 0.306 & 10.19 \\
\hline $80^{\circ} \mathrm{C}$. or $176^{\circ} \mathrm{F}$. & 6.85 & 0.446 & 7.85 \\
\hline $90^{\circ} \mathrm{C}$. or $194^{\circ} \mathrm{F}$. & 10.16 & 0.691 & 4.54 \\
\hline $100^{\circ} \mathrm{C}$. or $212^{\circ} \mathrm{F}$. & 14.70 & 1.000 & 0.00 \\
\hline $110^{\circ} \mathrm{C}$. or $230^{\circ} \mathrm{F}$. & 20.80 & 1.415 & 6.10 \\
\hline $120^{\circ} \mathrm{C}$. or $248^{\circ} \mathrm{F}$. & 28.85 & 1.962 & 14.15 \\
\hline $130^{\circ} \mathrm{C}$. or $266^{\circ} \mathrm{F}$. & 39.26 & 2.671 & 24.56 \\
\hline $140^{\circ} \mathrm{C}$. or $284^{\circ} \mathrm{F}$. & 52.55 & 3.576 & 37.85 \\
\hline $150^{\circ} \mathrm{C}$. or $302^{\circ} \mathrm{F}$. & 69.26 & 4.712 & $\$ \quad 54.56$ \\
\hline $160^{\circ} \mathrm{C}$. or $320^{\circ} \mathrm{F}$. & 89.96 & 6.120 & సె 75.26 \\
\hline $170^{\circ} \mathrm{C}$. or $338^{\circ} \mathrm{F}$. & 115.29 & 7.844 & w 100.59 \\
\hline $180^{\circ} \mathrm{C}$. or $356^{\circ} \mathrm{F}$. & 145.93 & 9.939 & Ð 131.23 \\
\hline $190^{\circ} \mathrm{C}$. or $374^{\circ} \mathrm{F}$. & 182.61 & 12.425 & o 167.91 \\
\hline $200^{\circ} \mathrm{C}$. or $392^{\circ} \mathrm{F}$. & 226.04 & 15.380 & 212.34 \\
\hline
\end{tabular}

156. Explanation of the Table.-In the first column is given the temperature of the steam arising from the boiling water; this is practically the same as the temperature of the water. 
In the second column is given the ABsolute PRESSURE, the actual pressure on the inside surface of the boiler, in pounds per square inch.

In the third column is given the absolute pressure in atmospheres. It will be noted that in the first half of the table the pressures are less than that of the atmosphere and in the last half they are greater than that of the atmosphere.

In the fourth column the gauge pressure is given. The gauge pressure shows the difference in pressure on the inside and the outside surfaces of the boiler. It will be noted that the VACUUM GAUGE reading is given for all pressures less than 1 atmosphere and that the PRESSURE GAUGE reading is given for all pressures greater than 1 atmosphere. It will also be noted that when the boiling point is $100^{\circ} \mathrm{C}$., or $212^{\circ} \mathrm{F}$., both gauges read zero. The vacuum gauge records the amount of the vacuum, or the decrease in pressure below 1 atmosphere; the pressure gauge records the amount of pressure above 1 atmosphere. If we had determined the pressure in Ex. 40, we should have used the vacuum gauge because the pressure was less than 1 atmosphere.

With the exception of steam boilers used in connection with VACUUM SYSTEMS of heating (Art. 163), practically all steam boilers carry pressures greater than 1 atmosphere. All steam boilers are therefore equipped with three safety devices, a pressure gauge (Art. 157), a safety valve (Art. 158), and a water gauge (Art. 159), for it is necessary, first, that the operator shall be able to see at once what pressure the boiler is carrying, second, that under no condition shall the steam pressure become greater than that which the boiler is intended to carry, and third, that the water in the boiler never gets below a certain level.

157. The Pressure Gauge.-The purpose of the pressure gauge is to indicate the steam pressure on each square inch of the boiler. Its essential parts are: (1) A curved, somewhat flexible, metallic tube, $A$, Fig. 99 ; this tube is connected by a small pipe to the boiler; (2) hinged to the free end of 
the curved tube is a short connecting rod, $B$; the other end of the rod is hinged to one end of the lever $C$; the opposite end of the lever $C$ carries a circular set of cogs; (3) these cogs on the end of the lever $C$ mesh into the cogs on the cog wheel, $D$, which carries the pointer or index.

As the steam pressure rises within the boiler, the pressure tends to cause the curved tube to straighten out. The tube then pulls up on the rod. The rod lifts the right-hand end of the lever. The cogs at the other end of the lever cause the cog wheel to rotate clock-wise. The index points to a scale printed on the face of the gauge. There is always 1 atmosphere of pressure on

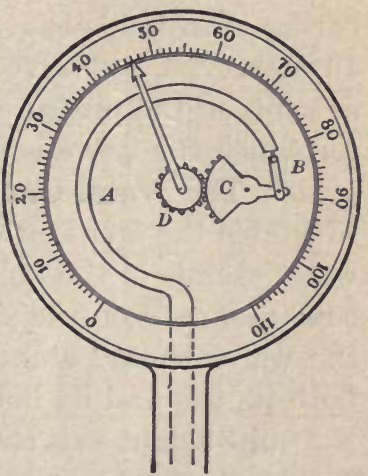

Fig. 99.-The pressure gauge. the exterior of the boiler. Now the pressure gauge indicates the excess of pressure, i.e., the pressure over and above 1 atmosphere, on the inside of the boiler.

158. The Safety Valve.-Safety valves are of two types: The BALL AND LEVER TYPE and the POP VALVE TYPE. In the

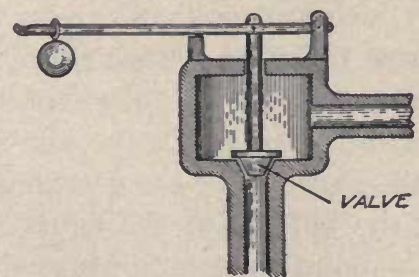

Fre. 100.-Ball and lever safety valve.

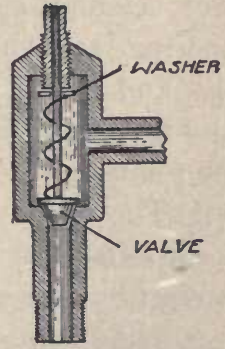

Fig. 101.-Pop safety valve.

ball and lever type, Fig. 100, the valve is held down by the weight of the ball upon the lever. The pressure is increased by slipping the ball farther out on the lever. Explain why. 
The principle of the pop valve is shown in Fig. 101. The valve in this case is held down by a spiral spring. The top of the spring rests against a metal plate, $P$. This plate may be forced farther down by turning down the screw, $S$. The spring then holds the valve down against a greater pressure. In each type, the valve opens and allows some steam to escape as soon as the pressure within the boiler exceeds the amount for which the valve is set.

159. The Water Gauge.-The purpose of the water gauge is to enable the operator or engineer to see exactly how high the water stands in the boiler. The gauge is merely a strong glass tube mounted on the side of the boiler at the height at which the water should stand. This glass tube is so connected at both its top and its bottom that the water stands within it at the same height as it stands within the boiler. This gauge is of the greatest importance, for the person in charge must never permit the water within the boiler to get lower than the bottom of the gauge. The danger from an explosion is very great if the water is permitted to get too low in the boiler. Point out the water gauges on the boilers shown in the illustrations (Figs. 96, 358, 359 and 360).

160. The Temperature-pressure Curve.-Many of the facts of science, especially those of physics, chemistry, and engineering are shown in their true relations much more readily and more clearly by using DIAGRAMS and CURVES than by merely giving the figures. Figure 102 is a curve showing the relation of temperature to pressure in the case of boiling water. The various temperatures of the steam are shown along the left-hand margin of the figure while the corresponding pressures are indicated along the bottom of the figure. The curve is a line connecting all the points of temperature and the corresponding pressures. For example, we have seen that water boils at $100^{\circ} \mathrm{C}$., or $212^{\circ} \mathrm{F}$., when the pressure is 14.7 lb. per sq. in. This fact is indicated by the point, $A$, on the curve. Likewise the boiling point of water is $50^{\circ} \mathrm{C}$, , or $122^{\circ} \mathrm{F}$., when the pressure is $1.78 \mathrm{lb}$. per sq. in. This fact is shown 
by the point, $B$. Similarly, the boiling point is $180^{\circ} \mathrm{C}$, , or $356^{\circ} \mathrm{F}$, when the pressure is $145.93 \mathrm{lb}$. This is shown by the point, $C$. You should study this curve till you understand it thoroughly.

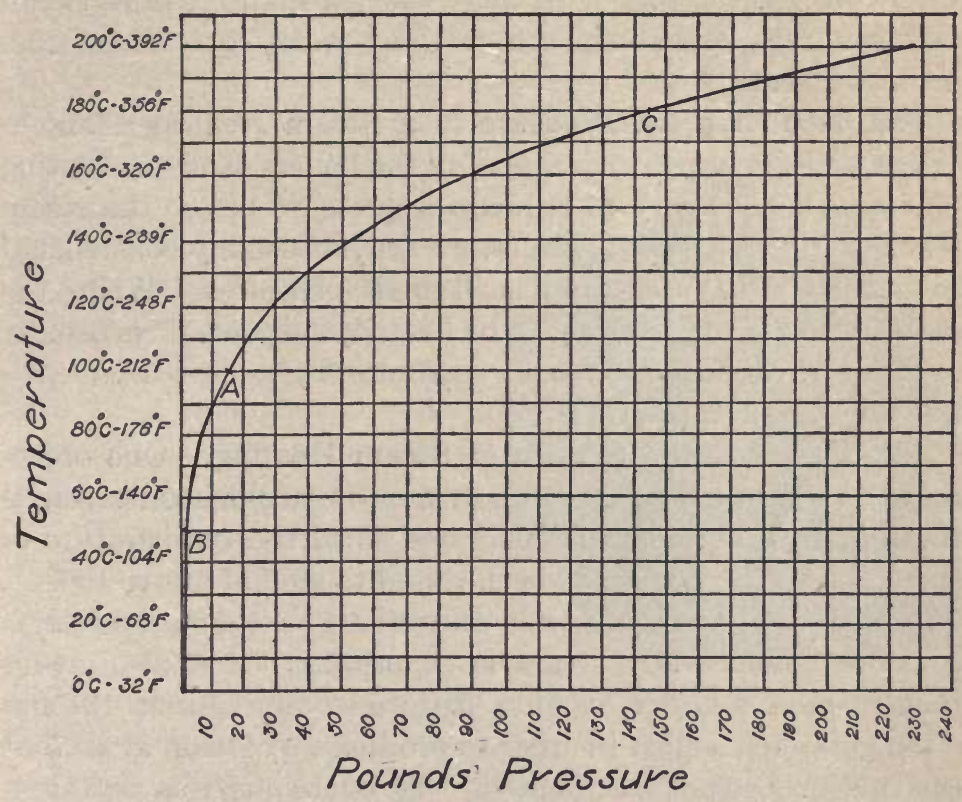

FIG. 102.-The temperature-pressure curve.

161. The Temperature of Steam in a Boiler.-The common steam boiler for residence heating usually carries from 3 to 8 lb. of steam as indicated by the pressure gauge. Supposing that the gauge on a boiler registers $6.1 \mathrm{lb}$. By using Table VI, Art. 155, or the curve, Fig. 102, we can tell the temperature of the steam in the radiators. Show that the absolute pressure is $20.8 \mathrm{lb}$. and that the temperature of the steam is $110^{\circ} \mathrm{C}$., or $230^{\circ} \mathrm{F}$.

In such a steam heating plant as is shown in Fig. 97, the boiler often carries 60 or even $80 \mathrm{lb}$. of pressure as indicated by the pressure gauge. If the gauge indicates $60 \mathrm{lb}$., show that 
the absolute pressure is $74.7 \mathrm{lb}$. and that the temperature of the steam is between $150^{\circ}$ and $160^{\circ} \mathrm{C}$, about $153^{\circ}$ or $154^{\circ} \mathrm{C}$. If the gauge indicated $80-\mathrm{lb}$. pressure, what would be the absolute pressure? What would be the temperature of the steam? Can you suggest why it is that, when a high-pressure steam boiler bursts, the steam scalds those near worse than does ordinary steam?

162. Reducing the Pressure in a Steam Heating Plant.When high pressures are carried on the boilers of steam heating plants, it is necessary to reduce the pressure before the steam reaches the radiators. Radiators are not usually constructed so as safely to withstand such high pressures. When the steam reaches the building to be heated, the pressure is usually reduced to about $5 \mathrm{lb}$. gauge pressure by a device called a REDUCING VALVE (Fig. 97).

163. The Vacuum System of Steam Heating.-One objection to the ordinary PRESSURE SYSTEM for residence heating is the fact that no steam is generated until the temperature of the water in the boiler has been raised to a point above $100^{\circ} \mathrm{C}$., or $212^{\circ} \mathrm{F}$. This means, not only that considerable fuel is consumed before any steam is generated, but it also means that in mild weather, when a little heat is required, the fire often gets such a start in order to produce any steam at all that the house becomes overheated. To overcome this defect in steam heating of residences the VACUUM SYSTEM is often used in place of the pressure system. The ordinary pressure system can usually easily be changed into a vacuum system. All that is necessary is that the system be made air- and steamtight and VACUUM valves be placed upon all radiators.

164. The Vacuum Valve.-The purpose of the VAcuum VALVE is threefold: (1) To permit any air which may be in the radiator to escape; (2) to prevent any steam from escaping; (3) to prevent any air from re-entering the radiator. One type of vacuum valve is shown in Fig. 103. The valve is screwed into the radiator near its top by means of the threaded nipple, $C$. At $E$ is a needle valve, the needle being supported 
by the post, $F$. This valve is usually closed. When steam begins to generate in the boiler, it begins to exert pressure. This pressure is transmitted to the radiator and hence to the valve. The upper half of the valve consists of a metallic, bellows-like capsule open below. The upper plate, $I$, of this capsule carries the seat of the needle valve, $E$. Now as long as the valve is cool the pressure of a few ounces within the valve is sufficient to spring the bellows-like capsule up, raising the plate, $I$, and therefore the valve seat, $E$, off from the needle. This opens the valve. If any air is in the radiator. it is at once forced out. The lower half of the valve consists of a closed bellows-iike capsule, $A$. The upper plate of this capsule carries the post, $F$. This lower eapsule contains a liquid which is very volatile, i.e., it turns to a vapor at relatively low temperatures. Its vapor pressure

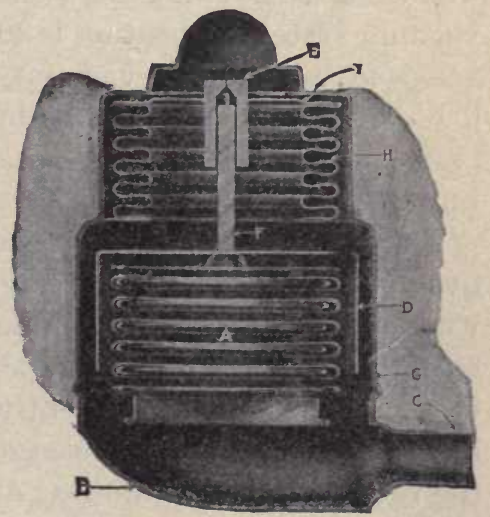

FIG. 103.-The vacuum valve. increases with increased temperature exactly as in the case of water, only much more rapidly. Now as soon as all of the air has been forced out of the radiator, the hot steam enters the valve. This heats the capsule, $A$, and greatly increases the vapor pressure of the liquid which it contains. This increased pressure expands the bellows-like capsule and forces the post, $F$, upward. The needle is thereby forced into the vent, closing the valve. This prevents the escape of steam into the room. After the air which was in the radiator and the pipes when the system was first set up has once been expelled, all the vacuum valves are supposed to remain closed to prevent any steam from escaping or air from entering the system. The entire system is supposed to contain a perfect vacuum except for the water vapor. 
165. The Pressure on a Vacuum System.-There is always some vapor pressure on a vacuum system. By turning to our temperature-pressure table, Art. 155, we can readily tell what that pressure is. A fire is not likely to be needed unless the temperature of the rooms falls below $68^{\circ} \mathrm{F}$, , or $20^{\circ} \mathrm{C}$. Turning to our table we see that the absolute vapor pressure at $20^{\circ} \mathrm{C}$., or $68^{\circ} \mathrm{F}$., is $0.34 \mathrm{lb}$. per sq. in. and that the vacuum gauge would read $14.36 \mathrm{lb}$. Another way of stating the same fact would be to say that the boiling point of the water in such a vacuum system of heating is $20^{\circ} \mathrm{C}$., or $68^{\circ} \mathrm{F}$., when the vacuum gauge reads $14.36 \mathrm{lb}$. vacuum, or the absolute pressure is 0.34 lb. In fact, in a vacuum system of steam heating, if it works perfectly, the water always begins to boil as soon as the fire is built.

\section{Advantages of the Vacuum System over the Pressure} System of Steam Heating. - It is evident that in mild weather, when but little heat is needed, it is quite unnecessary to heat the radiators to a point above $100^{\circ} \mathrm{C}$., or $212^{\circ} \mathrm{F}$., in order to warm the rooms sufficiently. Yet that is exactly what is necessary in any pressure system of steam heating, because the radiators receive no heat at all till the water in the boiler begins to boil. With the vacuum system in good working order, the heat is at once transferred to the radiators as soon as the fire is lighted. Since the radiators begin to warm at once, it is necessary to heat them only to the temperature required to warm the rooms. Therefore, on a mild day when little heat is required, the vacuum system is much superior to the pressure system. In its quick response to the fire the vacuum system resembles hot water and furnace heating and is in marked contrast to the pressure system of steam heating.

\section{The Open Grate}

167. The Low Efficiency of the Old Fireplace.-The old colonial fireplace was of immense size, often 6 or $8 \mathrm{ft}$. in width, and consumed immense quantities of fuel. Still the room was but poorly heated. The burning logs resembled a 
huge bonfire and the draft up the chimney was intense. To replace the large amount of air which passed up and out of the chimney, a blast of cold air poured in at every crack and crevice. A cold current was always crossing the room from the outside wall to the chimney. Probably nine-tenths of the heat was swept up and out of the chimney without warming the room at all. Only a little of the heat passed back into the room, and that was by RADIATION. It is an old saying that the old-fashioned fireplace roasted one side of a person while the other side froze (Art. 79).

168. The Common Modern Grate.-The common grate of today is not used extensively in the northern states for heating purposes. It is generally regarded as a secondary heating plant to be used in the fall and spring or in conjunction with some other system of heating in the winter. In the southern states, where little artificial heat is needed, it is often the only heating plant.

The modern grate consumes but little fuel compared with the old-time fireplace. The flue is much smaller and the amount of air passing up the chimney far less. The "roasting and freezing" effect is not nearly so marked as in the case of the old-fashioned fireplace. Still the efficiency is very low. Usually not more than 12 or 15 per cent. of the heat generated is utilized in heating the room in which the grate is placed. But even then, this common grate is invaluable from a sanitary point of view as will be shown later when considering ventilation (Chap. VI).

169. The Modern Ventilating Grate.-The efficiency of a grate is very greatly increased by constructing it with a flue up the back and the sides through which a current of fresh air passes. The air is admitted through a pipe in the basement, and after being heated in the flue, passes into the room through a grating above the open fire (Figs. 104 and 105). This constitutes an inlet for as much fresh air as is removed from the room by the draft up the chimney, and prevents the cold draft from the outside walls (Fig. 106). While the com- 


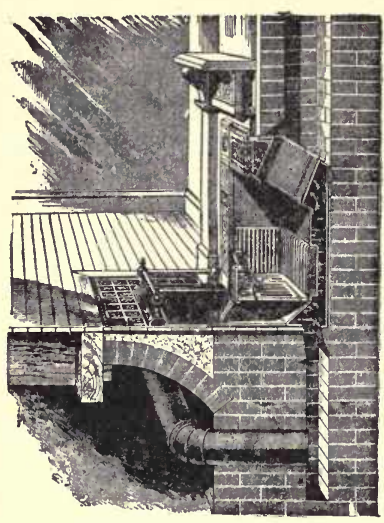

FIG. 104.-A ventilating grate.

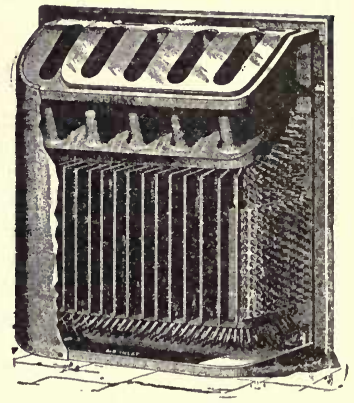

FIG. 105.-Rear view of the ventilating grate.
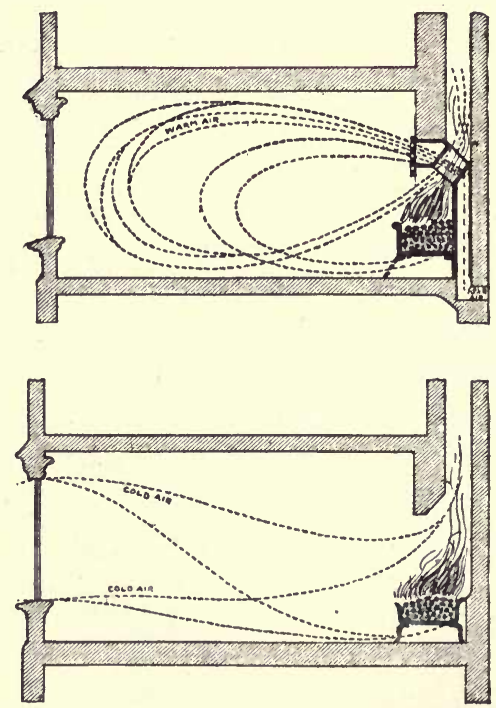

FIG. 106.-Air currents in a room heated by ventilating grate and a common grate. 
bustion of the volatile portion of the fuel can never be as complete in an open fire as in a modern stove or furnace, still the efficiency of these ventilating Grates is quite high, since most of the heat evolved from the fuel is utilized. As a secondary heating plant, such a grate is economical, while at the same time affording the many advantages of an open fire and ample ventilation.

\section{DEVELOPMENT OF COOKING DEVICES}

Stoves AND Ranges

170. Cooking Before the Days of Stoves.-Throughout the 18th century and until well into the 19 th, cooking stoves

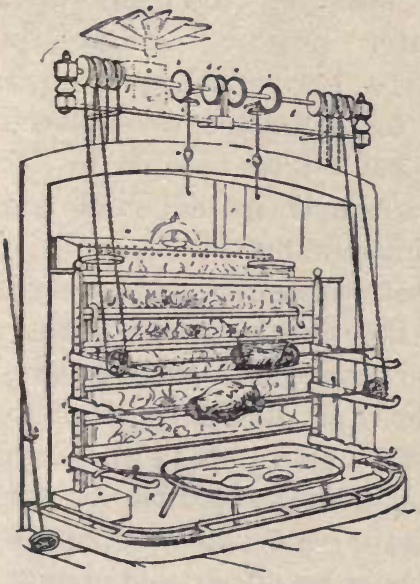

Fig. 107.

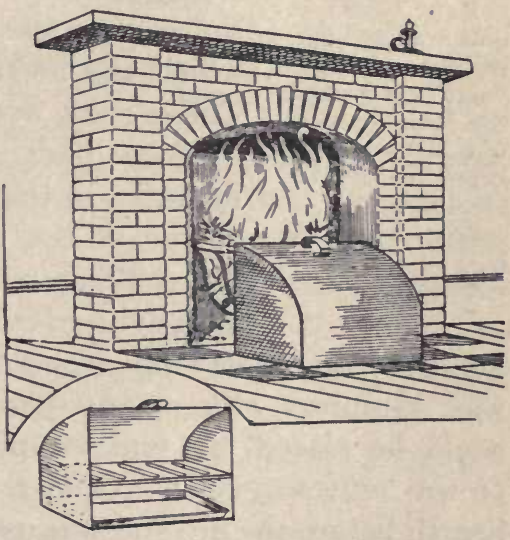

Fig. 108.

FIG. 107.-The kitchen fireplace at the City of London Club House, Broad street, London. Reproduced from an old wood cut. The "spits" upon which the joints of meat were mounted before the fire were kept revolving by a "smoke jack," a small windmill, mounted in the chimney flue.

FIG. 108.-Reflector formerly used for roasting and baking in the home.

were unknown in America. Most of the food was cooked by boiling in pots which hung suspended from the swinging crane in the fireplace. Some articles of food, such as apples 
and potatoes were roasted in the coals upon the hearth. Meats were generally roasted by being suspended by means of a cord or wire before the fireplace. In order that the meat be made to roast evenly it had to be turned almost constantly. This was usually a child's task in the private family. In many inns, where much meat had to be roasted,

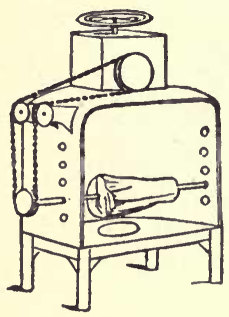

FIg. 109.-A reflector for home use in which the "spit" upon which the joint of meat was mounted was kept constantly revolving by a coiled spring in a box on top of the reflector. it was often mounted upon a SPIT, or sharpened stick of wood, in such a manner that it could be kept turning constantly, often by means of a tread mill operated by a dog. Figure 107 shows an ingenious device used in the London Club House, a fashionable hotel in London. The fire was built on a series of grates standing in front of a wrought-iron water heater. Before the several grates were horizontal spits upon which the meats to be roasted were placed. These spits were caused to revolve by the "smoke jack," a small metal wind mill mounted in the chimney flue.

One of the most frequently used utensils for cooking was the REFLECTOR. It was a semi-cylindrical box made of bright tin and so mounted that it lay upon one side (Fig. 108). Generally it was equipped with a grate-like shelf upon which the meat could be placed, the juices dripping through into the bottom of the reflector below. The reflector was placed upon the hearth before the fire and was used, not only for cooking meat, but for baking as well. A modified form of the reflector is shown in Fig. 109. A coiled spring in the box on the top of the reflector was wound up. The uncoiling of the spring was regulated by a sort of clock work. As the spring uncoiled, it revolved the spit upon which the joint of meat was mounted.

The old BRICK Oven built into the side of the fireplace, Fig. 64 , is known to every one, and has a permanent place in our mental picture of an old-fashioned kitchen. As a matter of 
fact, however, it usually was heated and used only one day in the week. A flue led from this oven into the chimney. On baking-day, a wood fire was built in it and when it was sufficiently heated, the coals and ashes were raked and swept out and the week's baking was placed in it.

171. The Early Cook Stoves. - The first American stoves intended especially for cooking were made about 1820 . The Conant stove, made at Brandon, Vermont, was one of the first (Fig. 110). It was a cast-iron stove with firebox at the

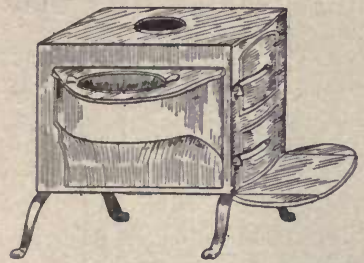

FIG. 110.-The Conant stove; made at Brandon, Vt., 1820.

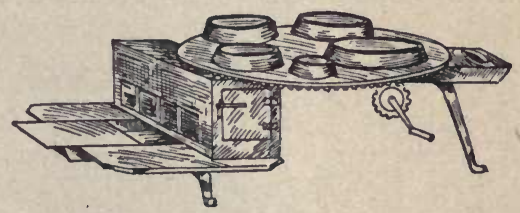

FIG. 111.-Stanley's rotary stove; made about 1835 .

bottom. The oven was above the firebox and had doors opening both at the front and the rear of the stove. The smoke pipe went up through the oven. On each side of the stove was a projection which held a cast-iron kettle whose bottom was exposed to the heat of the fire. Most of the food was cooked by boiling in these kettles, although some baking was done in the oven. The stove had an ample hearth, and roasting was accomplished by opening the firebox door and placing the old style reflector upon the hearth.

The Stanley rotary stove was made at Troy, New York, about 1835 (Fig. 111). It also had an ample hearth. Its top revolved by means of a crank and cogs. It carried five griddles of varying sizes. By revolving the top, any one of these griddle holes could be brought over the hottest part of the fire or placed in a cooler position as desired. The directions for using the stove read: "Roasting is done in the best manner by reflection in the tin oven under the stove (where it is to stand) and may at the same time be done on 
the front part of the stove in the common reflector which most families have."

Another early stove was the Yankee notion (Fig. 112). This was also a cast-iron stove. There were griddle holes on the top for kettles. At the rear of the stove arose a large, strong cast-iron pipe supporting the oven. The smoke and the products of combustion passed through flues around the oven and joined on top to enter the smoke pipe.

While these stoves appear to us to be crude and very unpromising as cooking stoves, we should remember that they were considered very excellent by our grandmothers.

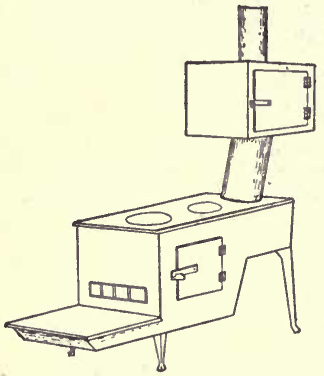

FIG. 112.-The Yankee notion; about 1835 .

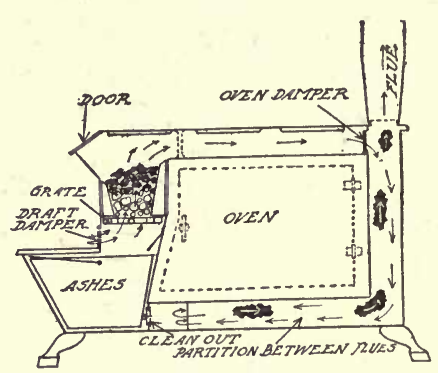

Fig. 113.-Common cook stove.

172. Modern Cook Stoves for Coal and Wood.-The modern cook stove for wood or coal differs from these early stoves in having its oven directly behind the fire-pot. Behind and beneath the oven is a DIVING FLUE. This space is really divided into two flues side by side connecting at the front. When the OVEN DAMPER is up as in the cut (Fig. 113), the smoke and the products of combustion must pass downward behind the oven, forward beneath the oven, around the end of the partition, thence backward again and upward to the pipe. This heats all around the oven except the two sides. Usually there are doors in both sides of the oven. When the oven damper is down, the products of combustion pass directly from the fire-pot over the oven and up the pipe. Examine a 
stove carefully to note the flues and see how they may be cleaned.

173. The Range.-A stove which was so arranged as to fit easily into a fireplace was called a RANGE. This term is still applied to a stove which has one of its long sides for the front and the other for the back. In the range, the oven flues are usually so constructed that the products of combustion pass downward at the side of the oven, then circle beneath the oven

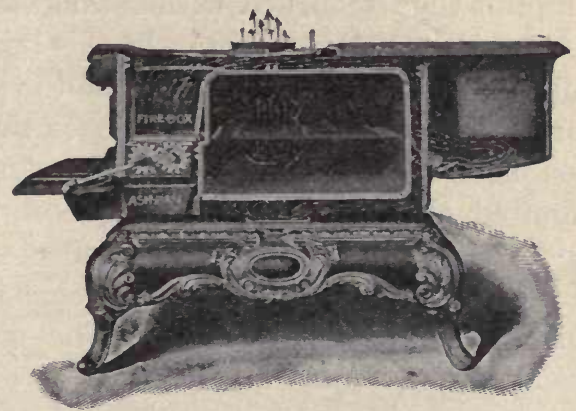

Fig. 114.-A range.

and up to the pipe which is connected at the center of the back of the range. The oven is thus heated on all sides but the front. Examine a range carefully to note the flues and see how they may be cleaned (Fig 114).

\section{Gasoline and Gas Stoves}

174. Principle of the Gasoline Stove.- It is evident from our study of gasoline and of gasoline lamps, that any stove designed to burn gasoline should meet the following requirements:

1. The can for holding the gasoline should be nearly closed, and should be at a safe distance from the flame.

2. Since much of the gasoline will vaporize as soon as exposed to the air, provision should be made to convert all of the liquid gasoline into vapor as quickly as it escapes from the pipes.

3. The gasoline vapor should be mixed with a sufficient 
quantity of air so that complete combustion may take place quickly, producing a blue or non-luminous flame.

There are gasoline stoves of many makes and styles. But since all gasoline stoves must conform to these principles a study of one will enable us to understand the others.

175. Self-generating and Non-self-generating Gasoline Stoves.-When we placed the gasoline in an open vessel and applied the lighted match, we found that the gasoline burned readily, but that it burned with a luminous and more or less smoky flame (Art. 104). To prevent this burning with a luminous flame, we must completely vaporize the gasoline and mix the vapor with fresh air before it reaches the flame and ignites. When thus mixed with the proper amount of air before being ignited, the vapor burns much more rapidly and completely and the luminous and smoky effects completely disappear. In Art. 105 we learned how to change the luminous flame into a non-luminous flame. The principle employed was exactly the one just described.

All gasoline stoves must be provided with some means of accomplishing this complete vaporization and mixing of the vapor with air. Stoves which are automatic in their operation after the gasoline is first turned on and lighted are said to be SELF-GENERATING; those which are not automatic in their operation at first but which have to be watched and attended to, as we would watch the gasoline lamp (Art. 41), until the generator becomes hot enough to vaporize all of the gasoline, are said to be NON-SELF-GENERATING (Fig. 115).

176. The Non-self-generating Stove.-

\section{Exercise 41.- - Lighting and Operating the Gasoline Stove}

Examine the can, or holder, for containing the gasoline. Is it nearly air-tight? Is it a separate can sitting within a larger outer can as shown in Fig. 115 or is it a single can attached to the FLOW PIPE? Is it provided with a valve to stop the flow of gasoline? Be certain that you see how the valve operates. Is there a valve on the flow pipe near the burner? In the gasoline lamp we heated the small flow pipe so as to produce complete vaporization by using an alcohol 
torch. In gasoline stoves it is common to use a little gasoline for this purpose. Is there a cup beneath the small flow pipe in which the gasoline may be burned? Just how is the gasoline collected in this cup? As with the lamp, so the gasoline stove has a CARBURETER, or MIXer. Of what does it consist? What is its purpose?

To light the stove, run a little gasoline into the cup. Light it. When this is all burned out, open the valve and see if any liquid gasoline escapes from the little opening in the small flow tube. If it does, you have not heated the tube hot enough, and you must run more gasoline into the cup and heat again. If no liquid gasoline is to be seen passing from the small tube, or generator, to the carbureter, light a match and hold it above the burner. You should get a blue flame which gives off much heat. Make a diagrammatic sketch similar to Fig. 115, showing the essential parts of your stove.

Caution: When handling the gasoline stove, all of the precautions given for handling gasoline should be observed.

177. The Gas Range.-The gas range is a stove constructed to burn either NATURAL GAS or manufactured ILLUMINATING AND FUEL GASES. In some large cities gas is manufactured especially for fuel purposes and another grade of gas

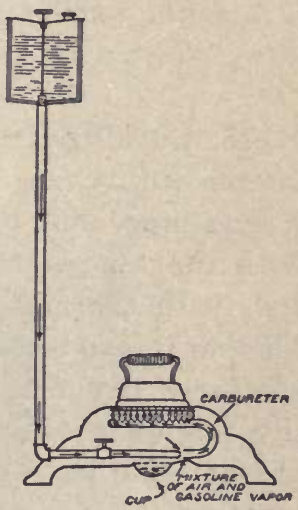

FIG. 115.-Gasoline stove. for illuminating purposes. In the smaller towns and cities the same gas is used for both purposes. This is usually made from coal, but crude petroleum may be used and pine wood and resin have been used in the past (see Sec. VI, page 101, Gaseous Fuels).

In principle, the gas stove burner is exactly like the gasoline burner shown in Fig. 115 with the cup for holding the gasoline used in heating the vaporizer omitted.

\section{Exercise 42.-Regulating the Air Supply of a Gas Stove}

Examine a gas stove carefully, noting the AIR REGULATOR at the front of each burner. Note carefully how the supply of air is regulated. Shut off the air supply from one burner. What is the effect upon the flame? Why does it become a luminous flame? 
Reopen the damper slowly, noting just the amount of air necessary to produce a non-luminous flame.

The most intense, i.e., the hottest, flame is secured when the damper is so set that there is just a sufficient amount of air to produce a non-luminous flame. An excess of air, not only reduces the intensity of the heat, but it also tends to cause the flame to "strike back," i.e., to burn down in the burner instead of above the burner as it should.

\section{Fireless Cookers}

178. Cooking Temperatures. - The cooking of foods is accomplished by raising them to a certain temperature and then maintaining that temperature for a certain length of time. Both the temperature required and the time required vary, first, with the nature of the food to be cooked, and second, whether it is to be cooked wet, i.e., STEWFD or BOILED, or cooked relatively dry i.e., BAKED. "Stewing" and "boiling" usually require a temperature near the boiling point of water, or from $180^{\circ}$ to $212^{\circ} \mathrm{F}$. Baking requires a much higher temperature. Bread is commonly baked at about $375^{\circ} \mathrm{F}$.

179. Conductors and Non-conductors.-If it were possible to discover a device which would entirely prevent the loss of heat, it is evident that it would be necessary only to bring the food once to the proper temperature; if no heat were lost, the food would then remain at that temperature indefinitely or until cooked. Unfortunately we know of no means of preventing heat from escaping through the walls of any vessel we can construct. Heat passes through every known material. However, it passes through some materials much more readily than through other materials. Materials through which heat passes readily are said to be GOOD CONDUCTORS OF HEAT; materials through which heat passes less readily are said to be POOR CONDUCTORS OF HEAT. All metals are good conductors of heat; air, asbestos, and paper are poor conductors. 
180. Fireless Cookers.-Fireless cookers are constructed of materials which are poor conductors. They are usually vessels of box-like construction with thick walls constructed of poor conductors and provided with closely fitting covers of similar construction (Fig. 116). The food to be cooked is usually brought to the desired temperature and then quickly placed in the fireless cooker. The cooker largely prevents the loss of heat; therefore the food may be maintained for many hours at an approximately constant temperature. A fireless cooker intended for baking is usually provided with

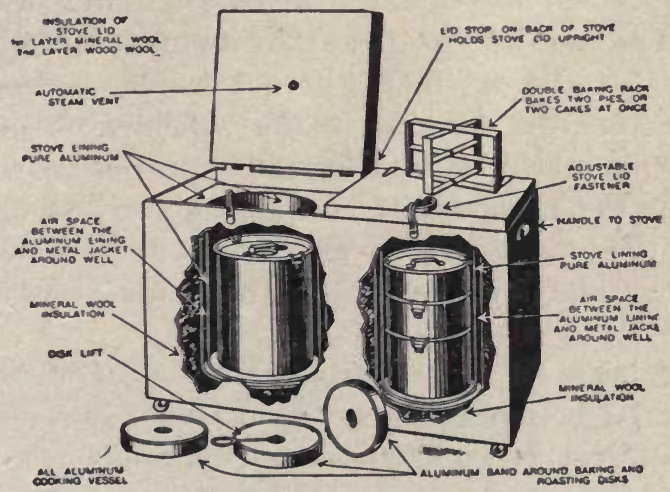

Fig. 116.-A fireless cooker.

one or more blocks of soapstone. These are cut to fit the cooker. Soapstone is used because of its great capacity of holding heat, i.e., its high specific heat (Art. 120). When baking is to be done, the soapstone is heated to a high temperature and placed in the cooker with the article to be baked. The temperature of the interior of the cooker is soon raised to the temperature necessary to bake the food.

The chief purpose of fireless cookers is to save fuel. They are very successful and, when properly handled, they effect a considerable saving of fuel and at the same time lighten the labors of cooking, since they require little or no attention while the cooking is in progress. 


\section{REFRIGERATION AND ITS USES}

\section{THE REFRIGERATOR}

181. Use of the Refrigerator.-The refrigerator is probably found in as many modern houses as is the furnace. It is probably also true that the health and comfort of the family depend upon the use of the refrigerator during the summer months in as large a measure as they do upon modern methods of heating-furnace, steam, or hot water heating-during the winter months. Owing to the difficulty of securing ice, the cellar must still be used in many rural districts as a substitute for the refrigerator, just as the stove is used in the place of the more modern and adequate heating devices. In most town and city houses, the refrigerator is now considered a necessity.

182. Principle of the Refrigerator-Most decay is the result of the action of MICROÖRGANISMS upon vegetable or animal matter. Microörganisms are minute plants or animals so small as to be seen only by means of powerful microscopes. Fermentation, or the action of microörganisms, is hastened by moderately high temperature and plenty of moisture. Lowering the temperature of foods, or lessening the moisture in the foods delays decay. The function of the refrigerator is to ward off or delay decay as far as possible. It does this by providing a stream of cool, very dry air in which the foods are placed. The effectiveness of the refrigerator depends largely upon the circulation of the air within it. The stronger the circulation, the more effective the refrigerator in preventing decay (see Chap. VIII, Microörganisms).

183. Construction of the Refrigerator.-The refrigerator is practically a box, the walls of which are usually made of 
several thicknesses, some of the materials being selected because they are poor conductors of heat. Because air is a poor conductor of heat, most refrigerators are constructed with an air space in the walls. This air space is usually packed somewhat loosely with some substance such as charcoal or mineral wool or other poor conductors. This packing serves to break up convection currents which otherwise would be produced in this air space (Fig. 117). Air is a poor conductor of heat when not in motion, but, as we saw in the study of furnaces, it is a very effective agent in the transference of heat when it is moving

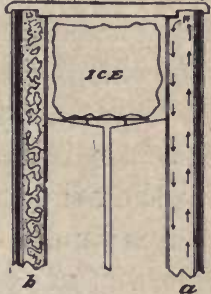

Fig. 117.-Walls of a refrigerator. in the form of convection currents.

184. Styles of Refrigerators.-Refrigerators are either TOP-ICING REFRIGERATORS (Fig. 118), Or SIDE-ICING REFRIGERATORS (Fig. 119). In the top-icing refrigerator the cold, descending column of air may pass downward at the center

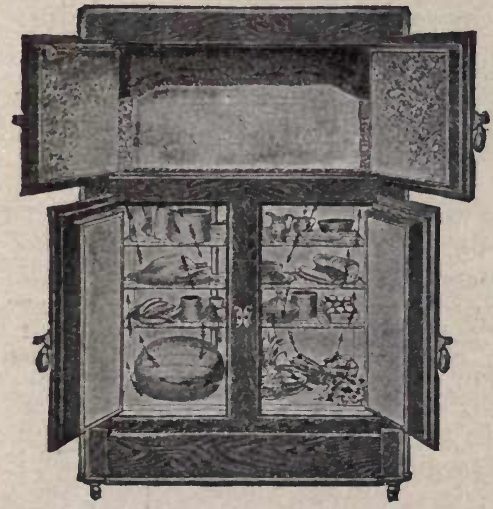

FIG. 118.-Top-icing refrigerator.

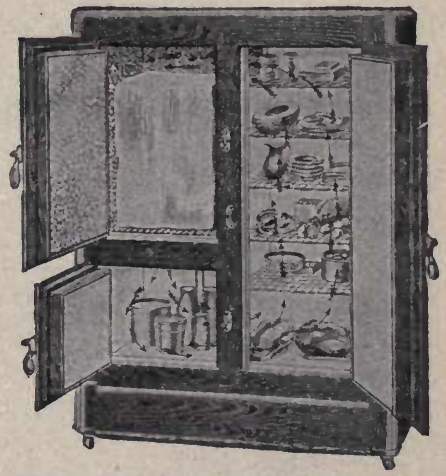

Fra. 119.--Side-icing refrigerator.

of the refrigerator while the warmer, lighter air passes upward at the two sides as shown in Fig. 118; or the cold, descending column may pass downward at one side of the refrigerator 
while the warmer, lighter air passes upward at the other side. In the side-icing refrigerator the air current is evidently always downward on the ice side and upward on the food side (Fig. 119). The top-icing refrigerator usually affords a much larger ice capacity compared with the food capacity than does the side-icing refrigerator. On this account, when both ice boxes are filled, we should expect a somewhat lower temperature in the top-icing than in the side-icing refrigerator. On the other hand, since in the side-icing refrigerator the food compartment extends the entire height of the refrigerator, the columns of cold air and of warm air are considerably higher than is possible in the top-icing refrigerator of the same capacity. This insures very perfect circulation, which is an essential feature of a good refrigerator.

185. Temperature Obtained and the Cause of Circulation.In a good refrigerator well filled with ice, the temperature of the air as it leaves the ice compartment and enters the food compartment is usually from $40^{\circ}$ to $45^{\circ} \mathrm{F}$. As the air leaves the food compartment and enters the ice compartment, its temperature is often raised to $55^{\circ}$ or even $60^{\circ} \mathrm{F}$. This difference in temperature is the cause of the circulation, the warmer, moist air being considerably lighter per cubic foot than the cooler, dry air (Arts. 130-137).

Table VII.-Weight of 1 Cu. Ft. of Air Saturated with

Water Vapor; Also, Weight of the Water Vapor in Each Cubic Foot of Air

\begin{tabular}{r|c|c||c|c|c}
\hline $\begin{array}{c}\text { Temperature, } \\
\text { F.॰ }\end{array}$ & $\begin{array}{c}\text { Weight of } \\
\text { saturated air, } \\
\text { grains }\end{array}$ & $\begin{array}{c}\text { Weight of } \\
\text { water vapor, } \\
\text { grains }\end{array}$ & $\begin{array}{c}\text { Temperature, } \\
\text { F. }{ }^{\circ}\end{array}$ & $\begin{array}{c}\text { Weight of } \\
\text { saturated air, } \\
\text { grains }\end{array}$ & $\begin{array}{c}\text { Weight of } \\
\text { water vapor, } \\
\text { grains }\end{array}$ \\
\hline-30 & 650 & 0.12 & 40 & 556 & 2.85 \\
-20 & 634 & 0.21 & 50 & 544 & 4.08 \\
-10 & 620 & 0.36 & 60 & 533 & 5.75 \\
0 & 606 & 0.56 & 70 & 521 & 7.98 \\
+10 & 593 & 0.87 & 80 & 509 & 10.93 \\
20 & 580 & 1.32 & 90 & 497 & 14.79 \\
30 & 568 & 1.96 & +100 & 487 & 19.77 \\
\hline
\end{tabular}


This difference in weight of a cubic foot of air at the different temperatures from $-30^{\circ}$ to $100^{\circ} \mathrm{F}$. is more clearly shown by the curve, Fig. 120. If the temperature of the air in a refrigerator varies from $40^{\circ}$ on the ice side to $55^{\circ} \mathrm{F}$. on the food side, the weight of $1 \mathrm{cu}$. $\mathrm{ft}$. of air will vary from 556 grains to about 538 grains. This means that the warmer air is only about $29 / 30$ as heavy as the cooler air. This difference in weight is sufficient to secure a convection current of considerable strength.

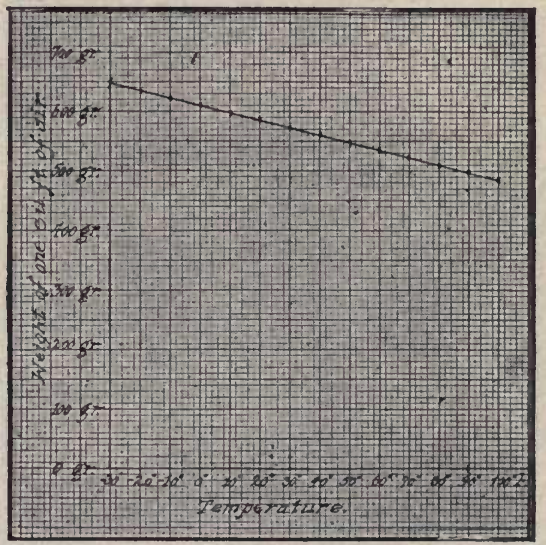

FIG. 120.-Curve showing density of air at different temperatures.

\section{Exercise 43.-A Study of the Temperature in a Refrigerator}

(a) Open the doors of a refrigerator and study carefully its construction. Is it top-icing or side-icing? If it is a top-icing refrigerator, determine whether the cold air drops out of the ice box at the center of the refrigerator or at one side. Also determine whether the warm air enters the ice compartment at one side only or at both sides.

(b) Having determined the course of the convection currents in the refrigerator, place the thermometer in this current close up to the opening through which the air passes as it leaves the ice compartment and enters the food compartment. Close all of the doors for about five minutes; then open one door and quickly read the thermometer 
without removing it from the air current. In like manner determine the temperature of the air as.it leaves the food compartment and enters the ice compartment.

If possible, repeat these experiments with a second refrigerator.

The temperature obtained in this experiment will depend upon several things: (1) Construction of the refrigerator; (2) amount of ice in the ice compartment; (3) temperature of the room; (4) amount and kind of food in the food compartment. Show how each of these factors affected the temperature in the refrigerator you examined.

186. Meaning of Absolute Humidity, Saturation, Relative Humidity, and Dew Point.-In order to understand how the temperature of the air determines the amount of moisture which the air within a refrigerator contains, it is necessary that we learn some new terms and their exact uses.

Definitions. -

Absolute Humidity.-By absolute humidity we mean the weight of moisture, or water vapor, actually contained in one unit volume of air.

SATURATION.-We speak of the air as being SATURATED or as having reached the POINT OF SATURATION when it contains all the moisture, or water vapor, it can possibly contain at that temperature.

In the table given above (Art. 185), the third column gives the absolute humidity of fully saturated air at the various temperatures given in the first column. For example, at $0^{\circ} \mathrm{F}$. the absolute humidity of saturated air is 0.56 grain per cu. ft., while at $70^{\circ} \mathrm{F}$. it is 7.98 grains, or nearly fifteen times as great.

Relative Humidity.-Relative Humidity is the ratio of the absolute humidity of air at any temperature to the absolute humidity of air were it saturated at the same temperature.

Suppose the air in a schoolroom is found to contain 4 grains of water vapor per cu. ft. when the temperature is $70^{\circ} \mathrm{F}$. The relative humidity of the air is then expressed as the ratio of 4 grains to 7.98 grains, or $4.00 / 7.98$, or very nearly $1 / 2$. The relative humidity is usually expressed, however, not as a 
fraction, but as a per cent. In this case we say the relative humidity is 50 per cent.

Dew PoINT.-Dew PoINT is the temperature at which air containing a certain amount of moisture per cubic foot, that is, having a certain absolute humidity, becomes saturated.

Suppose, as before, that the air in a schoolroom is at $70^{\circ} \mathrm{F}$. and that it contains 4 grains of moisture per cu. ft. Now, if the temperature in that room were lowered, the air would become more nearly saturated, that is, its relative humidity

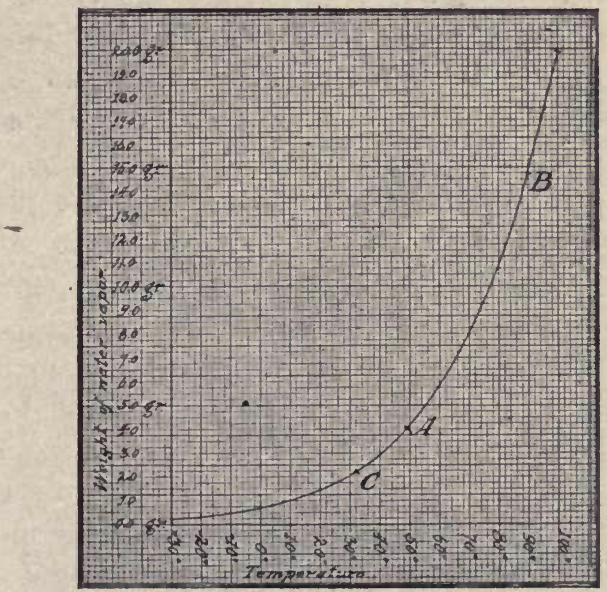

Frg. 121.-Curve showing weight of water vapor in saturated air at different temperatures.

would become higher, because the actual amount of moisture per cubic foot would remain the same while the amount of moisture it might contain would decrease with the fall in temperature. By examining the table above, or still better by examining the curve, Fig. 121, we see that the air will become saturated when the temperature has fallen a trifle below $50^{\circ}$, or about $49^{\circ} \mathrm{F}$. Its relative humidity would then be 100 per cent. This temperature at which the air becomes completely saturated is called the dew point. If any object whose temperature is at, or below $49^{\circ} \mathrm{F}$., is taken into this room, 
a portion of the moisture will be condensed upon this object, forming dew. This is exactly what takes place when a pitcher or glass of cold water stands for a few minutes on a warm summer day. The pitcher or glass becomes covered with dew. Often dew stands in drops on a pitcher or glass containing ice water.

187. Why the Air within the Refrigerator is Dry.-In many portions of the United States the air on a summer day frequently reaches a temperature of $90^{\circ} \mathrm{F}$., while at the same time the relative humidity is often as high as 80 or 85 per cent. We see, by reference to Table VII, Art. 185, or to the curve (Fig. 121, B), that this means that the air contains 12 or 12.5 grains of moisture per cu. ft. At the same time, the air within the refrigerator is still more nearly saturated. But, since the temperature of that air is not higher than $50^{\circ}$ or $55^{\circ} \mathrm{F}$., the largest amount of moisture it can possibly contain is only about 4 or 4.5 grains per cu. ft., or about onethird of that contained by the air outside. Again, as the air circulates through the ice compartment, much of it actually comes directly in contact with the ice. This must mean that the air for the moment is cooled nearly to $32^{\circ} \mathrm{F}$., the temperature of the ice. All of the moisture in this air in excess of about 2 or 2.5 grains per cu. ft., therefore, is deposited in the form of dew upon the ice. Show this to be true by reference to the curve (Fig. 121,C). It is, therefore, evident that the air, as it flows from the ice compartment into the food compartment, does not contain more than about one-fifth, or at most one-fourth, as much moisture as the air in the room. The air, then, as it flows from the ice compartment into the food compartment, is cold and contains but little moisture, notwithstanding the fact that it is saturated.

188. Effect of the Dry Air within the Refrigerator upon Foods.-When this stream of cold, dry air leaves the ice compartment and enters the food compartment, it takes up heat from all the contents of the food compartment. As this air rises in temperature, its capacity for holding moisture 
increases rapidly, that is, its relative humidity is lessened; it is no longer saturated. Since most of the provisions usually placed in the refrigerator contain considerable moisture, evaporation takes place and the foods become drier. It is for this reason that fruits, such as apples, oranges and lemons, as well as other kinds of provisions, often dry up and wither instead of suffering ordinary decay when placed in a good refrigerator. Common table salt often absorbs so much moisture in the summer that it can not be shaken from a salt shaker. This can be prevented by placing the shaker in the dry air of the refrigerator.

189. Care of the Refrigerator.-It is not possible to construct a refrigerator of such material and in such a manner as entirely to prevent heat from getting into it, even when all doors are closed. If this were possible, very little ice would be needed to operate it. Since heat is certain to penetrate the refrigerator from every side, and at all times, this heat must be taken up or absorbed by the ice. In Art. 150 , we learned that heat used in melting ice is called HEAT of Fusion. The cooling of the refrigerator is due almost entirely to the absorption by the ice of this heat of fusion; that is, the heat is consumed simply in melting the ice. Occasionally we hear of someone's wrapping the ice in paper, to prevent melting, before placing it in the refrigerator. This, of course, is an error. Just to the extent that wrapping actually prevents melting as intended, the presence of the ice in the refrigerator is useless. Nevertheless, good judgment on the part of the operator may lessen considerably the amount of ice required to operate the refrigerator. The refrigerator should be placed in the dryest and coolest place possible, consistent with convenience.

190. Rear-icing and Built-in Refrigerators.-Most manufacturers, when requested, now furnish refrigerators with a door to the ice compartment on the back, or rear, of the refrigerator. This device is often of great service, inasmuch as it enables the ice man to fill the refrigerator without com- 
ing inside the house. The refrigerator is placed with its back against the outside wall. An opening is made in the wall

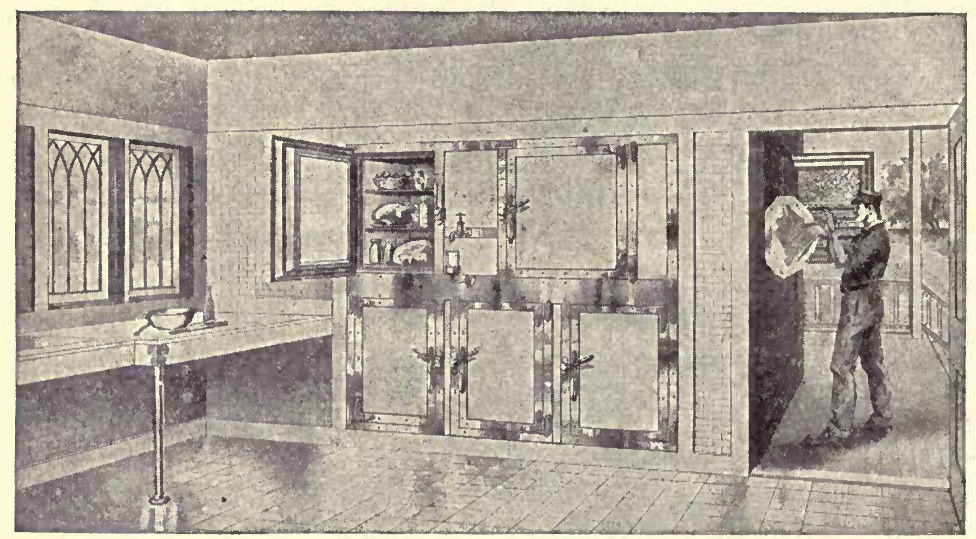

FIG. 122.-A built-in refrigerator.

corresponding to the rear door of the refrigerator. This opening is fitted with a door also. This opening is generally

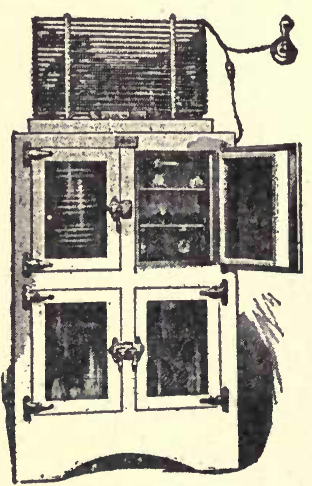

Frg. 123.-A mechanical refrigerator. reached from a porch; therefore, the refrigerator can be as easily filled from the outside as it could be from the inside of the house, thereby saving much dirt and inconvenience.

In many modern houses the refrigerator is "built-in," that is, it is constructed as a part of the house just as truly as is the stair case (Fig. 122).

191. The Refrigerating Machine for Home Use.-During recent years many devices have been constructed to take the place of the refrigerator in the home. They all involve the principles employed in the manufacture of ice and in cold storage plants (see next two sections). Figure 123 shows one such device. It is really a small cold storage plant 
attached to an ordinary refrigerator. On top of the refrigerator is a COMPRESSOR for compressing sulphur dioxide gas. The compressor is run by a small electric motor. The compressed gas passes through cooling coils where it is liquefied. It then passes into the refrigerating coils which are in the ice compartment of the refrigerator. Here the liquid sulphur dioxide is released from pressure and changes into a gas, producing a lower temperature and dryer air than can be secured by the use of ice.

\section{MANUFACTURED ICE AND FREEZING MIXTURES}

192. Need of Manufactured or Artificial Ice.-Without manufactured ice it would be impossible to make use of the refrigerator in many portions of the civilized world. Even in climates where natural ice is produced in sufficient quantities, artificial ice is regarded as a necessity for many purposes on account of its greater purity. Most towns and cities of any considerable size have their ice factories. Artificial ice is today in such common use that we should learn something about the principles involved in its manufacture.

193. The Ice Plant.-The essential parts of the ordinary plant for the manufacture of ice are: (1) Steam boilers and a steam engine; (2) an ammonia compressor (B, Fig. 124); (3) cooling coils, through which the ammonia passes and over which flows constantly a stream of cool water $(C$, Fig. 124); (4) a tank of brine through which the ammonia pipes run (Fig. 124); (5) cans containing purified water which is to be frozen ( $G$, Fig. 124). There are usually also mechanical devices for handling the blocks of ice, and frequently additional boilers for the distilling of the water which is to be frozen.

Before we can understand the use of these parts of the plant and the process followed, we need to know some of the special properties of ammonia.

194. Some of the Properties of Ammonia.-When studying evaporation (Art. 12, Ex. 10), we learned that when any liquid evaporates much heat is absorbed, or, as we commonly say, 
cold is produced. This last way of speaking is really not incorrect if we fully realize that cold is simply absence of heat. It is better, however, to speak of the heat's being absorbed. We should also recognize that it is the heat of vaporization (Art. 150) which is absorbed. We also saw that those liquids which evaporate most rapidly absorb heat most rapidly; they feel the coldest on the back of the hand. The substances

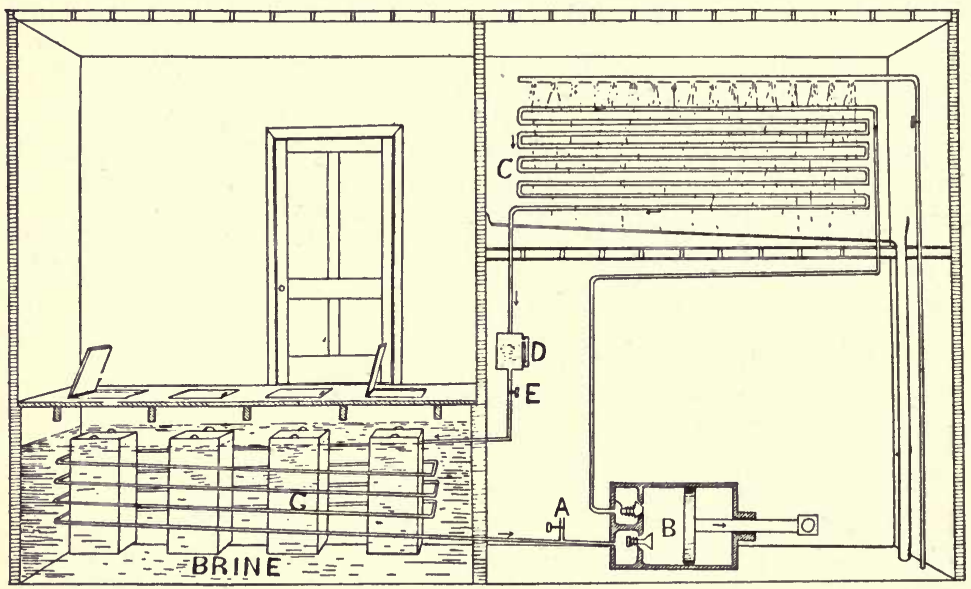

FIG. 124.-Diagram of an ice factory.

studied were water, alcohol, and gasoline. But each of these substances is a liquid at ordinary temperatures, and each of them boils under the pressure of the atmosphere at a temperature higher than that of the air about us. (Recall the boiling temperature of each of these substances.) Evidently, then, each of these three substances will change from the liquid form to vapor form rapidly, that is, it boils only when raised to a rather high temperature. Further, it is only when a liquid is boiling that it absorbs the heat of vaporization rapidly.

We see now that if we can obtain some substance in the liquid form which evaporates very rapidly, or even boils, at a 
temperature below the freezing point of water, we can then allow this liquid to evaporate and absorb heat, taking it from water till the water freezes. This is exactly the principle employed in the manufacture of ice, and AMMONIA is the liquid used.

Nearly everyone is somewhat familiar with ammonia. It is the gas that escapes from common AQUA AMMONIA, or SPIRITS OF HARTSHORN, which may be purchased at any drug store. This common aqua ammonia is simply water which has absorbed large quantities of ammonia. When aqua ammonia is exposed to the air, the ammonia escapes. Its stinging, biting odor is familiar to all and is easily recognized. The ammonia with which we commonly come in contact, then, is always in the gaseous form. This same ammonia, however, can be changed into liquid form by compressing it. The pressure required to change ammonia gas into liquid form depends upon its temperature; the higher the temperature, the greater is the pressure required. For any given temperature, there is a corresponding pressure which is just sufficient to liquefy the gas. This relation of temperature to pressure is often stated in another way: We often speak of the boiling point corresponding to a given pressure (see Art. 155 and Table VI). It must be clearly understood, however, that the boiling point corresponding to a given pressure is exactly the same temperature as the liquefying point corresponding to that pressure. Recall that water boils and steam condenses at the same temperature.

Table Vili.-Pressure and Corresponding Bolling Point of AMmonia

\begin{tabular}{|c|c|c|c|}
\hline $\begin{array}{l}\text { Pressure, } \\
\text { lb. per sq. in. }\end{array}$ & & Atmospheres & $\begin{array}{r}\mathrm{B} \\
\text { or lic }\end{array}$ \\
\hline & 1 & atmosphere. & \\
\hline $0 \mathrm{lb} . .$. & 2 & atmospheres. & \\
\hline 34 lb. & 2. & 3 atmospheres.. & \\
\hline $63 \mathrm{lb}$. & 4. & 2 atmospheres. & $\ldots$ \\
\hline $107 \mathrm{lb}$. & 7. & 1 atmospheres.. & \\
\hline $130 \mathrm{lb}$. & 8. & 6 atmospheres.. & \\
\hline $155 \mathrm{lb}$. & 10. & 3 atmospheres & \\
\hline
\end{tabular}


From this table we see that to change ammonia from a gas to a liquid at the ordinary temperature of $70^{\circ} \mathrm{F}$. requires a pressure of about $130 \mathrm{lb}$. per sq. in. We also see that at the pressure of 1 atmosphere, or $15 \mathrm{lb}$. per sq. in., the ammonia will be in the liquid form if the temperature is below $-29^{\circ} \mathrm{F}$. and in the gaseous form if the temperature be above $-29^{\circ} \mathrm{F}$. (Fig. 125).

NотE: It is important that we remember that the ammonia used in refrigerating plants is the pure, dry ammonia; never the water solution of ammonia, or aqua ammonia.

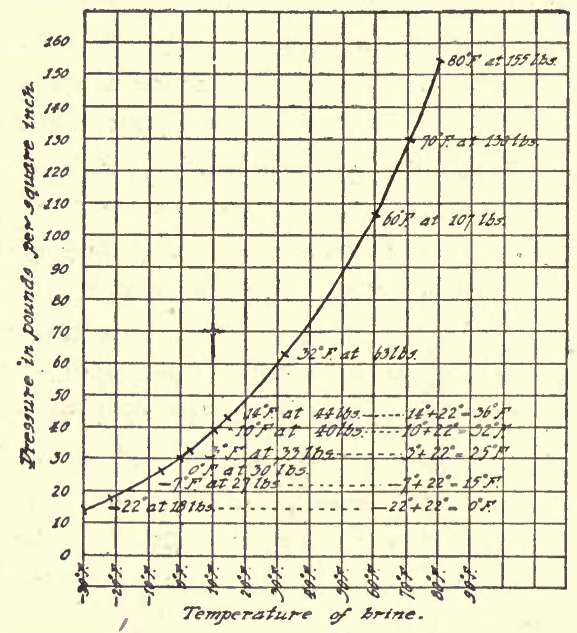

FIG. 125.-Curve showing the properties of ammonia.

195. How the Water is Frozen.-The ammonia to be used in the plant is received from the manufacturing chemist in strong metal containers. It is highly compressed and, therefore, is in the liquid form. This ammonia is fed into the system through the opening, $A$, Fig. 124. As the ammonia escapes from the high pressure, it boils violently and changes to the gaseous form. As the compressor is running, the ammonia is drawn directly through the lower valve into the 
cylinder of the compressor, B, Fig. 124. The piston then forces it through the upper valve into the pipe leading to the cooling coils, $C$. As the ammonia is compressed, it becomes very much heated, and, although the gas is subjected to a pressure of $140 \mathrm{lb}$. or more per sq. in., it still retains its gaseous form. The cooling coils are kept cool, however, by being constantly drenched with cool water. As the heated ammonia gas passes through these coils, it is cooled. Referring again to the table given in the last article, we see that the ammonia will liquefy under a pressure of $140 \mathrm{lb}$. as soon as the temperature drops to about $75^{\circ} \mathrm{F}$. Now the cooling coils can be kept at a temperature as low as $75^{\circ} \mathrm{F}$. by drenching them with water from the city mains or pumped from wells.

It should be carefully noted that the cool water carries away two distinctly different portions of heat from the ammonia. First, the highly heated ammonia gas is cooled down to the temperature of the water, that is, the water carries away the sensible Heat (Art. 149). Second, when the ammonia changes from the gaseous form to the liquid form, it gives up exactly as much heat as it absorbs- when it changes from the liquid form to the gaseous form. The heat given off when a gas liquefies is called HEAT of CONDENSation. This heat of condensation exactly equals the heat of vaporization.

The liquid ammonia accumulates in the reservoir ( $D$, Fig. 124). It is now at about $70^{\circ} \mathrm{F}$. and under about $140 \mathrm{lb}$. of pressure. When the liquid ammonia has accumulated in the reservoir to the desired amount, as shown by the glass gauge, the valve at $A$ is closed and no more ammonia is fed into the system. The valve, $E$, is now opened and the ammonia is permitted to flow into the coil of pipes submerged in the brine. Being released from pressure, as soon as it escapes through the valve, $E$, the ammonia begins to evaporate rapidly, even boil. This means that it takes up heat of vaporization. It receives this heat from the brine. The brine consequently drops in temperature. When cans of pure water are placed in this brine, as $G$, Fig. 124, the brine absorbs 
heat from the water and continues to do so till the water is frozen. As long as the compressor is kept running, the circulation of the ammonia continues.

196. Why Brine is Used and How the Temperature of the Brine is Regulated.-When studying the thermometer, we saw that Fahrenheit got the temperature which he called zero on his thermometer by mixing salt and crushed ice (Art. 17). Now if just enough salt is mixed with ice to make a saturated solution ${ }^{1}$ when the ice melts, the melting point of the mixture is a little lower than the lowest temperature Fahrenheit obtained. It is about $-7^{\circ} \mathrm{F}$. But it should be carefully noted that the melting point of such a mixture is also the freezing point of a saturated solution of salt and water, just as the melting point of pure ice is exactly the freezing point of pure water (Art. 16). The saturated solution of salt and water, then, can be frozen only by lowering the temperature to about $-7^{\circ} \mathrm{F}$., which is $39^{\circ}$ below the freezing point of water.

In operating an ice plant it is customary to cool the brine to about $16^{\circ}$ or $18^{\circ} \mathrm{F}$. The temperature of the brine can easily be governed by opening wider or partly closing the regulating valve. It will be noticed that the compressor, not only compresses the ammonia gas on the compression side of the regulating valve, i.e., in the cooling coils, but that at the same time it is reducing the pressure on the other side of the valve, i.e., in the pipes in the brine vat. It also becomes evident that if the regulating valve is nearly closed the pressure becomes great on the compression side while it is reduced on the exhaust side. On the other hand, opening the valve wider permits the pressure to become somewhat nearer equal on the two sides. Hence we speak of the HIGH SIDE and the LOW SIDE of the plant. The high side comprises that portion of the ammonia pipes from the com-

${ }^{1}$ Note: A saturated solution of salt is one in which no more salt will dissolve in the water. At ordinary temperatures $21 / 2 \mathrm{lb}$. of water will dissolve about $1 \mathrm{lb}$. of salt. 
pressor to the valve, $E$. The low side comprises the portion from the valve, $E$, to the compressor. Referring to the table (Art. 194), we see that at a pressure of $34 \mathrm{lb}$. the boiling point of ammonia is $5^{\circ} \mathrm{F}$. In operating the ice plant, the regulating valve is usually so set that the pressure on the low side of the valve, i.e., in the pipes in the brine vat, is maintained at about $34 \mathrm{lb}$. Since the temperature of the brine is usually from $10^{\circ}$ to $15^{\circ}$ above the temperature of the pipes, the temperature of the brine is about $16^{\circ}$ or $18^{\circ} \mathrm{F}$.

197. Purity and Cost of Manufactured Ice.-Practically, all impurities of every kind are removed from the water by distilling it before it is placed in the cans to be frozen. Even though air be the only impurity present when freezing takes place, the ice will be filled with small bubbles and therefore will be clouded and opaque. It is the presence of a very small amount of air which the water reabsorbs before freezing can take place, which gives the center of the ice cake the whitish, opaque appearance familiar to all users of artificial ice. Even small quantities of dissolved solids generally give the ice a yellowish or brownish tinge. When frozen in cans by the method here described, only pure water can give clear, colorless ice; therefore, only distilled water is used. As far as possible the exhaust from the engine which runs the compressor is used. Since this does not furnish sufficient water, generally, steam from the extra boiler mentioned above (Art. 193) is also condensed and used.

In the southern portion of the United States and in many northern portions which are remote from bodies of fresh water, manufactured ice can be produced at less expense than natural ice can be obtained. The average cost of producing artificial ice is now generally considerably less than $\$ 1$ per ton. The cost to the consumer is, however, much more than this, owing to the expense of handling and the large loss due to melting which necessarily accompanies its distribution during warm weather.

198. Freezing of Ice Cream.-The freezing of ice cream 
involves some of the principles just described. Finely broken or crushed ice is mixed with common salt and the mixture is then packed in the freezer around the can containing the cream to be frozen. As we saw in Art. 196, such a mixture of ice and salt has a melting point far below the melting point of pure ice. Or, we may express the same truth in another way: We may say that the freezing point of a saturated solution of salt and water is $-7^{\circ} \mathrm{F}$., or $39^{\circ}$ below the freezing

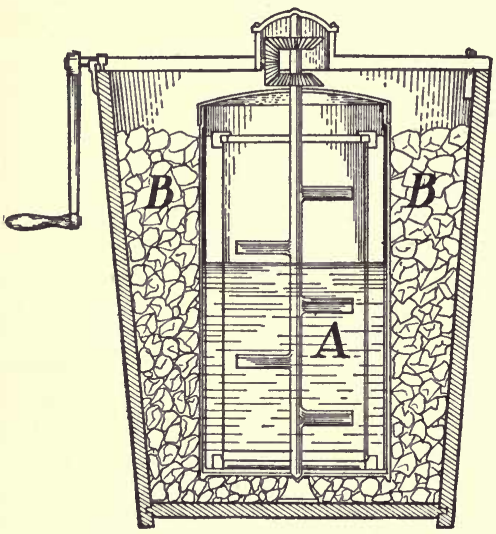

Fig. 126.-An ice cream freezer. point of pure water (Art. 196). If a mixture of onethird salt and two-thirds crushed ice is used in the freezer, the temperature of the mixture will tend to fall to this point as the ice melts.

It is evident that as the first portions of the ice melt, the water formed will dissolve some of the salt, forming a saturated solution of salt water. We also know that as the ice continues to melt it absorbs large quantities of heat. Most of the heat absorbed by the ice, when melting, must be taken from the freezer and from the can of cream. Both will, therefore, fall in temperature. Since the cream freezes at a temperature much higher than the freezing point of the mixture, it is evident that if a sufficient quantity of salt and ice is used the cream can be completely frozen (Fig. 126).

The only puzzling question in the process of freezing cream is this: Why does the ice continue to melt when the temperature falls below $32^{\circ} \mathrm{F}$., the ordinary melting point of ice? The answer is: A mixture of salt and ice can exist as salt and ice only at a temperature of $-7^{\circ} \mathrm{F}$., or lower. If salt is placed upon ice at a higher temperature, the ice melts and the 
salt dissolves in the ice water. If there is enough salt, a saturated solution of salt is formed. Now a saturated solution of salt will not freeze at a temperature above $-7^{\circ} \mathrm{F}$. In the ice cream freezer we have a mixture of the three substances, salt, ice, and a nearly saturated solution of salt. As long as the supply of salt and ice holds out, the ice continues to melt and absorb heat; the temperature of the mixture, therefore, tends to fall toward the freezing point of the salt solution, $-7^{\circ} \mathrm{F}$.

199. Other Freezing Mixtures.-Many other substances have the same effect upon ice that salt has. For example: If 1 part of common sal ammoniac be mixed with 4 parts of broken ice, the mixture has a melting point (or freezing point) of about $4^{\circ} \mathrm{F}$. If equal weights of sulphuric acid and crushed ice be mixed, the mixture has a melting point (or freezing point) of $-35^{\circ} \mathrm{F}$. A mixture of calcium chloride and ice has a melting point of $-55^{\circ} \mathrm{C}$. Still lower temperatures are obtained by using other mixtures.

Definition.-A freezing mixture is a mixture of two or more substances of such a nature that they act upon each other in such a manner as to absorb heat, or to produce cold.

\section{COLD STORAGE}

200. Effect of Cold Storage on Modern Life.-The development of plants for the production of cold by artificial means has not only given us ice in greater abundance and in greater purity, but it has also made possible the construction of many enormous COLD STORAGE PLANTS. In these cold storage plants, the surplus of perishable produce, such as eggs, butter, poultry, beef, fruits, and vegetables is stored during the seasons of abundance. In cold storage this perishable produce is preserved for weeks, or even months, much of it suffering but little deterioration. Before the establishment of cold storage plants, the markets were often flooded with certain fruits for a short period; in a few weeks, however, the entire year's supply of these fruits was either consumed or 
had decayed and was lost. Similarly, the production of eggs is much greater during the spring and early summer than at other seasons of the year. Formerly the supply of eggs during the spring was so greatly in excess of the demand that the price fell to a ridiculously low mark, and many eggs even went to waste. During the winter months, on the other hand, eggs were often practically unobtainable at any price. Since the advent of cold storage, however, many kinds of fruit, eggs, and other kinds of perishable produce, are obtainable at any season of the year and at prices which vary but little from season to season. In this and other ways, cold storage has greatly modified modern life.

201. Construction of a Cold Storage Plant.-A modern cold storage plant so closely resembles an ice plant that no extensive explanation is necessary. The plant consists of a compressor, $A$, operated by a steam engine, $B$ (Fig. 127). The ammonia is cooled and liquefied in the cooling coils, $C$. It then collects in the reservoir, $D$, and finally is permitted to pass through the regulating valve, $E$. The "high side," then, is exactly like the "high side" of a manufactured ice plant. After passing through the valve, $E$, the ammonia vaporizes in the pipes submerged in the brine in the vat, $F$. After vaporizing, the ammonia returns to the compressor through the pipe, $c-c$. Thus we see that the "low side" is also the same as in the case of the ice plant. The brine vat, however, is not usually within the storage room at all. The chilled brine is forced by the pump, $G$, through the pipe, $d-d$, to the absorbing coils, $H$ and $H$, in the storage rooms. After passing through these coils, the brine returns to the vat, $F$.

202. Temperature Required for Cold Storage and How Controlled.-Different kinds of produce keep best when stored at different temperatures. Some fruits are usually stored at about $36^{\circ} \mathrm{F}$.; others at about $32^{\circ} \mathrm{F}$.; fresh meat at about $25^{\circ} \mathrm{F}$.; poultry at about $15^{\circ} \mathrm{F}$; ; and fish at about $0^{\circ} \mathrm{F}$. To obtain a given temperature in the storage room it is necessary that the boiling point of ammonia be controlled. 
COLD STORAGE

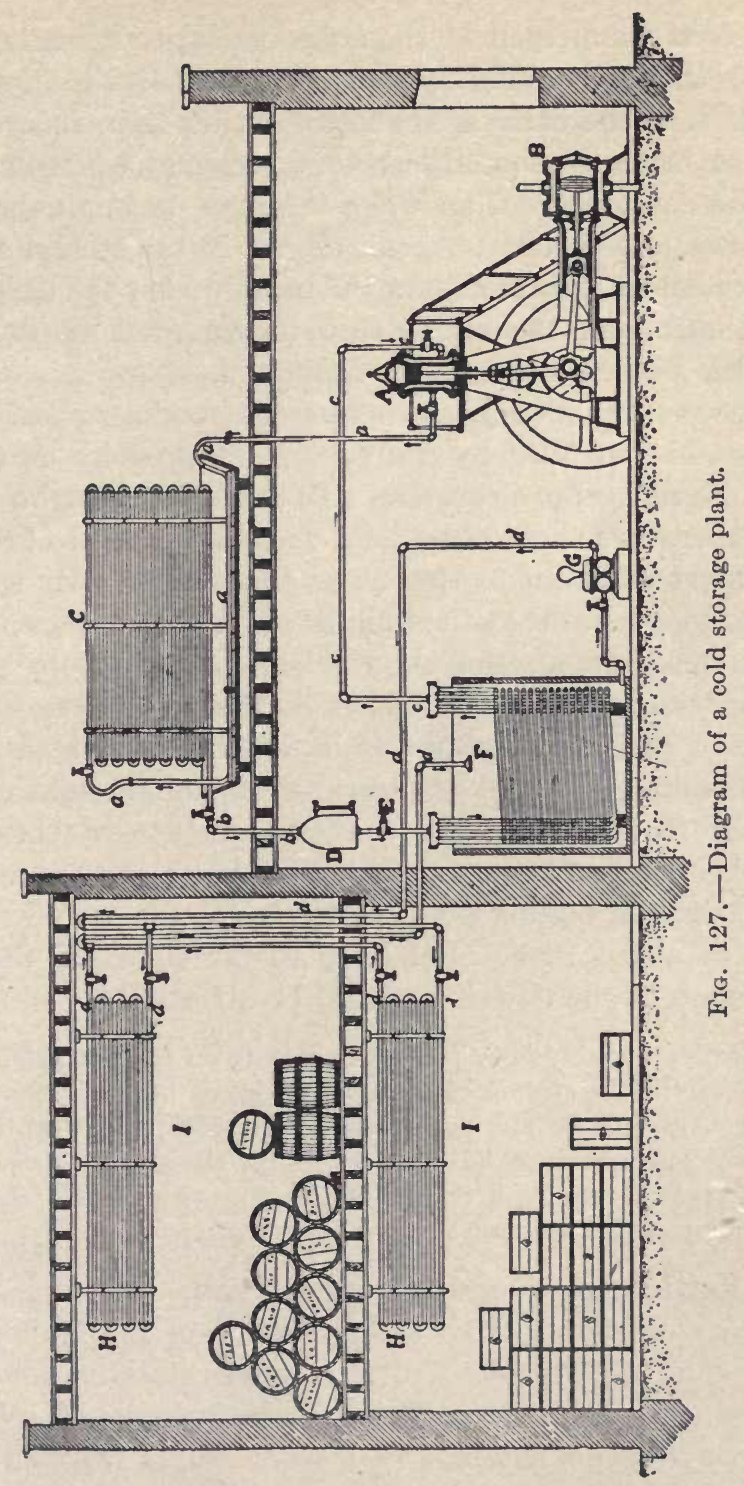


The coils submerged in the brine vat are evidently cooled about to the boiling point of the ammonia. But it is generally the case that the brine is about $10^{\circ}$ higher than this. Moreover, the brine is generally about $6^{\circ}$ warmer when it returns from the coils, $H-H$, than when it passes through the pump on its way to the coils. Again, the air in the storage room is usually about $6^{\circ}$ warmer than the brine within the coils, $H-H$. Altogether, then, the air in the storage room is about $22^{\circ}$ above the boiling point of the ammonia.

Now we have already seen how the boiling point of the ammonia is controlled by controlling the pressure on the low side of the refrigerating system. In the storing of fruits where the temperature should be $36^{\circ} \mathrm{F}$., the boiling point of the ammonia must be about $22^{\circ}$ lower, or about $14^{\circ} \mathrm{F}$. By referring to Fig. 125, we see that the boiling point of ammonia is $14^{\circ} \mathrm{F}$. when under a pressure of about $44 \mathrm{lb}$. to the sq. in. Therefore, in storing such fruits, the regulating valve is so set as to maintain a pressure of about $44 \mathrm{lb}$. on the low side.

Most kinds of fruit keep best when stored slightly above $32^{\circ} \mathrm{F}$. If it is found that the temperature of the air in the store room is $22^{\circ}$ above the boiling point of the ammonia, we see that the boiling point of the ammonia would need to be kept at about $10^{\circ} \mathrm{F}$. Referring to the curve we find that the pressure of the low side should be about $40 \mathrm{lb}$.

In a similar manner, show that the pressure on the low side must be about $33 \mathrm{lb}$. for the storing of meat which keeps best at about $25^{\circ} \mathrm{F}$; at about $27 \mathrm{lb}$. for the storing of poultry at $15^{\circ} \mathrm{F}$; and that the pressure on the low side must be about $18 \mathrm{lb}$. for the storing of fish which must be kept at zero F., if the air in the store room is $22^{\circ}$ above the boiling point of the ammonia in the low side pipes.

203. Refrigeration and Transportation.-A fruit has a life history extending from the formation of the fruit bud to the decay of the ripened fruit. Some fruits have short life histories, others, longer. Fresh fruits, when not overripe, are alive; they do not readily decay. Some fruits, such as strawberries, die very soon after reaching maturity; others, 
such as winter apples, remain alive for many weeks after being removed from the tree. The purpose of cold storage of fruits is to delay the ripening process so that the life of the matured fruit may be extended over as long a period as possible, in some cases even till the next year's crop matures. In the case of short-lived fruits it is necessary to get them into the hands of the consumer as quickly as possible. But the majority of the consumers live in the larger cities, like New York, Philadelphia, Boston, and Chicago, long distances from the more productive fruit growing sections.

It was formerly practically impossible to transport shortlived fruits from the field to the consumer. Today, however, by using modern refrigerator cars, oranges are shipped from California to New York; strawberries from Mississippi to Chicago; peaches from Florida, Georgia, and Texas to the Boston market with little or no deterioration. Similarly, the markets of the world are supplied with fresh meat and poultry, killed and dressed in the slaughter houses of Kansas City and Chicago. 


\section{GHAPTER IV}

\section{THE WEATHER}

The weather is the state of the atmosphere with respect to heat and cold, wind and calm, rain and snow, sunshine and cloudiness. The weather is one of the most important influences affecting the daily life of all the people. In ages past the weather has crumbled the rocks and formed the soil, smoothed the landscape and watered the fields. By its control of plant life, the weather has largely determined the location of the chief food-producing areas of earth. Food supply, in turn, has dominated the growth of civilizations and the progress of the human race. In all its work in the past, the weather has been controlled by the same interesting laws that govern the winds and storms of the present. Men today understand many of those laws. Some of them will be studied in this chapter.

204. Beginnings and Growth of Weather Knowledge.We do not know when man commenced to observe the weather; but from the beginning of the human race man, like the beasts of the field, must have sought shelter from storm and protection from cold. In time, he began to notice signs of coming tempests farther and farther in advance and so sought shelter in better season. Long afterward he learned enough to coin sayings and proverbs about the weather. Some of these date back more than 6000 years. The ancient Hindus measured the rainfall; the Chaldeans named the wind directions; the Greeks kept records of the wind, and one of their philosophers, 500 B. C., made a crude thermoscope by which changes of temperature could be shown. The modern thermometer and barometer were not invented until the 17 th century; then explorers soon began carrying thermometers on 
their journeys to measure the temperatures experienced in different lands. The beginnings of weather science appeared about 150 years ago, and much of our present exact knowledge has been gained in the last hundred years.

205. Weather Caused Primarily by the Sun.-All weather is made up chiefly of some combination of the temperature, moisture, and movements of the air. The moisture is carried by the winds; the winds are indirectly caused by temperature conditions; and the temperature conditions are controlled principally by the reception of heat from the sun and the loss of heat by radiation into space. The heat received from the sun (and lost to space) is the great primary cause of all weather. How the sun's heat produces wind and cloud and storm and cold as well as the bright and sunny day is an interesting story. To study weather best, we begin by observing the weather about us.

\section{OBSERVING THE WEATHER}

206. Observing Weather Without Instruments.-Can you describe yesterday's weather in your locality? Do so. Was the day clear or cloudy? Was it warm or cold for the season? What was the direction of the wind? Was it strong or light? What changes in direction occurred during the day? Can you tell anything about the clouds and in what direction they were moving? If there was rain or snow during what hours did it fall? Was the fall heavy or light? Describe today's weather fully, giving all changes that have occurred since morning.

207. Recording Weather.-Several features of the weather are best measured and recorded by instruments made especially for that purpose. The thermometer, the barometer, and the raingauge are needed in class work and will be studied later. But an interesting and useful record of many weather conditions may be made without any instruments. Such records are kept at weather stations all over the world in addition to the records made by weather instruments. 


\section{Exercise 44.-Daily Observations without Instruments}

Keep a record like the following. Observe the weather about 9 a.m. and 4 p.m. if practicable.

\begin{tabular}{|c|c|c|c|c|c|c|c|}
\hline Date & Hour & Clouds & $\begin{array}{l}\text { Temper- } \\
\text { ature }^{1}\end{array}$ & $\begin{array}{c}\text { Thermom- } \\
\text { eter } \\
\text { degrees }\end{array}$ & Wind & Remarks & $\begin{array}{c}\text { Indica- } \\
\text { tions }\end{array}$ \\
\hline Sept. 1. & 9 a.m. & $1 / 3$ dark-low & Warm & 80 & Brisk $\nearrow$ & Thunderstorm & Showers \\
\hline Sept. 1. & 4 p.m. & Cloudy, heavy & Cooler & .70 & High $\rightarrow$ & Rain ended & Rain \\
\hline Sept. 2. & 9 a.m. & 2/3 high & Cool & 62 & Mod. \ & in night & Clearing \\
\hline
\end{tabular}

For clouds, express the portion of sky covered, by the appropriate word from group " $a$ " below; for color or appearance, use words in group " $b$ "; for elevation, use " $c$ " words. Record the temperature as it seems to you, whether warm or cool, etc., for the time of year. Record the exact temperature if you have a thermometer.

Record the wind direction by arrows flying with the wind. Call the top of the page north, the right side (your right as you face it) east, etc. Record as follows:

Light, when just moving the leaves of trees.

Moderate, when just moving small branches.

Brisk, when swaying large branches.

High, when swaying entire tree and picking papers and dust up from the ground.

Gale, when breaking small branches and damaging light buildings.

Under "Remarks" note any special features.

Under "Indications" write the general appearance as it seems to you. This is not an exercise in forecasting, but merely a note of general appearances.

The following groups of words may be used in the proper columns of the record, to express the conditions:

\begin{tabular}{lc|l|l|l}
\hline \multicolumn{2}{c|}{ Clouds } & Temperatire & Wind & \multicolumn{1}{c}{ Remarks } \\
\hline \multicolumn{1}{c|}{$(a)$} & $(b)$ & Very warm & Calm & Raining \\
Clear & Light clouds & Warm & Light & Snowing \\
Few clouds & Dark clouds & Moderate & Moderate & Sleeting \\
$1 / 3$ cloudy & $(c)$ & Cool & Brisk & Threatening \\
$2 / 3$ cloudy & Low clouds & Cold & High & Storm clouds \\
Cloudy & High clouds & Very cold & Gale & Thunderstorm \\
& Heavy clouds & & & \\
\hline
\end{tabular}

${ }^{1}$ Use thermometer for temperature if available. 
The class should continue these daily observations and the record of them until ready to use weather instruments. (Art. 227).

The weather record should be earefully studied once each week and answers written to the following questions if possible:

1. Does the sky appear to be more or less cloudy for the few hours preceding a storm? - How is it for the few hours after the storm?

2. Is there any direction from which the wind appears to blow most frequently before a storm? If so, what direction? Is there any direction from which it blows most frequently after a storm?

3. Does the wind increase, or decrease, in the few hours before a storm? Does it blow harder before, or after, a storm?

4. Does the temperature seem warmer, or colder, before a storm? How does it change after a storm, if at all?

5. Does the "feeling" of the air ever tell you that a storm is coming? If so, can you tell what it is about the air that makes you think a storm is to come? How long before the storm did you notice that "feeling" of the air?

\section{THE USE OF WEATHER INSTRUMENTS}

The most important weather instrument is the barometer, which measures the pressure of the air.

208. Air has Weight.-When compared with any common liquid or solid, air is so light that its weight is not easily recognized. Yet smoke rises through the air, and balloons ascend out of sight. This is possible only because air is heavier, or denser, than the smoke or the gas in the balloon and crowds them upward, just as a cork rises to the surface of water because water is heavier, or denser, than cork and crowds it upward. But we can not see the air; we scarcely feel it; we seldom think of it. That such a substance constantly surrounds us, filling every nook and corner of our houses, even penetrating deep into the ground itself; that it is constantly pressing with great force upon our bodies; these things many of us have not realized.

It was not until 250 or 300 years ago that even men of science began to understand that air is a real substance and 
has weight as truly as has water or stone or iron. About 1630, Galileo made the first attempt to find the weight of air. $\mathrm{He}$ weighed a flask filled with air, then removed part of the air by heating the flask just as we did in Ex. 35, Art. 131. He sealed the flask while hot and then weighed it again. Since this method removed but part of the air, he placed the mouth of the inverted flask in water, unsealed it, and lowered it as it filled with water. $\mathrm{He}^{\prime}$ then closed the mouth and lifted the flask from the water. The volume of water remaining in the flask equaled the volume of air removed by the heating.

About 25 years later, Guericke constructed the first air pump. After that, the air could be removed by the pump. But no air pump will remove all of the air, and today when this experiment is performed, we must find some means of discovering how much air has been removed from the flask.

\section{Exercise 45.-Weighing Air}

Fit a 2-qt. or 4-qt. bottle with a new one-hole rubber stopper through which passes a short glass tube. To the glass tube attach about $2 \mathrm{ft}$. of rubber tubing. ${ }^{1}$ Fit the rubber tubing with a screw clamp. Now weigh the bottle full of air with all attachments, using trip scales (see Fig. 335). Attach the rubber tube to the air pump, making sure that all joints are tight. Vaseline the joints if necessary. Pump as much air as possible out of the bottle; close the rubber tube tightly with the screw clamp; detach the tube from the pump and quickly weigh the bottle and fittings. Place the tube and mouth of the bottle under water and open the screw clamp. The bottle quickly fills nearly full of water. Why? Hold the bottle so that the water inside and outside is on a level. Close the tube and lift the bottle from the water. Pour the water from the bottle into a measuring graduate and record the volume. This volume is the same as that of the air removed from the bottle. Compute the weight of 1 liter, 1000 c.c., of air.

A student performing this experiment obtained the following results (metric system):

\section{${ }^{1}$ Note: Thick-walled or pressure tubing should be used.}


Weight of bottle full of air........786.2 grams

Weight of bottle after removal of air... 784.8 grams

Therefore, weight of air removed..... 1.4 grams

Volume of water in the bottle.......1150 c.c. -

From these facts he computed the weight

of 1 liter of air to be nearly...... 1.22 grams

Prove the correctness of his computation.

Air varies much in weight at different times and places. Cold air is heavier, or denser, than warm air, and moist air is lighter, or less dense, than dry air. At sea level, dry air weighs about 1.29 grams per liter, or about $11 / 4 \mathrm{oz}$. per cu. ft. About $13 \mathrm{cu}$. ft. of air weigh $1 \mathrm{lb}$.

209. Air Pressure.-Though a cubic foot of air weighs but little, the atmosphere is many miles deep and presses down with great force upon the earth's surface. This fact was discovered soon after it was found that air has weight.

\section{Exercise 46.-To Study the Pressure of Air}

(a) Place a palm glass upon the stand of the air pump. Place rubber dam over the mouth of the palm glass and tie its edges down tight with a cord. Connect the stand with the pump. With the first stroke of the pump notice the effect on the rubber dam. If the rubber is fresh and strong, continued pumping may stretch it till it very nearly lines the inside of the receiver.

(b) Remove the rubber dam and carefully fit the hand over the mouth of the palm glass. Work the pump. Describe the "feeling" of the hand. Does your hand seem

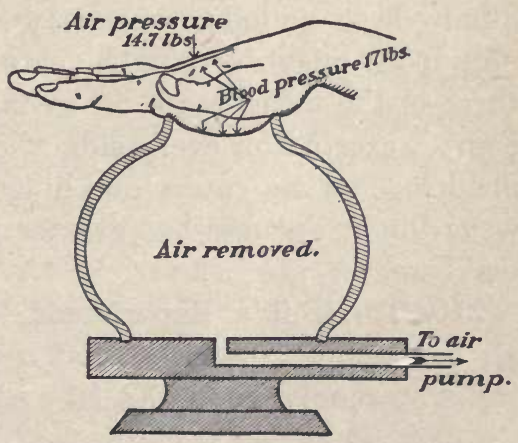

FIG. 128. to be sucked in? Is it really being drawn in, or is it being pushed in? What pushes it in (Fig. 128)?

(c) When all the air possible has been pumped out try lifting your hand steadily in a vertical direction, without prying it from the 
receiver. Do the palm glass and stand also rise with your hand? Are you really lifting the glass and stand in the sense that "lift" usually has? Just what does your muscular effort overcome? What force is it then, that holds the glass against your hand?

(d) If you are not thoughtful you will draw the wrong conclusion from experiment (b). The hand was not drawn into the palm glass, neither was there any extra pressure applied to the back of the hand. Was there blood pressure in the arteries and the capillaries lying just beneath the skin of the back of your hand? Was there blood pressure in the arteries and capillaries lying just above the skin of the palm of your hand? What, then, was the source of the pressure which forced the skin of the palm of your hand down into the opening of the palm glass?

(e) Tie the rubber dam over the mouth of a thistletube. Attach a rubber tube to the stem of the thistletube. Suck some of the air from the tube and note how the dam is pressed into the tube's mouth. Pinch the tube so that air cannot enter; then hold the thistletube with its mouth upward, downward, sidewise. May we conclude that air pressure is equal in every direction?

When we consider that the pressure upon the inner side of the skin of the palm of the hand became almost painful when the air was pumped from the palm glass, and when we are told that the total air pressure upon our bodies is many hundreds of pounds, we may wonder why we ordinarily feel no inconvenience from this great pressure. It is because there is the same pressure, so far as the atmosphere is concerned, exerted on every side of our bodies, both outside and inside. The air enters our lungs; our blood is therefore always under a somewhat greater pressure than the surface of our bodies. ${ }^{1}$

210. Torricelli's Experiment.-Galileo, who proved that air has weight, observed that a pump in a deep well raised the water only about $32 \mathrm{ft}$. All scientists before him had

1 Blood pressure usually increases with age. With children and young people it usually amounts to about $2 \mathrm{lb}$. to the sq. in. more than atmospheric pressure; with old people it usually amounts to $3 \mathrm{lb}$. or more. In some cases, even in middle life, it amounts to 3 or even $4 \mathrm{lb}$. Usually, abnormally high blood pressure indicates ill health, premature old age, and short life. Life insurance companies and physicians depend largely upon blood pressure to determine the probable length of life and general health of a person. 
taught that "Nature abhors a vacuum." Galileo remarked, when observing the pump, that nature's abhorrence seemed to stop at $32 \mathrm{ft}$. His experiments in search of the explanation were ended by his death in 1642. Torricelli, his pupil, at Galileo's request, continued the investigation. Torricelli concluded that air pressure had something to do with the action of the pump. He remembered that mercury is 13.5 times as heavy as water; he reasoned that if the air pressure raised water $32 \mathrm{ft}$. in the pump, it would raise or support mercury $1 / 13.5$ as high, or about 29 in. He experimented and proved his theory. One of his experiments, first performed in 1643 , is often repeated today.

\section{Exercise 47.-Torricelli's Experiment}

Secure a glass tube about $36 \mathrm{in}$. long, closed at one end. Fill it with mercury, working over a pan to catch spilled mercury. Pour the remaining mercury into a glass or iron cup (Fig. 129). Place your finger firmly over the top of the glass tube and invert the tube carefully, putting the open end into the mercury in the cup. Remove the finger. What happens? There is likely to be considerable air in the mercury column, which quickly rises as bubbles to the surface in the tube. To remove this air; slip your finger over the open end of the tube. Lift the tube from the cup and stand it upright. Add mercury till the tube is full. Invert it again in the cup of mercury. Measure the height of the mercury in the tube above the surface of the mercury in the cup. This should be about 74 or $75 \mathrm{~cm}$., or about 29.9 in. at sea level, becoming less at higher altitude.

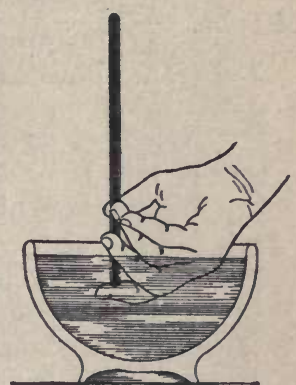

Fig. 129.-Torricelli's experiment. The tube is shortened very much in the illustration.

211. Measuring the Atmospheric Pressure.-The pressure of the air on the surface of the mercury in the cup supports the mercury in the tube. The height of the mercury column thus shows the weight, or pressure, of the air. The Torricelli tube, and the more elaborate barometer, are so often used to measure the atmospheric pressure that we have come to 
speak of the pressure as being so many centimeters or inches, meaning thereby that the atmospheric pressure supports a column of mercury that number of centimeters or inches in height. Another way of expressing the pressure is in pounds per square inch, or in grams per square centimeter.

\section{Exercise 48.-To Measure the Atmospheric Pressure}

Fill a Torricellian tube, getting the mercury free of air. Measure the height of the column; then raise the tube till its open end is just below the surface of mercury in the cup; slip your finger over the open end and raise it from the cup. Being careful not to lose any of the mercury, empty the tube into a beaker. Weigh the beaker and mercury and record the weight. Pour the mercury into a small measuring graduate. Weigh the empty beaker. Record the volume of mercury in the graduate. Now calculate the weight, or downward pressure, of mercury per square centimeter as follows: $\frac{\text { Volume }}{\text { Height }}=$ Area of tube. $\frac{\text { Weight of mercury }}{\text { Area }}=$ Pressure per square unit area.

A student obtained the following results:

Height of mercury.......... $74.6 \mathrm{~cm}$.

Weight of beaker and mercury...... 113.7 grams

Weight of beaker............ 12.2 grams

Therefore, weight of mercury....... 101.5 grams

Volume of mercury............ 7.46 c.c.

By calculation, area of tube....... $0.10 \mathrm{sq} . \mathrm{cm}$.

And, by calculation, pressure per sq. cm.1015 grams

Prove the correctness of his calculations.

At sea level the average atmospheric pressure is about 1030 grams per sq. cm., or about $14.7 \mathrm{lb}$. per sq. in.

1. A schoolroom is $30 \mathrm{ft}$. square and $13 \mathrm{ft}$. high. What is the weight of the air in the room? What is the amount of the air pressure upon the floor of the room? Upon each of its four sides? Upon its ceiling?

2. Measure the dimensions of your schoolroom. Compute the weight of air in it. Compute the pressure upon its floor; upon each of its walls; upon its ceiling. 


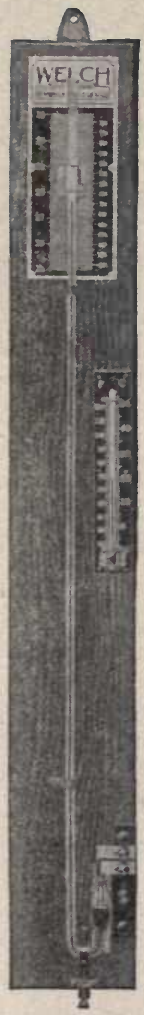

A

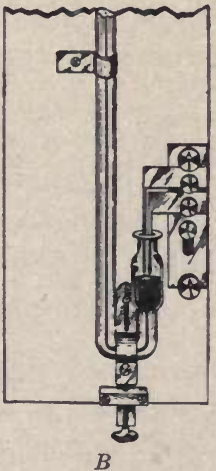

FIG. 130.

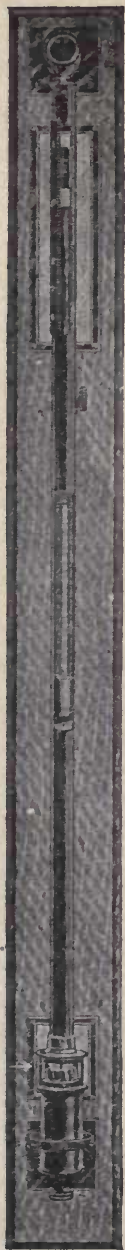

FIG. 131.

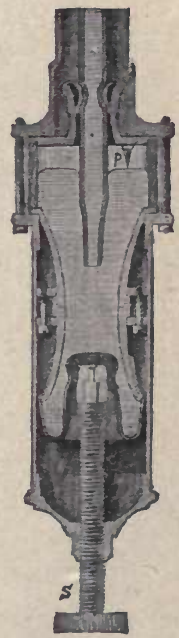

Fig. 132.

FIG. 130.- A. Siphon barometer. B. Device for adjusting the barometer tube so as to bring the surface of mercury in the cistern to the proper height.

Fig. 131.-Fortin's pattern barometer.

Fig. 132.- Sectional view of the cistern of a Fortin's pattern barometer. 
212. The Barometer.-The common mercury barometer is a Torricellian tube, mounted and provided with a scale for reading the height of the mercury column. One type is merely a barometer tube with its lower end bent upward forming a sort of cistern to hold the mercury (Fig. 130). Such an instrument is called a sIPHON barometer, and the cheaper barometers on the market are usually of this pattern.

For use by the United States Weather Bureau and for other accurate scientific work, barometers of FoRTIN's PATTERN (Fig. 131) are employed. In these the tube is straight; the sides of the cistern are metal and glass; the bottom is stout buckskin (Fig. 132), and is supported by a metal plate which can be raised or lowered by a screw. Extending down from the top

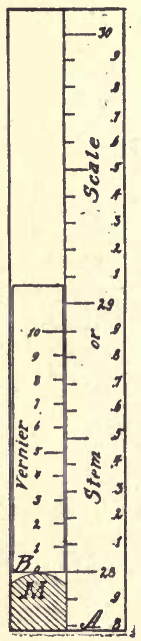

FIG. 133.-

The vernier. of this cistern is an ivory point, $P$. The scale near the top of the barometer is so adjusted that the line " 26 in.," for instance, is exactly 26 in. above the tip of this ivory point.

To read the barometer, first adjust the screw, $s$, at the bottom so that the surface of mercury in the cistern just touches the ivory point. Then read the height of mercury in the column by means of the scale.

213. The Vernier.-In order to read barometers more accurately most instruments are provided with a VERNIER. This enables one to read easily to $1 / 10$ of the smallest division marked on the scale, or to $1 / 100$ in. and $1 / 10 \mathrm{~mm}$.

\section{Exercise 49.-To Construct a Vernier and to Learn Its Use}

Using a stiff sheet of paper and a metric rule, lay off carefully a scale like $A$, Fig. 133,2 or $3 \mathrm{~cm}$. wide and 23 or $24 \mathrm{~cm}$. long. Make each small division exactly $1 \mathrm{~cm}$. long. Let these divisions stand for $1 / 10$ in., and number them as shown in the figure. On a separate sheet lay off the VERNIER SLIDE, "B." Here make each division exactly $9 / 10 \mathrm{~cm}$. long.

Nate how the vernier on a barometer slides up and down on 
the frame through which we see the mercury column. The vernier correctly shows the height of the column when its lower edge is on a level with the highest point of the mercury (" $M$," Fig. 133).

The reading of the barometer in the figure is $28 \mathrm{in.}$ If 1 on the vernier were opposite the next higher tenth (28.1) of the scale, the reading would be 28.01 . Why? If 2 of the vernier were opposite 28.2 , the reading would be 28.02 . Why? If 4 of the vernier were opposite 28.4, the reading would be 28.04 , etc. When this is clear, start with 28.1 of the scale and move the vernier up 1 division at a time in the same manner. For $28.11,1$ of the vernier is opposite the next higher tenth of the scale, which is 28.2 , and so on. Practice until clearly understood.

Using your scale and vernier, fill out the following:

\section{PROBLEMS}

1. When 2 on the vernier is opposite 28.2 on the scale the reading is... 28.02

2. When 6 on the vernier is opposite 28.6 on the scale the reading is... ?

3. When 1 on the vernier is opposite 28.2 on the scale the reading is... 28.11

4. When 3 on the vernier is opposite 28.4 on the scale the reading is... ?

5. When 4 on the vernier is opposite 28.9 on the scale the reading is... 28.54

6. When 1 on the vernier is opposite 29.8 on the scale the reading is... ?

7. When 1 on the vernier is opposite 28.9 on the scale the reading is... ?

8. When 9 on the vernier is opposite 29.1 on the scale the reading is... ?

9. When 6 on the vernier is opposite 29.4 on the scale the reading is... ?

10. When 7 on the vernier is opposite 30.0 on the scale the reading is... ?

11. When 10 on the vernier is opposite 30.0 on the scale the reading is... ?

12. When 9 on the vernier is opposite 29.9 on the scale the reading is... ?

13. When 8 on the vernier is opposite 28.8 on the scale the reading is... ?

The following rule may be followed in reading the barometer to the 1/100 in. by means of the vernier: Read off the number of whole inches and the number of tenths of inches; then running up the vernier, find the line which is just opposite some line on the scale; the number of this line on the vernier gives the number of hundredths of an inch.

\section{Correcting the Barometer Reading for Temperature.-} Since mercury expands when heated (as in thermometers, Art. 15), it follows that if two barometers, one warm and 
Table IX.-Reduction of Barometer Readings to $32^{\circ} \mathrm{F}$. Corrections are to be Subtracted from the Reading of THE BAROMETER

\begin{tabular}{|c|c|c|c|c|c|c|c|c|c|c|c|c|c|c|c|}
\hline 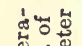 & & & & & & 3огот & neter & rodi & in & nche & & & & & \\
\hline Е马อ & 24.0 & 24.5 & 25.0 & 25.5 & 26.0 & 26.5 & 27.0 & 27.5 & 28.0 & 28.5 & 29.0 & 29.5 & 30.0 & 30.5 & 31.0 \\
\hline $\begin{array}{l}50 \\
51 \\
52 \\
53 \\
54\end{array}$ & $\begin{array}{l}.05 \\
.05 \\
.05 \\
.05 \\
.05\end{array}$ & $\begin{array}{l}.05 \\
.05 \\
.05 \\
.05 \\
.06\end{array}$ & $\begin{array}{l}.05 \\
.05 \\
.05 \\
.05 \\
.06\end{array}$ & $\begin{array}{l}.05 \\
.05 \\
.05 \\
.06 \\
.06\end{array}$ & $\begin{array}{l}.05 \\
.05 \\
.05 \\
.06 \\
.06\end{array}$ & $\begin{array}{l}.05 \\
.05 \\
.06 \\
.06 \\
.06\end{array}$ & $\begin{array}{l}.05 \\
.05 \\
.06 \\
.06 \\
.06\end{array}$ & $\begin{array}{l}.05 \\
.06 \\
.06 \\
.06 \\
.06\end{array}$ & $\begin{array}{l}.05 \\
.06 \\
.06 \\
.06 \\
.06\end{array}$ & $\begin{array}{l}.05 \\
.06 \\
.06 \\
.06 \\
.06\end{array}$ & $\begin{array}{l}.06 \\
.06 \\
.06 \\
.06 \\
.07\end{array}$ & $\begin{array}{l}.06 \\
.06 \\
.06 \\
.06 \\
.07\end{array}$ & $\begin{array}{l}.06 \\
.06 \\
.06 \\
.07 \\
.07\end{array}$ & $\begin{array}{l}.06 \\
.06 \\
.06 \\
.07 \\
.07\end{array}$ & $\begin{array}{l}.06 \\
.06 \\
.07 \\
.07 \\
.07\end{array}$ \\
\hline $\begin{array}{l}55 \\
56 \\
57 \\
58 \\
59\end{array}$ & $\begin{array}{l}.06 \\
.06 \\
.06 \\
.06 \\
.07\end{array}$ & $\begin{array}{l}.06 \\
.06 \\
.06 \\
.06 \\
.07\end{array}$ & $\begin{array}{l}.06 \\
.06 \\
.06 \\
.07 \\
.07\end{array}$ & $\begin{array}{l}.06 \\
.06 \\
.06 \\
.07 \\
.07\end{array}$ & $\begin{array}{l}.06 \\
.06 \\
.07 \\
.07 \\
.07\end{array}$ & $\begin{array}{l}.06 \\
.06 \\
.07 \\
.07 \\
.07\end{array}$ & $\begin{array}{l}.06 \\
.07 \\
.07 \\
.07 \\
.07\end{array}$ & $\begin{array}{l}.06 \\
.07 \\
.07 \\
.07 \\
.07\end{array}$ & $\begin{array}{l}.07 \\
.07 \\
.07 \\
.07 \\
.08\end{array}$ & $\begin{array}{l}.07 \\
.07 \\
.07 \\
.08 \\
.08\end{array}$ & $\begin{array}{l}.07 \\
.07 \\
.07 \\
.08 \\
.08\end{array}$ & $\begin{array}{l}.07 \\
.07 \\
.08 \\
.08 \\
.08\end{array}$ & $\begin{array}{l}.07 \\
.07 \\
.08 \\
.08 \\
.08\end{array}$ & $\begin{array}{l}.07 \\
.07 \\
.08 \\
.08 \\
.08\end{array}$ & $\begin{array}{l}.07 \\
.08 \\
.08 \\
.08 \\
.08\end{array}$ \\
\hline $\begin{array}{l}60 \\
61 \\
62 \\
63 \\
64\end{array}$ & $\begin{array}{l}.07 \\
.07 \\
.07 \\
.07 \\
.08\end{array}$ & $\begin{array}{l}.07 \\
.07 \\
.07 \\
.08 \\
.08\end{array}$ & $\begin{array}{l}.07 \\
.07 \\
.08 \\
.08 \\
.08\end{array}$ & $\begin{array}{l}.07 \\
.07 \\
.08 \\
.08 \\
.08\end{array}$ & $\begin{array}{l}.07 \\
.08 \\
.08 \\
.08 \\
.08\end{array}$ & $\begin{array}{l}.08 \\
.08 \\
.08 \\
.08 \\
.08\end{array}$ & $\begin{array}{l}.08 \\
.08 \\
.08 \\
.08 \\
.09\end{array}$ & $\begin{array}{l}.08 \\
.08 \\
.08 \\
.08 \\
.09\end{array}$ & $\begin{array}{l}.08 \\
.08 \\
.08 \\
.09 \\
.09\end{array}$ & $\begin{array}{l}.08 \\
.08 \\
.09 \\
.09 \\
.09\end{array}$ & $\begin{array}{l}.08 \\
.08 \\
.09 \\
.09 \\
.09\end{array}$ & $\begin{array}{l}.08 \\
.09 \\
.09 \\
.09 \\
.09\end{array}$ & $\begin{array}{l}.08 \\
.09 \\
.09 \\
.09 \\
.10\end{array}$ & $\begin{array}{l}.09 \\
.09 \\
.09 \\
.09 \\
.10\end{array}$ & $\begin{array}{l}.09 \\
.09 \\
.09 \\
.09 \\
.10\end{array}$ \\
\hline $\begin{array}{l}65 \\
66 \\
67 \\
68 \\
69\end{array}$ & $\begin{array}{l}.08 \\
.08 \\
.08 \\
.08 \\
.09\end{array}$ & $\begin{array}{l}.08 \\
.08 \\
.08 \\
.09 \\
.09\end{array}$ & $\begin{array}{l}.08 \\
.08 \\
.09 \\
-09 \\
.09\end{array}$ & $\begin{array}{l}.08 \\
.09 \\
.09 \\
.09 \\
.09\end{array}$ & $\begin{array}{l}.09 \\
.09 \\
.09 \\
.09 \\
.09\end{array}$ & $\begin{array}{l}.09 \\
.09 \\
.09 \\
.09 \\
.10\end{array}$ & $\begin{array}{l}.09 \\
.09 \\
.09 \\
.10 \\
.10\end{array}$ & $\begin{array}{l}.09 \\
.09 \\
.09 \\
.10 \\
.10\end{array}$ & $\begin{array}{l}.09 \\
.09 \\
.10 \\
.10 \\
.10\end{array}$ & $\begin{array}{l}.09 \\
.10 \\
.10 \\
.10 \\
.10\end{array}$ & $\begin{array}{l}.09 \\
.10 \\
.10 \\
.10 \\
.11\end{array}$ & $\begin{array}{l}.10 \\
.10 \\
.10 \\
.10 \\
.11\end{array}$ & $\begin{array}{l}.10 \\
.10 \\
.10 \\
.11 \\
.11\end{array}$ & $\begin{array}{l}.10 \\
.10 \\
.11 \\
.11 \\
.11\end{array}$ & $\begin{array}{l}.10 \\
.10 \\
.11 \\
.11 \\
.11\end{array}$ \\
\hline $\begin{array}{l}70 \\
71 \\
72 \\
73 \\
74\end{array}$ & $\begin{array}{l}.09 \\
.09 \\
.09 \\
.10 \\
.10\end{array}$ & $\begin{array}{l}.09 \\
.09 \\
.10 \\
.10 \\
.10\end{array}$ & $\begin{array}{l}.09 \\
.10 \\
.10 \\
.10 \\
.10\end{array}$ & $\begin{array}{l}.10 \\
.10 \\
.10 \\
.10 \\
.10\end{array}$ & $\begin{array}{l}.10 \\
.10 \\
.10 \\
.10 \\
.11\end{array}$ & $\begin{array}{l}.10 \\
.10 \\
.10 \\
.11 \\
.11\end{array}$ & $\begin{array}{l}.10 \\
.10 \\
.11 \\
.11 \\
.11\end{array}$ & $\begin{array}{l}.10 \\
.10 \\
.11 \\
.11 \\
.11\end{array}$ & $\begin{array}{l}.10 \\
.11 \\
.11 \\
.11 \\
.11\end{array}$ & $\begin{array}{l}.11 \\
.11 \\
.11 \\
.11 \\
.12\end{array}$ & $\begin{array}{l}.11 \\
.11 \\
.11 \\
.12 \\
.12\end{array}$ & $\begin{array}{l}.11 \\
.11 \\
.12 \\
.12 \\
.12\end{array}$ & $\begin{array}{l}.11 \\
.11 \\
.12 \\
.12 \\
.12\end{array}$ & $\begin{array}{l}.11 \\
.12 \\
.12 \\
.12 \\
.12\end{array}$ & $\begin{array}{l}.12 \\
.12 \\
.12 \\
.12 \\
.13\end{array}$ \\
\hline $\begin{array}{l}75 \\
76 \\
77 \\
78 \\
79\end{array}$ & $\begin{array}{l}.10 \\
.10 \\
.10 \\
.11 \\
.11\end{array}$ & $\begin{array}{l}.10 \\
.10 \\
.11 \\
.11 \\
.11\end{array}$ & $\begin{array}{l}.10 \\
.11 \\
.11 \\
.11 \\
.11\end{array}$ & $\begin{array}{l}.11 \\
.11 \\
.11 \\
.11 \\
.12\end{array}$ & $\begin{array}{l}.11 \\
.11 \\
.11 \\
.12 \\
.12\end{array}$ & $\begin{array}{l}.11 \\
.11 \\
.12 \\
.12 \\
.12\end{array}$ & $\begin{array}{l}.11 \\
.12 \\
.12 \\
.12 \\
.12\end{array}$ & $\begin{array}{l}.12 \\
.12 \\
.12 \\
.12 \\
.12\end{array}$ & $\begin{array}{l}.12 \\
.12 \\
.12 \\
.12 \\
.13\end{array}$ & $\begin{array}{l}.12 \\
.12 \\
.12 \\
.13 \\
.13\end{array}$ & $\begin{array}{l}.12 \\
.12 \\
.13 \\
.13 \\
.13\end{array}$ & $\begin{array}{l}.12 \\
.13 \\
.13 \\
.13 \\
.13\end{array}$ & $\begin{array}{l}.13 \\
.13 \\
.13 \\
.13 \\
.14\end{array}$ & $\begin{array}{l}.13 \\
.13 \\
.13 \\
.14 \\
.14\end{array}$ & $\begin{array}{l}.13 \\
.13 \\
.14 \\
.14 \\
.14\end{array}$ \\
\hline $\begin{array}{l}80 \\
81 \\
82 \\
83 \\
84\end{array}$ & $\begin{array}{l}.11 \\
.11 \\
.12 \\
.12 \\
.12\end{array}$ & $\begin{array}{l}.11 \\
.12 \\
.12 \\
.12 \\
.12\end{array}$ & $\begin{array}{l}.12 \\
.12 \\
.12 \\
.12 \\
.12\end{array}$ & $\begin{array}{l}.12 \\
.12 \\
.12 \\
.12 \\
.13\end{array}$ & $\begin{array}{l}.12 \\
.12 \\
.12 \\
.13 \\
.13\end{array}$ & $\begin{array}{l}.12 \\
.12 \\
.13 \\
.13 \\
.13\end{array}$ & $\begin{array}{l}.12 \\
.13 \\
.13 \\
.13 \\
.13\end{array}$ & $\begin{array}{l}.13 \\
.13 \\
.13 \\
.13 \\
.14\end{array}$ & $\begin{array}{l}.13 \\
.13 \\
.13 \\
.14 \\
.14\end{array}$ & $\begin{array}{l}.13 \\
.13 \\
.14 \\
.14 \\
.14\end{array}$ & $\begin{array}{l}.13 \\
.14 \\
.14 \\
.14 \\
.14\end{array}$ & $\begin{array}{l}.14 \\
.14 \\
.14 \\
.14 \\
.15\end{array}$ & $\begin{array}{l}.14 \\
.14 \\
.14 \\
.15 \\
.15\end{array}$ & $\begin{array}{l}.14 \\
.14 \\
.15 \\
.15 \\
.15\end{array}$ & $\begin{array}{l}.14 \\
.15 \\
.15 \\
.15 \\
.15\end{array}$ \\
\hline $\begin{array}{l}85 \\
86 \\
87 \\
88 \\
89\end{array}$ & $\begin{array}{l}.12 \\
.12 \\
.13 \\
.13 \\
.13\end{array}$ & $\begin{array}{l}.12 \\
.13 \\
.13 \\
.13 \\
.13\end{array}$ & $\begin{array}{l}.13 \\
.13 \\
.13 \\
.13 \\
.14\end{array}$ & $\begin{array}{l}.13 \\
.13 \\
.13 \\
.14 \\
.14\end{array}$ & $\begin{array}{l}.13 \\
.13 \\
.14 \\
.14 \\
.14\end{array}$ & \begin{tabular}{l}
.13 \\
.14 \\
\hdashline 14 \\
.14 \\
.14
\end{tabular} & $\begin{array}{l}.14 \\
.14 \\
.14 \\
.14 \\
.15\end{array}$ & $\begin{array}{l}.14 \\
.14 \\
.14 \\
.15 \\
.15\end{array}$ & $\begin{array}{l}.14 \\
.14 \\
.15 \\
.15 \\
.15\end{array}$ & $\begin{array}{l}.14 \\
.15 \\
.15 \\
.15 \\
.15\end{array}$ & $\begin{array}{l}.15 \\
.15 \\
.15 \\
.15 \\
.16\end{array}$ & $\begin{array}{l}.15 \\
.15 \\
.15 \\
.16 \\
.16\end{array}$ & $\begin{array}{l}.15 \\
.15 \\
.16 \\
.16 \\
.16\end{array}$ & $\begin{array}{l}.15 \\
.16 \\
.16 \\
.16 \\
.17\end{array}$ & $\begin{array}{l}.16 \\
.16 \\
.16 \\
.17 \\
.17\end{array}$ \\
\hline $\begin{array}{l}90 \\
91 \\
92 \\
93 \\
94\end{array}$ & $\begin{array}{l}.13 \\
.13 \\
.14 \\
.14 \\
.14\end{array}$ & $\begin{array}{l}.14 \\
.14 \\
.14 \\
.14 \\
.14\end{array}$ & $\begin{array}{l}.14 \\
.14 \\
.14 \\
.14 \\
.15\end{array}$ & $\begin{array}{l}.14 \\
.14 \\
.15 \\
.15 \\
.15\end{array}$ & $\begin{array}{l}.14 \\
.15 \\
.15 \\
.15 \\
.15\end{array}$ & $\begin{array}{l}.15 \\
.15 \\
.15 \\
.15 \\
.16\end{array}$ & $\begin{array}{l}.15 \\
.15 \\
.15 \\
.16 \\
.16\end{array}$ & $\begin{array}{l}.15 \\
.15 \\
.16 \\
.16 \\
.16\end{array}$ & $\begin{array}{l}.15 \\
.16 \\
.16 \\
.16 \\
.16\end{array}$ & $\begin{array}{l}.16 \\
.16 \\
.16 \\
.17 \\
.17\end{array}$ & $\begin{array}{l}.16 \\
.16 \\
.17 \\
.17 \\
.17\end{array}$ & $\begin{array}{l}.16 \\
.17 \\
.17 \\
.17 \\
.17\end{array}$ & $\begin{array}{l}.17 \\
.17 \\
.17 \\
.17 \\
.18\end{array}$ & $\begin{array}{l}.17 \\
.17 \\
.17 \\
.18 \\
.18\end{array}$ & $\begin{array}{l}.17 \\
.17 \\
.18 \\
.18 \\
.18\end{array}$ \\
\hline $\begin{array}{l}95 \\
96 \\
97 \\
98 \\
99\end{array}$ & $\begin{array}{l}.14 \\
.15 \\
.15 \\
.15 \\
.15\end{array}$ & $\begin{array}{l}.15 \\
.15 \\
.15 \\
.15 \\
.15\end{array}$ & $\begin{array}{l}.15 \\
.15 \\
.15 \\
.16 \\
.16\end{array}$ & $\begin{array}{l}.15 \\
.15 \\
.16 \\
.16 \\
.16\end{array}$ & $\begin{array}{l}.16 \\
.16 \\
.16 \\
.16 \\
.16\end{array}$ & $\begin{array}{l}.16 \\
.16 \\
.16 \\
.17 \\
.17\end{array}$ & $\begin{array}{l}.16 \\
.16 \\
.17 \\
.17 \\
.17\end{array}$ & $\begin{array}{l}.16 \\
.17 \\
.17 \\
.17 \\
.17\end{array}$ & $\begin{array}{l}.17 \\
.17 \\
.17 \\
.17 \\
.18\end{array}$ & $\begin{array}{l}.17 \\
.17 \\
.18 \\
.18 \\
.18\end{array}$ & $\begin{array}{l}.17 \\
.18 \\
.18 \\
.18 \\
.18\end{array}$ & $\begin{array}{l}.18 \\
.18 \\
.18 \\
.18 \\
.19\end{array}$ & $\begin{array}{l}.18 \\
.18 \\
.18 \\
.19 \\
.19\end{array}$ & $\begin{array}{l}.18 \\
.18 \\
.19 \\
.19 \\
.19\end{array}$ & $\begin{array}{l}.19 \\
.19 \\
.19 \\
.19 \\
.20\end{array}$ \\
\hline 100 & .15 & .16 & .16 & .16 & .17 & .17 & .17 & .18 & .18 & .18 & .19 & .19 & .19 & .20 & .20 \\
\hline
\end{tabular}


the other cold, are placed side by side where the air pressure is exactly the same on each, the warm barometer will read the higher, simply because its mercury is warmer. And, with the same air pressure, any barometer will read higher on warm days than on cold days. Therefore, in order to compare the pressure on different days the barometer must always be kept at the same temperature, or its reading must be corrected for different temperatures. Also, in order to compare the pressures at different places all the barometers used must be kept at the same temperature, or else the barometer readings must be corrected for temperature. It is much easier to correct the readings. This is done by subtracting the proper amount for any temperature above $281 / 2{ }^{\circ} \mathrm{F}$. Table IX gives the temperature corrections used by the U. S. Weather Bureau.

215. Correcting the Barometer for Altitude.-Since the barometer shows the weight, or pressure, of the air, it is evident that the higher we go up a mountain, or ascend in a balloon, the less air there is above to press upon the barometer and the lower the barometer will read. This fact was discovered soon after Galileo found that air has weight. Pascal, a Frenchman, heard of Torricelli's experiment in 1644. After several years of experimenting, Pascal concluded that the mercury in the tube would stand lower on a mountain top than at its base. He carried a tube to the top of a high tower and noticed a slight drop in the mercury column. He then asked his brother-in-law, who lived near the Puy de Dôme, a mountain in southern France, to carry a barometer to the summit of

Directions for Using TABle IX.-Notice that the table has a column for each half inch of the barometer from 24 to 31 in. At the left side is a temperature column. If the barometer reads 29.42 in. and its attached thermometer reads $68^{\circ}$, find the barometer column with heading nearest to 29.42 (in this case the 29.5 column); then follow that column down to the horizontal line running across from " $68^{\circ}$." Where that line crosses the barometer column you find " 0.10 ." This means that $0.10 \mathrm{in}$. must be subtracted from the barometer reading as a correction for temperature. The corrected reading is therefore 29.32 in, 
the mountain. This Perier did on September 19, 1648, and Pascal's theory was confirmed (Fig. 134).

The barometer is used in studying the weather. The weather stations of the United States are at many different elevations. Barometer readings at sea level are ordinarily about 30 in.; at the altitude of Chicago, about 29.4 in.; at Denver, about 23 in.; and at the top of Pike's Peak, about 15 in. Scarcely any two weather stations have the same elevation. Therefore, in order to compare barometer readings with those of other weather observers, all readings must be

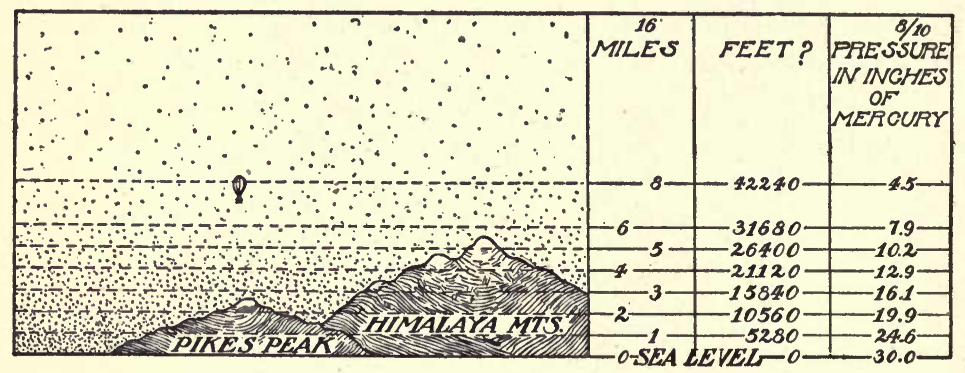

FIG. 134.-Atmospheric pressure varies with altitude.

corrected for altitude as well as for temperature. In doing this it is customary to change all readings to what they would have been if the barometer had been at sea level. These corrections are easily obtained from Table X.

Directions for Using TABLE X.-The proper correction is found from Table $\mathrm{X}$ in a manner similar to that followed in using Table IX. This correction, however, is added to the barometer reading.

Note.- Extensive tables for the correction of barometers for any altitude from the sea level up to several thousand feet have been prepared. It is intended that the teacher or student wishing to use this book at an altitude not given in this table shall ascertain the corrections necessary at the required altitude and the various temperatures by applying to some nearby weather station, and record them on the line marked X. 
Table X.-Reduction of Barometer Readings to Sea Level Corrections are to be Added to the Reading of the Barometer

\begin{tabular}{|c|c|c|c|c|c|c|c|c|c|c|c|c|c|}
\hline \multirow{2}{*}{ 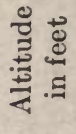 } & \multicolumn{13}{|c|}{ Temperature of outdoor air in degrees Fahrenheit } \\
\hline & $\overline{20^{\circ}}$ & $\overline{10^{\circ}}$ & $0^{\circ}$ & $10^{\circ}$ & $20^{\circ}$ & $30^{\circ}$ & $\circ$ & $0^{\circ}$ & $60^{\circ}$ & $0^{\circ}$ & $0^{\circ}$ & $90^{\circ}$ & 1 \\
\hline 20 & .03 & .03 & .03 & .02 & .02 & .02 & .02 & .02 & .02 & .02 & .02 & .02 & 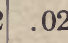 \\
\hline 40 & .05 & .05 & .05 & & & & .05 & & .04 & & & & \\
\hline 60 & .08 & .08 & .07 & & .07 & .07 & .07 & .07 & & & & & \\
\hline 80 & .10 & .10 & .10 & 0 & & & & & & & & & \\
\hline 100 & .13 & .13 & .12 & .12 & .12 & .12 & .11 & .11 & .11 & .11 & .20 & .10 & \\
\hline 120 & .1 & .15 & .15 & & & & .13 & .13 & .13 & & .12 & .12 & \\
\hline 140 & .18 & & .17 & & & .16 & .16 & .15 & .15 & .15 & .14 & .14 & - \\
\hline 160 & .21 & .20 & .20 & .19 & .19 & .18 & .18 & .18 & .17 & .17 & .17 & .16 & .1 \\
\hline 180 & .23 & .23 & .22 & .22 & .21 & .21 & .20 & .20 & .19 & '. 19 & .18 & .18 & .1 \\
\hline 200 & .26 & .25 & .25 & .24 & .23 & .23 & .22 & .22 & .22 & .21 & .21 & & .2 \\
\hline 220 & .28 & .28 & .27 & .26 & .26 & .25 & .25 & .24 & & & & & \\
\hline 240 & .31 & .30 & .30 & .29 & .28 & .27 & .27 & .26 & .26 & .25 & .25 & 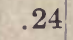 & \\
\hline 260 & .3 & & .32 & .31 & .30 & .30 & .29 & .29 & & & & & \\
\hline 2 & .3 & & .34 & & & .32 & & & 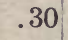 & & & & \\
\hline 3 & .39 & & .37 & & .35 & & .34 & 3 & 2 & .32 & 31 & 0 & 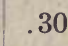 \\
\hline 3 & .41 & 40 & .39 & 8 & 7 & 7 & .36 & .35 & 34 & .34 & .3 & .32 & 3 \\
\hline 3 & .44 & 4 & .42 & .41 & .40 & . 39 & .38 & .37 & .36 & .36 & .3 & .34 & 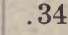 \\
\hline & .46 & .4 & .44 & .43 & .42 & .41 & .40 & .39 & .39 & .38 & .3 & .36 & .3 \\
\hline 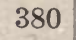 & .49 & .4 & .46 & .45 & .44 & .43 & .42 & .42 & .41 & .40 & .39 & .00 & .37 \\
\hline 400 & .51 & .5 & .49 & & .47 & .46 & .45 & .44 & .43 & .42 & .4 & .40 & .3 \\
\hline 42 & .5 & .5 & .5 & .50 & .49 & .48 & .47 & .46 & .45 & .44 & .4 & .42 & .4 \\
\hline 4 & .5 & .5 & .5 & & & .50 & .49 & .48 & .47 & .4 & .4 & .44 & .4 \\
\hline 4 & .59 & & .5 & & 4 & .53 & .51 & 50 & .49 & .48 & .47 & .46 & .4 \\
\hline & .62 & .6 & .59 & & .56 & .55 & .54 & .52 & .51 & .50 & .49 & .48 & 4 \\
\hline 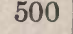 & .64 & .62 & .61 & .60 & .58 & .57 & .56 & .55 & .53 & .52 & .51 & .50 & 4 \\
\hline 520 & .67 & .65 & .63 & .62 & .61 & .59 & .58 & .57 & .56 & .54 & .53 & .52 & .5 \\
\hline 5 & .69 & .6 & .66 & .64 & .63 & .61 & .60 & .59 & .58 & .56 & .55 & .54 & .5 \\
\hline 56 & .7 & .7 & .68 & & & & & & .60 & .59 & .57 & & .5 \\
\hline & .7 & .7 & .7 & & .0 & .00 & .05 & .03 & .62 & .61 & .59 & .58 & .57 \\
\hline & .7 & .7 & .7 & .71 & .70 & .68 & .67 & .65 & .64 & .63 & .61 & .60 & .5 \\
\hline & .79 & .77 & .7 & .74 & .72 & .70 & .69 & .67 & .66 & .65 & .63 & .62 & 6 \\
\hline 640 & .82 & .80 & .78 & .76 & .74 & .73 & .71 & .70 & .68 & .67 & .65 & .64 & 6. \\
\hline 660 & .84 & .82 & .80 & .78 & .77 & .75 & .73 & .72 & .70 & .69 & .68 & .66 & 65 \\
\hline 680 & .87 & .85 & .83 & .81 & .79 & .77 & .76 & .74 & .72 & .71 & .70 & .68 & 67 \\
\hline 700 & .89 & .87 & .85 & .83 & .81 & .79 & .78 & .76 & .75 & .73 & .72 & .70 & .69 \\
\hline
\end{tabular}




\begin{tabular}{|c|c|c|c|c|c|c|c|c|c|c|c|c|c|}
\hline \multirow{2}{*}{ 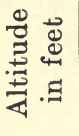 } & \multicolumn{13}{|c|}{ Temperature of outdoor air in degrees Fahrenheit } \\
\hline & $\overline{20}$ & $\overline{10^{\circ}}$ & $0^{\circ}$ & $10^{\circ}$ & $20^{\circ}$ & $30^{\circ}$ & $40^{\circ}$ & $50^{\circ}$ & $60^{\circ}$ & $70^{\circ}$ & $80^{\circ}$ & $90^{\circ}$ & $100^{\circ}$ \\
\hline 720 & .92 & .90 & .88 & .86 & .84 & 82 & .80 & .78 & .77 & .75 & .74 & .72 & .7 \\
\hline 740 & .94 & .92 & .90 & .88 & .86 & .84 & .82 & .80 & .79 & .77 & .76 & .74 & .73 \\
\hline 760 & .97 & .95 & .92 & .90 & .88 & .86 & .84 & .82 & .81 & .79 & .78 & .76 & .75 \\
\hline 780 & .99 & .97 & .95 & .93 & .90 & .88 & .86 & .85 & .83 & .81 & .80 & .78 & .77 \\
\hline 800 & 1.02 & .99 & .97 & .95 & .93 & .91 & .89 & .87 & .85 & .83 & .82 & .80 & .79 \\
\hline 820 & 1.04 & 1.02 & .99 & .97 & .95 & .93 & .91 & .89 & .87 & .85 & .84 & .82 & .80 \\
\hline 840 & .07 & 1.04 & 1.02 & .99 & .97 & .95 & .93 & .91 & .89 & .87 & .86 & .84 & .82 \\
\hline 860 & .09 & 1.07 & 1.04 & 1.02 & .99 & .97 & .95 & .93 & .91 & .89 & .88 & .86 & .84 \\
\hline 880 & .12 & 1.09 & & & 1.02 & 1.00 & .97 & .95 & .93 & .91 & .90 & .88 & .86 \\
\hline 900 & .14 & 1.12 & & & 1.04 & 1.02 & 1.00 & .97 & .95 & .94 & .92 & .90 & .88 \\
\hline 920 & .17 & 1.14 & & 1.09 & 1.06 & 1.04 & 1.02 & 1.00 & .98 & .96 & .94 & .92 & .90 \\
\hline 940 & .19 & & & & 1.09 & & & & 1.00 & .98 & .96 & .94 & .92 \\
\hline 960 & .22 & 1.19 & & & 1.11 & & & & 1.02 & 1.00 & .98 & .96 & .94 \\
\hline 980 & .24 & 1.21 & & & 1.13 & & 1.08 & & 1.04 & 1.02 & 1.00 & .98 & .96 \\
\hline 1000 & .27 & 1.24 & 1.21 & 1. & 1.15 & & 1. & & 1.06 & 1.04 & 1.02 & 1.00 & .98 \\
\hline 1020 & .29 & 1.26 & 1. & 1.20 & 1.18 & 1.15 & 1.13 & 1.10 & 1.08 & 1.06 & 1.04 & 1.02 & 1.00 \\
\hline 1040 & .32 & 1.29 & 1.26 & 1.23 & 1.20 & 1.17 & 1.15 & 1.12 & 1.10 & 1.08 & 1.06 & 1.04 & 1.02 \\
\hline 1060 & .34 & 1.31 & 1.28 & 1.25 & 1.22 & 1.19 & 1.17 & 5 & 1.12 & 1 & & 06 & 1.04 \\
\hline 1080 & .37 & 1.33 & 1.30 & 1.27 & 1.24 & 1.22 & 1.19 & 1.17 & 1. & 1 & 1. & 1. & 1.06 \\
\hline 1100 & .39 & & & 1. & 1.27 & 1.24 & 1.21 & 1.19 & 1.16 & 1 & 1. & 1 & 1.07 \\
\hline 1120 & .42 & & & & 1.29 & & 1.23 & 1.21 & 1.18 & & & 1 & 1.09 \\
\hline 11 & .44 & & 1. & & & & & 1.23 & 1.20 & & & 1.14 & 1.11 \\
\hline 11 & .46 & & 1. & & & & & 1.25 & 1.22 & 1.20 & & 1 & 1.13 \\
\hline 1 & .49 & 1. & & & 1. & & 1 . & 1.27 & 1.24 & 1.22 & 1.20 & 17 & 1.15 \\
\hline 1200 & .51 & 1.48 & 1.44 & 1.41 & 1.38 & 1. & 1.32 & 1.29 & 1.27 & 1.24 & 1.22 & 1. 19 & 1.17 \\
\hline 1220 & .54 & 1.50 & 1.47 & 1.43 & 1.40 & 1.37 & 1.34 & 1.31 & 1.29 & 1.26 & 1.24 & 1.21 & 1.19 \\
\hline 1240 & .56 & 1.53 & 1.49 & 1.46 & 1 . & 1. & 1.36 & 1.33 & 1. & 1.28 & 1.26 & 1.23 & 1.21 \\
\hline 1260 & . & 1. & 1. & 1. & 1.45 & 1. & 1.39 & 1.36 & 1.33 & 1.30 & 1.28 & 1.25 & 1.23 \\
\hline 1280 & .61 & 1.57 & 1. & 1. & 1.47 & 1. & 1.41 & 1.38 & 1. & 1.32 & 1.30 & 1.27 & 1.25 \\
\hline & .64 & 1.60 & 1. & & 1.49 & 1. & & 1.40 & 1. & 1.34 & 1.32 & 1.29 & 1.27 \\
\hline 1320 & & 1.62 & 1. & & 1.51 & & & & 1. & 1.36 & 1.34 & 1.31 & 1.29 \\
\hline 1340 & .69 & 1.6 & 1. & 1.57 & 1.54 & 1. & 1. & 1. & 1.41 & 1.38 & 1.36 & 1.33 & 1.30 \\
\hline 1360 & .71 & 1.67 & 1. & 1.60 & 1.56 & 1.52 & 1.49 & 1.46 & 1.43 & 1.40 & 1.38 & 1.35 & 1.32 \\
\hline 1380 & .74 & 1. 69 & 1. & 1.62 & 1.58 & 1.55 & 1.51 & 1.48 & 1.45 & 1.42 & 1.40 & 1.37 & 1.3 \\
\hline 1400 & .76 & 1.72 & 1.68 & 1.64 & 1.60 & 1.57 & 1.54 & 1.50 & 1.47 & 1.44 & 1.42 & 1.39 & 1.36 \\
\hline 1420 & .78 & 1.74 & 1.70 & 1.66 & 1.63 & 1.59 & 1.56 & 1.52 & 1.49 & 1.46 & 1.43 & 1.41 & 1.38 \\
\hline 1440 & 1.81 & 1.77 & 1.72 & 1.68 & 1.65 & 1.61 & 1.58 & 1.55 & 1.51 & 1.48 & 1.45 & 1.43 & 1.40 \\
\hline 1460 & 1. 83 & 1.79 & 1.75 & 1.71 & 1.67 & 1.63 & 1.60 & 1.56 & 1.53 & 1.50 & 1.47 & 1.45 & 1.42 \\
\hline 1480 & 1.86 & 1.81 & 1.77 & 1.73 & 1.69 & 1.66 & 1.62 & 1.59 & 1.55 & 1.52 & 1.49 & 1.46 & 1.44 \\
\hline 1500 & 1.88 & 1.84 & 1.79 & 1.75 & 1.71 & 1.68 & 1.64 & 1.61 & 1.57 & 1.54 & 1.51 & 1.48 & 1.46 \\
\hline$v$ & & & & & & & & & & & & & \\
\hline
\end{tabular}


The corrected barometer readings everywhere in the United States will be exactly alike unless there are differences in the actual pressure of the atmosphere over different regions. Differences in atmospheric pressure are not noticeable as are differences in temperature or cloudiness or wind. They could not be known if we had no barometers. But these differences in pressure cause most of the weather changes that occur. And when the corrected barometer readings differ, they show on the weather map where storms or fair weather areas are, and so enable the Weather Bureau to make forecasts of coming weather. Barometers, used in that way, are therefore the most important of weather instruments.

\section{PROBLEMS}

Find the corrected barometer reading from the following data:

\begin{tabular}{r|c|c|c|r|r|c|c}
\hline & $\begin{array}{c}\text { Bar.read., } \\
\text { in. }\end{array}$ & $\begin{array}{c}\text { Temp. } \\
\text { of mer., } \\
\text { oF. }\end{array}$ & $\begin{array}{c}\text { Correction } \\
\text { for temp., } \\
\text { in. }\end{array}$ & $\begin{array}{c}\text { Outdoor } \\
\text { temp., }\end{array}$ & $\begin{array}{c}\text { Altitude, } \\
\text { ft. }\end{array}$ & $\begin{array}{c}\text { Correction } \\
\text { for altitude, } \\
\text { in. }\end{array}$ & $\begin{array}{c}\text { Corrected } \\
\text { read., in. }\end{array}$ \\
\hline 1 & 29.00 & 70 & .11 & 10 & 800 & .95 & 29.84 \\
2 & 28.00 & 60 & .08 & 60 & .850 & $? 90$ & 28.82 \\
3 & 25.50 & 95 & $?$ & -10 & 1230 & $?$ & $?$ \\
4 & 26.30 & 50 & $?$ & 100 & 1335 & $?$ & $?$ \\
5 & 26.66 & 62 & $?$ & -20 & 1233 & $?$ & $?$ \\
6 & 28.75 & 89 & $?$ & 55 & 802 & $?$ & $?$ \\
7 & 29.15 & 50 & $?$ & 40 & 20 & $?$ & $?$ \\
8 & 30.05 & 100 & $?$ & 35 & 50 & $?$ & $?$ \\
9 & 27.50 & 90 & $?$ & 90 & 1500 & $?$ & $?$ \\
10 & 27.40 & 60 & $?$ & 40 & 1000 & $?$ & $?$ \\
11 & 29.10 & 80 & $?$ & 80 & 215 & $?$ & $?$ \\
\hline
\end{tabular}

216. The Barograph.- In the barograph, the record paper is wrapped around a brass cylinder that is turned by an eightday clock. The barometer portion consists of a series of six or eight hollow elastic shells shaped like a canteen or two saucers turned top to top (Fig. 135). These shells are made of corrugated metal and the air has been exhausted from them. They are soldered together one above the other. It is easily seen that the atmospheric pressure tends to crush 
them together as it would an empty bellows. But that is prevented by coiled springs within the shells which keep them more or less distended. The elasticity of the springs is practically constant, therefore, the gradual fluctuations in atmospheric pressure change the compression of these sections and result in a slow, up-and-down movement of the top of the set. This movement is transmitted by the levers to the pen which writes them on the record sheet on the revolving cylinder. In most barographs, the cylinder turns once round in a week, and each sheet holds a week's record. ${ }^{1}$

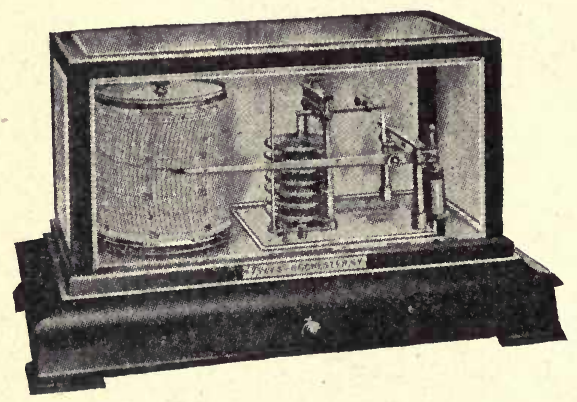

FIG. 135.-The barograph.
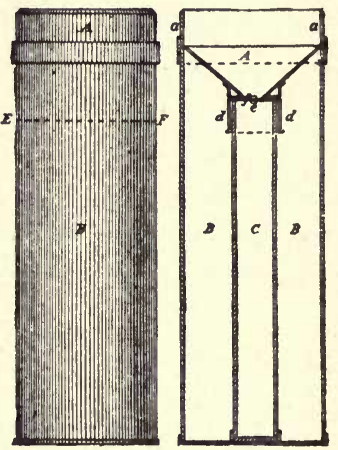

FIG. 136.-Rain-gauge.

217. The Measurement of Rain.-Rainfall may be caught in any flat-bottomed can or dish with vertical sides, placed with its top exactly horizontal, out in the open, away from objects that might prevent rain from falling into the gauge or cause wind eddies about the gauge and interfere with a proper catch. A common ruler trimmed as thin and narrow as practicable so as not to raise the water level when inserted, may be used to measure the depth after each storm. The gauge shown in Fig. 136 is better for accurate measuring of small

${ }^{1}$ In addition to the pressure of the air, fully equipped weather stations record its temperature, also the rainfall and snowfall, the direction and force of the wind, the duration of sunshine and cloudiness, the amount of moisture in the air, and a number of other conditions. Several of these are recorded automatically by specially designed apparatus. 
amounts. The rain caught in it runs through the funnel, $A$, into a smaller can, $C$, of the proper diameter to multiply the actual depth of rainfall by ten. The ruler is marked into tenths of an inch, and each tenth measured in the smaller can stands for one-hundredth of an inch actual rainfall. In very heavy rains, some of the water overflows into the outer can, $B$, and has to be poured back for measuring.

218. The Measurement of Snow.-For measuring snowfall the outer part of the same gauge is used alone. When there is little wind the snow falling into the gauge will generally be as deep as that outside, and the gauge measurement will be accurate. But usually some snow is blown out by the wind, and it is necessary to measure the fresh snow outside in several places to find its average depth. Then at a point where the new snow is of that average depth, cut out a section of the new snow by using the top of the inverted empty snow gauge after the manner of a biscuit cutter, and slide a shingle or piece of tin across the mouth of the gauge underneath the snow before lifting. The snow thus picked up is melted and the water measured and recorded as if it were rain. The density of snow varies considerably in different storms and in different portions of the country. It may require anywhere from about $7 \mathrm{in}$. to $30 \mathrm{in}$. of fresh snow to yield $1 \mathrm{in}$. of water.

The depth of snow affects winter travel, lumbering, railroading, teaming, the care of live stock on farms and ranches, and several other lines of business. It also influences the condition of the soil, of fall sown crops and of meadows and pastures during the following summer. The amount of water in the snow is important to agriculture, to many irrigation systems, to river navigation, and to districts subject to flooding when the snow melts. Moreover, unless snow is reduced to water, accurate comparisons cannot be made of the precipitation of different years, or that of winter and summer, or of warm and cold regions.

Peoria, Ill., in 1910, had 22.3 in. of rain and $8 \mathrm{in}$. of snow; and in 1914, 21.1 in. of rain and 36 in. of snow. In the total amount of water, 
1914 had 1.2 in. more than 1910. Kansas City averages about 34 in. of rain and 25 in. of snow annually; while Marquette, Mich., has about 20 in. of rain and $101 / 2 \mathrm{ft}$. of snowfall per year. We can not compare these unless the snow is melted and the water measured.

For these reasons the depth of snowfall and of the water it contains are both recorded. When the snow cannot be melted one-tenth of its depth is often taken as the estimated amount of water.

219. Measuring the Temperature; Value of Knowing the Temperature.-A good working knowledge of the temperature of a region is valuable, and requires systematic observations. Two localities may have the same yearly average of temperature, but one may have much warmer summers and much colder winters than the other. Two regions may have the same average summer temperature, but one may be much warmer in afternoon and much cooler at night than the other. One place may have a smooth, gradual change from summer to winter, and another section with similar average temperatures may have frequent and decided oscillations of temperature. In one region, alternating warm and cold periods in spring may destroy fruit buds and prevent successful orcharding, while, in another region with cooler but more even temperature, orcharding is successful.

Seattle and Omaha have about the same yearly average temperature, $52^{\circ}$ and $50^{\circ},{ }^{1}$ respectively. At Seattle, July is 33 degrees warmer than January, while at Omaha, July is 59 degrees warmer than January.

Spokane and San Francisco have about the same average temperature for July. At San Francisco the daily range (difference between the afternoon maximum and the night minimum) for that month averages 12 degrees, while at Spokane it is 28 degrees. At Galveston the daily range for July is 10 degrees, at Oklahoma City, 20 degrees, and at Huron, S. D., 26 degrees.

${ }^{1}$ Note: In recording temperature the United States Weather Bureau uses the Fahrenheit scale only. Therefore, in this chapter and in Chap. V, on Climate, all references to temperature will be understood to mean Fahrenheit scale, unless the centigrade scale is indicated. 
At Peoria, April, 1910, averaged 4 degrees warmer than April, 1911; but in April, 1911, the average change from one day to the next was only 3.6 degrees; while April, 1910, though a warmer month, had an average changeableness of 7 degrees and included both unusually warm weather and a disastrous freeze.

All these conditions affect the crops that can be raised, the industries that may be profitably carried on, and the comfort and health of the population. For example: Corn requires hot days, warm nights, and plenty of rain in July and early August. Grass and small grains thrive better in moderately cool and damp weather. People engaged in either physical or mental labor can accomplish more where the temperature oscillates considerably and becomes rather cool occasionally, than they can where it is too warm, or even too uniform at a moderate temperature. A thorough knowledge of the temperature of a region is, therefore, important in many ways (see Chaps. V and VI).

220. Measuring the Temperature of the Air.-In measuring air temperature, three classes of instruments are used: (1) Ordinary thermometers; (2) self-registering, maximum and minimum, thermometers; (3) recording thermometers, or thermographs.

221. Ordinary Thermometers.-Thermometers usually contain mercury. The tubes, while open at the top, are filled and the mercury heated till it completely fills the bulb and stem. The tubes are then sealed. This leaves a vacuum above the mercury when it cools. The scale is then placed on the stem as described in Arts. 16 to 21; or the scales may be determined by comparing with a standard thermometer. For very low temperatures, alcohol thermometers are generally used. Mercury freezes at $38.5^{\circ}$ below zero F.; therefore, mercury thermometers do not record a lower temperature.

222. Self-registering Thermometers. The Maximum.In the maximum thermometer (Fig. 137) the tube is narrowed near the bulb so the mercury passes with difficulty. The instrument is placed nearly horizontal. When the tem- 
perature rises the mercury is forced through the narrowed portion (B, Fig. 137) and may be seen slipping past in small drops. When the temperature falls and the mercury in the bulb contracts, the mercury in the tube remains there. Then if the bulb end be held a little lower than the top, so that the mercury is all joined together against the bulb end without crowding any back into the bulb, the top of the column shows the highest temperature reached since the instrument was last "set." To set the maximum, lower its bulb end to a vertical position. The mercury will then run past the narrowed point until the bulb is full. Sometimes the maximum must be jarred slightly, or whirled on its pivot, to make the mercury

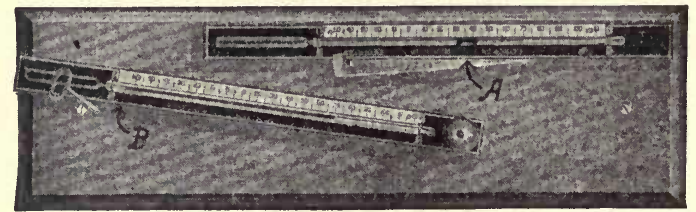

FIG. 137.-Maximum and minimum thermometers. $A$ marks the index in the minimum and $B$ the break in the mercury column of the maximum.

run down. After setting, the maximum should read practically the same as an accurate common thermometer placed beside it. The clinical or "fever" thermometer used by physicians is a small maximum.

223. Self-registering Thermometers. The Minimum.The minimum thermometer contains alcohol and rests in a horizontal position. Within the alcohol in the tube is a small, double-headed, pin-like index ( $A$, Fig. 137). Like other liquids, alcohol has a film over its free surface. When the temperature falls and the alcohol contracts, this surface film draws the index back toward the bulb. When the temperature rises, the index remains stationary and the expanding alcohol runs past it. The upper end of the index, farthest from the bulb, marks the lowest temperature reached since the instrument was last set. To set the minimum thermometer, 
the bulbrend is raised till the tube is nearly vertical. Then the index slides down to the "top" end of the alcohol column. Sometimes a slight jarring is needed to start the index. A minimum after setting should read practically the same as an accurate common thermometer beside it.

224. Recording Thermometers. The Thermograph.-The thermograph writes a continous record of temperature. A brass cylinder (Fig. 138) holds a recording sheet that is ruled with vertical hour lines and horizontal temperature lines. A clock inside the cylinder turns it slowly, moving the record sheet past the pen. The thermometer bulb is a flattened

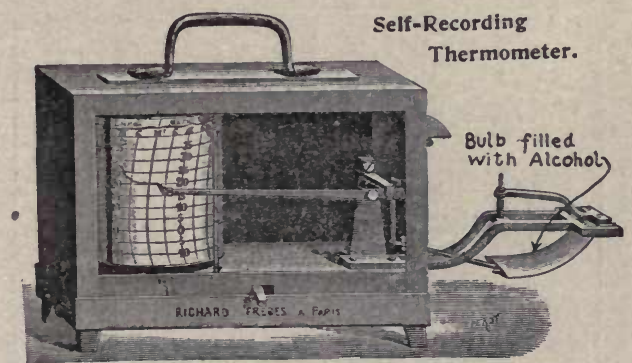

Fig. 138. - Thermograph. The clock turns the cylinder round once each week. The days and hours are marked by vertical lines; the degrees by horizontal lines. The pen rises and falls with all changes in temperature.

brass tube bent into a curve and filled with alcohol. One end of this bulb is fastened rigidly to the frame, the other connects with a set of levers ending at the pen. When the temperature rises the pressure of the expanding alcohol gradually straightens the curved tube and this raises the pen higher on the recording sheet. Falling temperature contracts the alcohol and curves the bulb more; this moves the pen downward. In this way the pen writes a complete record of the temperature, showing all changes and the time when they occurred. Thermographs are used at all Weather Bureau stations, and are in many high school laboratories.

225. Obtaining Accurate Temperature Records.-In making a correct record of the temperature it is necessary: (1) 
That the thermometers be accurate; (2) that the thermometers be sheltered; (3) that a proper set of observation hours be selected.

226. The Need of Testing Thermometers.-Not all thermometers are reliable. Inaccuracies may come from several causes. Two common defects are: (1) The scale may be

Correction Card for Mercurial

Thermometer, No. 4875

\begin{tabular}{|c|c|}
\hline Scale readings & $\begin{array}{c}\text { Corrections, in degrees } \\
\text { Fahrenheit, to reduce to } \\
\text { standard air thermometer }\end{array}$ \\
\hline$\circ$ & \\
-38. & -0.4 \\
-28. & +0.1 \\
-18 & -0.0 \\
-8. & -0.0 \\
+2. & -0.0 \\
12. & +0.2 \\
22. & +0.1 \\
32. & -0.0 \\
42. & -0.0 \\
52. & -0.0 \\
62. & -0.1 \\
72. & -0.0 \\
82. & -0.0 \\
92. & -0.0 \\
102. & +0.1 \\
112. & -0.0 \\
\hline
\end{tabular}

FIG. 139.

placed too high, or too low, on the tube, thus making all readings too low or too high; (2) the bore of the tube may be uneven, causing the mercury or alcohol to rise too slowly in some portions and too rapidly in others.

Every thermometer used by the Weather Bureau is carefully tested, and a correction card made showing all errors (Fig. 139). Where errors are more than half a degree the 
readings of the thermometer are corrected before writing them in the record.

\section{Exercise 50.-Testing Thermometers}

Test your school and home thermometers for the freezing point, ( and for the boiling point if convenient (see Arts. 20 and 22). Your teacher will advise you in the testing. Take the most accurate thermometer found by the class as a standard. Make correction cards for the others like that in Fig. 139.

\section{The Need of Shel- tering Thermometers.-} In recording weather conditions, thermometers must have a proper exposure. If three thermometers are hung out of doors in similar surroundings except that one is in the sun, another in the shade over a grassy plat, and the other in the shade over pavements or near buildings, there will often be considerable difference in their readings. Since the general weather conditions are the same for all three thermometers, their different readings are

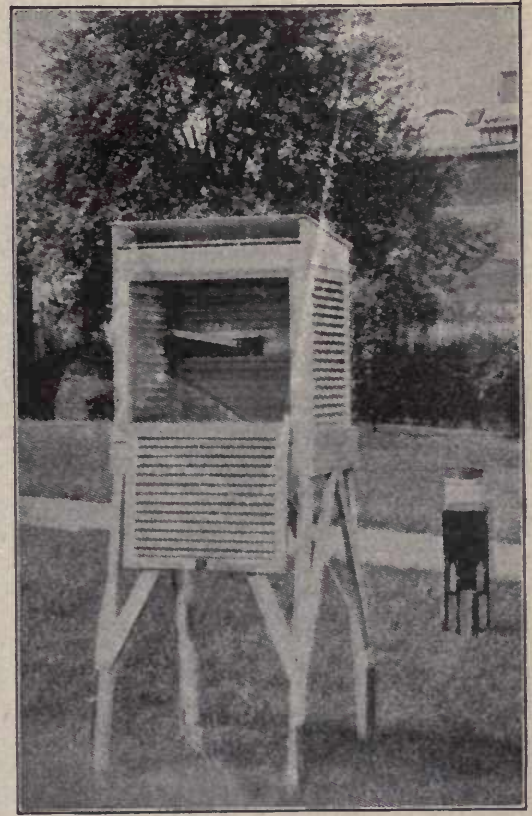

Fig. 140.-Thermometer shelter; U. S. Weather Bureau Pattern. Maximum and minimum thermometers are shown in position The ordinary rain-gauge is seen at the right. due to other causes. It may be the sun's rays shining directly upon the mercury; or it may be the heat reflected from pavements or buildings, etc.; near by. To show correctly the temperature of a locality the thermometer must record the temperature of the free moving air and be shielded from other special effects. For this reason ther- 
mometer shelters, or screens, are used by the weather bureaus of all countries. These are placed as nearly as possible at similar heights above sodded ground, where the winds blow freely. Figure 140 shows the American pattern. It has double roof, slatted sides, and is placed 5 to $10 \mathrm{ft}$. above the ground amid open surroundings. The door opens to the north to avoid the sun's effect when reading the thermometers. In cities, a similar shelter above a flat roof is often the best that can be had. Sometimes for schools a shelter placed just outside a second or third story north window is most convenient, though seldom as good.

The class should now use the thermometer, barometer and rain gauge in keeping the weather record for one or two months. A home-made rain gauge will do. Inexpensive thermometers may be tested and used with their correction cards. Keep the record as shown in the following condensed and convenient form. A part of the Weather Bureau records are kept in similar manner.

Weather Record

\begin{tabular}{|c|c|c|c|c|c|c|c|c|c|c|c|c|c|c|c|c|c|c|}
\hline \multirow[b]{2}{*}{ 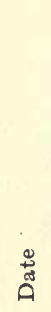 } & \multicolumn{7}{|c|}{ Barometer } & \multicolumn{3}{|c|}{$\begin{array}{l}\text { Temp. } \\
\text { outdoors }\end{array}$} & \multicolumn{2}{|c|}{ Wind } & \multicolumn{3}{|c|}{ Clouds } & \multicolumn{3}{|c|}{$\begin{array}{c}\text { Precipi- } \\
\text { tation }\end{array}$} \\
\hline & 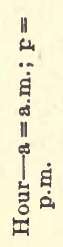 & 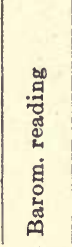 & 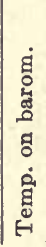 & 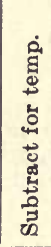 & 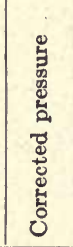 & 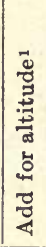 & 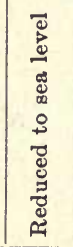 & 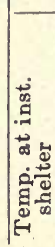 & 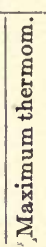 & 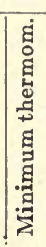 & 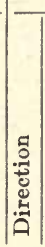 & $\frac{\overrightarrow{0}}{0}$ & 趨 & 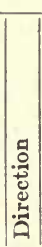 & 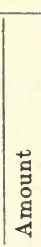 & 足 & $\vec{G}$ & 范 \\
\hline $\mathrm{Jan}_{20}$ & $9 \mathrm{a}$ & 29.14 & $68^{\circ}$ & .10 & 29.04 & .94 & 29.98 & $25^{\circ}$ & $38^{\circ}$ & $22^{\circ}$ & $\searrow$ & Mod & $\begin{array}{c}\text { Light } \\
\text { high }\end{array}$ & $\rightarrow$ & $1 / 10$ & $\begin{array}{l}3-5 \\
\text { p.m. }\end{array}$ & $\mathrm{S}$ & $\mathrm{T}$ \\
\hline & & & & & & & & & & & & & & & & & & \\
\hline
\end{tabular}

1 Altitude $830 \mathrm{ft}$.

Proper Hours for Observing Temperature

Reading a thermometer only once a day, in the morning, will make the record lower than the true daily average. Reading it only in the early afternoon will give too high a record. The following four methods have been used: 


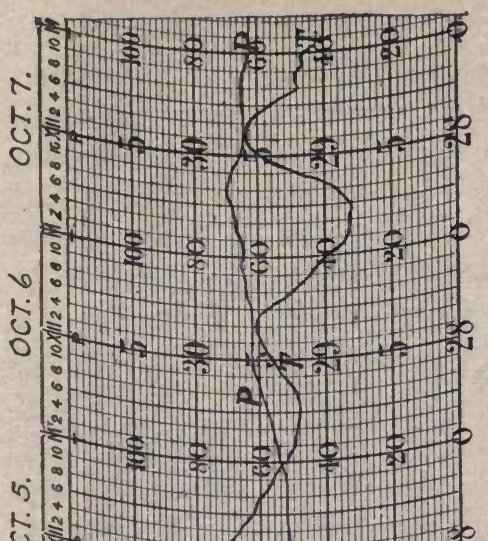

mi

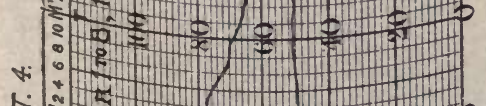

Ui

0

$\rightarrow$

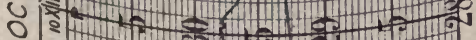

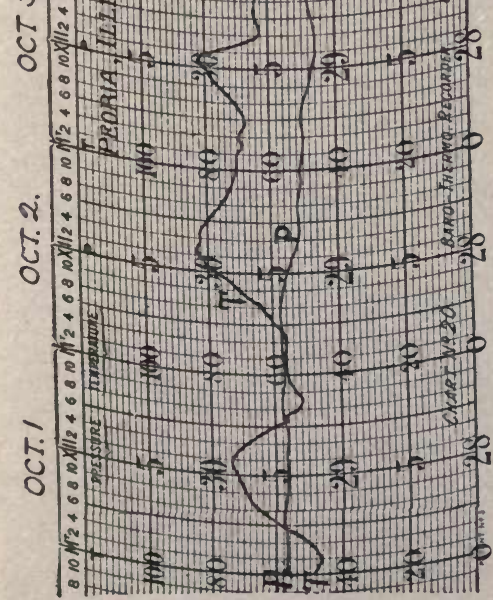

(1)

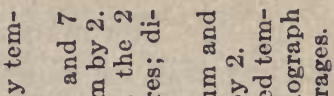

空

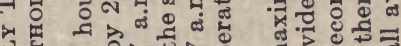

日

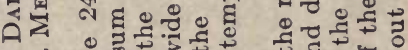

舟

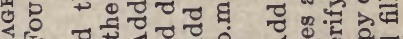

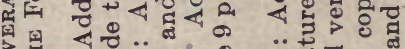

$\dot{0}$

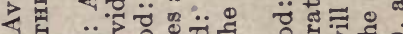

州

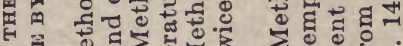

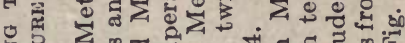

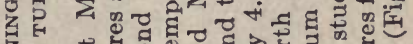

य

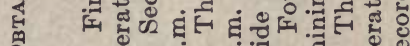

0

迅

* का का t

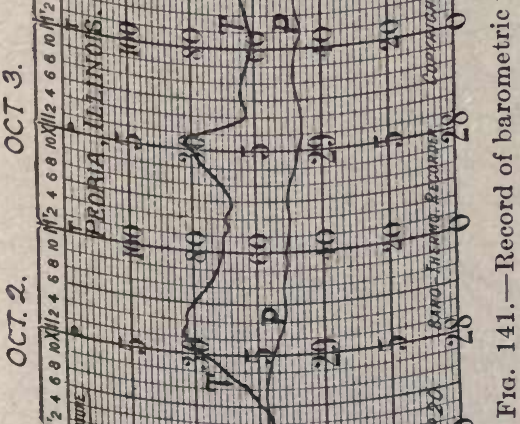

$\frac{0}{\frac{\pi}{7}} \mid \frac{8}{8}$

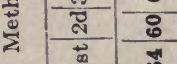

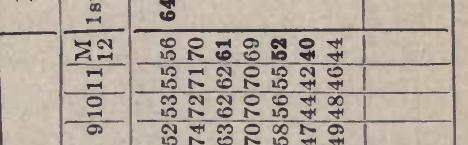

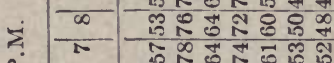

A - 0 - 000

क

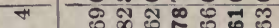

ल

त स

न $\int 8$ \%

zi n

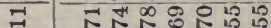

- - 000 क 000

a $\frac{0}{0} \sqrt{2}$

$\infty$ गु

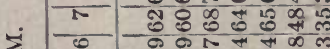

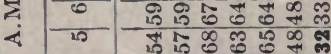

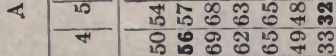

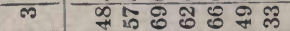

ल कํㅇำ

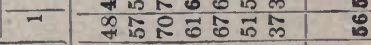

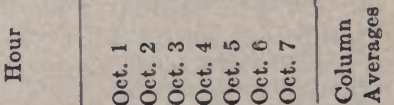


1. The thermometer has been read every hour, day and night; the 24 hourly readings have then been averaged. This method gives a correct daily average as well as the maximum and minimum, but is impossible for any observer long to continue. Men have thus taken hourly readings long enough to discover sets of hours that give a fairly correct average for the entire day in almost any kind of weather.

2. The average of the 7 a.m. reading and the 7 p.m. reading is convenient and gives a reasonably correct average for the day.

3 . The reading at 7 a.m. plus the reading at 2 p.m. plus two times the reading at 9 p.m., and the sum divided by 4 , is practically correct for the daily average. Moreover, usually the lowest temperature is near $7 \mathrm{a.m}$. and the highest near 2 p.m.; this method, then, tells us something about the extremes for the day.

4. The coöperating observers of the United States Weather Bureau now use self-recording maximum and minimum thermometers. These are set but once each day, near sunset being the best hour. Their record gives the extremes for the day and the average of these extremes gives a fairly correct average for the day. Comparing the maximum, or the minimum, or the average, with the same item for the preceding or following days shows the changeableness, or variability, of the temperature.

\section{Exercise 51. To Determine the Average Temperature of a Day or Week}

Obtain a thermograph sheet with a week's record of temperature. ${ }^{1}$ Rule a sheet of paper with lines for each day and columns for each hour as in the preceding table. Write in the proper spaces the temperature at the end of each hour during the week, as in the example just worked out. Find the average temperature of each day by each of the four methods, writing results in the proper spaces at the right. Average each of the 24 hourly columns, writing the average at the foot.

1 If necessary, ask the nearest Weather Bureau station for a copy of a week's thermograph record. 
Using these hourly footings, find the average for the week by each of the four methods.

How do the averages compare? A little difference may be expected.

In different weeks and different seasons, slightly different results may be obtained.

\section{Exercise 52.-To Determine the Average Monthly Temperature}

At the end of the month compute the average temperature of the month from the record kept by the class, using the maximum and minimum method. Note the extremes for the month. Work out also the prevailing wind direction for the month; the number of clear, cloudy, and partly cloudy days; the total rainfall, and the depth of snowfall, if winter.

\section{TEMPERATURE FACTS}

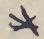

229. How the Atmosphere is Heated.-Instead of being warmed directly by the sun, the atmosphere receives most of its heat indirectly. The sun warms the earth, and the air is heated chiefly by contact with the warm earth and by heat reflected from the earth into the air. For this reason the air is nearly always warmest near the ground and grows colder with elevation. ${ }^{1}$ Recording thermometers sent up by kites or small balloons over the Missouri valley have shown the temperature at the height of a mile about $12^{\circ}$ colder than at the ground; at 5 miles $80^{\circ}$ colder; at 10 miles $120^{\circ}$ colder; and at 20 miles about $93^{\circ}$ colder than at the ground. These figures change somewhat with the season. In the lower 2 or 3 miles of air many changes in temperature occur.

230. Effect of Heat on the Atmosphere.-This greater heating of the air near the ground is one of the principal causes of all movements of the atmosphere. Heating expands air about 1/491 part of its volume for each added degree Fahrenheit (show that this is $1 / 273$ for $1^{\circ} \mathrm{C}$.), which means that warming air $50^{\circ} \mathrm{F}$. increases its volume about one-tenth.

\section{PROBLEM}

Show that, if the lower half-mile of the atmosphere is warmed $50^{\circ} \mathrm{F}$., the upper surface of the original half-mile would be raised

${ }^{1}$ This is true up to 8 or 10 miles. 
about $260 \mathrm{ft}$. How much would the weight of the air remaining below the half-mile level be reduced (Arts. 135 and 208)? Compute this decrease in pressure in tons for $1 \mathrm{sq}$. mi. of area.

Ans.-About 280,000.

231. Why a Windy Day Seems Cool.-In cool weather a wind makes the day seem colder because it forces air through the clothing and brings fresh supplies of cold air into contact with the body to carry away its heat. The faster the body loses its heat, the colder seems the day.

232. The Lag of Temperature; Afternoon and Night.Since all heat comes from the sun the hottest hour of the day might be expected at noon, and the coldest is often supposed to be at midnight. But we have seen that the warmest hour is usually in early afternoon and the coldest shortly before sunrise. The reason is that, while the earth receives heat from the sun by day, it is all the time losing heat by radiation into space. Commencing ordinarily about sunrise a locality receives more heat than it radiates. Therefore, heat accumulates and the temperature continues to rise. Usually about 2 or 3 p.m. the loss of heat by radiation becomes greater per minute than the receipt of heat from the sun. At that instant the temperature of the locality begins to fall; and it continues to fall throughout the night, until the increasing amount of heat received from the rising sun exactly balances that lost by radiation, when the temperature fall ceases. The temperature therefore usually rises during the forenoon and early afternoon, and falls through the remainder of the afternoon and all of the night.

There are exceptions to this rule: (1) The march of temperature on cloudy days is often different because clouds interfere with both sunshine and radiation. (2) In winter, the temperature is often controlled by the wind which brings air from warmer or colder regions, and may thus cause the maximum or minimum temperature to occur at any hour of day or night. 
233. Lag of the Seasons.-For a similar reason the warmest part of our summer usually comes in July, or in August, instead of at June 21 when the sun is farthest north, and the coldest part of winter in January instead of at December 22, when the sun is farthest south. A corresponding lag is found in the southern hemisphere where summer occurs during our winter.

234. Night-time Cooling and Radiation.-The cooling at night is caused chiefly by radiation, and is therefore greatest

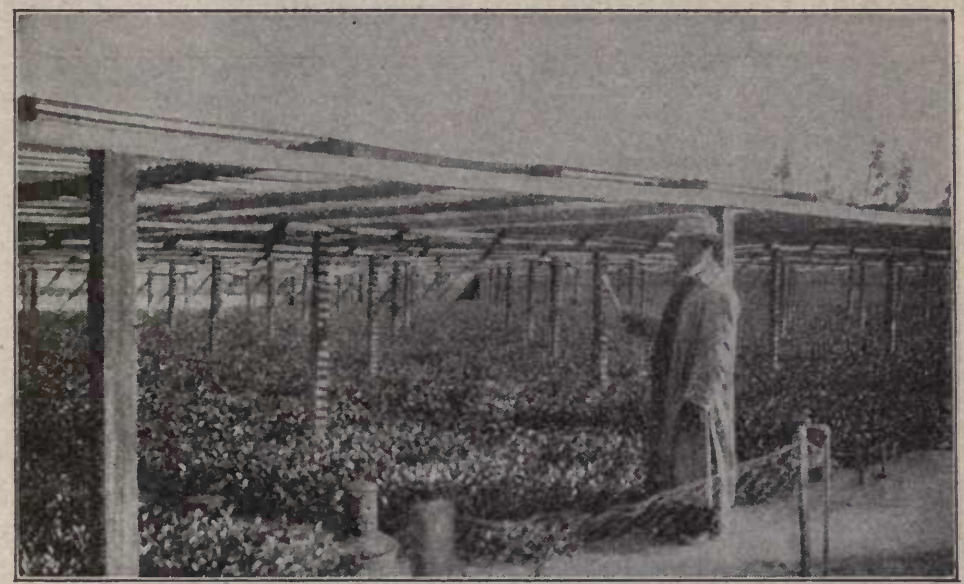

FIG. 142.-A lath screen. These are usually arranged to roll or slide aside to admit sunshine. Night temperatures under this screen averaged 4 degrees higher than in an unprotected orchard nearby. To left of center, in foreground, is seen one type of firepot used in warming the ground air.

(Illustration by F. A. Carpenter, in Monthly Weather Review.)

where radiation is greatest. On mountains and plateaus, the air is thinner, owing to elevation, and also, usually, contains less dust and smoke. This permits freer radiation and causes cool nights even in midsummer; night frosts occur there in portions of the year when the days are warm.

235. Radiation and Frost.-In any locality radiation is most rapid when the sky is clear; hence clear nights are coolest, and most likely to give frost in spring and autumn. 
236. Frost Fighting; by Checking Radiation.-Smudge pots, or fires of any fuel causing dense smoke, also various types of overhead screens (Fig. 142), are often used in orchards to prevent frost. The smoke or screens retard radiation and sometimes keep the temperatures near the ground $4^{\circ}$ to $6^{\circ}$ warmer.

237. Frost Fighting; by Warming the Ground Air.-The radiation that chills the night air takes place chiefly from the ground and vegetation. Therefore, the air cools in a comparatively thin layer next to the ground. Cooling makes

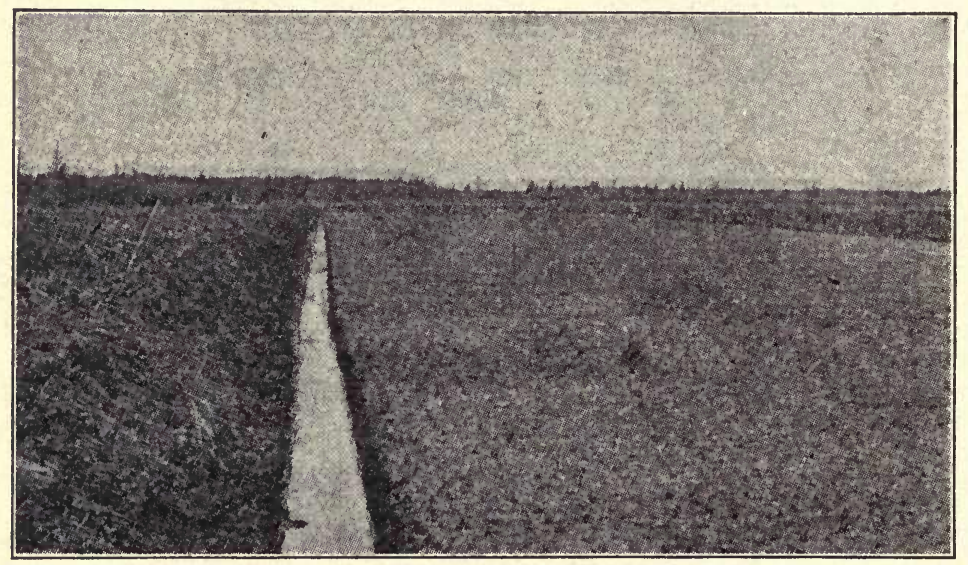

FIG. 143.-Newly planted cranberry bog. Two or three inches of sand were spread over the bog before the plants were set. The ditch at the side of the bog drains the water off quickly when danger of frost is passed.

it denser and heavier so that it remains on the ground and continues to cool, while the air a few feet or a few yards above remains considerably warmer throughout the night. Orchardists often prevent. frost by warming this shallow bottom layer of cold air with fires of oil, coal, wood, etc., placed on the ground, 30 to 50 , or more, per acre.

Cranberry marshes, in Wisconsin and elsewhere, are often flooded with water (often completely submerging the vines) to protect them from frost. Water holds its heat better 
than soil, and keeps the air above it too warm for frost. Covering the marsh soil with an inch or two of sand also keeps the ground warmer and prevents some frosts (Fig. 143).

The cost of these protective measures in orchards, fields, marshes, etc., varies with circumstances but is often a tenth or less of the value of the crop saved. The frost warnings

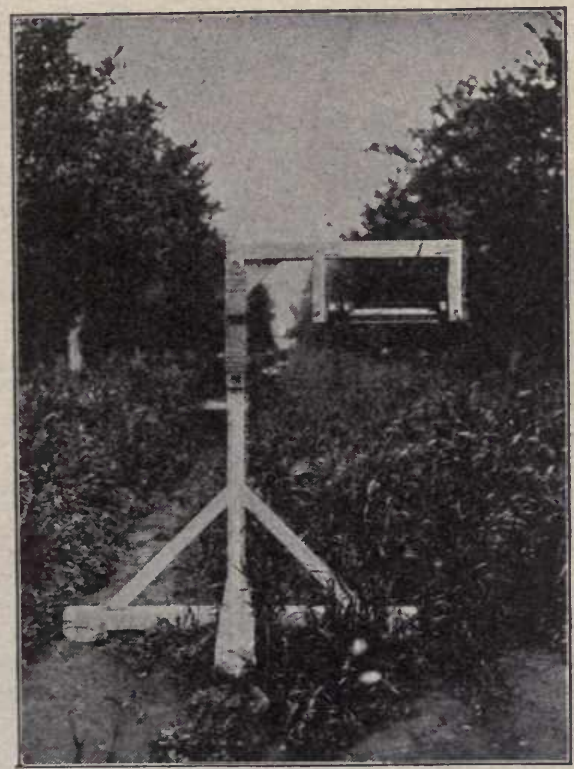

Fig. 144.-Frost fighting in a lemon grove. Firepots along path near middle. In foreground an alarm thermometer, arranged to ring a bell in the watchman's headquarters when temperature falls to danger point.

(F. A. Carpenter, in Monthly Weather Review.)

issued by the Weather Bureau 12 to 20 hours, or more, in advance are of great value (sometimes amounting to $\$ 100,000$ for one frost in a single state) in enabling preparations to be made before the cold arrives. Large orchards are often equipped with a system of alarm thermometers (Fig. 144) which are arranged to ring a bell in the watchman's quarters when the temperature drops to the danger point. This en- 
ables the lighting of the fires to be left until they are actually needed, and shows the attendants where the fires are needed first. All this saves expense.

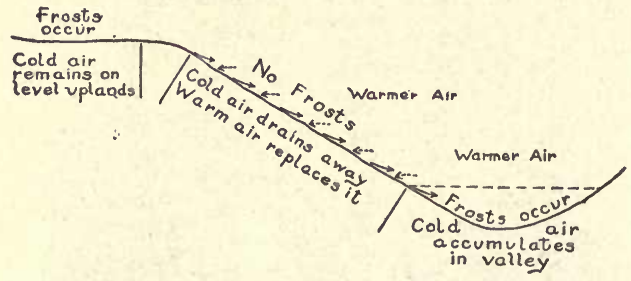

Fig. 145.-How frosts sometimes occur both on the uplands and in the valley bottom, while the slopes escape. Solid arrows, cold air; broken arrows, warm air.

238. Air Drainage and Frost.-On hilly or rolling land, the valleys have frost later in spring and earlier in autumn than the surrounding slopes and low hills. On a slope the cooled, heavier air, close to the ground, settles downward and out-

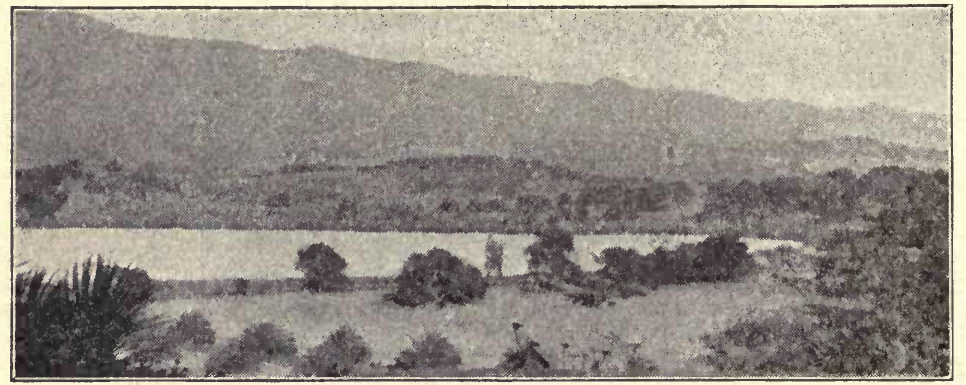

FIG. 146.--One type of landscape where orchards are successful on intermediate slopes, while frosts prevent them both above and below. Lemon groves beyond the rounded oak-forested hills across the lake.

(F. A. Carpenter, in Monthly Weather Review.)

ward and mixes with the warmer air above the lower slope; while at the same time its place next the ground is taken by warmer air moving in horizontally from the uncooled mass of air above the valley (Fig. 145). These mixing movements keep the temperature warmer on sloping ground; and often 
prevent frost on hillsides when frost forms in valleys or on level lowlands, and on the highlands above. The valley

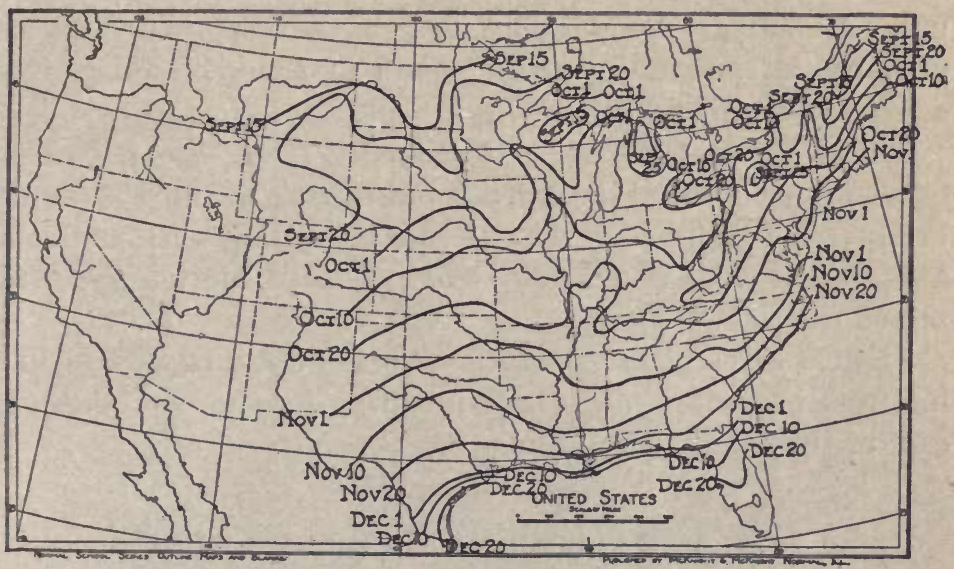

Frg. 147.-Average date of first killing frost in autumn.

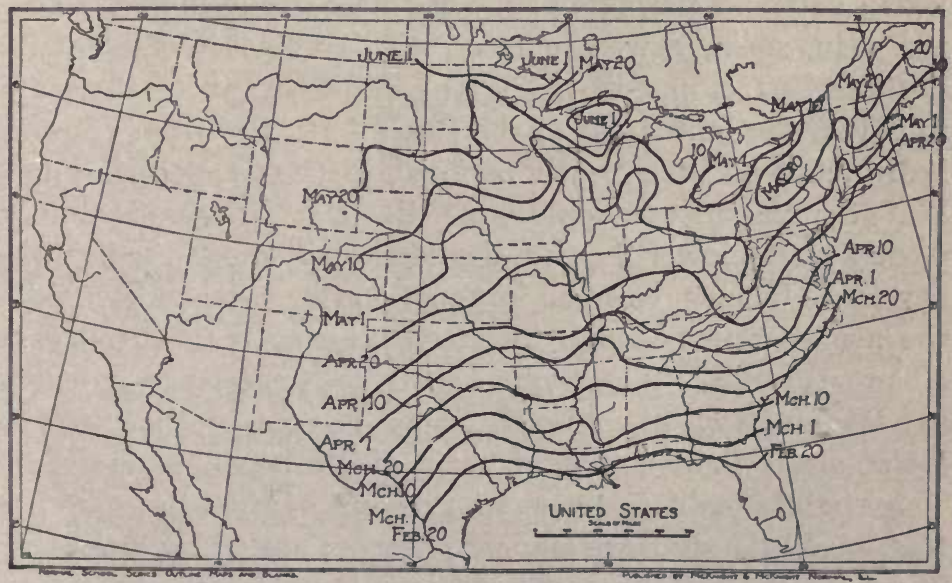

FIG. 148.-Average date of latest killing frost in spring.

frosts are caused by the continued cooling of the lowland air which cannot drain away, aided perhaps to some extent by 
the drainage of cold air from the lower surrounding slopes. On the level uplands, the chilled air does not drain away, also radiation is freer there because of elevation and so increases upland cooling. Because of these conditions many of the orchards in the fruit-growing regions of America and Europe are found on hillsides (Fig. 146).

239. Wind and Frost.-Occasionally frosts are prevented by wind. The wind by stirring and mixing the air constantly brings fresh supplies of warmer air in contact with the cooling ground and vegetation, and so keeps all temperatures above freezing.

Figures 147 and 148 show the average dates of earliest killing frost in autumn and latest in spring for the United States east of the Rocky Mountains.

\section{THE WATER VAPOR OF THE AIR}

240. The Moisture of the Air.-The presence of invisible water vapor in the air is shown by the formation of clouds, fog, rain, snow, dew, and frost. This vapor is of great importance. It supplies directly or indirectly all of the water found on the land areas of the earth. It affects our comfort, health, and business nearly as much as the temperature does.

Water vapor extends above the loftiest clouds but is mostly in the lower 2 or 3 miles of air. It mixes readily with dry air. When present in large amounts, water vapor makes the atmosphere occupy a little more space than the dry air alone would fill. Water vapor is about $6 / 10$ as dense, or heavy, as dry air, and when much vapor is present the resulting moist air is lighter than dry air at the same temperature. This slightly reduces the total pressure of the atmosphere in that locality and makes the barometer read slightly lower than it would under the same conditions if no water vapor were present.

241. Moisture of the Air; Its Source.-This vapor of water comes by evaporation, chiefly from water surfaces, vegetation 
and the soil. (1) The evaporation from water surfaces ranges from a very small amount per day in polar regions, in winter, to as much as $1 / 5$ in. per day, on some days, over tropical oceans and over inland lakes in hot dry regions like southwestern United States (Fig. 149). (2) All plants give off water vapor through their leaves. (3) Evaporation from the soil varies with the kind of soil, the amount of water in the soil, the method of surface tillage, the dryness of the

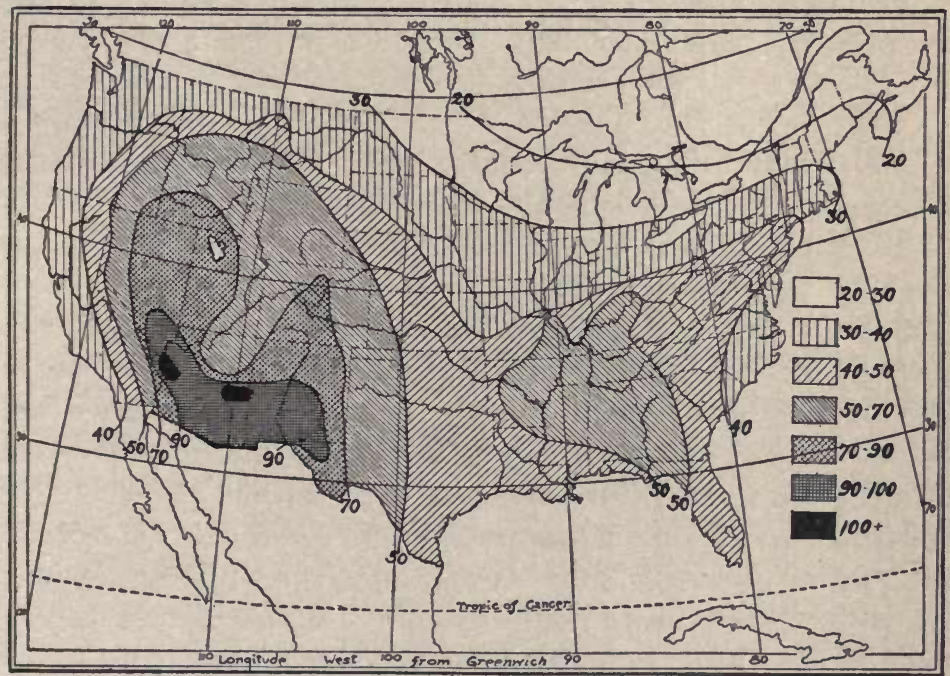

Fig. 149.-Mean annual evaporation in inches, from a water surface.

air and the velocity of the wind. Wet soil, dry air, or strong winds increase evaporation. Evaporation is greater from porous soils than from compact soils. Rolling a field checks evaporation from the soil. Tillage that forms a "dust mulch" an inch or so thick over the surface is an effective check and keeps the water in the soil (see Arts. 547 to 551). Both rolling and dust mulch tillage are used in "dry farming" regions of the plains, and are valuable to agriculture in dry seasons anywhere. 


\section{PROBLEMS}

1. An acre of clover loses probably 500 to 750 tons of water per season, largely given off through the plants themselves. What depth of rainfall is required to grow this crop? (Water weighs 62.5 lb. per cu. ft.)

Ans. From 4.4 to 6.6 . in.

2. A single corn stalk may lose $300 \mathrm{lb}$. of water during the season. At 3 stalks to the hill and the hills $31 / 2 \mathrm{ft}$. apart each way, what depth of rainfall is required to furnish this amount of water? Ans. $14.1 \mathrm{in}$.

3 . An apple tree, 30 years old, may give off $250 \mathrm{lb}$. of water per day or 18 tons during the growing season. If there are 40 such trees per acre, how much water would they require per season? What depth of rainfall is needed to replace this water? Ans.6.034 in.

242. Evaporation, How Controlled.-The amount of vapor given off is controlled by the temperature of the evaporating surface and the space above it, and by the amount of vapor already present over the evaporating surface (see Chap. I, Sec. III). An accumulation of vapor over the evaporating surface checks evaporation; calm air retards evaporation by leaving the accumulated vapor over the evaporating surface. Wind carries away the accumulated vapor and aids evaporation. High temperature increases evaporation.

243. Evaporation, Measurement of.-A rough idea of the rate of evaporation may be obtained by placing shallow trays filled with water out of doors and measuring the remaining depths at intervals of a few days in summer and less frequently in winter. The depth of rain falling into the pans must, of course, be considered. Place one tray in the sun, another in the shade, another where the wind blows freely, and another in calm air, and compare results. Fig. 149 shows the estimated yearly amount of evaporation from a water surface in the United States. Explain the large amount in the southwest.

244. Evaporation Effects; Cooling.-To evaporate a quart of water having a temperature of $32^{\circ}$ (i.e., to change it into vapor having the same temperature) requires about 1,075 times as much heat as would be needed to raise the tempera- 
ture of the quart of water $1^{\circ} \mathrm{F}$. (compare with Art. 150). ${ }^{1}$ Whenever water evaporates, this large amount of heat is taken from the surrounding air or objects and becomes insensible heat, which we can not feel (see Arts. 149-150). That is why sprinkling the floors or pavements in hot weather makes them and the air cooler. The evaporation of the water uses up some of their heat (review Art. 12, Ex. 10). All the heat thus used in forming water vapor is liberated again when the vapor is condensed into clouds, rain, snow, dew, fog, or frost. This liberated heat helps in the development of certain clouds and storms to be considered later.

245. Effect of Moisture upon Personal Comfort.-With a given temperature, the measure of comfort that we experience varies with the amount of water vapor in the air. A damp day is usually more uncomfortable in either summer or winter than a dry day at the same temperature. (1) In winter, the moisture, by increasing the conductivity of the air, enables it to take away heat faster from the body, and when the body thus loses heat too rapidly we have the uncomfortable sensation of chill. (2) In summer, the body is ordinarily kept cool by the evaporation of its perspiration. Damp air permits less evaporation and therefore less cooling. When the body thus loses too little heat we experience the sensation of uncomfortable warmth. This is why high humidity in summer causes more suffering and increases the danger of sunstroke. For a similar reason indoor air in winter that has enough moisture feels warmer and more comfortable than very dry air that is actually several degrees warmer. It follows that offices, school buildings and homes having a proper humidity are comfortable at a lower temperature. This saves fuel and is also more healthful for lungs and throat. In many modern school and office buildings humidifiers automatically

1 The quantity of heat needed to evaporate varies a little with the temperature of the water. If the water is at $212^{\circ} \mathrm{F}$. the heat needed to change it to vapor at $212^{\circ}$ is only 966 times that required to raise the temperature of the water $1^{\circ} \mathrm{F}$. 
throw moisture into the air ducts of the ventilating system whenever the humidity falls too low (Chap. VI, Ventilation).

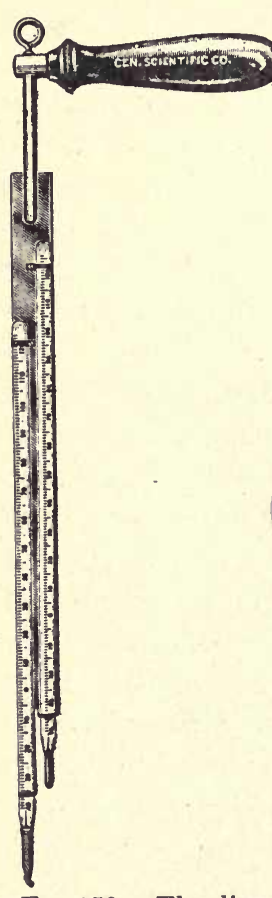

FIg. 150.-The sling psychrometer. The lower bulb is covered with muslin and is moistened before an observation. $\mathrm{Th}$ e thermometers are then whirled about the hand, and read every half minute or so until the wet thermometer ceases to fall.

246. Moisture and the Industries.-An even or uniform humidity aids some manufactures, such as cotton spinning; a high humidity interferes with other operations, as for instance the manufacture and storage of wooden articles and food or other products likely to swell or spoil by absorbing moisture. Cleopatra's Needle stood unharmed for centuries in the low humidity of Egypt, but the higher humidity, with the thawing and freezing in New. York City, soon began to crumble its surface.

247. Measuring the Moisture; Relative Humidity.-Relative humidity (Art. 187) may be measured with either a PSYCHROMETER or some other form of a HYGROMETER. The psychrometer consists of two thermometers, one with muslin around its bulb, which is either kept moist or is moistened shortly before an observation (Fig. 150). To find the humidity the wet and dry thermometers must be either whirled or fanned to secure a good circulation of air about them. Continue whirling till the wet thermometer ceases to fall; then record the reading of each. The principles governing the use of the psychrometer were studied in Arts. 12 and 13. Review Evaporation.

If the air around the thermometers is not in motion, the space close to the wet bulb becomes more or less saturated with water vapor. This checks evaporation and checks the cooling of the wet bulb that would have been caused by further evaporation. But, if the air about the thermometers is kept 
in motion, the moisture will be swept away as fast as it evaporates from the wet bulb, and the instrument will show a lower humidity than it would in still air with the same amount of moisture. The relative humidity table, Table XI, page 218 , assumes that the air about the thermometers is moving $12 \mathrm{ft}$. per second, or 8 miles per hour, which is a comfortable summer breeze. To secure this movement of air the sling psychrometer, or other whirling apparatus, is used when accurate observations are desired.

248. Use of the Relative Humidity Table.-A glance at the table shows how to use it in finding the humidity.

1. The temperature of the air, which is obtained from the dry thermometer, appears in the left-hand column of the table.

2. The cooling caused by evaporation, which is the differ-ence between the dry and wet thermometer readings, is found in the horizontal line across the top of the table.

3. The relative humidity is expressed in per cent. and is found in the table where the horizontal line from the dry temperature crosses the vertical column that is headed by the proper "difference" (dry minus wet) in the top line.

For example: If the dry thermometer reads $70^{\circ}$ and the wet $65^{\circ}$, their difference is $5^{\circ}$. Find $70^{\circ}$ in the left-hand column; follow that line across the page to the column headed $5^{\circ}$. In that $5^{\circ}$-column, on the $70^{\circ}$-line, is the number 77 . This 77 is the relative humidity, and means that the moisture present is 77 per cent. of what could exist as invisible vapor at a temperature of $70^{\circ}$.

\section{PROBLEMS}

If the dry bulb reads 50 and the wet bulb 44.0 , the rel. humid. is 62 . If the dry bulb reads 90 and the wet bulb 75.0 , the rel. humid. is ? If the dry bulb reads 80 and the wet bulb 68.0 , the rel. humid. is ? If the dry bulb reads 35 and the wet bulb 32.0 , the rel. humid. is ? If the dry bulb reads 40 and the wet bulb 35.0 , the rel. humid. is ? If the dry bulb reads 45 and the wet bulb 42.5 , the rel. humid. is 82.5 If the dry bulb reads 73 and the wet bulb 60.8 , the rel. humid. is 49 . If the dry bulb reads 40 and the wet bulb 38.8 , the rel. humid. is ? If the dry bulb reads 50 and the wet bulb 46.5 , the rel. humid. is ? 
Table XI.-Relative Humidity, Per Cent.-Fahrenheit Temperatures

\begin{tabular}{|c|c|c|c|c|c|c|c|c|c|c|c|c|c|c|c|c|c|c|c|c|}
\hline \multirow{2}{*}{$\begin{array}{l}\text { Dry } \\
\text { bulb } \\
\text { temp. }\end{array}$} & \multicolumn{20}{|c|}{ Difference between dry-bulb and wet-bulb temperature } \\
\hline & $\stackrel{0}{\circ}$ & $\stackrel{\circ}{\dot{N}}$ & $\stackrel{0}{\dot{0}}$ & $\stackrel{\circ}{\dot{*}}$ & is & $\stackrel{0}{0}$ & $\stackrel{0}{N}$ & $\begin{array}{l}0 \\
\infty\end{array}$ & $\dot{0}$ & $\dot{0}$ & $\stackrel{0}{=}$ & $\underset{\text { i }}{0}$ & $\stackrel{0}{\infty}$ & $\stackrel{0}{\circ}$ & : & $\begin{array}{l}0 \\
0\end{array}$ & $\stackrel{0}{N}$ & $\stackrel{0}{\infty}$ & 0 & 0. \\
\hline
\end{tabular}

30

31

33

34

35

36

37

38

40

41

42

43

44

45

46

47

48

49

50

51

52

53

54

55

56

57

58

59

60

61

62

63

64

65

66

67

68

63

70

71

72

73

75

76

77

78 \begin{tabular}{l|l|l|l|l|l|l|l|r}
89 & 78 & 68 & 57 & 47 & 37 & 27 & 17 & 8
\end{tabular}

\begin{tabular}{|l|l|l|l|l|l|l|l|l|}
89 & 79 & 69 & 58 & 49 & 39 & 29 & 20 & 10 \\
\hline
\end{tabular}

\begin{tabular}{|ll|l|l|l|l|l|l|l|}
90 & 79 & 69 & 60 & 50 & 41 & 31 & 22 & 13 \\
\hline
\end{tabular}

\begin{tabular}{|l|l|l|l|l|l|l|l|l|}
90 & บ० & 71 & 61 & 52 & 42 & 33 & 24 & 16
\end{tabular}

\begin{tabular}{l|l|l|l|l|l|l|l|l|}
90 & 81 & 72 & 62 & 53 & 44 & 35 & 27 & 18
\end{tabular}

\begin{tabular}{l|l|l|l|l|l|l|l|l|l|}
91 & 82 & 73 & 64 & 55 & 46 & 37 & 29 & 20 & 12 \\
\hline
\end{tabular}

\begin{tabular}{ll|l|l|l|l|l|l|l|l}
$\mathbf{9 1}$ & 82 & $\mathbf{7 3}$ & $\mathbf{6 5}$ & $\mathbf{5 6}$ & $\mathbf{4 8}$ & $\mathbf{3 9}$ & 31 & 23 & 14 \\
\hline
\end{tabular}

\begin{tabular}{l|l|l|l|l|l|l|l|l|l}
91 & 83 & 74 & 66 & 58 & 49 & 41 & 33 & 25 & 17
\end{tabular}

\begin{tabular}{r|r|r|r|r|r|r|r|r|r|r|r|r|}
91 & 83 & 75 & 67 & 59 & 51 & 43 & 35 & 27 & 19 & 12 & 4 \\
\hline
\end{tabular}

\begin{tabular}{lllllllllllll|l|}
92 & 84 & 76 & 68 & 60 & 52 & 44 & 37 & 29 & 21 & 14 & 7
\end{tabular}

\begin{tabular}{r|r|r|r|r|r|r|r|r|r|r|r|r|}
92 & 84 & 76 & 68 & 61 & 53 & 46 & 38 & 31 & 23 & 16 & 9 & 2 \\
\hline
\end{tabular}

$\begin{array}{lllllllllllllll}92 & 84 & 77 & 69 & 62 & 54 & \mathbf{4 7} & \mathbf{4 0} & 33 & \mathbf{2 6} & \mathbf{1 8} & \mathbf{1 1} & \mathbf{5}\end{array}$

\begin{tabular}{lllllllllllll|l|l|}
92 & 85 & 77 & 70 & 62 & 55 & 48 & 41 & 34 & 28 & 21 & 14 & 7 & 0
\end{tabular}

$\begin{array}{llllllllllllll}92 & 85 & 78 & 70 & 63 & 56 & 49 & 43 & 36 & 29 & 23 & 16 & 9 & 3\end{array}$

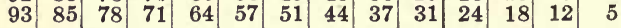

\begin{tabular}{l|l|l|l|l|l|l|l|l|l|l|l|l|l}
93 & 86 & 79 & 71 & 65 & 58 & 52 & 45 & 39 & 33 & 26 & 20 & 14 & 8
\end{tabular}

$\begin{array}{llllllllllllllll}93 & 86 & 79 & 72 & 65 & 59 & 53 & 46 & 40 & 34 & 28 & 22 & 16 & 10\end{array}$

\begin{tabular}{ll|l|l|l|l|l|l|l|l|l|l|l|l}
93 & 86 & 79 & 73 & 66 & 60 & 54 & 47 & 41 & 35 & 29 & 23 & 17 & 12
\end{tabular}

\begin{tabular}{lll|l|l|l|l|l|l|l|l|l|l|l}
93 & 87 & 80 & $\mathbf{7 3}$ & 67 & 60 & $\mathbf{5 4}$ & $\mathbf{4 8}$ & $\mathbf{4 2}$ & $\mathbf{3 6}$ & $\mathbf{3 1}$ & $\mathbf{2 5}$ & 19 & 14
\end{tabular}

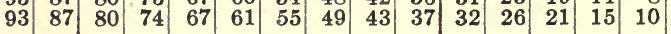

\begin{tabular}{ll|l|l|l|l|l|l|l|l|l|l|l|l|l|l|l|}
93 & 87 & 81 & 74 & 68 & 62 & 56 & 50 & 44 & 39 & 33 & 28 & 22 & 17 & 12 & 7 & 2 \\
\hline
\end{tabular}

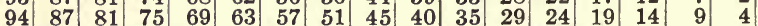

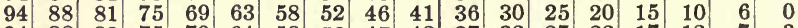

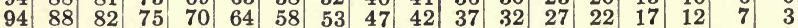

\begin{tabular}{lllllllll|l|l|l|l|l|l|l|l|l|l|}
94 & 88 & 82 & 76 & 70 & 65 & 59 & 54 & 48 & 43 & 38 & 33 & 28 & 23 & 18 & 14 & 9 & 5 & 0
\end{tabular}

\begin{tabular}{|l|l|l|l|l|l|l|l|l|l|l|l|l|l|l|l|l|l|l|}
94 & 88 & 82 & 76 & 71 & 65 & 60 & 55 & 49 & 44 & 39 & 34 & 29 & 25 & 20 & 15 & 11 & 6 & 2 \\
\hline
\end{tabular}

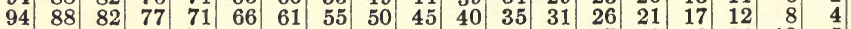

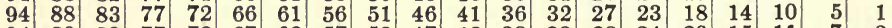

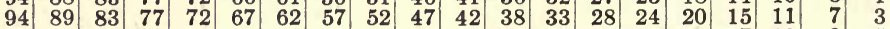

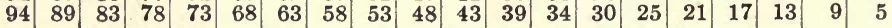

\begin{tabular}{l|l|l|l|l|l|l|l|l|l|l|l|l|l|l|l|l|l|l|l}
94 & 89 & 84 & 78 & 73 & 68 & 63 & 58 & 53 & 49 & 44 & 40 & 35 & 31 & 27 & 22 & 18 & 14 & 10 & 6
\end{tabular}

$\begin{array}{llllllllllllllllllllll}94 & 89 & 84 & 79 & 74 & 68 & 64 & 59 & 54 & 50 & 45 & 40 & 36 & 32 & 28 & 24 & 20 & 16 & 12 & 8\end{array}$

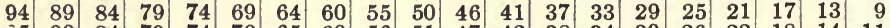

\begin{tabular}{l|l|l|l|l|l|l|l|l|l|l|l|l|l|l|l|l|l|l|l|l|l}
$\mathbf{9 5}$ & 90 & $\mathbf{8 4}$ & $\mathbf{7 9}$ & $\mathbf{7 4}$ & $\mathbf{7 0}$ & $\mathbf{6 5}$ & $\mathbf{6 0}$ & $\mathbf{5 6}$ & $\mathbf{5 1}$ & $\mathbf{4 7}$ & $\mathbf{4 2}$ & $\mathbf{3 8}$ & $\mathbf{3 4}$ & $\mathbf{3 0}$ & $\mathbf{2 6}$ & $\mathbf{2 2}$ & $\mathbf{1 8}$ & $\mathbf{1 4}$ & $\mathbf{1 1}$
\end{tabular}

$\begin{array}{llllllllllllllllllllll}95 & 90 & 85 & 79 & 75 & 70 & 66 & 61 & 56 & 52 & 48 & 43 & 39 & 35 & 31 & 27 & 23 & 20 & 16 & 12\end{array}$

$\begin{array}{llllllllllllllllllllllll}95 & 90 & 85 & 80 & 75 & 70 & 66 & 62 & 57 & 53 & 48 & 44 & 40 & 36 & 32 & 28 & 25 & 21 & 17 & 13\end{array}$

\begin{tabular}{llllllll|l|l|l|l|l|l|l|l|l|l|l|l|l}
95 & 90 & 85 & 80 & 76 & 71 & 66 & 62 & 58 & 53 & 49 & 45 & 41 & 37 & 33 & 29 & 26 & 22 & 18 & 15
\end{tabular}

$\begin{array}{llllllllllllllllllllll}95 & 90 & 85 & 80 & 76 & 71 & 67 & 62 & 58 & 54 & 50 & 46 & 42 & 38 & 34 & 30 & 27 & 23 & 20 & 16\end{array}$

$\begin{array}{lllllllllllllllllllll}95 & 90 & 85 & 81 & 76 & 72 & 67 & 63 & 59 & 55 & 51 & 47 & 43 & 39 & 35 & 31 & 28 & 24 & 21 & 17\end{array}$

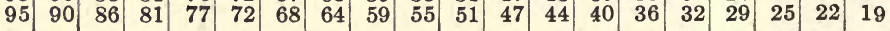

$\begin{array}{llllllllllllllllllllllll}95 & 90 & 86 & 81 & 77 & 72 & 68 & 64 & 60 & 56 & 52 & 48 & 44 & 40 & 37 & 33 & 30 & 26 & 23 & 20\end{array}$

$\begin{array}{llllllllllllllllllllll}95 & 90 & 86 & 82 & 77 & 73 & 69 & 64 & 60 & 56 & 53 & 49 & 45 & 41 & 38 & 34 & 31 & 27 & 24 & 21\end{array}$

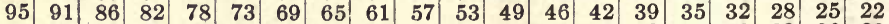

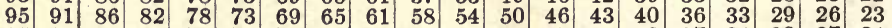
\begin{tabular}{l|l|l|l|l|l|l|l|l|l|l|l|l|l|l|l|l|l|l|l|l|l|l|}
$\mathbf{9 5}$ & $\mathbf{9 1}$ & $\mathbf{8 6}$ & $\mathbf{8 2}$ & $\mathbf{7 8}$ & $\mathbf{7 4}$ & $\mathbf{7 0}$ & $\mathbf{6 6}$ & $\mathbf{6 2}$ & $\mathbf{5 8}$ & $\mathbf{5 4}$ & $\mathbf{5 1}$ & $\mathbf{4 7}$ & $\mathbf{4 4}$ & $\mathbf{4 0}$ & $\mathbf{3 7}$ & $\mathbf{3 4}$ & $\mathbf{3 0}$ & $\mathbf{2 7}$ & $\mathbf{2 4}$
\end{tabular} \begin{tabular}{l|lllllllll|l|l|l|l|l|l|l|l|l|l|l}
96 & 91 & 87 & 82 & 78 & 74 & 70 & 66 & 63 & 59 & 55 & 51 & 48 & 44 & 41 & 38 & 34 & 31 & 28 & 25
\end{tabular} \begin{tabular}{l|l|l|l|l|l|l|l|l|l|l|l|l|l|l|l|l|l|l|l}
96 & 91 & 87 & 83 & 78 & 74 & 70 & 67 & 63 & 59 & 55 & 52 & 48 & 45 & 42 & 38 & 35 & 32 & 29 & 26
\end{tabular} $\begin{array}{lllllllllllllllllllllll}96 & 91 & 87 & 83 & 79 & 75 & 71 & 67 & 63 & 60 & 56 & 52 & 49 & 46 & 42 & 39 & 36 & 33 & 30 & 27\end{array}$ \begin{tabular}{l|l|l|l|l|l|l|l|l|l|l|l|l|l|l|l|l|l|l|l|l|l|l|}
96 & 91 & 87 & 83 & 79 & 75 & 71 & 67 & 64 & 60 & 57 & 53 & 50 & 46 & 43 & 40 & 37 & 34 & 31 & 28
\end{tabular}

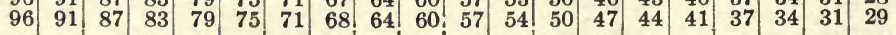


Exercise 53.-Making a Psychrometer and Determining the Relative Humidity

If the laboratory has no psychrometer (Fig. 150), make one by attaching two common thermometers to a piece of inch board 2 by 6 in. Fasten a strong cord to the upper end for whirling the psychrometer about the head. The whirling must be done with care until practice shows the best movements. Fasten a single wrapping of clean muslin about one bulb. Use as in Art. 247. Before using, the readings of the thermometers should be compared for all temperatures, and a correction card made (Art. 226, Fig. 139) for the wet bulb, showing all differences between the thermometers. Correct the readings before using Table XI. Find the humidity: (1) On a clear day; (2) a damp cloudy day; (3) in morning; and (4) in mid-afternoon of a clear day. Record all results.

249. The Hair Hygrometer.-This hygrometer shows relative humidity directly on a dial, and is more convenient than the psychrometer but not so accurate. Human hair, with the oil removed, lengthens with dampness and shortens with drying. A strand of this hair is attached at one end to a rigid frame, and at the other end to the circumference of a small cylinder. A spring holds the hair taut. A pointer is mounted on the

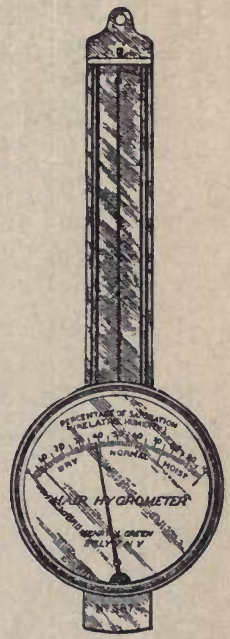

Fig. 151.- $\mathrm{H}$ a i r hygrometer. end of the cylinder. As the hair changes in length with varying humidity it turns the cylinder and moves the pointer over the dial (Fig. 151).

250. Measuring the Moisture; Absolute Humidity.-Table XII, page 220 , may be used together with the relative humidity as found from Table XI, to obtain the weight of the water vapor present, expressed in grains per cubic foot.

In the last problem (Art. 248), the temperature of the space was $50^{\circ}$. Table XII shows that space at $50^{\circ}$, if saturated (humidity 100 per cent.), would contain 4.076 grains of water vapor per cu. $\mathrm{ft}$. But in this problem the humidity was only 77 per cent.; therefore the vapor present is 77 per cent. of 4.076 grains, or 3.14 grains per cu. $\mathrm{ft}$. 
Table XII.-Weight in Grains of Water Vapor per Cubic Foot At Saturation. (Or the Absolute Humidity at Different Temperatures)

\begin{tabular}{|c|c|c|c|c|c|c|c|c|c|}
\hline$\underset{\text { TF. }}{\text { Temp., }}$ & Grains & Temp., & Grains & $\begin{array}{c}\text { Temp., } \\
\text { ॰F. }\end{array}$ & Grains & $\begin{array}{c}\text { Temp., } \\
\text { ॰F. }\end{array}$ & Grains & $\begin{array}{c}\text { Temp., } \\
\circ \mathrm{F} \text {. }\end{array}$ & Grains \\
\hline 0 & 0.481 & 20 & 1.235 & 40 & 2.849 & 60 & 5.745 & 80 & 10.934 \\
\hline+1 & 0.505 & 21 & 1. 294 & 41 & 2.955 & 61 & 5.941 & 81 & 11,275 \\
\hline 2 & 0.529 & 22 & 1.355 & 42 & 3.064 & 62 & 6.142 & 82 & 11.626 \\
\hline 3 & 0.554 & 23 & 1.418 & 43 & 3.177 & 63 & 6.349 & 83 & 11.987 \\
\hline 4 & 0.582 & 24 & 1.483 & 44 & 3.294 & 64 & 6.563 & 84 & 12.356 \\
\hline 5 & 0.610 & 25 & 1.551 & 45 & 3.414 & 65 & 6.782 & 85 & 12.736 \\
\hline 6 & 0.639 & 26 & 1.623 & 46 & 3.539 & 66 & 7.009 & 86 & 13.127 \\
\hline 7 & 0.671 & 27 & 1.697 & 47 & 3.667 & 67 & 7.241 & 87 & 13.526 \\
\hline 8 & 0.704 & 28 & 1.773 & 48 & 3.800 & 68 & 7.480 & 88 & 13.937 \\
\hline 9 & 0.739 & 29 & 1.853 & 49 & 3.936 & 69 & 7.726 & 89 & 14.359 \\
\hline 10 & 0.776 & 30 & 1.935 & 50 & 4.076 & 70 & 7.980 & 90 & 14.790 \\
\hline 11 & 0.816 & 31 & 2.022 & 51 & 4.222 & 71 & 8.240 & 91 & 15.234 \\
\hline 12 & 0.856 & 32 & 2.113 & 52 & 4.372 & 72 & 8.508 & 92 & 15.689 \\
\hline 13 & 0.898 & 33 & 2.194 & 53 & 4.526 & 73 & 8.782 & 93 & 16.155 \\
\hline 14 & 0.941 & 34 & 2.279 & 54 & 4.685 & 74 & 9.066 & 94 & 16.634 \\
\hline 15 & 0.986 & 35 & 2.366 & 55 & 4.849 & 75 & 9.356 & 95 & 17.124 \\
\hline 16 & 1.032 & 36 & 2.457 & 56 & 5.016 & 76 & 9.655 & 96 & $17: 626$ \\
\hline 17 & 1.080 & 37 & 2.550 & 57 & 5.191 & 77 & 9.962 & 97 & 18.142 \\
\hline 18 & 1.128 & 38 & 2.646 & 58 & 5.370 & 78 & 10.277 & 98 & 18.671 \\
\hline 19 & 1.181 & 39 & 2.746 & 59 & 5.555 & 79 & 10.601 & 99 & 19.212 \\
\hline
\end{tabular}

\section{PROBLEM}

Finding the Depth of Rainfall if All Moisture Were Precipitated.Supposing the humidity found in the foregoing problem extended to the height of 2 miles, how much water would be suspended as vapor above each square foot of ground? What would be the depth of rainfall if all moisture were precipitated?

Solution: Humidity 3.14 grains per cu. ft.; in 2 miles depth there are $2 \times 5,280=10,560 \mathrm{cu}$. ft. above each square foot of ground; $10,560 \times 3.14$ grains $=33,158.4$ grains $=4.737 \mathrm{lb}$. of water. $\mathrm{A}$ cubic foot of water weighs $62.4 \mathrm{lb}$. and would be $12 \mathrm{in}$. deep; 4.737 lb. is $\frac{4.737}{62.4} \mathrm{cu}$. ft. The rainfall would therefore be $\frac{4.737}{62.4} \mathrm{ft}$. or 
$0.076 \mathrm{ft}$., or $0.076 \times 12 \mathrm{in}$. in depth. $0.076 \times 12 \mathrm{in}$. equals $0.91 \mathrm{in}$., the depth of rainfall resulting.

Only a part of the moisture in the air is ever precipitated during a storm. In most storms the movements of the air bring additional vapor. Other special conditions assist in furnishing the heavy rains that sometimes fall.

\section{PROBLEMS}

Solve and fill out the additional problems in the following table in the same manner as the solved problem.

$\begin{array}{lccccc} & 1 & 2 & 3 & 4 & 5 \\ \text { Dry thermometer } & 50.0^{\circ} & 70^{\circ} & 60^{\circ} & 50^{\circ} & 30^{\circ} \\ \text { Wet thermometer } & 46.5^{\circ} & 60^{\circ} & 56^{\circ} & 45^{\circ} & 28^{\circ} \\ \text { Difference } & 3.5^{\circ} & 10^{\circ} & & & \\ \text { Relative humidity, } & 77 \% & & & & \\ \text { Grains vapor per cubic feet, } & 3.14 & & & & \\ \text { Pounds vapor in 2 miles of air, } & 4.737 & & & & \\ \text { Inches, rain if all precipitated } & 0.91 & & & & \end{array}$

251. The Dew-point.-Using the readings of the wet and dry thermometers and Table XIII we can obtain the dewpoint. This is the temperature at which dew or frost would begin to form. If the temperature is $70^{\circ}$ and the wet bulb reads $65^{\circ}$, the 62 found in Table XIII at the crossing of the $70^{\circ}$-line and the $5^{\circ}$-column, means that the moisture then present is all that could exist as vapor if the temperature fell to $62^{\circ}$, and dew would begin to form with any further cooling.

252. The Dew-point and the Fall of Temperature at Night. - In clear weather with calm or light winds, the temperature in late afternoon and night often falls at the rate of $3^{\circ}$ (or more) per hour until the dew-point is reached. Then the condensing of water vapor into dew liberates the heat of vaporization (Art. 150) that had been used in forming the vapor. The freeing of that large amount of heat warms the air and checks the rate of cooling, often to about $1^{\circ}$ or $1 \frac{1}{2}{ }^{\circ}$ per hour, after the dew-point is passed. 
Table XIII.-Temperature of DeW-point in Degrees Fahrenheit

\begin{tabular}{|c|c|c|c|c|c|c|c|c|c|c|c|c|c|c|c|c|c|c|c|c|}
\hline \multirow{2}{*}{$\begin{array}{l}\text { Dry- } \\
\text { bulb } \\
\text { temp. }\end{array}$} & \multicolumn{20}{|c|}{ Difference between dry-bulb and wet-bulb temperature } \\
\hline & $\stackrel{0}{-i}$ & $\begin{array}{l}0 \\
\text { i }\end{array}$ & $\dot{0}$ & $\stackrel{\circ}{+}$ & iे & $\stackrel{0}{0}$ & $\stackrel{0}{\circ}$ & $\left|\begin{array}{c}0 \\
\infty\end{array}\right|$ & $\begin{array}{l}0 \\
0\end{array}$ & $\dot{0}$ & $\begin{array}{l}0 \\
- \\
\beth\end{array}$ & $\underset{\stackrel{\sim}{\sim}}{\stackrel{0}{\mid}}$ & $\begin{array}{l}0 \\
\dot{\pi}\end{array}$ & $\begin{array}{l}0 \\
\dot{1}\end{array}$ & $\begin{array}{c}0 \\
10 \\
-1\end{array}$ & $\begin{array}{l}0 \\
\dot{-}\end{array}$ & $\stackrel{0}{\therefore}$ & $\begin{array}{c}0 \\
\infty \\
\sim\end{array}$ & $\begin{array}{l}0 \\
\dot{\sigma}\end{array}$ & $\stackrel{0}{0}$ \\
\hline $\begin{array}{l}30 \\
31 \\
32 \\
33 \\
34\end{array}$ & $\begin{array}{l}27 \\
29 \\
30 \\
31 \\
32\end{array}$ & $\begin{array}{l}25 \\
26 \\
27 \\
28 \\
29\end{array}$ & $\begin{array}{l}22 \\
23 \\
24 \\
25 \\
27\end{array}$ & $\begin{array}{l}18 \\
20 \\
21 \\
22 \\
24\end{array}$ & $\begin{array}{l}14 \\
16 \\
17 \\
19 \\
20\end{array}$ & $\begin{array}{r}9 \\
11 \\
13 \\
15 \\
16\end{array}$ & $\begin{array}{r}+3 \\
5 \\
8 \\
10 \\
12\end{array}$ & $\begin{array}{r}-2 \\
+1 \\
3 \\
6\end{array}$ & -2 & & & & & & & & & & & \\
\hline $\begin{array}{l}35 \\
36 \\
37 \\
38 \\
39\end{array}$ & $\begin{array}{l}33 \\
34 \\
35 \\
36 \\
37\end{array}$ & $\begin{array}{l}30 \\
31 \\
32 \\
33 \\
34\end{array}$ & $\begin{array}{l}28 \\
29 \\
30 \\
31 \\
32\end{array}$ & $\begin{array}{l}25 \\
26 \\
27 \\
28 \\
29\end{array}$ & $\begin{array}{l}22 \\
23 \\
24 \\
26 \\
27\end{array}$ & $\begin{array}{l}18 \\
20 \\
21 \\
23 \\
24\end{array}$ & $\begin{array}{l}14 \\
15 \\
17 \\
19 \\
21\end{array}$ & $\begin{array}{r}8 \\
11 \\
13 \\
14 \\
16\end{array}$ & $\begin{array}{r}+1 \\
4 \\
7 \\
9 \\
12\end{array}$ & $\begin{array}{r}-1 \\
+3 \\
6\end{array}$ & -3 & & & & & & & & & \\
\hline $\begin{array}{l}40 \\
41 \\
42 \\
43 \\
44\end{array}$ & $\begin{array}{l}38 \\
39 \\
40 \\
41 \\
42\end{array}$ & $\begin{array}{l}35 \\
37 \\
38 \\
39 \\
40\end{array}$ & $\begin{array}{l}33 \\
34 \\
35 \\
36 \\
38\end{array}$ & $\begin{array}{l}31 \\
32 \\
33 \\
34 \\
35\end{array}$ & $\begin{array}{l}28 \\
29 \\
30 \\
31 \\
32\end{array}$ & $\begin{array}{l}25 \\
26 \\
28 \\
29 \\
30\end{array}$ & $\begin{array}{l}22 \\
23 \\
25 \\
26 \\
27\end{array}$ & $\begin{array}{l}18 \\
20 \\
21 \\
23 \\
24\end{array}$ & $\begin{array}{l}14 \\
16 \\
17 \\
19 \\
21\end{array}$ & $\begin{array}{r}8 \\
11 \\
13 \\
15 \\
17\end{array}$ & $\begin{array}{r}+1 \\
4 \\
7 \\
10 \\
12\end{array}$ & $\begin{array}{r}-1 \\
+3 \\
6\end{array}$ & -2 & & & & & & & \\
\hline $\begin{array}{l}45 \\
46 \\
47 \\
48 \\
49\end{array}$ & $\begin{array}{l}43 \\
44 \\
45 \\
46 \\
47\end{array}$ & $\begin{array}{l}41 \\
42 \\
43 \\
44 \\
45\end{array}$ & $\begin{array}{l}39 \\
40 \\
41 \\
42 \\
43\end{array}$ & $\begin{array}{l}36 \\
37 \\
39 \\
40 \\
41\end{array}$ & $\begin{array}{l}34 \\
35 \\
36 \\
37 \\
39\end{array}$ & $\begin{array}{l}31 \\
32 \\
34 \\
35 \\
36\end{array}$ & $\begin{array}{l}29 \\
30 \\
31 \\
32 \\
\mathbf{3 4}\end{array}$ & $\begin{array}{l}26 \\
27 \\
28 \\
30 \\
31\end{array}$ & $\begin{array}{l}22 \\
24 \\
25 \\
27 \\
28\end{array}$ & $\begin{array}{l}19 \\
20 \\
22 \\
23 \\
25\end{array}$ & $\begin{array}{l}14 \\
16 \\
18 \\
20 \\
21\end{array}$ & $\begin{array}{r}8 \\
11 \\
13 \\
15 \\
17\end{array}$ & $\begin{array}{r}+2 \\
5 \\
8 \\
10 \\
13\end{array}$ & $\begin{array}{r}-4 \\
\pm 0 \\
+4 \\
7\end{array}$ & -2 & & & & & \\
\hline $\begin{array}{l}50 \\
51 \\
52 \\
53 \\
54\end{array}$ & $\begin{array}{r}48 \\
49 \\
50 \\
51 \\
52\end{array}$ & $\begin{array}{l}46 \\
47 \\
48 \\
49 \\
50\end{array}$ & $\begin{array}{l}44 \\
45 \\
46 \\
47 \\
49\end{array}$ & $\begin{array}{l}42 \\
43 \\
44 \\
45 \\
47\end{array}$ & $\begin{array}{l}40 \\
41 \\
42 \\
43 \\
44\end{array}$ & $\begin{array}{l}37 \\
39 \\
40 \\
41 \\
42\end{array}$ & $\begin{array}{l}35 \\
36 \\
37 \\
39 \\
40\end{array}$ & $\begin{array}{l}32 \\
34 \\
35 \\
36 \\
38\end{array}$ & $\begin{array}{l}29 \\
31 \\
32 \\
34 \\
35\end{array}$ & $\begin{array}{l}27 \\
28 \\
29 \\
31 \\
32\end{array}$ & $\begin{array}{l}23 \\
25 \\
26 \\
28 \\
29\end{array}$ & $\begin{array}{l}19 \\
21 \\
23 \\
24 \\
26\end{array}$ & $\begin{array}{l}15 \\
17 \\
19 \\
21 \\
23\end{array}$ & $\begin{array}{r}9 \\
12 \\
14 \\
16 \\
19\end{array}$ & $\begin{array}{r}+2 \\
6 \\
9 \\
11 \\
14\end{array}$ & $\begin{array}{r}-3 \\
+1 \\
.5 \\
8\end{array}$ & $\begin{array}{l}-5 \\
\pm 0\end{array}$ & & & \\
\hline $\begin{array}{l}\mathbf{5 5} \\
\mathbf{5 6} \\
\mathbf{5 7} \\
\mathbf{5 8} \\
\mathbf{5 9}\end{array}$ & $\begin{array}{l}\mathbf{5 3} \\
\mathbf{5 4} \\
\mathbf{5 5} \\
\mathbf{5 6} \\
\mathbf{5 7}\end{array}$ & $\begin{array}{l}\mathbf{5 2} \\
\mathbf{5 3} \\
\mathbf{5 4} \\
\mathbf{5 5} \\
\mathbf{5 6}\end{array}$ & $\begin{array}{l}\mathbf{5 0} \\
\mathbf{5 1} \\
\mathbf{5 2} \\
\mathbf{5 3} \\
\mathbf{5 4}\end{array}$ & $\begin{array}{l}48 \\
49 \\
50 \\
51 \\
52\end{array}$ & $\begin{array}{l}46 \\
47 \\
48 \\
49 \\
50\end{array}$ & $\begin{array}{l}43 \\
45 \\
46 \\
47 \\
48\end{array}$ & $\begin{array}{l}41 \\
43 \\
44 \\
45 \\
46\end{array}$ & $\begin{array}{l}39 \\
40 \\
42 \\
43 \\
44\end{array}$ & $\begin{array}{l}36 \\
38 \\
39 \\
40 \\
42\end{array}$ & $\begin{array}{l}34 \\
35 \\
36 \\
38 \\
39\end{array}$ & $\begin{array}{l}31 \\
32 \\
34 \\
35 \\
37\end{array}$ & $\begin{array}{l}28 \\
29 \\
31 \\
32 \\
34\end{array}$ & $\begin{array}{l}24 \\
26 \\
28 \\
29 \\
31\end{array}$ & $\begin{array}{l}21 \\
23 \\
24 \\
26 \\
28\end{array}$ & $\begin{array}{l}16 \\
19 \\
21 \\
22 \\
24\end{array}$ & $\begin{array}{l}11 \\
14 \\
16 \\
18 \\
20\end{array}$ & $\begin{array}{r}+4 \\
7 \\
10 \\
13 \\
16\end{array}$ & $\begin{array}{r}-1 \\
+3 \\
7 \\
10\end{array}$ & $\begin{array}{l}-2 \\
+2\end{array}$ & \\
\hline $\begin{array}{l}60 \\
61 \\
62 \\
63 \\
64\end{array}$ & $\begin{array}{l}58 \\
59 \\
60 \\
61 \\
62\end{array}$ & $\begin{array}{l}\mathbf{5 7} \\
\mathbf{5 8} \\
\mathbf{5 9} \\
\mathbf{6 0} \\
\mathbf{6 1}\end{array}$ & $\begin{array}{l}\mathbf{5 5} \\
\mathbf{5 6} \\
\mathbf{5 7} \\
\mathbf{5 8} \\
\mathbf{5 9}\end{array}$ & $\begin{array}{l}53 \\
54 \\
55 \\
56 \\
58\end{array}$ & $\begin{array}{l}51 \\
52 \\
54 \\
55 \\
56\end{array}$ & $\begin{array}{l}49 \\
51 \\
52 \\
53 \\
54\end{array}$ & $\begin{array}{l}47 \\
49 \\
50 \\
51 \\
52\end{array}$ & $\begin{array}{l}45 \\
46 \\
48 \\
49 \\
50\end{array}$ & $\begin{array}{l}43 \\
44 \\
46 \\
47 \\
48\end{array}$ & $\begin{array}{l}41 \\
42 \\
43 \\
45 \\
46\end{array}$ & $\begin{array}{l}38 \\
39 \\
41 \\
42 \\
44\end{array}$ & \begin{tabular}{|l|}
35 \\
37 \\
38 \\
40 \\
41
\end{tabular} & $\begin{array}{l}32 \\
34 \\
35 \\
37 \\
38\end{array}$ & \begin{tabular}{|l|}
29 \\
31 \\
32 \\
34 \\
36
\end{tabular} & $\begin{array}{l}26 \\
28 \\
30 \\
31 \\
33\end{array}$ & $\begin{array}{l}22 \\
24 \\
26 \\
28 \\
30\end{array}$ & $\begin{array}{l}18 \\
20 \\
22 \\
24 \\
26\end{array}$ & $\begin{array}{l}13 \\
16 \\
18 \\
20 \\
23\end{array}$ & $\begin{array}{r}6 \\
10 \\
13 \\
16 \\
18\end{array}$ & $\begin{array}{r}-3 \\
+2 \\
6 \\
10 \\
13\end{array}$ \\
\hline $\begin{array}{l}65 \\
66 \\
67 \\
68 \\
69\end{array}$ & $\begin{array}{l}63 \\
64 \\
65 \\
67 \\
68\end{array}$ & $\begin{array}{l}62 \\
63 \\
64 \\
65 \\
66\end{array}$ & $\begin{array}{l}60 \\
61 \\
62 \\
63 \\
64\end{array}$ & $\begin{array}{l}59 \\
60 \\
61 \\
62 \\
63\end{array}$ & $\begin{array}{l}\mathbf{5 7} \\
\mathbf{5 8} \\
59 \\
60 \\
61\end{array}$ & $\begin{array}{l}55 \\
56 \\
57 \\
58 \\
60\end{array}$ & $\begin{array}{l}\mathbf{5 3} \\
\mathbf{5 4} \\
56 \\
57 \\
58\end{array}$ & $\begin{array}{l}51 \\
53 \\
54 \\
55 \\
56\end{array}$ & $\begin{array}{l}49 \\
51 \\
52 \\
53 \\
54\end{array}$ & $\begin{array}{l}47 \\
48 \\
50 \\
51 \\
52\end{array}$ & $\begin{array}{l}45 \\
46 \\
48 \\
49 \\
50\end{array}$ & \begin{tabular}{|l|}
43 \\
44 \\
45 \\
47 \\
48 \\
\end{tabular} & $\begin{array}{l}40 \\
42 \\
43 \\
44 \\
46\end{array}$ & $\begin{array}{l}37 \\
39 \\
40 \\
42 \\
43\end{array}$ & \begin{tabular}{|l}
34 \\
36 \\
38 \\
39 \\
41
\end{tabular} & $\begin{array}{l}31 \\
33 \\
35 \\
36 \\
38\end{array}$ & $\begin{array}{l}28 \\
30 \\
32 \\
33 \\
35\end{array}$ & $\begin{array}{l}25 \\
27 \\
29 \\
30 \\
32\end{array}$ & $\begin{array}{l}21 \\
23 \\
25 \\
27 \\
29\end{array}$ & $\begin{array}{l}16 \\
18 \\
21 \\
23 \\
25\end{array}$ \\
\hline $\begin{array}{l}70 \\
71 \\
72 \\
73 \\
74\end{array}$ & $\begin{array}{l}69 \\
70 \\
71 \\
72 \\
73\end{array}$ & $\begin{array}{l}67 \\
68 \\
69 \\
70 \\
71\end{array}$ & $\begin{array}{l}66 \\
67 \\
68 \\
69 \\
70\end{array}$ & $\begin{array}{l}64 \\
65 \\
66 \\
67 \\
68\end{array}$ & $\begin{array}{l}62 \\
63 \\
65 \\
66 \\
67\end{array}$ & $\begin{array}{l}61 \\
62 \\
63 \\
64 \\
65\end{array}$ & $\begin{array}{l}59 \\
60 \\
61 \\
62 \\
64\end{array}$ & $\begin{array}{l}\mathbf{5 7} \\
\mathbf{5 8} \\
\mathbf{6 0} \\
\mathbf{6 1} \\
\mathbf{6 2}\end{array}$ & $\begin{array}{l}\mathbf{5 5} \\
\mathbf{5 7} \\
\mathbf{5 8} \\
\mathbf{5 9} \\
\mathbf{6 0}\end{array}$ & $\begin{array}{l}53 \\
55 \\
56 \\
57 \\
58\end{array}$ & $\begin{array}{l}51 \\
53 \\
54 \\
55 \\
56\end{array}$ & $\begin{array}{l}49 \\
51 \\
52 \\
53 \\
54\end{array}$ & $\begin{array}{l}47 \\
49 \\
50 \\
51 \\
53\end{array}$ & $\begin{array}{l}45 \\
46 \\
48 \\
49 \\
50\end{array}$ & \begin{tabular}{|l|}
42 \\
44 \\
45 \\
47 \\
48
\end{tabular} & $\begin{array}{l}40 \\
41 \\
43 \\
44 \\
46\end{array}$ & $\begin{array}{l}37 \\
38 \\
40 \\
42 \\
43\end{array}$ & $\begin{array}{l}34 \\
36 \\
37 \\
39 \\
41\end{array}$ & $\begin{array}{l}31 \\
32 \\
34 \\
36 \\
38\end{array}$ & $\begin{array}{l}27 \\
29 \\
31 \\
33 \\
35\end{array}$ \\
\hline $\begin{array}{l}75 \\
76 \\
77 \\
78 \\
79\end{array}$ & $\begin{array}{l}74 \\
75 \\
76 \\
77 \\
78\end{array}$ & $\begin{array}{l}72 \\
73 \\
74 \\
75 \\
76\end{array}$ & $\begin{array}{l}71 \\
72 \\
73 \\
74 \\
75\end{array}$ & $\begin{array}{l}69 \\
70 \\
71 \\
72 \\
73\end{array}$ & $\begin{array}{l}68 \\
69 \\
70 \\
71 \\
72\end{array}$ & $\begin{array}{l}66 \\
67 \\
68 \\
69 \\
70\end{array}$ & $\begin{array}{l}65 \\
66 \\
67 \\
68 \\
69\end{array}$ & $\begin{array}{l}63 \\
64 \\
65 \\
66 \\
67\end{array}$ & $\begin{array}{l}61 \\
62 \\
64 \\
65 \\
66\end{array}$ & $\begin{array}{l}60 \\
61 \\
62 \\
63 \\
64\end{array}$ & $\begin{array}{l}58 \\
59 \\
60 \\
61 \\
62\end{array}$ & \begin{tabular}{|l|}
56 \\
57 \\
58 \\
59 \\
61
\end{tabular} & $\begin{array}{l}54 \\
55 \\
56 \\
58 \\
59\end{array}$ & $\begin{array}{l}52 \\
53 \\
54 \\
56 \\
57\end{array}$ & $\begin{array}{l}50 \\
51 \\
52 \\
54 \\
55\end{array}$ & $\begin{array}{l}47 \\
49 \\
50 \\
52 \\
53\end{array}$ & $\begin{array}{l}45 \\
46 \\
48 \\
49 \\
51\end{array}$ & $\begin{array}{l}42 \\
44 \\
46 \\
47 \\
49\end{array}$ & $\begin{array}{l}40 \\
41 \\
43 \\
44 \\
46\end{array}$ & $\begin{array}{l}37 \\
38 \\
40 \\
42 \\
44\end{array}$ \\
\hline 80 & 79 & 77 & 76 & 75 & 73 & 72 & 70 & 69 & 67 & 65 & 64 & 62 & 60 & 58 & 56 & 54 & 52 & 50 & 48 & 45 \\
\hline
\end{tabular}


If, then, the temperature at 4 p.m. were $65^{\circ}$ and the rate of fall $3^{\circ}$ per hour, notice the difference in the fall of temperature that would occur with different dew-point conditions (assuming that the dew-point does not change during the night).

(1) If the dew-point were $29^{\circ}$ (this would seldom occur with a temperature of $65^{\circ}$ except in dry regions), the temperature would fall steadily through the night, reaching $29^{\circ}$ at 4 a.m. and, probably, $26^{\circ}$ or $27^{\circ}$ at 6 o'clock. (2) If the dew-point were $38^{\circ}$, the temperature would reach it about 1 a.m., and the slow fall thereafter would reach $30^{\circ}$ or $32^{\circ}$ by morning. (3) If the dew-point were $44^{\circ}$, the falling temperature would reach it before midnight, but would not go lower than $35^{\circ}$ by morning.

\section{Exercise 54.-To Construct Typical Daily Temperature and Dew-point Curves}

Figure 152 illustrates the rate of fall for somewhat different conditions. The student will prepare another similar diagram, using

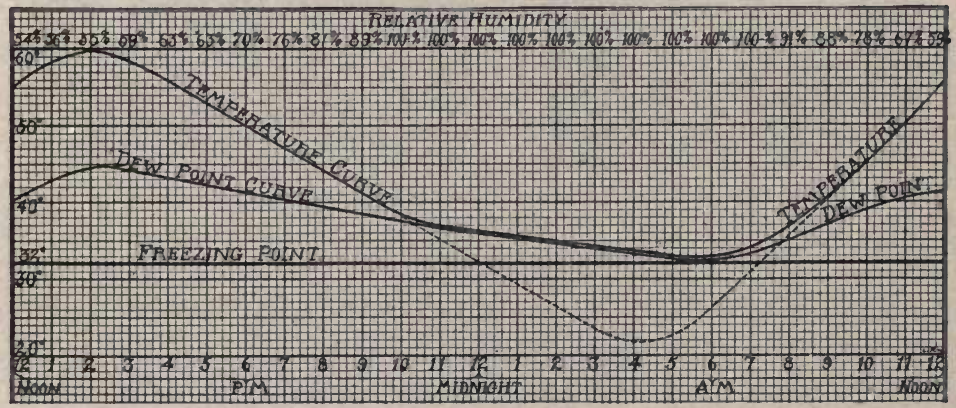

Fig. 152.-This figure shows the general or usual relation of temperature and the dew-point throughout the day. The dotted line shows about how the temperature would fall were it not for the heat of condensation set free when dew forms. Note the rather sharp bend in the temperature curve when dew begins to form.

the same dew-point curve, but drawing a temperature curve showing a maximum of $70^{\circ}$ at 2.30 p.m., $65^{\circ}$ at 4 p.m., and after that hour a fall of $3^{\circ}$ per hour until the dew-point is reached. 


\section{Condensation of Water Vapor ; Dew and Hoar Frost.-} As the ground and vegetation cools by radiation to a temperature below the dew-point, a thin layer of air is cooled by contact with the chilled ground or foliage, and dew or frost condenses from a thin film of air next the chilled object. If the temperature is above $32^{\circ}$ dew forms; if $32^{\circ}$ or lower, frost

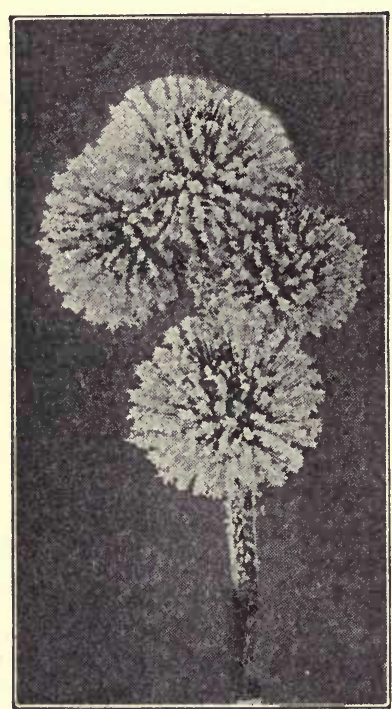

FIG. 153.-Frost on vegetation. Frost on windows often shows beautiful designs. results. Hoar frost is made of minute crystals of ice which arrange themselves in beautiful and sometimes fantastic designs (Fig. 153). Dew is water and is usually in small droplets. The large drops frequently seen on the edges or points of grass or leaves

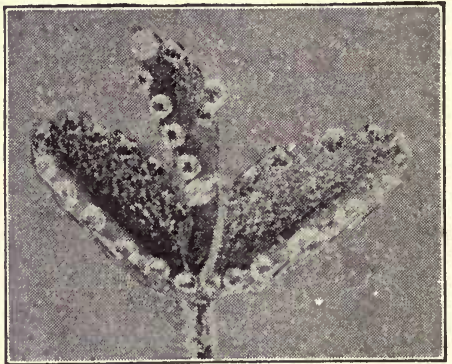

Fig. 154.-A photograph of dew.

are not always dew, but are often water that has been given off by the plant through its leaves. Figure 154 is a photograph showing both the small droplets of dew and other large drops, some of which may be "false dew" given off by the leaves.

254. Condensation; Ground Fog.-During the formation of dew or frost the air often remains clear. But the night cooling may go far enough to chill the whole mass of air near the ground below its dew-point. Then a part of the vapor within the chilled air is condensed into very small but visible particles of water that remain suspended in the air as FoG. 
Sometimes the beginning of this may be seen first in the few inches of air near the ground, gradually deepening as the air chills higher. Night fogs usually form first on low ground, partly because of air drainage from the slopes (Art. 238), and possibly, in part, because the low ground is usually more moist and may give off more water vapor to the air resting upon it. This raises the humidity over low ground so that the night cooling reaches the dew-point earlier there, and so begins sooner to form fog over the damp lowlands.

Deep, widespread fogs are formed in a different way; they are often formed by the mixing of masses of warm air with masses of cold air; sometimes, especially in winter, by warm damp winds blowing over a colder region.

255. Vapor Condensation; Clouds. - The lowest clouds and all the denser clouds resemble fog. Clouds are formed by the condensation of water vapor in the free air. They constitute an almost endless panorama, full of interest and often of beauty. Clouds are the messengers of the air; often they are harbingers of sunny days; frequently they are outriders of a storm; sometimes they are mere idlers in the vault of blue. They are useful indicators of local weather changes to come. What the clouds tell depends on what one knows of them, on the attention given to them, and also to some extent on the section of country. Clouds do not give the knowledge of general storms and their movements that weather maps give us; but they often give additional information of considerable use in one's own locality, and clouds may be valuable to those who do not promptly receive the map forecasts. To make clouds useful, the reader must become acquainted with them. The following paragraphs offer a beginning and suggest how to continue the study.

Clouds are grouped into several classes. Figure 155 shows the principal types in the order of their elevation. Some of these forms are further illustrated in Figs. 156 to 164. The following table gives the chief divisions and a number of their combinations. 
NAMES.

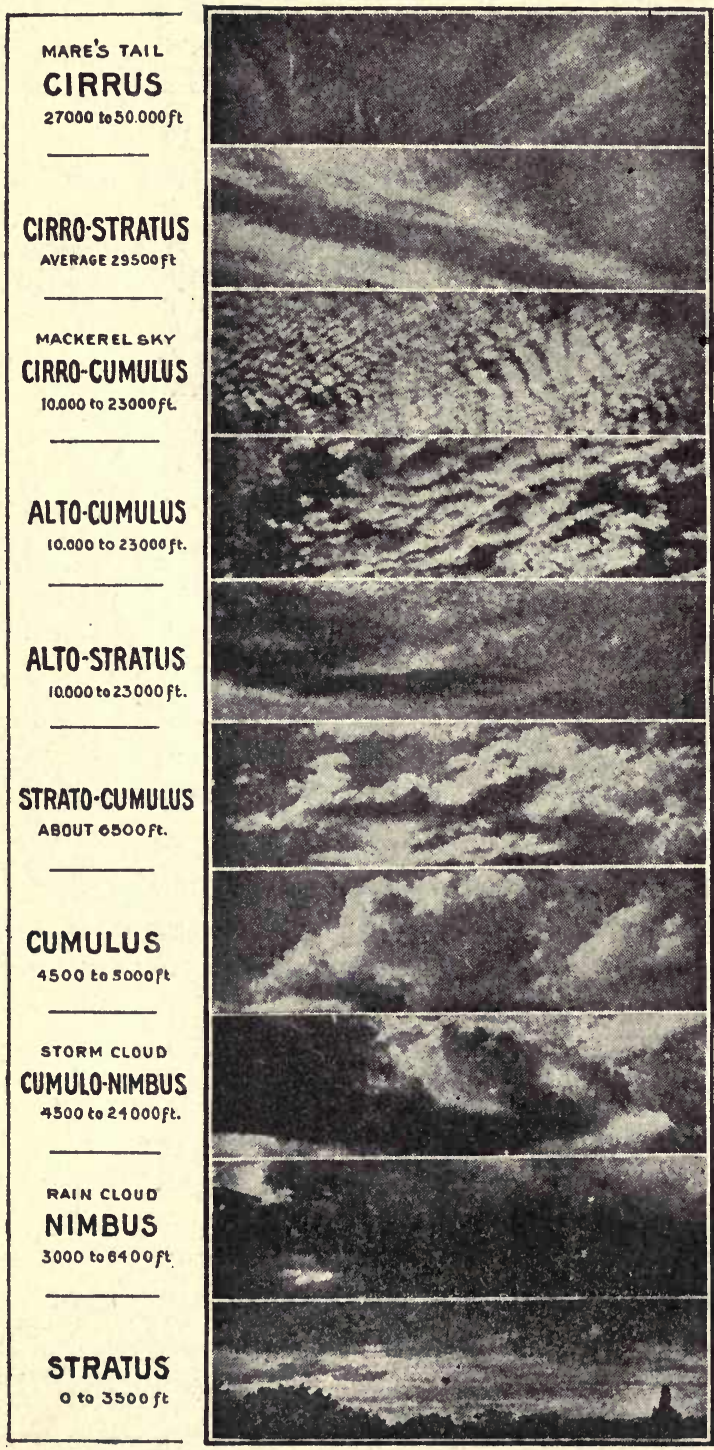

HEIGHT, COMPAFISON. OBJECTS

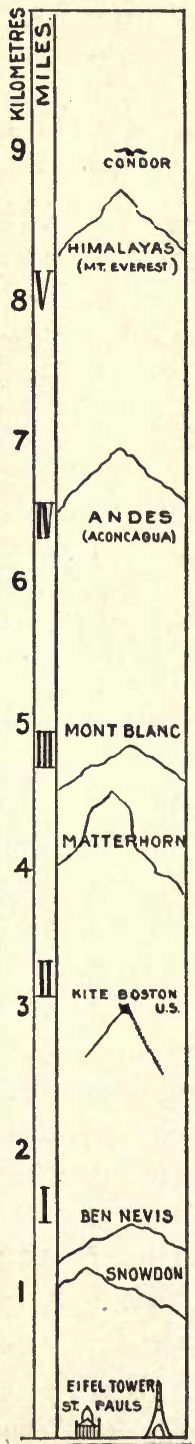

Frg. 155.-Cloud forms, in order of their elevation. 


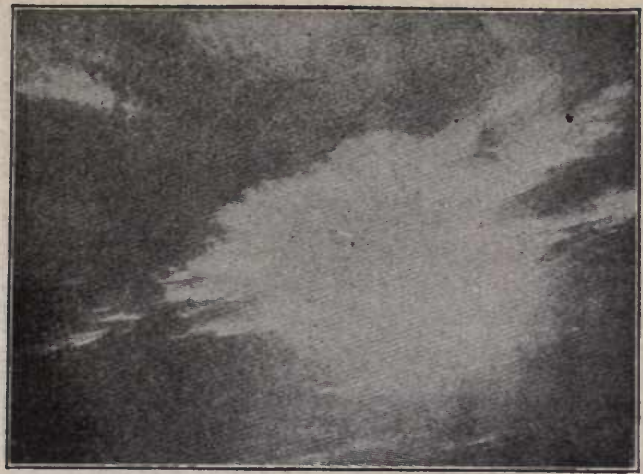

FIg. 156.-Cirrus clouds. Light feathery clouds that float at an elevation of 4 or 5 miles above the earth's surface. When in the form of plumes with frayed and torn edges increasing cloudiness and rain or snow are usually indicated, especially if the clouds are moving rapidly. Cirrus moving very slowly seldom indicate an approaching storm. In temperate latitudes cirrus nearly always move from a westerly direction.

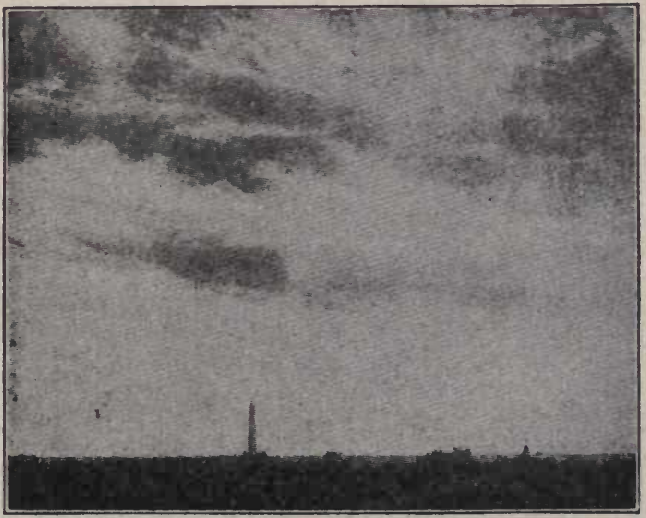

Fig. 157.-Cirrus, merging into cirro-stratus clouds. A form often seen when rain or snow is approaching. The cloud layer seems to thicken gradually until the sky is obscured. This thickening is sometimes partly due to the growth of the clouds themselves; usually it is caused mainly by the coming of denser masses as the earlier clouds pass on. 


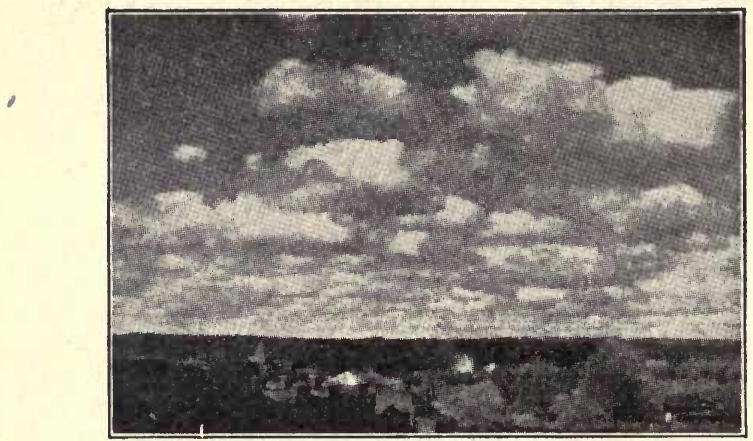

Frg. 158.-Fair-weather cumulus clouds. - This type of cumulus is of ten seen. Note the level bases and rounded tops. (The bases are all at the same height, though the distant bases appear lower because farther away.) These clouds do not indicate rain.

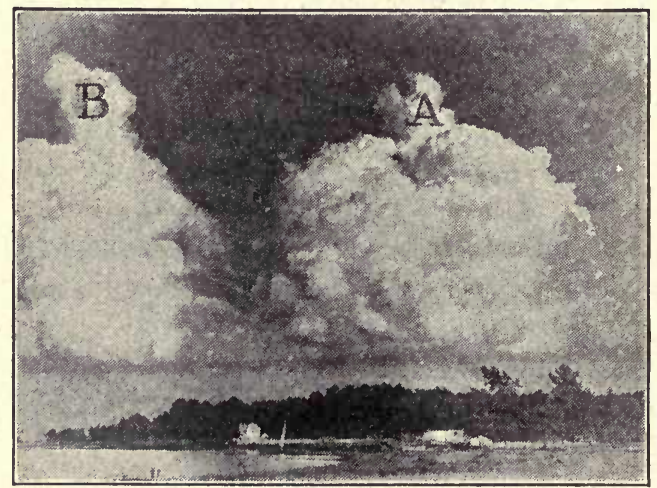

Fig. 159.-A large cumulus. Note the level base and high tops. The turret above each dome shows a much stronger upward current of air at those points. The slightly fringed appearance of turret " $A$ " shows the beginning of rain formation in that part of the cloud. 


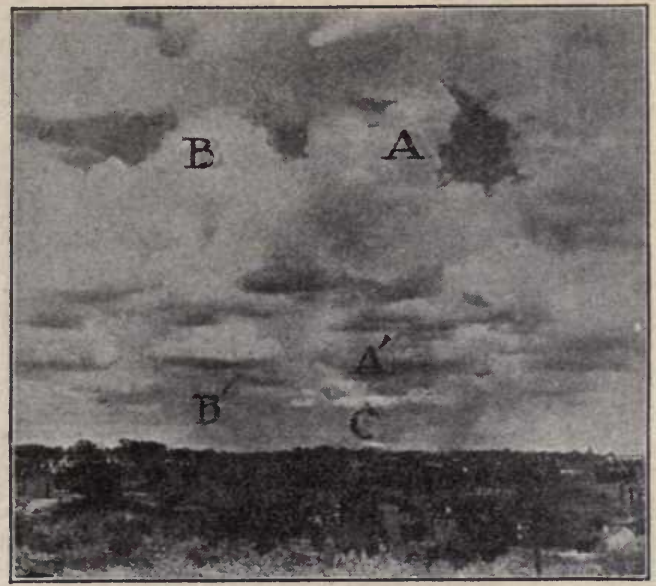

Fig. 160.-Cumulus Clouds. Types frequently seen in summer. Tops like " $A$ " are likely to develop showers, sometimes before long. The dark spot $A^{\prime}$ is the base of " $A$ " or of a similar top behind " $A$." The top " $B$ " is slightly fringed, showing that rain has begun. The rain seen at $B^{\prime}$ is probably falling from cloud " $B$." The rain at " $C$ " apparently falls from another cloud behind " $A$. "

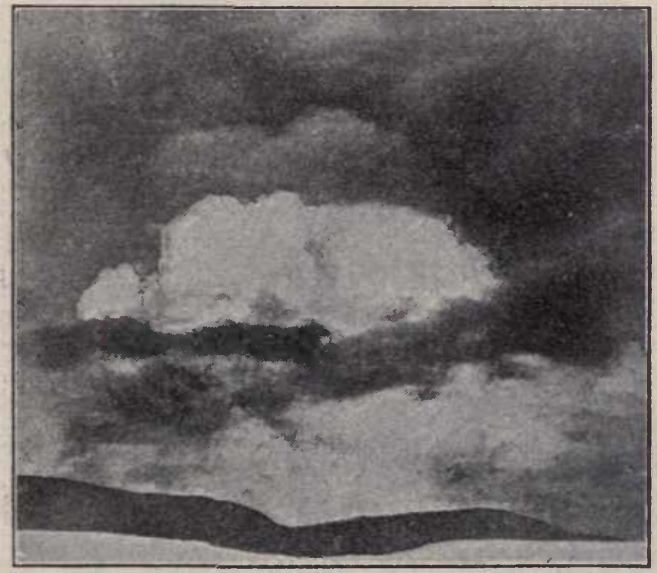

FIg. 161.--Large cumulus, partly hidden. The dark clouds across its front are rather low clouds much nearer the camera.... Note the brilliantly lighted top. The sharp, clean-cut outline above shows that no rain has developed in the portions visible. 


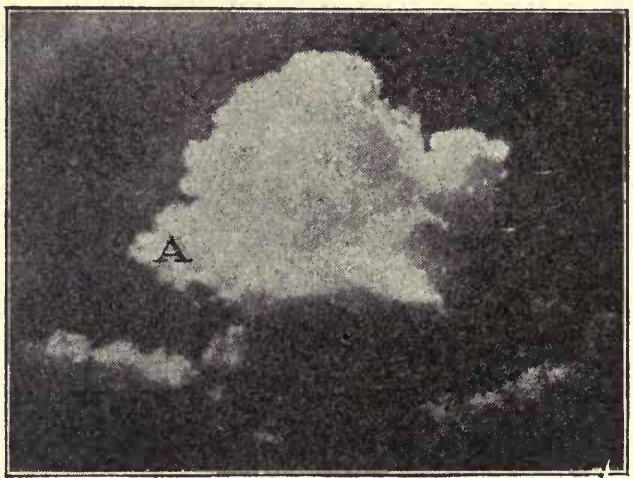

Fig. 162.-A Cumulo-Nimbus, or th!nder head. This cloud has begun to rain, but not long ago. The longer cirrus fringe at $A$ shows that portion probably began raining before the other visible portions.

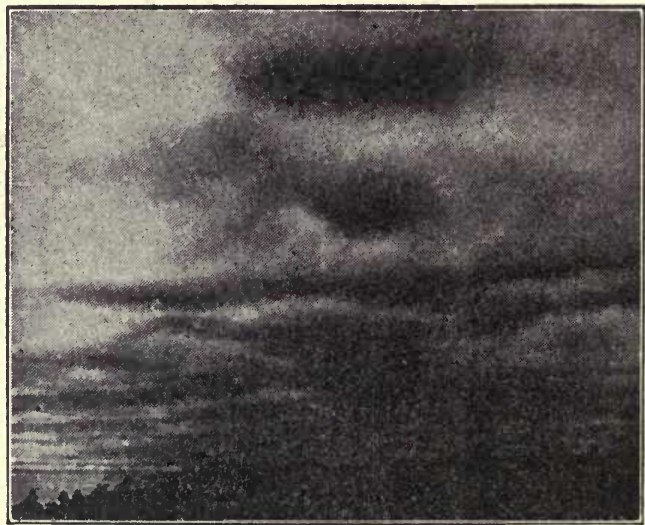

Fig. 163.-Strato-Cumulus, lower surface. Note the uneven shading. The dark spots are sometimes caused by the greater thickness of the cloud at those spots; sometimes by the shadows of higher clouds falling upon the strato-cumulus layer. 


\section{Clouds}

Class

1. Cirrus.

2. Cumulus.

3. Stratus.

5. Alto-stratus.

6. Cirro-cumulus.

4. Cirro-stratus. Striated or filament structure (Figs. 155, 156). Casts no shadow. Usually moves from westerly points. Usually 5 to 7 miles high. Speed, 0 to 120 miles per hour.

The heap cloud common in summer. Usually dense; shaded on side away from sun. Height, base $1 / 4$ to 1 ; top $1 / 2$ to 3 miles (Figs. 158 to 161 ).

The sheet or layer cloud of all seasons. Dark color, often more or less broken. Usually $1 / 4$ to $3 / 4$ mile high (Figs. 155,164 ).

Combination Types

Structure of cirrus. Filaments interlaced or interwoven in sheet or layer form; merges into alto-stratus; 2 to 6 miles high (Figs. 155, 157).

(Alto means high) A high layer cloud, sometimes resembling dense cirro-stratus, and sometimes of a lumpy structure; 3 to 5 miles high (Fig. 155).

Balls or heaps or "fleeces" showing some of the striated texture of cirrus, and casting no shadow. Usually 3 to 6 miles high (Fig. 155).

7. Alto-cumulus. A high cumulus; often does not move in same direction as ground wind. 2 to 4 miles high, (Fig. 155).

8. Strato-cumulus. Lower surface often like stratus; tops resemble cumulus grouped together in mass. Sometimes broken showing clear sky or higher clouds above; often appears in long rolls with gaps between. Grades all the way from stratus to cumulus, $1 / 2$ to 3 miles high (Figs. 155, 164, 165).

9. Cumulunimbus.

10. Nimbus.
A cumulus cloud that is raining; is generally of large size. This is the thunder shower cloud. Base usually $1 / 2$ to $11 / 2$ miles high; top 3 to 8 miles (Figs. 160, B, and 162).

Any cloud from which precipitation is falling. Has no special form. May be of any stratus or cumulus forms except cirro-stratus or cirrocumulus (Figs. 155, 162). 
Aside from the necessary connection of some cloud forms with rain or snow, cloudiness is important as a weather feature because it obstructs sunshine, and in that way affects nearly all other weather elements. In recording sunshine, a day is called clear if not over $3 / 10$ clouded; $4 / 10$ to $7 / 10$ is called partly cloudy, and $8 / 10$ or over, cloudy.

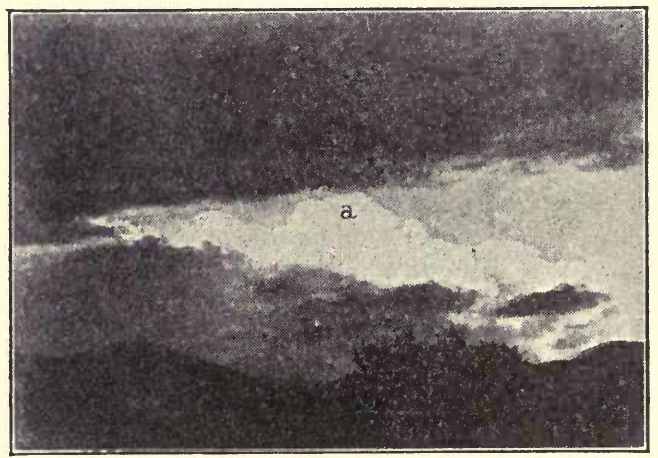

FIG. 164.- Strato-Cumulus, broken, showing irregular upper surface. The dark spots on the under surface are of ten caused by higher tops like " $a$ " above. Dark patches on strato-cumulus or stratus, are also caused by broken or irregular clouds of a higher type such as alto-cumulus above, whose shadows fall on the lower clouds.

256. The Formation of Clouds.-Clouds may be formed by several processes. The most important method is by the cooling that takes place in ascending currents of air that is relatively warm and moist. This cooling is due chiefly to the expansion of the rising air as the pressure of the surrounding air upon it grows less with its ascent. Such cooling is called dynamic cooling, and is the principal cause of cumulus clouds.

257. The Cumulus Cloud; Air Movements Forming It. - The cumulus (Figs. 155 and 159) is the familiar cloud of summer days, with rounded top and flattened base and great variety of size. The earth's surface is warmed by the sun and in turn heats the lower air. By mid-forenoon of a clear summer day, 
the lower air becomes considerably warmer, and, therefore, lighter, than the air above. The heavier air, then, is above, and rests upon a mass of warmer and lighter air next to the earth. Soon the warm air breaks through and ascends in broad streams here and there, while the cooler, heavier air settles downward between the streams of warm air (Fig. 165). The ascending streams continue to rise as long as their temperature is higher than the air through which they are ascending. They cool as they rise, and when they become as cool as the surrounding air their upward movement stops. ${ }^{1}$ Sometimes the current stops before it has risen high enough to form clouds ( $A$, Fig. 165), then nothing is seen of it. But when

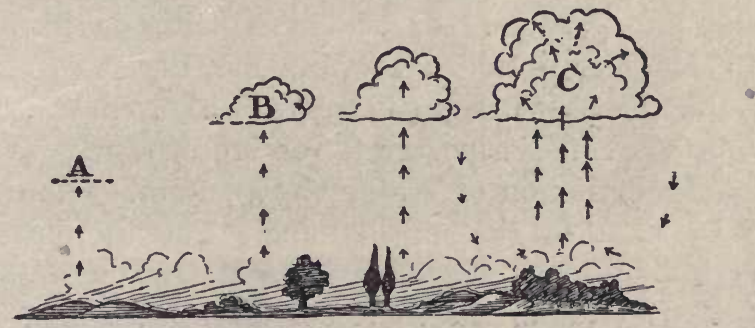

Fig. 165.-Rising air currents, due to warming of earth's surface.

At " $A$ ". no cloud is formed.

At " $B$ " a small cloud results.

At " $C$ " a stronger current builds a much higher cloud.

any current ascends high enough to cool below the dew-point of its rising air, cloud immediately begins to form. ${ }^{2}$ This point marks the base of the cumulus, and is at the same level for all cumuli (plural of cumulus) forming at that time and in that neighborhood.

258. The Size of a Cumulus Cloud.-(1) If the rising air at the cloud base is only a little warmer than the surrounding air, it will rise only a little higher and will form a low-topped cloud (Fig. 158). (2) If the rising air at the cloud base is con-

1 Effect of momentum is disregarded here.

${ }^{2}$ Special conditions such as supersaturation are not entered into in this discussion. 
siderably warmer than the surrounding air it will rise considerably higher than the base and so build a tall cloud (Figs. 159 and 160). (3) The volume of the ascending current and (4) the amount of water vapor in it also help determine the size of the cumulus. Cumulus clouds sometimes form over a large fire when none appear elsewhere. The heat of the fire aids in sending the air current high enough to develop cloud. Cumulus clouds over low islands in the sea are caused by the greater heating of the land surface and the air over it. The heating of a mountain slope and the upward deflection of the wind blowing against the mountain side, commonly cause earlier and larger cumuli over mountains.

Cumuli are often fair weather clouds; at other times they develop into showers. By watching their growth, one familiar with clouds can usually see whether or not showers are probable, and the paths they will follow. Showers will be studied after briefly considering the formation of rain.

259. Precipitation of Water Vapor; Rain.-Cumulus cloud particles float in the air like fog. The air current rising through the cloud aids in keeping the water droplets from falling. But under the right conditions of temperature and moisture, condensation goes so far that the lighter droplets join together and many become heavy enough to fall to earth. Rain drops reach the ground in various sizes ranging sometimes up to $1 / 4 \mathrm{in}$. or more in diameter. Their sizes may be measured by catching the rain in an inch or so of flour and measuring the pellets formed in the flour. Then a medicine dropper may be used to let artificial drops fall into the flour, first measuring their diameters. By comparing the sizes of the flour pellets formed by the artificial drops with those formed by the rain, a fair idea of the size of the rain drops may be obtained.

260. Precipitation; Snow.-When the temperature in the cloud is below freezing, snow forms instead of rain. Snow flakes, when not too much broken by the wind, show a great variety of beautiful forms. Those in Fig. 166 were caught 
on a board covered with dark cloth, arranged just outside a window so the flakes could be photographed through the glass. More than 1700 different forms of snow flakes have been photographed by Mr. W. A. Bentley of Jericho, Vt.
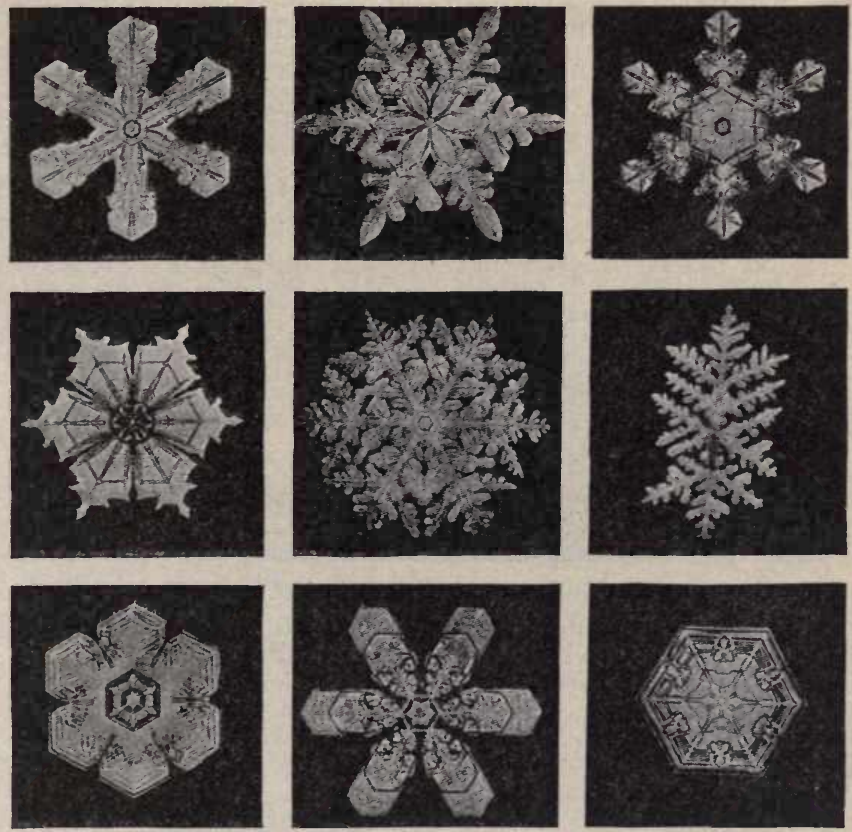

FrG. 166.-Types of snow crystals.

\section{LOCAL STORMS}

261. Local Storms; Showers.-The showers of summer nearly always develop from cumulus clouds. These showers are one of the most interesting weather features to observe. They sometimes form in an hour or two from a clear sky. Though they usually move eastward, they may come from any point of the compass. They sometimes appear to travel backward or sidewise instead of proceeding forward. Thus, the summer shower often seems to come with little or no warn- 
ing, and to travel without law or system of movement. This makes it a troublesome type of weather to those in outdoor occupations. But in most sections of the United States both the developing of these showers and the paths they will follow may usually be known some time in advance.

262. Showers from the Larger Cumuli.-A cumulus cloud that is likely to rain nearly always builds up higher than others

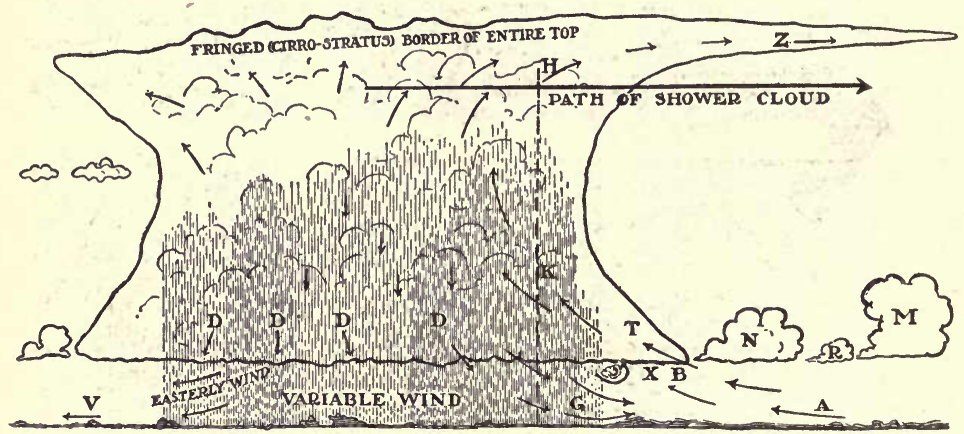

FIG. 167.-Diagram of a typical thunderstorm.

$A, B$. Warm air flowing into and up through the cloud, largely from in front but often also from sides.

$D$. Downward movement of air within a portion of the storm.

$Z$. Cirro-stratus advance sheet extending often far in front.

$M, N, R$. Lower clouds in front of storm, almost any size and amount may be present.

$G$. Outflowing wind of storm front.

$X$. Squall cloud, a ragged roll mixing and tumbling; not always present.

$T$. Front of main cloud.

$H, K$. Points mentioned in discussing hail.

$V$. Backward flow of air in rear of storm; not always present.

near by, and generally becomes denser in structure so that its bottom is darker. The high top is usually of rather solid texture, and is brilliant white or golden-white on the sunny side and dark on the shaded side. When rain begins to fall a wispy fiber-like fringe appears at the top of the raining portion (Figs. 160, $B$, and 162, $A$ ). As the shower develops, this fringe at the top spreads out in front and often on both sides, and sometimes also to the rear. It extends much the farthest in 
front, since the air current carrying the cloud moves faster above and so brushes the fringe ahead (Fig. 167, Z).

263. Showers; to Foresee Their Coming; the Path of the Cumulus.-To foresee the coming of local showers, first find the direction of path being followed by the larger cumuli. Lower cumuli or stratus may be present at the same time and may move in one or more directions. But in finding the shower path the higher cumuli are the ones to watch. To find the direction they are moving, take a position so that some conspicuous point on the cloud is directly in line with a convenient fixed point of roof or chimney or tower. Hold the head motionless and continue to "sight" past the chimney (or fixed point) to the cloud. As the cloud travels it will seem to move away from the chimney. Note carefully the direction it follows. If, for example, the cloud is exactly in the southwest, as $A$, Fig. 168, and appears to move directly

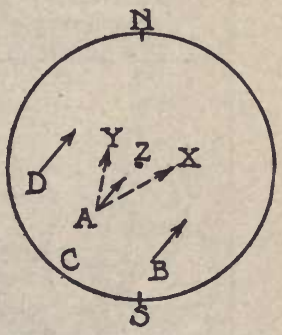

Fig. 168.-The path of a cloud. toward $Z$ (the point overhead), then the cloud is following the direction $A-Z$, which in this figure is from the southwest. If the cloud moves toward a point west of the zenith (point overhead), as toward $Y$, it is traveling in the direction $A-Y$. And if it moves toward a point east of the zenith, as $X$, the cloud is traveling in the direction $A-X$. Try to select a cloud and a place to stand, so that the cloud you are watching will move either directly toward the zenith or directly away from the zenith, as that makes it easier to find the direction accurately. Among the middle and upper types (Fig. 155) all clouds of the same kind and same height, within your horizon, àre moving in the same direction. This is not always true of lower clouds.

If, then, a large cumulus at $A$ (Fig. 168) is moving in the direction $A-Z$, all similar clouds are moving in the same direction. And such clouds, or showers from them, that appear at " $B$ " or " $D$ " will travel in the direction the arrows 
point and will not pass over your locality at " $Z$." It follows that, if you receive any rain at " $Z$," the rain clouds will approach from the direction " $A$."

264. To Foresee Showers; the Clouds that May Rain.After finding the direction from which shower clouds may

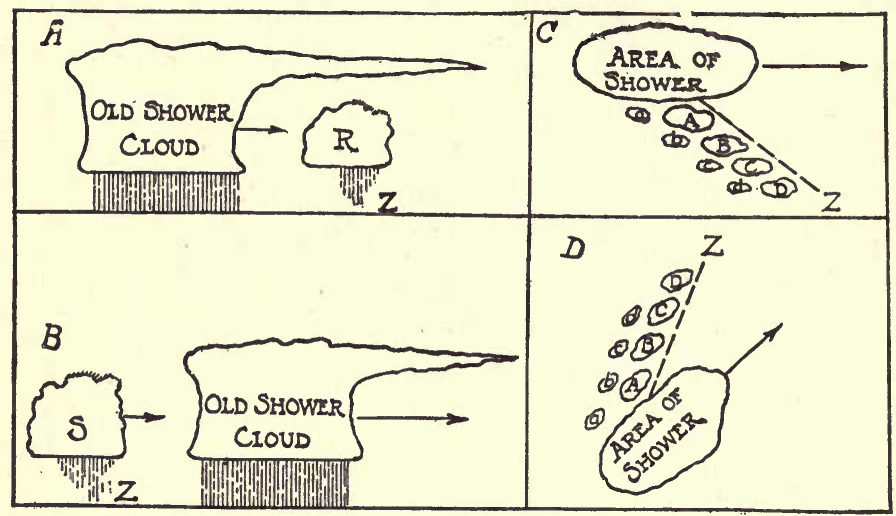

FIG. 169.-Growing shower clouds.

In $A$, the growing cloud, $R$, which is ahead of the main thunder shower, begins to rain just as it reaches the observer at $Z$. Side view.

In $B$, the growing cloud, $S$, follows the main storm, and begins to rain just as it reaches the observer at $Z$. Sometimes this occurrence gives the impression that the departed shower has returned. Side view.

In $C$, the small clouds, $a, b, c, d$, move eastward, but grow rapidly and begin to rain at the broken line. The edge of the shower thus reaches the observer at $Z$. Top view.

In $D$ a similar development accompanies a shower that is moving by to southeast of observer's locality. Top view.

come, the next step is to watch for the approach of clouds that might rain in your vicinity. Broadly speaking, these will be in either of two classes (Figs. 168 and 169):

A. Showers already in operation, that come from the direction " $A$ " and move over your locality at " $Z$ " (Fig. 168). As a rule, with a little attention, these may be seen some time in advance.

B. Growing clouds, not yet raining, that travel toward you from the direction " $A$ " and begin to rain before passing over you. Such clouds may be grouped into two classes: 
1. Isolated or independent clouds not connected with another shower.

2. Clouds that develop near a shower already in operation. This group includes:

(a) Clouds that develop ahead of another shower, and begin to rain before the older shower arrives (Fig. 169, A).

(b) Clouds that are behind another shower, and begin to rain at " $z$ " after the older shower had passed and its rain had ended at " $z$ " for a short time. This new shower (Fig. 169,B) sometimes gives the impression that the departed shower has returned.

(c) Clouds that develop at the side of an older shower (Fig. $169, C)$. When this occurs it widens the rain area of the old shower and often makes it appear as though the old shower was advancing obliquely instead of in the direction its clouds are moving. For example: in Fig. 169 C, a shower in the northwest is moving due east across the northern sky. A small cloud " $a$ " grows rapidly and begins to rain at the broken line. Meantime cloud " $b$," still farther south, is growing, and begins to rain at the broken line. Likewise the other clouds in succession, all moving due east, begin to rain at the broken line. The original shower has thus appeared to move southeastward over all the region east of the broken line. What happened was the southeastward growth or widening of the older shower. The same sort of extension may occur on either side of any shower in any part of the sky. Showers frequently spread in that way and this development needs careful watching to foresee your own weather correctly. Sometimes a shower continues to increase on one side and to exhaust itself on the other side.

The growth and movement of these clouds can often be seen. If the important clouds are hidden by a sheet of lower clouds, occasional breaks in the lower layer sometimes permit seeing the clouds and movements above (Fig. 164). Some experience in observing clouds is necessary, for showers develop somewhat differently in different sections of the country and in different seasons. Moreover, the various types and movements of clouds are not always easy for the beginner to recognize. 
265. The Older Thunderstorm; Its Advance Cloud.-Local storms often grow to cover large areas. After a thunder shower has become well developed, the cirro-stratus overflow at its top may reach 80 miles or more in advance, and is often the first indication of the storm to be seen in regions ahead. This high cloud sheet may seem to advance broadside, covering the whole sky as it comes. For a narrower storm, it may approach endwise, covering only a narrow band or strip of the sky. It may be more or less hidden by lower clouds not connected with the storm (Fig. 167, $M, N, R$ ).

266. The Thunderstorm; Its Approach and Passing.-As the storm draws near, there appears along the horizon the black or greenish-black mass of the main storm cloud (Figs. $167, T$, and $175, A)$. A little later can be seen the dense curtain of rain pouring from its base and hiding all behind (Figs. $175, B$, and $160, B^{\prime}$ and $C^{\prime}$ ). Along the front of the rain is often a roll or bank of low, ragged, gray, or dark cloud (Fig. 167, X), tumbled and tossed by the wind. With this "squall cloud" usually comes the first heavy dash of rain. The rainfall may last from a few minutes to an hour or two, and varies in intensity. Toward the last, it usually slackens gradually until it ceases. Not long after the rain ends, and sometimes before, the clouds break and the sky clears in part; and later, in the east, may often be seen the brilliant tops of the departing nimbus.

267. Winds of a Thunderstorm.-As the SQUALL CLOUD of the storm front arrives, the wind, which till then had blown from south or easterly toward the storm, shifts quickly and blows with greater force directly outward from the storm front (Figs. 167 and 170). Sometimes this wind is almost absent; occasionally it destroys light buildings. Usually it blows during the first of the rain, then dies away; often near the end of the shower it has changed to nearly the opposite direction and blows back from the departing storm (Figs. 167, $V$, and $170, R)$. When a well-developed thunder shower. passes near by on the north, a moderate or brisk breeze usually 
blows outward from the north and extends several miles south of the rain. When a thunder shower passes near on the south, a similar wind often blows out from the south, reaching several miles north of the storm (Fig. 170). These outflowing winds on all sides of the storm have no connection with its forward movement, and do not show the direction the storm is traveling. They are evidently caused by a downward rush or settling of air within the storm. This air must spread outward on approaching the ground and thus causes these winds. This downward moving air may be (1) colder air from above, (2) air cooled within the storm itself, or (3) air brushed downward by the falling rain. The air within a thunderstorm could be cooled by $(a)$ cool raindrops falling through the heated lower air; (b) evaporation from the falling rain. Probably all these processes share in causing the downward air movement and the outflowing winds. The outflowing wind is usually

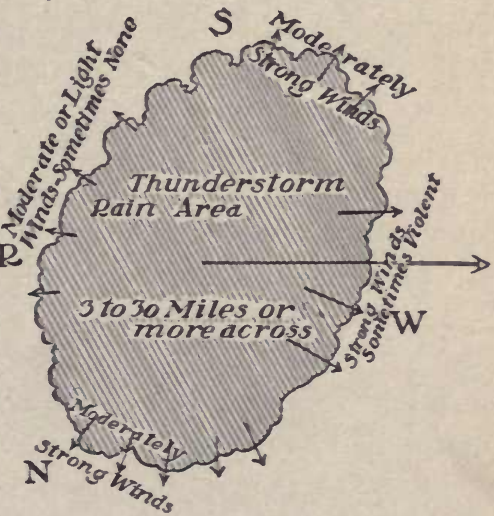

FIG. 170.-Outflowing winds at the ground in a summer thunderstorm. Storms differ; not all these winds are present in every storm. The area of storm may sometimes be either narrower or wider than shown in the figure. strongest in front, because there its velocity is added to the forward movement of the storm. The backward flowing wind in the rear is sometimes absent, because the forward movement of the storm may be faster than the rearward flow of air caused within the storm. The tumbling and rolling of the squall cloud in front is caused by its position between the rising air slanting upward into the storm front, and the downoutward flow of the squall wind (Fig. 167).

268. The Thunderstorm; Its Lightning and Thunder.LightNing is an electric flash or discharge, and seems to be 
produced only when rain forms in the air currents of a cumulus cloud (cumulo-nimbus). It is thought that the electricity in the cloud exists on the surface of the water droplets. When many small droplets join together into fewer and larger drops the total surface is much reduced and the intensity of the electric charge increased. In the rising air currents of a cumulo-nimbus cloud the larger drops may again be broken into spray or smaller drops, and the process repeated, until a discharge occurs. The discharge is the lightning flash, and may occur (1) between a cloud and the earth, (2) between two clouds, or (3) between parts of the same cloud. Flashes to earth are the only dangerous class. Tall objects like trees, chimneys, spires, etc., are most likely to be struck, and any object much taller than its surroundings should be avoided during a thunderstorm.

A distant thunderstorm at night often presents a beautiful display if the sky in its direction is otherwise clear. The so-called HEAT LIGHTNING at night is usually the reflection on nearer clouds of the lightning of a distant storm.

THUNDER is a series of sound waves in the air caused by the explosive effect of the intense heating along the path of the lightning flash. Thunder can sometimes be heard 15 or 20 miles.

Thunder often occurs in portions of the general storms of the colder months, but is not then accompanied by the other features of the summer thunder shower.

269. Thunderstorms; Frequency.-Thunderstorms in the United States (Fig. 171) occur most often in the southeast half of a low-pressure area (Art. 280, Fig. 180), or along the line of wind shift in elliptical "lows" (Art. 285, Fig. 186). Their appearance and behavior vary somewhat in different regions.

270. The Hail Storm.-Hail seems to occur only in thunderstorms having ascending air currents of more than average strength. Hail is usually made up of alternate layers of clear ice and cloudy ice or snow. Its formation is not fully under- 
stood. One of the principal theories is illustrated in Fig. 167. Suppose that a snowflake falls from $H$ in the upper part of the cloud, and is coated with water in the warmer portion near $K$, and is then carried aloft in the uprush of air and receives

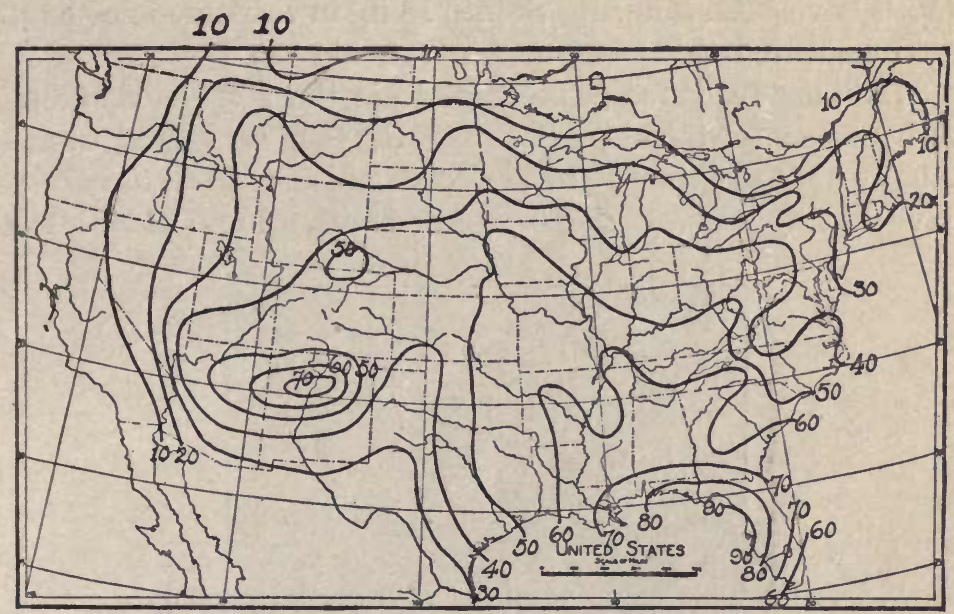

FIG. 171.-Average annual number of thunderstorms in the 10 years 19041913.

(W. H. Alexander, in Monthly Weather Review.)

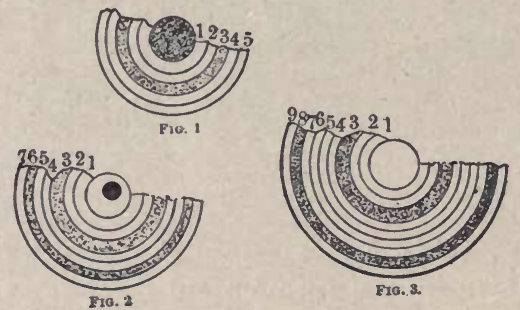

FIG. 172.- The layers of hail stones. Figs. 1, 2, and 3 show the formations of hailstones having five, seven and nine layers, respectively, outside the central nucleus. The stippled dark portions represent snow.

another coating of snow. Falling again, the process is repeated until the stone becomes too heavy and falls to the ground.

Hailstones may be split. with a sharp knife, showing the layers (Fig. 172). As many as 20 to 25 layers have sometimes 
been found. Pellets of solid ice about the size of rain drops are frozen rain, caused by falling through freezing air below the cloud. Such pellets are sometimes called sleet. Damaging hail is rare in most localities. Falls of hail $8 \mathrm{in}$. or a foot in depth have been known. Stones 13 in. in circumference have been measured.

271. The Tornado.- - The tornado is the most violent disturbance of earth's atmosphere. It, too, is a local storm usually not more than 50 to $500 \mathrm{yd}$. in width. A few tornadoes have destroyed everything in a path a mile or more wide. The

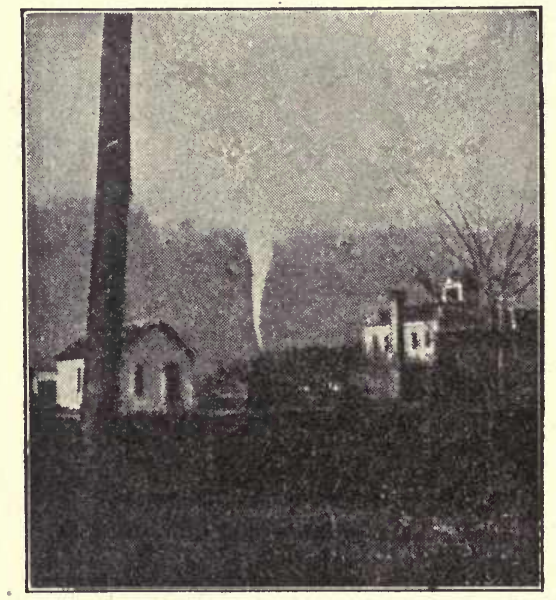

Fig. 173.-Tornado. Rather small funnel cloud extending to ground.

tornado appears to be caused by a special and violent development of the ascending air movements that are always present in a cumulo-nimbus cloud. The uprush of warm air is stronger in some cumuli than in others (see Figs. 159, $B$, and $160, B)$. Under favorable conditions it may become strong enough to form a whirl, or eddy, within the cloud as the air goes upward, much like the whirl that water forms in a tub or pan as it runs down through an opening in the flat bottom. This air whirl when well established within the cloud readily extends 
itself downward. It can not be seen below the cloud until the whirl becomes strong enough to form a column of cloud at its core. The centrifugal force of the whirling air creates a partial vacuum at the center (see Art. 620). In this partial vacuum, some of the moisture in the air condenses into cloud,

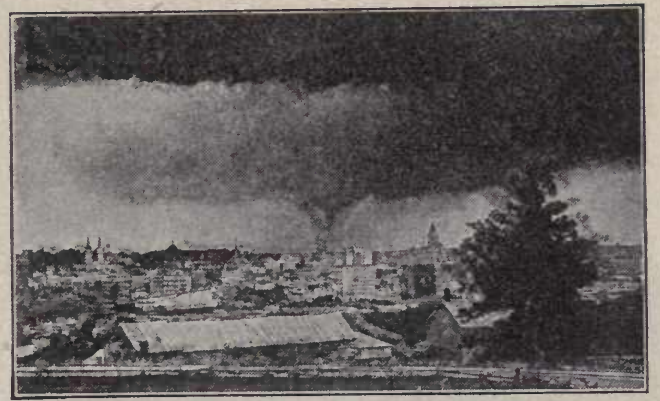

FIg, 174.- Tornado. Two miles or more distant. Funnel much larger than in Fig. 173.

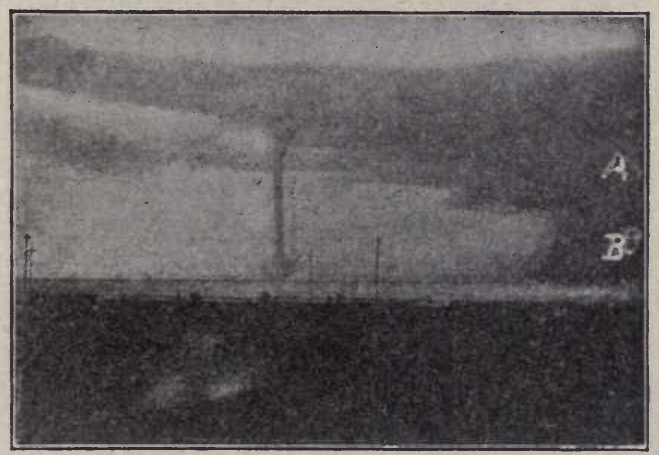

Fig. 175.- Waterspout. (Tornado over water.) Funnel is $3500 \mathrm{ft}$. in length from cloud to sea, and $300 \mathrm{ft}$. wide in its narrowest portion. $A$, Base of the Cumulo-Nimbus cloud. $B$, Rain curtain of a typical thunderstorm.

but it does not condense in the air of ordinary density outside the whirl. So the funnel cloud does not appear until the air whirl has developed considerable energy, and the stronger the whirl, the farther down the funnel cloud extends, and the wider it becomes (see Figs. 173, 174 and 175). If the funnel extends 
but a little way below the main cloud, the air whirl may be reaching the ground but is doing little or no damage. When the funnel cloud extends clear to the ground the whirl is usually violent enough to destroy whatever it strikes.

272. Tornado Effects.-The destruction wrought by the tornado is due both (1) to the violence of its rotary winds, which blow 200 to 400 miles or more per hour, and (2) to the explosive effect of the reduced pressure at the center of the whirl. If the air pressure at the center of the funnel is reduced one-third, the remaining pressure there would be $10 \mathrm{lb}$. per sq. in. Let

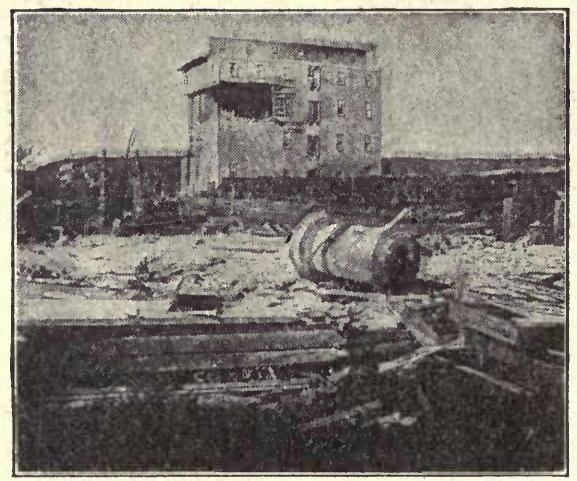

FIG. 176.-Explosive effect of tornado.

the core of this funnel pass for an instant just outside a building that is filled with air at the ordinary pressure of $15 \mathrm{lb}$. per sq. in.; instantly there is a force of $5 \mathrm{lb}$. per sq. in. on the wall pushing outward toward the center of the funnel. Compute the total pressure that would be exerted on the wall of one side of your schoolroom under those conditions. The difference in air pressure at the center of the funnel and outside of it is not known and may be greater, or less, than $5 \mathrm{lb}$. per sq. in. (see Figs. 176 and 177). Tornadoes have been known to carry heavy stones high in the air; to carry children a mile or more and lodge them unhurt in tree tops; to pluck the feathers from chickens, and to drive straws into boards (Fig. 178), 
and plank through sheets of steel. The tornado is confined principally to the United States east of the Rocky Mountains, and rarely occurs in other portions of the earth. Most tornadoes develop in the southeast half of a low-pressure area.

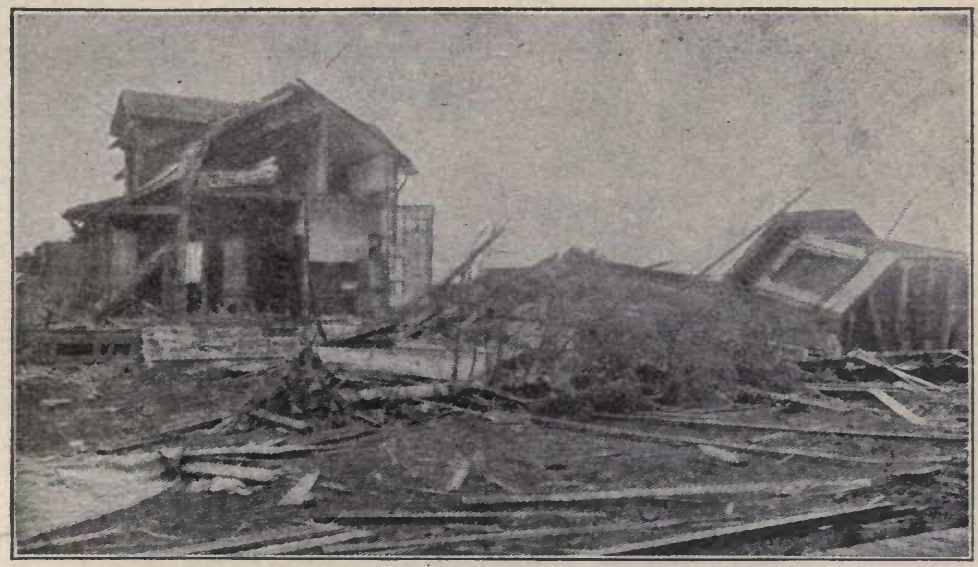

Fig. 177.-Effects of a tornado.

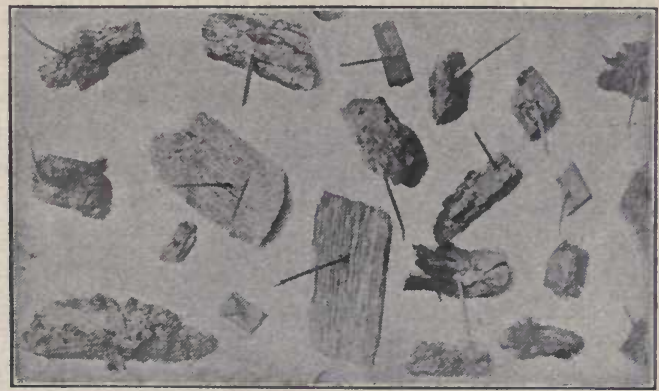

Fig. 178.-Effect of tornado; straws driven into wood.

Nоте.-The name "cyclone" belongs to a wholly different class of storms (see Arts. 284 and 302) and should never be used for a tornado. (1) The tornado always has the local twisting winds and a hanging core of revolving cloud; the cyclone never has either. (2) The diameter of the tornado is always a few hundred yards, or less; the diameter of the cyclone is always a few hundred miles or more. 


\section{THE GENERAL STORM}

273. The General Storm; How It is Studied.-The weather features thus far considered may be studied by one person working alone. The widespread storms of the country can not be understood unless we have observations taken at the same time at many different places. To study such storms and to predict their coming, many countries have weather services with a large number of stations that take simultaneous observations and telegraph them immediately to a central office. There the weather conditions at all stations are charted on a large map. The map is thus a bird's eye view, and shows the regions of storm and of fair weather, the areas of rising temperature and of falling temperature, and all other important features over the entire country. In the United States, the weather maps cover our own country and the inhabited portions of Canada, and are made both morning and evening. The forecasters study the maps. They see how the weather conditions are developing and traveling, and then publish the forecasts of what weather they expect will occur in each state during the next 36 to 48 hours.

The U. S. Weather Bureau distributes its forecasts to all parts of the country within a few hours. At more than 100 cities daily weather maps are printed and distributed, giving more complete information to the public. The daily temperature and rainfall observations of 4000 coöperating observers, located in almost every county of the entire country, are worked up each month and year and published in convenient form for the use of everyone desiring the weather information of any section. Special warnings of frosts are furnished to farming, fruit and gardening interests, and cold wave warnings to railroads, to shippers, and to many other interests. Warnings of gales on coasts and lakes are sent to shipping offices and to ships. The rivers are watched, and warnings of floods sent, to guard against damage by high water. The accumulated snow of the mountains is measured for the irrigation projects of the west, to show the amount of water available for the coming season. Scientific problems related to weather and climate are studied in search of other ways of assisting the public. The saving to the business of the country each year through the work of the Bureau is several times its total cost. 


\section{Weather Conditions, March 2, 1904, 8 A.m., 75Th Meridian} Time

\begin{tabular}{|c|c|c|c|c|c|c|}
\hline Places & $\begin{array}{c}\text { Tempera- } \\
\text { tures }\end{array}$ & $\begin{array}{c}\text { Wind } \\
\text { direction }\end{array}$ & $\begin{array}{l}\text { Wind } \\
\text { velocity }\end{array}$ & $\begin{array}{l}\text { Pres- } \\
\text { sure }\end{array}$ & Weather & $\begin{array}{l}\text { Precipi- } \\
\text { tation }\end{array}$ \\
\hline 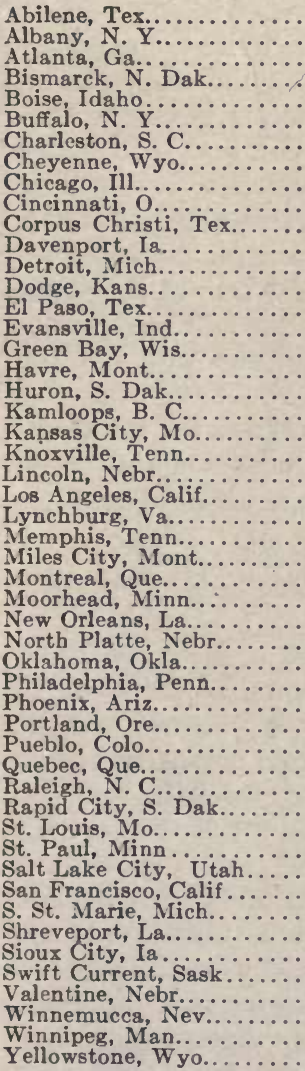 & $\begin{array}{r}60 \\
24 \\
60 \\
\text { Zero } \\
30 \\
38 \\
54 \\
48 \\
36 \\
36 \\
70 \\
36 \\
32 \\
36 \\
52 \\
38 \\
34 \\
-4 \\
22 \\
8 \\
48 \\
46 \\
44 \\
48 \\
38 \\
58 \\
\text { Zero } \\
26 \\
4 \\
66 \\
46 \\
64 \\
36 \\
52 \\
32 \\
58 \\
28 \\
42 \\
10 \\
40 \\
30 \\
50 \\
52 \\
24 \\
66 \\
36 \\
-22 \\
50 \\
48 \\
-4 \\
20\end{array}$ & $\begin{array}{c}\text { S } \\
\text { S } \\
\text { SE } \\
\text { NE } \\
\text { NW } \\
\text { S } \\
\text { NE } \\
\text { W } \\
\text { S } \\
\text { SE } \\
\text { S } \\
\text { SE } \\
\text { S } \\
\text { W } \\
\text { NW } \\
\text { SE } \\
\text { SE } \\
\text { NW } \\
\text { NE } \\
\text { Calm } \\
\text { SE } \\
\cdots \text { S } \\
\text { N } \\
\text { E } \\
\text { S. } \\
\text { N } \\
\text { SW } \\
\text { NE } \\
\text { SW } \\
\text { W } \\
\text { SW } \\
\text { SE } \\
\text { E } \\
\text { S } \\
\text { W } \\
\text { SW } \\
\text { NE } \\
\text { N } \\
\text { SE } \\
\text { E } \\
\text { S } \\
\text { SE } \\
\cdots \text { S } \\
\text { SE } \\
\text { CaIm } \\
\text { SW } \\
\text { NW } \\
\text { N } \\
\text { NW }\end{array}$ & 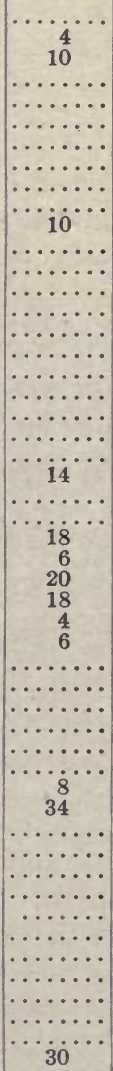 & $\begin{array}{l}29.80 \\
30.28 \\
30.10 \\
30.00 \\
30.14 \\
30.14 \\
30.16 \\
29.50 \\
29.94 \\
30.08 \\
29.98 \\
29.78 \\
30.10 \\
29.68 \\
29.90 \\
29.98 \\
29.90 \\
30.26 \\
29.52 \\
30.28 \\
29.74 \\
30.10 \\
29.56 \\
30.00 \\
30.26 \\
29.98 \\
30.16 \\
30.16 \\
29.88 \\
30.12 \\
29.56 \\
29.66 \\
30.32 \\
29.96 \\
30.32 \\
29.56 \\
30.12 \\
30.24 \\
29.74 \\
29.88 \\
29.70 \\
29.70 \\
30.12 \\
30.00 \\
29.98 \\
29.54 \\
30.32 \\
29.40 \\
29.88 \\
30.18 \\
29.68 \\
\end{array}$ & $\begin{array}{l}\text { Clear } \\
\text { Clear } \\
\text { Cloudy } \\
\text { Snowing } \\
\text { Cloudy } \\
\text { Clear } \\
\text { Cloudy } \\
\text { Clear } \\
\text { Clear } \\
\text { Partly cloudy } \\
\text { Cloudy } \\
\text { Partly cloudy } \\
\text { Cloudy } \\
\text { Cloudy } \\
\text { Clear } \\
\text { Clear } \\
\text { Cloudy } \\
\text { Cloudy } \\
\text { Cloudy } \\
\text { Clear } \\
\text { Partly cloudy } \\
\text { Cloudy } \\
\text { Cloudy } \\
\text { Cloudy } \\
\text { Partly cloudy } \\
\text { Partly cloudy } \\
\text { Cloudy } \\
\text { Snowing } \\
\text { Cloudy } \\
\text { Cloudy } \\
\text { Cloudy } \\
\text { Clear } \\
\text { Clear } \\
\text { Clear } \\
\text { Cloudy } \\
\text { Clear } \\
\text { Snowing } \\
\text { Cloudy } \\
\text { Cloudy } \\
\text { Partly cloudy } \\
\text { Cloudy } \\
\text { Cloudy } \\
\text { Raining } \\
\text { Cloudy } \\
\text { Cloudy } \\
\text { Cloudy } \\
\text { Partly cloudy } \\
\text { Cloudy } \\
\text { Cloudy } \\
\text { Cloudy } \\
\text { Cloudy } \\
\text { Cling }\end{array}$ & $\begin{array}{l}0 \\
0 \\
0.02 \\
0.06 \\
0.08 \\
\text { Trace } \\
0.01 \\
0 \\
0 \\
0 \\
\text { Trace } \\
0 \\
0 \\
0 \\
0 \\
0 \\
0 \\
0.20 \\
0 \\
0 \\
0 \\
0.04 \\
0 \\
0 \\
0 \\
0 \\
0.18 \\
0.60 \\
\text { Trace } \\
\text { Trace } \\
0 \\
0 \\
0.01 \\
0 \\
0.22 \\
0 \\
0.30 \\
0 \\
0 \\
0 \\
0 \\
\text { Trace } \\
0.10 \\
0 \\
\text { Trace } \\
0 \\
? \\
0 \\
0 \\
0 \\
0.24 \\
\\
\\
\\
\end{array}$ \\
\hline
\end{tabular}

The following exercises explain the weather map and much about the weather. In working them, the student will use blank weather maps ${ }^{1}$ and a set of morning weather reports,

${ }_{1}$ Blank weather maps may be obtained from the Weather Bureau at Washington, D. C. 
and will construct the weather map as it is done at a weather station, though the steps will be in a different order.

\section{Exercise 55.-Making the Weather Map of 8 a.m. (Eastern Time), March 2, 1904}

1. Using the foregoing table of weather reports, write the temperature of each place in small figures at its point on the map. Next, draw a light line with blue pencil through all points having a temperature of $40^{\circ}$. Draw other lines for $50^{\circ}, 30^{\circ}, 20^{\circ}$, and $10^{\circ}$. Label each line at its ends. These lines are called isotherms. Note their trend. They loop northward over the middle plains, showing that a temperature of $40^{\circ}$ extended farther north over the plains than elsewhere. We should expect cold in the north and warm in the south with the isotherms running east and west somewhat like parallels of latitude. Why? Also, if the isotherms ran east and west like the parallels of latitude, any two of them should be about the same distance apart all along their course. But the map shows the isotherms far apart in the eastern states and crowded near together over Nebraska and South Dakota; compare the temperature of western Nebraska with that of South Carolina. There must be a special cause for such peculiar temperature conditions. The next step will explain.

2. On the same map, place the wind direction at each city, using arrows pointing with the wind, i.e., for a wind coming from the southeast make the arrow point toward the northwest. Note that the winds in South Carolina and South Dakota are from northerly points, while from the Gulf Coast to Nebraska they blow from the south.

Notice also that the warm temperatures extend far to the north in the region of south winds, and cold temperatures extend southward where the north winds blow. Does this explain most of the bends in the isotherms? Does it explain the crowding together of the isotherms over Nebraska and South Dakota? The bending of the isotherms seems to be caused by the winds, blowing from different directions. But why should the winds blow in different directions at the same moment in different parts of the country? The next step answers.

3. Chart the barometer readings at each city in the same manner. We already know that air has weight and rests upon the earth with a pressure of nearly $15 \mathrm{lb}$. per sq. in., and that the pressure, at any moment, is not the same in all sections of the country (Art. 211). After charting the barometer readings on your map, draw a line in red pencil through all the places having a reading of $29.9 \mathrm{in}$.; another 
line for 30.0 in.; and other lines for each other tenth of an inch that appears on the map. North of Montana and on the Virginia coast the pressure is 30.3 in. Write the word High in each region. Write Low in Nebraska where the barometer reading was lowest (29.4 in.).

274. Winds Caused by Unequal Pressure.-In western Canada and on the Virginia coast the barometer stands nearly an inch higher than in Nebraska. Since the total weight or pressure of air at sea level is about $15 \mathrm{lb}$. per sq. in., and the barometer measuring that pressure reads about 30 in., it follows that each inch on the barometer scale stands for about $1 / 2 \mathrm{lb}$. of air pressure on each square inch of the earth's surface. Therefore on the morning of March 2, 1904, the weight or downward pressure of the air over western Canada was nearly $1 / 2 \mathrm{lb}$. greater per sq. in. than it was over Nebraska. Now $1 / 2 \mathrm{lb}$. per sq. in. equals $72 \mathrm{lb}$. per sq. ft., $648 \mathrm{lb}$. per sq. yd., nearly 10 tons per sq. rod, or more than $1,000,000$ tons per sq. mile. Wherever there is a difference of $1 \mathrm{in}$. in the corrected barometer readings, there is a difference of $1,000,000$ tons per sq. mile in the pressure of the atmosphere. For $1 / 2$ in. difference in barometer readings there would be about 500,000 tons per sq. mile of difference in air pressure, and so on. This immensely greater weight of air over the Virginia-New Jersey coast and over western Canada, crowds the bottom air outward in all directions away from the center of the greatest pressure (highest barometer). It is this greater pressure which causes the wind to blow, at the same moment, from the south at Albany, N. Y., from the southeast at Philadelphia, and from the northeast in the Carolinas. It causes north winds in Montana and the Dakotas, where the air is being crowded outward away from the high pressure in Canada.

In the same manner the air over the region surrounding a Low presses down with greater weight than the air over the center of the Low. This crowds the bottom air in from all sides toward the center of lowest barometer. That is why the winds on all sides are blowing toward Nebraska.

Such air movements always occur around HIGHs and Lows. 
The air at the ground is always crowded or pushed away from a region of higher pressure toward a region of lower pressure. Every wind that blows is caused chiefly in that way.

275. Pressure Areas Determine the Direction of Winds.It follows that the direction of all our winds is controlled chiefly by the positions of the nearest areas of high pressure or low pressure. A HIGH to the north or a Low to the south makes our winds blow from the north. A HIGH to the west or a LOW to the east causes our west winds. What two pressure conditions will cause easterly winds? Southerly winds? The wind directions due to pressure areas are modified by the rotation of the earth, as explained in Arts. 298 to 301.

276. The Velocity of the Wind.-The velocity of the wind is controlled principally by the amount of difference in pressure in a given distance. The greater the difference in pressure in, say, 500 miles, the stronger will be the winds in that region. For example, between Valentine, Nebraska, and Miles City, Montana, the pressure difference is $0.76 \mathrm{in}$. and the distance about 375 miles. The wind at Rapid City, S. Dak., is 34 miles per hour. Compare that with the similar distance from Valentine to Kansas City, having a pressure difference of only 0.34 in., where the wind between, at Lincoln, Nebr., is only 14 miles per hour. The difference in pressure is called the BAROMETRIC GRADIENT. Greater differences are "steeper" gradients, and cause stronger winds, other things being equal.

277. Winds ; Summary ; Effect on Temperature.-Looking again at your map, it is clear that all the apparently conflicting winds of that morning were merely obeying this universal law. They blow toward Nebraska from all sides because the lowest pressure is over Nebraska; and they blow away from western Canada and away from the Virginia coast in all directions because the highest pressure is at those places. To a considerable extent the winds carry their temperatures with them; thus warm air' is carried northward by the south winds, and cold air is swept southward in the north winds. The distribution of temperature is thus partly controlled by 
the pressure areas that cause the various winds. There are still other results from the wind movements.

\section{Exercise 56.-Completing the Weather Map}

Chart, next, the state of weather at each station, whether clear, partly cloudy, cloudy, raining, or snowing; also the amount of precipitation that had occurred in the last 24 hours. Note that the cloud sheet attended the low-pressure area, while the high-pressure area was mostly clear. Use the symbols given in the "Explanatory Notes" on a Daily Weather Map.

EXPLANATION.-The inflowing ground winds about a Low are continually pushed in from all sides by the surrounding higher pressure; having no other escape, they are crowded upward over the region in and around the cènter of the Low. In rising, they become cooled and their moisture is condensed into clouds and often into rain or snow. The amount of clouds and of rain or snow about a Low varies much at different times and in different Lows. Sometimes no rain or snow is produced, and in a few instances, only scattered cloudiness has resulted. In high-pressure areas, fair weather usually prevails, because the air in a $\mathrm{HIGH}$ is settling downward and warms by compression as it descends. This rising temperature increases the capacity of the air for water vapor (see Table XII, Art. 250) and enables it to evaporate clouds and clear the sky.

278. In Review.-The pressure differences cause the winds and give them their direction and velocity. The winds carry temperature conditions and help to make some regions warmer. others colder. The winds crowded upward in the low-pressure area furnish the moisture to form its cloud sheet and its rain or snow. The winds settling downward through the high-pressure area evaporate clouds and clear the sky and bring down the fresh invigorating air usually noticed in the clearing weather following a storm. Thus the pressure areas, i.e., the HIGHS and LOWs, by controlling the movements of the air become the chief cause of most of the general weather features of the temperate zones. 
Weather Conditions, March 3, 1904, at 8 A.m., 75Th Meridian Time

\begin{tabular}{|c|c|c|c|c|c|c|}
\hline Place & $\underset{\text { ture }}{\text { Tempera- }}$ & $\begin{array}{c}\text { Wind } \\
\text { direction }\end{array}$ & $\begin{array}{c}\text { Wind } \\
\text { velocity }\end{array}$ & $\begin{array}{l}\text { Pres- } \\
\text { sure }\end{array}$ & Weather & $\begin{array}{c}\text { Precipi- } \\
\text { tation }\end{array}$ \\
\hline 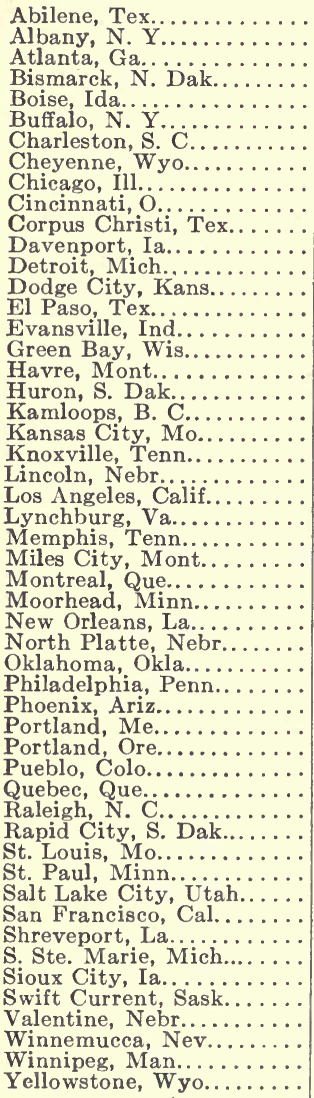 & $\begin{array}{r}30 \\
38 \\
60 \\
-10 \\
36 \\
46 \\
58 \\
8 \\
16 \\
48 \\
70 \\
12 \\
26 \\
6 \\
42 \\
30 \\
4 \\
-14 \\
-6 \\
12 \\
16 \\
64 \\
8 \\
52 \\
50 \\
48 \\
-8 \\
34 \\
-10 \\
66 \\
2 \\
20 \\
44 \\
52 \\
32 \\
38 \\
24 \\
30 \\
50 \\
8 \\
22 \\
-2 \\
24 \\
54 \\
54 \\
\text { Zero } \\
2 \\
2 \\
4 \\
30 \\
-14 \\
2 \\
\end{array}$ & $\begin{array}{l}\text { N } \\
\text { SE } \\
\text { SW } \\
\text { NW } \\
\text { SE } \\
\text { SW } \\
\text { S } \\
\text { SW } \\
\text { NW } \\
\text { NW } \\
\text { N } \\
\text { NW } \\
\text { NW } \\
\text { NW } \\
\text { N } \\
\text { NW } \\
\text { NW } \\
\text { NE } \\
\text { SW } \\
\text { Calm } \\
\text { NW } \\
\text { SW } \\
\text { NW } \\
\text { NE } \\
\text { SW } \\
\text { NW } \\
\text { S } \\
\text { S } \\
\text { SW } \\
\text { S } \\
\text { W } \\
\text { S } \\
\text { S } \\
\text { SE } \\
\text { SE } \\
\text { SW } \\
\text { NE } \\
\text { SW } \\
\text { W } \\
\text { NW } \\
\text { NW } \\
\text { E } \\
\text { S } \\
\text { NW } \\
\text { NW } \\
\text { NW } \\
\text { SW } \\
\text { W } \\
\text { S } \\
\text { S } \\
\text { S }\end{array}$ & 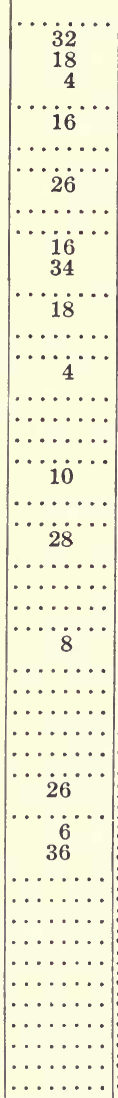 & $\begin{array}{l}30.50 \\
29.64 \\
29.86 \\
30.50 \\
30.34 \\
29.68 \\
30.04 \\
30.66 \\
30.06 \\
29.66 \\
29.94 \\
30.24 \\
29.58 \\
30.70 \\
30.18 \\
30.00 \\
30.10 \\
30.48 \\
30.60 \\
30.12 \\
30.50 \\
29.76 \\
30.64 \\
30.00 \\
29.80 \\
30.08 \\
30.53 \\
29.48 \\
30.46 \\
30.02 \\
30.72 \\
30.48 \\
29.74 \\
29.96 \\
29.88 \\
30.36 \\
30.54 \\
29.60 \\
29.94 \\
30.56 \\
30.24 \\
30.46 \\
30.42 \\
30.10 \\
30.06 \\
29.88 \\
30.58 \\
30.36 \\
30.66 \\
30.24 \\
30.24 \\
30.64 \\
\end{array}$ & $\begin{array}{l}\text { Clear } \\
\text { Cloudy } \\
\text { Cloudy } \\
\text { Clear } \\
\text { Cloudy } \\
\text { Raining } \\
\text { Partly cloudy } \\
\text { Clear } \\
\text { Clear } \\
\text { Raining } \\
\text { Cloudy } \\
\text { Clear } \\
\text { Snowing } \\
\text { Clear } \\
\text { Clear } \\
\text { Snowing } \\
\text { Clear } \\
\text { Clear } \\
\text { Clear } \\
\text { Cloudy } \\
\text { Clear } \\
\text { Cloudy } \\
\text { Clear } \\
\text { Cloudy } \\
\text { Cloudy } \\
\text { Cloudy } \\
\text { Clear } \\
\text { Cloudy } \\
\text { Clear } \\
\text { Clear } \\
\text { Clear } \\
\text { Clear } \\
\text { Cloudy } \\
\text { Cloudy } \\
\text { Raining } \\
\text { Raining } \\
\text { Clear } \\
\text { Snowing } \\
\text { Cloudy } \\
\text { Clear } \\
\text { Party cloudy } \\
\text { Clear } \\
\text { Clear } \\
\text { Cloudy } \\
\text { Cloudy } \\
\text { Cloudy } \\
\text { Clear } \\
\text { Clear } \\
\text { Clear } \\
\text { Clear } \\
\text { Clear } \\
\text { Partly cloudy }\end{array}$ & $\begin{array}{l}0 \\
0.10 \\
\text { Trace } \\
0.06 \\
0 \\
0.40 \\
0.01 \\
0.26 \\
0.16 \\
0.46 \\
0 \\
0.06 \\
0.28 \\
0 \\
0 \\
0.40 \\
0.10 \\
0 \\
0.04 \\
0 \\
0 \\
0 \\
0 \\
0 \\
0 \\
0.10 \\
0 \\
\text { Trace } \\
0.40 \\
0 \\
0 \\
0 \\
0 \\
0 \\
0.04 \\
0.24 \\
0 \\
0.02 \\
\text { Trace } \\
\text { Trace } \\
0.30 \\
\text { Trace } \\
0.10 \\
\text { Trace } \\
0 \\
0.30 \\
\text { Trace } \\
0 \\
\text { Trace } \\
0.02 \\
\cdots 008 \\
0.08\end{array}$ \\
\hline
\end{tabular}

\section{The Weather Map of the Following Day.-}

\section{Exercise 57.-Weather Map for March 3, 1904}

The map you have completed shows the weather conditions of 8 a.m. eastern time, of March 2, 1904. On another outline map enter 
the data from the table of weather reports for March 3, 1904. Follow the same order and complete the map in the same manner. Compare the two maps. Note the new position of the Low. Draw a light broken line along the path its center seems to have followed. Measure the distance it has traveled in 24 hours. Draw a similar line for the center of the HIGH that is following. How far has it traveled? Make a table showing the changes in temperature, the shift of the wind, and the amount of rain or melted snow in the last 24 hours, at each place on the map. Considering the facts already studied, explain what caused the changes in temperature and wind that occurred at the following places: Bismarck, Cleveland, Cincinnati, Dubuque, Green Bay, Hatteras, Kansas City, Lynchburg, Memphis, Moorhead, Pueblo, Rapid City, Shreveport, Valentine.

\section{A STUDY OF WEATHER MAPS}

280. A Further Study of Weather Maps.-After preparing the foregoing exercises, the reader will find it much easier to

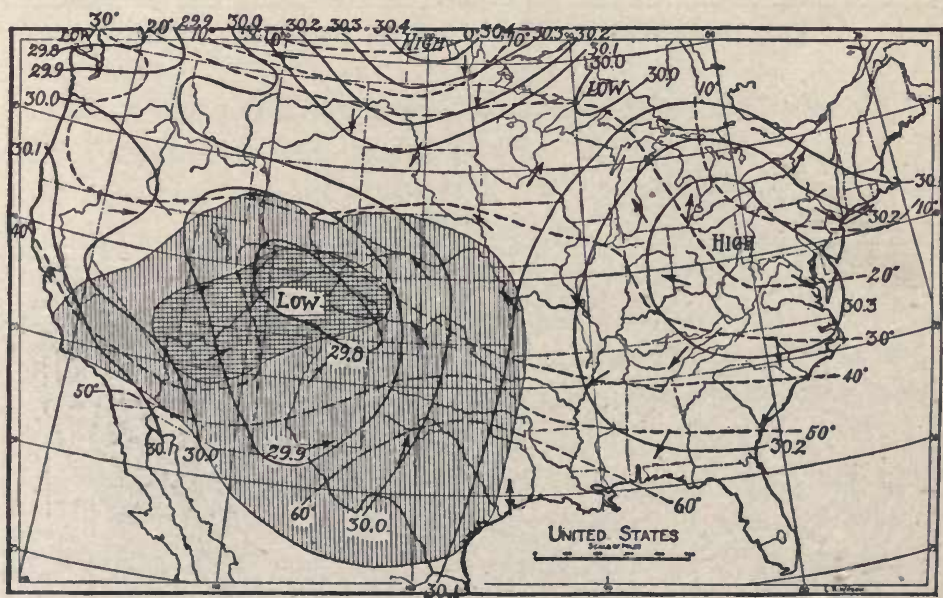

FIG. 179.-Weather map of 8 A. M., December 4, 1906. Solid lines show pressure. Broken lines are isotherms. Single shading shows area of cloudy sky. Double shading, area where rain or snow has fallen in last 24 hours. Cirrus clouds usually extend in advance of cloud area on east and northeast, but not enough to cover the sky.

see all there is on a weather map. The following completed maps show the progress of a typical storm across the United 


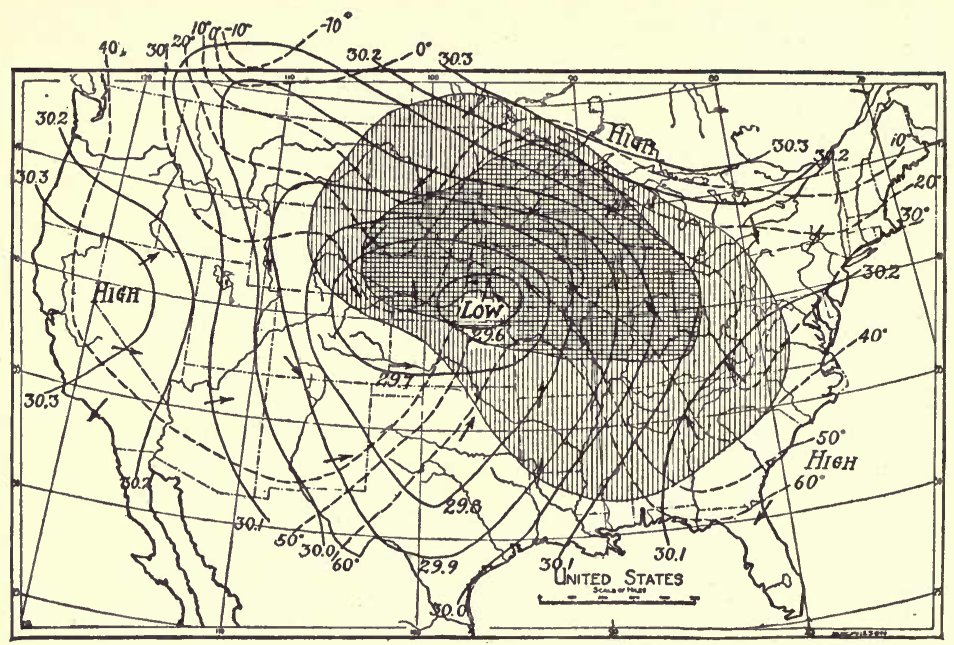

FIG. 180.-Weather map of 8 A. M., December 5, 1906.

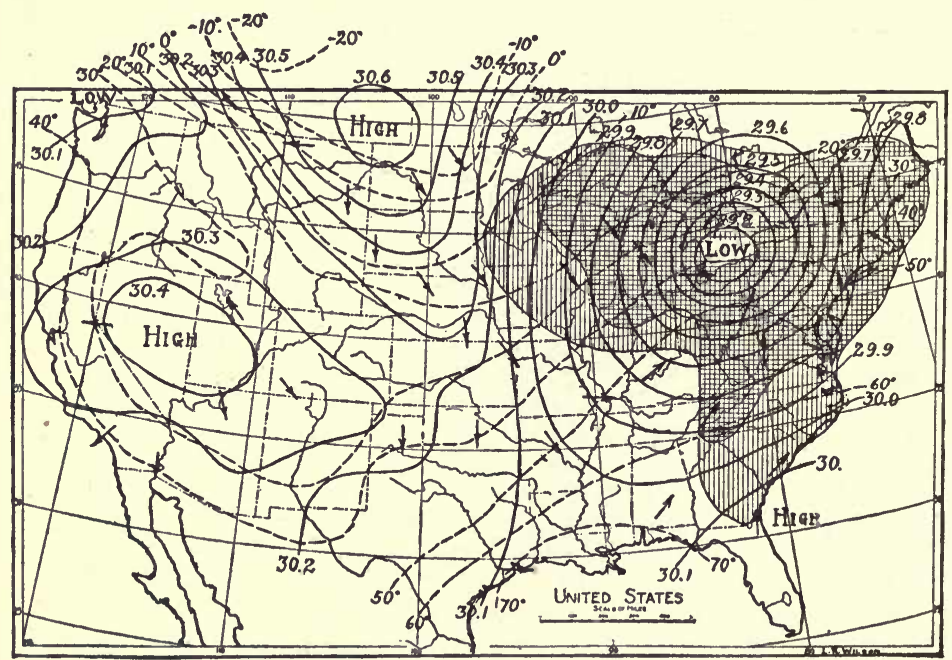

FIG. 181.-Weather map of December 6, 1906. 
States. Figure 179 is the morning weather map of December 4, 1906, and shows the Low centered over Colorado and HIGHS over western Pennsylvania and the Canadian plains. The inflowing winds about the LOW and the outflowing winds of the HIGHs are well illustrated. Note also the sheet of clouds surrounding the LOW, and the smaller area of rain. The isotherms show low temperature in the eastern HIGH and a warm area about the Low. Figure 180, the morning map of December 5 , gives a fine example of the circling winds about a Low and of the warm wave extending from the south and southeast up to the center of the Low. The cloud area is broader and the rain area much larger than the day before. Figure 181, the map for December 6, shows the warm wave shifted eastward with the Low. The rain area is still broader. A HIGH is coming from western Canada toward the Mississippi valley. Another center of high pressure is seen in the southwest.

281. Changes Caused by the Passing of the Storm; How the Barometer Changed.- Notice that on the morning of the 5th, the isobars show that the pressure at Omaha was 29.60 in. and at Detroit 30.16 in., while on the 6 th, the pressure at Omaha was 30.20 in. and at Detroit, 29.30 in. What change in the barometer occurred at Detroit as the storm approached? What change at Omaha as the storm departed? Describe the change that must have occurred at Chicago during the same 24 hours. What change in barometer at Pittsburg? At St. Louis? If you had a barometer, could you, by watching its changes, learn anything about the movements of Lows that cross your portion of the continent? If your barometer fell steadily for several hours, what would that indicate? After falling quite low, if it began a steady rise, what would that indicate?

If the pressure at the storm center on December 5 had been half an inch lower, with the storm moving at the same speed, would that have made any difference in the rate of rise or fall of the barometer at those cities near its path? Suppose the 
pressure at the center had remained 29.60 and the storm had moved twice as fast, would that have affected the rate of the change in pressure? Explain.

Noте.-The so-called "indications" sometimes printed on the dials of aneroid barometers are not reliable.

282. How the Winds Shifted.-Figure 182 shows the wind directions in solid arrows at a few places on the 5 th when the center of the Low was at Omaha, and in broken arrows on the 6th when the center was near Detroit. The winds of each day

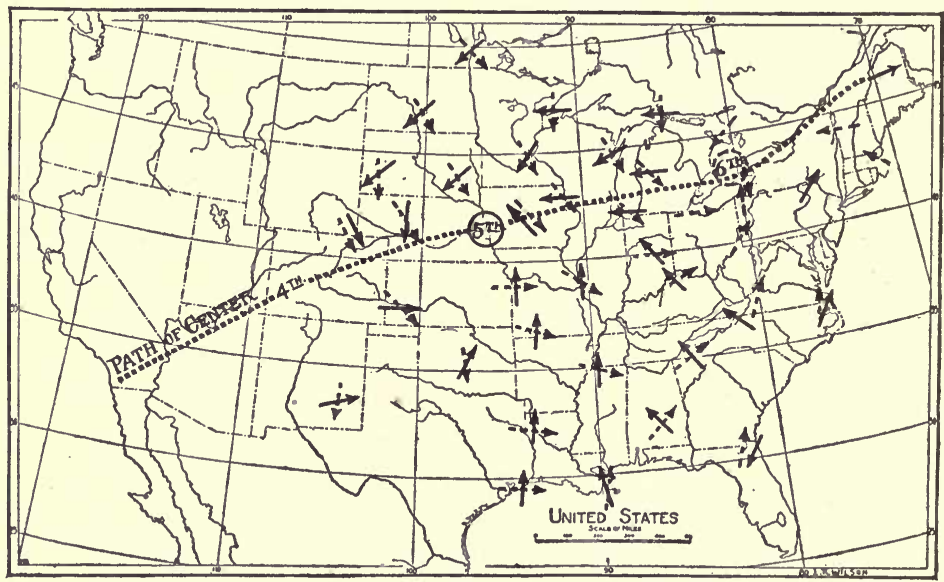

FIG. 182.-Changes of the wind, with the passing of a low, December 5-6, 1906.

circle about the center of the Low. The combined figure shows how the wind changed at different places as the Low passed eastward. Notice how the wind shifted at places north of the track of the storm center; and how it shifted at places south of the track. Note also the shift at Des Moines which was directly in the path of the center.

283. General Rule.-The winds of a circular Low always shift in the manner shown in Fig. 182. If the wind in a storm changes gradually from east through north to northwest, it is said to be a "backing wind" and the center of the Low is pass- 
ing south of you (Fig. 183). If the wind swings from southeast through south to west, it is said to be a "veering wind" and the center of the Low is passing north of you (Fig. 184). If an easterly wind gradually dies away and then springs up per-

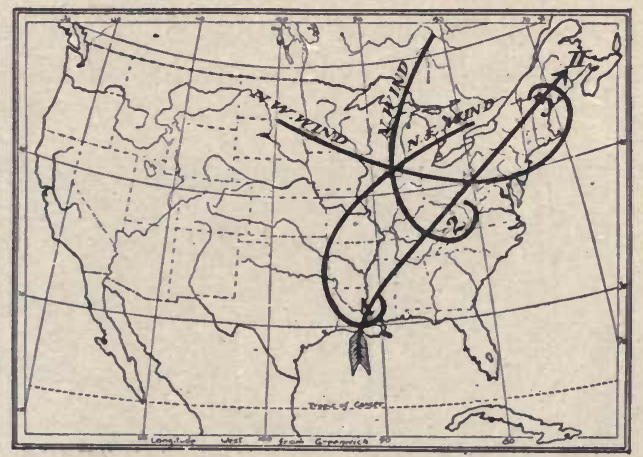

FIG. 183.-Backing of the wind as the low passes south of the observer at Chicago.

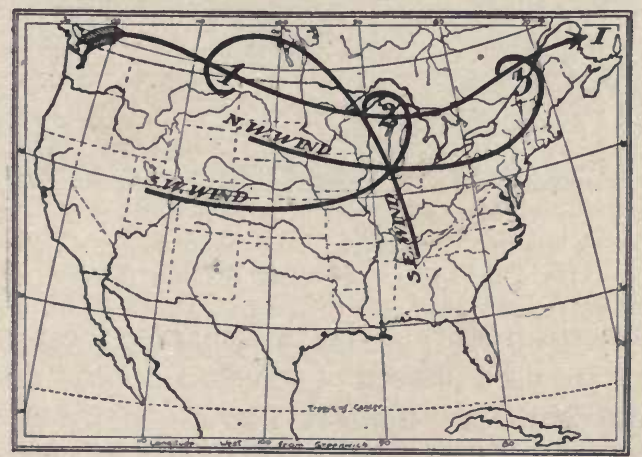

FIG. 184.-Veering of the wind as the low passes north of the observer at Chicago.

manently in the west or northwest, the center has passed near you.

LAW OF THE Winds IN A Circular Low.-The winds of a low that is circular in form blow obliquely toward the center along 
a path that curves to the left but passes on the right side around the center. (In the southern hemisphere they curve to the right. but pass on the left side around the center (Fig. 185).)

284. Cyclones. - In technical meteorology any widespread system of winds blowing around a center of low pressure is called a "cyclone" because of the "cycle" or eddy of its winds. The name "cyclone," however, is not in common use for the

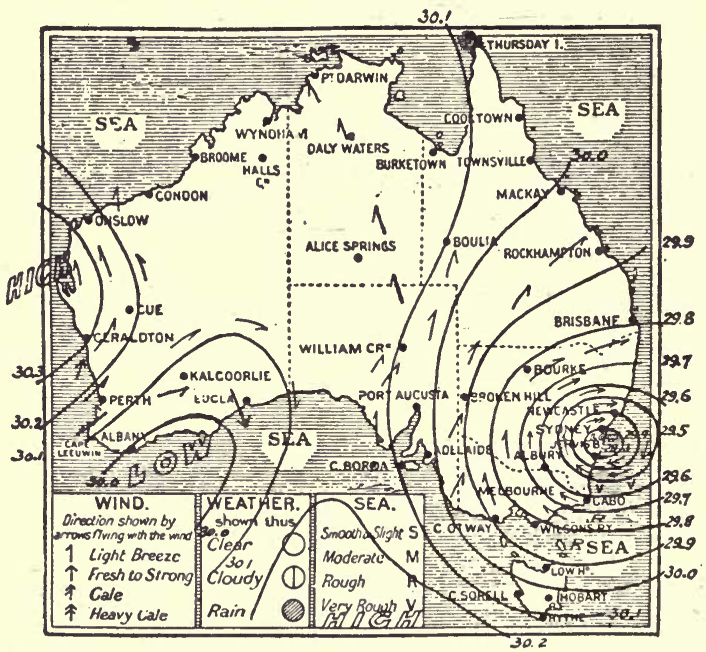

Fig. 185.-A low in the southern hemisphere has a clockwise whirl. (David J. Mares in Monthly Weather Review.)

ordinary American storm. In this chapter the terms "Low" and "HIGH" are used instead of "cyclone" and "anticyclone."

285. Wind Shift in Elliptical Lows.-Many Lows on the daily weather maps are elliptical or V-shaped. Sometimes they are merely "troughs" between two areas of higher pressure. In most of these the wind remains in a southerly direction until the central line, or axis, of the trough arrives; then the wind shifts rather quickly to a northerly direction (Fig. 186). Note that the wind at Davenport, Ia., is southeast, while 50 miles to westward it is from the northwest. 
Sometimes the south wind continues until the advancing front of NW. wind is only a few miles away, and the complete change from $\mathrm{S}$. to NW. occurs within a few minutes. If both Lows (Figs. 180 and 186) travel 40 miles per hour, compare the time required in each before the wind at Davenport completes the shift from southeast to northwest.

Review the law of winds in a Low, and how you can tell by the wind shift which side of you the storm center is passing.

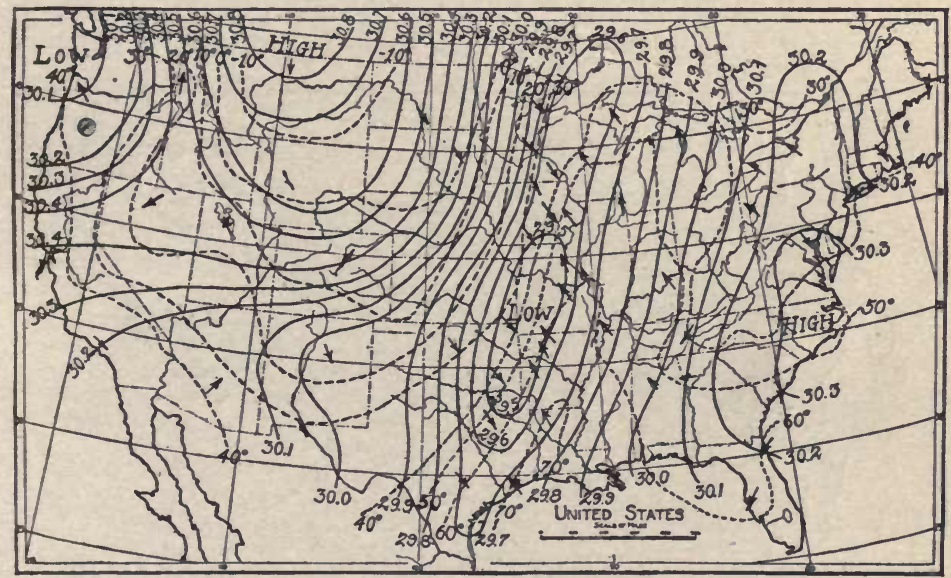

Fig. 186. - The winds of an elliptical low. Additional arrows have been entered to show winds more clearly. Solid lines are barometer, broken lines are temperature.

The U. S. Weather Bureau gives the following summary of wind and barometer indications:

"Wind, Barometer Indications.-When the wind sets in from points between south and southeast and the barometer falls steadily, a storm is approaching from the west or northwest, and its center will pass near or north of the observer within 12 or 24 hours with wind shifting to the northwest by way of southwest and west. When the wind sets in from points between east and northeast and the barometer falls steadily, a storm is approaching from the south or southwest, and its center will pass near or to south or east of the observer within 12 or 24 hours with the wind shifting to the northwest by way 
of north. The rapidity of the storm's approach and its intensity will be indicated by the rate and the amount of the fall in the barometer."

286. How the Temperature Changed.-Figure 187 shows the temperature changes in a circular Low as the storm traveled eastward. The isotherms of the 5th are solid lines; those of the 6th are broken lines. Notice that in front of the Low the isotherms moved northward as the Low approached; and in the rear they moved southward as the LOW

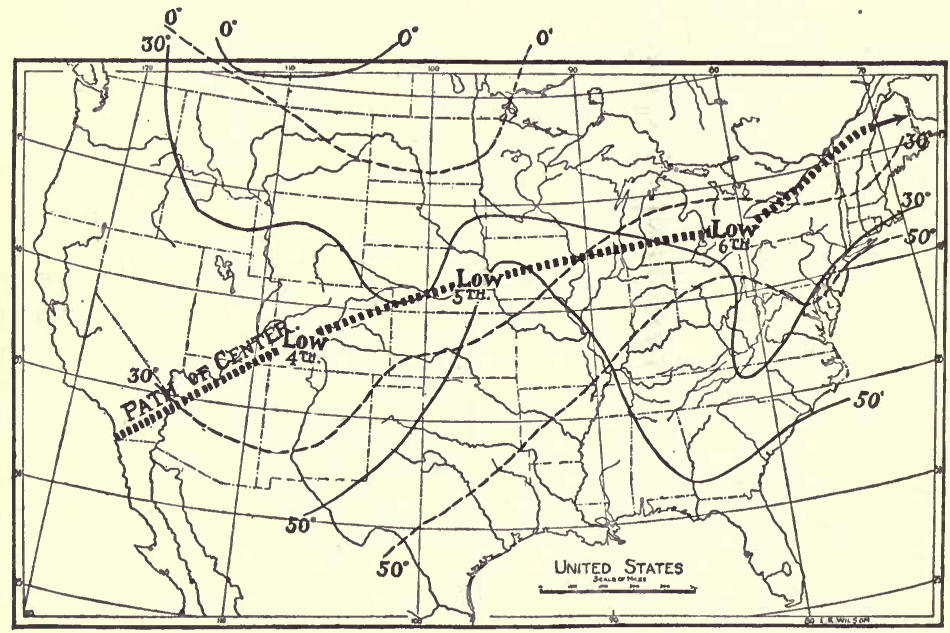

FIG. 187.-Temperature change with the passing of a low.

departed. What temperature change does that indicate in front of a Low? Behind a Low? How much was the change in 24 hours at Pittsburg? At Omaha?

In an oblong or elliptical Low the temperature changes are often grouped nearer the axis of the LOw, and the temperature fall is more rapid just after the axis passes. If the Lows of Figs. 180 and 186 both travel 40 miles per hour, how much would the temperature at Davenport change in each case, in eight hours? Also, at St. Paul? At Memphis? 
With the passing of an elliptical Low on November 11, 1911, the temperature at Peoria, Ill., dropped from $75^{\circ}$ at $4: 05$ p.m., to $52^{\circ}$ at 5 o'clock, freezing shortly after 7 p.m., and reaching $17^{\circ}$ at midnight. This was an exceptional storm.

Considering both types of Low, what portion has warm or rising temperature? Which portion cold or falling temperature? State the general law of temperature changes with the passing of a Low.

287. How the Clouds Changed.-Figure 188 is based on the map of December 5, when the storm center was near Omaha. It shows a vertical cross-section of the storm taken along a

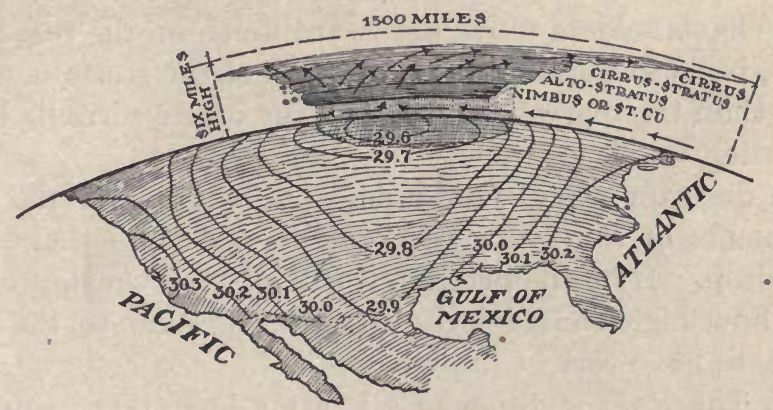

FIG. 188.-Cross-section of a storm on December 5th along a line from Omaha to Northern New York. The illustration shows a common arrangement of clouds and air movements in the lower few miles of air in such a storm.

line from Omaha to the St. Lawrence Valley. The clouds are shown in the order of their heights. Notice that the heavy lower clouds and the rain or snow extend at 7 a.m. from Nebraska to Lower Michigan. The cirrus extend to western New York in the morning. They reached the St. Lawrence Valley shortly before noon.

288. General Rule; Cloud Indications.-The cirrus clouds of a well-developed storm usually spread farthest ahead and appear first as the storm approaches. Lower and denser clouds follow. Often they come in the order, cirrus, cirrostratus, alto-stratus, strato-cumulus; but there is great variety. 
Frequently the forerunning upper clouds are more or less hidden by stratus that have no connection with the approaching storm. The direction and speed of the upper clouds should then be carefully noted through any breaks that appear in the lower sheet. Storms are usually preceded by cirrus, but cirrus alone do not always indicate a storm.

289. Other Features of the Illustration.- The illustration (Fig. 188) also shows, near the ground, the inflowing winds of a Low, blowing from east in front and from west in rear; it further shows what becomes of the winds as they approach the center. The highest clouds reach farthest ahead because the upper currents move faster than the body of the storm. The upper clouds seldom move backward much on the rear side of a Low, because the forward movement of the storm is usually faster than the rearward outflow of the upper currents behind the center.

The diagram covers 1500 miles of territory and the storm movements of the air were probably not more than 6 or 7 miles deep. If on the diagram it is 2 in. from Omaha to Montreal, how high should it be from the ground to the upper clouds, to have correct proportions?

290. The Rain or Snow of a Passing Low.-The rainfall of Lows in the United States is seldom distributed evenly around the center, and the distribution varies much in different storms. In fully developed storms, the precipitation is often well distributed after they reach the eastern third of the country. The heaviest falls are often in the front half, but may occur in almost any portion. In elliptical Lows, the rain area is likely to extend along or near the center, or axis.

291. Changes Caused by the Passing of a High.-After reviewing the weather changes caused by the approach and the passing of a well-developed Low, study Figs. 179, 181, and 186, and note the following:

1. The barometer rises as a HIGH approaches, and falls as the HIGH departs. The highest readings occur when the center of the HIGH is over us. 
2. The winds at the ground blow spirally outward on all sides of the center of the HIGH, curving to the right. If we stand with back to the wind, the center of the HIGH is behind and on our right. If the center of a HIGH passes eastward to the north of us, our wind will shift from northwest through north to easterly. If the center passes by to the south, our wind will shift from west through south to southeasterly. If the center passes directly over us, the northwest wind during its approach will be succeeded by light varying winds while the center is over us, and followed by east or south winds after the center passes eastward. (Contrast with General Rule of winds about a Low, Art. 283.)

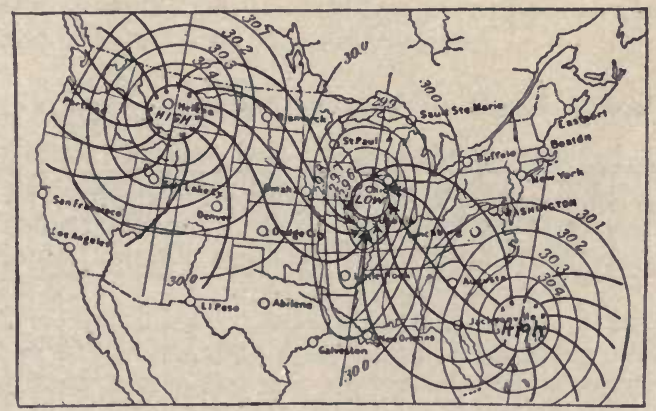

Fig. 189.-Paths of the winds between highs and lows.

3. The air near the center of a HIGH is settling downward.

4. The front portion of a $\mathrm{HIGH}$ is a region of cold or falling temperature and the rear side of a $\mathrm{HIGH}$ is a region of rising temperature.

5. The weather will be generally fair, with usually more than average sunshine, as long as a HIGH dominates our locality. (Contrast each of these weather changes about a HIGH with those about a Low.)

292. Paths of Winds between Highs and Lows.-We have seen that in HigHs the air settles downward and flows outward in all directions, and in Lows it is crowded in from all sides 


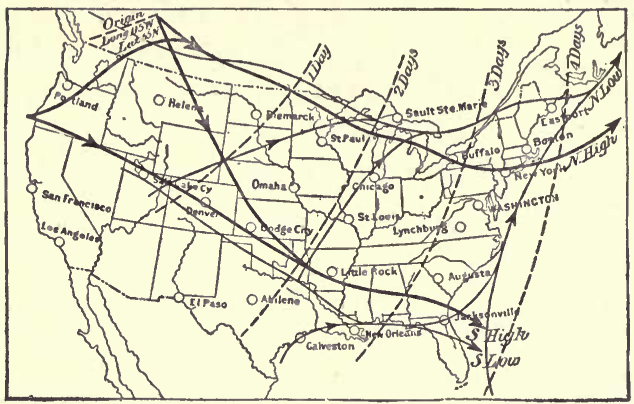

Fig. 190.-Average paths and average daily movement of lows and highs (U.S. Weather Bureau.)

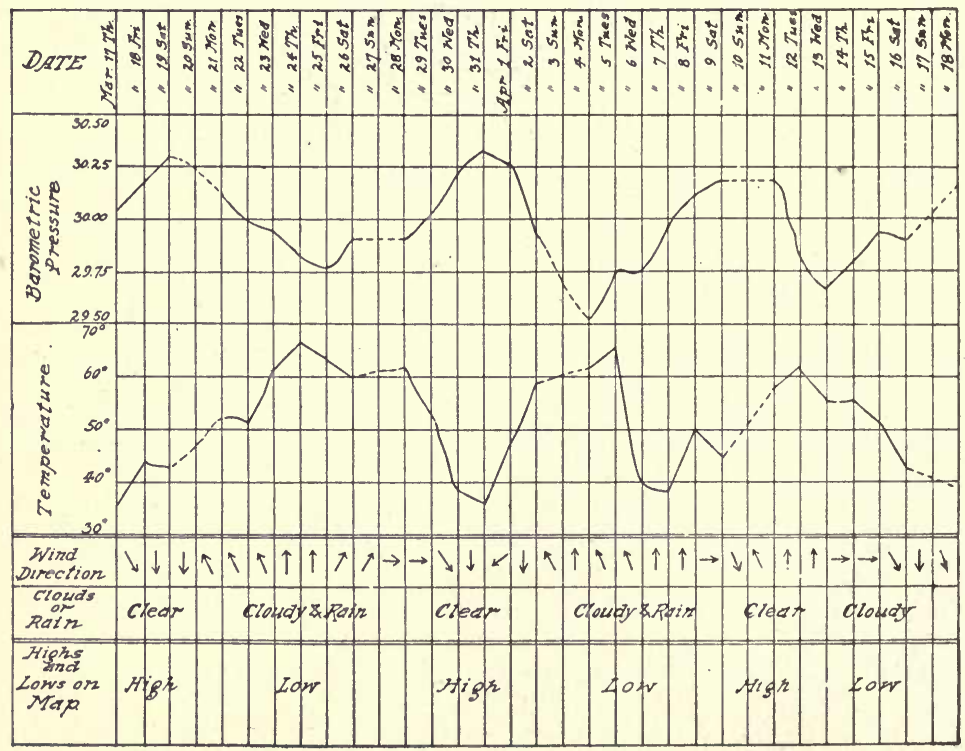

Fig. 191.-Weather chart. 
and ascends. Eigure 189 shows the average paths along which the winds move from HIGHS toward a Low.

293. The Paths of Highs and Lows.-We have seen that HIGHS and Lows usually move across the United States in a general direction from west to east. Observation of many HIGHs and Lows shows that they have a tendency to follow certain paths (Fig. 190).

\section{Exercise 58.-Plotting the Paths of Highs and Lows}

Obtain a month's maps from a Weather Bureau station. On a single blank map draw the paths of all the Lows that crossed the country during the month, making a dot or small circle for the position of the center on each day. On another map plot the paths of the HIGHS in similar manner. On a third map plot, from day to day, in the same manner the paths of both the HIGHS and Lows appearing on the weather maps as they are received.

\section{Exercise 59.-Making a Chart of the Month's Weather}

Prepare a chart like Fig. 191, showing the weather of your locality - for one month, using your class weather record. Make the chart as complete as practicable. The daily observations, especially of temperature, should be taken as nearly as possible at the same hour each day (Art. 227).

Exercise 60.-Explaining the Causes of the Daily Weather

Using the daily weather maps, for the month covered by Ex. 59, explain the causes of the principal weather changes (of wind, temperature, cloudiness, rain, or clearing) that came to your locality from day to day.

\section{CAUSES OF UNUSUAL WEATHER PERIODS}

\section{Further Control of Weather by Pressure Areas.-} Figures 192 and 193 show the average tracks of Lows and HIGHS in the United States during 10 years; and Fig. 194, the average tracks of Lows for the principal regions of the earth where they occur. Within these regions, there is considerable variation in the paths and behavior of Lows and HiGHS. We have seen that in the temperate zone most of the weather from day to day is controlled by passing Lows or HIGHs. 
It is also true that many of the periods of unusual weather are caused by the unusual behavior of HIGHs and Lows.

295. Unusual Paths of Lows.-Figure 195 shows the usual paths of autumn Lows in the United States. In Fig. 196 are the paths for November, 1909. Notice that most of the

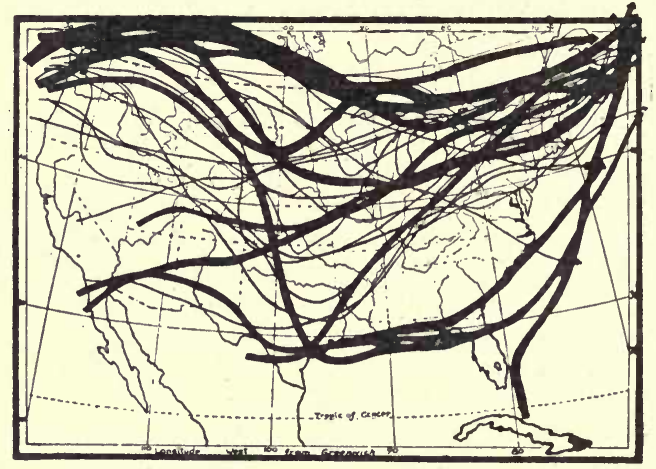

FIG. 192.-1160 lows classified, showing 27 paths.

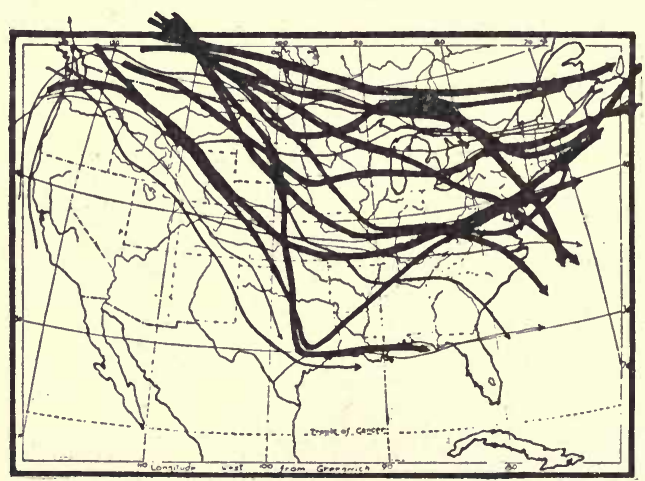

FIG. 193.- -928 highs classified, showing 21 paths.

tracks pass northeastward over Kansas and the upper Mississippi valley. Figure 197 shows the effect on the prevailing wind of the month, and on the average temperature over most of the Mississippi valley, and also on the distribution of rainfall. 


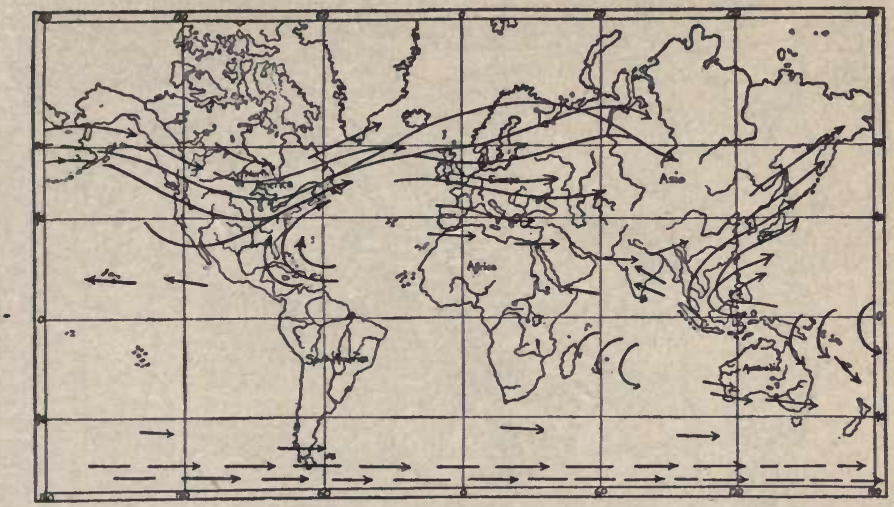

FIG. 194.- Principal paths of lows of the world (Approximate). Lows of South Temperate zone not charted. Lows in the tropics occur in late summer and autumn; in temperate zones, at all seasons.

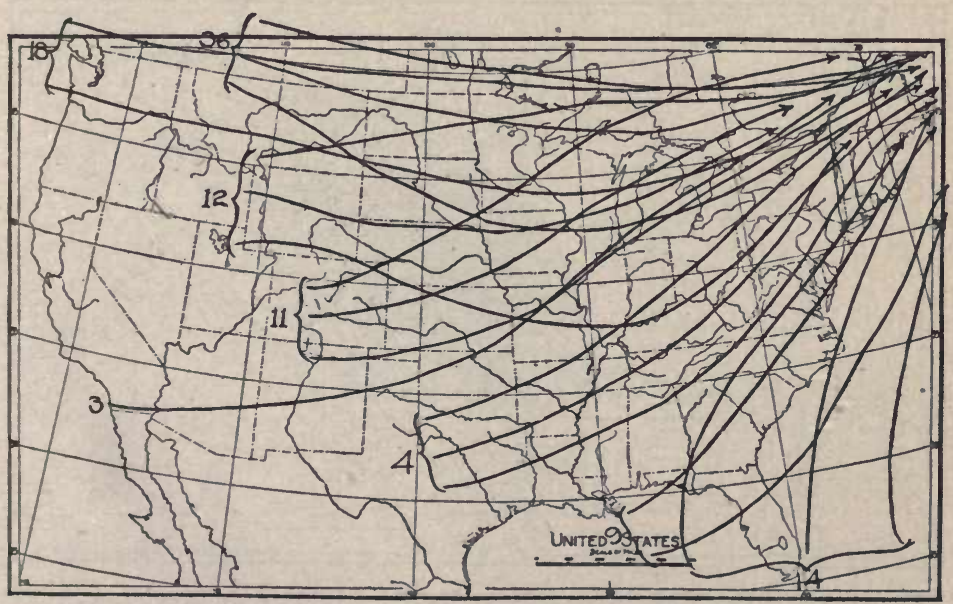

Fig. 195.-Paths of lows in an autumn month (10 years). Note the scattered distribution. Half the total number are near the northern border. Compare with Fig. 196, paths for November, 1909. 


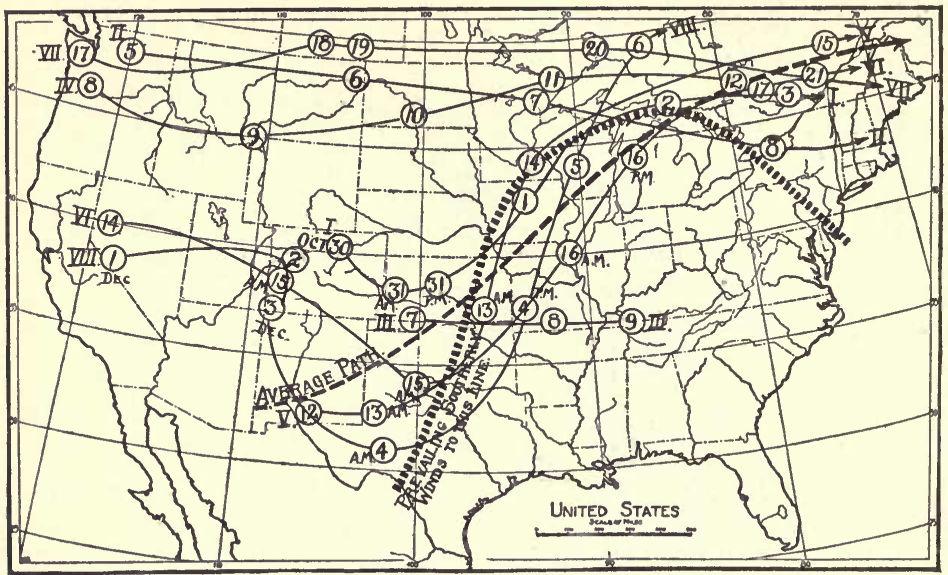

FIG. 196.-One cause of periods of unusual weather; paths of lows, November, 1909.

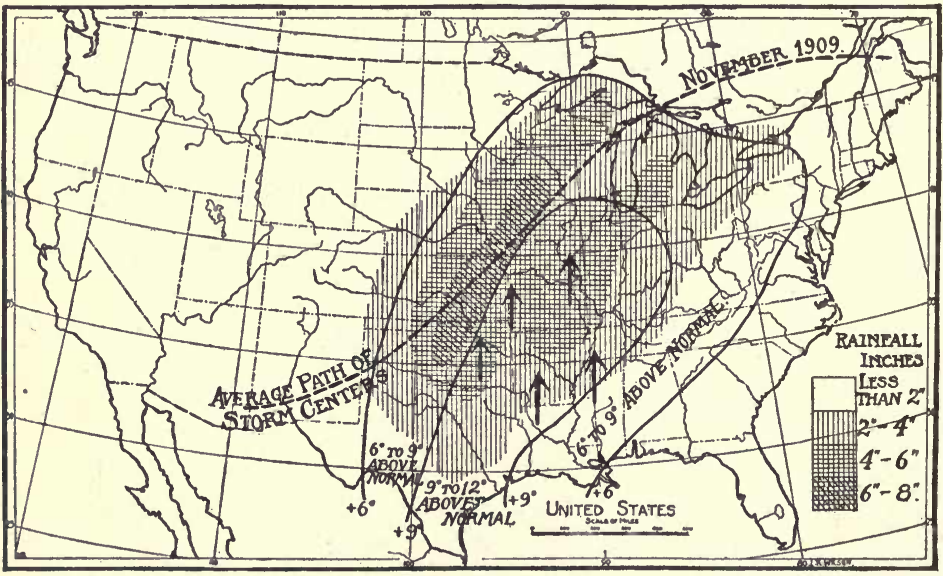

Frg. 197.-Storms followed unusual paths. Effect on prevailing winds, temperature, rainfall, of the month. Shading shows rainfall, inches. Solid black lines, temperature above normal. 


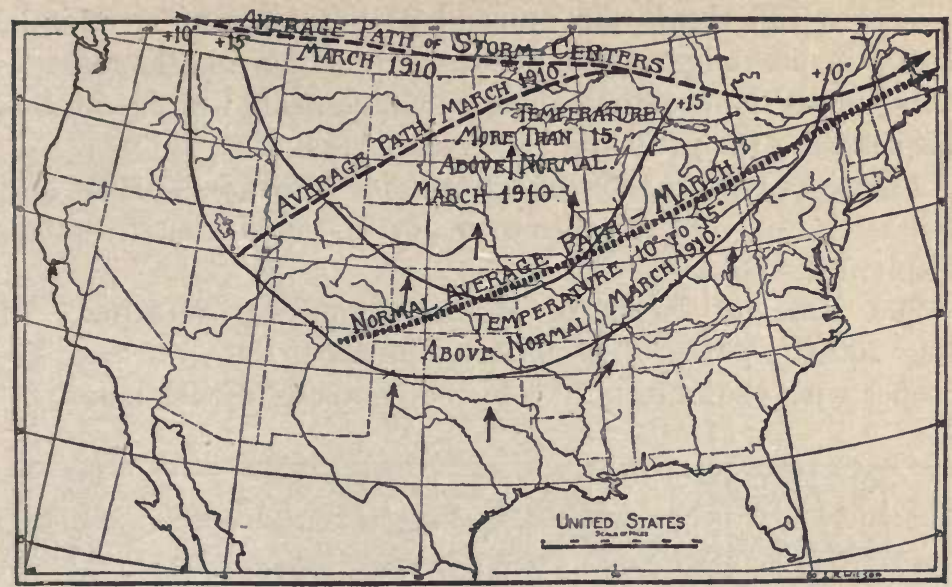

Fig. 198.-One cause of unusual seasons. Unusual paths of lows, March, 1910. Southerly winds over United States east of Rockies. Unusual tem. perature over North-Central United States.

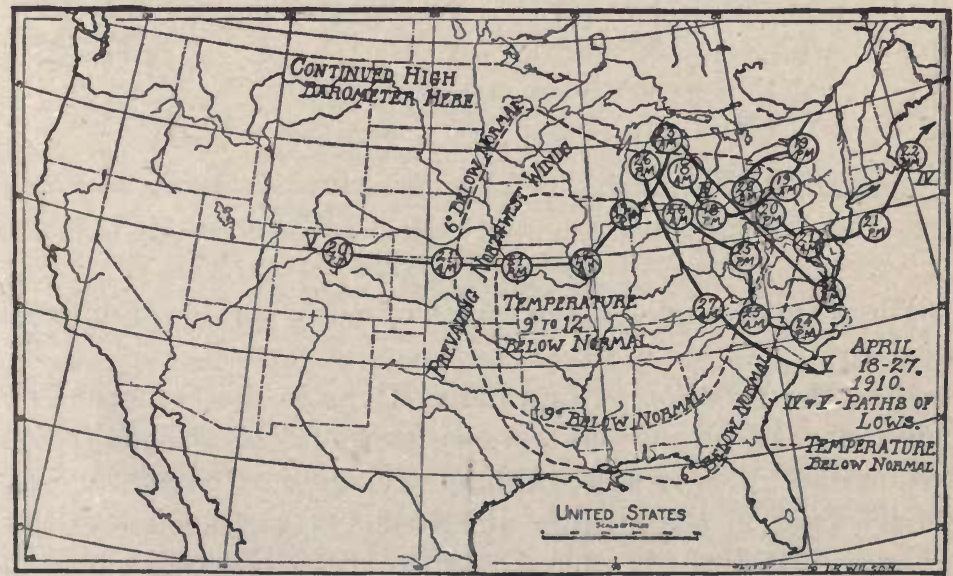

Fig. 199.-One cause of unusual seasons Remarkably cold weather, April, 1910. Paths of lows of that period. 
Figure 198 shows the unusual paths of Lows for March, 1910, the prevailing southerly winds resulting, and the remarkably high temperature over north-central United States. Explain the temperature.

Figure 199 shows the storm tracks for April 18-27, 1910, and the attending cold weather over north-central United States. Explain the cold.

296. Unusual Paths of Highs; Resulting Weather.-In Fig. 200 the paths of HIGHs for February, 1899, are seen, together with the unusually cold temperature of that month.

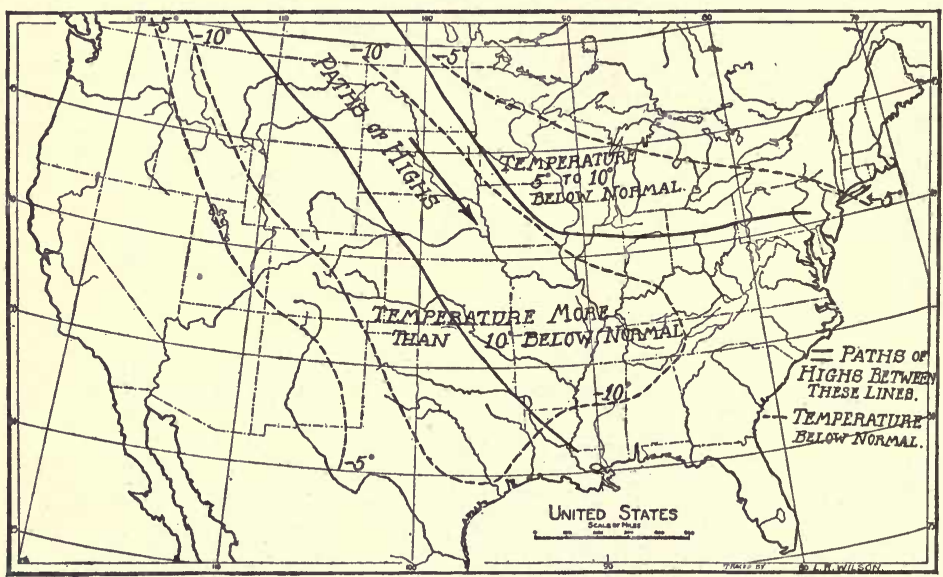

FIg. 200.-Unusual cold, February, 1899. Paths of highs that month.

These are examples of the causes of many periods of unusual weather.

297. The Relation of Lows and Highs to the General Circulation.-The HIGHs and Lows we have studied, although often a thousand miles or more in diameter, are only comparatively small eddies in the greater air streams of earth. They drift along with the broad, general air currents much as the eddies in a river drift along with the stream. Those broader movements make up the general circulation of the earth's atmosphere. 


\section{THE GENERAL CIRCULATION OF THE ATMOSPHERE}

298. The General Circulation of the Atmosphere.-The general circulation is caused by the unequal heating of the earth by the sun. The tropies receive most heat in a year; this makes the lower air warmest, and therefore lightest, near the

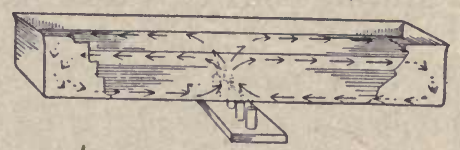

Fig. 201.

equator. Because of this, it is crowded upward by the cooler, heavier air on both sides, and spreads out above. Currents are thus set up in the atmosphere somewhat like those in the heated water pan in Fig. 201. If the earth did not rotate, the lower winds from each side would blow straight toward the equator and the upper winds would blow directly away from the equa-
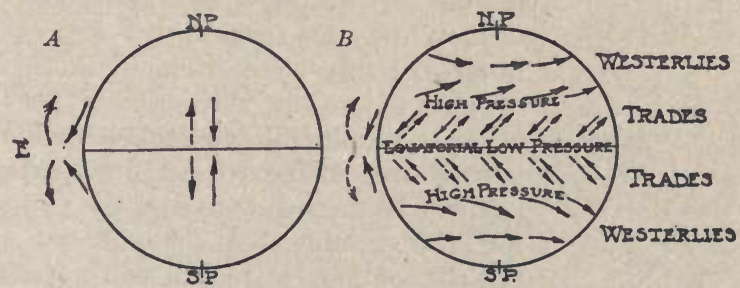

IF EARTH DID NOT ROTATE ON ROTATING EARTH $\longrightarrow$ UPPER WIMDS $\rightarrow$ GROUND WINDS

FIG. 202.-Principal features of the general circulation of the atmosphere. $A$. If the earth did not rotate.

$B$. As it is on the rotating earth.

tor. But the rotation of earth on its axis turns all winds toward the right in the northern hemisphere and toward the left in the southern. That causes the permanent wind directions shown on the world map, Fig. $202 \mathrm{~B}$. It also causes the outflowing winds of a high pressure area to curve spirally outward toward the right (in northern hemisphere), instead of blowing 
straight out from the center, and it makes the winds of a Low curve around the center instead of blowing straight toward the center (see Fig. 179). This turning or deflection of the winds is in accord with the law of mechanics first applied to the atmosphere by Wm. Ferrel, ${ }^{1}$ an American meteorologist, shortly before 1860 . This law may be stated as follows:

299. Law of a Moving Body on a Rotating Surface (Often Called "Ferrel's Law").-Any moving body on a rotating surface will travel in a curved path. If the surface rotates counter-clockwise (opposite the movement of the hands of a clock), the path will curve to the right; if the surface rotates clockwise, the path will turn toward the left.

\section{Exercise 61.- "Ferrel's Law" Illustrated-Counter-clockwise Motion}

Procure a smooth level table, a cardboard 2 or $3 \mathrm{ft}$. in diameter, a marble, and two wire nails. Drive one nail through the center of the cardboard into the table to serve as an axis. Push the other nail up

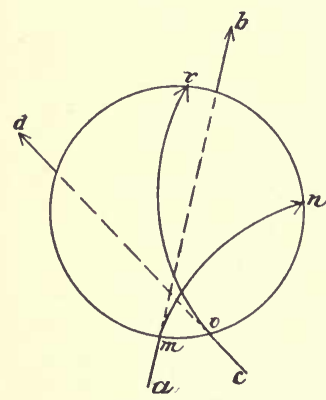

Fig. 203. through the cardboard from the under side about 5 in. from the center, to serve as a handle for turning the cardboard.

1. While one person revolves the cardboard steadily counter-clockwise at the rate of about two or three turns per second, another should roll the marble rather swiftly across the cardboard. A little experimenting will be necessary to find the proper speed for the marble. It should not roll too swiftly, or the cardboard will not have time to turn much while it is crossing. If the marble rolls too slowly, it may stop and be carried around by the cardboard. After finding the best speed, dip the marble in ink before rolling. Then roll it across the cardboard in several directions. Notice that when the marble is rolled in the direction $a-b$, Fig. 203, its path on the revolving cardboard makes the curved line $a-n$, and when it is rolled along the line $c-d$, its path curves to $c-r$.

2. Lay a yard stick on small blocks so that it extends across and above the cardboard. Hold the yardstick firmly in place and draw a pencil along it while the cardboard is revolving under it. Do this

\footnotetext{
${ }^{1}$ Note: It had been previously stated by Coriolis and others.
} 
in several directions and start the lines at different parts of the cardboard. Notice that every pencil line and every ink line, wherever it starts and whatever its direction, curves always to the right. This is because the cardboard moves to the left under the marble or pencil as they travel.

\section{Right-hand Deflection of Winds in the North Hemi-} sphere.-In Ex. 61 the revolving cardboard represents the north hemisphere of earth and the center nail represents the north pole. Any wind anywhere in the north hemisphere, starting in any direction, will, under natural conditions, always follow a curved path over the earth, as the marble or pencil did over the revolving cardboard; because the rotating earth moves sidewise from under the wind as it travels, just as the cardboard moved from under the marble or pencil.

It is through the application of this general law that we are able to explain: (1) That the trades in the northern hemisphere are

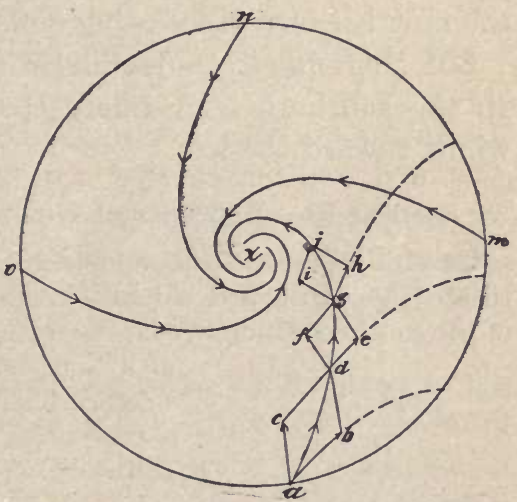

Frg. 204.-Analysis of the cause of the counter-clockwise whirl about a low in the Northern Hemisphere.

northeast winds instead of north winds; (2) that the returning upper currents are southwest winds instead of south winds (see Fig. 202); (3) that the ground winds about a HIGH blow spirally outward, curving to the right, instead of blowing straight out from the center of the HIGH (see Art. 291); and (4) that the winds blow into the Low from every side in curved, fish-hook shaped paths (see Fig. 189).

The path of any portion of air blowing into a Low is explained by Fig. 204. Let $x$ mark the center of the Low. The air at $a$ is being pushed straight toward $c$ and $x$ by the surrounding higher pressure; but the deflecting force (Art. 299) 
tends to deflect it to $b$ instead. The combined effect of these two forces acting, at the same time, upon the air, causes it to move along the path $a-d$ to the point $d$. At $d$, it is still being pushed toward $f$ and $x$ by air pressure, but the deflecting force tends to send it to $e$. The combined effect of these two forces sends it along the path $d-s$ to the point $s$. And thus it is that the air starting at $a$ toward the center of the Low actually follows the path $a-d-s-j$ toward the center, $x$. This path somewhat resembles a fish-hook in shape, and, while curving to the left, always passes to the right of the center of the Low because of its being deflected to the right.

301. Left-hand Deflection in the Southern Hemisphere.In the southern hemisphere the earth's rotation deflects all winds toward the left.

\section{Exercise 62.-Deflection of Winds in the Southern Hemisphere}

Carefully perform the same set of experiments as in Ex. 61, but rotate the cardboard clockwise (Fig. 205). Explain the direction of the southern trade winds; the return currents; the outflowing winds

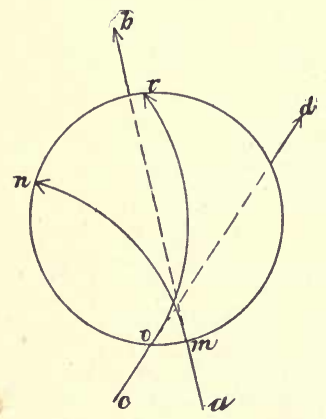

FIg. 205. of a southern high-pressure area; also draw a figure illustrating the path of the winds in a Low of the southern hemisphere (see Fig. $185)$.

\section{Weather Types in the General} Circulation.-Each of the several parts of the general wind system has a different prevailing type of weather.

In the Equatorial Calms, it is hot and moist, with light variable winds and frequent heavy showers that are often accompanied by wind squalls. There are no general storms.

In the TRADES, the winds are remarkably steady in direction and fairly so in force. Showers occur about islands and windward coasts. General storms occur only in late summer and early autumn. These are called Hurricanes in the West Indies, Crclones in the Indian Ocean, Typhoons off southeast 
Asia, and BAguios in the Philippine Islands. This class of storm is usually 300 to 500 miles or more in diameter, with strong or violent winds that circle about the storm center and sometimes blow 100 miles or more per hour. After traveling westward in the tropics, the storm usually curves out into the temperate zone and turns eastward, at the same time gradually becoming broader and less violent. West India hurricanes occasionally visit the Atlantic seaboard of the United States. Sometimes they enter the Gulf of Mexico and pass northward over the Mississippi or Ohio valleys. Examples of these are the storms that damaged Galveston, Tex., in September, 1900, and in August, 1915, and the city of New Orleans in September, 1915.

The Westerlies of the Temperate Zones are turbulent, and full of unequal temperatures, humidities and pressures. The areas, or waves, or surges of unequal pressure are the HIGIS and Lows that appear on the weather maps and control the daily weather of the temperate zone in the manner we have studied.

303. The Annual Migration of the Sun; Its Relation to the Weather of Summer and Winter.-The entire wind system of the earth is divided into two similar parts by the belt of equatorial calms which is located in the region of greatest heat. As the seasons move north and south with the sun, the entire wind system follows. This annual shift of the wind system indirectly affects the weather of the United States in two important ways.

1. The tropical hurricanes described in Art. 302 develop in the northern hemisphere principally from August to October and in the southern hemisphere principally from January to April.

2. Land warms by sunshine more rapidly than water. Therefore, when the sun moves northward in summer, the northern continents become much warmer than the oceans. This develops low pressure over the continents and causes the winds from all sides to blow more or less inward toward the 
center of the land division (Fig. 206). This results in prevailing southerly winds in summer over most of the United States east of the Rocky Mountains. These winds carry moisture from the Gulf of Mexico and Atlantic Ocean far inland and contribute largely to the ample rainfall of summer over the plains and the Missouri and upper Mississippi valleys. It is this feature of weather control that contributes largely to the fruitfulness of that portion of the country (Fig. 207).

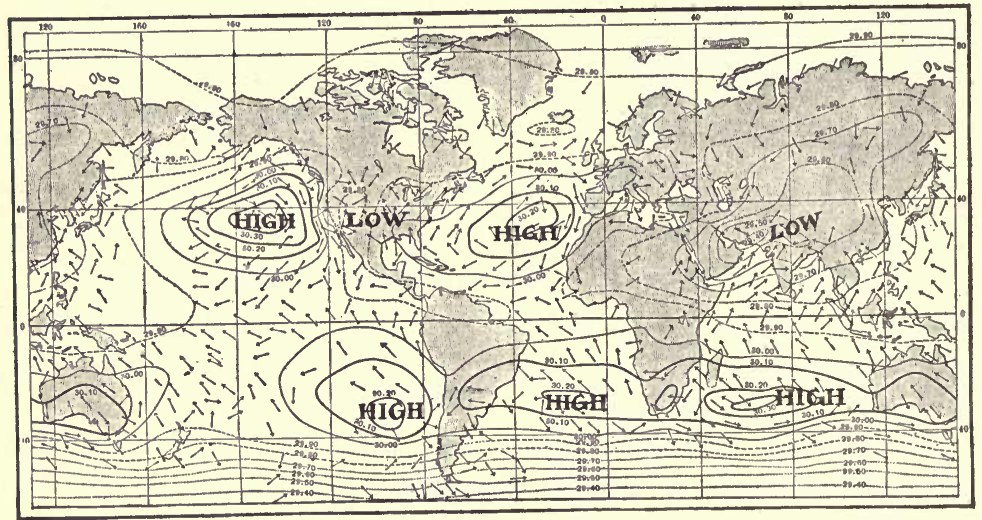

FIG. 206.-Pressure and prevailing winds of the globe for July.

In winter the land cools much more than neighboring oceans. This develops high pressure over the continents, and this, in turn, causes outflowing winds on all sides (Fig. 208). This results in prevailing west or northwest winds in winter over most of the United States east of the Rockies, with dry, cold weather in the interior, and most of the precipitation confined to the southeastern and eastern sections (Fig. 209).

304. Land and Sea Breezes.-A similar effect, on a much smaller and less important scale, is seen in the sea breeze of afternoon and the land breeze at night, that give comfort and prosperity to scores of summer resorts on many coasts.

305. Monsoons of India.-The Indian monsoons and the remarkable summer rains they carry to the land are a striking 
example of this control of summer and winter weather by the annual migration of the sun and the wind system.

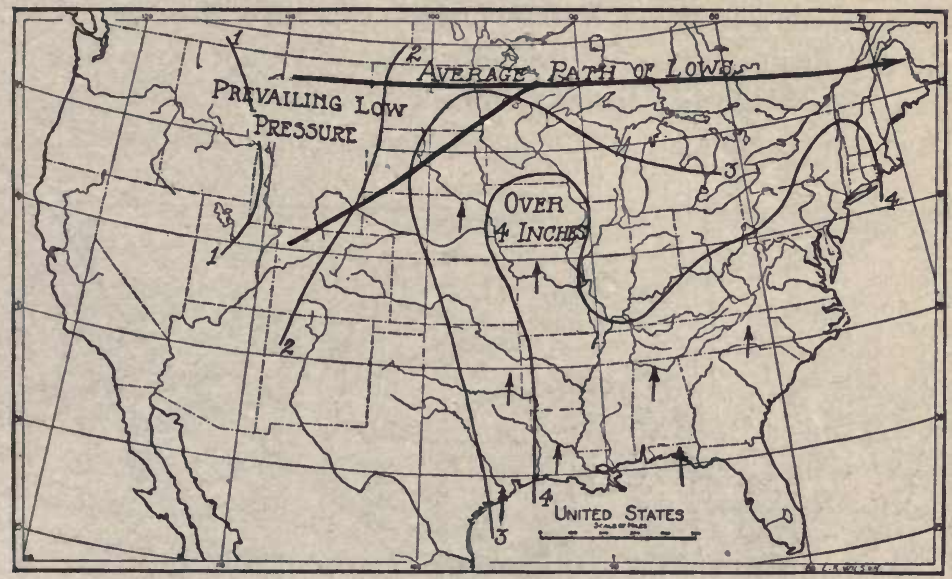

Fig. 207.-A summer month. Low pressure in interior. Storm tracks far to north. Prevailing southerly winds. Precipitation distributed far inland.

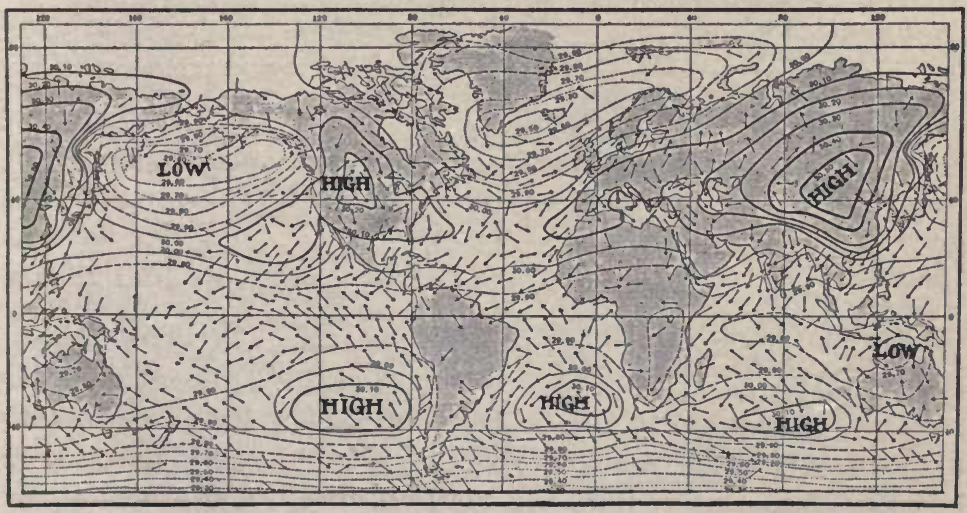

FIG. 208.-Pressure and prevailing winds of the globe for January.

306. Conclusion.-The heat of the sun and the rotation of the earth produce the general system of winds. This shifts 
north and south with the annual migration of the sun. The unequal warming of land and water modifies the general winds and causes special wind movements on and about the continents. Over and through these are the traveling pressure areas that appear in the trade wind belts in late summer and autumn and in the westerlies throughout the year. In the temperate zones, the traveling pressure areas cause the general weather

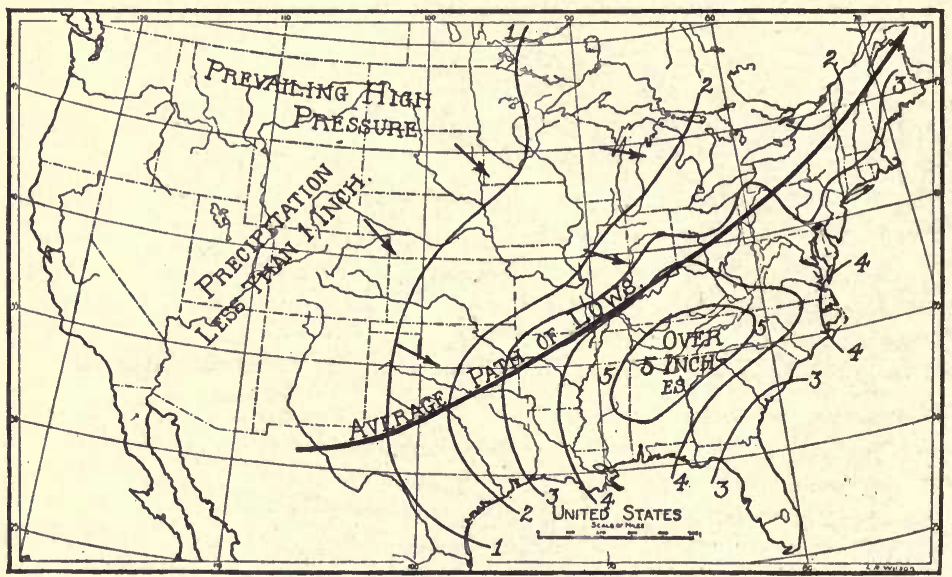

FIG. 209.-A winter month.

1. High pressure in interior.

2. Storm tracks farther south and southeast.

3. Prevailing northwesterly winds.

4. Distribution of precipitation.

changes from day to day, and, in summer, help to provide the conditions favoring the formation of local storms. These principal features operating together produce most of the weather of earth. In many countries of the temperate zone, man may watch the weather maps for knowledge of the broader changes to come, and may observe the sky for indications of local changes nearer at hand; and in both may profit by the study of the atmosphere. 


\section{CHAPTER V}

\section{THE SEASONS-CLIMATE AND HEALTH}

\section{THE SUN-THE CAUSE OF THE SEASONS}

307. The Sun's Altitude and Its Heating Effect.-The height of the sun above the horizon at noon is different for every different latitude upon any given day. It also is different for any given latitude upon different days of the year. The earth receives all its heat from the sun. We shall soon see that the nearer the sun is to being at the zenith (the point directly overhead), the greater is its heating power. Therefore, the changing altitude of the sun is one of the principal causes of seasons.

Exercise 63.-To Construct a Clinometer and to Measure the Altitude of the Sun

(a) On a piece of cardboard about 20 in. square, mark out the quarter of a circle as shown in Fig. 210. To do so, make a small loop at the end of a piece of wrapping twine. Slip a pencil point through this loop. Place one finger tightly upon the string so as to make the radius exactly 20 in. Draw the arc of the circle from $0^{\circ}$ to $90^{\circ}$. Next mark off the scale by dividing the distance from $0^{\circ}$ to $90^{\circ}$ into eighteen equal parts. Each space will then represent $5^{\circ}$. If the radius is exactly $20 \mathrm{in}$., the distance from $0^{\circ}$ to $90^{\circ}$ around the arc is $1 / 4$ of $2 \times 20 \times 3.14$ in., or 31.4 in. Each of the eighteen equal parts will then be a trifle less than $13 / 4$ in.

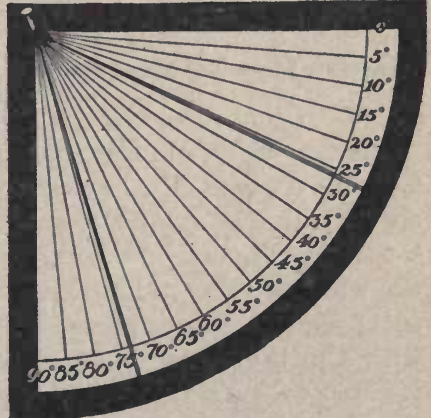

FIG. 210. These $5^{\circ}$ spaces may then easily be divided into five equal spaces, thus marking off degrees. 
(b) Tack this cardboard scale to a board about $2 \mathrm{ft}$. square. Drive a nail into the board at the center of the circle. Bore a hole in the board near its upper edge and in the center from right to left. Hang this instrument on the east side of the house where the sun can strike it at noon.

Note.-If the instrument is to hang on the west side of the house make the scale by beginning with $0^{\circ}$ in the upper left-hand corner.

(c) See that the clinometer hangs in a north and south line, and that no trees or buildings prevent the sun's striking it at noon. At 12 o'clock one day each week, note where the shadow of the nail falls across the scale. Read and record with date the angle made by the nail's shadow with the $\mathrm{O}^{\circ}$ line. This angle is equal to the angular altitude of the sun above the horizon. Explain why. After making several readings, state what you have discovered.

308. Effect of the Sun's Altitude upon Its Heating Power.In all portions of the United States the sun's rays are much more nearly vertical in summer than in winter. Throughout the United States the sun is at its highest altitude and its rays are most nearly vertical on June 21 ; it has its lowest altitude and the rays are most slanting on December 22. The highest and lowest altitude of the sun's rays vary with the latitude. At latitude $40^{\circ}$, which is about the latitude of Philadelphia, Columbus, Ohio, Springfield, Ill., and Denver, Colo., the highest altitude of the sun is $731 / 2^{\circ}$ and the lowest, $261 / 2^{\circ}$.

\section{Exercise 64.-To Measure the Length of Shadow when the Sun is at a Known Altitude}

Place a table or desk having a level top before a south window. Cut out a piece of cardboard just $1 \mathrm{ft}$. square. At 12 o'clock, noon, on a clear day read the sun's altitude from the clinometer. Then set the cardboard on edge in an east-and-west line on the table before the window (Fig. 211). Lean the top of cardboard toward the north till it exactly faces the sun. The cardboard will then form an angle with the table top which equals $90^{\circ}$ minus the altitude of the sun. Its shadow now falls upon the table top. Carefully read and record the length of the shadow. Is the length of the shadow more or less than $1 \mathrm{ft}$.? How many square feet in the shadow on the table top?

If the sun were not so high in the sky, would the shadow then be longer or shorter than you find it to be? Would the area of the shadow be greater or less? 
If the sun were higher in the sky, what would then be true?

How does the altitude of the sun affect the length and area of the shadow?

Do you see that if it were not for the cardboard $1 \mathrm{ft}$. square, or 1 sq. $\mathrm{ft}$. in area, the sun's rays would fall upon that portion of the table top which is covered by the shadow?

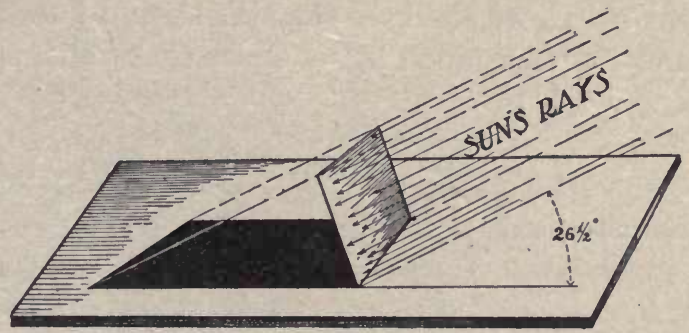

Fig. 211.-Measuring the board's shadow on December 22, at latitude $40^{\circ}$, North.

Would the energy in $1 \mathrm{sq}$. $\mathrm{ft}$. of sun's rays fall upon a larger or smaller area of table top if the sun were at a lower altitude?

What would be true if the sun were at a higher altitude?

When $1 \mathrm{sq}$. $\mathrm{ft}$. of the sun's rays is spread over a large area, is that area heated more or less than when the rays are spread over a small area?

\section{Exercise 65.-To Construct Figures Representing the Effect of the Sun's Altitude upon the Length of Shadow}

1. With a ruler, lay off a horizontal line to represent the table top. Then, using a protractor and ruler, draw a second line slanting at an angle of $731 / 2^{\circ}$ down to this line (Fig. 212). This is the angle of the sun's altitude on June 21 on the $40^{\circ}$ north latitude. Draw a third line parallel to the second line and the width of your ruler from it.

2. In a similar manner, construct two parallel lines the width of your ruler apart and slanting at an angle of $261 / 2{ }^{\circ}$ to the horizon line as in Fig. 212.

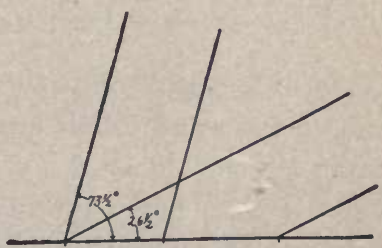

Fig. 212.- Slant of sun's rays at $40^{\circ}$ latitude.

This is the angle of the sun's altitude on December 22 at the $40^{\circ}$ north latitude.

3. Now measure accurately along the horizon line the distance between the pairs of parallel lines in each case. How does the dis- 
tance between the second pair of parallel lines compare with the distance between the first pair?

Explanation.- Now if we imagine two bundles of rays, each bundle being $1 \mathrm{ft}$. square, as coming from the sun and falling upon the earth, the first at an angle of $7312^{\circ}$ from the horizon and the other at $261 / 2^{\circ}$, we shall see that the second bundle of rays will be spread over a much larger space than the first bundle.

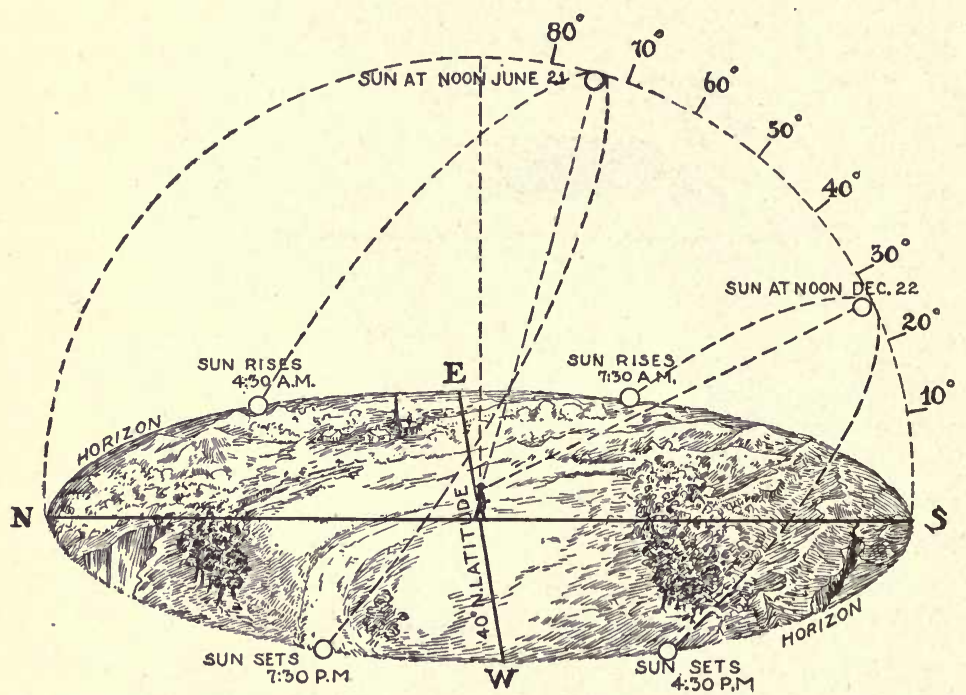

Frg. 213.- Showing the different positions, of the sun at sun rise, at noon, and at sun set on June 21 and on December 22 at $40^{\circ}$, North latitude.

Careful measurement shows that the second is spread over just about twice as much space as the first. This means that at noon the sun heats $1 \mathrm{sq}$. ft. of the earth's surface and hence of the earth's atmosphere but one-half as much at the $40^{\circ}$ latitude on December 22 as it does on June 21 (Fig. 213).

Exercise 66.-To Study the Heating Effect of the Sun's Rays at the North Boundary of the United States, Latitude $49^{\circ}$

On June 21 , the altitude of the sun at noon at $49^{\circ}$ north latitude is $641 / 2^{\circ}$; on December 22 , it is but $17 \frac{1}{2}{ }^{\circ}$.

Following the plan pursued in the last exercise, construct accurately 
a figure similar to Fig. 214. Measure and record the distances between the two pairs of parallel lines as they strike the horizon line as in the last exercise.

At latitude $49^{\circ}$, is $1 \mathrm{sq}$. ft. of sun's rays spread over a larger area in June or December?

State the proportion of these two areas according to your measurement.

At noon, at latitude $49^{\circ}$, the sun heats each square foot of earth's surface about how many times as much on June 21 as on December 22 ?

Accurate measurements show that $1 \mathrm{sq}$. $\mathrm{ft}$. of sun's rays at latitude $49^{\circ}$, are spread over about three times as large an area on December 22 as on June 21. This means that the earth's surface is heated only about $1 / 3$ as much at noon on December 22 as on June 21.

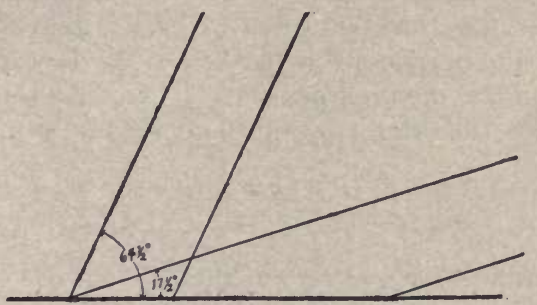

Fig. 214.-Slant of sun's rays at latitude $49^{\circ}$.

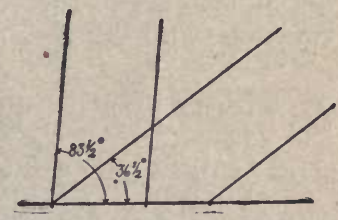

Fig. 215.--Slant of sun's rays at $30^{\circ}$ latitude.

Exercise 67.-To Study the Heating Effect of the Sun's Rays at the South Boundary of the United States, Latitude $30^{\circ}$

At noon, on June 21 , at latitude $30^{\circ}$, the altitude of the sun in $8312^{\circ}$; at noon on December 22 it is $3612^{\circ}$.

Construct accurately from these data a figure similar to Fig. 215 and measure the distances between the two pairs of parallel lines as they strike the horizon line.

At latitude $30^{\circ}$, about what is the relative areas over which the sun's rays are distributed on June 21 and on December 22 at noon?

What is the relative heating power of the sun at this latitude on June 21 at noon compared with that on December 22 ?

What do you now say is one of the chief causes of our summer and winter seasons?

Judging from the foregoing exercises, should we expect greater temperature differences between summer and winter in Texas or in North Dakota? Explain clearly your answer. 
309. Length of Day and Its Effect upon the Heating Power of the Sun.-The days and nights are always equal in length at the equator, 12 hours each. The poles of the earth have six months day and six months night. Between the equator and the poles, the length of day and night is constantly changing. At latitude $40^{\circ}$ north, the days vary in length from about nine hours on December 22 to 15 hours on June 21. The farther north we go the longer the summer day becomes till we reach the north pole when the day is six months in length. Just why this is so is easily shown by experiment.

\section{Exercise 68.- To Show Why the Length of Day Varies at Different Places on the Earth's Surface}

(a) Use an orange or a small schoolroom globe for this experiment, and perform it in the evening or in a darkened room. Place a lighted lamp upon the table and hold the orange a few feet from it. If you use an orange, let the stem and the bloom scars of the orange be the two poles and draw a line about the orange to represent the equator.

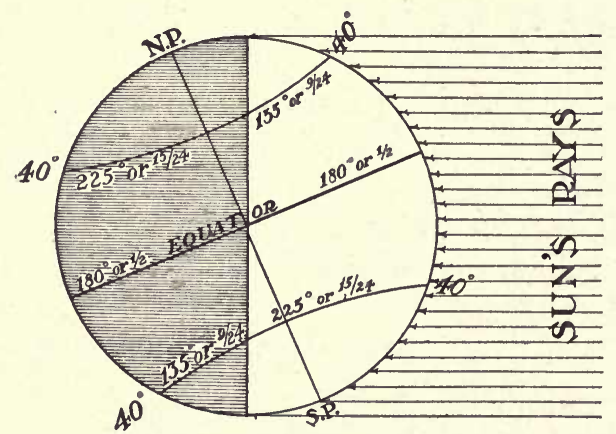

Frg. 216.-The length of day.

Let the north pole be tilted toward the lamp $231 / 2^{\circ}$. Now note as carefully as possible the position of the dividing line between the lighted and unlighted surfaces of the sphere. Draw a pencil line around the sphere to mark this line. If we now mark the 40 th parallel of latitude on the sphere, we shall find that about $15 / 24$ of it was lighted. This means that, if we revolve the sphere upon its axis, that any point upon the 40th parallel would be in the light during $15 / 24$ of a revolution. Therefore, the day at the 40 th parallel is 15 hours in length on June 21, or at the summer solstice. At this same time the pole is constantly in the light, and just $1 / 2$ of the equator is lighted. 
(b) Repeat the exercise with the north pole tilted $2312^{\circ}$ away from the light. We then find that but $9 / 24$ of the 40 th parallel is lighted; that the north pole is without light; and that the equator is again exactly half lighted (Fig. 216).

This increased length of day greatly increases the sun's power of heating the earth's surface and the atmosphere in the north latitudes during our summer months.

1. Notwithstanding the fact that the vertical rays of the sun never fall farther north than the Tropic of Cancer, $2312^{\circ}$ north latitude, it still is true that for the three months from May 5 to August 5 the zone of the sun's greatest heating is about $41^{\circ}$ north latitude.

2. During the 45 days from May 31 to July 16 , the region about the north pole actually receives more heat than does an equal area at any other portion of the earth's surface.

3. And again, it can be shown that, at the time of the SUMMER soLSTICE, the region of the north pole is receiving 36 per cent. more heat than an equal area at the equator is then receiving during the 24-hour day.

If these are facts, why does not the north polar region become warmer? 1. Because the north pole receives no heat whatever from the sun for six months each year. 2. Because nearly all of the heat furnished by the sun during the summer months is consumed in melting the ice and snow formed during the long winter months. During the following winter a fresh supply of ice and snow again accumulates in the polar regions.

Without a knowledge of these facts it is impossible to understand the seasonal changes of the weather of the United States.

The maximum temperature of a summer day in the United States rarely occurs in the southern states; it most frequently occurs in the region extending from Oklahoma and Illinois to South Dakota and Eastern Montana. Can you explain why this should be so?

Indian corn (maize) requires high temperature both day and night during about three months, or its growing season. Can 
you give some reasons why Illinois and Iowa are the greatest corn-producing states of the Union?

310. Summary. - There are two chief causes of our summer and winter seasons in the United States: (1) The change in the altitude of the sun and the consequent change in its heating power; (2) the great difference in the length of day. Both of these are, of course, caused by the tipping of the earth's axis $231 / 2^{\circ}$ from the perpendicular to the plane of the earth's orbit, and the earth's revolution about the sun. Since these facts are studied in geography further study of them is omitted here.

\section{CLIMATE AND LIFE}

311. Meaning of "Climate" and "Weather."-By weAther, we mean the condition of the atmosphere at some particular time and at some particular place. The weather at Chicago frequently differs considerably from that at Buffalo or Albany upon any particular date, but the climate of these cities is quite similar. In speaking of the weather we refer to the temperature, the percentage of sunshine or cloudiness, the wind, and the precipitation upon a particular date.

By climate, we mean the average atmospheric conditions existing in a certain locality for a period of time, especially as they affect the animal and plant life of the region and the health and comfort of the inhabitants. When considering the climate of any region in reference to health we note:

1. The average temperature and the changes in temperature.

2. The average relative humidity and the changes in humidity.

3. The prevailing direction and strength of the winds and how they vary.

4. The average relative amounts of sunshine and cloudiness.

5. The average rainfall for the year and the particular seasons at which it is heaviest and lightest.

6 . The prevalence of fogs and of dust and smoke in the air.

7. The altitude of the region and the consequent density of the air.

All these factors taken together determine, in a large measure, the plant and animal life of the region and the health and comfort of the inhabitants. 
312. Plant Life Determined by Climate.-So completely does the climate of any region control plant life, that it is usually with considerable difficulty that man is able to grow plants in any other than their native land or one having a similar climate. The character of the soil has, of course, considerable influence in determining plant life, but climate is the chief factor. The trained botanist can tell, practically, the climate of a certain region by observing the native flora, or plant life, of that region. As the climate of a certain region changes, the

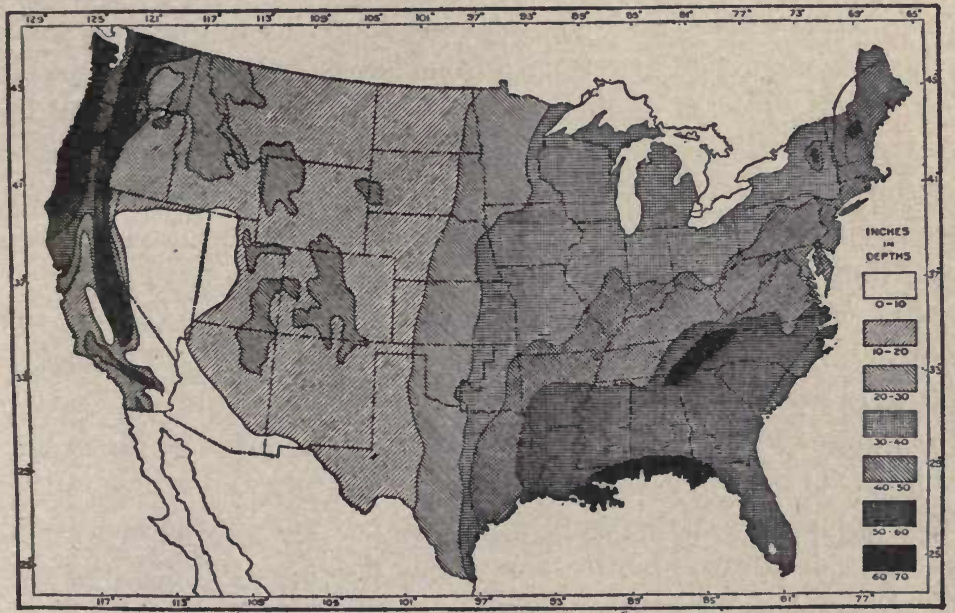

Fig. 217.- Average annual rainfall map of the United States.

flora of that region also changes. In ages past, during the Glacial Period, most of central North America north of the 40th parallel of latitude, was covered with ice. The climate then must have been similar to that of the arctic zone today. The flora, or plant life, which developed as the ice sheet retreated must have been similar to that now existing in British America near the arctic circle. In certain moist, cool canyons as far south as Illinois and Kentucky, specimens of this northern flora still linger, while the flora of the rest of the region long ago changed to that typical of the temperate zone. 
While it is true that plants may survive when transplanted to a region having a climate somewhat different from that of their native haunts, they do not thrive; they develop only as dwarf and inferior specimens. The cactus and yucca, natives of our arid western plains, often survive when transplanted to the fertile plains of the Mississippi valley, but they little resemble the sturdy specimens growing in their native climate.

To the extent that man is able to control and modify the climate of a given region, he can raise successfully plants of almost any species anywhere on the face of the earth. In the green houses and conservatories of the temperate zone, tropical vegetation grows with luxuriance in the dead of winter. When irrigation is applied to our western plains, they blossom forth with all the productiveness of the most favored regions of the earth; yet, all that man has done is to devise a plan for supplying the moisture to take the place of the rainfall which is insufficient (Fig. 217, Rainfall Map).

313. Animal Life Dependent upon Climate.-Animal life is also largely dependent upon climatic conditions. The higher forms of animal life, however, show greater power of adaptation to changed climatic conditions than do the forms of plant life. While it is true that the polar bear of the arctics and the monkey and the parrot of the tropics live side by side in the zoölogical gardens of the temperate zone, it is not from choice, nor are they healthy, vigorous, happy, or comfortable while doing so. In a large measure man must provide a modified climate in order to save their lives. To the extent that either plants or animals become adapted to changed climatic conditions, we say that they have become ACCLIMATIZED.

314. Man's Relation to Climate.-By nature, man is one of the hardiest of animals. His power of endurance equals, if, in fact, it does not exceed, that of any other form of animal life. A lone man on foot has been known to run down and tire out the wild horse and the wild turkey. From choice, man dwells contentedly in almost every climate on the face of the earth. He even delves into the bowels of the earth and soars aloft 
among the clouds. He survives extreme exposure and retains his health, strength, and bodily vigor while engaged at the hardest labor for many hours each day. As long as he labors out of doors in the fresh air and in the sunshine, receives an abundance of nourishment, and sleeps eight hours each night in the open air, he outstrips nearly every other type of animal life in health, bodily vigor, and power of endurance.

Usually, it is when man violates one or more of these conditions that he becomes a puny, delicate creature, an easy prey for disease. The experience of every polar expedition in history is positive evidence of the truth of this statement. Pioneer life, with all its exposure and privations, has always developed a people of exceptional vigor and hardiness.

It is almost wholly man's unwise and unintelligent attempts to protect himself against the inclemency of weather and climate which have produced conditions favorable to the transmission of disease from one person to another and at the same time have so weakened his bodily resistance that he easily succumbs to almost any disease. Among all classes, from the wealthy to the very poor, two other causes of ill health are evident: (1) Lack of sufficient and suitable nourishment; and (2) lack of proper amount of sleep and rest. The wealthy suffer from these causes because of self-indulgence, the poor suffer because of their poverty.

\section{THE FACTORS WHICH DETERMINE CLIMATE}

\section{A. Temperature ${ }^{1}$}

\section{Seasonal Changes in Temperature.-}

\section{Exercise 69.-Study of the Average Temperature Maps of United States} for July and January (Figs. 218 and 219.)

What and where is the highest average temperature for July?

What and where is the lowest average temperature for July?

What and where is the highest average temperature for January?

What and where is the lowest average temperature for January?

In which month, then, July or January, is found the widest difference of temperature within the boundaries of the United States?

${ }^{1}$ See foot note page 196. 
Review the study of the effects of the sun's altitude and length of day upon the temperature (Arts. 307 and 308) and explain why January should cause a wider range of temperature than does July.

Does New Orleans, La., or Grand Forks, N. D., have the greater variation in temperature between summer and winter? Why should this be so?

Why should the $70^{\circ}$ isotherm bend so far south during July in Colorado and New Mexico? Trace the $70^{\circ}$ isotherm throughout its length explaining all the bends in it. Remember that the principal factors in determining temperature are: (1) Altitude of the sun; (2)

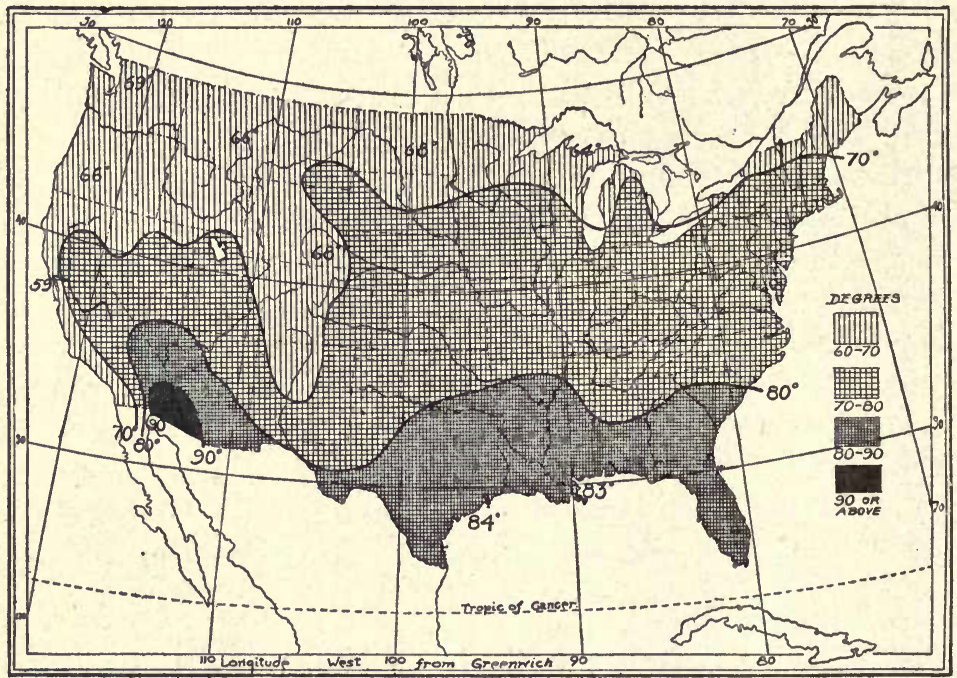

FIG. 218.-Average temperature for July, 25 years.

length of day; (3) prevailing wind direction; (4) proximity to bodies of water; (5) presence of mountain ranges.

What portions of the United States are so situated that the climate, especially the temperature, is largely determined by the ocean? (Recall the most frequent paths of Lows and HIGHs across the United States.) Account in part, at least, for the temperature along the coast of California?

After studying the July and the January maps, state whether the Atlantic or the Pacific Ocean has the greater effect upon the nearby portions of the United States. Why should this be so?

In studying such maps as these, we must learn to estimate the 
temperature of any locality on the map. Chicago, for instance, has an a yerage temperature for July of about $71^{\circ}$ or $72^{\circ}$; St. Louis, of about $76^{\circ}$ or $77^{\circ}$; New Orleans, of about $82^{\circ}$. For January, Chicago has an average temperature of about $22^{\circ}$; St. Louis, of about $29^{\circ}$; and New Orleans, of about $52^{\circ}$.

About what average temperature has Boston for July? New York City? Baltimore? Charleston, S. C.? New Orleans? Santa Fe, N. Mex.? San Francisco? Denver? Bismarck, N. D.? St. Paul, Minn.? Portland, Oregon?

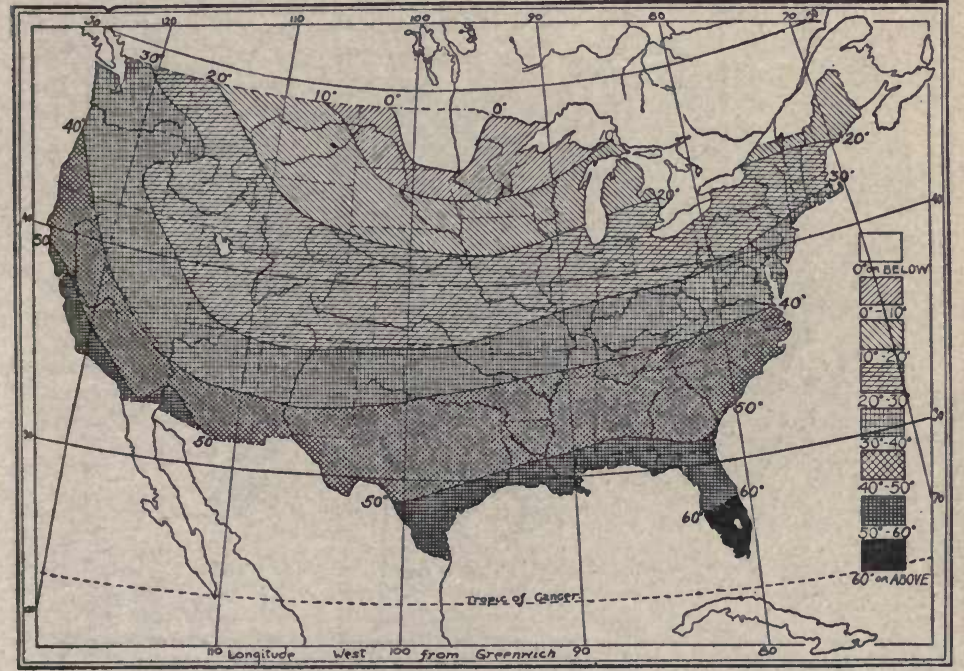

FIG. 219.-Average temperature for January, 25 years.

Estimate the average temperature of each of these places for January.

\section{B. Relative Humidity}

\section{Seasonal Changes in Relative Humidity.-}

Exercise 70.-Study of the Average Relative Humidity of the United States, Summer Months and Winter Months, Figs. 220 and 221

Taking the United States as a whole, is the relative humidity higher in the summer or in the winter?

Locate several cities such as Chicago, Pittsburg, Charleston, 
S. C., Lincoln, Neb., Santa Fe, N. Mex., Denver, Salt Lake City, Portland, Ore., St. Paul, Grand Rapids, Mich. Note the average relative humidity of each for the summer months and for the winter months. Find the difference in the per cent. of relative humidity of each of these places for the summer and winter months.

Do certain portions of the United States have about the same relative humidity both summer and winter? Name them. Can you see why this should be so?

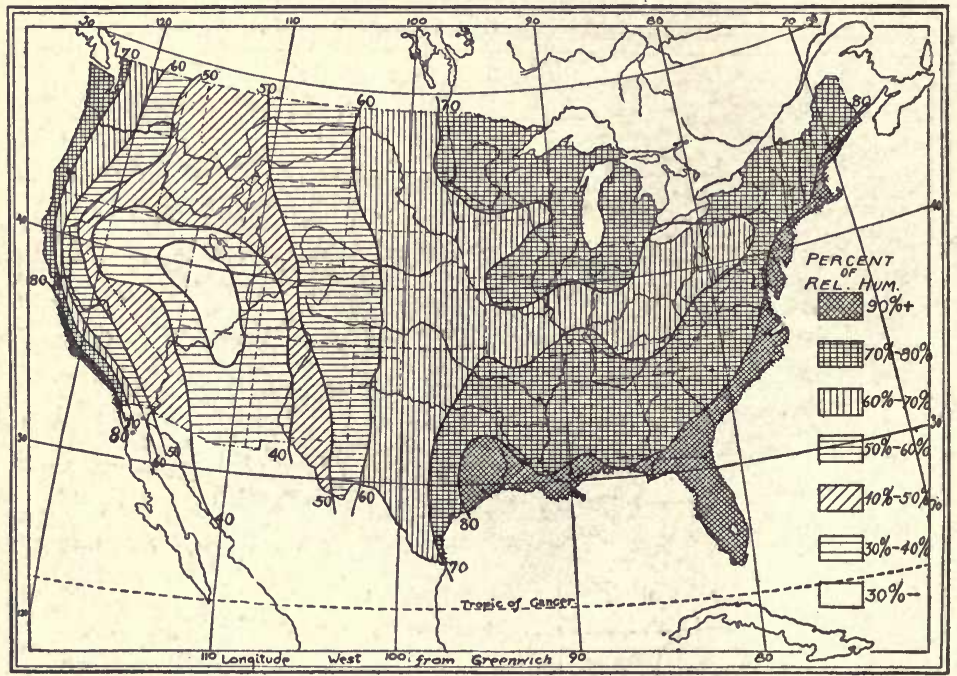

FIG. 220.-Relative humidity, U. S. 15 years, June, July, August.

Note the comparatively low relative humidity in Kentucky, southern Ohio, and West Virginia. How do you account for this region of low humidity?

Note the comparatively high relative humidity of the Great Lakes region and extenting westward into northern Minnesota. Recall the average temperature of this region especially in January, also the most frequent paths of the Lows. Do these facts help to explain the high average relative humidity of this region? Explain.

Account for the high humidity in Oregon and Washington, especially in the winter months.

We sometimes hear the residents of the Upper Michigan Peninsula and northern Minnesota say that they do not feel the cold more 
when living in that region than when living farther south, in Iowa, Illinois, Indiana, or Ohio, "because the atmosphere is so dry." Does the winter relative humidity map confirm this theory? From Table XII, page 220 , compute the absolute humidity of these regions. Review Art. 245, page 215, and state whether relative humidity or absolute humidity is the more important factor in this case. Why? Remember that conductivity of heat depends upon absolute humidity. Where is the dryest region of the United States? Explain why this is so.

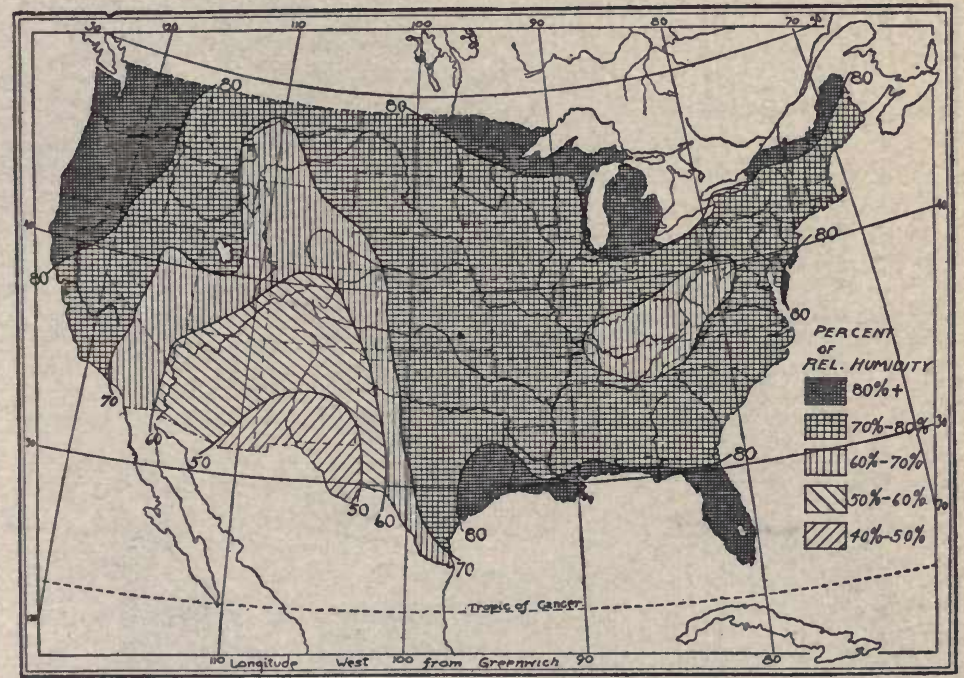

FrG. 221.--Relative humidity, U. S. 15 years, December, January, February.

\section{Daily Changes in Relative Humidity.-}

Exercise 71.-Study of the Daily Changes in Relative Humidity, Figs. 222 and 223

Study carefully the two maps showing the average relative humidity at 8 o'clock in the evening and 8 o'clock in the morning.

Note the relative humidity of several cities both in the evening and in the morning. At which hour, 8 in the evening or 8 in the morning, is the relative humidity higher? What is the approximate difference?

Recall the fact that the highest temperature of the day is usually 


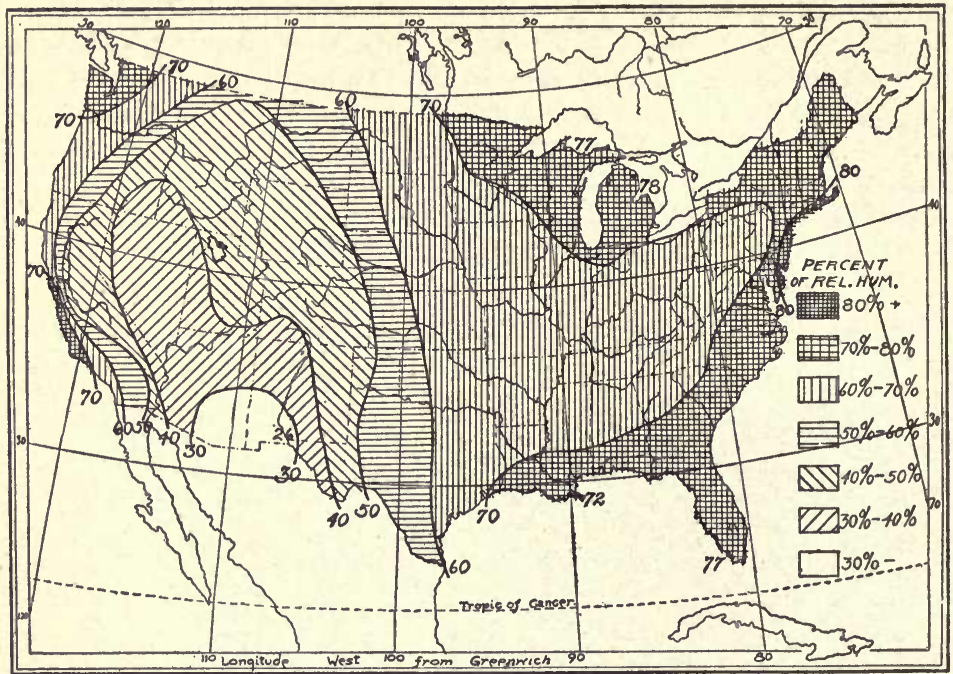

FIG. 222.-Average relative humidity, 8 P. M. 15 years.

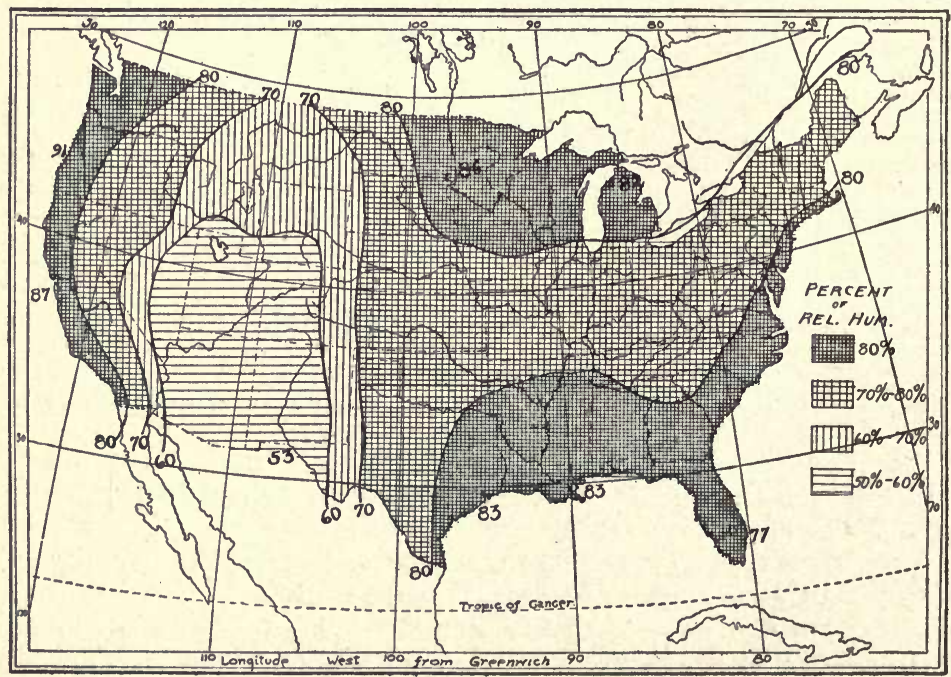

Frg. 223.-Average relative humidity, 8 A. M. 15 years. 
about 2 o'clock in the afternoon, and that the lowest temperature is usually about 5 or 6 o'clock in the morning. The records of the Weather Bureau show that the relative humidity is usually highest at about the hour of the lowest temperature and that the relative humidity is lowest at about the hour of the highest temperature. Review Art. 248 and explain why this should be so. Show that this would necessarily be so unless there were a change in the absolute humidity. Since weather changes alone produce changes in the absolute humidity of the atmosphere, and since such weather changes are likely to occur at any hour of the day, show that on the average we should expect to find the morning relative humidity considerably higher than the evening humidity.

We frequently hear people speak of the dampness of evening air and the danger of "catching cold" through being out in the evening. Rarely do we hear any suggestion that morning air is damp, and we never hear that there is danger of "catching cold" on account of morning dampness. Judging from the average relative humidity, evening and morning, as shown by these maps, and also from the fact that the temperature is almost always lower in the morning than in the evening, would you say that the theory that people "catch cold" through exposure to the evening air because of its dampness or low temperature is well founded?

The Explanation.- It is very possible, however, that there is some truth in the supposition that we are more likely to suffer from exposure in the evening than in the morning, not on account of the dampness or low temperature of the evening air, but on account of our own physical condition. In the evening we are more or less exhausted - tired out by the exertion of the day's work; our vitality is at low ebb. During the day's labor, waste materials accumulate in the system; our resisting powers are correspondingly reduced. In the morning, after the night's rest, our bodies are recuperated; our vitality and resisting powers are at full flow. It is also often true that we dress more warmly in the morning than in the evening. We sometimes fail to put on extra wraps soon enough with the fall of temperature in the evening. We doubtless do often first realize that we are developing a cold during the evening rather than the morning hours. But, if this is so, it is not because of damp air but is due to insufficient clothing and to our 
low vitality and low resistance to the attack of the influenza germ, or other similar germs, which produce the effects we commonly hear spoken of as "catching cold" (see Arts. 512 and 513).

When we come to realize that the relative humidity changes greatly from day to day, sometimes changing 10,20 , or even 50 per cent. within a few hours, we see how unscientific and unwarranted the assumption is that we are likely to "catch cold" in the evening on account of the low temperature and dampness of the air. The importance of studying humidity and of knowing how to secure the proper indoor relative humidity will become more evident when we study ventilation, Chap. VI.

The student should keep a daily record of relative humidity out of doors for one month, noting the changes in weather during that period.

\section{Winds}

318. Wind, Another Important Element of Climate.-The temperature and humidity may be the same for two different localities. But if one be a sheltered place where wind velocities are low while the other be exposed to high wind velocities, we know from experience that the exposed place seems to be much the colder and more uncomfortable in winter and much the cooler and more comfortable in summer (Art. 231). Protection against the chilling effect of the wind in winter is necessary. The clothing we wear, the wool, the fur and the hair of animals, and the feathers of birds, all serve as a protection against the chilling wind by retaining a layer or envelope of warm air next to the body. High winds disturb this layer of warm air, thus cooling the body.

319. Wind Velocities in the United States.-The Weather Bureau records for years past give fairly satisfactory information regarding the wind velocities. The principal facts of wind velocity over the United States are easily shown (Fig. 224). From this map we see that the highest average wind 
velocities, i.e., 10 miles per hour or more, are along the coasts, over the Great Plains Region east of the Rocky Mountains, and in the region of the Great Lakes.

The records of the Weather Bureau also show the following facts:

1. The lowest average wind velocities are found in the valleys of the interior.

2. The greatest wind velocities are found to occur in the months of

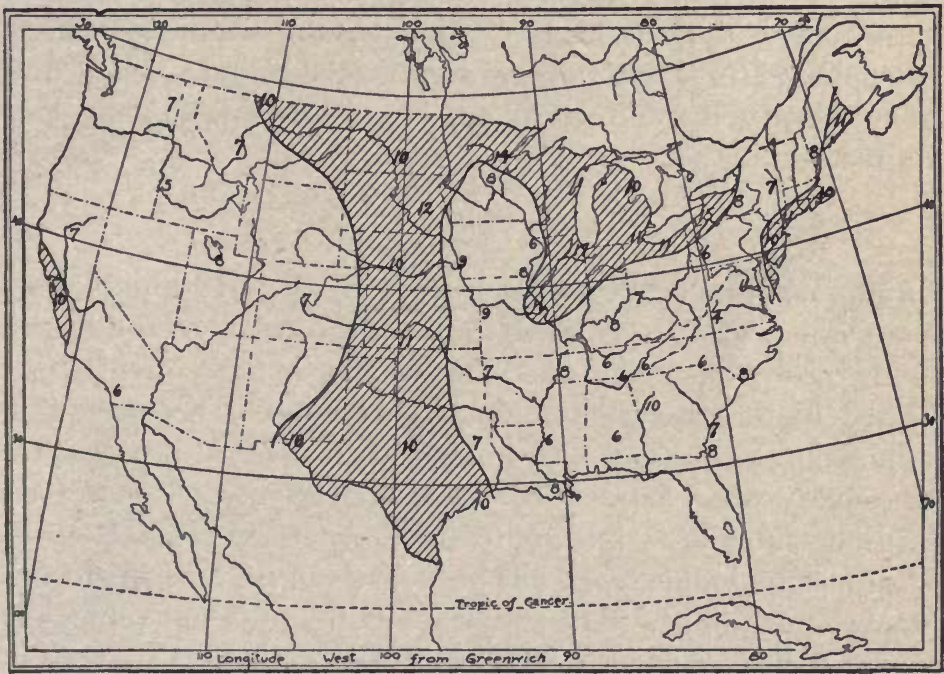

Fig. 224.- Average wind velocity, miles per hour.

March and April, while the lowest velocities occur in the months of July and August.

3. All high altitudes have a tendency toward high winds, the sharper the point, the higher the winds.

4. In general the west slope of mountain ranges has a higher average wind velocity than the east slope.

How do you explain each of these facts?

There are really two regions of relatively high winds in the interior of the United States: (1) The Lake Region, and (2) the region of the Plains States. The high winds of the Lake 
Region are to be accounted for, first, because this region lies in the path of the numerous northwest storms, and second, because the water surfaces offer less resistance to the moving air.

The high winds of the western plains may also be accounted for, first, by noting the even slope of the land from the Rockies eastward and the treeless character of this region, and second, the marked difference in the temperature of the mountain region on the west and of the Mississippi valley on the east during the summer months (see Fig. 218).

As an aid in selecting a location having a suitable climate little general information regarding winds can be given. Both their velocity and direction are largely determined by local conditions.

\section{Sunshine}

320. Sunshine.-Physicians, as well as all thinking and observing people, have great faith in the curative and healthgiving power of sunshine. The sun bath is frequently prescribed in the treatment of many diseases. Direct sunlight is known to be one of the best of germicides; most disease germs die quickly when exposed to the direct rays of the sun. Even diffused sunlight is known to have great germicidal effects. So widespread and strong has become the faith in the beneficial effects of sunlight, that modern architecture has felt its influence. Modern dwellings as well as hospitals and sanatoriums are being constructed more and more with the view of admitting the largest amount of direct sunlight possible. Figs. 225 and 226 show the relative amounts of sunshine for the United States for the summer months and winter months.

\section{Exercise 72.-Study of the Sunshine Maps, Figs. 227 and 228}

What portion of the United States has the highest percentage of sunshine? What portion the lowest?

Is the percentage of sunshine greater in the summer or in the winter?

Compare the sunshine map for the summer months with the relative humidity map for the same months. Is there any similarity? 


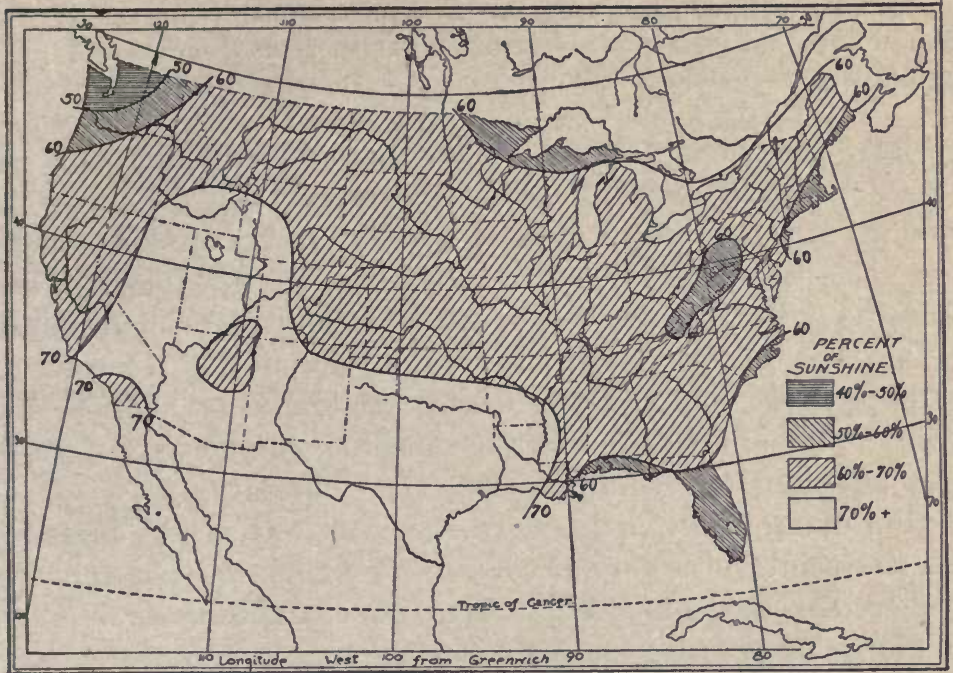

FIG. 225.- Sunshine average for 15 years, June, July, and August.

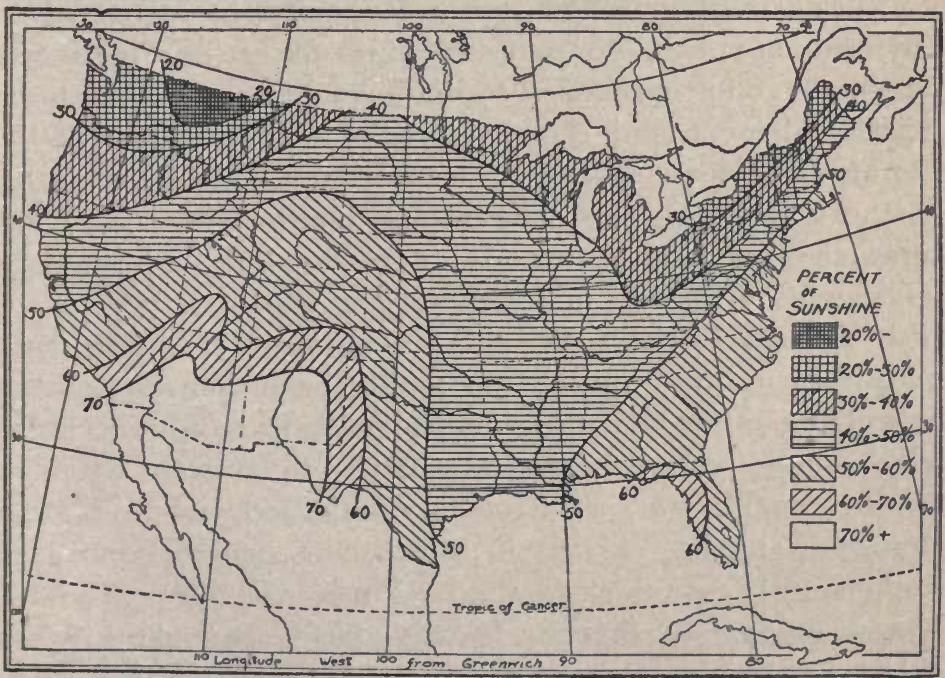

FIG. 226.--Sunshine average for 15 years, December, January, and February. 
Compare the sunshine map for the winter months with the relative humidity map for the same months. Is there any similarity? Explain why this should be so.

321. The Ideal Climate.-There is no such thing as a climate which is ideal for all people or for any person every month in the year. A climate which exactly suits one person may be unacceptable to another. Many people are well pleased with the climate of southern California near the coast. What are the characteristics of that climate, as regards: (1) Temperature, summer and winter; (2) humidity, summer and winter; (3) annual rainfall; (4) sunshine, summer and winter; (5) altitude; (6) wind velocity; (7) evaporation?

For many years northeastern New Mexico has been regarded as the center of a very favorable region for the treatment of tubercular patients. What are the characteristics of that region?

322. Seeking Health in a Change of Climate.-Just as Ponce de Leon and other adventurers of the 15th and 16th Centuries were journeying over the earth in search of the "fountain of youth," so thousands of people are now constantly on the move in search of a climate which insures them better health. They spend their winters in southern California or Florida and their summers in the Adirondacks or on the northern lakes and are ever seeking renewed health. Sometimes these changes of climate are made at the advice of the physician. Probably many experience beneficial effects from such changes of climate and occupation. However, some questions may well be asked: Do the beneficial effects result entirely from the change in climate? Was that the only climate which would have benefited the patient? To what extent do other elements, such as change of occupation, rest from labor, change in habits, change in companions, and freedom from responsibility, enter as factors? Those who have given the largest amount of thought to this matter and who are best able to judge agree that these are difficult questions to answer. 


\section{CLIMATIC REGIONS OF THE UNITED STATES}

323. Climatic Areas.-The area of the United States presents nearly every variety of climate to be found in the temperate zone. The United States may be divided roughly into nine fairly well-defined climatic areas. But within each of those areas there is considerable variation due to local causes. Altitude largely affects temperature and wind. Nature of the earth's surface largely determines wind velocity and direction

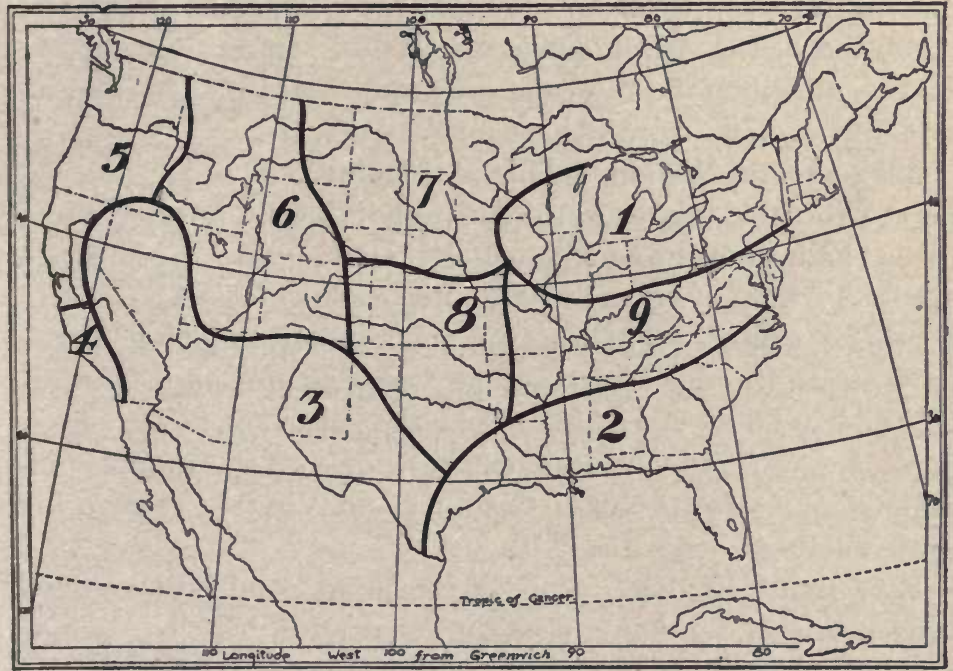

FIG. 227-Climatic regions of the United States.

and often rainfall. The proximity of cities, forests, and bodies of water largely determines the purity of the air, the presence of dust and smoke, the prevalence of fogs and of local winds (Fig. 227).

324. First Region.-The first region comprises southern Wisconsin, much of Iowa and Illinois, Indiana, Ohio, the Lower Peninsula of Michigan, Pennsylvania, New York, and New England. This region has an average temperature for July of $70^{\circ}$ to $75^{\circ}$ and for January of $20^{\circ}$ to $30^{\circ}$. It has a 
summer humidity of about 70 per cent. and a winter humidity of about 80 per cent. It has about 60 per cent. of sunshine in the summer and 40 per cent. in winter. Its wind velocities range from moderate to high. It lies in the pathway of a large majority of the storms which pass across the United States and therefore is subject to sudden and severe changes of weather. Its average rainfall is about $40 \mathrm{in.}$ In this territory live about $40,000,000$ people, nearly one-half of the population of the United States. Here is found also more than one-half of the wealth and influence of the nation. With the exception of the Adirondacks, the White Mountains, northern Maine, and the lake shores of northern Michigan, this region is seldom frequented by the seekers after health.

325. Second Region.-This is the Gulf States Region, with its comfortable winter temperature and high humidity and its rather high percentage of sunshine. Portions of it are used as a winter resort by those who do not wish to face the rigor of a northern winter. The summer climate of the Gulf Region is unpleasant. Its high average temperature, high humidity and nearly 60 in. of rainfall are neither pleasant nor invigorating. Nevertheless, the higher altitudes of the mountainous regions of western North Carolina and Virginia receive high praise as health resorts.

326. Third Region.-This is the great semi-arid region of the southwest, including western Texas, New Mexico, Arizona, southern Utah, Nevada, and southeastern California. High temperatures, high evaporation, high percentage of sunshine, low rainfall and low humidity characterize this region. For many years this region has been highly recommended for consumptives. Most of this region has the "throb and glow of the tropics."

327. Fourth Region.-Southwestern California has a climate of perpetual warmth, much sunshine, soft humid air with moderate rainfall. Dr. Woods Hutchinson says, "This region escapes the bane of the tropics, steaming days and sweltering nights, by virtue of the snow-capped mountains on the 
one hand and the cool blue sweep of the Kuro-Siwo, or Japan Current, on the other. Southern California has the sun electricity of the tropics, with the cool nights of the green rain belt, the fire of the South with the stamina of the North. The blue sea, bright sunshine and white mountains that made the glory that was Greece and the grandeur that was Rome, are also hers. She will some day be the Greece of the New World."

328. Fifth Region.-The Northwest Coast, comprising Washington, Oregon, some of Idaho and northern California, has a summer climate as delightful as the winter climate of southern California. The temperature is relatively even and moderate, while during the winter season the humidity and rainfall are high and the percentage of sunshine correspondingly low.

329. Sixth Region.-This is the mountain climate of the United States, the climate of the "backbone" of the continent. In many respects this is a region of unsurpassed climate for those who wish life, vigor, and energy. It is characterized by moderate severity in winter and a pleasant warmth in summer. Its humidity ranges from 50 to 60 per cent. the year around. It has a high percentage of sunshine both summer and winter, and plenty of pure, relatively dry, crisp air, free from dust and fogs.

330. Seventh Region.- The Dakotas, Minnesota, and northern Wisconsin comprise most of this region. Lying as it does in the path of storms, this is a region of sudden and severe weather changes. Its winters are severe; its summers are fairly moderate but with high temperatures frequently during the middle of the day. The relative humidity of the eastern portion of this region is rather high the year around.

331. Eighth Region. - The eighth region comprises Nebraska, Kansas, Oklahoma, and northern Texas. It is characterized by high winds, low amount of rainfall, fluctuating temperature, rather low humidity, and high percentage of sunshine. It has the most characteristically continental climate of any region of the United States. 
332. Ninth Region.-This region has some of the characteristics of the Eighth Region but has lower wind velocities and higher amount of precipitation. Its average temperature is fairly moderate, being affected in portions by the higher altitudes of the Appalachian Mountains. Its humidity is considerably lower than that of either the First Region or the Second Region between which it lies. It has an average summer temperature of $75^{\circ}$ to $80^{\circ}$ and an average winter temperature of $30^{\circ}$ or $40^{\circ}$. The amount of rainfall is ample, about 40 or 50 in.

\section{PROTECTION AGAINST UNFAVORABLE CLIMATE}

333. Accepting a Climate.-Whether it is best so or not, the fact remains that it is impossible for most of us to choose the climate in which we would live. Most of us are obliged to spend all the year, if not all our lifetime, in the climate where we find our place of labor. Even were we convinced that a certain climate, southern California for instance, is the most favorable for our health and comfort, it is evident that we can not all take up our abode there. The First Region with its extreme climatic changes will never again, within the lifetime of anyone now living, be less densely populated than it is today. On the contrary the population of that region will doubtless double and redouble in the next quarter- and halfcentury. The real question, then, is not whether the climate of this or any other region is the most healthful to be found. The real question concerning a climate is whether it is reasonably healthful. As a second question we should ask, Is it possible so to live, so to condition our surroundings, that we may be strong and healthy even in a region having an unpleasant climate?

334. Problem of Indoor Climate.-Only in recent years has the problem of protecting ourselves against severe climatic conditions received close attention. Most people, even now, give little or no attention to any element of indoor climate 
other than temperature. They make no special provision for fresh air and but little provision for direct sunshine in their rooms; they pay no attention to the humidity of the air in which they live. In the winter they shut themselves up in stuffy, nearly air-tight, often sunless, drought-stricken, over-heated, dust-laden rooms. Their only thought is to maintain a temperature of $70^{\circ}$ or more. The highest and best authorities say that about one-half of all deaths are the result of preventable diseases, and that a more intelligent and rational plan of protecting ourselves against the inclemency of climate and weather would materially decrease sickness and death from these causes. Those among us who disregard the laws of sanitation find their powers of resistance so weakened, their vitality so lessened, that they are easily attacked by colds, influenza, tuberculosis, pneumonia, and other diseases. And they, in turn, spread these diseases among all with whom they come in contact.

335. The Ideal Indoor Climate or Air Condition.-We all know how delightful and pleasant is the soft balmy air of spring and early summer. We know how we long to be out of doors in the sunshine on a spring day and what renewed life and vigor such conditions give us. The ideal conditions for indoor air are those which closely resemble outdoor air of spring or early summer. These conditions are: a gentle breeze, a flood of health-giving sunlight, a humidity of 50 to 70 per cent., air nearly free from dust, and, lastly, a temperature which varies with the occupation, clothing, habits, and age of the individual. We cannot completely control the amount of sunlight, but we can so construct our houses that we may enjoy all the sunshine there is; the other conditions we can usually secure without great cost or effort.

336. Why a Change of Climate may be Beneficial.-The climate of the Southwest is chiefly beneficial during the winter months because one is most comfortable there when out of doors and, therefore, is inclined to remain out of doors. Even when indoors, one is most comfortable with the doors and 
windows wide open, therefore, the doors and windows are left open. In the severer climate of the North, during our waking hours and when engaged at ordinary occupations, we can not be comfortable with doors and windows open. We must, then, condition the air to approximate the ideal climate. During our sleeping hours, however, we can be comfortable with open windows by using sufficient covers. We should, therefore, learn to sleep, summer and winter, with open windows and in the pure outside air.

\section{Living and Sleeping in the Open Air}

337. Open-air Rooms.-The open-air treatment has been found very beneficial in the treatment of both tuberculosis and

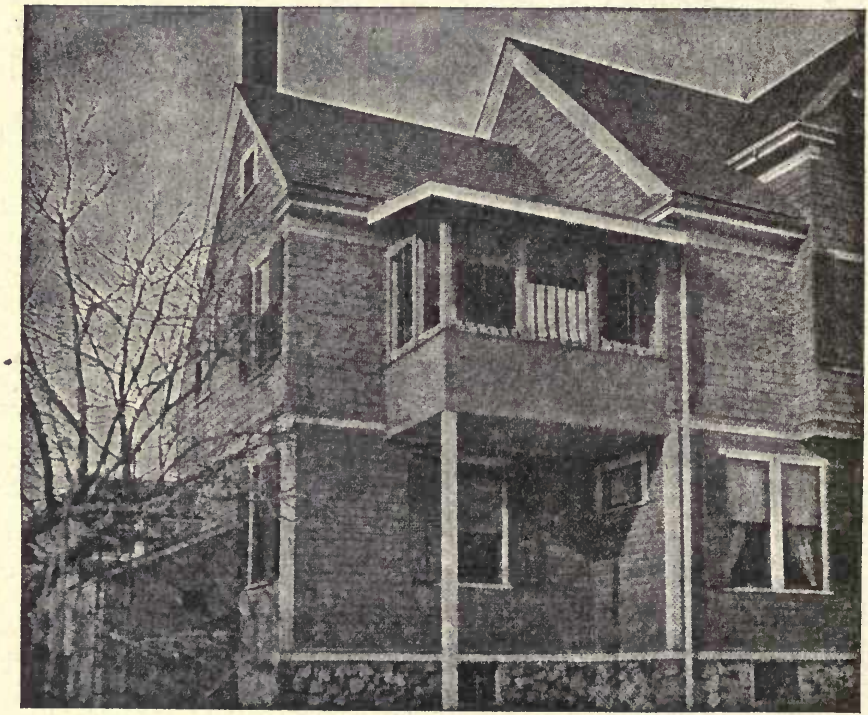

FIG. 228.-Sleeping porch. (Courtesy of Dr. S. A. Knopf.)

pneumonia. In fact, the patient suffering from either of these diseases frequently lives and sleeps continually in the open air. There is every reason for believing that such open-air living is 


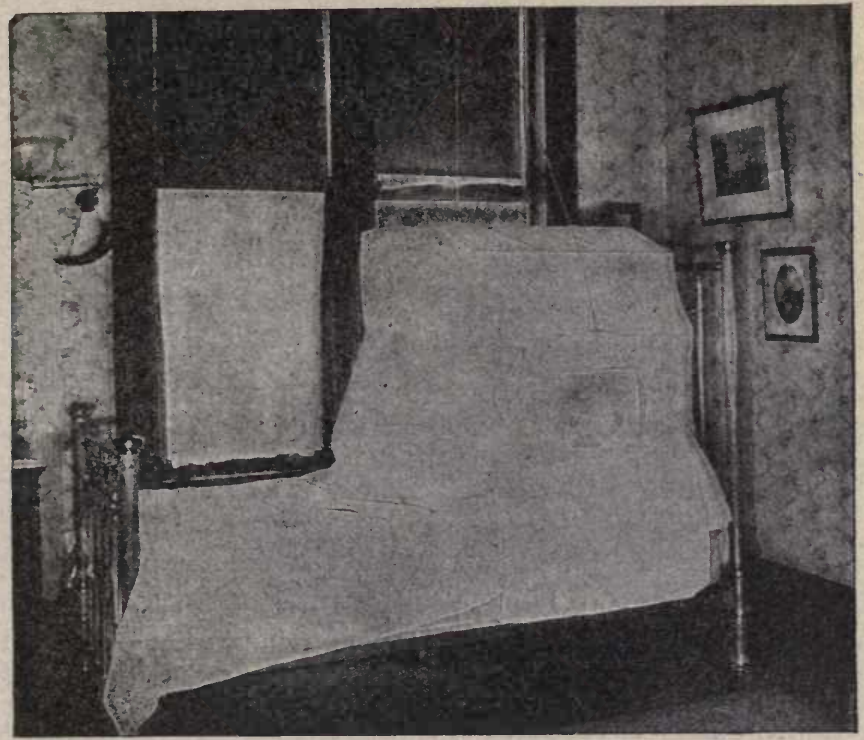

Fig. 229.-Window tent, in use. (Courtesy of Dr. S. A. Knopf.)

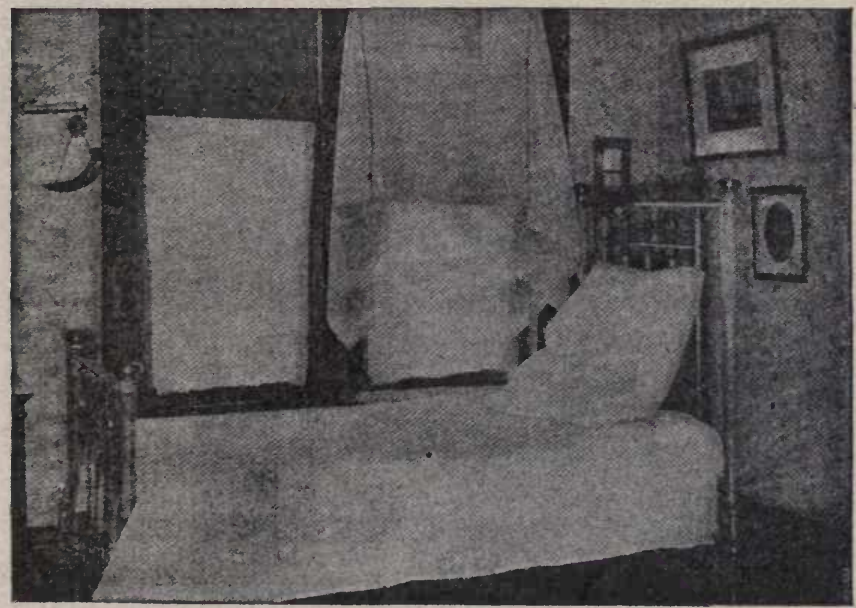

Fig. 230.-Window tent, folded up. (Courtesy of Dr. S. A. Knopf.) 
equally beneficial as a preventive measure. Well informed people have become convinced of this fact and many modern houses are being constructed with open-air living rooms, with sun rooms, and with open-air sleeping rooms.

It is usually an inexpensive matter to construct a sleeping porch such as shown in Fig. 228. Many houses have porches which may be easily screened in for living purposes.

Many devices have been perfected, especially for the accommodation of tubercular patients who can not afford to build sleeping porches or who live in rented houses. Most of these devices are fitted to the open window in such a manner as to permit the patient to breathe the cool, fresh, outside air while resting and sleeping. Figures 229 and 230 show two views of one of these devices, first, when in use, and second, when folded up out of the way. This window tent has a celluloid window which enables the patient to see all that takes place in the room. Such devices are very useful for several reasons: (1) They are easily attached to, and removed from any window; (2) they are economical because they prevent the loss of any considerable amount of heat from the room; (3) in case of severe sickness, the attending nurse and the members of the patient's family are able to use the room with comfort even in the severest weather; at the same time the patient really lives in outside air. 


\section{CHAPTER VI}

\section{VENTILATION}

\section{PRINCIPLES OF VENTILATION}

338. Need of Ventilation.-While the beneficial effects of outdoor life are being more and more recognized, still many people must necessarily spend much of their lives indoors. School children must spend many hours each day in the schoolroom. Factories, shops, stores, and offices are filled with working men and women who find it impossible to spend much time in the open air. Often their chief recreation is a visit to an overcrowded theater or moving-picture show where adequate ventilation is seldom provided. Even when at home few people enjoy fresh air. Relatively few houses have been constructed with any recognition of the fact that fresh, pure air is of even greater importance than is warmth. For these reasons, what constitutes good ventilation and how it may be obtained should receive careful study.

339. Composition of Pure Country Air.-Pure country air is composed chiefly of nitrogen, oxygen, carbon dioxide, and water vapor. The proportions of these constituents vary slightly from day to day and at different places, by far the greatest variation being in the amount of water vapor present. Pure country air consists of about the following proportions:

Nitrogen...................about 77 per cent. by volume Oxygen.....................about 21 per cent. by volume Carbon dioxide............... about 0.03 per cent. by volume Water vapor-variable, from 0.3 per cent. to 3 per cent. by volume.

In addition to these constituents of air there are usually present more or less dust, smoke, pollen from plants, and microörganisms of different kinds. 


\section{Effect of Breathing upon the Composition of Air.-} When man, or any animal, breathes this air, oxygen is consumed and carbon dioxide and water vapor are given off. When many people are gathered together in a closed, nearly air-tight room for some time, the air becomes much changed We say that the air becomes vitiated. If some of those present are suffering from colds, pneumonia, tuberculosis, or other communicable diseases, the disease-producing germs (see Chap. VIII) are certain to be present in the air.

341. Theories Regarding Vitiated Air.-For many years the most objectionable factor in vitiated air was supposed to be small amounts of poisonous volatile matter, organic compounds, expelled from the lungs with the breath. This supposition gave rise to the term CRowd PoIsonING. Some years ago doubt arose as to the correctness of this supposition. Very careful experiments by skillful investigators employed by the government, failed to show the presence of this supposed objectionable matter. Few scientists now believe in the CROWD POISON THEORY of vitiated air. It is now generally believed and taught by teachers of hygiene and sanitary science, that, as far as there is any offensive odor in the breath, it is probably due to decayed teeth, effects of catarrh, decomposition of food in the mouth, or disordered stomach.

Moreover, it is now believed that most of the unpleasant odors noticeable when any crowd gathers indoors come from the unclean bodies and clothing of those present. The skin of even the cleanliest person is constantly giving off waste material. A considerable portion of the waste materials of the body is given off through the pores of the skin. The offensive odors so characteristic of theaters, moving-picture shows, schoolrooms, auditoriums, and churches are now generally believed to be caused chiefly by excretions from the skin, not from the lungs. In general, the theory of crowd poison has been abandoned.

342. Theories Regarding Ventilation.-As already stated, pure country air usually contains about 0.03 per cent., or 3 
parts in 10,000 , of carbon dioxide. It was assumed many years ago that air had become too vitiated for use when the proportion of carbon dioxide had been increased more than about 0.03 per cent., or 3 parts in 10,000 , due to breathing, i.e., when the proportion of carbon dioxide had been increased from 0.03 per cent. to more than 0.06 per cent. While it has been conclusively proved that the breathing of air containing as much as 5 per cent., or 500 parts in 10,000 , of carbon dioxide, has not the slightest depressing effect, still the old rule laid down years ago is the rule which controls in nearly all ventilating systems today. Even those who admit that a large amount of carbon dioxide in the air is harmless and that the theory of crowd poison can not be proved, still maintain that the percentage of carbon dioxide in the air is a good indication of the wholesomeness or degree of vitiation of the air.

343. Calculation of the Amount of Fresh Air Needed per Minute by Each Person.- If we admit that the amount of carbon dioxide in the air produced by breathing must not be permitted to rise above 0.03 per cent., or 3 parts in 10,000 , we need only to know how much carbon dioxide is exhaled per hour by each person in order to determine the amount of fresh air which must be supplied him. This is easily calculated as follows: Physiologists tell us that the average amount of the TIDAL AIR, i.e., of the air inhaled and exhaled at each breath, is about 28 or $30 \mathrm{cu}$. in. and that a person ordinarily breathes about 17 times per minute. Many analyses of exhaled breath have been made and they show that exhaled breath usually contains about 4 per cent. by volume of carbon dioxide. From these facts, we see that each person exhales about $7 / 10 \mathrm{cu}$. $\mathrm{ft}$. of carbon dioxide per hour. (Show that this calculation is correct.) Now, if the air of the room is to be so diluted by the admission of fresh air that the proportion of carbon dioxide derived from the breath is not greater than 0.03 per cent. or 0.0003 of the whole, we see that there should be provided $0.7 \div 0.0003$ or $2333 \mathrm{cu}$. ft. of fresh air per hour for each person in the room. 
Several years ago, Massachusetts enacted a law requiring that all schoolrooms should be ventilated on practically this basis. It was soon discovered, however, that such a requirement meant that practically every schoolhouse in the state would have to be rebuilt or remodeled. A compromise was therefore effected by which all schoolrooms were to be supplied with $1800 \mathrm{cu}$. ft. of fresh air per person each hour. Several other states have followed the example of Massachusetts. It is now common practice to provide $1800 \mathrm{cu}$. $\mathrm{ft}$. of fresh air per person each hour in modern buildings. This means that, if a schoolroom contains 30 pupils and has a fresh air inlet of 4 square feet that the air must enter at the rate of $3.75 \mathrm{ft}$. per second. This is about the same rate of motion as that of wind blowing $21 / 2$ miles per hour, a very light breeze. (Prove the correctness of this calculation.)

344. Fallacy of This Theory of Ventilation.-Students of sanitation are now generally agreed that this theory of ventilation, namely, that air is necessarily so vitiated as to be unwholesome if it contains more than 0.06 per cent. of carbon dioxide, i.e., 0.03 per cent. as in pure country air plus 0.03 per cent. from breathing, is not scientifically well founded. They are raising the question whether the system of ventilation in common use is, after all, the best. Some are inclined to question the necessity of providing so much fresh air as 1800 cu. ft. per person each hour. Nearly all are convinced that we should give much more attention to temperature, to keeping the air in the room in motion, and to the proportion of water vapor in the air than we are now giving, and that possibly these conditions are of even greater importance than the proportion of carbon dioxide.

In order to understand the reason for this growing belief we must consider the total lung capacity of a person and the volume of air he ordinarily inhales and exhales at a breath. The following diagram from Colton's Physiology will aid us in our study. 


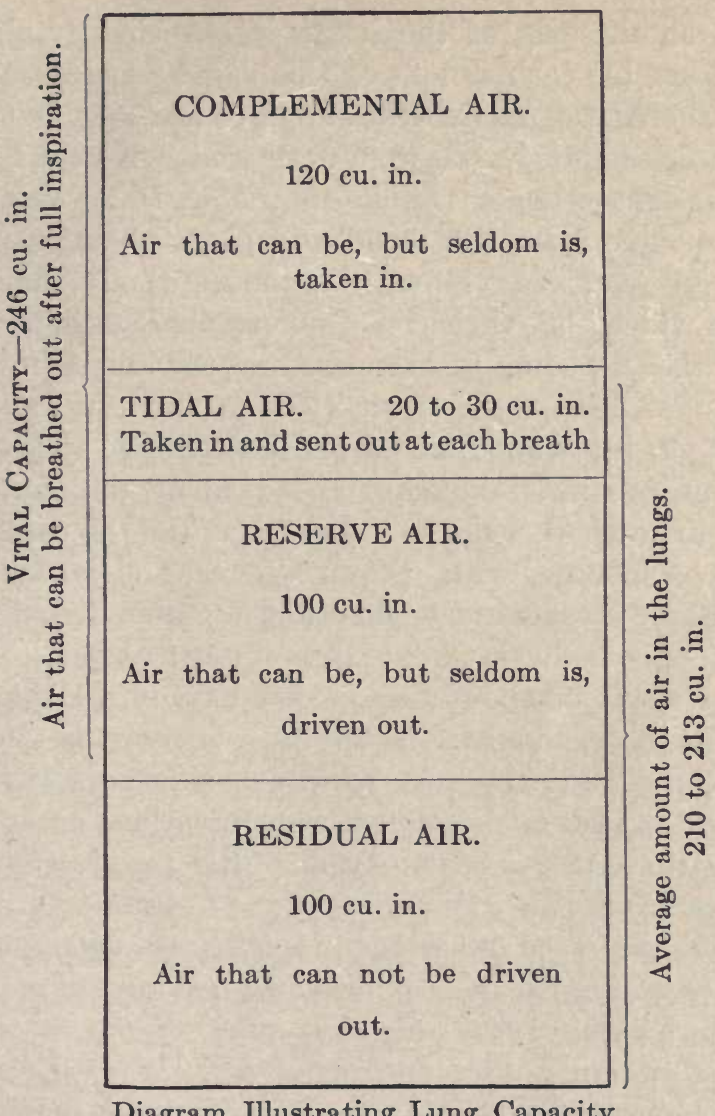

Diagram Illustrating Lung Capacity

From this diagram, we see that the average amount of air in the lungs is 210 to $215 \mathrm{cu}$. in., while the tidal air is only 20 to $30 \mathrm{cu}$.in. Now, as already stated, it is known that exhaled tidal air contains about 4 per cent. carbon dioxide. It must be remembered that the exhaled tidal air is the very purest air in the lungs. The $100 \mathrm{cu}$. in. of RESERVE AIR is somewhat mixed with the $30 \mathrm{cu}$. in. of tidal air and therefore diluted by it. But the $100 \mathrm{cu}$. in. of RESIDUAL AIR, being the air in the 
vesicles, or air cells, of the lungs, is but slightly altered in composition by each inflow of tidal air. Considering these facts, authorities agree that the amount of carbon dioxide in the residual air can not be less than 6 per cent. Now this residual air in the lung cells, or vesicles, is the air which receives the carbon dioxide from the blood and gives up oxygen to the blood. In a very true sense, it is almost wholly this residual air upon which the efficiency of our respiration depends.

From the preceding facts we see that the lungs contain constantly over $200 \mathrm{cu}$. in. of air (100 cu. in. being reserve air and $100 \mathrm{cu}$. in. being residual air) containing, at least, some 5 per cent. of carbon dioxide. It is evident, therefore, that it matters little whether the 20 to $30 \mathrm{cu}$. in of tidal air contains 0.04 per cent. or 0.06 per cent. or even 4 per cent. of carbon dioxide.

345. Same Reasoning Applied to the Other Constituents of the Air.-Fresh air is about 21 per cent. oxygen. Exhaled air is known to be about 16 per cent. oxygen. Evidently the oxygen in the residual air in the lungs can not be more than about 15 per cent. oxygen. Now, experimenters have shown that a person feels no discomfort when breathing air containing no more than 15 per cent. oxygen. We are, therefore, forced to the conclusion that it is not the effect of breathing air with an increased percentage of carbon dioxide, nor with a decreased percentage of oxygen, nor of breathing air containing "crowd poison" which constitutes the chief cause of the evil effects of living in an atmosphere of vitiated air. Investigators have come to believe that other factors have quite as much bearing upon the problems of ventilation.

346. Relation of Humidity of Ventilation.-We have already seen that the rate of evaporation from any surface depends upon temperature and the degree of saturation of the air surrounding that surface (Art. 247). We also know that when evaporation takes place much heat is absorbed. In fact, it requires 1037 British thermal units of heat to evaporate $1 \mathrm{lb}$. of water at the temperature of human blood, $98,4^{\circ} \mathrm{F}$. (compare with Arts. 150 and 244). 
Now exhaled air contains much moisture - it is nearly saturated at blood temperature, or $98^{\circ} \mathrm{F}$. Our bodies also give off considerable quantities of moisture in the form of perspiration through the skin. In poorly ventilated rooms where crowds gather, the humidity of the air rises rapidly. The result is that the evaporation from the skin is checked and we soon become uncomfortable. This effect of increased humidity is often greatly aggravated by increase in temperature due to the heat given off from our bodies. Taken together, the three conditions: (1) high humidity, (2) high temperature, and (3) foul odors soon produce headache and a feeling of weariness and exhaustion. Many recent experiments indicate that these three conditions of the air, high temperature and high humidity, and disagreeable odors in crowded, ill-ventilated rooms are large factors in producing what we know as vitiated air.

347. Control of the Temperature of the Body.-The temperature of the human body in health is maintained with great constancy at $982 / 5^{\circ} \mathrm{F}$. No matter what the fluctuations of external temperature, the mechanism of the human body is so delicately adjusted that, in health, it perfectly corrects the effects of all temperature changes. If the external temperature is low, the temperature of the body is kept up by an increase of heat production within the body. If the external temperature is high, the temperature of the body is kept down by the cooling device of increased perspiration, and the consequent increased surface evaporation and cooling. But any effort which the body must thus put forth to counteract external temperature is necessarily a drain upon the vital forces of the body.

348. Metabolism.-By metabolism we mean a sort of double process: On the one hand, the living cells of the body are built up and nourished by the food materials assimilated. On the other hand, it includes the breakdown of some of the living material of the cells into waste products. This latter phase of the process is always accompanied by the liberation of 
energy. It is a term by which we express the entire process of nutrition, both the building up and the nourishment of the living cells and the production of energy. This whole process of metabolism, however, is intimately connected with the control of bodily temperature.

In the process of metabolism considerable quantities of oxygen are consumed and considerable carbon dioxide and other wastes are given off. This process of metabolism continues as long as life exists. It is increased by exercise and work, and is least when we are in a state of respose. Experimenters generally calculate the amount of metabolism taking place by determining the amount of carbon dioxide exhaled in a given period of time.

Now, it should be noted that metabolism still continues even though we cease to take nourishment. In this case, however, there is a consumption of the tissue of the body, and a consequent decline in weight. We grow thin and poor when we fast. These facts must be noted in order that we may understand what experimenters have done in the study of the effects of external temperature upon metabolism.

349. Effect of External Temperature upon Metabolism.-In studying the effect of external temperature upon metabolism, experimenters have determined the amount of carbon dioxide exhaled by a fasting man when in repose and in a room kept at different temperatures for certain periods of time. Voit gives the following table showing the number of grams of carbon dioxide exhaled by such a fasting man during several six-hour periods:

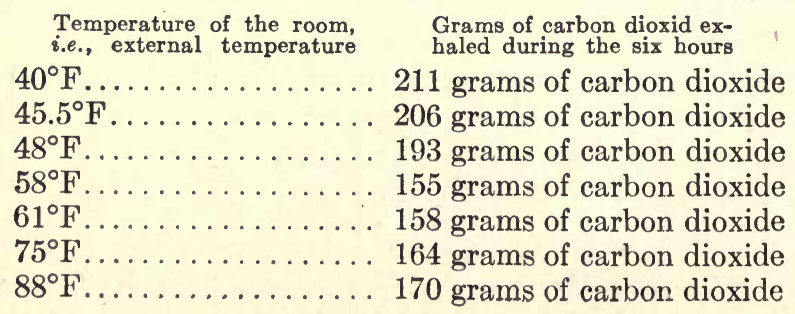


These figures indicate that the external temperature requiring the least metabolism to maintain the normal bodily temperature of this man dressed as he was dressed, was about $60^{\circ} \mathrm{F}$. It is now generally accepted that there is one certain temperature which is best adapted to, i.e., most agreeable to each individual when that individual is dressed with a certain weight of clothing and is in repose.

The experience of stockmen shows that stock exercising but little, as is usually the case with dairy cows and with beeves and hogs being fattened for the market, thrive best when the temperature is moderate. 'Extremes of temperature, either high or low, reduce the flow of milk in the dairy cow and tend to prevent the fattening of the beefcattle and hogs. In each case, nourishment taken by the animal is expended in effecting the control of bodily temperature. We also know that work horses are not able to do so much work in extreme temperatures as in moderate temperatures, although the best temperature for the horse at hard work is considerably lower than when at rest.

350. The Ideal Temperature of Indoor Air.-The best temperature for indoor air depends largely upon the occupation and dress of the occupants. The proper temperature for a gymnasium or a factory would certainly not be the proper temperature for a schoolroom or a church. Even the best temperature for a schoolroom or a church might prove to be too low a temperature for the home, owing to the fact that most people are likely to be more warmly clad when at school or church than when at home.

As will later be shown, the relative humidity of the air in the room also largely determines the proper temperature. Reasonably moist air at $65^{\circ} \mathrm{F}$. is as comfortable as very dry air at $70^{\circ}$. The temperature usually demanded by Americans is several degrees higher than that preferred by the English and Germans. Our own physical condition also largely determines the most agreeable temperature. In the morning when our vitality is highest, we are comfortably warm at a temperature 
which is uncomfortably low in the evening when our vitality is lowest. Still another factor affecting the most agreeable temperature of air is that of air movements. Air in rapid motion must be a few degrees warmer than quiet air in order that we may be comfortable. Why? (See Art. 318.)

The best temperature, then, depends upon many factors such as the occupation, dress, physical condition, and temperament of the occupants of the room, on the one hand, and the humidity and movements of the air, on the other hand. The effect of air motion and of high or low humidity should be further studied.

351. Some Fluctuation in Temperature is Desirable.-A German, Flügge, seems to have proved that a perfectly uniform temperature is not desirable. Many students of ventilation now maintain that reasonable fluctuations in temperature are necessary to stimulate us and to keep our physical and mental powers alert, awake, and active. A perfectly uniform temperature, even though it be the most agreeable, lacks the stimulating effect of a reasonably fluctuating temperature (see Arts. 219, 324 and 335.)

352. Effect of Air Movement.-Dr. Leonard Hill of London and others, have shown that proper air movement is a large factor in ventilation. Dr. Hill placed eight healthy medical students in a small, air-tight, glass-sided box, or cage, $41 / 2 \mathrm{ft}$. square and $8 \mathrm{ft}$. high. In a few minutes they became very uncomfortable. The temperature of the air in the cage had risen to $85^{\circ} \mathrm{F}$. and had become nearly saturated with moisture. The air then contained about 4 per cent. of carbon dioxide and but about 15 per cent. of oxygen. Three electric fans in the top of the cage were then set in motion, causing the air to more rapidly. The students were soon greatly relieved and became again comfortable, although the composition and the temperature of the air remained unchanged.

Students of ventilation generally agree that quiet air, no matter how pure it may be or what its temperature and relative humidity may be, does not furnish adequate ventilation 
for the body. In such cases, an envelope of highly heated, highly humidified air accumulates within one's clothing. Moreover, when many people are quietly seated in a room containing quiet air, as in the case of a schoolroom or a church, there is a strong tendency toward the accumulation of a layer of impure exhaled air at the height of the "breathing zone," i.e., at the height of their faces. Authorities now agree that the air in any room should be kept moving with such rapidity that the air motion is perceptible to all.

A careful study of the relation of air motion to ventilation has led Dr. W. A. Evans of Chicago to declare that, "A drafty room is a healthy room - a windy city is a healthy city."

353. Importance of Proper Humidity. - It is now a generally accepted theory that just as there is a best average temperature from which there should be no great variation for any long period of time, so there is a best humidity from which there should be no great or sudden variation. Dr. Hill's students, enslosed in their cage, soon raised both the temperature and the humidity to such a point as to cause great discomfort. The heat from their bodies caused a rapid rise in the temperature of the confined air, while the moisture from their breath and from perspiration soon raised the humidity nearly to the point of saturation. High temperature, excessive humidity, still air, and offensive odors were probably the chief causes of their discomfort. Exactly in the same manner, the air in a crowded, ill-ventilated room is likely to be at too high a temperature, the humidity is likely to be excessively high, the air is almost certain to have but little motion, and soon offensive odors become noticeable.

Dr. Hill has stated the principle of good ventilation in a single sentence, thus: "The question of ventilation is primarily one of keeping the temperature, relative moisture, and movement of the air in proper state, so that the heat-regulating mechanism of the body works without strain, and the nervous system is stimulated by pleasant cutaneous [skin] conditions and the 
circulation, respiration and metabolism of the body is invigorated."

354. Humidity Sometimes too Low.-While in an ill-ventilated, crowded room the humidity is likely to be too high for the comfort and well-being of the occupants, in the best ventilated room or house, where artificial heating is required, the humidity is nearly certain to be too low, in cold weather; unless special effort is made to correct this tendency. It is generally accepted that the best indoor humidity is about 50 to 70 per cent. We shall see best just how much and just why this indoor air is too low in humidity, if we study a particular case.

Suppose we take as an example the case of a typical schoolroom anywhere in southern Wisconsin, northern Illinois, southern Michigan, or northern Indiana, or Ohio, or anywhere in Pennsylvania, New York, or New England (First Climatic Region, Art. 324). By turning to the map (Fig. 221) showing the average relative humidity of the United States for the months of December, January, and February we see that the average humidity for this region is about 80 per cent. for these winter months. Again, turning to the average temperature map for January (Fig. 219), we find that the average temperature for this region is about $25^{\circ} \mathrm{F}$. Turning now to the table showing the weight of water vapor in saturated air, i.e., absolute humidity at saturation (Table XII, page 220) we see that each cubic foot of saturated air at $25^{\circ} \mathrm{F}$. contains about 1.6 grains of water vapor. Since the outside air is but 80 per cent. saturated, it therefore contains but about 1.3 grains of water vapor per cu. ft. Now, in most cases, when adequate ventilation is attempted, it is the practice to admit this outside air to the schoolroom, merely heating it to $70^{\circ} \mathrm{F}$. and without paying any attention to humidity.

What is the relative humidity of the air when thus admitted to the schoolroom? Again turning to the table of saturated air (Table XII), we find that to saturate each cubic foot of air at $70^{\circ} \mathrm{F}$. there must be 7.98 grains of water vapor in each cubic 
foot. But the air admitted to the room contains but 1.3 grains; it therefore has a relative humidity of but 16.3 per cent. This is less than one-third of the relative humidity of outdoor air in the very dryest portion of the United States at this time of year (see Fig. 221). The pupils in such a schoolroom are often living in an atmosphere dryer than outdoor air at the center of the Sahara Desert, or any inhabitable portion of the earth's surface.

Such air is greedy for water vapor and robs every object in the room of all available moisture. As a consequence, the floor-cracks open, the furniture begins to creak, every joint in woodwork and furniture opens, even pianos made of the best kiln-dried wood show the effects of the drought, leather backs of books become dry and sometimes crack, and house plants begin a struggle for life itself,

355. Some Evil Effects of Such Dry Air.-Is such dry air beneficial to the human system? Physicians say it is not. They tell us that such excessively dry air causes rapid evaporation from the nasal passages, and from the throat and bronchial tubes, and thus keeps the mucous membrane in a constant state of irritation; the mucous membrane thus irritated becomes swollen and spongy and affords an easy lodging place for disease germs.

Even physicians who do not object to very dry air, or even see benefits to be derived from living in a dry climate constantly, are among those who object most seriously to this desert-like air in our homes and schoolrooms in northern latitudes. They object most seriously to the change we necessarily encounter when we are obliged to step from an indoor atmosphere heated to $70^{\circ}$ with a humidity of 20 per cent. into an outdoor atmosphere at $20^{\circ}$ with a humidity of 80 per cent.

356. Dry Air Requires High Temperature.-One has but to consider the effect of dry air upon the wet-and the dry-bulb thermometers to realize that a high temperature is necessary in order that we may be comfortable in a room having such low 
humidity. Turning to the table of relative humidity (Table $\mathrm{XI}$, page 218) we see that when the dry-bulb thermometer reads $70^{\circ}$ and the relative humidity is 20 per cent., that the wet-bulb thermometer reads $20^{\circ}$ lower, i.e., the wet bulb then reads $50^{\circ}$. Now, the human body is constantly moist; more or less evaporation is constantly taking place from the skin. While the clothing, by enclosing an envelope of air

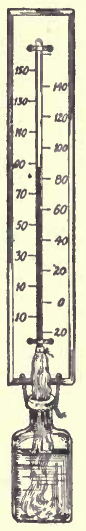

FIG. 231. -A homemade wetbulb thermometer. about the body, checks this evaporation somewhat, still, if the air in the room is in as rapid motion as it should be, we feel decidedly the chilling effect of evaporation. One is more comfortable in a room heated to $65^{\circ}$ with the humidity 50 per cent. than in a room heated to $70^{\circ}$ with the humidity 20 per cent. This is especially true if the air be in motion. For this reason many physicians now advocate the use of the wet-bulb thermometer only, to determine room temperatures.

Any common house thermometer can be converted into a wet-bulb thermometer by suspending a 3- or 4-oz. bottle of water from the frame and wrapping the thermometer bulb with a wick of soft muslin (Fig. 231). Such a thermometer will closely indicate the actual temperature in which we are living.

\section{Large Amounts of Water must be Evapo-} rated.-Many people, who have become convinced that a higher indoor humidity is desirable than is usually obtained during the winter months in the northern states, find difficulty in evaporating the necessary amount of water. In fact, much larger quantities must be evaporated than most people realize. It is an easy matter to calculate the amount of water which must be evaporated in order to raise the humidity to the proper point under given conditions.

Let us suppose that our problem is that of ventilating the school room considered in Art. 354. We will suppose that this room contains 30 pupils and is supplied with the accepted amount of fresh outside air, namely, $1800 \mathrm{cu}$. ft. per hour for 
each pupil. If it is in the month of January, it will be remembered that the average outdoor temperature is $25^{\circ} \mathrm{F}$. and the average humidity is 80 per cent. Each cubic foot of outside air contains 1.3 grains of water vapor. But if the inside air is to have a humidity of 50 per cent. at the temperature of $70^{\circ}$, it must contain $1 / 2$ or 7.98 grains, or 3.99 grains per cu. ft. This means that we must add 2.69 grains of water vapor to each cubic foot of air. If each of the 30 pupils is to be supplied with $1800 \mathrm{cu}$. ft. of fresh air per hour, the room must be supplied with $54,000 \mathrm{cu}$. ft. But each cubic foot of air requires the evaporation of 2.69 grains of water. We therefore see that this room requires during the month of January, on the average, the evaporation of 145,260 grains, or $21 \mathrm{lb}$, or about $2 \frac{1}{2}$ gal., of water per hour ( 1 gal. of water weighs about $8 \mathrm{lb}$.) in order that the relative humidity may be maintained at 50 per cent. Verify these data and the computation. A room less well ventilated will, of course, require less water evaporated. Why?

\section{Exercise 73.-Determining the Relative Humidity of Indoor Air}

During the months when artificial heat is being used, the student should frequently determine the humidity of the schoolroom air. If a hair hygrometer is used, it should occasionally be checked by using the wet and the dry-bulb thermometers and be properly adjusted whenever found to be inaccurate (see Arts. 247 and 248).

358. How the Necessary Amount of Water may be Evaporated.-Where stoves are used to heat the room, it is usually possible to place a pan of water having a large surface on the stove and thus secure sufficient evaporation. In such cases, however, the percentage of humidity in the room is likely to vary much.

In buildings heated by steam, it is generally possible to permit the live steam to escape from the system, thus furnishing the required water vapor.

Where hot-water heating is used, small stoves to evaporate the water appear to be the only adequate means of humidifying the air. 
Furnaces are generally provided with water pans, set in the casings, but they usually have little value as humidifiers. Any device used as a humidifier which will not readily evaporate 1 or 2 qt. of water per hour, in a well-ventilated residence having 6 or 8 rooms, is inadequate when used anywhere in the United States north of the 40th parallel of latitude. Most furnaces are so constructed that it is possible to equip them with a more nearly adequate humidifier easily and at slight

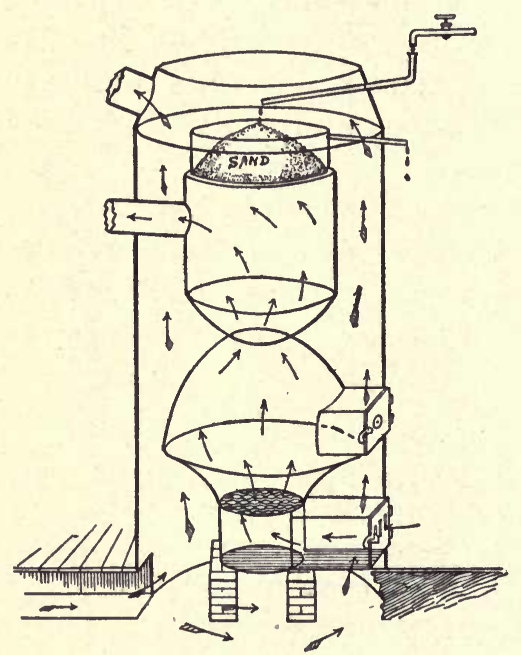

Frg. 232.-Humidifier. expense. Figure 232 shows how such a humidifier may be installed in a furnace by any furnace setter. A large, seamless galvanized iron or copper pan filled with clean sand is set on the top of the radiator of the furnace inside the casing. A galvanized iron pipe is passed through the casing. The inner end of this pipe is directly over the center of the pile of sand. The outer end of the pipe carries an "elbow," turned so as to open upward. A supply pipe (leading from the water system or from a supply tank) equipped with a valve for regulating the flow, is so adjusted that water drips into the upturned elbow. The operator can see exactly how fast the water is being supplied, and the amount delivered by the supply pipe per hour can be determined at any time.

Such a humidifier is nearly automatic in its operation. The sand forms a reservoir which is capable of holding a large amount of water. But it is evident that the sand becomes heated when the fire is burning up freshly. This heated sand then continues to evaporate water even when the fire has died 
down. In practice it is found that the humidity of the air delivered to the room above a furnace equipped with such a humidifier is fairly constant.

359. Humidifying the Air of Schoolrooms.-The humidifying device which is adequate for ordinary schoolroom use north of the 40th parallel of latitude must be capable of evaporating about 2 gal. of water per hour for each room. We have already seen that $21 / 2$ gal. are required for the proper humidifying of a typical 30-pupil room, well ventilated. To evaporate this amount of water is difficult. Nevertheless, many schoolroom heaters are so constructed that a humidifier similar to that shown in the last article may be installed with good results.

360. Summary.-1. When is Air Vitiated?

When its temperature is too high, when its humidity is too great, when foul odors are noticeable, or when its stagnation is such that one's body is continually wrapped in an envelope of unchanged air. The air may also be too low in temperature, or have too low humidity for good health and comfort. Any ordinary increase in percentage of carbon dioxide, or any ordinary decrease in percentage in oxygen is now considered relatively unimportant.

\section{Why Does Vitiated Air Produce Immediate} Discomfort?

Because abnormal conditions of temperature, humidity, or air motion cause a disturbance of, and overtax the heat-regulating mechanism of the body, and fail to stimulate properly the respiration, circulation, and metabolism of the body. Vital energy is being consumed and when carried to extreme, great discomfort and physical exhaustion results.

3. Why is Continued Living in Vitiated Air to be Avoided?

Because abnormal metabolism means decreased vitality. Decreased vitality means decreased power of resistance to disease. Moreover, conditions which produce vitiated air are generally favorable for the spread of infectious diseases. 
4. How is Air to Be Kept from Becoming Vitiated?

It is not enough that the carbon dioxide in the air be kept down to 0.06 or 0.07 per cent. and the oxygen be kept up to 20.5 per cent. These conditions may be worth while, but in addition, the wet-bulb temperature should be maintained near the optimum point, which will vary probably from $50^{\circ}$ or $55^{\circ} \mathrm{F}$. for the gymnasium, work shop and factory to $65^{\circ}$ or $70^{\circ} \mathrm{F}$. for the home library; the humidity should be maintained at 50 to 55 per cent., if possible, and the air should be kept in constant motion, this motion being sufficient to produce a pleasant, stimulating sensation very much like that of the early summer breeze.

Some authorities insist that moderate fluctuation in temperature is preferable to constant temperature. They prefer to have the room frequently "flushed out" to any system of ventilation based upon the constant dilution of the vitiated air (see the next section). Dr. W. A. Evans says, "A ventilating system based on the dilution of breathed air is inefficient and, at the same time, expensive. It is wasteful because it requires $2000 \mathrm{cu}$. ft. of fresh air per person per hour, while, if the temperature is kept down, the humidity up and the room blown out from time to time, a much less quantity gives better results."

5. What Then is the Real Purpose of Ventillation?

Adequate ventilation prevents the accumulation of vitiated air about the body, thereby securing those conditions which are favorable to normal metabolism and the highest possible vitality. Secondly, in crowded rooms it is highly desirable to change the air either rapidly (constant dilution system) or frequently (flushing out system) because it is likely to be more or less laden with unpleasant odors and disease germs.

\section{SYSTEMS OF VENTILATION}

361. How Ventilation was Obtained in Colonial Days.With all its faults, the old fireplace of colonial days had its advantages. Even the one room in which the fireplace was 
located was rarely overheated. That room was certainly supplied with an abundance of fresh air. Great volumes of air swept up the wide, open-throated chimuey, to be replaced by fresh air which crept in through the numerous cracks between the logs or around the loosely fitted windows and doors. This was all in marked contrast to our modern houses with their nearly air-tight walls, heated by means of stoves or radiators, often with no provision whatever for the entrance of fresh air or the exit of foul air. It is a fact worth noting that although the colonists did suffer greatly with the cold they did not suffer as we do today with colds and pneumonia.

362. Modern Systems of Ventilation.-Even the humblest dwelling, heated by means of stoves, may be fairly well ventilated by being flushed out at frequent intervals by throwing open doors or windows. Besides this flushing method, there are several systems of ventilation in more or less common use all of which are based upon the constant dilution of the vitiated air. They all fall into one or the other of two classes: NATURAL, or Gravity System, and the Forced System.

\section{Systems of Ventilation}

1. Natural or Gravity System.

(a) By means of doors and windows.

(b) By means of special air - shafts.

Generally used in private residences and small buildings.
2. Forced Systems.

(a) Air moved by propulsion, "Plenum System."

(b) Air moved by suction.

(c) Combination of propulsion and suction.

Generally used in large public buildings.

363. Ventilation of Dwellings. - The system of ventilation employed in dwelling houses is largely determined by the method of heating employed. When heated by means of stoves the dwelling is usually ventilated either (1) by frequent flushings or (2) by window ventilation. The latter is a form of the gravity system. The cooler, outside air is permitted to flow in at the bottom of the window and force the warmer, 
vitiated, inside air out at the top of the window. In this manner the vitiated air is being constantly diluted.

When the dwelling is heated by means of a furnace, the fresh air is admitted by means of a fresh-air flue, or intake, entering the base of the furnace (Fig. 91). The circulation is maintained by convection currents (Chap. I, Sec. IX). It is evident that an outlet must be provided for the foul air. The most efficient outlet is provided by an open grate, or fireplace, especially if a fire is maintained in it. Explain why this is so.

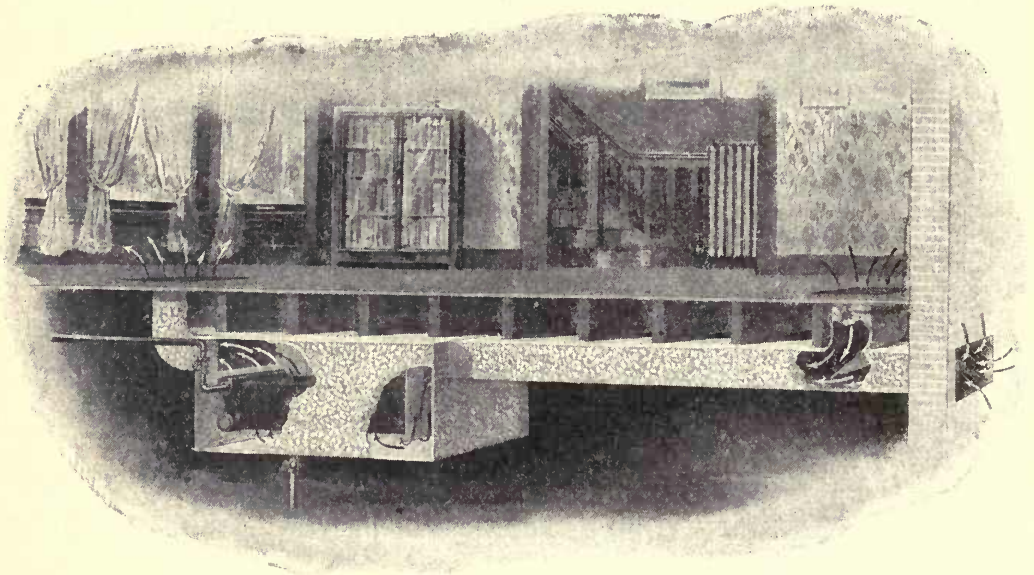

FIG. 233.-Indirect radiation.

When a dwelling is heated by steam or hot water, either of two systems of ventilation may be employed. They are known as the (1) INDIRECT RADIATION SYSTEM, and (2) the DIRECT-INDIRECT SYSTEM OF RADIATION. In the INDIRECT RADIATION SYSTEM the radiator is placed in a box-like compartment beneath the floor. Fresh air is admitted through the fresh air duct as shown in Fig. 233. It is heated as it passes through the box surrounding the radiator and then passes through the register into the room above.

When the DIRECT-INDIRECT SYSTEM is used the radiator 
stands within the room as in the case of ordinary DIRECT RADIATION. At the base of the radiator, however, an opening is made in the floor. Cold, fresh air is admitted through an opening in the wall of the building; it then passes upward through the opening in the floor past the radiator where it is heated (Fig. 234). Usually a base board of wood or metal around the base of the radiator prevents the cold air from entering the room until it has been heated by the radiator. This direct-indirect system is uncertain in its action and generally considered rather unreliable as well as expensive. Recall the principles of furnace heating and the rule of installing a furnace (Arts. 141-143) and explain why it is that this direct-indirect system is not more reliable.

364. Ventilation of School Buildings.-The problem of ventilating school buildings is also largely determined by the size of the building and

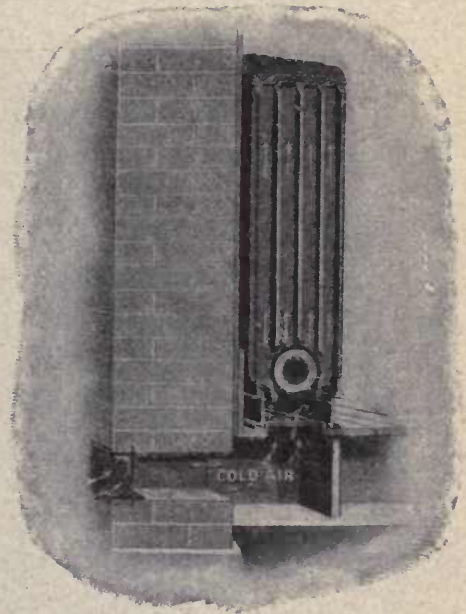

FIG. 234.-Direct-indirect radiation. the mode of heating. The usual mode of heating a one-room school is by means of a stove, occasionally by means of a furnace, and rarely by hot water or steam. The heating of large, many-roomed school buildings is usually by means of steam heat, sometimes by hot water, rarely by means of stoves or furnaces.

\section{Heating and Ventilating the One-room School.-} Several practical devices have been perfected which accomplish the heating and ventilation of the one-room school by means of stoves. They are based upon the principle of the jacketed stove (Art. 140) with the addition of devices for the admission of fresh air and the removal of foul air. Since any 
jacketed stove tends to keep all of the air in the room in constant circulation, it is possible to place such a stove in one corner of the room, thus economizing floor space (Fig. 235). Being placed near the outside wall, fresh air is readily admitted through a wall register into the space within the jacket (Fig. 236). Here the fresh air is heated and joins the general circulation of room air. A ventilating flue, with its bottom open and top extending through the roof, is attached to the

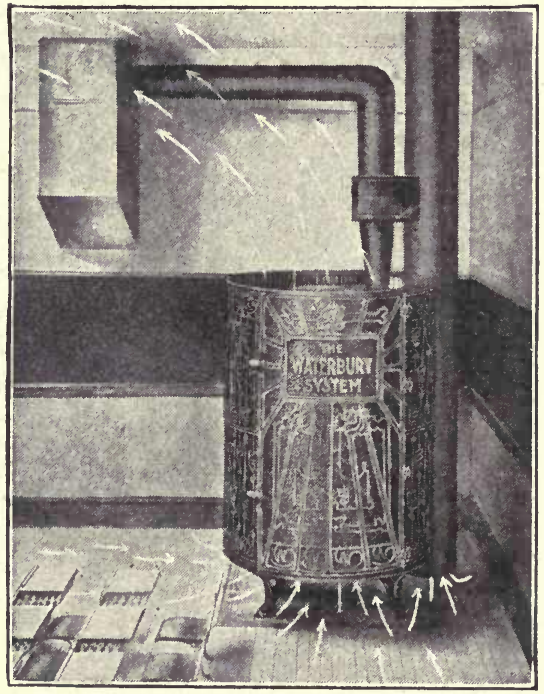

FIG. 235.-Jacketed heating and ventilating stove.

side of it. This flue constantly removes foul air from near the floor. By means of a lever, conveniently located and operating a set of vanes, the amount of fresh air admitted is easily controlled. In the morning, till the room is heated, or on a day when the temperature is low and the wind high, these vanes may be closed, thus heating the room by inside circulation alone. In recent years many of these heating and ventilating devices have been installed in rural schools, thus greatly improving their sanitary condition. 
366. Heating and Ventilating the Several-room School Building.-Forced systems of ventilation are generally used in modern school buildings containing several rooms. As was the case in the one-roomed school, so here we find that the heating and ventilating systems are usually combined. When such large quantities of air must be moved the gravity system is not adequate, the forced system must be employed. Moreover, school buildings containing several rooms are likely to

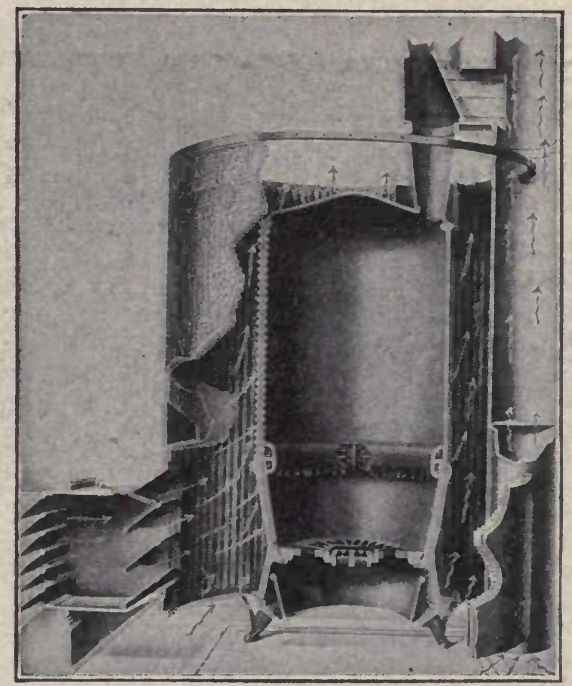

FIG. 236.-Stove with jacket cut away.

be heated by steam and steam power is therefore available for driving the FAN, or BLOWER, if desired.

Forced systems of heating and ventilation may be of the propulsion type, known as the PLENUM SYSTEM, or it may be the suction SYSTEM, or a combination of the two systems.

367. The Plenum System.-In the PLENUM System the blower or fan is usually placed in the basement and forces all the fresh, heated air needed for heating and ventilation through air ducts into the various rooms. The air in all the rooms is, 
therefore, somewhat compressed, that is, the air in all the rooms is under somewhat greater pressure than is the air outside the building. Hence the name PLENUM meaning FULL.

Figure 237 shows the usual construction of the plenum type of heating and ventilating systems. The fresh air enters at the window $A$. It then passes through a bank of steam pipes called the TEMPERING COILS, or TEMPERING STACK, $B$. Here the temperature of the air is raised to about $65^{\circ} \mathrm{F}$. It then passes through a washer, a spray of water, $C$, which

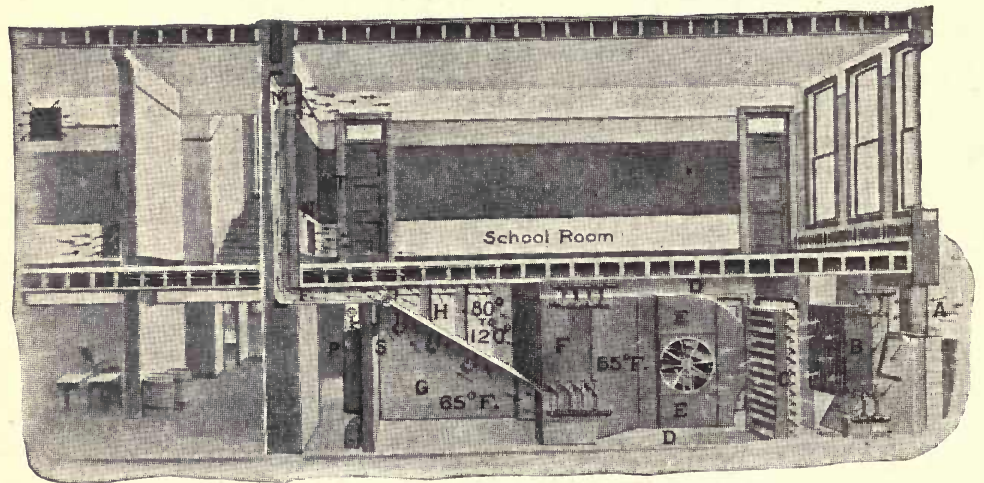

FIG. 237.-Showing the plenum system for warming and ventilating a school building. A tempering stack is shown at the right, next (to the left) is an air washer to insure pure and reasonably moist air, next is a fan or blower, and following that a re-heater, which warms the air to any desired temperature.

washes the air removing all dust particles and increasing the humidity. The air thus warmed to about $65^{\circ}$, washed and humidified, passes into the TEMPERED AIR ROOM, $D$. It then passes into the BLOWER, $E$, which forces it, blows it, strongly to the left. The upper two-thirds of the exit from the blower contains another bank of steam pipes called the нот corLs, or RE-HEATER, $F$. Just beneath the hot coils is a horizontal partition, or false floor. The air from the blower may pass through the re-heater into the нот RоOм, $H$, or it is equally possible for it to pass beneath the false floor directly into the second 
TEMPERED AIR ROOM, $G$. In both of these rooms, $G$ and $H$, the air is under increased pressure due to the force with which the blower forces the air into them. The air in the hot room, $H$, however has been re-heated as it passed through the hot coils, $F$. The temperature of this heated air depends upon the outside temperature. It may be $80^{\circ}$ or $85^{\circ} \mathrm{F}$. on a mild day, or $110^{\circ}$ to $120^{\circ} \mathrm{F}$. on a cold day. The air in the tempered room, $G$, remains at about the same temperature as in the first tempered air room, $D$. From the rooms, $G$ or $H$, or both, the air passes through the flue, $F$, to the wall register, $M$, thence into the room to be heated. The foul air escapes from the room through the other wall register, $N$, into a flue which extends up through the roof.

368. The Thermostat Control of Temperature.-The plenum system is operated on the principle of maintaining a constant temperature. It is necessary, therefore, to control the proportion of heated air from the hot room, $H$, and of tempered air from the tempered air room, $G$, which passes through the flue, $F$, to any room. This control is accomplished automatically by a THERMOSTAT SYSTEM.

The iron cylinder, $P$, Fig. 237, contains air which is maintained under a constant absolute pressure of 2 atmospheres. The pressure gauge, therefore, reads about 15 lb. to the sq. in. (see Art. 157). A small tube leads from the cylinder to the wall

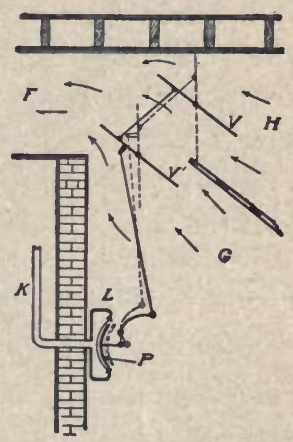

Frg. 238.-Diagram of thermostat. thermostat, $T$, in the schoolroom. A second similar tube, $K$, Fig. 238, leads from this thermostat down to the controlling thermostat, S, Fig. 237, in the tempered air room.

When the schoolroom is below the desired temperature the wall thermostat, $T$, Fig. 237, closes the tube, thus preventing - the compressed air from passing down the tube $K$; when the schoolroom is too warm the compressed air passes more freely through the thermostat, $T$, and down the tube $K$ to the controlling thermostat, $S$. 
The controlling thermostat, (Fig. 238) consists of an iron saucer-shaped capsule, $L$, with its edges turned in. Across the face of this capsule is a stout rubber diaphragm. A smaller saucer-shaped metal plate, $P$, presses against this rubber diaphragm.

When the compressed air enters the capsule it forces the diaphragm and plate, $P$, outward as shown by the dotted lines. A system of levers transmits this motion to the vanes $V^{\prime}$ and $V$, forcing them more nearly into a vertical position. Thus the flow of heated air is lessened and the flow of tempered air is increased.

When the schoolroom is too cool the wall thermostat, $T$, closes the tube $K$, thus preventing the compressed air from passing to the controlling thermostat, $S$. The pressure upon the diaphragm and the plate, $P$, lessens and the vanes tend to fall back into a more nearly horizontal position. When the vanes are in a horizontal position more heated air and less tempered air passes to the room in which the thermostat, $T$, is located.

\section{PROBLEM}

If the plate, $P$, Fig. 238 , is 4 in. in diameter and the pressure gauge shows an air pressure of $15 \mathrm{lb}$. per sq. in., with what force will the plate, $P$, be forced outward?

369. The Suction System of Heating and Ventilating.-In the suction system the fan, or blower, is usually placed in the attic of the building. The purpose is to suck the air out of the building (see Art. 374). The air within the room is, then, under less than 1 atmosphere of pressure. The suction system is not often used alone; it is often used in connection with the plenum system to secure more perfect ventilation of laboratories, toilet rooms, kitchens, or other rooms.

\section{DUST AND ITS DANGERS}

370. Live Dust and Dead Dust.-All dust may be classified as LIVE DUST or DEAD DUST. While all dust looks alike to the 
housekeeper and the janitor, it is now known that the chief danger to man lies in coming in contact with live dust. We shall see in Chap. VIII that many communicable diseases such as tuberculosis, pneumonia, colds, grippe, diphtheria, and others are caused by living microörganisms. These and other similar organisms constitute live dust. Most, if not all, of these disease germs die quickly when exposed to direct sunlight or high temperature. Therefore, the dust blown in from the street, or the fine ashes coming from the stove or furnace, can not be looked upon as particularly dangerous, no matter how annoying such dust may be.

371. House Dust.- House dust is almost certain to consist of both live dust, living organisms, and dead dust. It is of great importance, therefore, that so far as possible all dust be removed from rooms where people live or congregate, not simply because it looks bad, but principally because it endangers the health of the occupants. Ordinary sweeping with a broom or carpet sweeper does not remove the most dangerous portions of the dust. Dusting the room with a dry dusting cloth does not remove much of the dust. Such methods remove only the large particles of dirt which are not particularly dangerous, merely unsightly, and remove the finer dust from the more exposed surfaces allowing it to settle again in the unobserved places. No system of house cleaning and dusting is effective or much worth while, so far as health of the occupants is concerned, unless it really removes the dust from the house.

\section{Exercise 74.-Observing Dus in the Air of a Room}

Darken a room by drawing the window shades (either a living room at home or the schoolroom will do) leaving a small crack at one window through which the direct sunlight may enter. Observe the dust particles floating in the air. Why is it that they now become visible? With a broom sweep the floor or carpet near the window. Does the amount of dust floating in the air increase? With a dry dusting cloth wipe the walls or furniture and shake the cloth in the ray of sunlight. Note the result. 
Remember that this is the air which we are constantly breathing and which is constantly coming into contact with our food as it is being prepared in the kitchen or served upon our dining table.

372. Carpets, Drapery, and Bric-a-brac Dangerous.-Carpets are exceedingly difficult to keep free from dust. Ordinary sweeping removes but little of the fine dust from the carpeted floor; much of the fine dust lodges in the carpet or passes through it. One has but to recall the condition of the floor as it appears after the carpet has been taken up for the annual or semi-annual cleaning, in a house where the floors have been cleaned by sweeping with broom or carpet sweeper, to be convinced that ordinary sweeping is unsanitary. If the floors are to be kept clean by sweeping they should be oiled, painted or waxed and then covered with rugs which are easily removed and beaten. Such floors may be kept in a sanitary condition. Drapery and bric-a-brac on the walls are dust catchers and exceedingly difficult to clean. The more thoughtful people of today are discarding bric-a-brac from

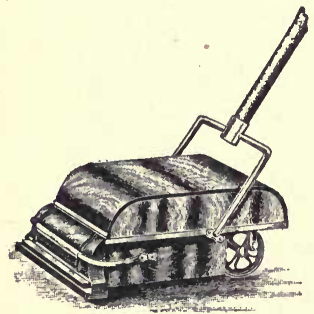

FIG. 239. their houses and using fewer draperies than formerly. The fewer dust catchers there are in any living room or any sleeping room, the easier it is to care for it and the more sanitary it may be kept.

373. Vacuum Cleaning.-In recent years many devices for VACUUM CLEANING have been put upon the market. They range from simple, inexpensive devices, operated by hand, Figs. 239 and 240, for use in private dwellings, to large, expensive plants, operated by electric motors or steam engines for the cleaning of the largest hotels, railroad stations, office buildings, school buildings, and stores. They all operate by producing a partial vacuum. In most large types a tube or pipe leads from the machine to the cleaning tool. This cleaning tool fits closely to the carpet or other surface which is 
to be cleaned. Air pressure causes a strong current of air to rush into the vacuum carrying dirt and dust with it. On its way to the pump where the vacuum is produced, the dustladen air passes through a thick, closely woven cloth, or is washed by a spray of water, thus removing all dirt and dust. The air which actually passes through the pump is, therefore, practically dust free.

In the sweeper type (Fig. 239) the vacuum is produced by

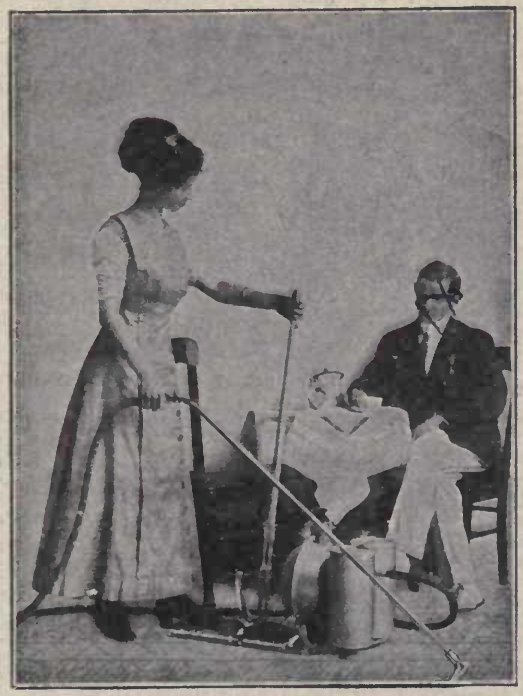

FIG. 240.

bellows, or movable diaphragms, operated by the friction of the wheels upon the floor or carpet. In this type of cleaner the cleaning tool is a part of the machine itself.

Many modern dwellings, churches, auditoriums, office buildings, stores, and school buildings are equipped with stationary vacuum cleaners. In such cases the machine is usually located in the basement and the suction pipes are run to the various rooms of the building. Rubber hose carrying 


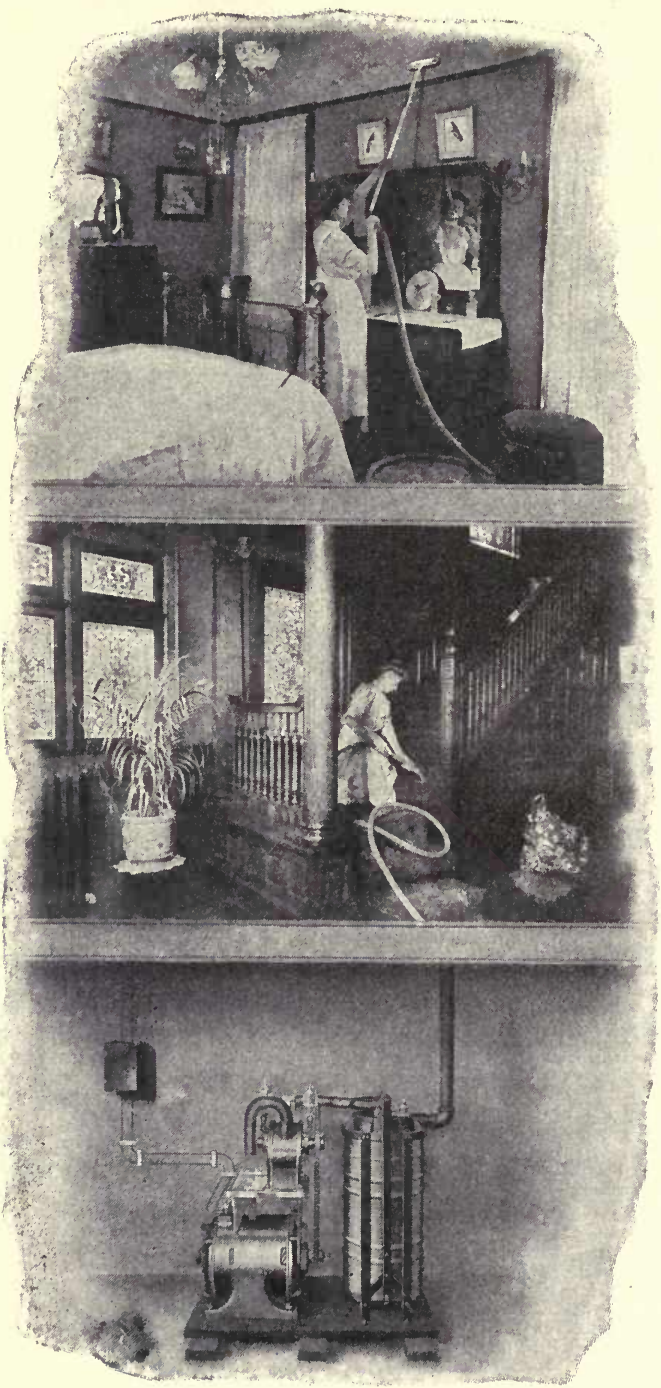

FIG. 241.-A vacuum cleaner operated by an electric motor. 
the cleaning tool may be attached to the suction pipes at convenient points throughout the building (Fig. 241). In some cities vacuum cleaners have been successfully used in street cleaning (Fig. 242).

374. Meaning of Suction.-Many people use the word sUCTION without knowing its real meaning. The words SUCTION and SUCKING are good, common English words, and express ideas not easily expressed in other words. When we use these words we ought, however, to know just what they mean. Suction does not mean drawing or pulling as many peo-

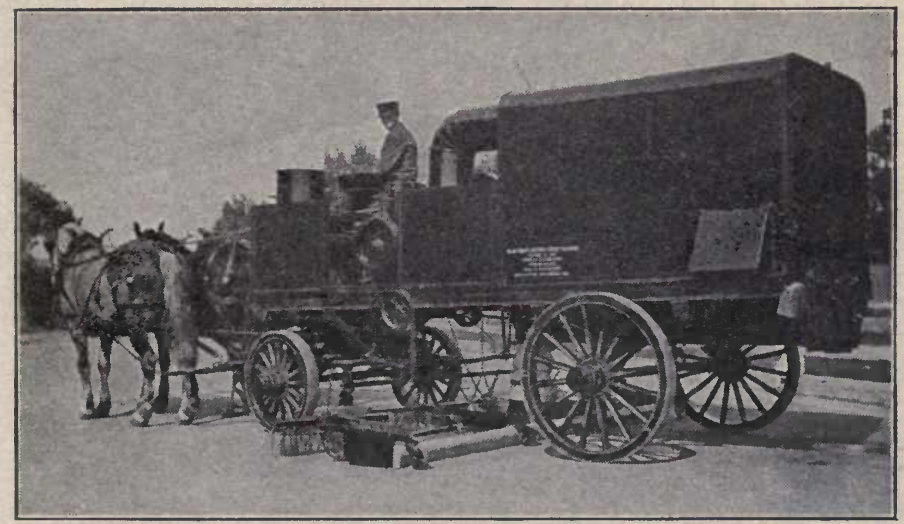

FIG. 242.-A street vacuum cleaner. (By permission of the Municipal Journal.)

ple believe. Sucking soda water up a straw does not mean drawing it up the straw. Liquids and gases can not be drawn or pulled; they must be moved by being pushed.

Definitions.-Suction is the process by which a partial vacuum is produced into which a fluid, either a liquid or a gas, is forced by outside gaseous pressure, usually the pressure of the atmosphere.

SUcKING is the act of producing a partial vacuum into which the surrounding atmospheric pressure tends to flow.

When we suck soda water up a straw we merely enlarge the mouth cavity and thereby produce a partial vacuum into which 
the atmospheric pressure forces the soda water. When we clean a carpet by means of a vacuum cleaner, the tool fits tightly against the top surface of the carpet. In entering the tool the air must come up through the carpet; as it does so it carries all loose dust and dirt with it.

\section{Exercise 75.-A Study of Vacuum Cleaners}

Study several different types of home vacuum cleaners, determining exactly how they work. Write a description of one or more of the cleaners studied. 


\section{CHAPTER VII}

\section{FOOD AND NUTRITION}

\section{A STUDY OF FOODS AND DIETARY}

375. Importance of Studying the Food Problem.-The business of obtaining food is the most important one in which man is engaged. This business includes, not only agriculture, which is the art of obtaining foods indirectly from the soil, but also the carrying of the food from the farm to the market, the milling, the packing, and the other manufacturing processes by means of which the food is prepared for the consumer, and the retailing of the finished product to the consumer. A large portion of our population is engaged in the work of obtaining, transporting, preparing, and retailing food. The food bill of our country amounts to more than any other single bill.

With the early pioneer, the food problem was comparatively simple. He raised his own wheat and corn. He took them to mill and had them ground into flour or meal. His wife made the bread in her own kitchen. The pioneer produced his own meat and slaughtered it himself. He produced his own sugar, maple sugar, or sorghum. He produced, of course, his own milk, butter, and cheese. Very few foods were purchased at the grocery.

Now all is changed. Even the farmer often buys his flour, meat, cheese and butter. The population of cities has largely increased. Food must be produced for city dwellers as well as for those directly engaged in the production of food. We have a greater variety of foods offered for sale in our modern markets than the pioneer ever thought of. Food is brought from all parts of the world. Much of the food offered for sale has passed through one or more manufacturing processes. The 
problem of getting food in these days is, not only a question of getting enough to eat, but it is also a problem of selecting the best and the cheapest foods from the great varieties offered for sale in the markets. The purpose of this chapter is to study the use of food to the body, the composition and value of food, its cost, and some of the methods of preparing it for our use.

376. What Foods Do for the Body.-We eat that the body may be kept in health. Health demands that the foods shall keep the body strong and vigorous. The foods must supply the body with the materials of which it is made. They must also supply the body with energy (Art. 85) so that its work may be carried on. In some respects, foods are to the body what coal or gasoline is to the steam or gasoline engine. The fuel must be burned in the engine in order to make the engine go. In a similar way, the foods eaten supply the body with the

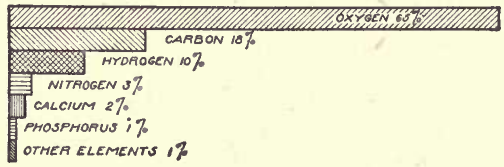

FIG. 243.-The composition of the human body.

energy to do its work. But the foods do more for the body than the fuel does for the engine. The foods provide for the growth and the repair of the body. The fuel does no such thing for the engine. The engine is not self-repairing by the fuel supplied to it. If one part wears out it must be replaced by a new part from the machine shop. It is evident then that the foods must furnish the body with the materials out of which it is made as well as to furnish it with energy.

377. What Substances Must the Foods Furnish to the Body?-While the body is known to be composed of many complex chemical compounds, it is also known that these compounds are composed of but few chemical elements (Fig. 243). The following table from Sherman's Chemistry of Food and Nutrition gives the names and the amounts of the chemical elements composing the human body. 
Per cent.

Oxygen, about 65.00

Carbon, about 18.00

Hydrogen, about 10.00

Nitrogen, about 3.00

Calcium, about 2.00

Phosphorus, about 1.00

Potassium, about 0.35

Sulphur, about 0.25
Per cent.

Sodium, about $\mathbf{0 . 1 5}$

Chlorine, about 0.15

Magnesium, about 0.05

Iron,

about 0.004

Iodine

Fluorine Very minute traces.

Each of these elements will be found in the list of chemical elements given in Art. 84. The oxygen, carbon, hydrogen, and nitrogen are the elements to which most attention is directed. The carbon and nitrogen come exclusively from the foods eaten. Much of the oxygen in the body comes from the air we breathe and the water we drink. Water also supplies much of the hydrogen found in the body. The other elements are usually present in the food in such abundance that we give very little thought to getting enough of them.

378. Foods Must Supply the Body with Energy.- The gasoline engine transforms the chemical energy (Art. 86) of the gasoline into heat and power. The body likewise transforms the chemical energy of foods into heat, muscular activity, power to digest foods, power to think, to see, to feel, to hear; in short, into all processes included in "LIFE."

379. How the Energy of Foods is Liberated to the Body.Just as the fuel for the engine must unite with oxygen in order that its energy may be delivered to the engine, so the materials composing the food must undergo oxidation in the body in order to liberate their energy to the body. However, in the case of the fuel, the oxidation is rapid and takes place at a high temperature. Such oxidation is known as combustion. In the human body, oxidation is slow and proceeds at the body temperature. The process is called sLOw oxidation. Without this slow oxidation there is no liberation of energy to the body. Hence, it is evident that oxygen is just as necessary as food for the maintenance of the body activities. The oxygen comes from the air. As a result of the combination of 
oxygen with the two most important elements found in foods, viz., carbon and hydrogen, carbon dioxide and water are the common products.

\section{Exercise 76.-To Show that Water and Carbon Dioxide are Produced in the Human Body}

(a) Blow the breath against a cold window pane or some other cold surface and observe the film of moisture deposited. Where did the water come from? In what state was it in the breath? In what state is it now on the cold surface? What caused the change? Much of the moisture expelled in the breath comes from the water drunk, but a part also comes from the water formed in the body by the combination of the hydrogen of foods with oxygen.

(b) By means of a glass tube blow the exhaled breath through clear lime water contained in a clean bottle. What happens to the limewater? What substance does it show is present in the exhaled breath (Ex. 25f)? Now take a bottle filled with such air as you are inhaling, place some clear limewater in the bottle, cover the mouth of the bottle, and shake the liquid with the contained air. What håppens to the limewater? Can you detect any evidence of carbon dioxide in this fresh air? Was carbon dioxide more abundant in the exhaled breath than in the inhaled breath? Where did the extra amount come from?

380. Where Do the Foods Obtain Their Energy?-It is a notable fact that all energy-giving power of the foods of animals and of the higher plants is traceable to the work of green plants. Green plants are the only living things in all the world that have the power to take up the non-nutritious materials like water, carbon dioxide, and mineral matter and build them into the nutritious foods like sugar, fat, and protein. If we eat the flesh of animals, we are still dependent upon the green plant for our food, for the animal either got its food from plants or from some other animal which subsisted on plants. Sunlight is necessary for the growth of the green plant. Sun energy is taken into the plant through the leaves and is stored in the food made by the plant. Thus it is that the green plants are the food factories of the world, gaining their raw materials from the earth and the air, and storing in the finished product the energy derived from the sun. 
381. The Carbon Cycle.- Of the raw materials coming to the green plant, water and mineral matter come to it from the earth by way of the roots, while the carbon dioxide is absorbed through the leaves. Out of the raw materials and with the energy derived from the sun, the plant makes a simple sugar in the leaves. Oxygen is liberated at the same time. This escapes into the air. From the simple sugar, the plant, by means of other materials, produces other foods. When the plant or an animal consumes the food the plant has produced, oxygen is taken from the air, the food is oxidized, its energy is liberated, and carbon dioxide and water are produced. The carbon dioxide is returned to the air, subsequently to be built

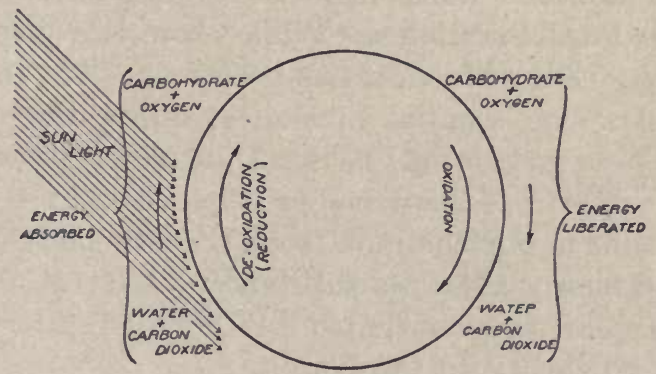

FIG. 244.-The carbon cycle.

into a food again by some green plant. This round of changes goes on continually. It is known as the "CARBON CYCLE" (Fig. 244). All of the energy possessed by fuels is traceable to the work of green plants.

382. What is Food?-

Definition.- A food is anything from which the lody may obtain its substance and energy.

Many of the substances we eat furnish both of these for the body and are therefore rightly called foods. Some of the other substances we eat and which are sometimes called foods, are without the ability to supply the body with energy. They ought not to be thought of as foods in the same sense as those materials which furnish both for the body. Thus our meats 
and cereals supply both for the body. They are foods. Salt and water which are taken into the body yield no energy to the body. They are not to be thought of as foods in the same way as we think of meats and cereals.

383. Classes of Foods.-Our foods may be broadly classed as foods derived from animals and foods derived from plants. The animal foods include such foods as beef, pork, mutton, fish, game, poultry, milk and its products, and eggs. The foods derived from plants include a greater variety. The cereals, such as corn, wheat, oats, rye, rice, and barley are used. Other plant materials such as the potato, pea, bean, sugar cane, sugar beet, and nuts are used. Still other plant materials commonly called fruits are widely used.

384. The Food Principles.-While there is a great variety of substances used as food, it has been found that they are all made up of a few essential substanees called the FOOD PRINcIPLES. These include: (1) FATs, (2) CARBohydrates, and (3) PROTEINS. It is from these food principles contained in greater or less amount in our common foods that the body derives its energy and nearly all of its substance. Mineral matter and water are sometimes included in the food principles, but they yield no energy to the body.

385. The Fats.-FAts are compounds of carbon, hydrogen, and oxygen. They are found in plants and animals in both the solid and the liquid states. The liquid fats are frequently called oils. But the oils would become solid at a sufficiently low temperature. Petroleum and its products, though commonly called oils, are not fats. They are without food value to the body.

Our common fats come from animals, from the cotton seed, from corn, from the olive, and from certain nuts such as the peanut and the cocoanut.

386. Carbohydrates.-Like the fats, the carbohydrates are compounds of carbon, hydrogen, and oxygen but in different proportions from those in fats. Carbohydrates are found chiefly in plants, no considerable amount of them coming from 
animal bodies. The following is a list of the common carbohydrates:

1. Cellulose (cotton is nearly pure cellulose).

2. Starch.

3. Dextrin (commonly called British gum).

4. Sucrose (cane sugar, beet sugar, maple sugar).

5. Maltose (malt sugar).

6. Lactose (milk sugar).

7. Dextrose (grape sugar).
8. Levulose (fruit sugar). Found in ripe fruits and honey.

Sucrose, maltose, lactose, dextrose, and levulose are sweet and are commonly called sugars. Dextrin is also sweet. It is used as an adhesive. Stamps and envelopes have dextrin as an adhesive. When it is remembered that cotton is very widely used in clothing, it is seen that the carbohydrates are of vast importance aside from their use as food. Wood contains cellulose.

387. Simple Tests for Carbohydrates.

\section{Exercise 77.-Tests for Carbohydrates}

1. The Sugars Melt. - Place half a teaspoonful of granulated sugar in a large spoon and carefully heat it until it melts.

2. The Carbohydrates Char When Heated Hot ENovgh.-Continue to heat the melted sugar until a solid black residue, carbon, is left behind. This residue contains most of the carbon that was in the original sugar. Repeat the charring test with starch.

3. The Iodine Test for Starch.-Apply a drop of iodine

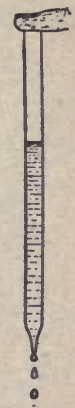

FIG. 245.

- Using the pipette. solution by means of a pipette to a little starch (Fig. 245). What color is produced? Apply the iodine test to the inside of the following grains, corn, wheat, oats; also apply it to the following fruits and the vegetable, apple, banana, potato. In which ones of these do you find starch? If possible compare ripe and green fruits as to the presence of starch.

388. Proteins.-These substances contain nitrogen in addition to carbon, hydrogen, and oxygen. Many proteins also contain sulphur and phosphorus. The proteins are found in the cereals, in many vegetables, in meats, in milk and its 
products, in cheese and butter, and in eggs. The skin, hair, and nails contain protein substances. Wool and leather, glue and gelatin also contain protein substances. The white of egg is nearly pure protein mixed with water. Milk is a mixture of protein, fat, carbohydrate, mineral matter, and water, while cheese is a mixture of the same substances but with less water.

The proteins are the most expensive of the food principles. Animal bodies are generally rich in proteins and poor in carbohydrates, while the cereals are relatively poorer in proteins but rich in carbohydrates.

\section{Exercise 78.-Tests for Proteins}

1. The Burning Test.-Because of the nitrogen they contain, protein substances burn with a characteristic odor, that of burnt hair. Burn a little wool and note the odor. Compare it with the

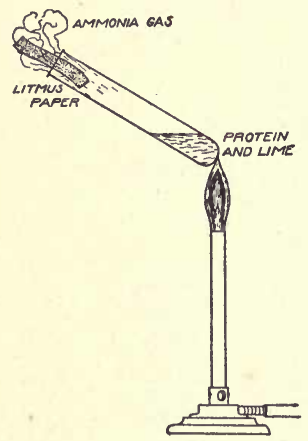

FIG. 246.-Test for proteins. odor arising from burning cotton. Heat a little wheat flour and dried beef in separate evaporating dishes or crucibles. Note the odor of the burning materials.

2. The Ammonia Test.-When protein substances are heated with lime (calcium hydroxide, not the solution, but the dry material) ammonia is produced. The ammonia may be identified either by its odor or by the fact that it turns moist red litmus paper blue. Place small equal amounts of dry gelatin and lime in a test tube and mix them. Heat the mixture strongly, holding a piece of moist red litmus paper in the gases escaping from the tube (Fig. 246). Be careful that the paper does not touch the side of the tube where it may meet lime which would turn the paper blue just as the ammonia does. When you get a strong test for ammonia, note the odor of the gases escaping from the tube. Disregard the odor of burnt hair and give attention only to the ammonia. Ammonia was formerly made almost entirely by heating animal products with lime. The ammonia was called sPIRITS OF HARTSHORN because the horns of the hart deer were frequently used as the animal substance. (See Art. 194.)

3. The Nitric Acid Test.-Place a little dry gelatin in a test tube and moisten it with a single drop of concentrated nitric acid. 
Warm the mixture gently. What color is produced? Now add ammonia solution until the mixture smells of the ammonia. What has happened to the color just observed? Care should be used to prevent any nitric acid from getting on the skin for it produces a disagreeable stain. Why?

389. The Protein Foods Absolutely Necessary. - While the protein foods yield energy equal in amounts to equal weights of carbohydrates, their chief value to the body lies in the fact that they alone contain nitrogen. Proteins must be found in every diet. The body may obtain energy quite as well from fat and carbohydrate as from protein, but neither fats nor carbohydrates can furnish the body with the nitrogen which it needs. Moreover, the protein foods, as a rule, are higher in price than either the carbohydrates or the fats. It would be folly therefore to consume protein foods for the sole purpose of producing energy for the body when this energy can be obtained more cheaply from carbohydrates and fats. Moreover, the waste products from protein are much harder to get rid of than the waste products from carbohydrates and fats. However, enough protein must be supplied the body at all times to keep the body in repair.

390. How Much Protein?-This is a matter which has caused a great deal of discussion. But authorities are now agreed that the body should be supplied with from 3 to 5.3 oz. of protein per day. Dr. Atwater gave the following as the protein requirement of persons engaged in different occupations:

Man with hard muscular work............ 5.3 oz. per day Man with moderately active muscular work..... 4.4 oz. per day Man at sedentary or woman with moderately ac-

tive work........................ 3.5 oz. per day

Man without muscular exercise or woman at light to

moderate work..................... 3.17 oz. per day

Exercise 79. Weighing the Amount of Protein Needed by the Body for a Day

Weigh a dozen eggs and calculate the average weight of one egg. By the use of Table XIV on page 353 or Fig. 247 which gives the percentage of protein in whole eggs, calculate the weight of egg 
needed to furnish protein enough for a man of sedentary occupation. How many eggs will be required per day if eggs are to furnish the protein for the body? Weigh a quart of whole milk and by use of Table XIV or Fig. 248 calculate the weight of milk a man would have to consume daily to furnish $3.5 \mathrm{oz}$. of protein. Calculate the weight of round steak needed to furnish $3.5 \mathrm{oz}$. of protein.

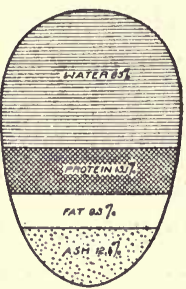

FIG. 247.-Composition of the whole egg.

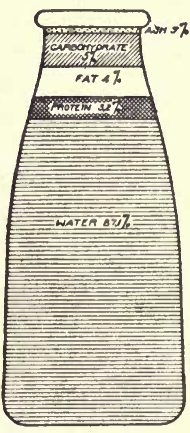

FIG. 248.-Composition of whole milk.

391. How Much Food? - The food eaten must, not only supply protein to keep the body in repair, but it must also furnish enough energy for the needs of the body. The ability of foods to produce energy in the body is measured by the amount of heat they produce when burned. This is determined by burning the food in a calorimeter just as the heat value of coal or other fuels is determined (Art. 122). Now the food requirements of the body are measured in heat units, usually the greater calorie (Art. 121). Dr. Atwater in Farmer's Bulletin No. 142, U. S. Department of Agriculture, gave the following as the energy requirements per day for persons in different occupations:

Man with hard muscular work......... 4150 greater calories Man with moderately active muscular work... 3400 greater calories Man at sedentary or woman with moderately

active work.................. 2700 greater calories Man without muscular exercise or woman at

light to moderate work............. 2450 greater calories 
Table XiV.-Composition and Calorific Value of Foods

(1) Cereals and Cereal Products

\begin{tabular}{|c|c|c|c|c|c|}
\hline Kind of Food & $\begin{array}{c}\text { Per cent. } \\
\text { of } \\
\text { water }\end{array}$ & $\begin{array}{c}\text { Per cent. } \\
\text { of } \\
\text { protein }\end{array}$ & $\begin{array}{c}\text { Per cent. } \\
\text { of } \\
\text { fat }\end{array}$ & $\begin{array}{l}\text { Per cent. } \\
\text { of carbo- } \\
\text { hydrate }\end{array}$ & $\begin{array}{l}\text { Heat value } \\
\text { in greater } \\
\text { calories } \\
\text { per pound }\end{array}$ \\
\hline 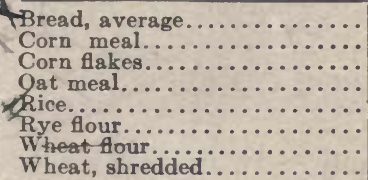 & $\begin{array}{r}35.3 \\
12.5 \\
7.3 \\
7.7 \\
12.3 \\
12.9 \\
12.0 \\
9.0\end{array}$ & $\begin{array}{r}9.2 \\
9.2 \\
10.1 \\
16.7 \\
8.0 \\
6.8 \\
11.4 \\
10.5\end{array}$ & $\begin{array}{l}1.3 \\
1.9 \\
1.8 \\
7.3 \\
0.3 \\
0.9 \\
1.0 \\
1.4\end{array}$ & $\begin{array}{l}53.1 \\
75.4 \\
78.4 \\
66.2 \\
79.0 \\
78.7 \\
75.1 \\
77.3\end{array}$ & $\begin{array}{l}1200 \\
1635 \\
1680 \\
1800 \\
1620 \\
1620 \\
1640 \\
1650\end{array}$ \\
\hline
\end{tabular}

(2) Eggs and Dairy Products

\begin{tabular}{|c|c|c|c|c|c|}
\hline 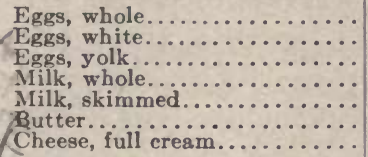 & $\begin{array}{l}65.5 \\
86.3 \\
50.0 \\
87.1 \\
90.5 \\
13.0 \\
34.2\end{array}$ & $\begin{array}{r}13.1 \\
12.8 \\
16.0 \\
3.2 \\
3.4 \\
0.5 \\
25.9\end{array}$ & $\begin{array}{r}9.3 \\
0.4 \\
33.0 \\
4.0 \\
0.3 \\
85.0 \\
33.7\end{array}$ & $\begin{array}{r}\text { None } \\
\text { None } \\
\text { None } \\
5.0 \\
5.1 \\
\text { None } \\
2.4\end{array}$ & $\begin{array}{r}635 \\
250 \\
1705 \\
325 \\
165 \\
3600 \\
1885\end{array}$ \\
\hline
\end{tabular}

\section{(3) Meats, Edible Portion}

\begin{tabular}{|c|c|c|c|c|c|}
\hline 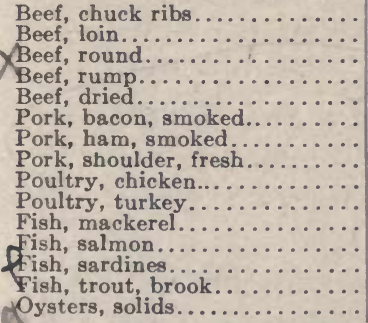 & $\begin{array}{l}57.3 \\
60.5 \\
65.8 \\
56.7 \\
50.8 \\
18.2 \\
40.7 \\
57.5 \\
74.2 \\
55.5 \\
73.4 \\
69.1 \\
56.4 \\
77.8 \\
88.3\end{array}$ & $\begin{array}{l}17.4 \\
18.3 \\
19.7 \\
16.8 \\
31.8 \\
10.0 \\
15.5 \\
15.6 \\
22.8 \\
20.6 \\
18.2 \\
18.2 \\
25.3 \\
18.9 \\
6.1\end{array}$ & $\begin{array}{r}24.4 \\
20.2 \\
13.5 \\
25.6 \\
6.8 \\
67.2 \\
39.1 \\
26.1 \\
1.8 \\
22.9 \\
7.1 \\
11.4 \\
12.7 \\
2.1 \\
1.4\end{array}$ & $\begin{array}{l}\text { None } \\
\text { None } \\
\text { None } \\
\text { None } \\
\text { None } \\
\text { None } \\
\text { None } \\
\text { None } \\
\text { None } \\
\text { None } \\
\text { None } \\
\text { None } \\
\text { None } \\
\text { None } \\
\text { None }\end{array}$ & $\begin{array}{r}1355 \\
1190 \\
935 \\
1395 \\
845 \\
3020 \\
1940 \\
1390 \\
500 \\
1350 \\
640 \\
820 \\
1010 \\
440 \\
235\end{array}$ \\
\hline
\end{tabular}

(4) Fruits and Fruit Products, Edible Portion

\begin{tabular}{|c|c|c|c|c|c|}
\hline 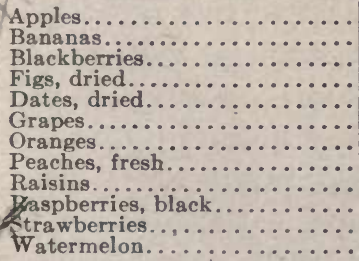 & $\begin{array}{l}84.9 \\
76.1 \\
86.8 \\
21.2 \\
16.7 \\
77.9 \\
79.4 \\
89.8 \\
18.0 \\
84.7 \\
91.0 \\
92.7\end{array}$ & $\begin{array}{l}0.4 \\
1.3 \\
1.3 \\
4.3 \\
2.1 \\
1.3 \\
0.8 \\
0.7 \\
2.6 \\
1.7 \\
1.0 \\
0.4\end{array}$ & $\begin{array}{l}0.5 \\
0.6 \\
1.0 \\
0.3 \\
2.8 \\
1.6 \\
0.2 \\
0.1 \\
3.3 \\
1.0 \\
0.6 \\
0.2\end{array}$ & $\begin{aligned} 14.2 \\
22.0 \\
10.9 \\
74.2 \\
78.4 \\
19.2 \\
11.6 \\
9.4 \\
76.1 \\
12.6 \\
7.4 \\
6.7\end{aligned}$ & $\begin{array}{r}285 \\
447 \\
262 \\
1437 \\
1575 \\
437 \\
233 \\
188 \\
1562 \\
300 \\
169 \\
136\end{array}$ \\
\hline
\end{tabular}

(5) Miscellaneous, Edible Portion

\begin{tabular}{|c|c|c|c|c|c|}
\hline 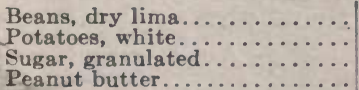 & $\begin{array}{l}14.5 \\
79.3 \\
\text { None } \\
11.2\end{array}$ & $\begin{array}{l}18.1 \\
2.2 \\
\text { None } \\
25.8\end{array}$ & $\begin{array}{l}1.5 \\
0.1 \\
\text { None } \\
38.6\end{array}$ & $\begin{array}{r}65.9 \\
18.4 \\
100.0 \\
24.4\end{array}$ & $\begin{array}{r}1586 \\
378 \\
1815 \\
2490\end{array}$ \\
\hline
\end{tabular}


Chemists have analyzed nearly every food, and have determined its heat-producing ability by burning in a calorimeter (Art. 122). The results of these investigations on some of the common foods are given (page 353 ). By reference to Table $\mathrm{XIV}$, it is an easy matter to see just what food principles each food furnishes the body, what proportion of the food principles is furnished, and just how much energy, measured in greater calories, is furnished.

392. Some Observations on the Table.-It is evident to anyone who will study the table that some of our foods contain much water. Their calorific value is, therefore, rather low.

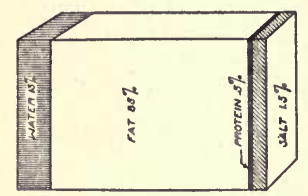

Fig. 249.-Composition of butter. Watermelon, for instance, contains over 92 per cent. water and its heat value is but $136 \mathrm{Cal}$. per lb. while butter contains about 13 per cent. water and its calorific value is $3600 \mathrm{Cal}$. per $\mathrm{lb}$. This must mean that butter is a much better fuel for the body than watermelon. A man could scarcely eat enough watermelon to supply the energy needs of his body, while a rather small amount of butter would meet the energy demands easily (Fig. 249).

It is also evident that some foods are much richer in certain of the food principles than others. Thus butter contains about 85 per cent. fat and no carbohydrate, while sugar contains 100 per cent. carbohydrate and no fat. The cereals are all rich in carbohydrate while their fat and protein percentages are rather low. The meats, on the other hand, contain, as a rule, no carbohydrate while their percentages of fat and protein are rather high. In general, fruits contain much water, little protein and fat, and relatively much carbohydrate. In selecting foods, then, a knowledge of their composition is necessary.

393. The Heat Value of the Food Principles. - When the pure food principles are burned in the calorimeter it is found that they produce the following amounts of heat: 
Protein............ 2562 greater calories per pound

Carbohydrate ........ 1860 greater calories per pound

Fat.............. 4286 greater calories per pound

But the body does not realize the full heat value of the food principles when they are oxidized in the body. This is because of incomplete digestion and incomplete oxidation. The following is the net value in heat units of the above to the body:

Protein.............. 1815 greater calories per pound

Carbohydrate......... 1815 greater calories per pound

Fat.............. 4084 greater calories per pound

It will thus be observed that protein and carbohydrate are of equal value to the body as producers of energy, while fat produces about $2 \frac{1}{4}$ times as much energy. It is a well-known fact that fatty foods are greater heat producers than other kinds. Inhabitants of cold climates consume and relish large quantities of fat. Most of us have a better appetite for fat in the winter than in the summer. Why?

391. Bread and Butter; Pork and Beans.-These are wellknown combinations of food. Why are these foods thus combined? It will be observed that bread is composed of 9.2 per cent. protein, 1.3 per cent. fat, and 53.1 per cent. carbohydrate. It is therefore rather poor in fat. Butter on the other hand is rich in fat, so that a thin coat of butter on a slice of bread supplies the deficiency of fat in the bread. Explain why the combination of fat pork and beans is better than either one alone. What combination would you suggest with eggs? Why do we relish cheese with bread or crackers? Why do we combine meat and potatoes? Why combine milk, eggs, and sugar in a custard?

395. Food for a Day.- Let us consider the daily menu of a man at moderately active muscular labor. Suppose we consider that he eats the following amounts of food: Bread, $1 \mathrm{lb}$; round steak, $1 / 2 \mathrm{lb}$; bacon, $1 / 4 \mathrm{lb}$.; milk, $1 \mathrm{lb}$; potatoes, $1 \mathrm{lb}$; butter, $1 \mathrm{oz}$; and sugar, $1 / 4 \mathrm{lb}$. What amounts of energy and of protein will such a menu furnish him? Our 
method of calculating is as follows: Since bread contains 9.2 per cent. protein, $1 \mathrm{lb}$. of bread will furnish $1 \times 0.092=0.092$ lb. of protein. In like manner the bread will yield $1 \times 0.013=$ $0.013 \mathrm{lb}$. of fat; and $1 \times 0.531=0.531 \mathrm{lb}$. of carbohydrate. For the round steak the calculation is as follows: $0.5 \times 0.197=$ $0.099 \mathrm{lb}$. of protein; $0.5 \times 0.135=0.067 \mathrm{lb}$. of fat. The steak contains no earbohydrate. The other articles on the menu are calculated in a similar manner, using the amount of the article in the menu and the percentage composition of the article as given in Table XIV. The student should make these calculations and verify the figures given in the following table. Calculate the greater calories for each article of food.

Table XV.-Food for One Day for a Man Engaged in Moderately Active Muscular Labor

\begin{tabular}{|c|c|c|c|c|c|}
\hline Article & Amount & $\begin{array}{l}\text { Pounds of } \\
\text { protein }\end{array}$ & $\underset{\text { fat }}{\text { Pounds of }}$ & $\begin{array}{c}\text { Pounds of } \\
\text { carbohydrate }\end{array}$ & Calories \\
\hline Bread. & $1 \mathrm{lb}$. & 0.092 & 0.013 & 0.531 & $?$ \\
\hline Round steak. & $1 / 2 \mathrm{lb}$. & 0.099 & 0.067 & $\ldots \ldots$ & $?$ \\
\hline Milk. . . . . . & $1 \mathrm{lb}$. & 0.032 & 0.040 & 0.050 & $?$ \\
\hline Potatoes..... & $1 \mathrm{lb}$. & 0.022 & 0.001 & 0.184 & $?$ \\
\hline Butter....... & $1 \mathrm{oz}$. & $\ldots \ldots$ & 0.053 & $\cdots \cdots$ & $?$ \\
\hline Bacon... & $1 / 4 \mathrm{lb}$. & 0.025 & 0.168 & - & $?$ \\
\hline Sugar...... & $1 / 4 \mathrm{lb}$. & $\cdots$ & & 0.250 & $?$ \\
\hline Total. & & 0.270 & $?$ & $?$ & 3804.0 \\
\hline
\end{tabular}

The $0.270 \mathrm{lb}$. of protein are equivalent to $4.32 \mathrm{oz}$. of protein $(0.270 \times 16=4.32)$. It will thus be seen that the above menu furnishes enough calorific value and protein for a man engaged in moderately active muscular work (see Arts. 389 and 390$)$.

396. The Results of Eating too Much.-Many people consume more food than the body needs. No good can come from such a practice. The food in excess of 3500 or 4000 Cal. per day is not only unnecessary, but more than this, it interferes with the proper working of the body. The organs of excretion 
have an added and useless burden placed upon them. Physicians tell us to eat slowly, to chew the food until it becomes creamy in the mouth, and to let the act of swallowing be largely involuntary. By following this plan, the appetite is satisfied with less food and the danger of overeating is diminished. Half an hour should be used in eating a meal. The food should not be washed down, improperly chewed, by use of large draughts of water.

Many people partake too liberally of a protein diet. Having an appetite for meats they eat this kind of food to the exclusion of foods containing more carbohydrate. This is especially likely to happen with people who have the privilege of selecting from a large variety of foods, as at a hotel. Unless care is exercised, a selection will be made which is entirely too high in protein. The accompanying menu shows several meat courses, all of which are high in protein. Only one selection from the meat course should be made.

397. Choice of Food.-

\section{Exercise 80.-Selection of Articles from a Menu}

By means of your pencil, check the articles you would select from the menu given below and submit the menu to your teacher and classmates for criticism.

\section{DINNER}

Boston Clam Chowder

Green Shallots

Queen Olives

Consomme Colbert Sliced Cucumbers

Fried Silver Smelts, Chambord

Saratoga Chips

Boiled German Sausage with Potato Salad

Chicken Cutlets, Macedoine

Spaghetti, Milanaise

Roast Prime Rib of Beef, Pan Drip 
Roast Young Lamb, Currant Jelly

Lyonnaise Potatoes

Buttered Beets

Steamed Rice

Fruit Salad

Peach Pie

Banana Pudding Souffle

White Cake

Cherry Ice Cream

Navel Oranges

Vanilla Cream Pie Assorted Cookies

Royal Ann Cherries in Syrup

Stewed Peaches

Roquefort and American Cheese

Toasted Johnsburys

Japan Tea

Coffee

Postum Cereal

Questions on the Menu.-(1) How many kinds of meats are offered? (2) What food principles do the meats furnish chiefly? (3) What foods will furnish carbohydrates? (4) Should one order more than one meat dish? (5) Which articles in the menu are mere relishes without much food value? (6) Would you expect to make a meal from such? (7) Which articles are beverages without much food value? (8) Looking at the menu as a whole would you say that it furnishes enough protein? Enough fat? Enough carbohydrate? (It should be borne in mind that bread and butter which do not appear on the menu are furnished as a side dish with the dinner.) (9) Which food principle is one most likely to eat to excess unless his choice from the menu is made with some thought of food composition and food values? (10) A patron of the hotel feeling very hungry ordered smelts, roast beef, roast lamb, peach pie, Roquefort cheese and coffee. He ate very little bread and none of the vegetables served with the meat dishes. What was wrong with his choice?

\section{THE MANUFACTURE OF FOODS}

398. Many Foods now Prepared Outside the Home.-The art of preparing foods from the raw materials produced on the farm has almost disappeared from the home. Now we have great factories in which food is manufactured from the products of the farm. Some of the processes employed are 
very complex. Many foods are ready cooked when purchased at the store. Others require but slight cooking before they are brought to the table. Fresh fruits and vegetables are preserved in proper containers near the farm where they are grown and are then shipped long distances to be consumed when the fresh product is not in the market. Many foods are preserved by cold storage from a season of plenty to a season of scarcity. A part of the abundant egg crop of the spring is placed in cold storage to be sold in the winter when eggs are scarce.

\section{The Dairy Products}

399. Milk.-MILK is the food of the infant for the early months of his life. It contains all of the ingredients needed for the child. It is also largely used as food by adults. Milk should not be looked upon as a mere beverage. Its food value should be taken into account in the dietary. Milk is especially liable to become impure through the introduction of filth and germs in the dairy. It is an ideal breeding ground for bacteria and its production and handling should be done under the most sanitary conditions possible. Because milk contains so large a proportion of water ( 87 per cent.) it is sometimes made a more concentrated food by removal of a part of the water by evaporation. The resulting product, CONDENSED MILK, is sterilized and sealed in air-tight cans when it can be kept for a long time in a usable condition. Condensed milk contains about 27 per cent. of water. Often considerable sugar is added during the condensing process. Sometimes all of the water is evaporated from milk and the resulting MILK POWDER is used in the preparation of self-rising pancake flour. When water is added to the flour, the milk powder dissolves and the result is much the same as that obtained by adding milk to the flour. Condensed milk is used in the preparation of ice cream and candies.

400. The Percentage of Fat in Milk.-Whole milk ordinarily contains from 3 to 5 per cent. fat. Cream contains from 
18 to 45 per cent. fat. Much attention is given to the amount of fat in milk, and it is commonly supposed to be a safe guide in judging the quality of the milk. But it must be remembered that there are other food materials in milk besides fat. Milk also contains about 3.2 per cent. protein and 5 per cent. carbohydrate, MILK sUGAR (see Fig. 248). But in general, if the fat percentage is low, the other constituents are likely to be low also. But there is much food value in SкIм мILк. Skim milk contains the valuable protein. One might purchase skim milk and make up for the fat it lacks by purchasing a cheaper fat as oleomargarine. Most states and cities have laws fixing the lowest amount of fat that milk can contain to be sold as whole milk. These laws usually place the lowest limit at 3 per cent. or 3.5 per cent. of fat.

401. The Babcock Method of Determining Fat in Milk.The method of the test is as follows: A certain amount of milk is placed in a test bottle having a graduated neck. Concentrated sulphuric acid is then added to the milk and the mixture is well shaken. The sulphuric acid dissolves all of the constituents of the milk except the fat. The bottle and the mixture are then placed in the Babcock machine in which they are whirled at a high rate of speed. The fat, being the lighter, rises to the surface of the mixture in the bottle and by getting the fat into the graduated neck the percentage of fat may be read directly.

\section{Exercise 81.-The Babcock Test}

(1) Mix the milk to be tested by pouring it from one bottle to another several times. This mixes the cream with the remainder of the milk. (2) By means of a milk pipette (Fig. 250) draw 17.6 c.c. of the mixed milk and place it in an 8- or 10-per cent. milk bottle (Fig. 250). Do not insert the tip of the pipette so far into the milk bottle that the milk is spilled as the air escapes from the bottle. Draw out another 17.6 c.c. portion and place it in another bottle. (3) Place 17.5 c.c. of concentrated sulphuric acid in the acid measure (Fig. 250) using care to avoid spilling any of the acid on the hands or clothing. Now carefully pour the concentrated acid into the test bottle of milk containing the 17.6 c.c. of milk allowing the 
acid to run to the bottom of the bottle. Do not shake the acid and milk until the other bottle is prepared. Measure another 17.5 c.c.
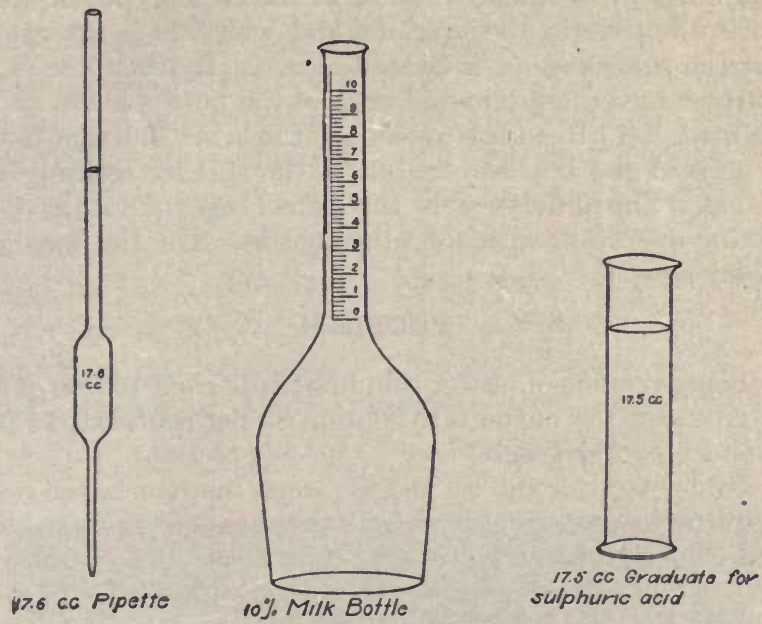

Fig. 250.

portion of the acid and pour it into the second bottle of measured milk. (4) Now carefully shake the bottles containing the milk and acid so as to mix thoroughly. Do not try to mix the liquids by placing the finger over the mouth of the test bottle or the finger will be burned. In shaking, be careful that the curd does not become lodged in the neck of the bottle. The mixture becomes very hot and it is to be kept hot during the entire test from this point on. The acid has now dissolved all of the constituents in the milk except the fat. The fat is now to be separated by use of the machine. (5) Have about a pint of water heating so it will be ready for use later on. (6) Place the test

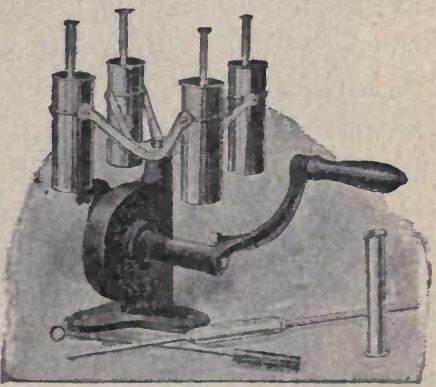

FIG. 251.-The centrifuge machine. bottles at opposite points in the centrifuge machine (Fig. 251) and place bottles filled with water in the other holders so as to balance the machine. Turn the handle of the machine at the rate of about 70 revolutions per minute for five minutes. Remove the test 
bottles and carefully fill them with boiling water until the liquid comes up near the top of the neck of the bottle. Be careful to avoid pouring in so much water that the fat runs out of the bottle. Return the bottles to the machine and whirl them for one minute more at the same rate as indicated above. By this process, the fat is all thrown into the graduated neck of the bottle where its amount may be read. (7) Read the upper and the lower limits of fat column in the neck of the bottles. Subtract the smaller reading from the larger one. The difference is the percentage of fat in the milk. Repeat the operation with the other bottle. Do the two percentages of fat agree?

\section{PROBLEM}

How many pounds of butter could be made from $100 \mathrm{lb}$. of the milk tested, provided the butter is to contain 85 per cent. fat, 13 per cent. water, and 2 per cent. salt?

If possible, test for fat by the Babcock method to see how completely the fat has been removed, milk that has been skimmed by hand. Also test milk that has been separated by means of a cream separator (see Arts. 617-621). For accurate work on the latter kind of milk, a skim-milk bottle should be used.

402. Butter.-When cream is allowed to "ripen" (Arts. 446 and 624) and is then agitated in a churn the fat gathers together in masses known as BUTTER. These masses of butter are gathered together, washed with water, worked to remove the excess of water, and then salted to impart an agreeable flavor. Churning is most quickly accomplished by having the temperature of the cream about 65 or $70^{\circ} \mathrm{F}$., but more solid butter, and butter of better grain or texture is obtained by churning at a lower temperature. The composition of butter is shown in Table XIV. According to a standard established by Congress, butter for interstate traffic must not contain more than 16 per cent. of water nor less than 82.5 per cent. of fat (see Fig. 249).

\section{Renovated or Process Butter.-Through careless} methods of handling milk and cream and carelessness in manufacturing butter, it sometimes happens that the butter is of inferior grade. Moreover, it may be held so long that it has become rancid and unfit for food. Such butter is renovated 
in specially constructed factories. The butter is melted and air is blown through the melted fat. This removes the disagreeable odors. The salt and many undesirable materials in the butter sink to the bottom of the vessel containing the melted fat. The purified fat is then drawn off and mixed with sweet milk, then it is churned, much as cream is churned. The product is sweet and resembles true butter in many respects. The manufacture and sale of RENOVATED, OR PROCESS BUTTER, is regulated by law. The law intends that the purchaser shall know that he is buying such an article and not true butter. All renovated butter must be properly labeled.

404. Butterine, or Oleomargarine.-Because of the high price of butter fat, various cheaper fats are sometimes used for the

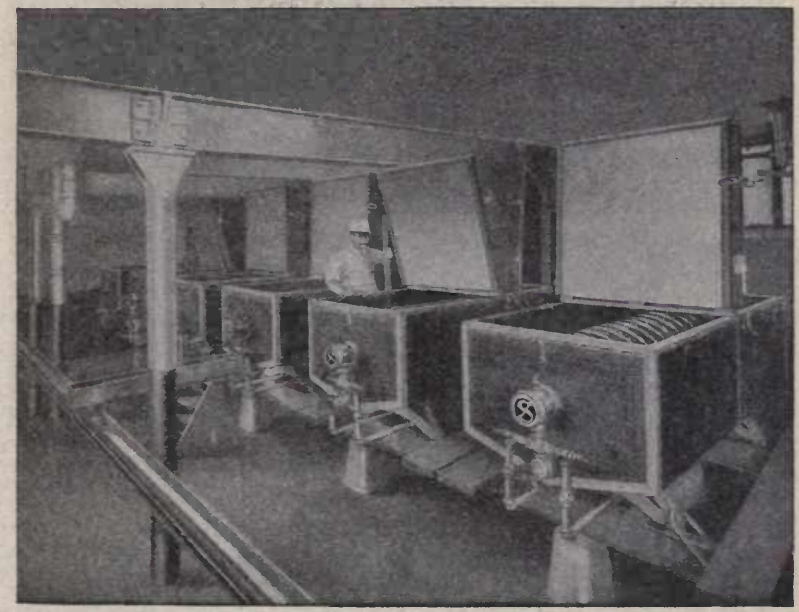

FIG. 252.-Ripeners for oleomargarine.

manufacture of substitutes for butter. These substitutes are called BUtTerine, or Oleomargarine. Butterine is a healthful and nutritious food and may be used instead of butter in the diet. Good butterine is better than poor butter. Because unscrupulous manufacturers and dealers in butterine have tried to sell their product as butter, the manufacture and sale of 
butterine is surrounded by many legal restrictions. Many grades of butterine are manufactured. In the best grades a considerable quantity of butter fat is used to impart a flavor of real butter to the product. In the cheaper grades very little butter fat is used. The fats used as substitutes for butter fat in butterine come from animals and from the cotton seed. One of the substituted fats is called Neutral. Neutral is made from the leaf lard of hogs by RENDERING (trying out) the material at a very low temperature and then EXPRESSING

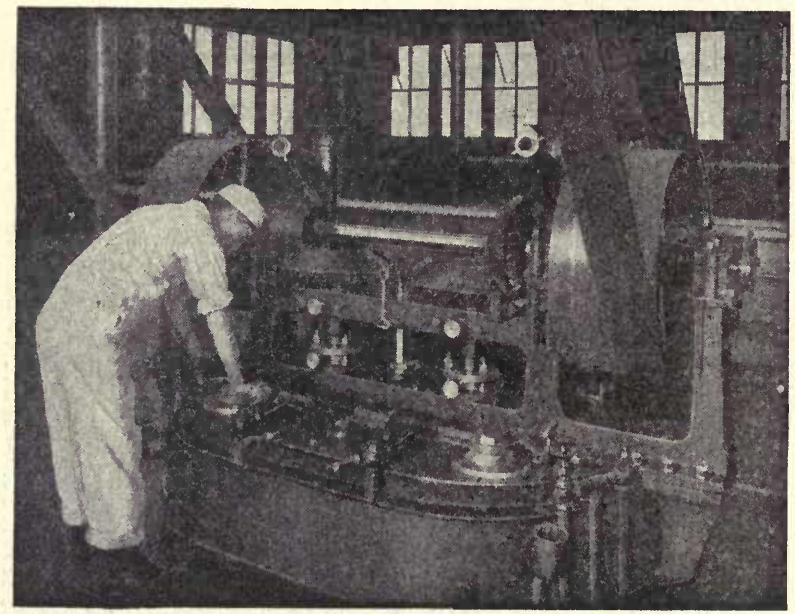

Fig. 253.-Churning oleomargarine.

(pressing out) the liquid fat from the tissues. It is without odor and taste. Another substituted fat is called OLEO OIL. This oil is expressed from the fat of cattle. These animal oils are prepared from animals which have been inspected by United States inspectors and passed. They are prepared in a sanitary manner and are wholesome articles of food (Art. 410). Cotton seed oil products (Art.412) are sometimes used in butterine in addition to the fats mentioned. Such amounts of these fats are used as will give with the butter fat a mixture resembling true butter. The cream in the milk is RIPENED (Fig. 252) 
as for the ordinary methods of churning. The proper amounts of neutral, oleo oil, and cotton seed oil product are then mixed with the ripened cream and the mixture is churned (Fig. 253). The fats gather much as true butter gathers. They are re-

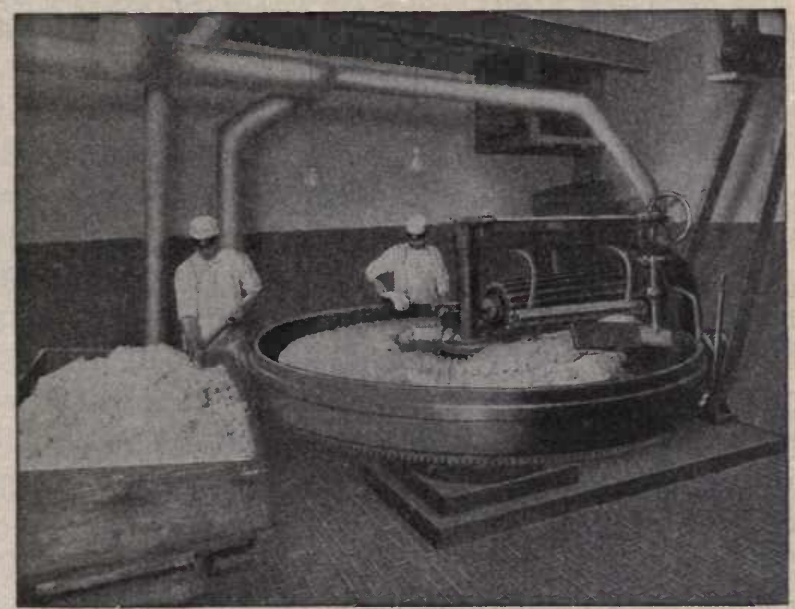

FIG. 254.-Working oleomargarine.

moved from the milk and worked and salted as in the case of butter (Fig. 254). Uncolored butterine is taxed $1 / 4 \mathrm{ct}$. per $\mathrm{lb}$. If the butterine is colored so that it resembles butter, an additional tax of 10 cts. per $1 \mathrm{~b}$. is levied by the Federal government.

\section{Exercise 82.-The Foam Test for Butterine and Butter}

Place a lump of butterine in a tablespoon and heat it over a flame until it melts (Fig. 255). Continue the heating, noticing the absence of foam and sputtering. Now treat a lump of butter in like manner and notice the foaming and sputtering which accompany the escape of water from the butter. By this test,

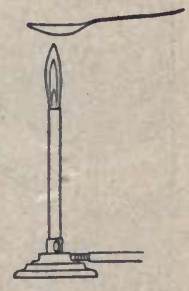

FiG. 255.Foam test for butterine and butter. it is easy to distinguish butterine and butter. If obtainable, test some renovated butter in the same manner. Renovated butter behaves in a manner similar to that of butterine. 
405. Cheese.-Both cheese and butter have been used by pastoral people for ages. Abraham set butter and milk before his guests. When a lad, David was sent by his father with cheeses for the captain of the company in which his brothers were serving in the army of Israel. Cheese is the fermented cURD of milk. When milk sours, the CASEIN (curd) of the milk separates from the watery portion called the wHEY. The curd contains nearly all of the food substance in the milk except the sugar. The curd may also be produced by adding RENNET to the milk. Rennet is extracted from the stomachs of calves. The curd is separated from the whey and then pressed to remove as much of the fluid substance as possible. The pressed material is then allowed to ripen in a properly prepared room. During the ripening process the different constituents of the curd undergo certain chemical changes, largely caused by bacteria, producing the flavor and odor of cheese. If the cheese is made from whole milk the product is called FULL CREAM ChEESE. The composition of this kind of cheese is given in Table XIV. It will be noticed that cheese still contains a considerable amount of water but much less than whole milk (Fig. 256). In a sense then, cheese may be looked upon as a sort of condensed-milk product. In some cases, the valuable milk fat is removed from the milk

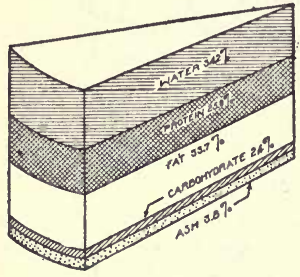

FIG. 256.-Composition of cheese. before making cheese. In this case cheaper animal or vegetable fats, as neutral and cotton seed oil products, are put in to compensate for the milk fat removed. Such cheese is known as FILLED CHEESE. Its manufacture is regulated by law as in the case of butterine, and the consumer is supposed to be informed that he is buying filled and not full cream cheese. When good fats are used as substitutes for the milk fat, filled cheese is wholesome and nutritious. 


\section{Meat Foods}

406. Importance of Meat in the Diet.-Meats are eaten for the protein and fat which they contain. As we have seen, fat is useful to the body as a producer of energy, while protein is needed for its nitrogen. That protein may be obtained from vegetable substances there can be no doubt. 'Some people eat no meat whatever, obtaining all their protein and fat from vegetable substances. It is a much debated question whether we can get along just as well without meat. But there can be very little question whether, as a nation, we do not eat too much meat. It is doubtless true that most of us could get along quite as well if we were to eat less meat and more vegetable foods, such as grains and vegetables.

407. Meat Rapidly Deteriorates When Stored.-The fat and protein compounds of meat undergo changes rapidly when they are kept. On the other hand, the food substance stored in the grains may be kept for a considerable length of time without damage. For this reason meats must be consumed soon after the animals are slaughtered. In order to prevent decay several methods are used.

408. Preserving Meat by Cold Storage.-When the freshly prepared meat is placed in cold storage (Chap. III, Sec. III), the rate of decay is greatly lessened. However, changes do take place in the meat, rendering it less fit for food. Refrigeration during shipment is very useful as a means of transporting meat from the packer to the dealer and to the consumer. Fresh meat should not be exposed for sale in the open air. It should be kept cool and free from dirt until it reaches the consumer. By freezing fresh meat it has been possible to preserve it for months with apparently very little change in the product. But the aim should not be to see how long meat may be kept, but rather to deliver it to the consumer as soon as possible after the animal is killed.

409. Preservation of Meat by Use of Salt and Other Chemicals. - When fresh meat is immersed in a strong brine, 
the meat is preserved from decay. Such treatment is known as pickling. Often other preservatives than salt are used. Saltpeter is often employed. It is not known that salt and saltpeter injure the meat in any way. But other and poisonous materials are sometimes used. These include borax, boric acid, sulphurous acid, and sulphites. They are powerful

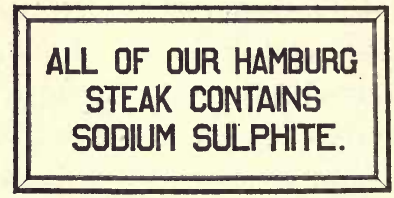

FIG. 257.-Sign in a meat market. preservatives, and when taken in large amounts with the food are injurious to the health. Sulphurous acid and sulphites also impart a red color to the meat, thus causing it to appear fresh. Chopped meats are often treated with sulphites to prevent decay and to keep the meat red. Many states have laws which limit the amount of such preservatives that may be used and also provide that the purchaser shall be informed, of the presence of the chemical in the meat (Fig. 257). In this latter respect the law is often disobeyed.

410. Meat Inspection.-At all establishments at which animals are slaughtered for food which is to be shipped from one state to another, the United States Government stations officers whose duty it is to inspect all animals that are to be slaughtered and also to inspect the meat produced to see that it is fit for human food. Diseased animals are condemned and destroyed so as not to be used for food purposes. Food that is passed by the inspectors is marked "U. S. INSPECTED AND PASSED." The United States inspectors work in conjunction with state and city food inspectors and thus largely prevent the coming on the market of meat unfit for human consumption.

411. Lard and Lard Substitutes.-When the fat of the hog is rendered, LARD is obtained. Because of its rather high price lard is frequently adulterated with cheaper fats, beef tallow and cotton seed oil being used for the purpose. Such mixtures are highly nutritious. They must be sold, however, as a COMPOUND LARD. 
412. Cotton Seed Oil.-Since cotTon SEED oIL has been mentioned so frequently in the foregoing discussion, it is proper that it should be discussed here, although it is a vegetable and not an animal product. The seed of the cotton plant is rich in fat. For each bale of cotton weighing $500 \mathrm{lbs}$., about $1000 \mathrm{lb}$. of seed are produced. About 6,000,000 tons of cotton seed are produced annually in the United States, two-thirds of which is worked to produce oil. This gives an annual production of about $125,000,000$ gals. of oil, more than 1 gal. per capita. After the cotton lint has been removed from the seeds, the hulls are taken off and the pulp pressed to liberate the oil. The oil is further refined and finds use in butter and lard substitutes, as a salad oil, in packing sardines, and in soap making. The pulp from which about 85 per cent. of the oil has been expressed is then broken into small pieces and used as stock feed. The use of this vegetable oil takes the place of much animal fat. Its nutritive value is equal to that of the animal fats.

\section{The Cereal Foods}

413. The Cereals That are Used for Food.-Wheat, corn, oats, rye, rice, barley, and buckwheat are commonly used as foods. The cereals contain large amounts of starch and smaller amounts of fat and protein. They are the chief sources of the starchy foods, and for great numbers of the human race they furnish the chief source of protein. The use of the cereals as food will doubtless increase in importance as meats become less abundant and higher in price.

414. Wheat.-This is the cerreal that is most extensively used as human food. It grows in many parts of the world. In North America, wheat is known as WINTER or SPRING WHEAT according to whether it is sowed in the fall and allowed to lie in the field through the winter or whether it is sowed in the spring of the year in which it is to be harvested. Winter wheat can not be grown in the northern climates because of 
the cold winters. These regions grow only spring wheat. This cereal is rich in protein, containing about 12 or 13 per

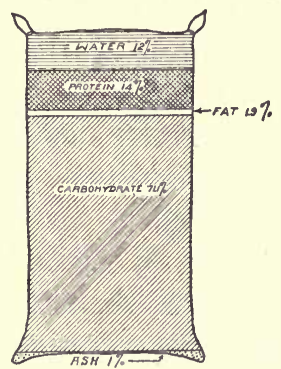

Fig. 258.-Composition of wheat flour. cent. It is poor in fat, but rich in carbohydrate.

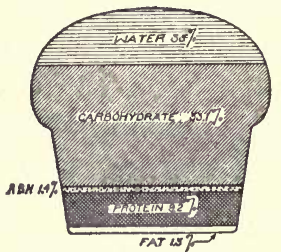

FIG. 259.-Composition of wheat bread.

415. Wheat Flour.-The wheat is ground between revolving rollers to extreme fineness. The ground material is then sifted through very fine bolting cloth which grades the ground material into several grades. These grades may be classified as PATENT FLOUR, BAKER'S FLOUR, and LOW-GRADE FLOUR. Beside these different grades of flour the wheat also produces BRAN, SHORTS, and screENINGS. To produce a 48-lb. sack of patent flour requires nearly $83 \mathrm{lb}$. of wheat, or about $1.4 \mathrm{bu}$. (Fig. 258). Besides the patent flour, about $9.3 \mathrm{lb}$. of baker's flour and $5.6 \mathrm{lb}$. of low-grade flour are produced. The remainder of the $83 \mathrm{lb}$. of wheat appears as bran, shorts, screenings and waste (Fig. 259).

416. Graham Flour.-True GRAHAM FLOUR is made by grinding the entire grain without bolting. It, therefore, has the same composition as wheat. Most of the graham flour that is produced at present is bolted, so that much of the bran covering of the grain is removed.

417. Whole or Entire Wheat Flour.-This name is applied to a flour produced by removing the bran covering of the grain and grinding. It, therefore, has about the same composition as the so-called graham flour.

418. Gluten.-GLuten is the name given to two of the important proteins in flour. It is the material which gives to 
the flour its sticky character when wet. Without the gluten in the flour, bread, as we know it, could not be made. The gluten is insoluble in water and helps the flour to make a dough when wet. The starch and fat in the flour may be washed away from the gluten.

\section{Exercise 83.-Preparation of Gluten from Flour}

Weigh 30 grams of flour and wet it with just enough water to make a stiff dough. Be careful to incorporate all of the flour into the dough. Now place the dough in a bag of cheese cloth and allow a stream of water to run upon the outside of the bag while the dough is kneaded with the fingers. In this manner the starch and fat are washed out of the dough leaving the gluten behind. Continue until no more starch appears in the stream of water (test for starch, Art. 387, Ex. 77, (3)). Remove the gluten from the bag, press it into a flat cake to remove as much water as possible and then place it in a warm (not hot) oven to dry, or place the cake on a steam radiator. When it has dried for a few hours weigh the cake and calculate the percentage of gluten in the flour.

419. Shredded Wheat.-This is a whole wheat preparation, cooked and ready to serve. It is one of the common wheat breakfast foods. The wheat is thoroughly cleaned and is then steam cooked until soft. The excess of water is then dried from the wheat and it is put into machines which crush the grains and form them into shreds which are delivered to an endless belt. The shreds are here cut into lengths to form the biscuits. These biscuits are then placed on trays and baked in electric ovens. Subsequently the crisp biscuits are packed in cartons and sealed. The wheat food is made light entirely by mechanical means, no yeast or other leaven being used in the process. The finished product has nearly the same composition as the wheat from which it is made.

420. Corn; Its Use as Human Food.-This cereal is more largely produced in the United States than is wheat. Corn contains the same food principles as wheat does. It contains more fat, however, and somewhat less protein. The proteins of corn do not include very much gluten. For this reason, corn flour has not been used to a very great extent, even in the United States, for bread. Moreover, the high percent- 
age of fat in whole corn meal causes the meal or flour to become rancid in warm weather and hence unfit for food. Besides the corn consumed as flour, there is much of it worked up into breakfast foods, while a still larger part of the grain is carried through various chemical transformations for the making of starch, corn syrup, alcohol, and vinegar. There is every reason for believing that corn food products will be more extensively used in the future. But by far the largest part of the corn crop of this country is now consumed on the farm as stock feed. From it, are produced the various animal products so useful to man, including beef, pork, and dairy products. Food for man thus produced indirectly from corn, is much more expensive than when corn is used directly as food.

421. Corn Flakes.-The well-known corn flakes represent a successful attempt to produce a food from the corn which is at once palatable and nutritious. The operation of making corn flakes begins with the hominy, or corn grit, mills which are usually located in the "Corn Belt" of our country. Here the shelled corn is steeped in water until it is soft. It is then put through mills which loosen the germ and the skin which are removed from the remainder of the grain. The germ contains nearly all of the fat of the grain and much of the protein. The germs and skins are made into cattle feed, much being consumed on dairy farms. The hominy, or grits, of the corn are dried and shipped to the flaking mill. Here the grits are steam cooked until soft; then the cooked material is put through flaking machines which convert the grits into flakes as thin as paper. The flakes are then toasted in great gasheated ovens and packed in air-tight packages while crisp. In this condition they are delivered to the consumer. Large quantities of corn are thus flaked and find their way to the breakfast tables of American homes.

422. Corn Starch.-Most of the starch used in the United States is prepared from corn, although wheat and potatoes are also used to a limited extent. In Europe, the potato is extensively used. Corn contains about 55 per cent. starch, while 
the potato contains about 18 per cent. However, an acre of land in Europe planted to potatoes can be made to yield a larger amount of starch than an acre of corn. About 50,000,$000 \mathrm{bu}$. of corn are annually converted into starch and allied products in the United States, which represents, however, but one-fiftieth of the annual production.

423. Preparation of Corn Starch.-The shelled corn is steeped for three or four days in great tanks containing water and sulphur dioxide. This serves to loosen the skin and the germ. The soaked corn is then gently ground in mills which crush the grain, loosening the skin and germ from the part of the grain containing most of the starch. The ground material is then placed in tanks containing water in which the germs float because of the oil which they contain while the starch and skin sink. The germs are dried, ground, and pressed in filter presses, thus removing the oil. Corn oil has many uses as human food. The cake remaining after removal of the oil is called OIL CAKE. It is ground and largely used as stock feed. The starch and skins are re-ground and then put through the shakers which separate the starch from the skins. The skins, or bran, are again ground and again treated to remove the remainder of the starch. The starch suspended in water is then run into long troughs, inclined at a gentle slope. As the starch water flows through the troughs, the starch settles, while the gluten and water flow out at the end of the trough. The gluten is removed from the water, dried, ground, and marketed as GLUTEN MEAL which is used for stock feed. The accumulated starch in the troughs is removed, dried, pressed, and made into lump starch. The product still contains from 12 to 15 per cent. moisture.

424. Glucose.-Much starch is converted into syrups and sugar known as GLUCOSE SYRUP, Or CORN SYRUP, and GRAPE SUGAR. Corn syrup is very extensively used as a food. It is sweet, but less sweet than ordinary sugar. It is without flavor and consequently the table syrups are frequently prepared by blending corn syrup and cane sugar, or REFINER's 
sYRuP, the latter imparting a pleasing flavor. A popular brand of corn syrup also contains vanilla flavor.

Commercial glucose is composed of the following carbohydrates: DeXTrose; MALTOSE; and DEXTRIN (Art. 386). Dextrose is one of the constituents of honey; maltose, or malt sugar is formed when certain grains sprout; while dextrin is the adhesive commonly used on postage stamps. Each of these materials has a nutritive value equal to that of ordinary sugar. These materials are prepared from starch by the action of dilute acids upon starch.

425. Preparation and Uses of Glucose.-The starch used in the preparation of glucose is obtained as already described

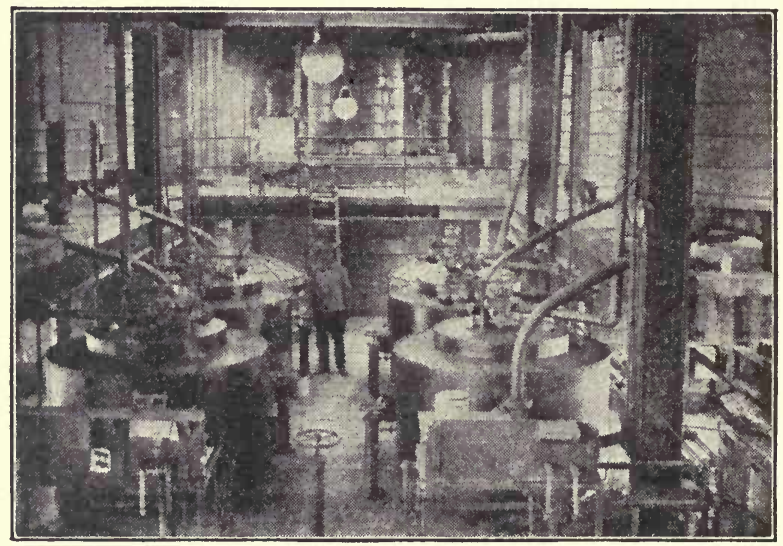

FIG. 260.-Manufacture of glucose. Shows the tops of the copper converters and the working floor around them, also the neutralizers on the balcony just above and surrounding the converter floor.

except that it is not dried after it has been collected in the troughs. The wet material "green starch" is mixed with water to make a thick, creamy liquid, and then it is mixed with the proper amount of hydrochloric acid for the change; the mixture is then run into a CONVERTER where the transformation of starch into glucose takes place (Fig. 260). In the converter the mixture is subjected to a steam pressure of $50 \mathrm{lbs}$. 
What temperature does this correspond to (see Steam Tables, Art. 155)? Under these conditions the conversion is rapid. When the starch has disappeared, the liquid is blown by the steam pressure into the NEUTRALIZER (Fig. 260) where soda is added to neutralize the acid used in the conversion. The neutralization forms salt as one product of the chemical reaction. The salt remains in solution in the glucose, but there is so little of it that it is not noticed in the final product. After neutralization the liquid, which is cloudy because of impurities, is filtered, first, through great suspended bags called bag filters, then through BONE CHAR. Bone char, as its name indicates is made by charring bones. When liquid is filtered through the bone char, the impurities are absorbed into the pores of the char while the clear liquid runs on through. The bone-char filters are great tanks filled with the char, and through the char, the liquid is forced. The glucose liquid comes from the filter, bright and clear, but much thinner than the syrup used on the table. The liquid is next concentrated by evaporating a part of the water in EVAPORATORs. Here evaporation is carried out at a low temperature so as to prevent the darkening of the syrup. Evaporation at a low temperature is accomplished by reducing the pressure of the steam within the evaporator. (See Art. 155 for corresponding temperatures and pressures.) After the required amount of evaporation, the liquid is placed in barrels and cans for delivery to the consumer. Grape sugar is made by evaporating the syrup still further and subsequently crystallizing the sugar.

Aside from its use as a table syrup, glucose is used in making jellies, preserves, and candy. Large quantities are used for the last-named purpose. Many medicines contain glucose syrup as body.

426. Sugar.-Sugar is one of the most widely used foods. There are but few manufactured foods found in the markets which are as nearly pure as sugar. While the term "sugar" is usually taken to mean the common article of food of the table, it will be remembered that there are several kinds of 
sugar (Art. 386). Sucrose is the sugar meant as we commonly use the term. Sucrose is found in nature in the sugar cane, in the sorghum plant, in the sugar beet, in the sugar maple, and in certain kinds of palms. When puré sucrose is obtained from any one of these sources it is found to be like that from any of the other sources. Pure sucrose from the cane is the same as that from the beet. There is a popular prejudice against beet sugar. Many people think it inferior to cane sugar. They are equally nutritious. Maple sugar is prized because of its peculiar flavor. But when maple sugar is entirely purified and its sucrose extracted it is the same as sucrose from the cane or the beet. Nearly all of the sugar of commerce is derived from the cane and the beet. The sugar beet grows in temperate climates while the cane is limited to the tropical or semi-tropical countries.

427. Preparation of Sugar from Cane.-The sugar cane contains about 14.5 per cent. sucrose of which less than 90 per cent. is usually extracted. The cane is stripped of its leaves, cut, and carried to the mill where it is run between great rolls in which the cane is crushed and the juice containing the sugar is squeezed out. Water is applied to the crushed cane to remove more of the sugar. The crushed cane is finally burned beneath the boilers of the mill for the generation of steam for power. The juice is strained and then treated with lime. Upon being heated a scum arises on the juice. This scum is removed and the purified juice is then evaporated in vacuum evaporators as in the manufacture of glucose. The sugar solution is evaporated until crystallization of sugar begins when it is run into tanks where it is stirred until the crystallization is complete. The crystals are then separated from the syrup or molasses. The latter finds extensive use in the baking industry and in making stock feed. The sugar, known as RAW SUGAR in commerce, is then shipped to the refinery to be converted into the article which we know.

428. Preparation of Sugar from Beets.-Sugar beets contain from 14 to 17 per cent. sucrose. The beets are harvested 
and the tops removed. After being carried to the factory they are washed and sliced in thin slices. The sliced beets are placed in a series of great tanks called DIFFusers, which we shall call, in turn, $A, B, C, D$, and $E$. Fresh water is fed into the top of $A$ and as it passes down through the slices the sugar is extracted. Emerging from the bottom of $A$, the solution is next fed into the top of $B$. As it passes through the slices in $B$, it dissolves more sugar, but removes relatively less sugar than was removed in $A$. Thus the solution is led, in the same manner, through $C, D$, and $E$, each time becoming a more concentrated solution of sugar, but removing, relatively, less and less sugar from the slices in each diffuser in turn. Finally as it emerges from $E$, the solution is almost as concentrated in sugar as is the natural juice contained in the slices in $E$. The solution is then purified and the sugar extracted.

Meanwhile, the continuous passage of water through $A$ has removed as much sugar from the slices as it is profitable to remove. The exhausted slices in $A$ are then removed, and $A$ is refilled with fresh slices and it is then placed next in series after $E$. Fresh water is then fed into $B$. From $B$ the solution passes in turn through $C, D, E$, and $A$. The solution from $A$ is purified and the sugar extracted. Meanwhile the sugar has been quite completely removed from the slices in $B$. Its contents are emptied and it is refilled with fresh slices and placed next after $A$ in series. Fresh water is then fed into $C$, passing, in turn, through $D, E, A$, and $B$. The solution from $B$ is then purified and the sugar extracted. So the process is a continuous one. In this manner the maximum quantity of sugar is removed from the sliced beets by means of the minimum quantity of water.

In beet sugar factories the raw sugar is refined in the one establishment, whereas cane sugar is usually refined in other factories than those that produce the raw sugar.

429. Sugar Refining. - In the process of refining sugar, the raw sugar is dissolved in water and the syrup is then purified 
by means of lime and acid, after which the syrup is filtered through bag filters and then through bone char for clarification. The clarification is similar to that used in glucose. The purified syrup is then evaporated in vacuum evaporators until it crystallizes. The crystals are separated from the syrup and later they are dried in a machine called a granulator in which the crystals are separated from one another. By pressing the moist crystals in a mold the loaf sugar is made. The cubes are later dried.

\section{THE COST OF FOOD}

430. The Cost of Food.-The price paid by the consumer for his food is determined not only by the actual cost of production on the farm, but also by the cost of transporting the food from the farm to the consumer, the cost of manufacture, including milling, packing, and other processes, and the cost of distribution, including retailer's and middlemen's profits and advertising. In purchasing the food, the consumer

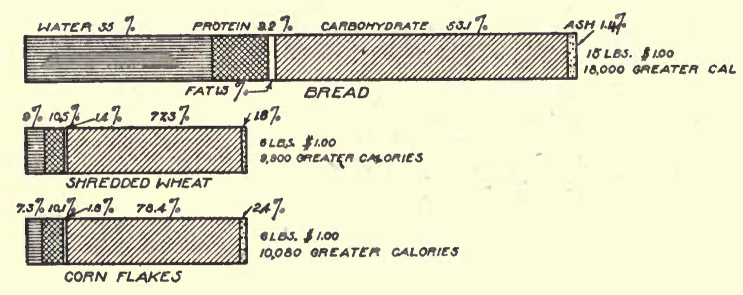

FIG. 261.-The cost of different foods.

needs to have a general knowledge of the composition of the food, and the nutritive value of the food constituents. Water is a common constituent of foods and should be considered in counting the cost of the food. Thus eggs contain 65 per cent. of water, milk, 87 per cent. and beef about 60 per cent. The proportions of other constituents of the food must also be considered. Cane sugar contains 100 per cent. carbohydrate and ordinarily sells for about 5 cts. per lb. Potatoes contain about 18 per cent. carbohydrate and ordınarily sell. 
for about 1 ct. per lb. (60 cts. for a bushel of $60 \mathrm{lb}$.). Carbohydrate of potatoes will, therefore, cost $5.5 \mathrm{cts}$. per lb. at this rate. Moreover, the potato must be cooked and this adds to the cost of the food, while the sugar does not require cooking. There is waste in preparing the potato for the table while there need be no waste of the sugar. However, the potato contains slightly more than 2 per cent. protein while the sugar contains none. This, of course, adds to the value of the potato.

The preceding diagram, Fig. 261, represents the relative amounts of three foods, cooked and prepared for the table, that $\$ 1.00$ will buy. The heat value of the foods is also represented.

\section{Exercise 84.- Representing the Cost of Certain Foods}

From the grocer ascertain the cost per pound of corn meal, of oat meal, of rice and of wheat flour. Calculate the weights of each of these foodstuffs that may be purchased for $\$ 1.00$ and represent these weights by rectangles. Thus, if $\$ 1.00$ will buy $33 \mathrm{lb}$. of wheat flour, use a centimeter ruler and let each centimeter represent $5 \mathrm{lb}$. This will call for a line $6.6 \mathrm{~cm}$. long. Lay off a horizontal line of that length and construct on it a narrow rectangle. In like manner represent the weights of the other foodstuffs that $\$ 1.00$ will buy. Find the composition of each of these foodstuffs in Table XIV on page 353 , and represent the proportion of each food principle in each of the five foodstuffs selected, shading as in Fig. 261. Also calculate the number of heat units produced by each lot. Finally label each diagram neatly.

Represent the weight of protein that $\$ 1.00$ will buy in eggs, in whole milk, in cheese, in round steak, in oat meal, and in wheat flour using the market prices of these commodities and Table XIV, Composition of Foods. Use the weight of eggs determined in Ex. 79, and consider that a pint of milk weighs a pound. Shade and label these diagrams neatly. 


\section{CHAPTER VIII}

\section{MICROÖRGANISMS}

431. Microörganisms. - We have seen in the last chapter (Arts. 377 to 380 ) that every living thing, whether animal or plant, requires energy with which to carry on its life processes. We have seen also that energy is derived directly by living organisms only from certain very complex chemical compounds which we call foods. Again, we have seen that the only living organisms which have the power of manufacturing these foods out of the relatively simple materials found in the soil and air are the green plants (Art. 380). Every substance in the world which is capable of serving as energy-giving food for a living organism has derived its energy-giving power either directly or indirectly from a green plant. Thus, the green plants are the food makers of the world and all other organisms are dependent on them for nourishment. Since this is true, it is easily seen that all animals and all non-green plants, such as molds, yeasts, and bacteria must be constantly competing with each other for possession of the food that comes either directly or indirectly from the green plants. Every one is familiar with the fact that animals in general consume essentially the same kinds of food as man does. Corn, wheat, and oats are food for the lower animals as well as for man. Birds, mice, insects, and other wild animals do not hesitate to help themselves to the food that man has provided for himself and for his domestic animals.

432. Plants That Attack Our Foods.-People in general, however, are not so familiar with the fact that the worst competitors which man has for possession of the food which he wishes to preserve, are the non-green plants. We are all 380 
familiar with the result of the action of these organisms on our food and other materials, but we are likely to overlook the agents of this destruction and to say that the food decays or spoils. The reason that we do not recognize these plant competitors as well as our animal competitors lies in the fact that most of the former are so small as to escape our notice unless we make a special study of them. Most of these nongreen plants are so small that they can be seen only with the aid of a microscope. For this reason, they are conveniently grouped together with a host of microscopic animals under the general name, MICROöRGANISMs.

In Sec. I of the present chapter, we shall make a study of these plant microörganisms and of the methods which have been devised to enable man to ward off the attacks which they make on the food and other materials which he wishes to preserve. We shall learn also that, aside from the consumption of materials which man wishes to preserve, these organisms render man a very valuable service by consuming materials which are worthless to him and changing them into forms which are available again as raw materials for the green plants. We shall see that the fertility of the soil which means so much to man and to all the rest of the living world is largely dependent on the action of these organisms.

433. Saprophytes and Parasites. - In Sec. II of the present chapter, we shall see that some of these microörganisms find their food in the living bodies of man and other animals and of the higher plants. Organisms which thus live and find their nourishment in the living bodies of other organisms are known as PARASITES. Many animals can live only within or on the bodies of other living animals and are therefore ANIMAL PARASITES. We shall be concerned here, however, mainly with the PLANT PARASITES. Fortunately, the vast majority of the plant microörganisms can not live in the bodies of other organisms and are therefore detrimental to man's interests, if at all, only because they consume food and other materials which he wishes to preserve. We say "other materials" here 
because some of these organisms are able to nourish themselves on many materials which are not food for man. Plant organisms which are thus able to nourish themselves on the nonliving bodies or products of animals and plants are known as SAPROPHYTES. We have no special name for animals which feed on like materials.

\section{SAPROPHYTES-PLANTS WHICH LIVE UPON DEAD ORGANIC MATTER}

434. Plant Relationships. - It is a fact known to botanists that the different kinds of plants which we see on the earth today are actually related to one another much as the different individuals of a human family are related. That is, the different kinds of plants which we see today and which we commonly call species have all descended from a common ancestry and therefore actually have "blood relationship," as we say. In the long ages which have passed since life began on the earth, plants have tended to vary in every possible direction and there have come to be many thousands of different kinds; or species, of plants. Some of these species resemble one another closely and are, therefore, closely related, while others differ widely in their makeup. For convenience in the study of plants, botanists have attempted to classify them according to their actual relationships into groups of different sizes. Thus, species that are closely related are put together into groups called GENERA; the genera are combined into FAMILIES, and the families are combined into larger groups. The plants with which we shall be concerned in the present chapter may, for our purposes, be grouped into three of these larger groups. These groups are BACTERIA, YEASTS, and MOLDS.

435. Classification of Plants.-In classifying plants into these larger groups, botanists rely mainly on the characters which they show in connection with the process of reproduction. Thus, the bacteria reproduce only by CELL DIVISION. Each bacterium consists of only a single cell and reproduction is accomplished by the single cell's dividing equally into two. 
Since this is the only method of reproduction possessed by bacteria, they are often called FISsion FUNGI (Fig. 262). All non-green plants whose bodies are not differentiated into root, stem, and leaves are known as FUNGr (singular, fungus).

The characteristic method of reproduction possessed by the yeasts is known as BUDDING (Fig. 263). A yeast plant, like a bacterium, consists also of a single cell but it does not reproduce by dividing this cell into two equal parts. Instead of this, a small bud begins to grow on one side of the original cell and,

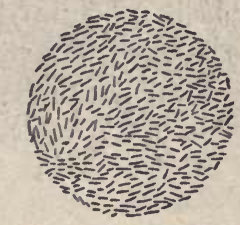

Frg. 262.-Bacteria.

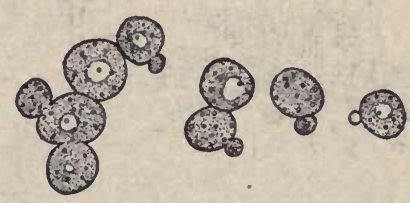

FIG. 263.-Yeast cells.

after it has attained some size, cuts itself off from the parent cell. A single yeast plant may give rise to several offspring in this way, whereas a single bacterium can give rise to but two immediate offspring and neither of these can be regarded as the parent of the other. On account of the method of reproduction found among the yeasts, they are often called BUDDING FUNGI.

The characteristic method of reproduction among the molds is by means of spores (Fig. 264). The plant body of a mold generally consists of several or many cells and certain portions of this plant body produce great numbers of very small ovalshaped cells which are called spores. These spores are capable of growing into mold plants like the ones that produced them whenever they are surrounded by suitable conditions. A study of different kinds of molds will reveal the fact that they do not all produce their spores in just the same way, and that their plant bodies differ widely in important features. In fact the plants which we shall here group under the general name MoLD belong to several distinct groups of fungi, and so they do not 
constitute a well-defined scientific group of plants like those of bacteria and yeasts. We are using this name for the group of plants which we propose to study, because it is commonly applied to them by people who are not botanists and because a more scientific classification of them would lead us into needless difficulties.

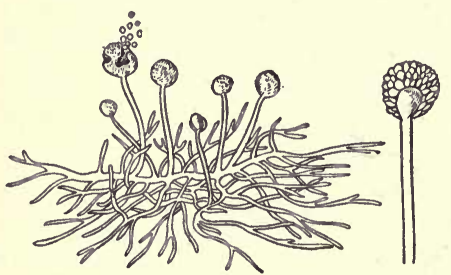

A.

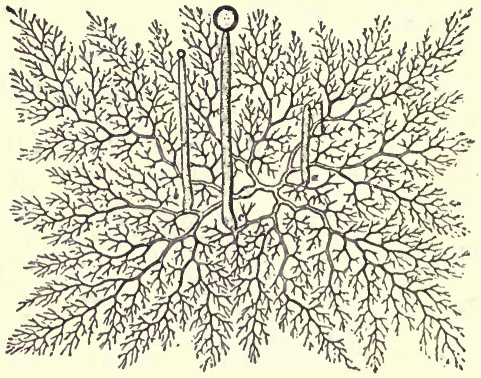

$B$

FIg. 264.-Mold-mucor. $B$ shows a diagrammatic representation of mucor, showing the profusely branching mycelium, and three vertical hyphæ (sporophores), sporangia forming on $b$ and $c$.

\section{MoLds}

\section{Study of Molds.-}

\section{Exercise 85.-I. Growing Molds}

Soak several pieces of bread in water until they become saturated, and then place them in enclosed vessels of some kind where they will remain moist. Set the vessels in a warm place and observe daily for the growth of mold on the bread. When the mold first begins to grow on the bread, it will appear as a soft, white, felty mass over the surface of the bread or extending up from the surface resembling a piece of very light gray fur. After a day or two, the mold will begin to show some color. It may be pink, green, brown, black, blue, or almost any color, depending on the kind of mold that you chance to get. The plant body of the mold is always of the whitishgray color that appears first. The color, which appears later and which helps us to distinguish the different kinds of mold is, in the spores.

\section{Collecting Molds}

Search the garbage can at home, the fruit and vegetable cellar, and the back yards of grocery stores for molds growing on decaying fruits and vegetables. Almost any decaying object of this kind is 
likely to contain mold, whether the mold is apparent on the exterior or not. Place the material collected in this way in moist, enclosed vessels for further growth of the mold. Transfer some of the spores from the different kinds of mold that you collect to fresh pieces of soaked bread and thus raise as many kinds of mold as you can on the bread. Note how rapidly the mold grows and how soon a new growth produces spores. Can you suggest some reasons why molds are able to grow so rapidly? Considering the fact that molds can grow only when supplied with an abundance of moisture, do you see that it is essential to the success of molds that they be able to grow rapidly and come to fruit in a short time?

\section{Exercise 86.-Study of Molds under a Microscope}

When you have a good collection of different kinds of molds, make a comparative study of them under the microscope. You will observe that the plant body consists of numerous very small and, usually, very much branched threads. These threads are called HYPHA (singular, hypha) and the whole network formed by the branching hyphæ is called the MYcELIUM. In some molds, you will note that the hyphæ are broken up into distinct cells by numerous cross walls, while in others these cross walls are missing and the whole hypha is one continuous tube-like structure. If you study under the microscope a very small piece of the pulp of a badly decayed apple or banana which shows some signs of mold on the exterior, you will find that the mycelium of the mold has completely permeated the pulp of the fruit.

437. Digestion by Molds. - We know that food generally needs to be digested before it becomes available as nourishment for a living organism and we know something of the nature of digestion. Molds digest their food in essentially the same way as animals do but they have no organ like a stomach or alimentary tract in which this process is carried on. The molds secrete their digestive enzymes and permit them to diffuse out into the material in which they are growing much as the glands in the walls of our stomachs produce the gastric juice, and permit it to diffuse out into the stomach. In like manner, the molds absorb and assimilate the food which their enzymes digest in the material about them much as the walls of our stomachs absorb some of the food that is digested within it. 
Thus, when we say that molds have caused an apple to decay, we might describe more specifically what happens if we were to say that the molds have digested and absorbed and grown on the foods contained in the apple. We can not say that the mold eats the apple for as we commonly use that term, it involves chewing and swallowing and this the mold does not do. In the light of this discussion of the way in which a mold gets its food, can you suggest how it is that the delicate hyphæ of the mold are able to make their way through the solid pulp of an apple?

438. Methods of Spore Production.-After you have studied the mycelium of a given mold under the microscope, mount a little of the portion of it which is just beginning to show spores

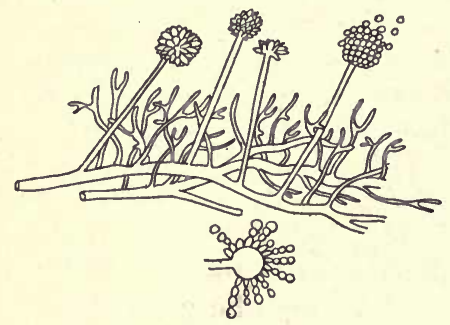

Frg. 265.-Aspergillus. and observe the character of the structure which bears the spores. The spores are generally borne on vertical branches of the mycelium which extend some distance above the SUB-STRATUM, or mass of food, within which the main body of the mycelium is growing. At the top of this vertical branch which is called a sporoPHORE, the spores are borne in different ways in different kinds of molds (see Fig. 264). In MUcor, the common black bread mold, a cross wall cuts off a cell at the tip of the sporophore. This cell grows larger and assumes a spherical form. At the same time, the cross wall bulges into this uppermost cell and forms a smaller sphere within the larger one. Next, the protoplasm of the outside cell breaks up into numerous spores. Such a spore-producing organ is called a sporangrum. The accompanying figures illustrate the manner in which some other common molds produce spores (Figs. 265, 266, and 267).

Note the countless number of spores that you get on your microscope slide from a very small quantity of the material. Remembering that these spores are always borne up in the air 
above the substratum, and that they are light and powdery, do you wonder that the spores of mold are abundant everywhere? Do you see that the molds are highly fitted to compete with us for possession of our food?

In this way, study all the different kinds of molds that you have collected. Your instructor will be able to tell you the names of several of the different kinds of mold that you study and you will be able to identify some of them by comparing them, as you study them, with the different figures in the text.

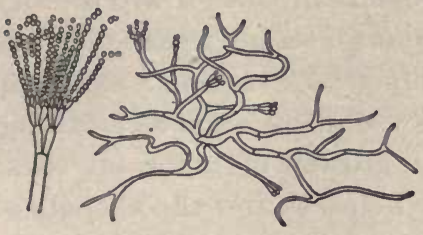

FIG. 266.-Penicillium.

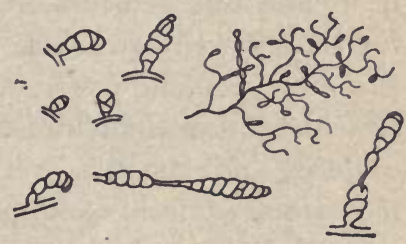

Fig. 267.-Antenaria.

\section{Exercise 87.-Identifying Molds on Different Materials}

After you have learned to identify several different kinds of molds, select one or two of them and see how many different kinds of material you can find them growing on. If you select the common green mold, Penicillium, for example, you should find it growing on a great variety of different substances (Fig. 266). Cheese, cured meats, stale bread, old clothing, old shoes, indeed, almost any kind of plant or animal matter may afford food for this mold. Note that the general appearance of a given mold varies considerably as it grows in different situations.

439. Conditions which Favor Mold Growth.-If we are to be successful in warding off the attacks which molds make on the things which we wish to preserve, we must understand the conditions which are favorable for mold growth. Everyone is familiar with the fact that molds do not grow on materials which are quite dry. One of the earliest methods which man ever devised for the preservation of food is that of drying it. A certain amount of moisture must be present before molds can grow at all and a considerable amount is necessary for a lux- 
uriant growth. When there is barely enough moisture present in a given material to support a mold growth, the mycelium development is very slight and there is little visible evidence of the presence of the mold except the spores. The spores are borne on very short sporophores and present a powdery appearance over the surface of the substratum. It is common to speak of mold when it presents this appearance as MILDEw. Mildew is simply mold which has grown on a scant moisture supply. During most of the year, the outdoor air and the air in houses and, consequently, dry objects in this air are too dry for the growth of molds. In the damp, sultry weather of the summer time, however, the air sometimes becomes so damp as to lend sufficient moisture to dry objects, such as clothing, carpets, and the like, to permit a growth of mold on these materials. Clothing hung in closed closets and the carpets of unused rooms which are closed up, are more likely to suffer from mold growth during damp, warm weather than if they were well aired, for it has been found that air movement is detrimental to the growth of mold.

Molds will grow to some extent at comparatively low temperatures, some even growing a little at only a few degrees above freezing. For any rapid growth, however, a rather high temperature is usually necessary. We take advantage of this fact in keeping our food from molding between meals and over night by putting it into a refrigerator. We should remember, however, that the temperature of a refrigerator is sufficiently high to permit of some mold growth, and for this reason we should not attempt to keep food in a refrigerator very long.

440. Effect of Mold Growth on Food.-Food is not necessarily ruined by the growth of mold in it. In fact, every time we eat an apple that is partly decayed, we are likely to eat a considerable quantity of mold which has already penetrated the apparently sound parts of the apple. Similarly, when we eat apple sauce or other similar food which has stood in a refrigerator for a day or more, we are likely to eat some mold even though we are unable to detect it. An abundant growth 
of mold in food, however, will give it a changed flavor and this we may not like. We are not likely to be harmed in any way, though, by eating food in which the mold can be tasted. When mold grows in food, the food loses some of its value for us, for the mold has consumed some of the food which we might otherwise have had, and our consumption of the mold does not wholly make up for this. Ultimately, the molds, and the bacteria which are likely to accompany them, will completely consume the food and render it worthless for our use. On the other hand, the growth of some molds in certain of our foods greatly enhances their value by giving them a delicate flavor which we very much desire. If you have ever eaten Roquefort cheese, you have had experience with one of these useful molds.

\section{YeAstS}

441. The Prevalence of Yeasts.-Yeasts have been used by man for raising bread and for making fermented liquors since before the time of historical records. Yet, notwithstanding this, the actual relation which yeasts bear to these processes was never clearly demonstrated until after the middle of the nineteenth century We do not even yet need to put yeast into fresh fruit juice in order to make a fermented liquor out of it, for yeasts, like mold spores, are widely distributed and are always sure to be present wherever there is suitable material for them to feed on. Similarly, it is possible to make raised or leavened bread without putting prepared yeast into the mixture. Probably you have eaten what is called "salt rising" bread. This bread is made by putting a little salt into some milk and allowing it to stand in a warm place for a time, and then using this milk for mixing the bread. The salt keeps other organisms from growing in the milk, and yeasts fall into it and multiply until they are numerous enough to raise the bread when it is made.

In essentially these ways, yeasts have been used for many centuries, but it was not until after the perfection of the micro- 
scope that men were able to find out much about them. In recent years we have learned many interesting things about yeasts, but there are still many things that we do not understand about them. You will doubtless be interested in learning some of the things that are known about these little plants that play so large a part in our lives. Without them we should have no leavened bread but we should also be without a temperance problem, for they are responsible for all the alcohol that is used in intoxicating drinks.

442. Study of Yeasts.-

\section{Exercise 88.-Growing Yeast}

Mix about 2 tablespoonfuls of molasses of some kind with a quart of warm water in a suitable glass vessel. Stir the mixture thoroughly and then add about one-half of a cake of compressed yeast, breaking the yeast cake into small particles. (If compressed yeast is not available, dried yeast cake will answer, but it will be very much slower in action.) If possible, keep the mixture at a temperature of from $70^{\circ}$ to $90^{\circ} \mathrm{F}$. Note the bubbles of gas that soon begin to rise in the mixture. Mount a small drop of the mixture on a microscope slide and study under the high power of the microscope. Note the size, shape, abundance, and general character of the yeast plants. In this fresh mixture, you will probably not find any budding cells for, in the yeast cake, the plants are more or less dormant. If you study in the same way an older mixture of the same kind which your instructor may have prepared a couple of hours or more before class, you will find many budding plants. Recall the statement previously made that it is this peculiar method of reproduction which distinguishes the yeasts from other fungi and which gives them the name, budding fungi.

\section{Exercise 89.-Growing Yeast Produces Carbon Dioxide}

Fill a small bottle about two-thirds full with the yeast mixture. Fill another small bottle up to the neck with clear lime water. Put a perforated cork into the bottle containing the yeast mixture and connect the two bottles by a U-shaped glass tube as shown in Fig. 268. As the gas which you have observed rising from the yeast mixture accumulates above the liquid, it will be forced through the glass tube over into the limewater. Observe the white milky 
cloud that forms in the limewater near the open end of the tube. The white substance which forms as the gas from the yeast mixture is forced into the limewater is essentially the same as common chalk. It is formed by the chemical action of carbon dioxide on limewater, and, therefore, its appearance here indicates that the gas which the yeast mixture is giving off is carbon dioxide. You are familiar with the fact that your own breath contains carbon dioxide. Take some fresh clear limewater in a small bottle or test tube and by means of a small glass tube, force your breath through the limewater. Note that the same white substance forms in the limewater. From this, you might conclude that the carbon dioxide which arises from the yeast mixture is formed by the respiratory process of the yeast plants. One trouble with this conclusion, however, is the fact that there is en-

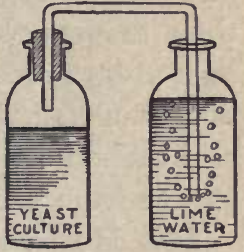

Fig. 268.-Carbon dioxide produced by growing yeast. tirely too much carbon dioxide produced by yeasts for us to explain it as being produced by ordinary respiration. We shall refer to this matter again later. (Review Arts. 92 and 93, especially Ex. 25f.)

\section{Exercise 90.-Growing Yeast aiso Produces Alcohol}

Permit your original yeast mixture to stand in a warm place for several days until signs of fermentation have about ceased. Now, taste the mixture to see if you can detect the sharp sting and the sweet taste of alcohol. Place the mixture in a distilling flask and distill the alcohol as in Ex. 16, Art. 24. What is the first of the distillate? Do you secure enough alcohol to burn?

443. Yeasts and Fermentation.-All the practical uses which we make of yeasts center in the peculiar relation which they bear to sugar. In the first place, sugar seems to be their natural food. It has been found possible to grow them in certain mixtures which do not contain sugar but in all the practical processes in which we use them, a sugar solution of some kind is used as a culTuRE, or material in which to grow them. In addition to sugar, yeasts must have certain mineral salts which are necessary in the building of protoplasm, but these are always present in sufficient quantities in all natural sugars such as the molasses you used in your culture. 
Under certain conditions, and probably in all cases in which yeasts are able to grow and multiply, they digest, absorb, assimilate, and respire sugar, essentially as other fungi do or as animals do. But under other conditions, especially in the absence of oxygen, and to some extent at all times when they are supplied with plenty of sugar, they simply digest and absorb the sugar into their bodies where by the action of an ENZYME, the sugar molecules are each split up into alcohol and carbon dioxide. The alcohol and the carbon dioxide then escape from the yeast cell into the culture.

444. How Yeast may Derive Benefit from Changing Sugar into Alcohol and Carbon Dioxide.-Sugar is made up of the elements, carbon, hydrogen, and oxygen; likewise alcohol is made up of carbon, hydrogen, and oxygen while carbon dioxide is composed of carbon and oxygen. The chemist is able to show, however, that all of these elements which were originally in the sugar reappear in the alcohol and carbon dioxide produced. None of the material is lost or disappears. Consequently, it is evident that, in this process, the yeast plant does not use any of the sugar for building up its own body. It is true, however, that the alcohol and carbon dioxide which result from this breaking up of a molecule of sugar do not together contain quite so much energy as did the sugar molecule. Therefore, in the process, a little energy must be liberated within the yeast plant and the plant is probably able in some unknown way to utilize this energy. If this latter thing is true, it may explain the rôle that this process plays in the life of the yeast. At the best, however, the yeast gets very little energy out of the process, for the alcohol that results contains very nearly as much energy as does the sugar from which it comes.

It has been suggested that another possible good that the yeasts derive from this process lies in the fact that the accumulation of alcohol in a yeast culture hinders the growth of other organisms in the culture, and thus gives the yeasts a better chance to multiply. It is also a fact, however, that 
the yeasts go on producing alcohol in the culture until they themselves are killed by it. It has been found that yeasts can stand from 10 to 18 per cent. of alcohol in the culture before being killed by it while nearly all other organisms which grow in such cultures are injured by from 4 to 10 per cent. of alcohol.

445. Alcoholic Fermentation.- Now that you have a more or less clear idea of this process by which yeasts produce alcohol and carbon dioxide from sugar, you are in need of a name for the process. The name in common use is ALCOHOLIC Fermentation. Formerly, just the word Fermentation was given as the name of the process but since it has been found that the sugar is broken up into the alcohol and carbon dioxide by an enzyme which is always held within the yeast cell, it is seen that the process is essentially identical with the process of digestion and other processes induced by enzymes. Therefore, the word fermentation has come to be applied to a number of processes which were formerly given different names because they were thought to be essentially different processes. Since we have learned that the processes of decay induced by molds, bacteria, and other fungi are in large measure only the digestion of the decaying material by the organism concerned in the decay, we now speak of these processes as fermentation. Even the digestion that takes place in our own stomachs is often spoken of as fermentation, and the enzymes which bring it about are spoken of as FERMENTs.

446. Different Kinds of Fermentation.-Different kinds of fermentation are often named after the principal product that results from the process. It is in this way that we call the fermentation that yeasts produce alcoholic fermentation. In a similar way, we have BUTYRIC FERMENTATION which is the fermentation of milk sugar by certain bacteria and which produces BUTYRIC ACID. It is this fermentation which underlies the production of the desirable flavors of butter and cheese. Again, LACtic Fermentation is the fermentation of milk sugar by a different kind of bacteria which results in the formation of LACTIC ACID, and thus in the souring of milk. When 
proteins are attacked by certain bacteria, several bad smelling gases are produced and this process has long been known under the name PUTREFAction but, while the details of this process are not well known, it is known that it does not differ essentially from other processes of fermentation and it is often called PRotein FERmentation. Numerous other kinds of fermentation are known and all are named either after the substance that is fermented or after one of the products that result.

447. Yeasts and the Production of Alcoholic Liquors.-We have said that all intoxicating liquors derive the alcohol they contain from the process of alcoholic fermentation carried on by yeasts. In the making of all the different kinds of liquors, a sugary solution of some kind is always provided. This is INOCULATED with a quantity of yeast and kept at a suitable temperature until the fermentation has gone as far as desired, or until the accumulating alcohol has killed the yeast and stopped the process. In the case of wines, beer, and ale, the mixture is next put into bottles or kegs and is ready for use. In some of these undistilled liquors, the bottling is done before fermentation has entirely ceased, and thus a considerable quantity of carbon dioxide remains in the liquor. This adds to the flavor of the liquor and is responsible for its sparkling quality. The color and part of the flavor of wines is derived from the fruit juices used in making them. In the making of distilled liquors, such as whiskey, rum, and brandy the process of fermentation is carried as far as possible and then some of the water of the mixture is removed by the process of distillation (see Art. 24). In making liquors from cereals, such as corn, rye, and barley, the starch of the cereal is first changed to sugar by the process described in Art. 424, and then the sugar is fermented by yeasts.

448. Yeasts and the Making of Bread.-It is the carbon dioxide which results from fermentation which is of use in making bread. The flour which is used in making bread contains some sugar and usually a little more sugar is added 
to the dough as it is mixed. The yeast that is mixed with the dough ferments this sugar and produces both alcohol and carbon dioxide. The flour also contains a considerable quantity of a protein substance, GLUTEN (Art. 418). This gives the dough its sticky character and makes it more or less impervious to gases. Consequently, as the yeast produces carbon dioxide throughout the dough, this gas collects and forms little cavities in the dough and is thus responsible for the characteristic porous quality of light bread. You have seen (Art. 12) that alcohol is a very volatile substance. Consequently, in baking the bread, all the alcohol is caused to escape by the heat. As the bread is baked, the gluten of the dough is so changed in character as to become quite pervious to gases and it thus allows both the alcohol and the carbon dioxide to escape. You thus see that we use yeast in making bread, primarily, for a sort of mechanical effect which it produces on the bread, making it light and porous, and probably on this account more easily digested. In addition to this, the yeast adds a nut-like flavor to the bread which we like very much.

If the knowledge of the rôle that yeast plays in bread making is of any practical value, it lies in the fact that the bread maker will realize that she is dealing with living organisms. If she has this fact in mind, she is likely to be more intelligent in providing favorable conditions for the growth of the yeast. In general, it may be said that the best bread results from a moderately rapid fermentation, but the details of managing yeast for bread making are too numerous for us to enter into here.

449. Wild and Cultivated Yeasts.-All the different kinds of yeast used in bread making except that used in making salt rising bread, and all that are used in the breweries and distilleries, are what may be called cultivated yeasts. These consist of several distinct species and varieties which vary in their usefulness for different purposes and all have been in use by man for so long a time that their origin from the wild state cannot be traced. In addition to these, WILD YEASTS of 
several kinds are widely distributed in the soil and air and it is these that are used in fermenting fruit juices in making wines.

\section{Exercise 91.-Study of Wild Yeast}

Place a little fresh apple cider or other available unfermented fruit juice in a glass tumbler and allow it to stand in a warm place for several days. After the fruit juice has shown signs of fermentation, mount a drop of it on a microscope slide and examine it under the high power of the microscope for yeasts. You will probably be able to notice that the yeast cells differ in shape somewhat from the tame yeasts that you formerly studied.

450. Yeasts and the Preservation of Food.-It is obvious that, since wild yeasts are floating in the air everywhere, they will be constantly coming into competition with us for possession of the sugar-containing foods that we try to preserve for ourselves. Such foods as apple sauce, canned fruit, and others that contain sugar are always in danger of being fermented by yeasts unless they are protected by the low temperature of the refrigerator or in other ways. It is a rather peculiar fact, however, that some foods which contain very much sugar, such as preserves, apple butter, and jelly are seldom attacked by yeasts. Thus, while sugar is the principal food of yeasts, strong concentrations of it serve as a preservative against yeast as well as against bacteria. Molds, however, are much more likely to grow in such foods than are either of the other two classes of organisms.

\section{BACTERIA}

We have seen that molds and yeasts are rather important factors in our environment. In some ways they render us important service and in other ways they are the cause of great inconvenience to us. Bacteria are of tremendously greater importance to us in both these ways than are either molds or yeasts. Bacteria are the smallest of living things and they are doubtless the most widespread in their distribution. We might well consider ourselves fortunate that we are living in 
'these days since the perfection of the microscope which has enabled men to learn something of this teeming invisible world of life which touches us on every hand.

451. Development of the Science of Bacteriology.-The first authentic report which we have of bacteria having been seen by man was in 1683. Anthony Van Leeunenhoek, a Dutch linen weaver, who spent his leisure time in grinding lenses and in using them to study various materials, was the

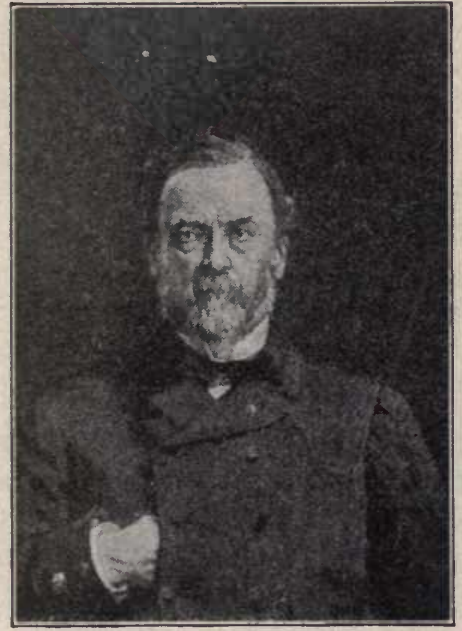

FIG. 269.-Louis Pasteur.

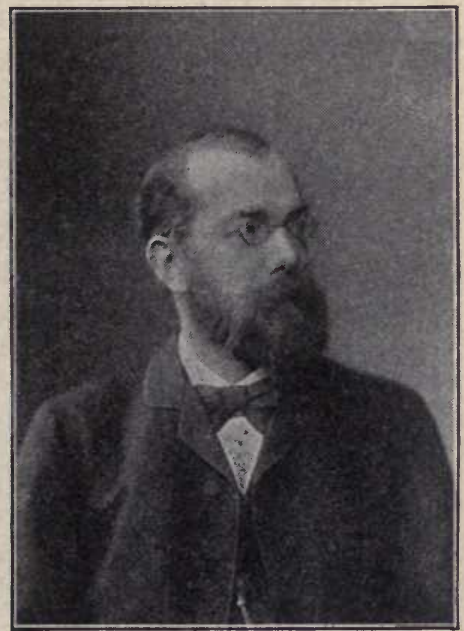

FIG. 270.-Robert Koch.

first man to see and to describe these wonderful little living creatures which you are soon to have the privilege of seeing. In a letter to the Royal Society of London, he said: "I saw with wonder that my material contained many tiny animals which moved about in a most amusing fashion." Are you going to see these organisms for the first time "with wonder," or are you going to consider it a commonplace experience just as we do many wonderful things these days? Very little progress was made in the study of bacteria for nearly two centuries after Leeuwenhoek's discovery. It was not until the 
latter half of the nineteenth century that the science of bacteriology had its wonderful development. This development of a science from the faintest beginnings to one that ranks in the very forefront of the various branches of knowledge within the time of a single generation, is very largely the work of two great men. These men are Louis PASTeUr (Fig. 269) who may be called the father of bacteriology and RoвERT Kосн (Fig. 270) who may be said to be the man who made bacteriology an independent science. You should improve the first opportunity to learn something of the personal lives and of the work of these men.

\section{Exercise 92.-Study of a Hay Culture}

Fill a large glass jar with water, preferably water from some pond or stagnant pool, and put a good sized handful of timothy hay into the water. The hay should be cut into small pieces before it is put into the water. Place the jar in a warm place and continue to study the organisms that appear in it for several days. If the temperature of the water does not fall below $70^{\circ} \mathrm{F}$. you should find it teeming with bacteria at the end of 24 or 48 hours. Bacteria will continue to be abundant in the culture for several weeks. If you study a sample of the water about every other day for a period of two or three weeks, you will find that different forms of bacteria will be most abundant at different times. If the jar is allowed to stand for a month or two, all bacterial action will finally cease and the water will become quite clear. Can you suggest the reason for this?

452. Life History of a Hay Culture.-Along with the different kinds of bacteria which from time to time will appear in the culture, you will find a great many different kinds of microscopic animals. As you study the culture from time to time, you will find that each kind of animal, like each kind of bacterium, will seem to have its day and then gradually disappear to give place to some other form. The reason for this shifting panorama of life which a culture like this exhibits is found in the varying chemical conditions of the culture which are brought about by the organisms themselves. Thus, a given organism becomes the leading type whenever the con- 
ditions of the culture are most favorable for it. This type of organism gradually consumes the food available to it and at the same time contributes harmful waste materials to the culture. When this continues for a time, the conditions of the culture become gradually more unfavorable for this original form, but at the same time it becomes more favorable for a succeeding form of life. This succeeding form then becomes the leading type in the culture for a time and then, in its turn, in the same way, and for the same reasons, gives way to a new successor.

Now, if you can imagine, not one line of succession like this, but many such lines going on at the same time, you will have a fairly accurate picture of what is going on in your culture. Not only this, but this picture of change in your culture is a fairly accurate representation of what is going on in nature everywhere where plant and animal matter are being changed back to the simple inorganic compounds for which the green plants originally built them up.

453. Decay in General.- It is a long and interesting story from the planting of an acorn to the final dissolution by natural processes of the body of the giant oak that results. One might think that the story is ended when the tree has come to its death, but with this picture of your culture in mind you will see that probably the most interesting part of the story begins with the death of the tree. Thousands of different forms of life take part in its destruction and all bear perfectly definite but extremely complex relations to each other. It is in this work of the dissolution of organic bodies that microorganisms play their most important rôle in the life of the earth. Were it not for the work that these organisms do, the earth would become strewn with the dead bodies of animals and plants, and the chemical elements which composed these bodies would never again become available for succeeding forms of life.

454. Forms of Bacteria.-As you study your culture from time to time, you will have opportunity to observe the three 
different forms of bacteria (Fig. 271). Sometimes you will have all three forms on your slide at once. The three forms are: first, $A$, spheres, called coccI (singular, coccus); second, $B$, rods called BAcILLI (singular, bacillus); third, $C$, spirals called SPIRILLA (singular, spirillum). Some of each of these forms possess locomotor, or swimming, organs in the form of FLAGELLA ( $B$, Fig. 271) and are therefore able to swim through the water like an animal. Others lack these organs and are therefore non-motile. The relative abundance of the three different forms is indicated by the work of Migula, a German bacteriologist, who, in the year 1900 enumerated and described 833 bacilli, 343 cocci, and 96 spirilla.

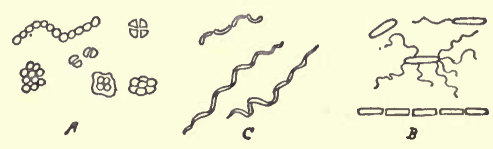

FIG. 271.-Cocci, spirilla, and bacilli.

Since the structure of bacteria is very simple and since all the different kinds fall under one of these three different forms, it is obvious that the different kinds of bacteria can not be distinguished merely by microscopic examination. Bacteriologists have devised many ways of distinguishing them, but these methods are too difficult and too intricate for us to enter into. It is enough to say that bacteria differ from each other physiologically rather than structurally. Two bacteria may look for all the world alike under the microscope, and yet their waste products and secretions may differ very widely. These products of the one may be a violent poison in our bodies, while those of the other may be perfectly harmless to us.

344. Where Bacteria may be Found.-It would be easier to say where bacteria are not found, for they are found almost everywhere. They are doubtless absent in the midst of deserts, in the depths of the sea, in the frigid regions near the poles, and in the tissues of healthy animals and plants, but in almost any other place on or near the surface 
of the earth they are present in great abundance. Bacteria are ever present in the soil, water, and air, in the food and, consequently, in the mouths and alimentary tracts of animals, and in all decaying organic substances everywhere.

They are never growing and active, however, unless they are supplied with an abundance of water, a suitable food supply, and a favorable temperature. In the ordinary form, they can endure drouth and remain alive for some time; the different kinds vary greatly in this power, however. Some kinds have the power of forming spores which endure drying for many months, some even for many years, and still retain the power of growing whenever they fall into suitable conditions. In the formation of these spores, the whole living part of a bacterium contracts into a spherical body within the original cell wall, a new and thicker wall is secreted about this body, the original wall bursts and the spore is set free. The spore is thus a means of living over an unfavorable season, or of resting until suitable conditions for growth return. The fact that bacteria are able to endure drought either in the spore form or in the ordinary form, accounts for their wide distribution and for the fact that they are present and ready to begin active growth whenever and wherever any suitable material is found for them to grow in.

\section{Soll Bacteria}

\section{Study of Soil Bacteria. -}

\section{Exercise 93.-Soil Bacteria}

Procure some rich soil from a stable lot or a garden. Fill a glass tumbler half full with the soil and then fill the tumbler to the top with water. Stir the mixture thoroughly and allow it to settle. After the soil has settled, examine a drop of the water under the high power of the microscope for bacteria. Examine a drop of clean well water in the same way and compare the number of bacteria in the two samples of water.

You will get the idea from this experiment that the soil contains myriads of bacteria. In the water taken from the 
tumbler containing the soil, you will doubtless find some microscopic animals similar to those you found in your hay culture. The two kinds of organisms in the soil bear the same relations to each other as they do in the hay culture. That is, the bacteria of the soil feed on the decaying organic matter of the soil, and the microscopic animals in turn feed on the bacteria.

457. The Nature of Soil.-Before taking up the relation of bacteria to the soil, it is necessary for us to know something of the nature of soil. Geologists tell us that the outer crust of the earth was originally solid rock, and that through the influence of weathering agencies, such as the sun and wind, freezing and thawing, and the flowing of water, much of this crust of rock has been ground into exceedingly fine particles. These fine particles now make up a deep layer of soft material which we know as clay, sand, and gravel and which covers the deeper solid rock of the earth's crust. For a few inches or feet below the surface, this clay and sand and gravel is, in most places, well mixed with decaying remnants of the bodies of plants and animals. It is these few inches or feet on the surface of the soft blanket of the earth that are well mixed with organic matter that we call soil. It is in this thin layer of soil, mainly, that the materials are contained which the higher plants take in through their roots and use in building up the more complex foods with which they nourish themselves and the rest of the living world. The organic matter in the soil is collectively spoken of as Humus and it is this humus which supplies food to the soil bacteria (see Art. 550).

458. Soil Bacteria and Carbon.-The soil bacteria complete the work of destruction of the particles of plant and animal matter which fall into the soil. All these materials contain large quantities of carbon combined with other chemical elements and when the bacteria have digested, absorbed, assimilated, and respired them, the carbon escapes to the air in the form of carbon dioxide gas. This you will remember is the form in which the green plants take up carbon from the air 
and again combine it in a form which serves as food. Thus it is that bacteria, and other agents, such as other non-green plants and animals keep constantly returning carbon dioxide to the air where it becomes available for the green plants.

459. Soil Bacteria and Nitrogen.-We have seen in Chap. VII, Art. 377, that only a comparatively small number of chemical elements are needed to make up the numerous chemical compounds that constitute the human body. This is true of all living bodies. Among these few necessary elements, there is none that gives us greater concern than nitrogen. This element constitutes approximately four-fifths of the atmosphere, but it is not found in a combined form in the natural rock of the earth. It is therefore not in the soil in a combined state except as it has been put there by living organisms. ${ }^{1}$ On this account, the nitrogen supply of the soil is usually more limited than that of the other soil elements which were present in the original rock of the earth from which the soil was made. At the same time no living thing can exist without nitrogen for it is one of the necessary elements in the makeup of protoplasm.

The green plants take up the nitrogen from the soil in certain definite chemical compounds, usually in the form of NITRATES, such as potassium nitrate. The green plant has the power of combining the nitrogen in this form with other elements to form proteins and these are food for the green plant and for other organisms. The nitrogen which is thus formed into protein compounds by green plants is practically the sole available supply of nitrogen for the animal world, for animals do not have the power of making proteins out of the nitrates or other similar compounds. We get proteins when we eat the flesh of other animals, but this, in turn, may ultimately be traced back to proteins formed by some green plant (see Art. 380).

${ }^{1}$ Note: Small amounts of combined nitrogen are carried down by rain during storms, especially thunder showers. Lightning causes some of the nitrogen and oxygen of the atmosphere to unite into chemical compounds, gases, which are absorbed by the falling rain. 
460. Some Classes of Soil Bacteria.-Now, it is probably evident to you why we are so greatly concerned about the supply of nitrogen in the soil in a form available to the green plants. With this thought in mind, you will doubtless be interested to know the part that the soil bacteria play in keeping up this supply of available nitrogen in the soil. The bacteria which do this work may conveniently be divided into three groups: (1) The nitrifying bacteria, (2) the nitrogen fixing bacteria, and (3) the nodule bacteria.

461. The Nitrifying Bacteria.-The NITRIFYING BACTERIA transform the various nitrogen-bearing compounds of the soil humus into the nitrate form. This is not a simple process, as you might suppose, but consists of three distinct steps. Each step in the process is performed by a different set of bacteria, but several different species of bacteria are known for each step.

The first step in the process is the changing of the proteins and other nitrogen-bearing compounds of the humus into ammonia (Chap. III, Art. 194). If you turn over a rapidly decaying mass of organic matter, you can usually detect the characteristic odor of ammonia along with various other odors.

The second step in the process is carried on by an entirely different set of bacteria and results in changing the ammonia to NITRITES. Nitrites differ, chemically, from nitrates in having relatively less oxygen in their composition.

The process is completed by another set of bacteria which changes the NITRITES to NITRATES.

It is obvious that these bacteria which simply transform the nitrogen-bearing compounds of the soil humus into a form available for the higher plants do not actually add any nitrogen to the soil. They only transform nitrogen that is already there. If you recall the fact that the original rock of the earth does not contain any fixed nitrogen, you will see that we, so far, have no means of accounting for the origin of the present nitrogen content of the soil. The bacteria of this group only 
aid in keeping the nitrogen in circulation, they do not add to the total stock.

462. Nitrogen Fixing Bacteria.-A second group of bacteria which have to do with the nitrogen content of the soil consists of several species which recently have been isolated and proved to be able to take the free atmospheric nitrogen and fix it in compounds which ultimately become available for the higher plants. These bacteria live in the soil and derive their carbohydrate food from the humus just as others do, and, if fixed nitrogen is abundant in the soil, they also use this. In the case, however, of the scarcity or absence of fixed nitrogen, they are able to draw on the great ocean of free atmospheric nitrogen. Unlike the first group discussed above, these bacteria are thus able to add to the total nitrogen content of the soil. It is doubtless true that these organisms have been, at least,important factors in bringing about the gradual increase in the nitrogen content of the soil that has occurred during the ages.

In ancient times, the custom of FALLOWING land was largely practised. This consists of cultivating the land for a season to keep down the weeds without attempting to raise a crop on it. It was believed by the ancients that in some way through this practice, the land was enabled to produce a very much better crop the following season, and this belief was abundantly supported by practical experience. We now have, at least, a partial explanation of this fact in these bacteria which add atmospheric nitrogen to the soil.

463. Nodule Bacteria.-The third group of bacteria that affect the nitrogen of the soil, like the second group, have the power of fixing atmospheric nitrogen but they seem to be able to do this only when they live within the root tissue of certain higher plants, mainly those that belong to the botanical family which includes clover, alfalfa, beans, peas, and the like. When these organisms grow in the roots of the host plant, they cause little outgrowths, or knots, to form on the roots, which are called NODULES, and the bacteria themselves are often spoken of as NODULE BACTERIA (Fig. 272). The nitrogen 

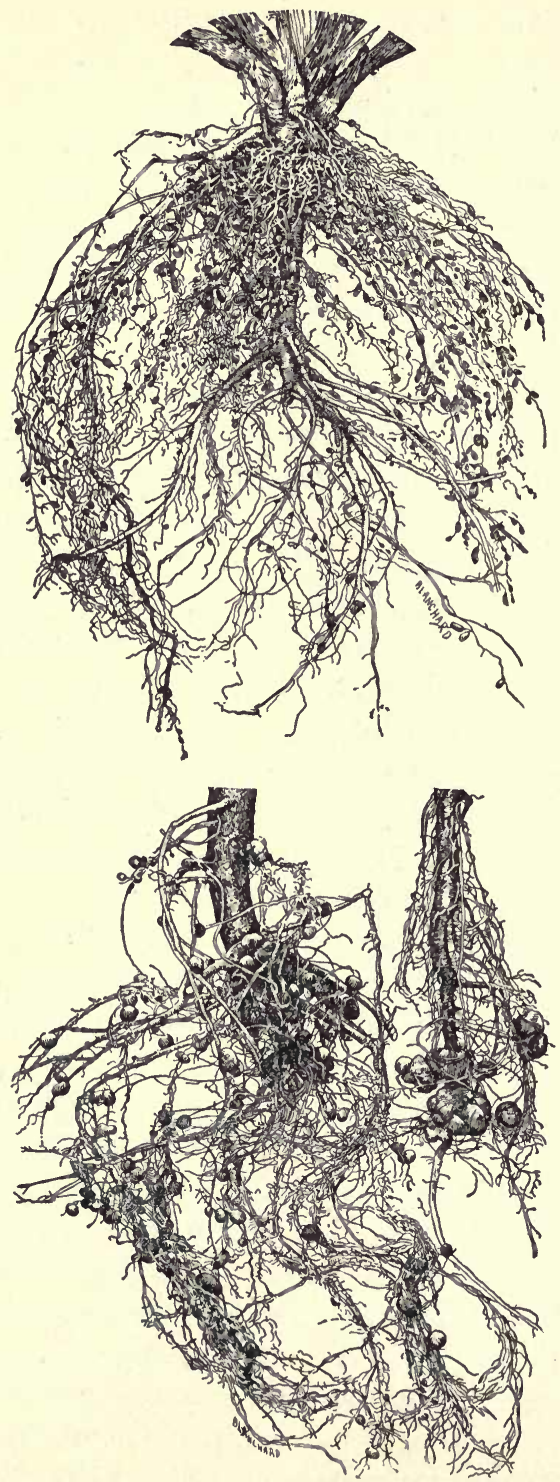

FIG. 272.-Roots of red clover (above) and of soy bean (below), showing nodules. 
which these bacteria combine within the nodules later becomes available to the host plant and is built up into its protoplasm. When the host plant dies and disintegrates, the nitrogen thus fixed by the nodule bacteria becomes a part of the soil. It has long been known by practical farmers that plants belonging to this clover family tend to increase the productivity of the soil on which they are grown. We now know, however, that it is not the higher plant, but the nodule bacteria that are directly responsible for this increased fertility.

464. Effect of Cropping on Soil Nitrogen.-Thus, in these last two groups of bacteria, we have agencies which transform some of the atmospheric nitrogen into forms in which it becomes a part of the soil and available to the higher plants. In the first of these three groups, we have agencies which ultimately return the nitrogen to the soil which the higher plants take from it. In a state of wild nature, in which all the plants that grow on the land die where they stand, and ultimately disintegrate and return their nitrogen to the soil, we naturally have a gradual increase in the soil nitrogen. This generally means a gradual increase in the fertility of the soil and in the luxuriance in the plant growth that it supports. Under modern agriculture, however, through which the larger portion of the plants grown on the land is often removed, there is danger that the soil nitrogen may be reduced. If the nitrogen removed from the land in the crops together with that which is carried away in the drainage, is greater than that added by bacteria and by manures and other fertilizers, there must be a decrease in the amount of nitrogen remaining in the soil. If this is kept up for many years, the soil is gradually impoverished, and it may in the end become too unproductive to pay for the work of tillage. This thing has actually occurred in many originally fertile soils of the world. All of the older states of this country contain many abandoned farms which have become so unproductive through the exhaustion of the nitrogen, and possibly of other elements of fertility, that their owners have ceased to till them. 
465. Interrelations of Soil Bacteria.- - In this account of the relation of bacteria to soil fertility, we have given only the mere thread of the story. Many interesting interrelations exist between the different kinds of soil bacteria which our limited space will not permit us to consider.

Some different kinds of bacteria are helpful to one another. In some cases they are almost powerless to carry on their processes without this mutual aid. In other cases, different kinds are seriously detrimental to one another, not only competing for food, but through their wastes and secretions hindering one another's development. Some even undo the work that others do. For example, there are great numbers of bacteria in barnyard manure and some of them in the soil generally that have the power of breaking up the nitrates of the soil and setting the nitrogen free in the atmosphere. These are called DENITRIFYING BACTERIA and they tend to undo the work accomplished by the three groups discussed above.

Some of the soil bacteria must have free gaseous oxygen supplied them for respiratory purposes, while others can, not only get along without free oxygen, but can not carry on their processes in its presence. These latter obtain the oxygen which they use in respiration from chemical compounds which contain it. The kinds of bacteria that must have free oxygen are known as AEROBIC BACTERIA; those that do not require it are known as ANAEROBIC BACTERIA.

Many other details like these are known to bacteriologists and doubtless there are very many more important relations that exist among these organisms and between them and their environment which have not yet been discovered. Furthermore, other soil elements are affected by bacteria in ways very similar to those in which nitrogen is affected, and numerous complex relations exist among these different elements and among the organisms that affect them.

Thus you see that the soil is not the dead, inert, and unchanging thing that you might suppose it to be. It is teeming with life and endless change. It presents an endless list 
of problems to man for solution and as fast as man is able to solve these problems, he is able to deal with the soil more intelligently. Our knowledge at present is very incomplete but it is sufficient to enable us greatly to increase the productivity of the soil if the men who till the soil only knew and practised what is known to men of science.

466. Bacteria and Other Soil Elements.-We have seen in Art. 457 that one result of the action of bacteria in the soil is the liberation of carbon from the humus of the soil in the form of carbon dioxide in which form it becomes available as raw material for the food-making process of the green plants. We have also seen that another result of the action of bacteria is the production of nitrates in the soil. This is another important and necessary raw material for the green plant. The other so-called necessary raw materials for the green plant, i.e., the other chemical elements which the green plants must be able to obtain in order to live and thrive are the following: OXYGEN, HYDROGEN, PHOSPHORUS, POTASSIUM, MAGNESIUM, SULPHUR, CALCIUM, and IRON.

Oxygen is abundant in the air and oxygen and hydrogen are the elements which compose water. Therefore, these two elements are readily available to the plants without the aid of bacteria. The other elements of this list, namely, phosphorus, sulphur, potassium, magnesium, calcium, and iron were all resident in the original rock of the earth and therefore are present in the clay and other materials of the soil which have been derived directly or indirectly from this original rock. These elements in their original compounds are exceedingly stable, i.e., they do not readily break down into simpler compounds; they are also nearly insoluble and are therefore only slightly available to the higher plants. Since all plants require these elements for their life processes, all plant bodies contain them and therefore these, like the nitrogen, are locked up in the humus in practically insoluble compounds. Bacteria and other fungi serve to liberate these elements from the nearly insoluble compounds of both the humus and the clay 
and to leave them in the soil in soluble compounds which are available to the higher plants.

Each of these elements has its own peculiar chemical relations and therefore its own peculiar relations to bacterial action. Consequently, the story of the transformations of each of these elements is different from every other and each is quite as interesting as is the nitrogen story, but our limited space will not permit us to study them. It is sufficient to say that different kinds of bacteria produce in one way or another many different kinds of acids. These acids attack the insoluble mineral compounds of the soil and soluble compounds result.

Foremost among these acids which result from bacterial acid is CARBONIC ACID. This acid results from the chemical union of carbon dioxide, liberated by the bacteria, with water. Numerous other organic acids, i.e., acids which contain carbon, are produced in the soil by bacteria. Not much is known of the detail of the action of most of these acids on the mineral compounds of the soil but there is little doubt that most of them are serviceable in rendering materials available for higher plants.

Numerous other chemical reactions induced by bacteria, aside from the production of acids, result in the formation of available materials for the higher plants. It should be said also that molds and other fungi are active in these processes in the same way as bacteria are.

467. Bacteria and Soil Leaching.-It is evident that, if the materials that compose the soil should remain insoluble, they would, not only be unavailable to the higher plants, but they would also remain where they are and would not be carried away by the water as it percolates through the soil. Much of the water that falls on the soil as rain, soaks in and keeps sinking to deeper levels until it finally finds an outlet to some stream and then makes its way to the sea. As it does this, it naturally carries with it much of the soluble material that it passes. In this way, the soil is constantly losing some of the very elements which the higher plants need. This process by which 
the elements of fertility are gradually washed out of the soil by the drainage water is known as LEACHING.

It is evident that, if bacterial action is too rapid and sets free soluble materials faster than they can be taken up by the growing crop, these materials will be wasted by leaching. Leaching is more rapid in cultivated soil than in soil covered by a turf, for, in the first place, water soaks into the cultivated soil more rapidly, and, in the second place, more air enters the cultivated soil and this leads to more rapid bacterial action. For a similar reason, loose, sandy soils which permit the air and water to enter them freely lose their humus more rapidly than do heavy clay soils.

468. Bacteria and Soil Acidity.-We have seen that bacterial action in the soil results in the liberation of considerable quantities of carbon dioxide in the soil. Some of this carbon dioxide escapes immediately to the air, while some of it goes into solution in the soil water. A portion of the gas that goes into solution in the soil water combines chemically with the water to form CARBONIC ACID. The soil water which thus contains carbonic acid readily dissolves limestone, or CALCIUM CARBoNATE, and other similar chemical compounds of the soil (see Fig. 285). These soil compounds may now be taken up by the roots of higher plants or they may escape from the soil by leaching. Other acids formed in the soil by the action of bacteria have similar powers of rendering the inert materials of the soil soluble. Most natural soils contain originally large quantities of these materials which can combine with the acids formed by the microörganisms in the soil but by continuous cropping for many years, these materials are likely to become more or less exhausted in the surface soil. When these materials which are called BASEs by chemists, become too scarce to combine with the acids as fast as the latter are formed by the microörganisms, the acids accumulate in the soil and we have what are known as ACID solls.

469. The Correction of Soil Acidity.-The accumulation of acids in soil hinders its productiveness in several ways. In 
the first place, the acids, being in a sense waste products of the soil microörganisms, are injurious to the organisms which produce them, and thus check their normal useful rôles in the soil. In the second place, most of the higher plants are seriously injured directly by an excess of acid in the soil. Consequently, it is important that the farmers have some way of correcting the acidity of the soil. This is accomplished by adding to the soil some of the materials which have the power of combining with the acids. Finely ground limestone is probably the most widely used substance for this purpose.

\section{Bacteria and Decay}

470. Real Meaning of Decay.-So far, we have considered bacteria mainly from the standpoint of the service they render us and the rest of the living world, by keeping up the fertility of the soil and by helping to keep in circulation the chemical elements which living organisms need. We shall now change our point of view, for a time, and consider how they tend to destroy many things which we wish to preserve. The disintegration of organic materials through the agency of bacteria or other fungi is commonly spoken of as DECAY, ROTTING, SPOILING, or PUTREFACTION. These different terms came into use before the real nature of the process referred to was recognized and they are still used to some extent, though more or less vaguely, to represent different forms of the process. Thus, for example, when disagreeable odors result from the process, as often occurs in the disintegration of proteins, the process is often spoken of as putrefaction. All of these terms really mean the same thing; they are different names for a single process by which the nature of matter is changed. They are different terms applied to the chemical changes brought about by living organisms. Hence, we shall use the single word DECAY to represent the process in all its forms.

Doubtless, you have already recognized the disintegration of the soil humus as decay. In this instance, we are interested 
to have the decay go forward at a rate sufficiently rapid to supply our growing crops with an abundance of mineral salts. So it is with many things that are useless to us; we are quite willing that they shall be disintegrated and not allowed to encumber the earth, but there are many things such as our food, clothing, and lumber which we wish to preserve and which the bacteria and other fungi stand ready to consume.

\section{Conditions which Favor Bacterial Growth}

471. Warding off Attacks of Bacteria.-We can ward off the attacks of bacteria by so conditioning the material which we wish to preserve that bacteria can not grow in it. In doing this, we need to know the conditions which favor bacterial growth. These briefly stated are as follows: a suitable food, an abundance of water, a favorable temperature, suitable chemical conditions, absence of bright light for most of them, presence of free oxygen for some, and absence of free oxygen for others. We shall consider these briefly in separate paragraphs.

472. Food for Bacteria.-Bacteria can feed on a wide diversity of substances. Almost all organic compounds are food for one or more different kinds. Almost all species of bacteria can feed on protein substancès and yet some can get along with no protein at all in their diet. Some, even, can nourish themselves on inorganic salts alone. Since the organic materials which we wish to preserve are almost always a mixture of many different kinds of compounds, we may be quite sure that any of these things of plant or animal origin are subject to the attacks of bacteria.

473. Water Necessary for Bacterial Growth.-A mass of food material, in order to support an active growth of bacteria, must contain from 25 per cent. to 30 per cent. of water. This is considerably more water than is required to support a growth of mold, and so many materials will be found to mold when they are entirely free from bacterial action. The high percentage of water required for bacterial growth enables us to preserve 
many materials from their attacks by merely drying them. It is by drying out when ripe and remaining dry for long times that seeds of plants are able to avoid being consumed by bacteria during the resting period before germination. Many kinds of foods, such as fruits, vegetables, and the seeds of plants can be kept indefinitely by drying them out and keeping them dry. Building materials which are of plant origin, such as lumber may be preserved indefinitely against the attacks of bacteria if they can be kept dry. We paint our houses largely for the purpose of enabling the lumber to shed water and to remain dry, and thus to avoid the attacks of bacteria.

474. Temperature Required.-Bacteria vary widely in their temperature relations. Some are able to grow at almost the freezing temperature, while others thrive at temperatures as high as from $160^{\circ}$ to $190^{\circ} \mathrm{F}$. Three temperature limits may be distinguished for each bacterium as follows: a MINIMUM, or the lowest temperature at which growth is possible; an optimuM, or the temperature at which they grow best; and a MAXIMUM, or the highest temperature at which growth is possible. In some species the range between the minimum and maximum is wide while in others, it is comparatively narrow. The minimum temperature of some species is higher than the maximum of others. Considering this wide range of temperature relations, it is obvious that it is very difficult entirely to prevent the action of bacteria through the agency of temperature in substances which are injured by freezing. At very low temperatures, just above the freezing point, very few bacteria are active and none are very active. This fact makes possible the preservation of many kinds of food for comparatively long times by the method of cold storage.

475. Necessary Chemical Conditions.-Many chemical substances have been found to be detrimental to, or destructive of, bacterial life. Most bacteria, for example, do not thrive in acid media and on this fact rests the preserving power of vinegar and other organic acids. Common salt, saltpeter, 
and other similar materials used in preserving meats prevent the growth of bacteria but in ordinary concentrations do not kill them. On the other hand, there are certain substances like corrosive sublimate, carbolic acid, and formaldehyde which in comparatively weak solutions are deadly to bacteria. A substance which checks the growth or development of bacteria but does not kill them is called an ANTISEPTIC, and one which kills them is called a DISINFECTANT.

476. Antiseptics.-Antiseptics of many kinds are widely used in the preservation of food. Common salt, vinegar, spices, and sugar are the ones most commonly used in the household. Sugar is a good food for some bacteria and particularly so for yeasts and molds, but in very strong concentration such as is found in jellies, preserves, and the like, neither yeasts nor bacteria can grow. Molds, however, are more able to endure these strong concentrations of sugar. Boric acid is sometimes used in the preservation of meats and butter: formalin, in the preservation of milk; and benzoate of soda, in the preservation of jams, catsups, and the like, but most authorities are agreed that these and several other substances like them are, in the long run, injurious to the health of the consumer and therefore their use is unwise.

477. Disinfectants.-Disinfectants are used, not only for the destruction of bacteria in houses after a case of bacterial disease, but also in the preservation of lumber, railroad ties, fence posts, mine props, and the like. Among the disinfectants used for these latter purposes are creosote and zinc chloride. The material to be preserved is soaked in a solution of the disinfectant and this prevents, not only the action of bacteria, but also the attacks of wood borers and other insects.

478. Effect of Light upon Bacteria.-Most bacteria are readily killed by direct sunlight or other bright light. Even strong diffused light is highly detrimental to their growth. This fact, however, is of little value in the preservation of materials, for the bacteria in the interior of the substance are effectively shielded from the light. 
479. Oxygen and Bacteria.-We have mentioned in Art. 465 , the fact that some bacteria require free oxygen in order to be able to carry on their processes, while others can, not only get along without free oxygen, but can not thrive in its presence. The only importance that this fact has in connection with the preservation of food is that it shows that we can not hope to preserve the food by shutting it away from free oxygen. As far as the oxygen relation is concerned, the anaerobjc bacteria find ideal conditions within a sealed can of fruit or vegetables.

\section{Preservation of Food by Canning}

480. Why We Can Food.-We know that one of the most extensively used methods of preserving food at the present time is that of canning. This consists of putting the food into cans, heating it to a high temperature for a time sufficiently long to kill both the active growing bacteria and the more resistant spores, and then sealing it air-tight.

Canning has been practised to some extent as a household industry for about a century, but the large canning factories which now preserve annually immense quantities of food have come into existence during the last 20 or 30 years. The importance of canning and other modern methods of preserving food as means of cheapening the cost of living is very great. Before these methods came into use, many kinds of food could be used only while it was fresh and in season, and a large percentage of each crop was allowed to go to waste for the lack of suitable methods for preserving it. Now, the whole crop may be saved and be sold at reasonable prices throughout the year. It is a remarkable fact, however, that, during the same period of time in which the process of canning and other methods of preserving food have been brought to their present high state of development, the cost of food has greatly increased instead of decreasing. The increase in the cost of food has come about, however, in spite of the perfection of these processes which naturally have the opposite 
tendency. Food would doubtless be much more expensive today than it is if we did not have these modern methods of preserving it.

481. Domestic Canning.-As stated above, the canning of certain things, such as fruits and some of the vegetables, has been practised in the homes for a long time. This practice began long before the development of the science of bacteriology and, therefore, the reasons for the success of the methods used were not understood. The methods ordinarily used in the home are successful only with fruits and with certain vegetables like tomatoes which contain a considerable quantity of acids. You will recall the fact that acids are generally detrimental to the growth of bacteria. It is doubtless on account of the influence of these acids that food, which contains them in sufficient quantities, may be canned successfully with the moderate degree of heat available in the ordinary household.

It is difficult to heat food in the ordinary household to a temperature higher than that of boiling water and this is not sufficient to kill, in a reasonable length of time, the resistant spores of certain bacteria which are always found on such foods as green corn, beans, and peas. Consequently these foods are seldom successfully canned in the home. There is a method, however, by which such foods may be successfully canned in the home without special apparatus. This consists in heating the food in the cans to the boiling temperature for about a half hour on each of three successive days and then sealing up the cans with lids and rubbers which have also been heated along with the vegetables. The heating the first day kills all active growing bacteria and probably serves to stimulate the spores to begin to grow. These then are killed with the second heating, and the third heating serves to kill any that may have escaped the first two heatings. If the fuel used in this process is expensive, it is likely that the food canned in this way will, in the end, cost about as much as it would cost to buy the same amount of food which has been canned in a factory. 
482. Factory Canning.-As has been stated, the canning process as ordinarily carried on in the household, finds its limitations in the fact that the temperature of boiling water, which is the highest temperature conveniently obtainable without special apparatus, is not sufficiently high to kill the more resistant spores of molds and bacteria in a reasonable length of time. Canning factories, however, are equipped with special apparatus by means of which the food that is canned may be raised to any desired temperature in the process. Such apparatus generally consists of what might be called a large steamer of boiler iron construction. A large number of cans containing the food, are placed in this steamer and then steam is turned into this apparatus until a certain pressure is reached. You are familiar with the fact that steam arising from boiling water is practically of the temperature of the boiling water; that when the steam is under 1 atmosphere of pressure its temperature is $100^{\circ} \mathrm{C}$., or $212^{\circ} \mathrm{F}$.; but when steam is held under pressure, the temperature increases with the pressure (see Arts. 155 and 160). Consequently, by surrounding cans containing food with steam under pressure, the food may be raised to a temperature sufficiently high to kill in a few minutes the most resistant spores of microörganisms.

When the cans are placed in the heating apparatus, they are generally sealed up except for a very small hole in the top of the can. As soon as the cans come from the heating apparatus, a drop of solder is dropped on this hole and it is sealed. This hole is left in the can while it is being heated for the purpose of permitting the air which is contained in the can to escape as it is expanded by the heat. Since the hole is sealed up while the contents of the can are still very hot and therefore more or less expanded, the contents of the can will shrink slightly on cooling and the ends of the can will become slightly concave as a result of the atmospheric pressure on the outside. This fact is important as it affords a means of detecting cans which have not been perfectly preserved, for some kinds of bacteria are gas producers and when 
they begin action on the food in a can, they soon liberate sufficient gas to cause the ends of the can to bulge out and become convex. Cans which thus show this swelling are discarded before they leave the factory. Some kinds of bacteria, however, do not produce gases by their action and so the failure of a can to swell is not an absolute guarantee that the food is perfectly preserved.

In ordinary practise in canning factories, the food is heated to a temperature of from $110^{\circ} \mathrm{C}$. to $125^{\circ} \mathrm{C}$. for from 20 minutes to a half hour. The operator determines the temperature by noting the reading of the steam gauge. What pressure is required for $110^{\circ} \mathrm{C}$. ? for $125^{\circ} \mathrm{C}$. ? (Table VI, page 135.) The time and temperature vary with the kind of food that is being preserved and with the size of the cans. Equipped with this power to destroy by heat the most resistant forms of microörganisms, the canning factories are able to preserve any kind of food that is not seriously injured by the high temperatures. Fruits and vegetables of every kind, milk, meats, soups, and many other forms of food prepared ready for use are now preserved by canning.

These foods are preserved when they are in season and generally in the part of the country where they are produced. They then become available throughout the year and in every part of the country. Before the introduction of canning, the food of the people naturally varied considerably at different times of the year. Fruits and vegetables were abundant in the summer time and scarce in the winter, but now we may have practically the same variety of foods throughout the year at very little added cost.

Canning factories, like most other modern factories, have many forms of labor-saving machinery which help to cheapen the cost of their products. A discussion of these, however, would take us outside our present topic, and besides this, you could learn more in an hour's visit to a neighboring factory than we could tell you in several pages.

483. Sterilization and Pasteurization.-It is obvious from 
the foregoing that the process of canning depends on the complete destruction of all forms of living organisms in the food. The process of killing all microörganisms in a given substance is known as sterilization. If foods which from their moisture content and other conditions are favorable food for bacteria are to be kept for any considerable time, they must be completely sterilized and sealed up so as to be free from the entrance of bacteria, for, if a single bacterium or spore is left in the food in a living condition, it will soon multiply and the food will be destroyed.

Many times, however, we care to preserve food for only a short time. In such cases complete sterilization is not necessary. Furthermore, some foods, like milk, are seriously injured by the high temperature necessary for complete sterilization. If milk is heated even to boiling, some of the proteins which it contains are coagulated and the flavor of the milk is greatly changed. The coagulated protein is not so easily digested as it is in the fresh state and the changed flavor makes it less palatable than fresh milk. Consequently, since milk is usually consumed within 24 to 48 hours after it is drawn from the cow, the bacterial action which might otherwise cause it to sour within that time may be effectively prevented by heating the milk after it is bottled to a temperature sufficiently high to kill only the active growing bacteria which it contains. If milk is heated to $60^{\circ} \mathrm{C}$., or $140^{\circ} \mathrm{F}$., for 20 minutes, all the active bacteria in it will be killed, but the milk will not be changed essentially in flavor or digestibility. Such an amount of heating is not sufficient to kill the bacterial spores in the milk and these will soon begin to grow and multiply and the milk will ultimately sour. The souring is delayed by this process, however, and this delay usually makes it possible for the milk to be delivered to the consumer and consumed before the souring occurs. This process of heating food to a temperature sufficiently high and for long enough time to kill the active bacteria but not to kill the spores, is called pasteurization. You will note by the spelling of the 
term that it is named for PAsteur (see Art. 451). Pasteur did not originate the process, but he perfected it and applied it in several practical ways and succeeded in inducing people to make use of it.

484. Pasteurization and the Spread of Disease.-This delay in the souring of milk is by no means the most important result of the practice of pasteurizing milk. A far more important result lies in the fact that disease-causing bacteria which the milk may chance to contain are effectively killed by the process. Milk is an ideal food for most bacteria and, for this reason, it often becomes a means for the spread of bacterial diseases, such as typhoid fever, tuberculosis, and diphtheria. None of the bacteria which cause the more common contagious diseases are known to form spores and, therefore, any such bacteria are effectively killed by pasteurization.

\section{Il. PARASITES}

485. Parasites and Their Hosts.-You will recall the statement made in Art. 433 that organisms which live and find their food within the bodies of other organisms are known as PARASITES. The organism within whose body a parasite lives is known as the Hоsт. Parasites often produce certain poisons, or toxins, in the body of the host. These poisons attack certain parts of the body of the host and thus the parasites become the cause of what we commonly call diseases. The larger animals are affected by many kinds of animal parasites, such as tapeworms, trachina, and the malarial parasite, but most of the common diseases are caused by plant parasites and the bacteria are by far the worst offenders in this way. A good many different kinds of bacteria, however, are known to live and thrive within the mouths and alimentary tracts of man and of other animals which are not known to cause any harm to their hosts. Indeed, it is thought by some bacteriologists that some of these bacteria are of benefit to their hosts in some unknown way. 
486. Former Theories of Disease.-Before taking up a discussion of the nature of bacterial diseases, it might be well to consider briefly some of the early theories that have been held concerning the cause of disease. One of the earliest of these theories consisted in a belief that the diseases were caused by an "evil spirit" which entered into the body and behaved in such a manner as to bring pain and suffering to the patient. Such a theory was more or less of a natural inference from a superficial study of the symptoms of an ordinary disease, and it seemed to fit particularly well as the explanation of the various forms of diseased condition which we know as insanity. This theory was held longest in regard to diseases of this type.

Two different lines of treatment were followed in attempting to cure diseases according to this theory. It was thought that the spirit could either be induced to leave the body of the patient by sacrifices or promises or it could be forced to leave by charms, by the beating of tom-toms, or by torturing the body of the patient, and thus making it uncomfortable for the intruder. You have doubtless read of some of the strange customs practised by savage tribes today in the treatment of their sick. Most such customs grow out of some form of this theory of disease, for it seems that most present-day primitive peoples, as well as the savage ancestors of civilized man, hold to this theory in some form.

487. Semi-scientific Theory of Disease.-Hippocrates, a Greek philcsopher, who was born about $460 \mathrm{~B}$. C. and who is often called the "Father of Medicine," promulgated a new and semi-scientific theory of disease. According to this celebrated theory, the body contains four humors: blood, phlegm, yellow bile, and black bile. Health consisted of a proper mixture of these four humors and disease consisted of an improper mixture. The treatment of diseases according to this theory, consisted in an effort to keep the humors in a proper relation to one another. This was done by administering powerful drugs. This theory soon gained world wide 
acceptance and it was the dominating theory of disease throughout the whole of the dark ages. Indeed, its influence is still potent in much of the current thought and practice in medicine today. By the giving of drugs of many kinds for many kinds of diseases, a large number of really valuable medicines which are in wide use today were thus empirically discovered, i.e., discovered by experiment. Quinine, for example, was known to be a cure for malaria long before it was known that the disease is caused by a little microscopic animal which is killed by the quinine.

It must be some little surprise to you to realize that it was not until a comparatively recent date when the GERM THEORY OF DISEASE began to be generally accepted that the practice of medicine, really began to be placed on a sound scientific basis. The year 1876 is a memorable year in the history of medicine for it was in that year that Robert Koch succeeded in demonstrating beyond the possibility of a doubt that a certain disease of domestic animals was caused specifically by a certain rod-shaped bacterium which is now known as Bacillus anthrax. Since this is a typical bacterial disease and one about which a great deal is known, we shall use it to illustrate the nature of a bacterial disease.

\section{Anthrax}

488. Animals Affected.-ANTHrax, or sPLENIC FEver, as it is sometimes called, is, in nature, primarily a disease of cattle and sheep though it sometimes attacks a large number of other animals including man. Horses, hogs, and dogs have a relatively high degree of resistance to the disease though none of them is entirely free from occasional attacks of it. Rabbits, guinea-pigs, and white mice are extremely susceptible, especially so when the bacteria are injected under the skin of the animal. A single bacterium injected under the skin of a white mouse is sufficient ultimately to cause the death of the animal. Carnivorous, or flesh-eating animals are, as a 
rule, more resistant to the disease than are herbivorous, or plant-eating animals, but the former are not entirely free from attacks, as epidemics have at different times broken out in zoological gardens among leopards, lions, bears, and other animals of this class. Wild deer, elk, and goats are subject to occasional outbreaks.

489. Symptoms of the Disease.-In cattle, sheep, and other animals which the disease attacks readily, the bacteria multiply rapidly, become enormous in numbers, and swarm throughout the entire body of the animal. They float in the blood and accumulate in large numbers in the spleen, liver, kidneys, and lungs. This general distribution of the bacteria throughout the system is known as sePticemia. Internal hemorrhages, or bleeding, occur in different parts of the body, a high fever results, and death occurs very suddenly. In animals which offer a high resistance to the disease, the condition septicemia seldom results but local infections in the form of large carbuncles develop instead. If these are lanced and kept cleaned out, healing and recovery usually occur. Men who handle hides from infected animals often have these carbuncles on their hands or shoulders where they carry the hides. In such cases, the spores of the organism are supposed to enter the body of the victim through the skin. Men who handle wool from infected sheep often contract the disease in a form which is known as wOOL-SORTER's DISEASE. In this case, the spores are taken into the lungs and cause a disease resembling pneumonia.

490. Character of the Bacterium (Bacillus anthracis).The organism which causes this disease is a rod-shaped bacterium and one of the largest of the known PATHOGENIC, or disease-causing, bacteria (Fig. 273A). Under certain conditions, it forms spores which have remarkable powers of endurance (Fig. 273B). Spores have been known to remain alive in pastures and still to be able to cause the disease for as long as 30 years. The bacteria can be grown artificially on GELATIN CULTUREs and, if grown at a suitable temperature (their 
optimum temperature, $37^{\circ} \mathrm{C}$, or $983 / 5^{\circ} \mathrm{F}$., the temperature of human blood), they retain their virulence, or disease-causing power, and will speedily cause the death of a susceptible animal if injected into its body.

491. Methods of Prevention and Cure.-Since the discovery of a method of preventing this disease was an event of unusual importance in the history of medicine, you will be interested in knowing something of the circumstances which lead to its discovery. The great "Father of Bacteriology," LouIs Pasteur, discovered the principle

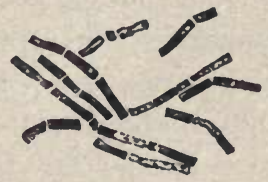

A

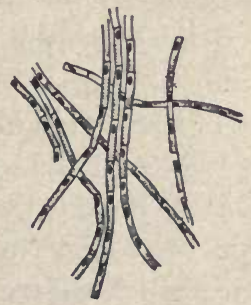

$B$

Frg. 273. - A. Bacillus anthrax. B. The same with spores.

involved in the method in the year 1880 and perfected the method of preventing anthrax during the following year. After RoBert Kосн had established beyond all possible doubt that Bacillus anthracis is the specific cause of the disease anthrax, PASTEUR turned all his powerful energies and his genius to the study of infectious diseases.

At this time, anthrax was known and dreaded all over the world and in some years it had caused a loss in France alone of 20,000,000 francs, or 4,000,000 dollars. The burden of the scourge fell heavily upon the peasants or farmers, many of whom had suffered the loss of their entire flocks. Pasteur, some years before, had been of great service to the peasants of his country and the world by showing them how to avoid the terrible silk-worm diseases which had nearly ruined the silk industry of the country and he now longed to find some method of combatting anthrax. He had in his laboratory many cultures of different kinds of pathogenic bacteria and among these were cultures of the bacteria that cause the com- 
mon disease, chicken cholera. He had labored with his experiments so strenuously that he was finally forced on account of ill health to take a short vacation. This he dreaded to do for he feared that lack of care would cause all his valuable cultures to die. When he returned to his laboratory, you can imagine his dismay when he found that all his cultures were apparently ruined. This would have meant that much of his labor had been lost and that the final result which he hoped for would have been delayed. He made every effort to revive his cultures by transferring them to new culture media and among other things, he inoculated some chickens with one of these old cultures of the bacteria that cause chicken cholera. These chickens failed to develop any symptoms of the disease; Pasteur considered the cultures lost. He was greatly surprised, however, to find that later when he inoculated these same chickens from fresh virulent cultures, they failed to take the disease. He quickly prepared other cultures and allowed them to stand in test tubes as these original ones had done and then repeated the experiment of first inoculating chickens with the weakened cultures and then later inoculating the same chickens from fresh virulent cultures. He was thus soon able to prepare weakened, or ATTENUATED, cultures, as he called them, which would regularly serve to prevent the chickens from taking the disease when inoculated from strong virulent cultures.

This method of treating, or vaccinating, chickens, as the process has come to be called, has never come into general use, for later experience showed that some fowls are really given the cholera by it. It served, however, to give Pasteur a principle to work on, and he was soon able to produce a VACCINE for anthrax which has proved to be of inestimable value.

After numerous experiments in which Pasteur grew the anthrax bacillus under almost all possible conditions and then used them to inoculate susceptible animals, he finally discovered that, when the bacteria are grown at a temperature 
of from $42^{\circ}$ to $43^{\circ} \mathrm{C}$., or $10835^{\circ}$ to $1092 / 5^{\circ} \mathrm{F}$, they gradually lose their viRULENCE, or disease-producing power, but do not lose the power to stimulate the animal to build up its resistance to the disease.

492. Preparation and Application of Anthrax Vaccine.-In the ordinary practice of preparing the vaccine, bacteria whose virulence has been tested by inoculation experiments on rabbits or guinea-pigs are grown at the temperature of from $42^{\circ}$ to $43^{\circ} \mathrm{C}$. for varying lengths of time. Whenever it is found that the culture has been so weakened that it will just kill white mice but not quite kill guinea-pigs, about $1 / 4$ c.c. of the culture is injected into cattle and half this amount into sheep. About twelve days later, a similar dose of a culture that will just kill guinea-pigs but not quite kill rabbits is injected. After this, virulent cultures may be injected with impunity, and the animal so treated will not contract the disease in any natural way.

493. Nature of Immunity:- When an organism is free from liability of attack by a given disease, it is said to be IMMUNE or to possess IMMUNITY from the disease. All organisms are naturally immune to certain diseases that affect other organisms. Thus man is not at all susceptible to chicken cholera or to a good many other diseases that affect domestic animals and, on the other hand, the domestic animals are not affected by very many of the diseases that affect man. We call this sort of immunity, NATURAL IMMUNITY. But you are familiar with the fact that when you have once had an attack of measles or whooping cough you are not liable to have these diseases again, even though you be repeatedly exposed to them. You are thus rendered immune to these and other diseases by having had them. This kind of immunity, we call ACQUIRED IMMUNITY. You will note that the method of vaccinating an animal with an attenuated culture of the organism that causes a certain disease gives the animal an acquired immunity against the disease without the necessity of the animal's having the disease. 
494. Results of Anthrax Vaccination.-In 1894, after the anthrax vaccine had been in use for twelve years, Professor Chamberland, who had been made responsible for the production of the vaccine, reported that $3,296,815$ sheep and 438,824 cattle had been vaccinated in France with a mortality due to the vaccination, of only about 1 per cent. for sheep and of 0.34 per cent. for cattle. At that time, it was estimated that the average annual loss from anthrax among unvaccinated sheep was 10 per cent. and among unvaccinated cattle was 5 per cent. You can see by this that this single discovery by Pasteur has been, and will be for all time to come, of enormous value to stock raisers throughout the world. Vaccination of cattle and sheep and sometimes of other animals is now regularly practised in all countries where the disease has occurred. This includes practically all countries in which cattle and sheep are raised.

\section{Vaccination and Smallpox}

You are familiar, in a way, with vaccination against smallpox. Since the principle involved in this is essentially the same as that in vaccination against anthrax or any other disease, a little discussion of smallpox vaccination will serve to make the process clearer to you.

495. The Origin of Smallpox Vaccination.-Prior to about the year 1800, smallpox was an extremely common disease. It was so very common that few people escaped having it sometime during life, and it has been estimated that fifty million people died of it in Europe during the eighteenth century. In the early part of this century, it was discovered that, if a little of the pus taken from a patient suffering with the disease is injected under the skin of a healthy person, a mild form of the disease generally results, and that this has the same immunizing result as a more virulent attack of the disease which might be contracted in some natural way. This practice was introduced into England in the year 1717 and for 
over a hundred years was widely practised until it was prohibited by an act of Parliament in 1840. The danger of this practice lies mainly in the fact that persons artificially infected in this way become new centers for the spreading of the disease in the virulent form.

In 1796, Edward Jenner, a country physician, in England, observed that persons who had been affected with cow-pox, a mild eruptious disease of cattle, were very unlikely to contract smallpox even when repeatedly exposed to it. This led him to recommend, and to practise on his patrons the use of the virus of cow-pox instead of that of smallpox as a means of producing immunity to the latter disease. His method proved to be a remarkable success and soon came into general use. At present, the vaccine is produced by inoculating a healthy calf with the cow-pox virus and then after about five days, the virus of the pustules, which develop near the place of inoculation, is removed, mixed with glycerine and kept until it is proved to be free from bacteria and other organisms, and then it is ready for use in vaccination.

496. Cause of Smallpox not Known.-You will note that this method of vaccinating against smallpox was discovered more or less accidentally long before the germ theory of disease came to be generally accepted. Consequently, at the time of its discovery, no one had any idea of the nature of the process by which the immunity is brought about. We have not even yet been able to discover the organism which is the cause of this disease, and our only reason for believing that it is caused by some microörganism, is its general resemblance to other diseases that are known to be thus caused. Since we do not know the organism, we can judge of the nature of the immunizing process only by comparison with other better known diseases. From this point of view, it is the opinion of most students of the subject, that the organism which causes cow-pox is the same as the one which causes smallpox and that in passing through the body of the calf, the organism becomes attenuated, or weakened, so that it 
is unable to produce smallpox when introduced into the human body, but is still able to stimulate the body to build up its defenses against the virulent form of the organism.

497. The Effectiveness of Smallpox Vaccination.-The comparative rarity of smallpox in recent years in most countries as compared with the eighteenth century is ample evidence of the effectiveness of vaccination as a preventative of the disease. More striking evidence, however, can be found in countries in which vaccination is made obligatory. In 1870-71, during the Franco-Prussian war, the armies of both Germany and France were attacked by smallpox. Vaccination had been compulsory in the German army since 1834 but was not compulsory in the French army. As a consequence, the French lost 23,000 soldiers from smallpox and the Germans lost only 273 from that cause. Vaccination has been compulsory in Sweden since 1810. From 1774 to 1801, smallpox had caused an annual death rate of 2,050 per million of inhabitants in that country. During the years from 1810, when vaccination was made compulsory, to 1855 , this death rate had fallen to 169 per million, and in the period from 1884 to 1894 , the average annual death rate was only 2 per million. This shows that, if all countries would follow the example of Germany and Sweden in requiring that every citizen be vaccinated, smallpox might entirely disappear from the earth. It shows further that as long as frequent outbreaks of the disease are allowed to occur as they do every winter in this country, an individual is very foolish if he does not submit to vaccination as often as it will take.

498. How Often Should One be Vaccinated?-In a report of the Board of Health of the city of Berlin, the following sentence may be found: "Vaccination in infancy, renewed at the end of childhood, renders the individual practically as safe from death from smallpox as if that disease had been survived in childhood, and almost as safe from attack." In a recent report of the Illinois State Board of Health, occurs the following sentence: "A recent successful vaccination is a 
positive protection against an attack." Obviously, then, everyone should be vaccinated in infancy and at least once after reaching maturity. Anyone who travels or mingles much with people in the winter time should be vaccinated every four or five years.

\section{DIPHTHERIA}

There is probably no other serious bacterial disease which attacks the human race whose story is so well known as is that of diphtheria. Our knowledge of the details of this disease and of its cure and prevention is well-nigh perfect and it thus constitutes the most complete triumph of the science of bacteriology. This being the case, a somewhat detailed account of the disease will serve to acquaint us with the general theory of bacterial diseases, their cure and prevention.

499. Discovery of the Organism and Its Relation to the Disease (Bacillus diphtheriæ).-In 1883, KLEBS discovered and described the organism and in the following year LöFFLER succeeded in obtaining pure cultures of it from the throats of patients suffering with the disease. This seemed to indicate plainly that the organism is the specific cause of the disease, but Löffler himself was at that time inclined to doubt this, for he had found the same organism in the throats of perfectly healthy children and at the same time had failed to find it in the throats of some patients who showed strong symptoms of the disease. These causes for doubt have since been completely cleared away, however, for it is now known that certain other bacteria can cause a condition of the throat which is practically indistinguishable from that caused by the diphtheria bacillus, and again it is now known that some people carry diphtheria bacilli about in their mouths and throats and yet are entirely unaffected by them. This latter fact is an important factor in the spread of the disease, for people who thus carry the organism about may give the disease to more susceptible persons.

The final discovery which proved beyond all doubt the 
relation of the organism which Klebs had discovered to the disease was made in 1888-89 by Roux and Yersin. These men showed that the organism forms a toxine or poison which may be isolated from the organism and which, when injected into a susceptible animal, causes all the characteristic symptoms of the disease.

500. Symptoms of the Disease.-The organism usually finds lodgment and develops on the mucous membrane of the throat, nose, and rarely of the lungs. Even the eyes or the middle ear may become the seat of infection, though, in the great majority of cases, it is the pharynx that is affected. The form of the disease that is sometimes called membranous croup is an affection of the larynx. In rare cases, the organisms enter the general circulation and give rise to septicemia but usually they are confined to some local area of the mucous membrane where they develop and secrete their toxine and cause a white membrane to develop. The toxine is absorbed into the system where it attacks certain vital organs, principally the heart, nerves, and kidneys. In these organs, it causes a fatty degeneration and, therefore, a weakening of the organs. This weakening of the heart is doubtless responsible for many sudden deaths from what are apparently mild attacks of the

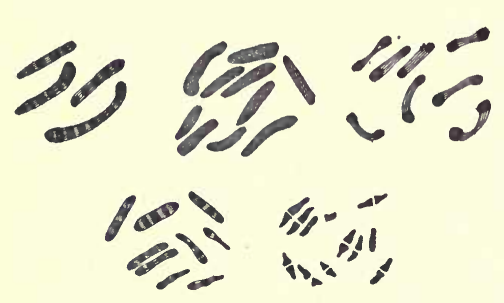
disease, and the weakening of the larger nerves and of certain tissues of the brain are the cause of many cases of paralysis which follow attacks of the disease.

501. Character of the FIG. 274.-Bacillus diphtheria. Organism. - The diphtheria bacillus is a slender rodshaped organism of moderate and somewhat variable size (Fig. 274). When it is stained by a method invented by Löffler, it presents a sort of beaded or granular appearance which is so characteristic that a trained bacteriologist can recognize it with certainty. This makes possible certain 
diagnosis of the disease and enables a physician to determine with certainty when a patient may safely be freed from quarantine. The organism grows readily on several different kinds of culture media and grows abundantly in milk if kept at a suitable temperature. This latter fact is an important factor in the spread of the disease and a good many epidemics have been known to be caused by the handling or distributing of milk by some person suffering with a mild attack.

The organism is not known to form spores but it has a rather high resistance to drying and has been known to live and retain its virulence for several months in dried membrane or sputum. This makes necessary the disinfection of houses in which cases have occurred.

502. Nature of the Toxine.-When the bacteria are grown in a nutrient broth, a soluble toxine is produced in the broth. This may now be passed through a fine porcelain filter which effectively separates the bacteria from the broth containing the toxine in solution. This sterile toxine, when injected into the body of a susceptible animal, produces all the symptoms of the disease except the false membrane in the throat. The false membrane is caused, in a normal case, by the bacteria themselves together with certain fibrinous excretions of the mucous membrane. Since the bacteria are not present in the body of a healthy animal inoculated with the sterile toxine, the membrane does not form.

Little or nothing is known of the chemical nature of the toxine or of the manner of its production. It is only known that it is a powerful poison which is thrown out from the bodies of the bacteria and which attacks certain tissues of the animal body.

503. The Antitoxine.-In 1890, Benring and Kitasato took the next step in the mastery of this disease by discovering a method of producing an ANTITOXINE which is both a cure and a preventive for this disease. They experimented with rabbits by first inoculating them with attenuated (weak- 
ened) cultures of the bacteria and later with more virulent cultures. After the rabbits had been treated in this way, they were completely immune from the disease. Next, these experimenters discovered that the blood serum of the immunized rabbits, when injected into other rabbits that had been inoculated with virulent cultures of the bacteria, had the power of neutralizing or destroying the toxine produced by the bacteria. In other words, they had discovered that the blood serum of immunized rabbits contained some substance which destroys the toxine of the diphtheria bacteria and which, when present in the blood of an animal, protects the animal against the toxine. It is thought that in some way, the diphtheria toxine stimulates the body of the animal to produce this neutralizing substance or antitoxine, as it is called. Since these first experiments, it has been found that the body of an animal can be caused to produce the antitoxine by merely injecting into it some of the sterile toxine which has been freed from the bacteria.

504. Preparation of the Antitoxine.-The antitoxine now in use in the treatment of diphtheria is manufactured in the bodies of horses. The methods by which this is done are of the most careful and painstaking kind and every possible precaution is taken to insure the purity and safety of the product. In the first place, perfectly healthy. horses are secured and they are surrounded with every condition conducive to continued good health. When found to be perfectly healthy by the most searching examination, a small fraction of a cubic centimeter of sterile broth culture, containing a standard quantity of diphtheria toxine is injected under the skin of the horse. This causes some fever and swelling at the point of injection but the horse soon recovers and is able to stand a stronger dose the next time. The dose of toxine is gradually increased as fast as the condition of the horse will permit until as much as from 300 to 500 c.c. of the broth containing the toxine are injected at one time. The reason that the horse can stand gradually increasing doses, lies in 
the fact that his body is all the time producing more and more of the antitoxine which neutralizes the toxine when it is injected. After the period of toxine treatment which lasts usually about six weeks, the horse is given about two weeks rest to make sure of the neutralization of all the last dose of toxine. Next, the horse is bled from the jugular vein in the neck and as much blood is taken as the horse can well stand. The blood is taken in a manner to insure its freedom from bacteria of any kind and is allowed to stand until it clots, or until the serum separates from the corpuscles. The serum contains the antitoxine in solution. The serum is now drained off from the clot, carefully tested as to its freedom from bacteria, and standardized as to its strength in antitoxine. It is now put up in small tubes to which sterilized needles for injection may be attached and is ready for use.

505. Curative Value of the Antitoxine.-The curative value of the antitoxine lies in its power to neutralize or destroy the toxine and thus prevent the latter from attacking the tissues of the body. The antitoxine also seems to be detrimental to the development of the organisms at the seat of infection; therefore by repeated doses the patient usually soon begins to improve rapidly and the white patch begins to disappear from the throat. It happens that neither the horse serum nor the antitoxine which it holds in solution are in any way harmful to the human body, and so almost any quantity of the serum may be injected. In ordinary practice, 3000 or 4000 units of antitoxine are given as a dose in cases of moderate severity, but in cases of great severity or in cases which are far advanced when a physician is called, as many as 8000 to 10,000 units are given as a dose.

506. Results of the Use of Diphtheria Antitoxine.-Ever since the early nineties of the last century, the horse serum for the treatment of diphtheria has been in common use throughout the civilized world and its effect on the death rate from this disease has been remarkable. This is shown by the following table which shows the average death rates, from diphtheria, 
per 10,000 of population in the leading cities of the world during the decade just preceding and the one just following the introduction of the serum.

$$
\text { Before Use of Antitoxine }
$$

Paris.........

Berlin........

London....... .

New York.... .

Boston........

Chicago.......
6.41

9.93

4.85

15.19

11.76

14.29
1895-1904 Antitoxine Period

1.49

2.95

3.88

6.62

6.34

5.13

It might appear that, since the serum is such a perfect cure for the disease, the death rate should be reduced much lower than the preceding table shows. It is a fact, however, that for the best results the serum needs to be used in an early stage of the disease and, since there are so many other types of sore throats which may be confused with an early stage of diphtheria, many people fail to call a physician in time to give the serum a fair chance.

507. Antitoxine as a Preventive of Diphtheria.-Diphtheria antitoxine is not only a specific cure for the disease but it has been found very effective also as a preventive. When a case of diphtheria breaks out in a family, the physician who attends the case, the nurse, and members of the family who are liable to exposure are generally given regular doses of the serum. This treatment is usually effective in preventing further spread of the disease.

\section{Other Bacterial Diseases}

It will be impossible for us to consider other bacterial diseases as fully as we have considered diphtheria. This study, however, has given us considerable knowledge of the general theory of such diseases and some brief mention of some of the more important ones that remain will be of value.

508. No Two Diseases Just Alike.-It might appear to you that, since we have worked out so perfectly methods of cure and 
prevention for one bacterial disease, it should be easy to work out similar methods for all other diseases. This is far from being true. To understand this, you must remember that these different diseases are caused by different species of bacteria and that these different species vary very widely in their characteristics and in their relations to the animal body. For example, not all disease-causing bacteria produce a soluble toxine which can be easily separated from the organism and used in the production of antitoxine as in the case of diphtheria. Again, the antitoxines, when produced, are not always so effective in the neutralization of the toxine or so harmless to the body of the patient as is that of diphtheria. Many other differences exist which can not be explained here because of the technicalities and difficulties they involve. It is enough to say here that almost every bacterial disease presents its own peculiar difficulties and that little headway has been made up to the present time in dealing with some of them.

509. Prevention and Cure.-In general, it may be said that the efforts of bacteriologists in seeking to gain control over bacterial diseases are directed along three general lines.

First, they seek to find some method of preventing the disease or of giving the people or animals artificial immunity from the disease. As a result of efforts along this line we have the various vaccines, such as Pasteur's vaccine against anthrax which consists of attenuated cultures of the bacteria, or the cow-pox virus as a vaccine against smallpox. When vaccines are used, you will note that the body of the patient is stimulated by the presence of the toxine or the attenuated bacteria to secrete its own antitoxine or to raise its resistance to the disease in some other way.

Second, the bacteriologists seek to find some method of producing an antitoxine and therefore a cure for the disease as in the case of diphtheria and some others that will be mentioned later.

Third, bacteriologists seek to learn the methods by which the different diseases are ordinarily spread from patient to 
patient. Knowing this, they are able to devise methods of preventing such spread of the disease.

It is obvious that the first two of these lines of effort must be left to the bacteriologists and physicians but it is quite as obvious that the value of the known methods of preventing the spread of disease depends very largely on the faithful coöperation of all the people. Therefore, it is quite important that as nearly as possible, everyone should come to know how the common diseases are ordinarily disseminated and how this dissemination might be prevented. For this reason, this latter phase of disease should be emphasized in a book like this.

\section{Important Facts about Common Diseases}

510. Pneumonia.-This is primarily a disease of the lungs and is usually caused by a specific spherical bacterium called PNEUMococcus. In most serious cases, however, the organism finds its way into the general circulation and is distributed over the body. While pneumococcus is the cause of a majority of the cases of pneumonia, other organisms, such as Bacillus diphtheriæ, and Bacillus influenzæ, and others may cause an inflammation of the lungs which is difficult to distinguish from that resulting from pneumococcus. Often two or more of these organisms are involved in an attack of the disease.

Pneumococcus and the several other organisms which may cause this disease are very widespread and are very commonly present in the mouths and throats of healthy persons. As long as the body is in a vigorous state of health, however, it is usually able to ward off an attack but often when weakened by other illness, or by exposure to extreme cold, hunger, fatigue, or lack of fresh air or other similar causes, the resistance of the body seems to break down and the disease gets a start. This fact explains why the disease so often follows other forms of illness and also why it is more prevalent in the winter time than in the summer. Lack of fresh air in the winter time is a fruitful cause of pneumonia. Hence it is 
obvious that the surest means of escaping this disease lies, not in an effort to escape the bacteria for that is practically impossible, but in keeping the body in a vigorous state of health. Fear of this disease should be a strong stimulus to sanitary living. Good food in moderate amounts, warm clothing, plenty of exercise, and plenty of fresh air are the best means of protection against this disease.

A person who has suffered one attack of pneumonia shows little or no increased resistance to a second attack. Therefore, it seems that the organism does not form a soluble toxine nor does it stimulate the body to form an antitoxine. Consequently, we have no serum treatment for it of any kind. It is not definitely known just how the body finally overcomes the organism and recovers.

511. Typhoid Fever.-This is one of the most common and important of all bacterial diseases (Fig. 275) and yet it need not be if every one knew and practised some very simple things concerning it. The disease affects primarily the alimentary tract and is contracted almost wholly by taking the organism into the mouth with food or drink. The organism escapes from the body of the patient suffering from the disease with the wastes from the alimentary tract and in the -

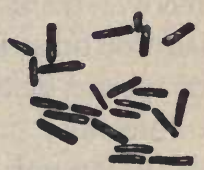

FIG. 275.

Bacillus typhosus. urine. Since the organism can not multiply or live for any great length of time outside the human body, it is evident that it must be carried more or less directly from the wastes of the sick patient to the alimentary tract of the next victim. This transfer could be quite effectively cut off if all the wastes from sick patients and convalescents everywhere were treated with disinfectants as soon as removed from the body. If this is not done, however, there are many ways in which the organisms may be spread to other persons. Flies may carry them directly to the food or water used by healthy persons; the nurse and other persons who wait upon the patient may carry them on their hands to the food or 
dishes used by other members of the family; they may get into water supplies or wells, into the milk distributed by dairies, or on fresh fruits and vegetables distributed by groceries and be widely spread through a community. In many such ways the transfer of the organism from the wastes of the sick patient to the food or drink of healthy persons is accomplished if it is not shut off at its source by the use of disinfectants.

If the wastes from a typhoid patient are all collected in a suitable vessel and treated with a 5 per cent. solution of carbolic acid for an hour before they are put into the sewer or outdoor vault, and due care is taken by those who attend the patient, there is little chance for further spread of the disease. This sterilization of the wastes needs to be kept up, however, until the patient is known to be free from the organism. The time when a patient is free from the organism after recovery can be determined by a bacterial examination. Some persons recover from the disease and yet carry myriads of the organism for months or even years and may, all the time, be a source of spread of the disease. Such persons are kncwn as TYPноID CARRIERS.

We do not have any successful serum treatment for typhoid fever but we do have vaccines which consist of the dead bacteria or materials derived from them that have proved wonderfully successful in rendering persons immune from the disease. Soldiers in the armies are regularly vaccinated against typhoid now and the result is that this disease which was once a principal danger to the soldier has, in many instances, nearly disappeared from the army camps. Vaccination is also widely practised in cases of epidemic outbreaks of the disease among private citizens. The immunity produced either by an attack of the disease or by vaccination is only temporary and so vaccination must be repeated at intervals.

512. Influenza or Grippe.-This very common disease is now known to be caused by a very small rod-shaped bacterium known as Bacrllus INFLUENZer. The disease is of common 
occurrence, especially in the winter time, and at times has swept over the country as severe epidemics. The organism generally invades only the mouth, throat, and air passages, the toxine being absorbed from such local infection. It follows from this that the organism is expelled from the body of the patient mainly through coughing and sneezing and in the sputum. It has been found that very little drying serves to kill the organism and therefore the disease is generally contracted through rather intimate association with a patient or convalescent. Due observance of this fact may enable one to avoid contracting the disease.

513. Common Colds. - What we commonly call "bad colds" are infectious diseases which are due to a variety of organisms. Streptococcus, pneumococcus, and the bacilli of influenza and diphtheria as well as other organisms may each be the cause of what is generally regarded as a bad cold. The first stages of the more virulent diseases caused by these organisms show essentially the same symptoms as a cold. This fact makes a cold deserving of more serious attention than it commonly receives. When one goes about his work, mingling with other people, when suffering from a cold, he is, not only running a serious risk himself, but is exposing other people to danger. We should be taking a long stride toward the prevention of seyeral serious diseases, if we could induce everyone to give proper attention to bad colds.

514. Tuberculosis. - This disease is often spoken of as the GREAT WHITE PLAGUE, and it richly deserves that name for it is, each year, responsible for more deaths than any other single cause. It has been estimated that in 1907, 153,000 persons died from tuberculosis in the United States. It has also been estimated that it cost the people of the country annually $\$ 200,000,000$. Another bad feature of the disease is the fact that it usually results in a comparatively early death. The average age of persons dying from tuberculosis in the U.S. has remained at about 35 years ever since 1860 , when statistics first began to be collected. Death at this age is about the 
saddest, for it usually means broken families and motherless and fatherless children. Another bad feature of the disease is that it usually means a long lingering illness that is more or less hopeless.

It is difficult to paint the picture of this disease too darkly and yet it is important that everyone come to know how great a scourge it is. If every citizen could realize how great a danger threatens him from this source we might have a more united effort in our endeavor to do away with the disease or lessen its attack.

There is hardly any part of the human body that the TUBERCULAR BACILLUS (Fig. 276) may not attack. The lungs

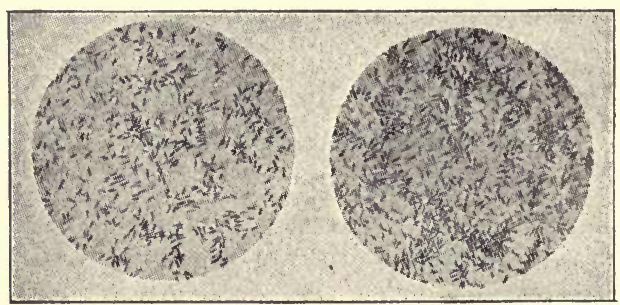

FIG. 276.-Tuberculosis bacilli.

constitute the chief seat of infection but the intestines, the various glands of the body, the skin, the throat, the bones and joints and other parts of the body are frequently attacked. The organism generally finds entrance to the body through the mouth or nose and it also leaves the body to become a source of infection to others through the same openings. The sputum of a consumptive contains myriads of the organism and it has been found that in dried sputum, some of these organisms may retain their vitality for as long as eight months. This fact makes it obvious that all sputum from tubercular patients should be completely destroyed or sterilized. The droplets of water that are usually thrown violently into the air when a tubercular patient coughs or sneezes usually contain great numbers of the bacteria and are thus a source of danger to 
others intimately associated with the patient. The spoons, forks, and dishes used by a tubercular person are likely to be infected with the organism and should always be sterilized by boiling water before they are used by others. Strict observance of these and other similar precautions may enable one to live in the same family with a tubercular person and yet avoid infection.

515. Where Danger Lurks.-It seems that the average healthy person has a rather high natural resistance against tuberculosis, provided that he is properly conditioned but many occupations and customs of modern life are highly conducive to the contraction of the disease. People who work indoors, particularly where there is much dust, poor ventilation, and bad sanitary conditions are much more likely to contract the disease than are those who work in a better environment. This is shown by the following table which shows the number of persons per 100,000 of population in the specified occupations, who died from tuberculosis of the lungs in the year 1900.

\section{Occupation}

Marble and stone cutters............ 540.5

Cigar makers and tobacco workers...... 476.9

Compositors, printers, and pressmen..... 435.9

Servants.................. 430.3

Bookkeepers, clerks, and copyists........ 398.0

Laborers (not agricultural) .......... 370.7

Farmers..................... 111.7

Other sickness such as measles, whooping cough, scarlet fever, and influenza which leave the body in a weakened condition are often a predisposing cause of tubercular infection. During attacks of these and similar diseases and during convalescence, one should be extremely careful to avoid all chance of tubercular infection.

We often hear the statement made that tuberculosis is hereditary and that it tends to run in families. While the former statement is entirely untrue, it is doubtless true that susceptibility to the disease does run in families, or in other 
words, that the amount of resistance against the disease is a matter of heredity. For this reason, people who have tuberculosis in the family need to be extremely careful to avoid infection and to avoid conditions which are conducive to infection, for they are likely more susceptible than are others who have no tuberculosis in their ancestry.

516. Tuberculosis Curable.-We hear a good deal in these days in newspapers, in popular magazines, and in the advertisements of sanitariums to the effect that tuberculosis is a curable disease. This is no doubt true and the means of cure sound comparatively simple. They consist of rest, plenty of fresh pure air day and night, and plenty of good wholesome food. But no one should be deluded by the fact that the disease is curable by these means into being careless about contracting it. One great danger of the disease lies in the fact that one may be affected by it for months or even years before the fact is easily determined and then it is often too late to hope for a cure. If one is once seriously infected with tuberculosis, he is not likely ever to be able to do much else but obtain a cure, if he is ever successful in so doing. Many people with apparently high resistance have slight attacks of tuberculosis and recover without ever knowing that they had it. One investigator made a comprehensive study of the bodies of 500 persons who had died from various causes and he found evidences of former tubercular infection in 97 per cent. of the bodies. Doubtless most of these people had never known of the attack.

Our chief defenses against this disease are our natural resistance, and vigorous health. As long as the disease is as prevalent as it is, we can hardly hope to escape entirely chances of infection. We should do what we can to escape the organism but we should rely mainly on being able to overcome it when it attacks us. We should all try to live all the time much as a tubercular patient must live. We may not need so much rest but we all need the fresh air and the wholesome nourishing food. 
517. Malaria.-This disease is caused, not by a bacterium, but by a very small animal organism which, during an attack of the disease, swarms in the blood and attacks the red corpuscles. The life history of the organism and its method of being spread from one patient to another one are quite remarkable. When the organism gets into the human system, it enters a red blood corpuscle and there multiplies by a peculiar method of division. Finally, the corpuscle breaks down and sets the new organisms free in the blood plasma. These soon attack other corpuscles and repeat the process of reproduction. The breaking down of the corpuscles and the setting free of the young parasites which seems to occur at about the same time throughout the body of the patient, brings on the chill which is characteristic of the disease. This process is repeated through generation after generation of the organism and so the patient has a chill at regular intervals.

When a mosquito of a certain kind known as ANOpHeles bites a person suffering with malaria, it takes some of the malarial parasites into its stomach along with the blood. Here the organism takes a very different course of development. It first buries itself in the walls of the mosquito's stomach and a complicated method of reproduction takes place. Finally, great numbers of the organism collect on the salivary glands of the mosquito and may later be injected into the body of another human subject who is bitten by the mosquito. From eight to ten days are required for the organism to complete its development in the body of the mosquito and the mosquito is incapable of infecting a person during that time. The disease is normally spread from person to person in no other way than through the agency of mosquitos.

It has been found that quinine is a poison to the malarial parasite and therefore a specific cure for the disease. The quinine seems to be more deadly to the young parasites just set free from the blood corpuscles and, therefore, the time to administer the quinine is just after the chill.

Knowing the life history of the organism as we do, and 
knowing that the organism can be killed in the human system by the use of quinine, we are in a splendid position to combat the disease and it is surely possible to completely eradicate it in many places. If all persons suffering with malaria in a given locality were promptly and completely cured by the use of quinine, the mosquitos could do no harm for they could not become infected. On the other hand, if all Anopheles mosquitos in the locality were destroyed, no one could contract malaria from those suffering with it. It is probably best to make use of both of these methods at the same time. The parasite is able to linger in the human body for many months if it is not eradicated by quinine. During this time, the patient is likely to be fairly well part of the time and then to have repeated relapses. In this way, a few people in every malarial district carry the organism over winter while the mosquitos are not active and give the disease a fresh start when the mosquitos return. Consequently, the winter time is an important time for the treatment of malarial patients.

518. Other Diseases.-There are several other diseases which have been quite thoroughly studied and more or less mastered by bacteriologists but they are either unimportant or else occur so seldom in the United States as not to warrant discussion here. Among these are the bubonic plague and plague pneumonia, leprosy and Asiatic cholera.

\section{DISEASES WHOSE CAUSES ARE UNKNOWN}

We have several very common contagious diseases which from all appearances are due to bacteria or to microörganisms, and yet they have so baffled all efforts to determine their cause with certainty. In this list is included smallpox which we have already discussed sufficiently. We shall mention the others only briefly.

519. Rabies or Hydrophobia.-This disease in the human being generally results from the bite of a dog or other animal 
which is suffering from the disease. It is a disease of the nervous system and in many respects resembles tetanus or lockjaw. Although the cause of the disease is not known, Pasteur was able to devise a very efficient treatment which is administered at the various Pasteur institutes to be found in many of the large cities throughout the civilized world. There is plenty of time for the administration of this treatment after the person is bitten by a rabid dog, and no one should fail to take this treatment when bitten, however slightly, by a dog that is supposed to be mad. It has been found that a dog is able to infect a person for a day or two before it shows any signs of the disease.

520. Whooping Cough. - A bacterium resembling that which causes influenza is thought by some bacteriologists to be the cause of this disease but the fact may not yet be said to be fully established. The disease is extremely contagious and a patient is sometimes able to infect others for some time after apparent recovery. The disease is too often regarded as a simple disease and is not avoided as it should be. With very young children or with delicate children, it is often fatal. In 1907, 4856 children died of this disease in the United States.

521. Scarlet Fever and Scarlatina.-It is important for every one to know that these two diseases are one and the same. The severest type of scarlet fever may be contracted from a mild case which is sometimes called scarlatina. The disease seems to vary much in its virulence at different times and in the case of different people.

522. Measles. - We have almost no clue whatever as to the organism that causes this disease. It is probably entirely too small to be seen with the highest power of the microscope. This disease like most of the others of this list is subject to serious complications with other troubles and, consequently, the patient needs the very best of care to avoid, if possible, the complications. No one should think of getting along without calling a physician in case of an attack of any of these diseases.

523. Mumps.-There is strong evidence that a certain 
spherical bacterium is the cause of this disease but we may not yet consider the matter finally settled. The disease is extremely contagious and in many cases quite serious.

524. Infantile Paralysis.-This disease is not entirely confined to children as its name implies but it is true that children are much more frequently attacked by it than are grown people. It seems to be spread from person to person by contact and there is strong evidence that the little black horse fly which resembles the house fly very closely in appearance is also instrumental in its spread. It is an extremely serious disease and has lately been called the GREAT RED PLAGUE.

\section{PUBLIC HEALTH}

525. Our Duty Regarding Public Health.-It is perfectly evident that in matters that have to do with health, no one lives unto himself alone. One may do much for his personal health through proper attention to personal cleanliness, to food and clothing, to fresh air and exercise but in the matter of contagious diseases, no one person by his own efforts can guarantee his own safety. Those who supply us with milk and other foods may bring infection to us, we may get it from those with whom we associate, or we may get it from the strangers with whom we mingle as we travel. The city water supply may give us disease, or flies may carry it to us from garbage or sewage which are not properly disposed of. We may be endangered by the failure of public officials to properly enforce quarantine. In all these ways, we are dependent on others for protection against disease. If these others on whom we depend for protection are ignorant or careless, we are bound to suffer. Consequently, if we would seek to better our conditions with reference to contagious diseases, we must rely mainly on our efforts ta raise the general level of intelligence and sense of responsibility in regard to these things on the part of the whole people. Every one who has the grand privilege of a high school education and who learns concerning matters of 
health, even what may be learned in this book, should consider himself or herself eligible for leadership in matters of public health. There are needed in every community many people who will practise good sanitation and observe all the laws of public health and who will insist that others do the same. What we learn in school should be for use in our daily lives and it is to be hoped that what you have learned here concerning health and disease will be made a foundation for your daily practices. 


\section{SOIL PHYSICS, WATER SUPPLY, AND SEWAGE DISPOSAL}

\section{THE VALUE OF WATER}

526. Män's Dependence upon Water.-When we read nowadays that "a house has modern conveniences" it means that it is, not only provided with modern appliances for lighting and heating, but also that the house is supplied with water and suitable plumbing for the disposal of sewage. This is especially true of city houses and is becoming more and more true of country and farm houses. While we may be quite comfortable without having the water piped into the house, we must have a sufficient supply of wholesome drinking water close at hand.

A supply of wholesome water is much more important to man than is artificial light. It is also true that in all but severe winter weather and in the colder portions of the country, man can endure much longer without artificial heat than he can without water to drink. Persons deprived of water soon become crazed by thirst, and unconsciousness and death come much sooner than they do when caused by hunger.

527. Man Has Always Recognized His Dependence upon Water.-From the earliest antiquity, man has recognized the importance of securing an ample supply of wholesome water. Most of the great cities and nations of the past have been located upon rivers or lakes containing fresh and wholesome water. If the natural water supply was not sufficient, great AQUEDUCTS were built to bring a supply from a distance and huge RESERVOIRS were constructed to store a supply in times of plenty. Some of the greatest structures erected by ancient man were these great stone aqueducts and reservoirs (Fig. 277). 
Recognizing their dependence upon water, campers and hunters always make camp, when possible, near some spring or stream. For a similar reason the earliest settlers of the Mississippi valley and of the great plains to the west settled first upon the lands bordering the streams.. When all of the land bordering the streams was taken and the settler was obliged to take land farther back, the first improvement he made was to dig a well, for he must have water.

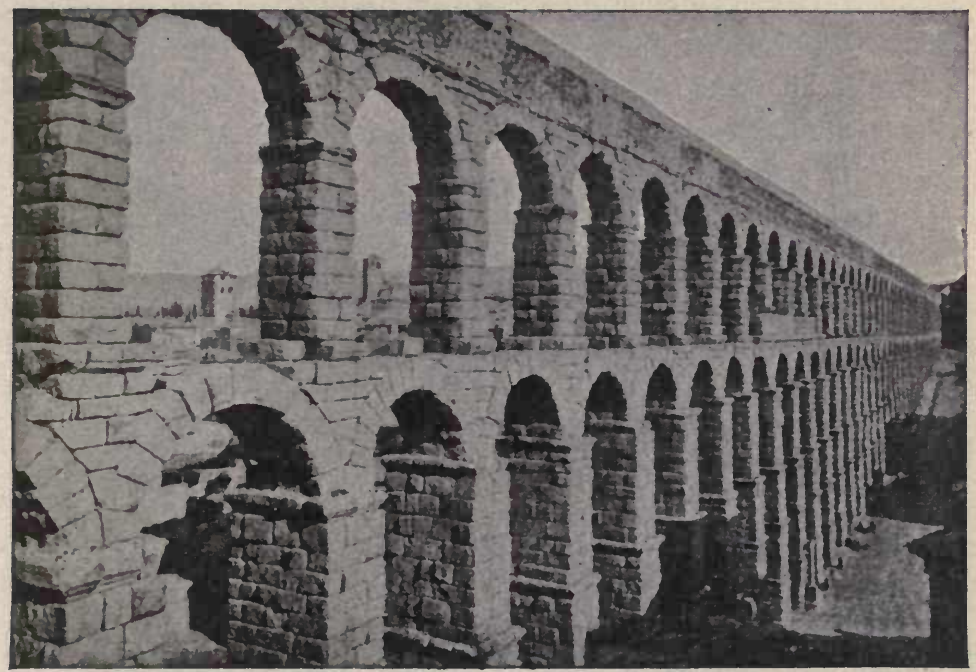

FIG. 277.-Aqueduct of Segovia, Spain. Nearly one-half mile in length. Over 1800 years old. From History of Sanitation, Cosgrove.

\section{Water Valuable for Purposes Other than Drinking.-} Streams and other bodies of water have always been the highways for commerce. Until the invention of the locomotive and the perfecting of the modern railroad, which have taken place within the last century, the means of transportation by land were very poor and costly; in fact, there had been scarcely any improvement in modes of travel since the dawn of history. The ox and the horse were but "little improvement over the 
equally rapid-moving camel, which was the beast of burden in the earliest Biblical times. For this reason practically all of the world's commerce up to about a half-century ago was carried on by water.

For centuries, man has used the power of running water to help him perform his labor It has ground his corn and wheat; it has sawed his lumber and run his looms when no other force was available.

Plant life as well as animal life is largely dependent upon water for its very existence. From prehistoric times man has used water from near-by streams to IRRIGATE his crops. Some of the greatest nations of the past have lived on soil where the natural rainfall was insufficient, and artificial watering, or irrigation, was necessary.

In each of these cases to which we have been referring, man has made use of the visible supply of water, i.e., to the water which stands or flows above the surface of the land. We shall soon see, however, that the ground itself is a great reservoir of water and that to this vast supply of hidden water man owes as much, possibly, as he does to the visible supply.

\section{SOL PHYSICS}

\section{Ground-water}

529. The Source of Well Water. - While it is true that upon the frontier of civilization men still get their water supply from streams, and while it is true that most large cities consume so large an amount of water that they, too, are obliged to take their supply from streams or lakes, still it is probable that in the United States a larger number of people are using drinking water from wells. Since wells are such a common source of water supply, we may well ask, Where does the water come from which we pump from our wells?

There is no mystery as to where the water comes from in certain seasons of the year. When heavy rains have been frequent and the ground is soaked full of water, it is easy to 
see that wells, which often are merely holes in the ground, will also be filled. But where does the water come from which fills our wells partly full even after months of hot, dry weather? There are weeks, even months, at a time, in some sections, when but little rain falls and this merely wets the surface of the soil, which is soon dried by evaporation. Evidently the ground must in some way serve as a great reservoir storing a supply of water which we are able to draw upon as needed. That this must be so is made more evident by the fact that a good, "never failing" well pumped empty at a certain time is found soon to contain as much water as it did before the pumping took place.

530. The Earth a Great Sponge.-The fact is that the earth is not unlike a great sponge. We have all seen a pail of water quickly disappear when poured upon the dry earth. We have all seen several inches of rain fall within a few hours, and still it all disappeared nearly as fast as it fell if the earth was very dry when it began to rain. Over most of the earth's surface, the earth's crust is composed chiefly of porous soil. This porous soil holds water much as a sponge does.

531. Ground-water.-The earth's crust is not composed of the same material at all depths as that at its surface. Through the upper Mississippi valley, for instance, we often find 2 or 3 $\mathrm{ft}$. of black soil at the surface. Beneath this there may lie 6 or $8 \mathrm{ft}$. of yellow clay. Then, perhaps, is found a 2- or 3$\mathrm{ft}$. vein of sand and gravel. Next, possibly, lies $10 \mathrm{ft}$. of blue clay. This may rest upon a foot of gravel. Beneath this gravel may lie a thick bed of almost impervious clay called hardpan. And so on down through bedrock we find layer upon layer of different substances. Each layer differs from the one above it not only in material of which it is composed, but also, and more important for our present purposes, in the ease with which water can pass through it, or its Porosity.

No matter how many different layers, or STRATA, of material there may be, or of what material those layers may be composed, in time, water finds its way down through into bedrock. 
Throughout the thousands, even millions of years, which have passed since the beginning of this earth, the water which has been falling in the form of rain has been soaking down through these layers of soil till the earth's crust in most places is quite saturated. This water is called the GROUND-WATER.

Over much of the earth's surface, then, the rainfall has been, and is, sufficient nearly to saturate the soil with water. This does not mean that the ground is completely filled with water from bed rock quite to the surface all the year around. But it does mean that the GROUND-WATER has sunk deeper into the earth than man has as yet been able to penetrate, and that over much of the earth's area it comes nearly to the surface of the soil. When rains are frequent and heavy, the ground may be completely saturated even to the surface. During most of the months of the year, however, the spaces between the soil particles are not filled with water for some distance from the surface downward. If we penetrate the ground deeply enough, however, we come to a place where there is so much water in the soil that it fills the spaces between soil particles completely. This leads us to the point where we must state definitely the meaning of a new term, WATER PLANE, or WATER TABLE.

532. The Water Table, or Water Plane.-While all of the soil is more or less moist, the moisture in the upper portions of the soil usually is not free, unabsorbed water. It is water which adheres closely to the soil particles and cannot be removed by ordinary means. Of this moisture, FILM WATER, we shall learn more, later. At present we are interested in the portion of GROUND-WATER which is unabsorbed. This water does not adhere as moisture to the soil particles, but lies as free, unabsorbed water between the soil particles. It is the surface of this free, unabsorbed ground-water which is called the WATER TABLE, Or WATER PLANE.

533. Relation of the Water Table to the General Surface of the Land.- It has been determined by experiment that the water table follows, in the main, the general surface of the land. 
The water in any shallow well stands at exactly the height of the water table if no water be used from the well. The water in the well varies in height just as the water table varies. Numerous wells have been sunk on the rolling ground lying beside a lake. The well at the lake's shore has water standing in it at the lake's level. A well farther up the hill is found to have water standing in it at a level somewhat higher. The next well, still farther up the hill, has water standing at a still higher level. In almost every case the level at which the water stands in the various wells scattered over a considerable area of land bordering upon a lake, indicates that the water table

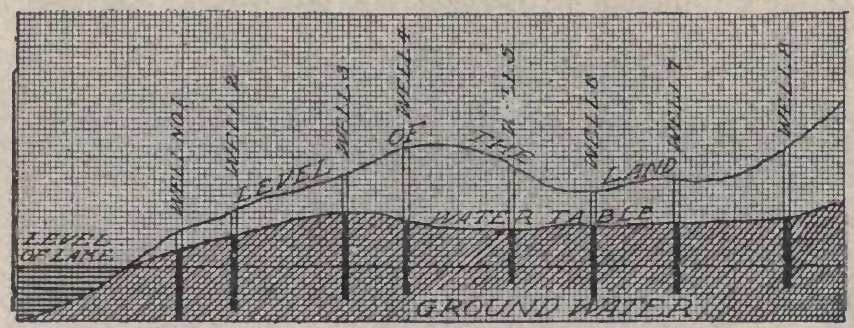

FIG. 278.-Relation of water table to the land surface.

tends to follow more or less closely the general level of the land. Where the land rises the highest; there the water table shows the same tendency to stand high in the soil (Fig. 278). This same fact may be seen manifested on a much larger scale in the study of the geographical facts of the Lower Michigan Peninsula.

534. The Lower Michigan Peninsula.-By the Lower Michigan Peninsula is meant that portion of Michigan which lies between Lake Michigan and Lake Huron. The peninsula is about 300 miles in length and 200 miles in width. The surface of the land is generally what is called level. It is, however, over most of this area slightly rolling. From each lake the land rises gradually. The line of highest land, the wATERSHED, lies somewhat to the east of the center of the state and extends 
in a general north and south direction. The line of highest land does not usually rise more than about $100 \mathrm{ft}$. above the level of the two lakes. Since the average distance of the water shed is about 100 miles from the lake on either side and since the shed has an average height of $100 \mathrm{ft}$., it is evident that the slope is about $1 \mathrm{ft}$. to the mile.

Much of this peninsula is covered by a thick layer of fine soil, or GLACIAL DRIFT. In many places this drift is several hundred feet deep. It is composed quite largely of clay, although, in places, considerable sand and gravel is mixed with it.

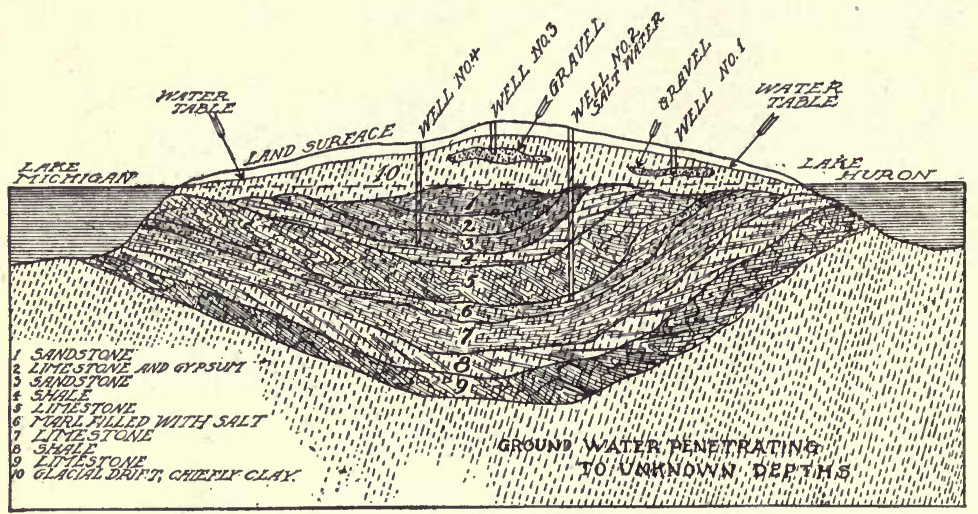

FIG. 279.-Cross section of the rock underlying the Lower Michigan Peninsula.

The clay is generally fine grained and water passes through it slowly. Beneath this drift, lie beds of sandstone and other rock, all of which hold large quantities of ground-water. It happens that these layers of rocks do not lie in horizontal layers but that they are depressed at the center of the state as shown in Fig. 279.

The average yearly RAINFALL over this region is between 30 and 40 in. (see Fig. 217). The average yearly RUN-OFF, that is, the amount of water which is known to run off in the open streams, is between 10 and 20 in. (Fig. 280). The average yearly rate of EVAPORATION of water standing in an open 
vessel or a lake is between 20 and $30 \mathrm{in}$. (see Fig. 149). From these facts it is clear that, if all of the rain which falls upon the peninsula were to remain upon the surface of the earth, the portion which does not run off would completely evaporate during the year. But much of the water which falls as rain immediately sinks into the earth and becomes GROUND-WATER. This ground-water evaporates very slowly and, as only a small portion of the peninsula is covered by open water, the

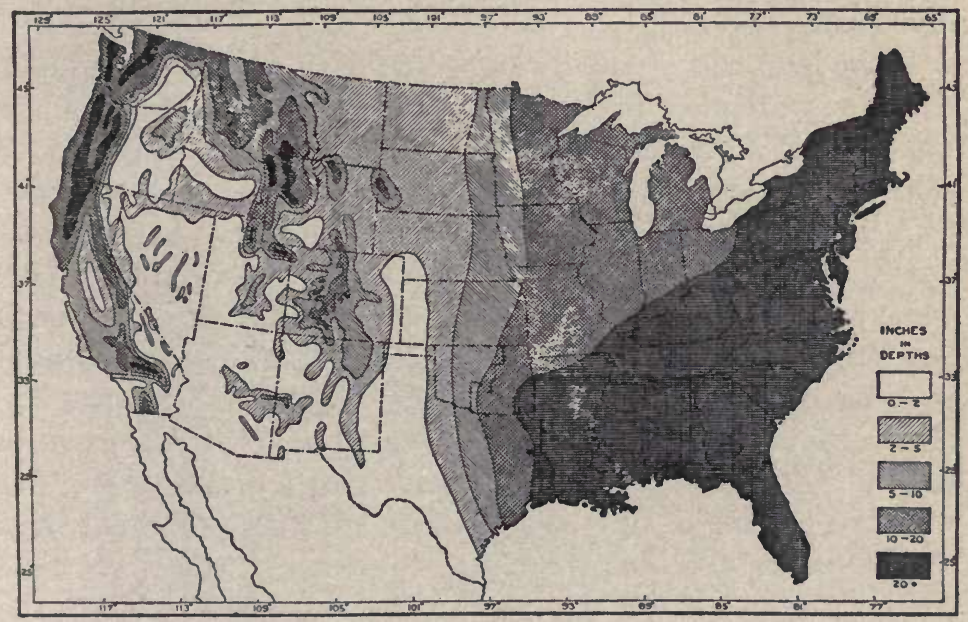

Frg 280.-Mean annual run-off, United States.

total evaporation from it is much less than the amount which would evaporate were it completely covered with open water.

535. The Origin of Lakes and Rivers.-As stated, much of the rain which falls upon this land sinks down into the soil. Some of it evaporates from the soil, as will be shown later. Much of it reaches the water table. The consequence is that the ground-water becomes piled up at the center of the state, for it cannot run off readily through the soil into the lakes. While it tends to flow off to the lakes from the highest point, its passage is constantly blocked by the soil, just as a stream is 
blocked by a dam of pebbles or of sand. It is this blocking of the flow of the ground-water which causes the water table to stand high under the higher portion of land.

This portion of the state of Michigan is dotted with many small lakes. A lake may now be defined as a portion of the ground-water which rises above the surface of the ground. When the land surface and the water table remain at about the same level all the year round, certain aquatic vegetation grows in abundance over the water-soaked area and we have a swAMP or MARSH.

If the land had originally sloped off with perfect smoothness from the watershed to the lake on either side, like the roof of a building, it is evident that the water table would also have sloped off evenly to each lake. The water table would have formed the counterpart of the land surface. At times of heavy rainfall and slight evaporation, the soil would have become completely saturated. As more rain fell, it would have been impossible for it to soak into the soil. This water would then have flowed over the surface of the ground toward the lakes. Soon furrows or channels would have been washed in the soil. These channels would have grown deeper and wider with the passing of time and flowing into these main channels would have been many smaller branches. Many of these channels would soon have been cut so deep as to lie below the water table throughout the year. Such a channel is called a RIVER. This is, in general, the history of river formation.

536. Drainage through the Soil.- Since the river channel is cut considerably below the general level of the water table, it is evident that there is a constant drainage of ground-water through the soil laterally into the river channel. This lateral PERCOLATION of water through the soil is usually very slow. It varies much in different regions and under different circumstances. Different tests have shown the rate to vary from $5 \mathrm{ft}$. to $100 \mathrm{ft}$. per day. In one instance (the valley of the Loup River, Nebraska), evidence was found to show that considerable quantities of ground-water traveled a distance of 20 miles 
in 60 days, or $1 / 3$ mile per day. This is, without doubt, a very unusually rapid motion for soil-waters, amounting as it does to more than a foot per minute. Even at this rate, if the ground-waters of Michigan moved evenly down the slopes to the east and the west to the lakes it would take the water a year to move from the watershed to the lake. That the state is drained to a considerable extent by this lateral percolation is shown by the fact that over many large areas of this portion of the state there are no visible streams to carry off the surplus rainfall. The drainage in such places is entirely by means of percolation.

537. Relation of the Ground-water to the River-water.It is interesting and important to note the relation of the

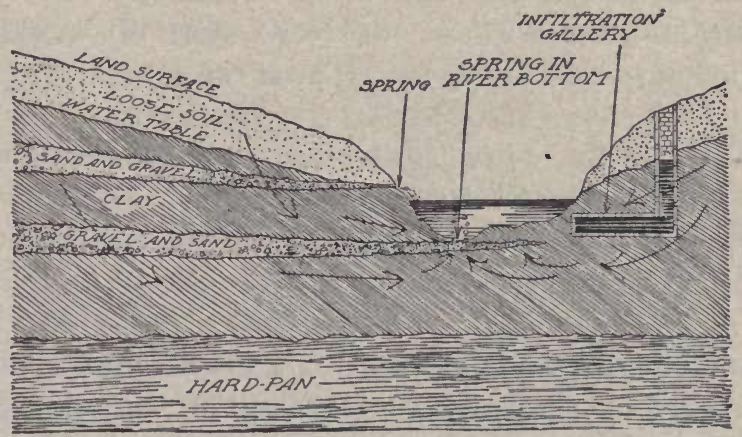

FIG. 281.-Ground-water and river-water.

ground-water near a river to the water in the river bed. Anyone who has followed the course of a river far is aware that, in most cases, springs are common along its banks. In many cases where no running water flows down the bank, the banks are very moist, showing the near presence of free ground-water. The cause of springs is easily seen when we know that the conditions shown in Fig. 281 are not uncommon. On the river bank to the left we have the ideal conditions for a SPRING.

Swimmers are aware of the fact that springs of cold water are often located in the very bottom of river beds. The colder 
ground-water rises into the river at many points. Figure 281 also shows how this may be so.

Many cities, in attempting to secure an adequate water supply, have constructed what are known as INFILTRATIoNGALLERIES (Fig. 281). These are merely wells sunk beside the rivers. Sometimes from the bottom of the wells long horizontal galleries extend along beside the river or out beneath it. Each gallery is, of course, bricked up to prevent the ground from caving into it. Other cities have buried FILTER-CRIBS in the bottom of the stream itself. In many cases it was expected that the river-water would find its way into the galleries and cribs. Such has rarely been the case. Repeated and frequent examinations of the water in such cases by chemists have nearly always shown that the gallery or the crib contains ground-water, not river-water. It is evident that the gallery or the crib has intercepted the ground-water on its way into the river. The general movement, then, of the groundwater along a river bed is nearly always into the river from either side and up into it from beneath. What forces the water up into the river from beneath? The answer to this question will be evident when we have studied the pressure of standing water. (See Art. 574.)

In some arid regions the flow of water along a river valley is the reverse of that just described. For example, along the Platte River in Colorado and western Nebraska the percolation of water is generally from the river off to either side into the soil. The river is fed by the melting of the mountain snows and, as the water runs out on the arid plains, its surface is higher than the general level of the water-plane. The water of the river, therefore, soaks out into the soil and in the dry season completely disappears. In the spring 'or early summer the river is said "to come down" from the mountains. Explain what is meant.

\section{GROUND-AIR}

538. Importance of Ground-air.-Closely related to groundwater and, more or less controlling its movements, is the GROUND- 
AIR. The upper portion of soil, down to the water table, is saturated with air. The spaces between the soil particles are completely filled with this GROUND-AIR, or SOIL-AIR, as it is often called. Each soil particle above the water table is surrounded by a thin film of water, FILM WATER, which can be removed only by the roots of plants and by evaporation (Art. 13). Since this moisture can be removed by evaporation, the soil-air will constantly be nearly saturated with moisture. Plant life is largely dependent upon this moist soil-air and upon the film water for its very existence (see Art. 547). The chief purpose of artificial drainage is so to lower the water table that the soil-air may reach the plant roots.

539. Movements of Soil-air.-The soil-water moves through the soil chiefly through the influence of its own weight; we say it is moved by gravity. It is constantly moving down hill toward the sea level or toward the level of some lake or river. The movements of soil-air are strikingly different. Soil-air does not move, to any considerable extent, in response to the pull of gravity. Its motion is controlled almost entirely by: (1) Changes in the temperature of the soil, (2) changes in atmospheric pressure (see Chap. IV, Sec. II), and (3) by diffusion.

540. How Heat Causes Movements of Soil-air.-We know that when air is heated it expands. In fact, we have learned that when air is heated $1^{\circ} \mathrm{C}$. it expands $1 / 273$ part of its volume at $0^{\circ} \mathrm{C}$. (Art. 131, Ex. 35); if it is heated $10^{\circ}$ it will expand $1 \frac{1273}{2}$ of its volume. Now, if the soil temperature should rise $5^{\circ} \mathrm{C}$., it is evident that $1 \mathrm{cu}$. ft. of air out of every 55 cu. ft. would be forced out of the soil, i.e., the earth would exhale, or breathe out, $1 \mathrm{cu}$. ft. to every $2 \mathrm{cu}$. yd., of soil-air which it contained. Prove that this is so.

The earth receives its supply of energy from the sun. The sun sends down a greater amount of energy at noon than at any other hour of the day. Why is this so (Chap. V, Sec. I)? But if we were to take the temperature each hour of the day for a few days with the thermometer hanging on the north side of a tree or a building, we should find that the atmosphere 
becomes warmest, generally, not at noon, but at about two o'clock. Explain this lagging of the hottest hour of the day behind the time when the sun sends down its greatest heat (Art. 232, page 206).

541. Soil Temperatures.-The temperature of the soil is most easily taken by means of the soIL THERMOMETERs. These are mercury thermometers which are usually encased in wooden cases capped with metal tips (Fig. 282). This protecting case makes it possible for the thermometer to be pushed into the soil without danger of its breaking. Repeated experiments show that at the depth of 1 or $2 \mathrm{ft}$. the soil reaches its highest temperature late in the afternoon or in the evening. At a still greater depth, the soil reaches its highest temperature during the early portions of the night. The change in temperature lessens rapidly as greater depth is attained until, at a depth of a few feet, no appreciable daily change is noticeable. It can also easily be shown that the soil at the depth of 1 or $2 \mathrm{ft}$. reaches its lowest temperature during the day time, usually during the forenoon. This is not at all mysterious; it is simply the application of the

FIG. 282 . Soil thermometer. principle referred to in the last paragraph: If the changes in temperature of the atmosphere lags two hours behind the sun, we can easily see that the changes in temperature of the soil should lag still further behind.

542. Earth's Breathing.-We have seen that the soil becomes warmest during the evening and earlier portion of the night. As long as it is growing warmer, the soil-air is expanding and therefore rushing out. This is the EARTH's Exhalation. The soil-air which is expelled is warm, often warmer than the air above ground, and saturated with moisture. The formation of DEW is partly because of this warm, moist air's coming into contact with the colder bodies close to the surface of the ground (see Art. 253, page 224). The EARTH's inhalation 
takes place in the early morning and the forenoon. Thus we see that the earth takes one long, slow breath each day.

543. Effect of Pressure upon the Volume of Air.-But the change in the soil temperature is not the only cause of the earth's breathing. Changes in the pressure of the atmosphere, ATMOSPHERIC Pressure (Chap. IV, Sec. II), also affects the soil-air.

It is easily proved in every high school laboratory that increasing the pressure upon a certain quantity of air decreases the volume of the air. In fact, it was shown by an English philosopher, Robert Boyle, about 1650 , that, if the pressure was doubled, the volume of the gas was reduced one-half; if the pressure was made four times as great, the volume became one-quarter its former value. In general, the volume of a gas decreases

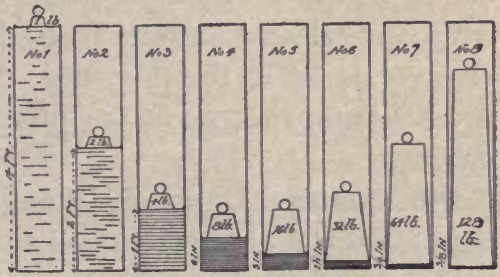

FIG. 283.-Effect of pressure upon volume of air. just as rapidly as the pressure increases. Figure 283 makes plain the operation of this law, which is known as BoyLE's LAw. We shall suppose that No. 1 represents a tube $4 \mathrm{ft}$. long. At its top, fitting into it air-tight, is a piston. Suppose that all of the atmospheric pressure is removed from the piston and simply a 1-lb. weight is placed upon it. Evidently the $4 \mathrm{ft}$. of air in the tube is supporting $1 \mathrm{lb}$. of weight. If the pressure be increased to $2 \mathrm{lb}$., the volume of gas will be compressed to a column $2 \mathrm{ft}$. in length, as in No. 2. If $4 \mathrm{lb}$. of pressure be placed upon the air as in No 3 , the column will become $1 \mathrm{ft}$. And so 8 lb., 16 lb., $32 \mathrm{lb}$., 64 lb., and $128 \mathrm{lb}$, will compress the air to 6 in., 3 in., $1 \frac{1}{2}$ in., $3 / 4$ in., and $3 / 8$ in., respectively.

544. Changes in Atmospheric Pressure Cause the Earth to Breathe.-We have seen (Chap. IV) that the ATMospheric PRESSURE varies considerably from day to day, and that it even 
varies somewhat from hour to hour. At the time of storms the pressure is often considerably less than on the day before or upon the day following. This variation frequently amounts to $1 / 30$ of the entire pressure of the atmosphere. Generally, however, the change is less than this.

Now, if the soil-air is relieved of $1 / 30$ of the pressure which it has been sustaining, it will expand $1 / 30$ in volume, according to Boyle's Law. This means that $1 / 30$ of the soil-air will be expelled from the soil. After the storm has passed and the atmospheric pressure has again increased, fresh air again enters the soil. Since on the average, fairly well-marked storms pass over central and eastern United States about once every four or five days, it follows that the earth takes an additional breath, or rather an extra breath, about once in four or five days.

545. Another Cause of Change in Soil-air.-While it is true that both the changes in soil temperature and the changes in atmospheric pressure cause the changes in soil-air as shown, it is also true that they are not the only, nor even the chief causes of the exchanges of soil-air which take place. Experiments have shown that a still more important cause of this exchange is that oF DIFFUSION.

\section{Exercise 94.-Diffusion of Gases}

Close all the windows and doors of the room. Open a bottle of the oil of peppermint or musk (camphor or ammonia will do) in one corner of the room and let a few drops fall upon the floor. Let another person be at the opposite corner of the room. Let him notice carefully to see how long it is before he can detect the odor of the liquid you are using. It will not be very long before he can do so. How does it happen that he can thus detect the presence of the liquid so distant from him?

Explanation.-Evidently the liquid does not reach him It must be that it first changed to a vapor, or gas, and that the gas by some means reaches him. The truth is that all gases are made up of many rapidly moving particles. The particles of air, for instance, under the usual conditions of temperature 
and pressure are known to be moving, on the average, at the rate of about $1 / 4$ mile per second. But the particles are so very small and so very numerous that even at this rate of motion no particle moves more than a very small portion of an inch before striking another particle and being turned off in some new direction. Every gas and every vapor is thus made up of millions of particles to each cubic inch and each of these particles is moving with great speed. When we know this to be true, it is not wonderful that the vapor from the musk or oil of peppermint quickly passes across the room, even though there be no apparent movement of the air in the room. The mixing of gases and vapors in this manner is known as the DrFFusion of GASES.

546. Diffusion of Soil-air.-It has been shown that this same DIFFUSION OF GASES applies to soil-air. It is known that this diffusion of the soil-air causes a constant exchange to be taking place between the soil-air and the air above the ground. Particles of soil-air are constantly escaping into the atmosphere and particles of fresh air from the atmosphere are constantly entering the soil. This diffusion of the soil-air causes more of an exchange of the impure, moisture-laden air for fresh air from the atmosphere than all other known causes put together. The whole process of change of soil-air is of great interest to agriculturalists and is called the AERATION OF THE SOIL, or AIRING OF THE SOIL.

The soil-air removes considerable moisture from the soil above the water table. The soil-air is constantly more or less saturated with moisture which it has taken up from the soil particles. With each exhalation, as well as by the constant process of diffusion, this moist air is being replaced by the drier air from the atmosphere. The effect of soil aeration, then, is to reduce materially the amount of soil moisture.

\section{Conservation of Soll Molsture}

547. Plant Life and Moisture.-All plants must be supplied with moisture in order that they may live and grow. The 30 
abundance or scarcity of moisture is a large factor determining the character of plant life in any region. Different plants require different amounts of moisture. Certain plants, such as water lilies, reeds, cat-tails, eel grass, bulrushes, wild rice, sedges, and many grasses live and thrive only when growing in shallow ponds or swamps or marshes. Such plants are said to be water plants, or HYDROPHYTES (hydrophyte meaning water plant).

At the opposite extreme are plants which live and thrive only when growing in extremely dry soil in regions of scant rainfall. The southwestern portion of the United States, western Texas, New Mexico, Arizona, and southeastern California, is such a region. Here the various forms of the cactus, the yucca, sage brush, and a few other forms of plant life live and thrive although only a scanty amount of moisture is available. Such
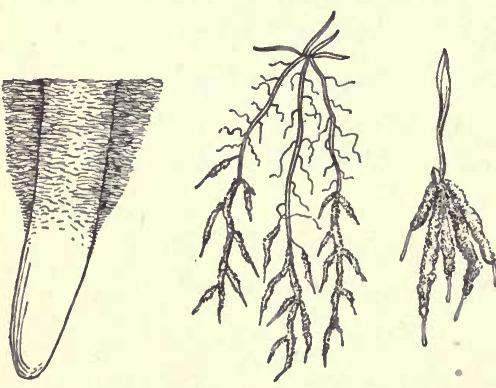

FIG. 284.-Root hairs-on corn roots and on roots of wheat. The soil is still clinging to the wheat root hairs.

plants are called xERoPHYTES (xerophyte meaning dry plant).

Most of the common plant life of the United States, and especially our common cultivated crops require a medium amount of moisture. Our common forest trees, the grasses of our meadows, our corn, oats, wheat, and other grains, potatoes, beans, peas, and all the rest of our common field and garden plants thrive best where a moderate amount of moisture is available. Such plants are called MEsopHyтEs (mesophytes meaning middle plants).

548. How Plants Absorb Soil Moisture.-Plants requiring but little moisture, xerophytes, and plants requiring a medium amount of moisture, mesophytes, obtain their supply of moisture principally by absorbing the film moisture from the soil. 
Their roots are often finely branched or divided and the small rootlets are covered with minute hairs (Fig. 284). These root hairs come into close contact with the film of water surrounding the small particles of soil and absorb the moisture from this film as it is needed for plant growth. As the moisture in the film is thus absorbed, more moisture rises from the deeper portions of the soil to take the place of the absorbed moisture. This moisture rises in the same manner and for the same reason as kerosene rises in the wick of a lamp. It is said to rise on account of CAPILLARITY.

549. Need of Increasing and Conserving Soil Moisture.-In most regions, the soil contains sufficient moisture in the spring and the early part of the growing season. But in many regions the supply of soil moisture becomes too scanty to insure the most rapid growth and full development of plant life later in the season. In most portions of the United States the farmer, gardener, and fruit grower find it desirable so to prepare the soil in the fall or spring as to increase its capacity for moisture and also to conserve the soil moisture as far as possible during the growing season.

550. Increasing the Capacity of Soil for Moisture.-The capacity of soil for holding moisture depends upon several conditions. In regions where the rainfall is likely to be deficient, during the growing season, it is of the greatest importance that the soil be so prepared as to increase as much as possible its capacity for holding moisture. There are several ways in which the capacity of the soil may be increased:

1. Its capacity may be increased by FALL PLOWING. A considerable portion of the annual precipitation in many regions occurs during the winter months. If the surface of the soil is left hard, smooth, and compact in the fall, much of the winter precipitation will run off the surface and never enter the soil. Fall plowing leaves the surface of the soil loose and open, rough and broken, thereby tending to prevent the loss of this moisture.

2. By increasing the amount of Humus (Art. 457) in the soil, the capacity of the soil for holding moisture is greatly increased. 
Scarcely any other kind of soil has equal capacity for holding moisture.

3. The capacity for holding moisture is greatly increased in most soils by providing good UNDER DRAINAGE. Well-drained soils remain porous while soils not well drained become hard and solid. The rainfall readily enters porous soils and passes down through such soils to the water table (Art. 532) below.

551. How Moisture may be Conserved.-As we have seen (Art. 546), at best, considerable soil moisture is evaporated and passes into the atmosphere on account of soil aeration. Moreover, many soils, when dry, tend to become hard and solid, and shrink. The result is, frequently, that cracks open in the surface soil. Sometimes these cracks are numerous, wide, and deep. Such cracks permit freer circulation of air through the soil and consequently more evaporation takes place; worst of all, such evaporation takes place at considerable depth. This evaporation greatly lessens the amount of film water within the reach of the plant roots.

Loss of soil moisture through evaporation may be lessened by covering the soil with mulch. This mulch may be provided by either of two methods:

1. By the application of a coat of manure, straw, dead grass, or any similar material. Mulch of this nature is difficult to obtain in sufficient quantities for use on large cultivated fields.

2. By the preparation of soIL MULCH. A soil mulch consists simply of a layer of finely pulverized soil. This is produced by thorough tillage after every rain. If the top 1 or $2 \mathrm{in}$. of soil is kept in a finely pulverized condition, loose and open, during the growing season, the loss through evaporation from the surface is greatly reduced. It does this by breaking the capillary action at the lower surface of the loose soil. The soil moisture rises readily to that point but does not rise farther. It is much the same condition we should have in our kerosene lamp were the wick cut in two a short distance down in the wick tube of the burner. Keeping the surface of the soil covered with this soil mulch is the only practical method of 
preventing excessive evaporation from large cultivated fields. What effect will such mulch have upon the cracking of the soil? Explain.

\section{Relation of Ground-water to Wells}

552. The Fallacy of Underground Streams.-By many people it has been supposed that to "strike a vein of water" when boring a well means that the drill has tapped an UNDERGROUND STREAM. While it is true that underground streams

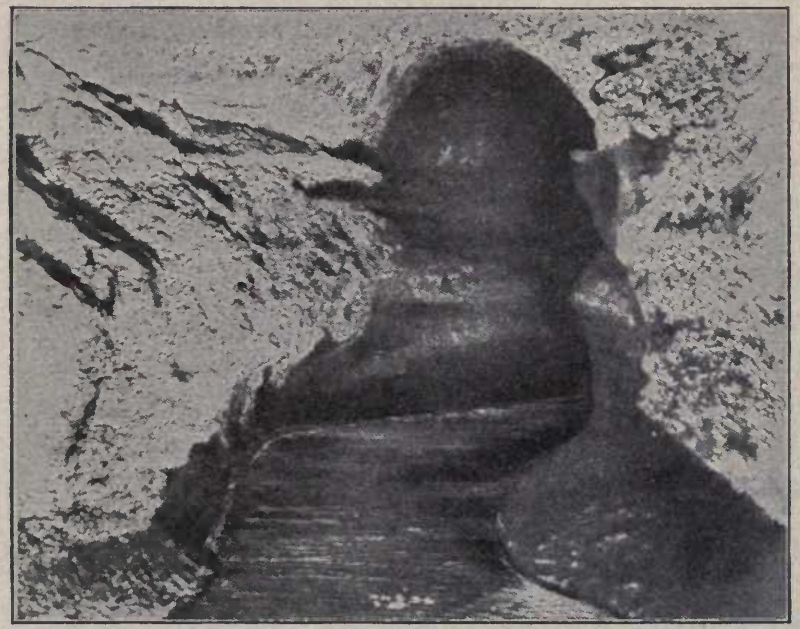

FIG. 285.-An underground stream in limestone. The carbonic acid has dissolved the limestone and the ground-water drains away in a true underground stream.

exist in some places, the supposition that most wells tap something that may properly be called an underground stream is false.

We have already seen that all of the free ground-water moves slowly through the soil down hill, or toward a lower level. In many places it is doubtless true that the nature of the soil strata is such that through certain strata the water moves much more rapidly than through others. If a layer of coarse gravel 
and sand slopes down hill, it is undoubtedly true that the ground-water passes much more rapidly through it than it does through the layers of fine clay above and below the gravel. But this would scarcely be called an underground stream; it certainly is not what most people mean by that term.

The term "underground stream" may properly be applied only to those comparatively rare cases where the water has dissolved portions of the rock (Art.466), washing the dissolved portion entirely away and leaving an open channel through which the water flows (Fig. 285). But such conditions are so rarely found that the underground stream is not of any importance when considering the source of water supply for wells.

553. A Vein of Water.-If to "strike a VEIN OF WATER" does not mean the tapping of an underground stream, what does it mean? In meeting this question we shall also be meeting the question, What is the real difference between a good well with plenty of water and a poor well yielding but little water?

In Art. 533 we saw that the relation of the water table to the land surface has been determined by noting the height of water in wells. We have

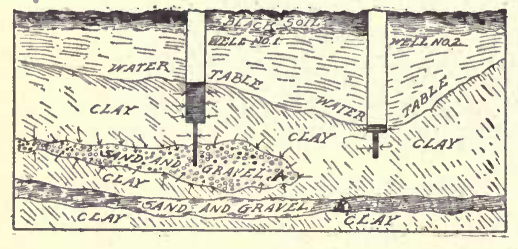

FIg. 286.-A vein of water. also seen that the water in a shallow well will stand at exactly the height of the water table, provided that no water is used from the well. Why should using water from the well affect the height of the water in the well? If the well is sufficiently deep so that its bottom is below the level of the water table, why should not the well contain a sufficient supply of water at all times? The answer to these questions is this: Although the well does reach below the water table we cannot expect much of a flow till we reach a "vein of water." But what is a vein of water? It is certain that it is rarely, almost never, an underground stream. 
When a vein of water is struck, it is always found in a layer of sand and gravel, or some other open, porous soil; it is always a layer which allows the ground-water to percolate easily through it. Figure 286 represents an ideal case. The soil above and below the bed of gravel, A, is so fine in texture that water passes through it slowly. Therefore neither well No. 1 nor well No. 2 receives water freely from it. But the gravel bed, or GRAVEL POCKET as the geologists call it, increases immensely the exposed surface of the well. This pocket of gravel performs exactly the same function for this well No. 1, as the infiltration-gallery performs for the well in Fig. 281. Well No. 2 would evidently have to be extended till it reached gravel bed, $B$, before it could be supplied with water from any other source than from the clay. It is evident, then, that a vein of water is merely a vein of sand or gravel, porous soil, through which the ground-water percolates rapidly. The trouble with a poor well is that it is sunk in clay or other material through which water moves but slowly. When water is removed from the well the water nearest in the soil soaks into the well and it too is removed. If the pumping continues long enough the water table about the well is lowered as shown about well No. 2, Fig. 286 ; in fact, the water table may be lowered to the very bottom of the well. This could not take place if the well were sunk in soil which was sufficiently open and porous so that water flows readily through it.

554. Witching for Water.-It has not been long since it was common to find people who believed that a vein of water could be located by use of a DIVINING ROD. In almost every community some person could be found who honestly believed that he could, by using the divining rod of a favorite wood and shape, actually determine the location of an adequate supply of underground water. If asked to give a good, scientific reason for the fact that the stick turned downward in his hands as he walked over the supposed vein of water, he was invariably unable to do so but insisted that experience proved it. $\mathrm{He}$ drew his conclusion from the fact that wells sunk in accord- 
ance with the behavior of the divining rod seldom failed to bare water.

We have already seen that every well which extends below the water table is certain to contain some water and that the efficiency of the well depends upon its tapping a bed, or pocket, of loose, porous soil through which water may percolate readily. Unless some reasonable connection can be shown to exist between the divining rod and the bed of gravel buried deep in the soil, "witching for water" must be classed with the outgrown superstitions of the past.

555. Deep Well Water.-Wells are usually divided into two classes, SURFACE WELLS and DEEP wells. In speaking of wells as "surface wells" we do not mean that they are necessarily shallow wells. We mean simply that they are fed by the surface water, that is, by the ground-water near the surface of the earth. In speaking of "deep wells" we mean that such wells are fed from deep-seated veins of water. The water which enters the surface wells has not usually passed through much soil. It is water which has fallen as rain or snow near the well; it has sunk into the ground, joined the ground-water, and found its way more or less quickly into the well.

The veins of deep-seated water, on the other hand, are separated from the surface waters by layers of nearly impervious clay or other material. Their source of supply is usually at considerable distance from the well, often even hundreds of miles. They are often Rock wATERs, that is, water which has collected in porous layers of rock, such as sandstone (wells No. 2 and 4, Fig. 279). It is easily seen, therefore, that local rains can make but little difference in the height of water in deep wells. Most well water contains considerable mineral matter in solution; this mineral matter produces a whitish, curdy material when mixed with soap. Such water is called HARD WATER.

556. Artesian Wells.-By artesiaN wells we mean deep wells. In most cases the water rises above the surface of the ground. Such wells tap veins of water which usually, not only 
have their source at a great distance from the well, but also at a higher level. The water-bearing material lies between impervious layers of clay or shale, or at least has such a layer overlying it. This overlying layer of clay or shale tends to prevent the water from rising, no matter how great the pres-

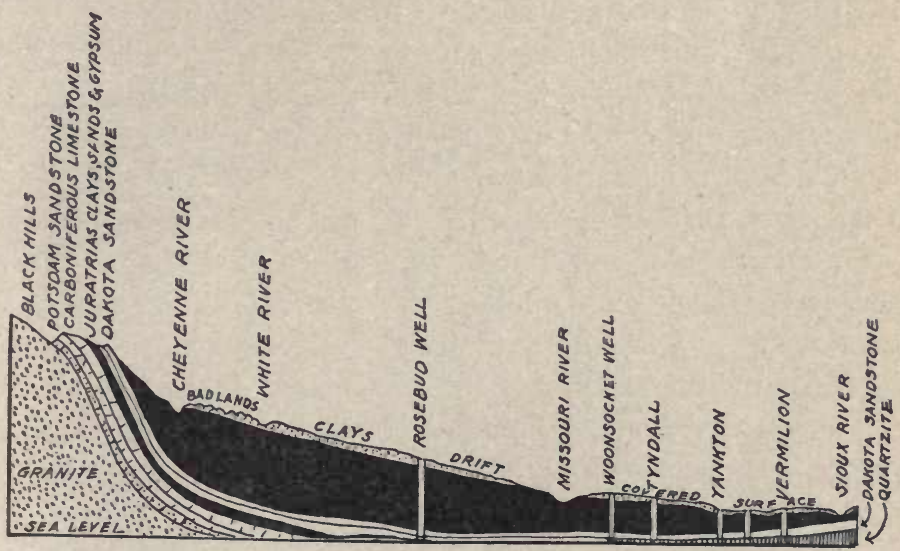

FrG. 287.-Geologic section from the Black Hills eastward across South Dakota. The illustration immensely exaggerates the vertical distance as compared with the horizontal distance.

sure upon it. Figure 287 illustrates the layers of rock, which underlie South Dakota.

Throughout the eastern half of South Dakota there are numerous artesian wells. These wells receive their supply of water from a layer of sandstone, known to geologists as "Dakota sandstone." This sandstone comes to the surface at the eastern edge of the Black Hills. Much of the water which falls upon these hills soaks into this sandstone and then passes through this porous sandstone down the slope toward the east. Since the sandstone comes to the surface at about $3000 \mathrm{ft}$. above the sea level and since the surface of the land in the eastern portion of the state where the artesian wells are so numerous is less than $2000 \mathrm{ft}$. above the sea level, we should expect the water to rise above the surface of the land. From many of these wells the water issues with great force, 
sometimes with a pressure of nearly $200 \mathrm{lb}$. to the sq. in. Figure 288 is a reproduction of a photograph of a well at Woonsocket, South Dakota, showing a 3-in. stream which rises to the height of nearly $100 \mathrm{ft}$. The water exerts a pressure of about $135 \mathrm{lb}$. to the sq. in. when the pipe is closed so as to prevent the escape of the water.

In northern Illinois there are many artesian wells. These wells obtain their supply of water from St. Peters sandstone which is often reached at a depth of from 1000 to 2000 feet. This sandstone is very porous. It comes to the surface in central and northern Wisconsin where the altitude is somewhat greater than in Illinois. Water freely enters the layer of sandstone where it comes to the surface and slowly percolates through it. If the altitude of Wisconsin were as much greater than that of Illinois as the altitude of the Black Hills is greater than that of eastern South Dakota, all of these deep wells in northern Illinois would be flowing wells.

II. WATER SUPPLY FOR FARMHOUSE AND COUNTRY HOME

557. New England Well-sweep and the Oaken Bucket.The earliest settlers of New England had little difficulty in securing a sufficient supply of good water. Springs are numerous throughout New England. In many localities most farmhouses are supplied with water brought in pipes from nearby springs. Many villages and towns also receive their supply from springs or hillside brooks fed by springs. Where the water does not come to the surface, it is nearly always easily obtained by digging shallow wells. These wells are often not more than 10 or $15 \mathrm{ft}$. deep.

In the days of the colonies the usual method of raising the water from these shallow wells was by means of the WELLswEEP and the OAKEN BUCKET. A heavy weight was fastened to the short end of the long sweep to balance the long arm of the sweep. The lifting of the bucket full of water thus became an easy task. This method of raising water from a well has been immortalized in the familiar song "The Old Oaken Bucket"' (see Frontispiece, Fig. 289). 


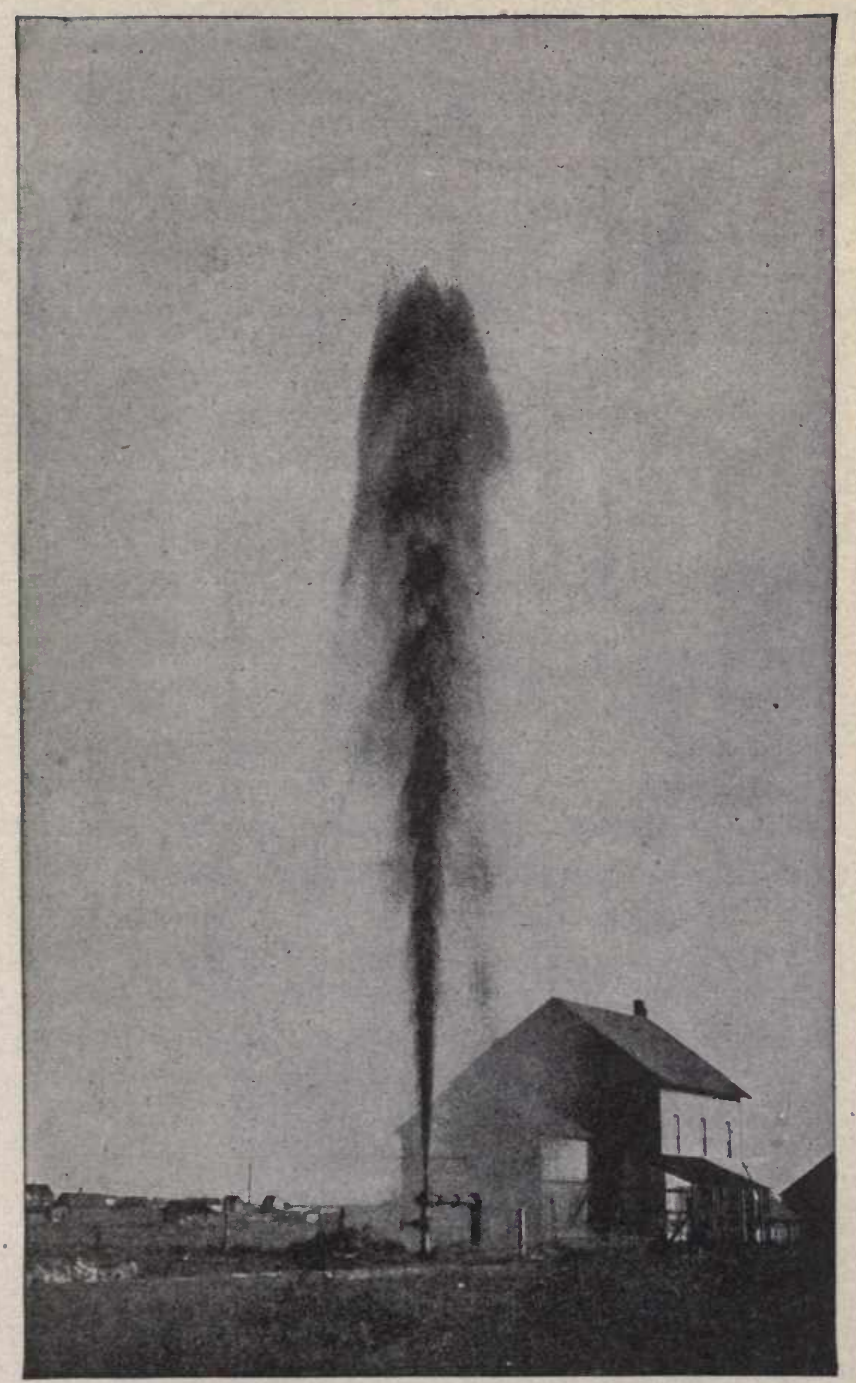

FIg. 288.-Artesian well at Woonsocket, South Dakota. 
558. The Suction-pump.-Water for household and farm use is usually lifted out of moderately deep wells by suctionPUMPS. A common suction-pump consists of two parts, the PUMP-HEAD, and the PUMP-RUN. When made of wood, the head is usually from 6 to $8 \mathrm{in}$. square and about 7 or $8 \mathrm{ft}$. in

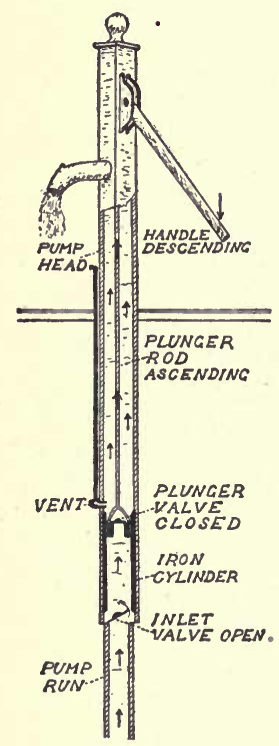

FIG. 290.-The suction pump. length. This head is hollow, that is, a hole 3 or $4 \mathrm{in}$. in diameter is bored throughout its length (Fig. 290). Into the lower end of the head a metal tube, the CYLINDER, is fitted. The cylinder is made smooth and true on its inner surface; when of iron it is often lined with enamel. Fitting closely into this cylinder is the PLUNGER or BUCKET. This plunger, or bucket, carries the PLUNGER-VALVE which opens easily upward but which prevents any water above it from passing downward. The plunger is raised and lowered by means of the PLUNGER-ROD, attached to the PUMPHANDLE.

Fitting closely into the lower end of the HEAD is the PUMP-RUN, or the SUCTION-PIPE. In the common wooden pump this run is about 4 in. square and has a hole about $1 \frac{1}{2}$ or 2 in. in diameter bored throughout its length. At the lower end of the cylinder, below the plunger, is a second valve, the InLET-Valve. This valve also permits the water to pass upward but prevents a downward "flow.

559. How the Suction-pump Works. - The way in which the suction-pump works is made clearer by studying the sketches of the common iron cistern pump (Fig. 291). As the handle is forced downward, the plunger rod and plunger are raised. The water which is already above the plunger, or bucket, is lifted till it stands higher than the spout, out of which it runs. But what raises or lifts the water in the run and cylinder below 
the plunger? We say it is raised by suction, or that it is SUCKED UP (see Art. 374).

In the suction-pump, as the plunger is raised there is a tendency to produce a VAcuUM just beneath it. The atmosphere pressing down upon the surface of water in the well forces the water up the run and through the inlet-valve to fill the vacuum. The work we do, then, in pumping with the suction-pump is really expended in lifting the small amount of water in the pump-head already above the plunger and in lifting the atmospheric pressure which is pressing downward

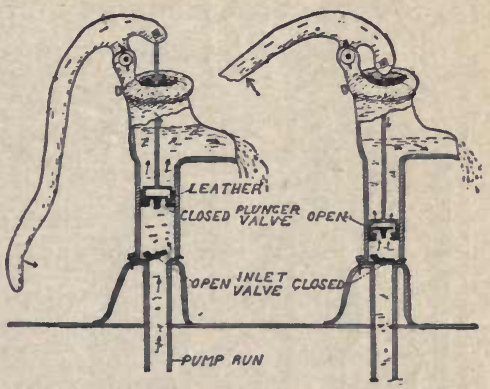

FIG. 291.-Common iron cistern pump. upon the surface of that water, and not in pulling or drawing the water up the pump-run. Define suction and sucking (Art. 374). Explain the process of "sucking" soda water up a straw.

560. Lift-pump. - A LIFT-PUMP is constructed exactly like the head of a suction-pump. Were the head of a suction-pump long enough to reach to the bottom of the well, it would become a lift-pump. The inlet valve, then, is at the bottom of the well and the cylinder and plunger are at all times below the surface of the water in the well. The water is therefore lifted and not sucked up.

561. The Force-pump.-It is often necessary to raise water to a level above that of the pump spout. In farmhouses and in dwellings in small towns, where there are no city water works, it is often desirable that water be pumped into a tank in the attic so that sink faucets may be supplied with water under pressure at all times. Unless some such plan is adopted, modern plumbing conveniences can not be installed in such dwellings; with such a tank, common farmhouses may be equipped with most of the conveniences of city dwellings. 
Any pump so constructed that it may be used to force water to a height above the pump is called a FORCE-PUMP.

As far as the lower portion of a force-pump is concerned, it may be either a suction-pump or a lift-pump. Figure 292 shows the construction of an iron force-pump. It differs from the ordinary iron suction-pump only in having a portion of the head somewhat enlarged so as to enclose a

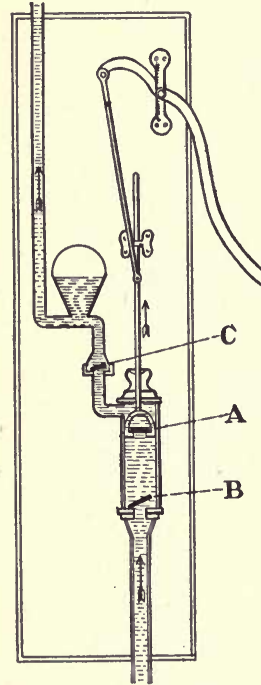

FIG. 292.-The force pump. considerable quantity of air, forming an AIR CUshIoN, and in having the opening at the top through which the plunger rod passes packed air-tight. Explain the use of the three valves, $A, B$, and $C$.

The air cushion is necessary on all forcepumps if we are to secure a fairly steady stream from the pump. With each upward stroke of the plunger, the air in the air cushion is compressed. While the plunger is descending, this compressed air, pressing downward upon the water in the pump, keeps forcing a steady stream of water through the delivery pipe into the tank.

562. The Pneumatic Tank System.The convenience and comfort derived from having an ample supply of water under pressure in a dwelling can be appreciated only by those who have lived with, and again without, such conveniences. Not only can all of the conveniences of modern plumbing be obtained, but a reasonable protection against fire is thus secured. Figure 293 shows how such a system may be installed and the conveniences which it makes possible. In such a system the tank is placed in the basement of the house, safe from frost and easy of access.

The water is raised from the well or cistern and forced into the tank by means of a force-pump. The lower portion of the tank contains water and the upper portion compressed air. This compressed air constantly presses downward upon the 
water in the tank, forcing it into the pipes. Special provision must be made to pump more air into the tank occasionally. If this is not done the tank will in a short time become "water-

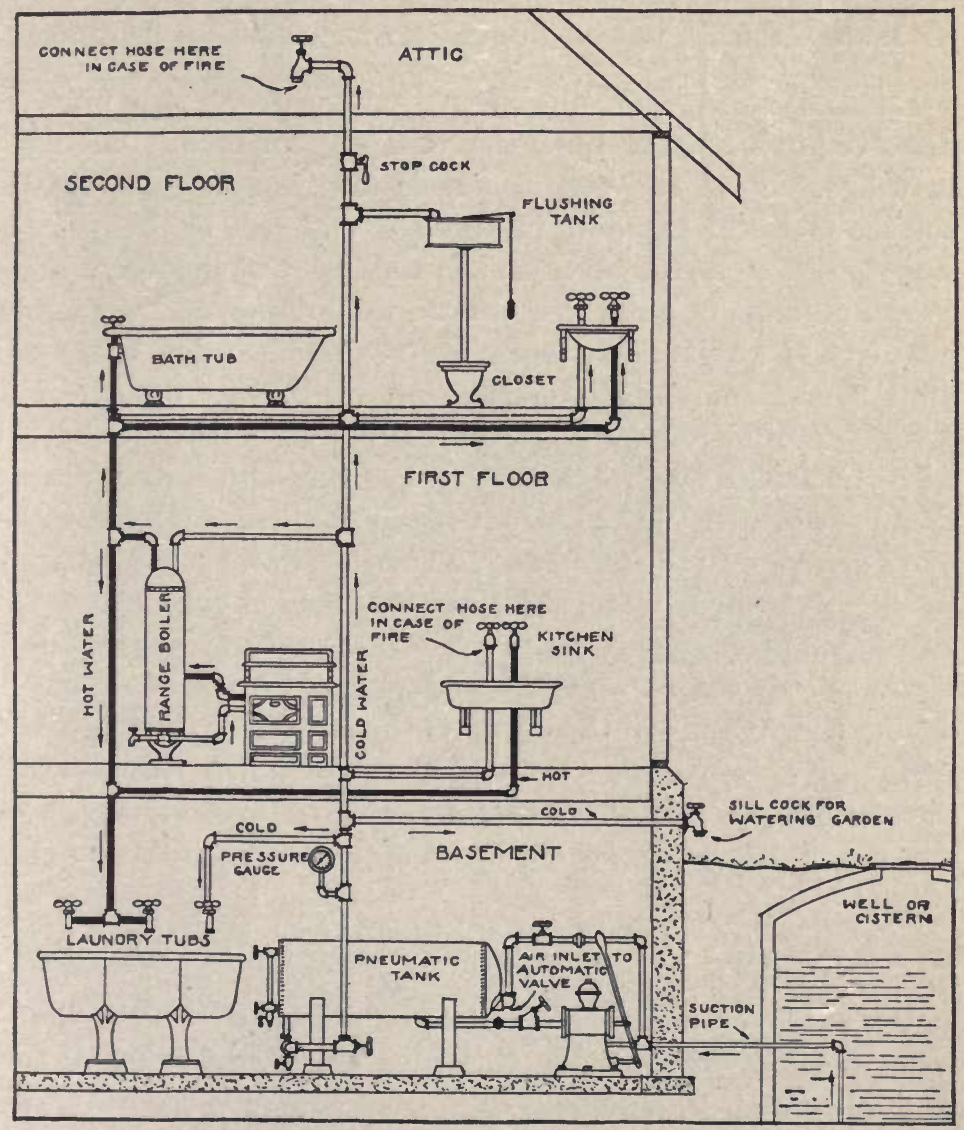

Frg. 293.-Pneumatic tank system.

logged," that is, all of the air will be removed from the tank by the water which passes through it. How this may be so is more clearly seen after performing the following exercise. 


\section{Exercise 95.-Removing the Air from Water}

Place a tumbler or flask filled with water under the receiver of the air pump, first noting the temperature of the water. Begin pumping the air from the receiver. While taking the first few strokes watch carefully to see if any bubbles are rising through the water. Pump out most of the air, watching constantly for bubbles of rising air.

Explanation.-We all know that sugar or salt may be dissolved in water; in much the same way air readily dissolves in water. Since the atmosphere is always resting upon the surface of water standing in an open vessel, it is always possible for air to be dissolved in the water. But is there a limit to the amount of air which will be thus dissolved by a given quantity of water? We know from experience that there is a limit to the amount of sugar or salt which will dissolve in a given quantity of water. After the water is "saturated" with the salt or sugar, adding more of the solid simply means that it will settle to the bottom of the liquid and remain there undissolved. In the same way, a vessel of water standing open to the air is soon "saturated" with dissolved air; it contains all the air it is possible for it to contain under the given conditions. From Ex. 95 what do you conclude is the effect of reducing the pressure of the air upon the surface of the water?

HeNRY's LAw. - The amount of gas dissolved in water is directly proportional to the pressure, that is, doubling the pressure doubles the amount of gas which dissolves in a given quantity of water.

One cu. ft., or $1728 \mathrm{cu}$. in., of water at $0^{\circ} \mathrm{C}$. and at the pressure of $15 \mathrm{lb}$. per sq. in., that which the atmosphere exerts at the sea level, dissolves about $45 \mathrm{cu}$. in. of air. By Henry's Law we see that doubling this pressure would cause about $90 \mathrm{cu}$. in. of air to be dissolved in each cubic foot of water, or reducing the pressure to $5 \mathrm{lb}$. to the sq. in. reduces the amount of dissolved air to $15 \mathrm{cu}$. in. per cu. $\mathrm{ft}$.

The need of pumping more air into the tank occasionally to prevent it from becoming "water-logged" is now' evident. The water in the well or cistern is under 1 atmosphere of 
pressure; therefore there are about $45 \mathrm{cu}$. in. of air in solution to each cubic foot of water as it enters the tank. The water in the tank is kept constantly under a pressure of, at least, 2 atmospheres; the water, therefore, as it escapes from the tank through the pipes and faucets, contains at least twice as much air as it did in the well. Evidently, if no additional air were pumped into the tank, the tank would soon become "water-logged." What would be the result?

563. Shallow Well Water Often Dangerous.-We have seen that wells are supplied by the ground-water. It is evident

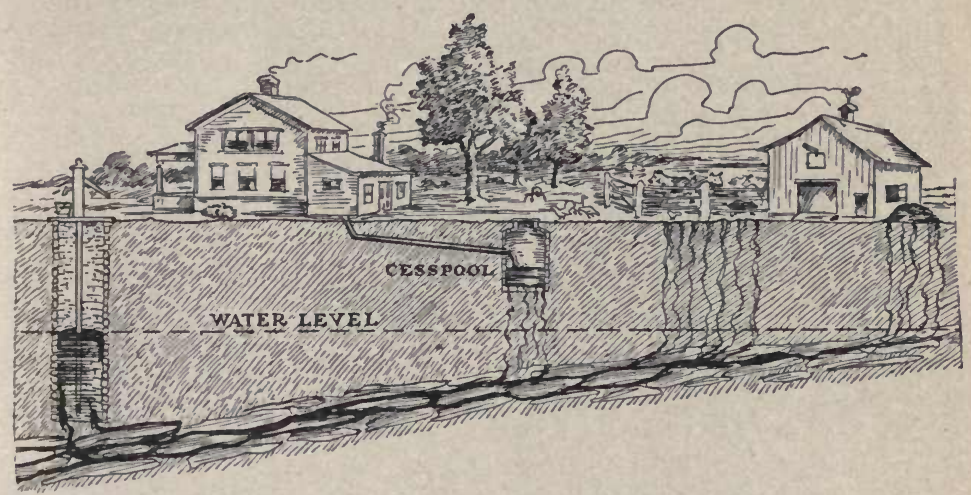

Fig. 294.-Why shallow wells are dangerous.

that, if the walls of the well are merely bricked up to prevent the walls from caving in, they will not be water-tight. In such cases surface water, at times of frequent and heavy rains, will readily enter the well very near its top. If such a well be located near a barnyard on a farm or in a somewhat thickly settled portion of a town or city, especially one not provided with sanitary sewers, the surface soil about the well will be contaminated with manure and other decaying animal and vegetable matter. The surface waters, at times of heavy rains, may enter at the surface or, at best, merely soak a few feet into the soil before finding its way into the well (Fig. 294, also the Frontispiece). 
Such surface water will necessarily carry with it much undecayed or but partially decayed vegetable and animal matter. Such matter later decays (Art. 470, Chap. VIII) rendering the water unwholesome for use and not infrequently causing sickness and sometimes death. The danger is greatest when the waste matter is from the human body. This is so because the waste matter thrown off from the human body is very likely to contain microörganisms which cause human diseases. Typhoid fever is often caused by drinking water containing typhoid bacilli (Art. 511).

564. Protecting a Shallow Well against Surface Water.All shallow wells should be protected against surface water. Some protection is provided by constructing the walls and cover of the well water-tight. When the walls and cover of a shallow well are water-tight, there is no opportunity for the contaminated surface water to get into the well until it has percolated through the soil to the bottom of the well. In passing thus through the soil, the water is fairly well filtered, and the danger of contamination is lessened.

\section{CITY WATER SYSTEMS}

565. Privately Owned and City Owned Water Systems.In communities where the families live in homes separated by considerable distances, each family must provide its own water supply. But as soon as a region becomes thickly settled, it becomes somewhat less expensive and in every way better for the whole community to be served by a common water system. City governments generally maintain such water systems to supply all who live within the city limits. Sometimes a private corporation is granted a FRANCHISE by the terms of which the corporation may lay pipes in the public streets and may sell the water to customers under certain conditions and regulations stated in the franchise. In a similar manner, private corporations very frequently are granted franchises to furnish customers with electric current and gas for lig'ting, cook- 
ing, and for power purposes, and occasionally to furnish heat for heating homes and places of business (Arts. 77 and 153). Inasmuch, however, as public health is so largely dependent upon a safe, uncontaminated water supply, the water system of a city is more commonly controlled by the city government.

566. Amount of Water Used.-It has been estimated that the amount of water used for household purposes in homes not

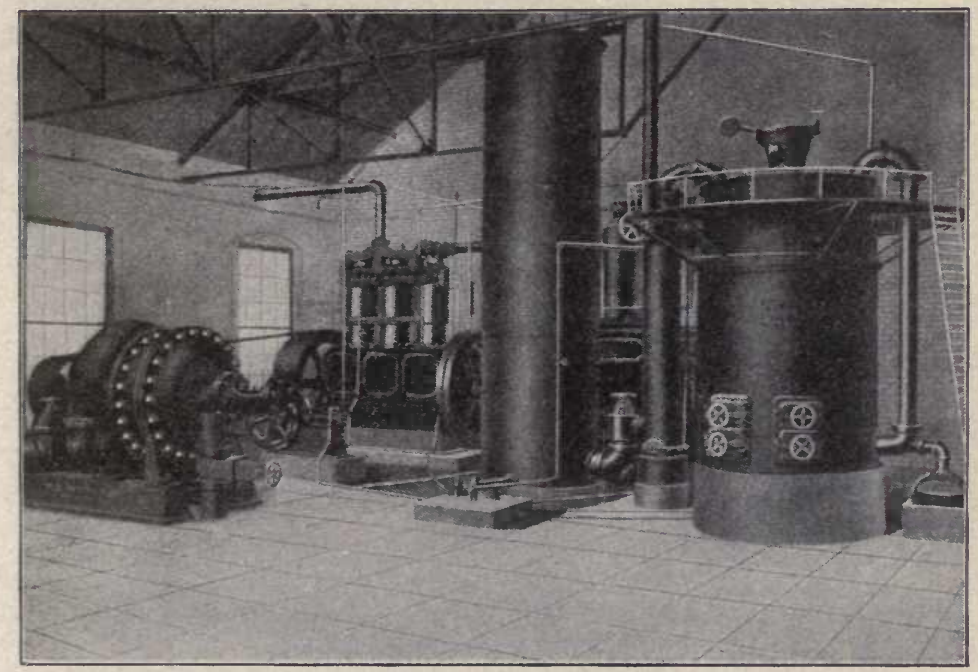

FIG. 295.-A modern city pumping station. Three-stage centrifugal pump, belt-driven by 150 h.p., three-cylinder gas engine, with suction gas producer.

supplied with running water or water under pressure is from 1 to 4 gal. daily per person. The amount of water required per person in any city depends upon the occupation of the inhabitants. A manufacturing city requires generally a much larger supply of water than does a residence city. It is common practice to construct water plants capable of furnishing about 15 gal. daily per capita in the ordinary city where the demand is not great for manufacturing purposes. In some American cities containing many factories and other industries 
requiring large amounts of water, as much as 100 or even 200 gal. per capita are required. To furnish such immense amounts of water, elaborate pumping and distributing systems are necessary. Figure 295 shows a modern pumping station for a small city. The pump used is a CENTRIFUGAL PUMP; it is driven by a gas engine (page 574) which uses producer gas as fuel (Art. 119).

The Centrifugal Pump.-In principle, the centrifugal pump resembles the fan or blower of the plenum system of heating

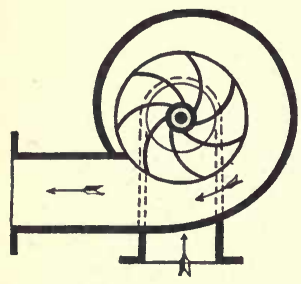

FIG. 296.-Diagram of a centrifugal pump. and ventilation (Art. 367 and Fig. 237). Within the circular casing of the pump are rapidly revolving fan-like vanes (Fig. 296). The water enters the casing at its center and is thrown violently outward by CENTRIFUgal ForCE (Art. 622 and Ex. 102). The casing prevents its escape at all points except through the discharge pipe. Centrifugal pumps may be so constructed as to handle large quantities of water at low pressure or smaller quantities at high pressure.

567. Sources of City Supply.-It is often a serious undertaking for a city to secure an adequate supply of water of such a degree of purity that it may be used safely for drinking purposes, that is, in its unboiled, or "raw," state. Many of our larger cities are located on rivers or lakes where an abundance of water is obtainable. But the purity of such water is frequently not such as to warrant its use without purification. Sometimes sufficient purification is secured by pumping the water into a SETTLING TANK where most of the sediment is removed and then passing it through sand filters where most of the finer suspended matter is removed. Sometimes it is found necessary to treat the water chemically in addition to filtering it. This is most frequently the case when a city gets its water supply from a river into which other cities nearer its source have emptied their sewage. 
568. Development of City Water Systems.-The modern city water system has been developed within the last century. We shall see in Chap. X, Sec. VI, that the steam engine was

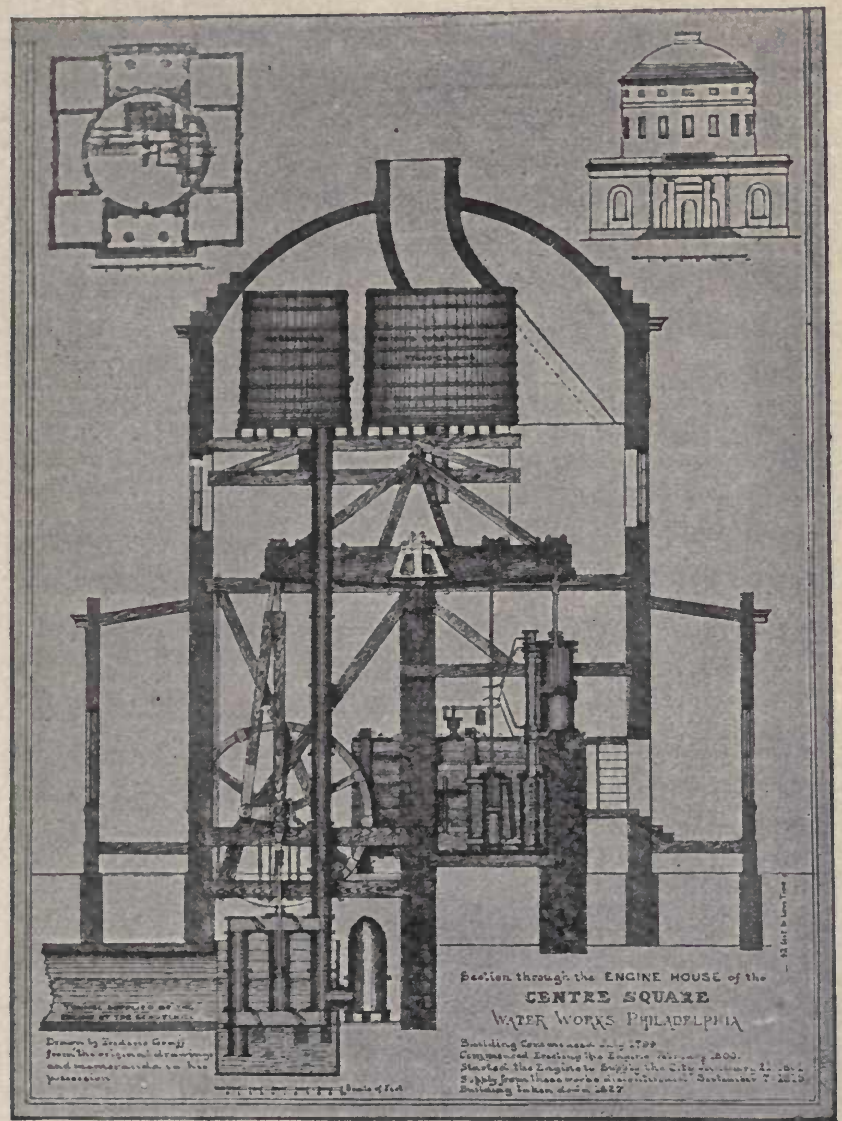

FIG. 297.-Central Square Water Works, 1800. From History of Sanitation, Cosgrove.

still a very crude machine at the beginning of the 19th century. City water systems were still less well developed. Philadelphia was one of the first of American cities to construct a city water system. Figure 297 is a section through the 
Central Square water works of that city constructed in the year 1800. Its crudeness is evident when compared with a modern city water plant. The boiler was constructed of 5-in. pine plank with iron firebox and flues (Fig. 298). The distributing pipes were also of wood, being logs with the center bored out. The system was never very satisfactory; the boiler leaked steam and the pipes leaked water. In 1804, Philadelphia began laying iron pipes and is believed to have been the first city in the world to do so. New York City's water system, as well as modern plumbing in America, really dates from the completion of the Croton Aqueduct about 1850.

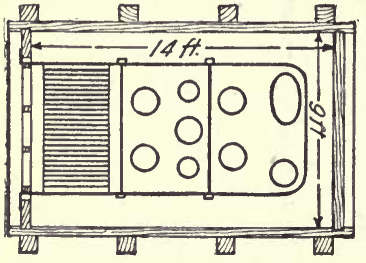

Top view.

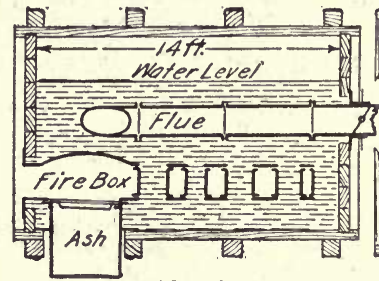

Side view.

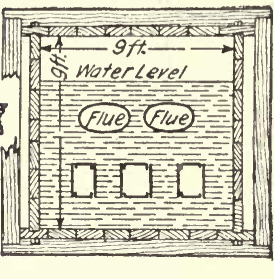

End view.

FIg. 298.-Boiler of the Central Square water works, 1800. From History of Sanitation, Cosgrove.

569. Water System of New York City.-Many of our larger cities have spent immense sums of money in obtaining an adequate water supply. In 1842, New York City first began using water from the Croton Reservoir. An immense dam had been constructed across the Croton River forming the reservoir. An aqueduct, the Croton Aqueduct, conveyed the water to the city. In 1890 this water system was enlarged. The cost of the Croton Aqueduct and Reservoir is said to have been $\$ 160$,000,000 and the labor required in their construction was equal to that of 600 men working for 10 years. In spite of the immensity of the Croton supply, about 500,000,000 gal. daily, the city is outgrowing its water system. At the present time a second source of supply is nearing completion. The city acquired possession of an area of $900 \mathrm{sq}$. miles of mountainous land in the Catskill Mountains and is constructing an aque- 


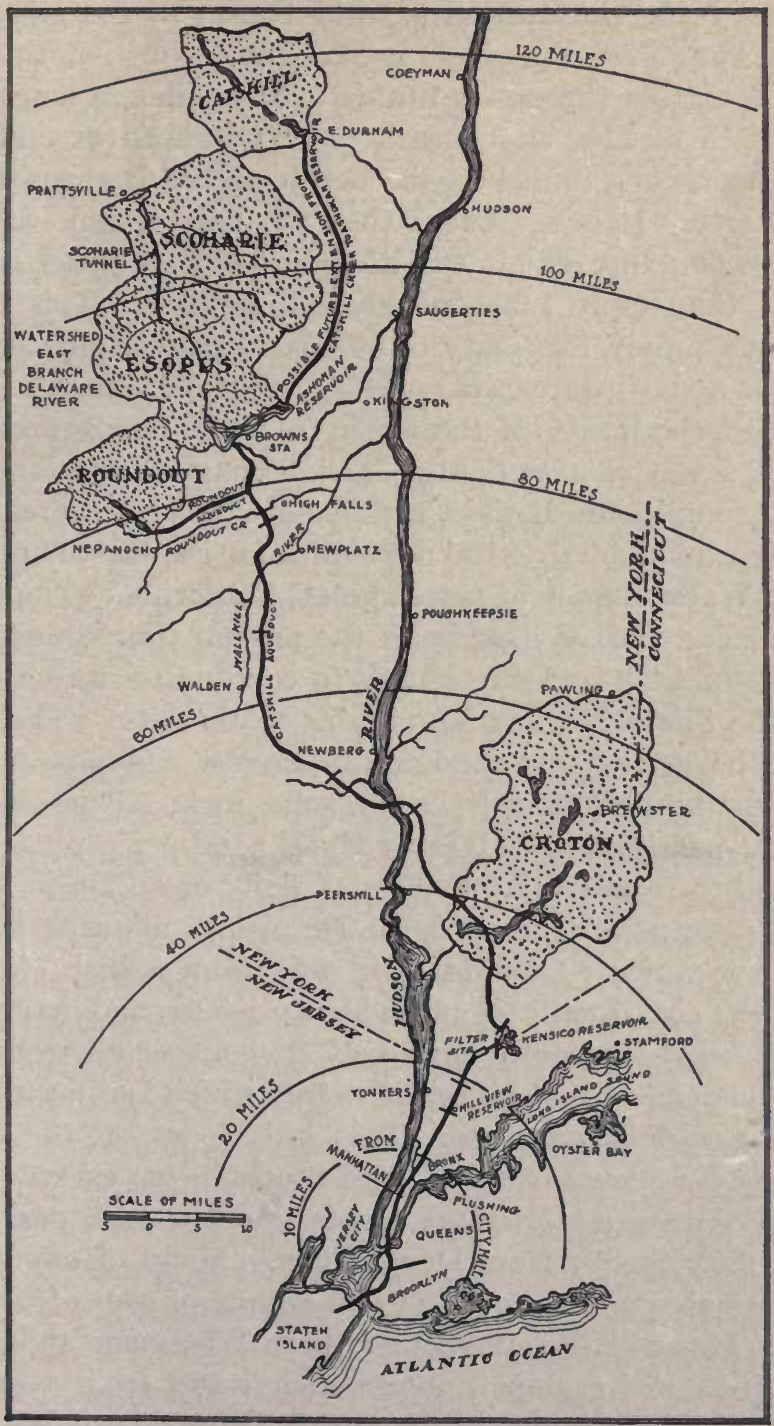

Fig. 299.-The water supply of New York City. 
duct to bring the rainfall of that region to the city (Fig. 299). The new aqueduct is 127 miles in length. The water is carried through a tunnel over 4 miles in length and at a depth of $1100 \mathrm{ft}$. beneath the Hudson River and later through another tunnel at the depth of $700 \mathrm{ft}$. beneath the East River. It is estimated that the new system will cost $\$ 200,000,000$ and that it will double the city's water supply, making the supply 1,000,000,000 gal. per day. This will be an ample supply for a city of $8,000,000$ population, allowing 125 gal. a day per capita. Every effort is being made to safeguard the purity of the water from the new source. To do this, seven villages in the Catskills have been abandoned. At the completion of the Catskill development the city will have expended nearly $\$ 100$ per capita for its water supply.

570. Water Supply of Los Angeles, California.-The city of Los Angeles, Cal., is likewise at the present time constructing an aqueduct 246 miles in length to conduct its water supply from the Sierra Nevada Mountains to the city. The water has to be carried over mountains, across canyons, and for 18 miles through tunnels in the solid rock. This aqueduct will cost nearly $\$ 25,000,000$, or about $\$ 160$ per capita, and is designed to supply $300,000,000$ gal. daily or an ample supply for a future population of 2,000,000 people, allowing 150 gal. daily per capita. Coming as it does from a high elevation above the city, it will be under high pressure, and may, therefore, be used for power purposes. It is expected to produce 150,000 horsepower of electrical energy which may be sold and used for various purposes. This will be one of the largest water power plants in the United States, being exceeded only by the Niagara and Keokuk plants (see Art. 668, page 560).

571. City Supply from Deep Wells.-Many of our smaller cities are able to obtain a sufficient supply of water from deep wells. Many of the cities of southern Wisconsin and northern Illinois, for example, obtain their water from a layer of sandstone which comes to the surface in northern Wisconsin but which is generally reached at a depth of $1000 \mathrm{ft}$. or more 
in Illinois. The source of this water supply is at a somewhat higher elevation; therefore, many of these wells are flowing wells. London, Eng., and Brooklyn, N. Y., have in the past secured a considerable portion of their water supply from wells.

572. City Water must be under Pressure.-The city is fortunate which has its source of supply at a considerable elevation above the level of the city. It is necessary that the city supply shall be under pressure, not only in order that the water may be used on the upper floors of tall buildings, but also to aid in the fighting of fires. It is also of great service that the water be under pressure in a city, for it may then be used for power purposes. In many cities the elevators in office buildings, stores, warehouses, and dwellings are operated by water power. Water motors are frequently used where small amounts of power are occasionally used, as in running the family washing machine. All modern plumbing is constructed to be used in connection with a water system where the water is under considerable pressure.

Figure 300 shows the arrangement of the plumbing in a modern city dwelling. It will be seen that both city water and soft, or cistern water, are provided. The city water being under pressure is made to pump the soft water into the storage tank in the attic. The hydraulic pump by which this is accomplished is generally called a WATER-LIFT. One-half of the water-lift, the left half in the figure, is really a water motor operated by the city water; the other half is a pump operated by the motor and it pumps the cistern water. Such a waterlift may be so constructed and installed that it will pump 1 gal. of cistern water into the attic tank for each gallon of city water used. Would this be possible if the attic tank were at as great an elevation as the city standpipe? Explain.

573. How Pressure is Maintained on the City System.Most cities obtain their supply of water from a level lower than the general level of the city. This is evidently the case with all cities obtaining their water supply from rivers and lakes upon the banks of which the cities are built. This must also 
generally be true for cities obtaining their supply of water from wells. How, then, is the city supply of water kept under

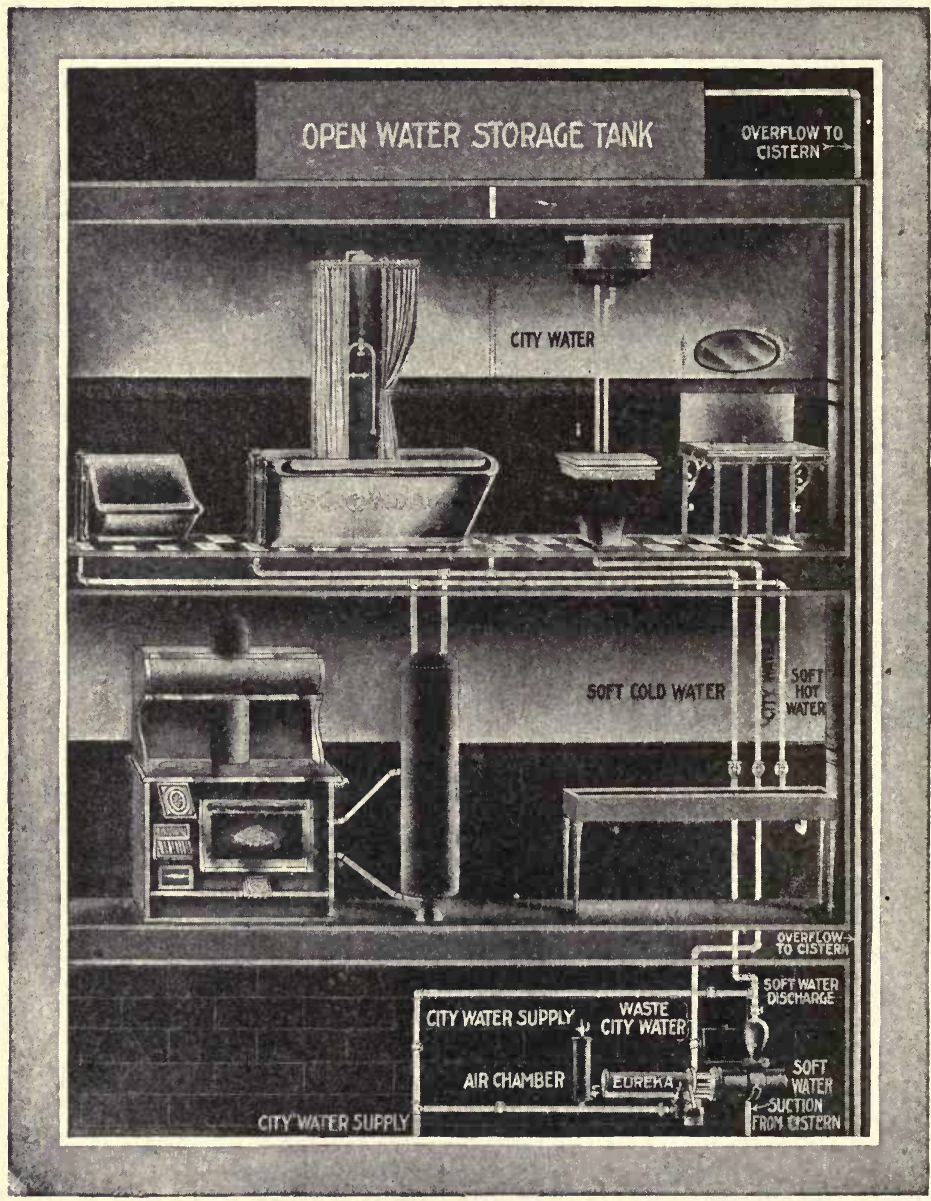

FIG. 300.-Plumbing in a modern city dwelling.

pressure? One of two methods is generally followed. First, in practically all city systems formerly, and in many small city systems today, an elevated tank, generally called a STAND- 
PIPE, is connected with the city water mains. As the water is pumped into the main it backs up into the standpipe until the latter is full. The height of the standpipe determines the water pressure.

The SECOND METHOD of maintaining pressure on the city system, now generally followed, is to pump the water directly into the city main which is provided with a RELIEF VALVE, a sort of safety valve (see Art. 158) at the pumping station. This valve is so adjusted that it opens when the pressure has reached the desired amount. If it is desired to maintain a pressure of $100 \mathrm{lb}$. per sq. in., the valve is so set as to open as soon as the water pressure has reached that point.

574. Head of Water and Resulting Pressure.-The height of the surface of the water above the faucets or taps, is called the HEAD OF WATER. What head of water is required to produce a certain pressure? The pressure of a liquid in a vessel, open at the top, is caused by the weight of the liquid. Each cubic foot of water weighs $62 \frac{1}{2} \mathrm{llb}$., but a cubic foot is 1728 iu. in Now suppose we had a pipe having a cross-section, or area, of just 1 sq. in., and $144 \mathrm{ft}$. or $1728 \mathrm{in}$. long. If we were to stand this pipe up vertically, that is, on end, plug the lower end and fill it with water, it would hold exactly $1 \mathrm{cu} . \mathrm{ft}$. of the liquid. The entire weight of the water, $62 \frac{1}{2} \mathrm{lb}$., would then rest upon the plug closing the lower end. A column of water $144 \mathrm{ft}$. high, then, produces a downward pressure of $621 / 2$ lb. to the sq. in. A column of water $1 \mathrm{ft}$. high will produce a pressure of $1 / 144$ of $621 / 2 \mathrm{lb}$. or about $.43 \mathrm{lb}$. A column of water about $2.3 \mathrm{ft}$. high produces a pressure of $1 \mathrm{lb}$. to the sq. in. Calculate this.

575. Pressure the Same in All Directions.-We have seen that if the head of water is $144 \mathrm{ft}$., the resulting downward pressure is $621 / 2 \mathrm{lb}$. to the sq. in. We must also note the fact that this pressure is exerted in every direction, downward, upward, and sidewise. If the water in the standpipe stands $144 \mathrm{ft}$. above the level of the city mains, then the pressure upon those mains will everywhere be $62 \frac{1}{2} \mathrm{lb}$. to the sq. in. 
What must be the height of a standpipe which will produce $100 \mathrm{lb}$. of pressure to the sq. in. upon the city mains?

576. Pressure Low at the Top of Tall Buildings.-Let us suppose that the top floor of an eight-story building is $100 \mathrm{ft}$. above the level of the city mains. What pressure will a 144-ft. standpipe produce in the faucets on that eighth floor? It is evident that $100 \mathrm{ft}$. of water in the house pipes will just balance $100 \mathrm{ft}$. in the standpipe. A head of only $44 \mathrm{ft}$. is then available. There will be a pressure of about $19 \mathrm{lb}$. to the sq. in. on the eighth floor, whereas the faucets in the basement of the building will have a pressure of about $62 \frac{1}{2} \mathrm{lb}$. to the sq. in. Calculate this.

577. The Loss of Pressure by Friction.-Thus far we have not considered any loss of pressure due to the friction of the water flowing through the pipes. At times of large fires in cities when many large streams of water are being used, the flow of the water through the city mains is so hindered by friction that often the pressure is greatly reduced. In such cases fire engines, which are merely steam force-pumps, are used to produce the necessary pressure to throw the stream of water to the top of the building.

Some modern cities maintain a high-pressure water system through the business portion for the special purpose of fighting fire (Fig. 301). With the construction of twenty-story buildings, $300 \mathrm{ft}$. or more in height, it has been found necessary to maintain a pressure of $200 \mathrm{lb}$., sometimes even $300 \mathrm{lb}$. to the sq. in. in order to fight fire effectively.

578. The Fire Hydrant.-In cities, fire hydrants are attached to the city main at frequent intervals. Fire hose can be attached quickly to the fire hydrant at the connection near the top of the hydrant (Fig. 302). By opening the cutoff valve the full pressure on the city main may then be utilized in fighting fire. $A$, Fig. 302, shows the position of the valve when the city pressure is cut off the hydrant; $B$, Fig. 302 , shows the position of the valve when it is open and the city pressure is on the hydrant. The valve is controlled by a rod extending 
from the top of the hydrant to its bottom. A screw thread is cut on the rod opposite the point where connection is made to the city main. The upper half of the thread is left-handed,

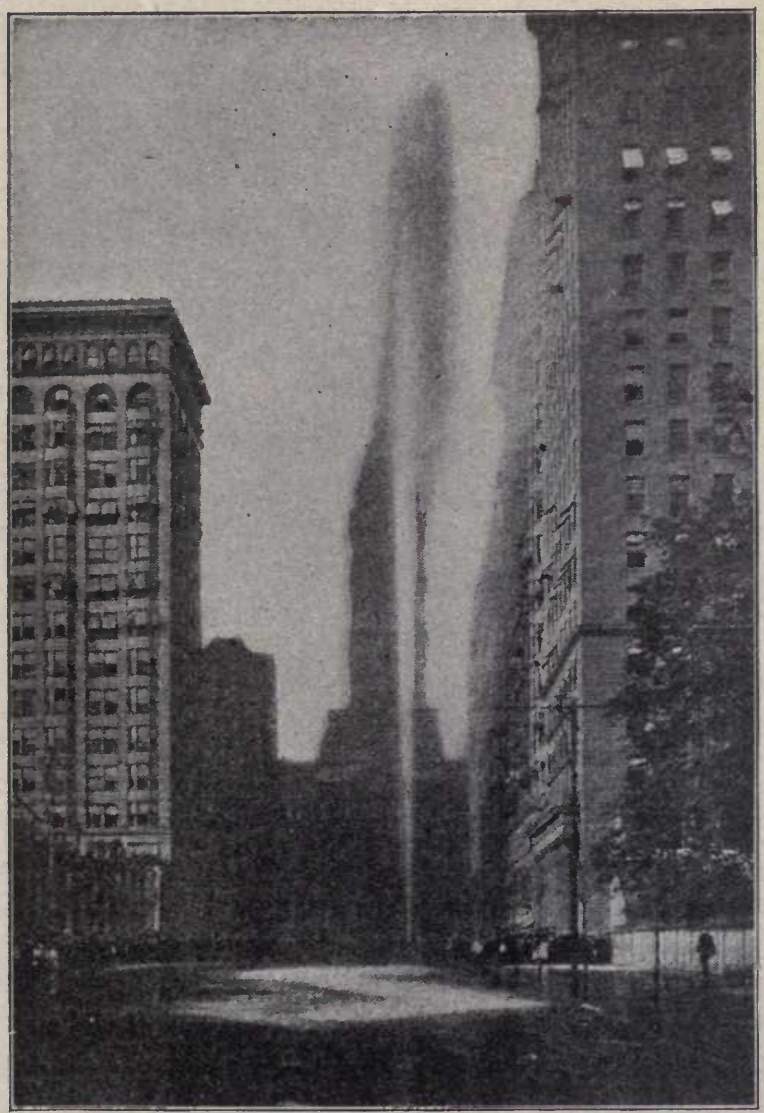

FIG. 301.-Philadelphia high-pressure fire service. Vertical stream made in underwriters' test.

the lower half is right-handed. The upper, left-handed thread carries a left-handed burr; the lower, right-handed thread sarries a right-handed burr. To these burrs are attached 
short rods or levers which control the valve. When the valve is to be opened, a wrench applied to the projecting portion of the rod at the top of the hydrant is turned counter-clockwise. This revolving of the rod forces the upper burr upward and the lower burr downward. The levers spread as the burrs separate and the valve is drawn back away from its seat, thus permitting the water from the main to rush into the hydrant.

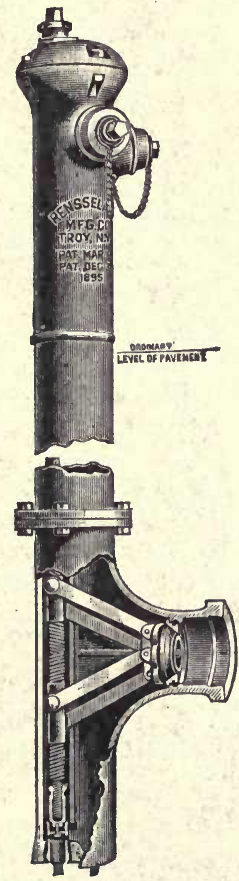

A

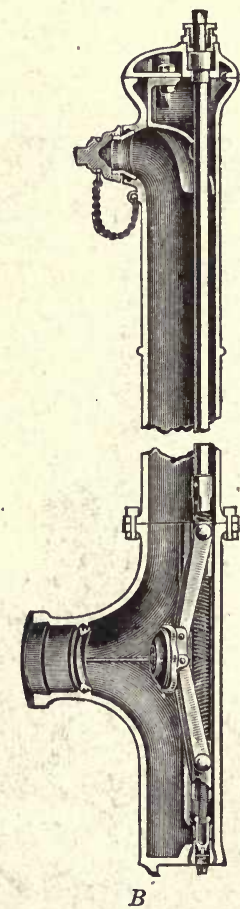

FIG. 302.-City fire hydrant.

579. The Fire Hydrant Drip.-To prevent the water in the city main from freezing and bursting the pipe, the main must be laid below the frost line. It is evident that the water in the fire hydrant will also freeze and burst the hydrant if permitted to remain in it. The draining of the hydrant is accom- 
plished by means of the DRIP VALVE at the lowest point of the hydrant. The drip valve is controlled by a right-hand screw on the lower end of the rod which controls the cutoff valve. When the rod is turned clockwise closing the cutoff valve, it opens the drip valve by raising it as shown in $A$, Fig. 302 . When the rod is turned counter-clockwise opening the cutoff valve, it lowers the drip valve, thus preventing any loss of water at the drip. To insure better drainage, the lower end of the hydrant is usually set in a bed of small stone, broken brick, or coarse gravel.

580. The Water Pressure-gauge.-Water pressure is usually indicated by PRESSURE-GAUGE. The pressure-gauge consists essentially of an elliptically shaped, thin-walled tube bent into a nearly circular form (Fig. 303). When the pressure within the tube increases, the tube tends to straighten out. This motion is transmitted to the pointer which moves over the face of the dial. The mechanism is so adjusted that the instrument shows directly the pressure per square inch.

581. The Water Meter.-While the pressure-gauge is a necessity at the pumping station indicating to the engineer the exact pressure on the city mains, the majority of

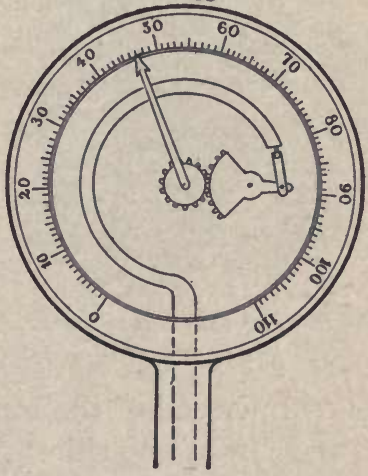

FIG. 303.-Pressure-gauge. consumers are more concerned with the water meter. The pressure-gauge merely indicates the pressure under which the water is kept; the water meter indicates the number of gallons or cubic feet of water which flow through the pipes. Generally, the consumer pays for the amount of water consumed, no account being taken of the pressure maintained. This is so, notwithstanding the fact that it requires more work (see Art. 636, and Chap. X) and costs much more to pump the same number of gallons of water into the city mains when a high 
pressure is maintained than it does when a low pressure is maintained.

582. Construction of the Water Meter.-There are water meters of many different forms, but most small meters are of the form known as the DISK TYPE. The only moving part in the measuring chamber is a hard rubber disk. This disk is borne, at its center, on a small sphere of the same material. The case of the meter is usually constructed of bronze so that it will not rust or corrode. The measuring chamber is of the

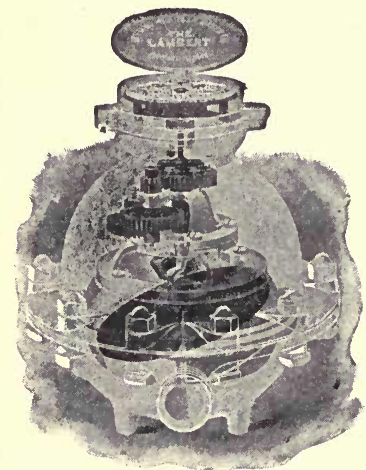

FIg. 304.-The water meter. $\mathrm{X}$-ray illustration. shape of the central portion of a sphere (Fig. 304). As the water passes through the meter, it causes the disk to move with what is known as NUTATION MOTION (nutation from a Latin word meaning nodding). The center of the rubber sphere is the point about which the disk moves. If we were to place a common wagon wheel upon the ground so that it rests upon its hub and we were then to walk around the wheel stepping upon its tire, we should be giving the wheel a nutation motion.

The upper end of the hub would move with a nodding motion as seen from one side. The water flowing through the meter produces just this sort of motion in the disk. The disk at all times divides the measuring chamber into two separate and equal-sized chambers. A certain amount of water passes through the meter for each complete nutation of the disk. Projecting above the disk at its center is a pin which engages a short horizontal lever. As the disk rotates, or rather nutates, this lever is carried around and around. A train of gears transmits this motion to the dials, thus recording the amount of water which flows through the meter.

583. Water Meters Generally Reliable.-A good meter is long lived and usually records the amount of water used fairly 
accurately. If in error it is generally owing to wear. In that case the meter will likely register too small an amount of water because some slips past the disk without causing it to rotate. Water users sometimes complain of the meter's reading too high. If a meter reads correctly when first installed, it is almost certain later to read too low on account of wear. Excessively high reading is generally on account of some undiscovered leak in the piping or too lavish use of water. Leakage is easily discovered, however, by means of the TEST-DIAL, a pointer which indicates the consumption of a cubic foot and fractions of a cubic foot (Fig. 305). To test for leakage, close all taps in the building and watch the test pointer for a few minutes. If any serious leakage is taking place, the test pointer will be seen to keep moving.

584. How Water is Sold to the Consumer.-Although water is generally sold by the 1000 gal., meters often record the amount used in cubic feet. There are $231 \mathrm{cu}$. in. in 1 gal., while there are $1728 \mathrm{cu}$. in. in $1 \mathrm{cu}$. ft. There are, then, nearly 7.5 gal. in a cubic foot.

\section{PROBLEM}

If water costs 25 ets. for 1000 gal. and the daily consumption for a city school building is $350 \mathrm{cu}$. ft., what is the cost of water per day?

Ans. $65+$ cts.

585. Reading the Water Meter.-A water meter may have either a STRAIGHT-READING REGISTER or a DIAL-READING REGISTER. The straight-reading register needs no explanation (Fig. $305)$. The dial-reading register is so constructed that it requires a complete revolution of the pointer on any circle to indicate the whole number of cubic feet indicated above or below that circle. The circumference of each circle is divided into tenths. In the illustration (Fig. 306) the highest reading pointer stands between 9 and 0 . The circle is labeled $1,000,000 \mathrm{cu}$. ft. The pointer, therefore, indicates a reading of something more than $900,000 \mathrm{cu}$. ft. The next pointer 
indicates a reading of $80,000 \mathrm{cu}$. ft.; the third pointer 8,000 ; the fourth pointer 0000 ; the fifth pointer 90 and the sixth pointer $7 \mathrm{cu}$. ft. If desired, the number of tenths. of cu. $\mathrm{ft}$. may be estimated by estimating the position of the pointer when it stands between any two figures on the 10-ft. dial.

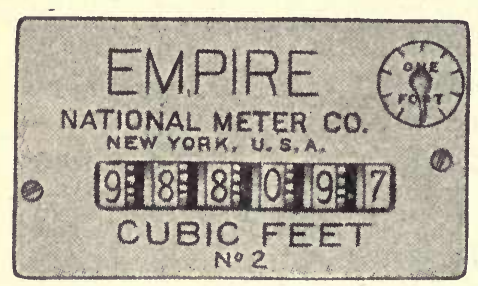

FIG. 305.-The straight reading register.

It reads $988,097 \mathrm{cu}$. $\mathrm{ft}$.

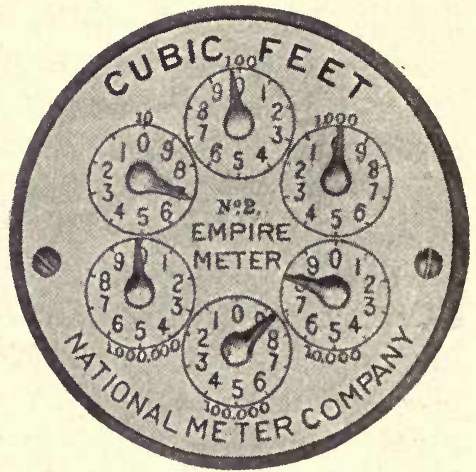

FIG. 306.-The dial register It reads $988,097 \mathrm{cu}$. $\mathrm{ft}$.

Exercise 96.-Reading a Water Meter and Computing the Cost of Water

Read the water meter at home or at the school on several successive days recording carefully the reading each day. Ascertain the price charged for water and compute the cost of each day's supply.

\section{SANITARY PLUMBING}

586. Development of the Art of Plumbing.-The art of modern plumbing has been developed within the past halfcentury. The word plumbing is derived from the Latin word plumbum, meaning lead. From the early days of plumbing, lead pipes have been used to convey water, hence the name plumbing has come to be applied to the entire art of supplying water to buildings and to the disposing of the sewage.

The Greeks and Romans, especially the Romans, made much progress in developing the art of plumbing, although many of their efforts would be considered very crude today. During the 600 years from 300 B. C. to 300 A. D., the Romans 
built no less than 20 aqueducts, with a total length of 400 miles, to supply the city of Rome with water. It has been estimated that while Rome's population was about $1,000,000$, still the city was supplied with sufficient water from these aqueducts, and from other sources, to permit the use of from 30 to 100 gal. a day by each inhabitant. To dispose of this large amount of water after it had been used, immense sewers were constructed, many of which are still in use.

Rome developed the most extensive and luxurious system of public baths the world has ever known. The public baths of Diocletian alone accommodated 3200 bathers at a time; the baths of Caracalla, still more famous and luxurious, accommodated 1600 at once. These baths were not free, the usual fee being one quadran, the smallest of Roman coins, about the equivalent of one-fourth of a cent in our money. The bath was not taken by the Roman merely for the sake of health or cleanliness; it was regarded as a luxury and was often repeated many times each day. The bath was always taken by the Romans after exercising and before the principal meal, and it has been said that it was frequently taken also after the meal in order to stimulate an appetite whereby they might eat in a more gluttonous manner. Emperor Nero, who reigned during the 1st century, is said to have indulged in this practice. Historians often declare that the downfall of Rome was partly due to these indulgences which tended to weaken the physical strength and vitality of the people.

Rome was repeatedly invaded and plundered by the fierce barbarians from the north and east for two centuries till the empire finally came to an end in $476 \mathrm{~A}$. D. During this period nearly all the works of art, the bronzes, precious marbles, and nearly every other evidence of civilization which had been accumulated during centuries were destroyed. The famous aqueducts and baths were largely destroyed along with the rest.

587. Hot Water Systems of the 18th Century.-After the destruction of Rome, many centuries passed before man again 
paid much attention to the development of the art of plumbing. In time, however, man again began to think of improving his conditions for comfortable living. The reproduction of an old woodcut (Fig. 307), shows the method of heating water in the most fashionable hotels of London in the 18th century. The water was pumped by hand into an attic tank. By means of an iron pipe it was conveyed down again into the bottom of the

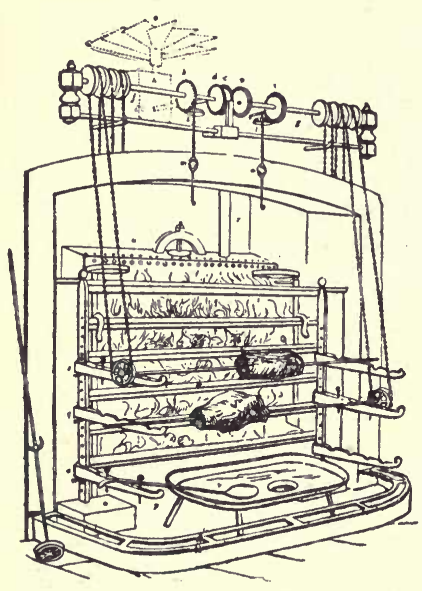

Fig. 307.-The 18th century hot water system. wrought-iron, riveted boiler at the back of the kitchen fireplace. Here it became heated. A second iron pipe, shown in the illustration, extended from the top of the boiler to the guests' rooms. The weight of the column of cold water forced the heated water up to the guests' room whenever needed. Thus to be able to have hot water in one's room whenever needed was considered to be a great luxury (Art. 170, p. 145).

588. Hot Water System in the Modern Residence.-Today no modern residence is complete without a supply of hot water. In Fig. 307 it will be seen that one side of the boiler was heated directly by the fire. In the modern residence, however, the water is heated by circulating through a WATER-BACK or WATER-FRONT in the kitchen range, or a HEATING COIL in the furnace, or by circulating through a special heater supplied for this particular purpose.

When the heater forms the front plate of the firebox it is called a WATER-FRONT; when it forms the back plate of the firebox it is called a WATER-BACK. Figures 293 and 300 also illustrate the usual manner of connecting the boiler with the heater. The arrows in Figs. 293 and 308 show the direction of flow of water. Explain why the water circulates as it does. 
What effect does heating water have upon its volume? What is the effect upon its density (Ex. 11)? What is the cause of convection currents (Art. 135)? The circulation of water through the heater is just as truly due to convection as the circulation of air through a furnace and the furnace pipes. Why is it best that the cold water supply pipe should extend nearly to the bottom of the boiler? In which portion of the boiler is the water the hotter, the bottom or the top? Why?

589. The Faucet or Bibb.There are many different styles of FAUCETS, or BIBBS, as the plumber calls them. The FuLLER FAUCET is a common type (Fig. 309). The figures show its construction and how it works. After being used for some time, especially if used on a hot water system, the rubber ball is likely to become softened and expanded, thus interfering with the flow of the water. New balls are easily inserted by anyone handy with tools. Most types of faucets occasionally need slight repair.

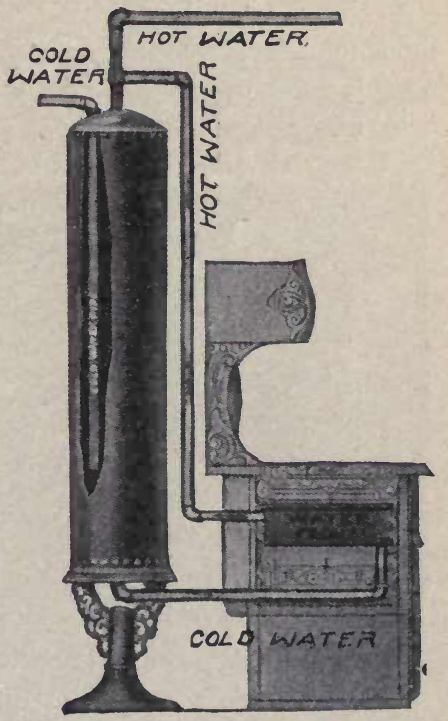

FIG. 308.-The water front and its connections with the boiler.

Faucets used in hotels, public places, and especially in schoolhouses, are often of the SELF-CLOSING type (Fig. 310). This is a modified form of the common COMPRESSION FAUCET. As is the case with any compression faucet, a right-handed tread on the post lifts the valve from its seat when the handle is turned counter-clockwise. But in this faucet a stiff spiral spring surrounding the post is thereby compressed. As soon as the pressure upon the handle is removed, this spring forces the valve down again upon its seat. What is the advantage of a self-closing faucet? 


\section{Exercise 97.-A Study of Faucets}

Secure from a plumbing house as many types of faucets as possible and study each carefully, noting its construction and how it is operated. Make a sketch of each and write a brief description of it telling how it works.

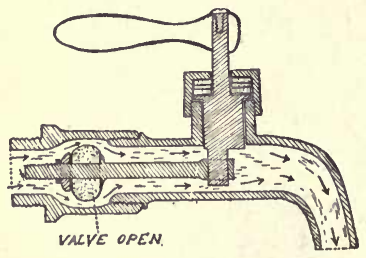

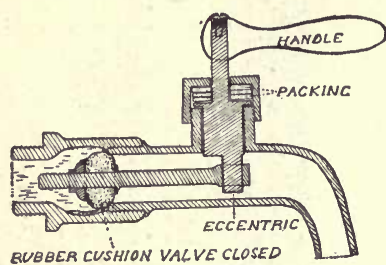

FIg. 309.-The Fuller bibb.

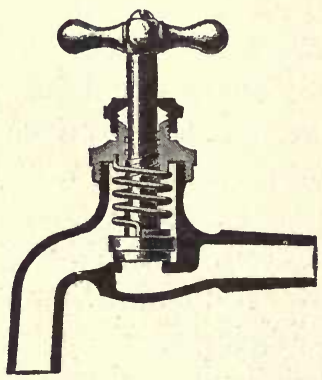

Fig. 310.-The self-closing compression bibb.

\section{Importance of Good and Sanitary Plumbing.-No} portion of a modern residence needs to receive more careful attention than the plumbing. Faulty or cheaply constructed plumbing is likely to prove both dangerous to health and, in the end, very expensive because no other kind of repair work is more expensive than repair of plumbing. In fact, good, safe plumbing is considered so important that the laws of most states and cities require that all plumbing work be done by licensed plumbers who have passed examinations intended to test their knowledge of sanitary plumbing. These laws require that all plumbing shall be constructed in a sanitary manner; in many cases they state exactly the way in which the plumbing shall be constructed.

591. Sanitary Fixtures.-Such fixtures as bath tubs, sinks, lavatories, wash tubs or laundry trays, and closets have been 
greatly improved within very recent years. Only 30 or 40 years ago the fixtures used in the most expensively furnished residences were very insanitary as well as very expensive as compared with those used today. Figure 311 shows an expensively furnished bathroom of about 1875 . It was thought desirable in those days to conceal all piping and other metal work within elaborately carved woodwork. In those days such fixtures were not made of single, water-tight pieces as they are today. The result was that more or less moisture was certain to collect within the wooden cabinetwork sur-

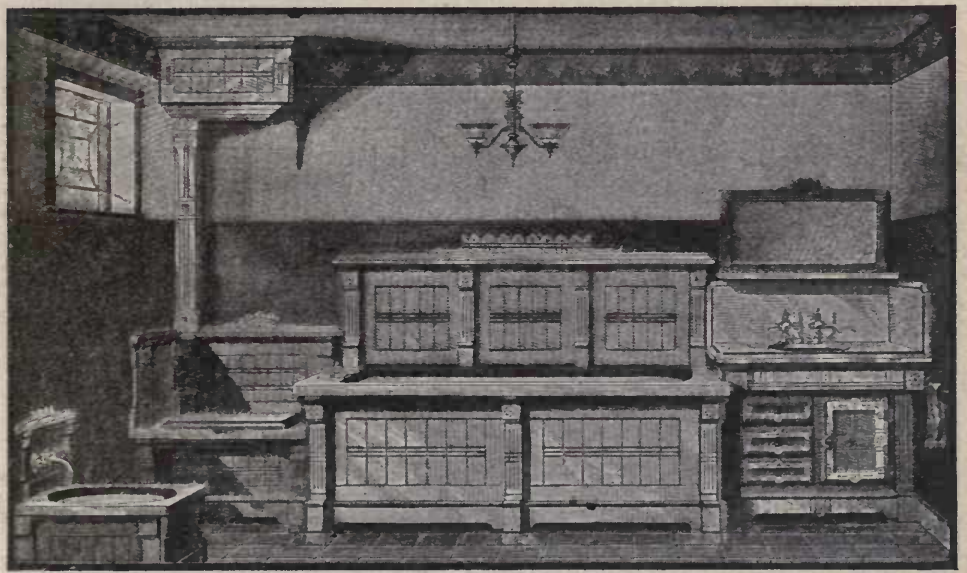

Fig. 311,-An expensively furnished bathroom in 1875 .

rounding the fixtures. Such spaces were dark and moist, ideal places for the growth and development of microörganisms. A glance at the cut shows the utter impossibility of keeping such a bathroom clean and in a sanitary condition.

The fixtures used in modern plumbing are strikingly different from those used a few years ago. Figure 312 shows the equipment of a modern bathroom. Notice (1) that all these fixtures are of one-piece construction, (2) that they are of solid porcelain or enameled iron, (3) that they are so raised from the floor that the space beneath is light, airy, and easily 
cleaned, (4) that all piping is exposed so that possible leaks are easily discovered. Carefully compare the fixtures and plumbing of this room with those shown in Fig. 311. What advantages do you see in their use?

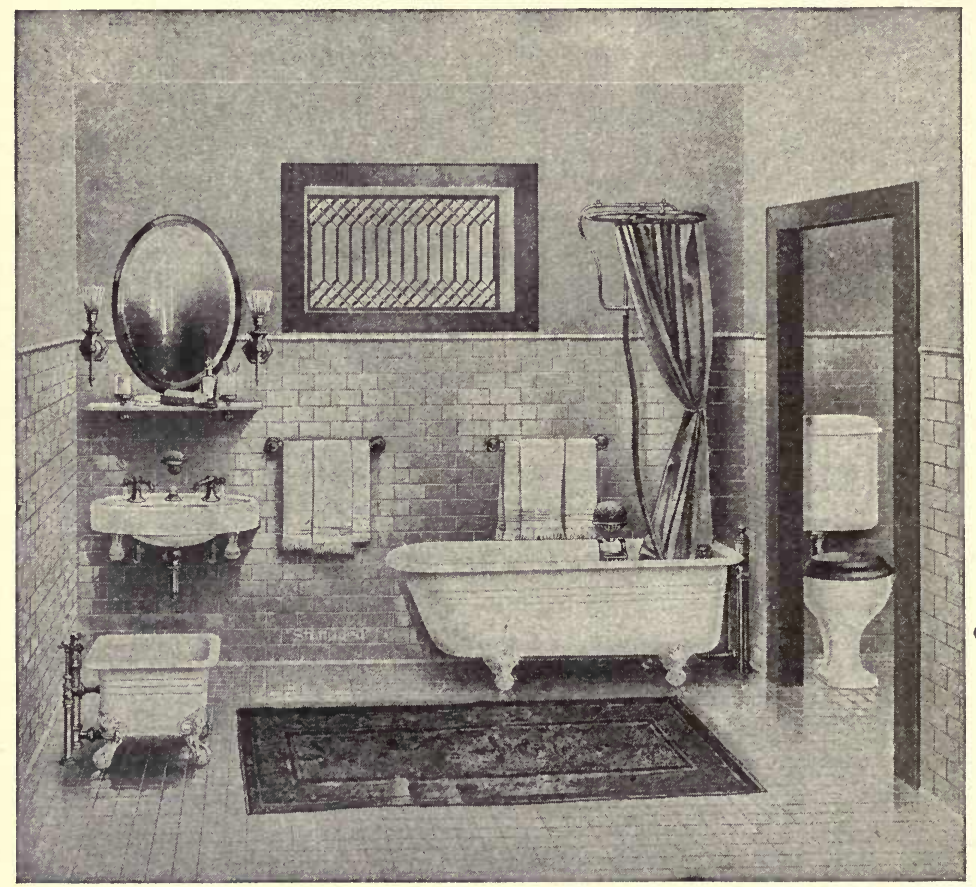

- FIG. 312.-A modern sanitary bathroom.

592. The Drains.-The drains in any building are of the greatest importance, so far as sanitation is concerned. They must be as constructed as quickly to dispose of all waste matter. They must also be air-tight within the building. We have seen that all organic matter is decomposed by microörganisms (Art. 505). These microörganisms attack and decompose the waste matter in the drains. During the process of decomposition this waste matter often gives off large amounts 
of gases. Many of these gases have offensive odors and they are genreally regarded as being very unhealthful. Some of these gases while nearly without odor are just as unhealthful. The drains must be so constructed as to prevent the escape of these gases into the building.

To insure air-tight construction all drains within the build-

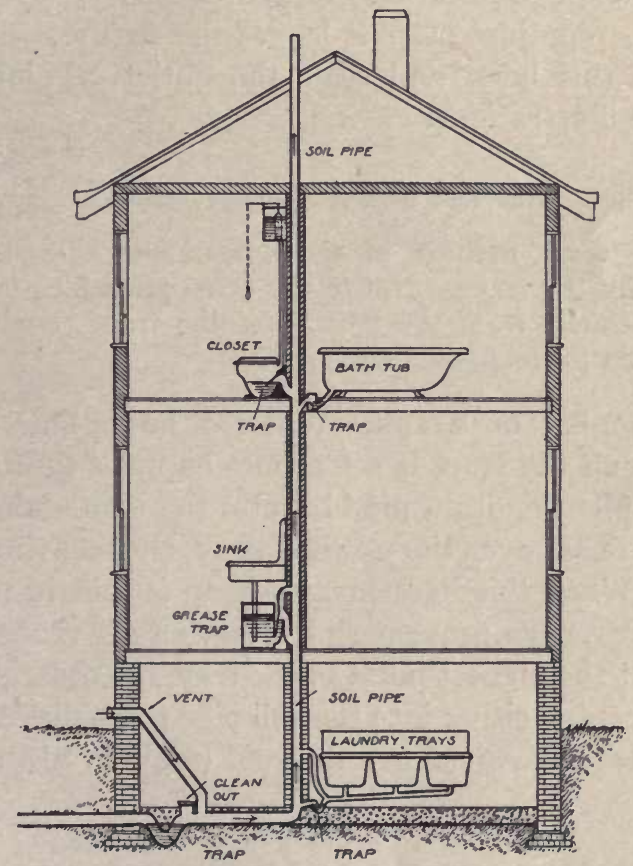

FIG. 313.-Plumbing in a residence.

ing must be of metal. The larger and straighter pipes are generally of iron with all joints closed by means of calking with oakum and lead; the smaller and bent pipes are often of lead with all joints wiped, i.e., soldered.

593. Venting the Drains.-The main drain pipe should be thoroughly ventilated, i.e., provision should be made whereby a current of fresh air passes constantly through the drain pipe 
and out through the sorl PIPE (Fig. 313). The air and gases within the drain and soil pipe are nearly certain to be warmer and less dense than outside air. Explain clearly the circulation of air through the drain pipe and its cause.

594. The Trap.-Every opening into the drain, whether it be from sink, lavatory, bath, or closet should be sealed by means of a trap. Most traps consist of a sharp upward bend in the drain pipe just after it leaves the fixture. The water settles into this bend and seals the outlet. Point out the traps in the illustrations.

\section{Exercise 98.-A Study of Traps}

Examine several fixtures in the schoolhouse or residence and study carefully the traps. Notice the provision which is made for removing obstacles from the bottom of the trap. Such openings are called CLEANOUTS.

595. Siphoning of Traps.-When a large flow of water passes through the trap, it sometimes happens that the water completely fills the drain pipe beyond the trap and causes all the water to pass over the upward bend, thus leaving the trap unsealed. When this happens, the trap is said to have been SIPHONED OUT. To prevent siphoning, an air vent is usually connected at the highest point of the trap, the other end of the vent pipe opening either into the soil pipe some distance above or opening into the air above the roof (see Fig. 313).

\section{Exercise 99.-A Study of the Siphon}

Place one end of a small clean rubber tube into a vessel of water and hold beneath the surface of the water. Place the other end between the lips and suck out the air (see Art. 374). When the tube is filled with water, close the erd of the tube near your lips by pressing between the thumb and finger. Now lower this end to a point lower than the level of the water in the vessel. Remove the pressure from the tube. Does the water flow through the tube? If not, try refilling the tube. Now carefully raise the open end of the tube, noting the effect upon the ra: of flow of water. Does the water continue to flow after the free end of the tube has been raised above the 
level of the surface of water? Such a piece of apparatus is called a SIPHON; the water is said to have been removed from the vessel by SIPHONING.

596. Explanation of the Siphon.-In the experiment, the water in the long arm of the siphon fell through the tube. In so doing it tended to produce a vacuum in the upper portion, the bend, of the tube. Air pressure upon the surface of the water in the vessel forced the water up into the vacuum. This water then fell and more water was forced up into the bend. Thus the action continues till the level of the water falls below the open end of the tube in the vessel. How does the air vent provided in plumbing, then, prevent siphoning? If a hole were made in the rubber tubing used in Ex. 98 at the top of the bend, would it destroy its siphoning action?

\section{The Siphon Flushing} Tank. - The principle of the siphon is utilized in the ordinary flushing tank used in connection with water closets.

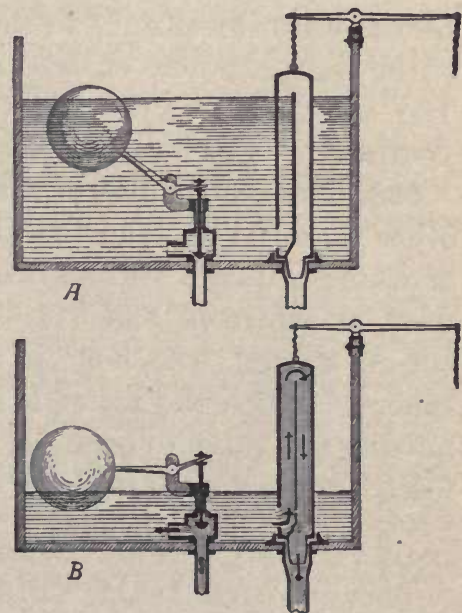

FIG. 314.-The siphon flushing tank. $A$. When not flowing; $B$. When flowing.

Figure 314 shows the construction of such a flushing tank. The trap consists of a hollow cast-iron cylinder about 3 in. in diameter and 12 in. in length. A vertical partition extending nearly the entire length of the trap divides its interior into two chambers, or rather into two passages. One side of the trap, near its base, is so cut away as to produce an opening into one of the two passages at that point; the other passage opens downward directly into the discharge pipe. The lower end of the trap fits tightly upon a cushion so as to seal the passage into the discharge pipe 
when the trap is properly seated. When raised an inch or two, the trap permits the water to rush directly into the discharge pipe. If the trap be again dropped upon its seat, the discharge pipe, now filled with water, together with the two arms, or passages of the trap, becomes a perfect siphon. The discharge pipe and the right-hand passage in the trap form the long arm of the siphon and the left-hand passage forms the short arm. From our study of the siphon, it is evident that the water will continue to flow through the siphon thus formed till the water level sinks to the level of the opening in the side of the trap, air there enters and destroys the siphoning action. The tank then again fills to the height permitted by the AUTOMATIC FLOAT VALVE.

598. The Float Valve or Automatic Cut-off.-In many cases other than the flushing tank it is desirable to have the height of water in tanks automatically controlled. In such cases a float, as shown in Fig. 314, is frequently used to operate the cut-off valve. The float is a light, hollow, brass or copper sphere. When the water is lowered, the float falls, thus permitting the valve to open; as the water rises again, the float is forced upward until it closes the valve.

\section{DISPOSAL OF SEWAGE}

599. Disposal of City Sewáge.-In cities having sewer systems the final disposal of sewage gives the individual citizen little or no worry. He has merely to connect his drain in proper manner with the city sewer; the city is responsible for the final disposal of the sewage. In many cases, city sewage is merely conveyed to, and emptied into, the nearest stream, always polluting it more or less, depending upon the amount and kind of sewage and the size of the stream. Our little friends, the ever-present bacteria, however, at once begin their work of decomposing the organic matter in the sewage and, under favorable conditions and with sufficient dilution, most of the polluting matter is soon destroyed and the stream again 
becomes reasonably clean and pure before its waters have proceeded far down stream. Sanitarians regard this as a primitive and unscientific method of disposing of sewage. It is generally believed that this method of disposing of city sewage will, sometime in the future, be abandoned and more scientific methods adopted. Most states in the east and central west now control stream pollution, through Boards of Health, proper disposal of sewage being required to suit conditions.

600. Disposal of Sewage from Isolated Residences. - In the case of isolated buildings, such as farmhouses, country residences, and institutions out of reach of city sewer systems, provision must be made for the final disposition of sewage. In solving this problem, the laws and principles of science, as far as they are understood, must be observed at every step. Before this problem had been carefully studied many serious mistakes were made.

601. The Leaching Cesspool.-Formerly the sewage from an isolated residence was often conveyed into a cesspool (see Fig. 294). Such a cesspool was merely a small, brick-walled, well-like receptacle a few feet in depth dug in the ground. No attempt was made to construct the cesspool water-tight. It was intended that the liquid portions of the sewage should soak, or LEACH, out into the surrounding soil. This, of course, polluted the soil and, since the water table frequently rises to a point near the surface of the soil, the ground-water became contaminated. In fact, in cases where much water was sent into the cesspool, the sewage constantly found its way down into the ground-water, thus endangering all nearby wells (Fig. 315). If this same sewage had been spread thinly over the surface of the soil, or better still had been covered by a few inches of soil, it would quickly have been decomposed by bacteria and rendered harmless. Such bacteria are abundant only near the surface of the soil; at the depth of the bottom of a cesspool they are not numerous nor can they become numerous, therefore, the sewage which leached from the old-style cesspool into the ground-water was practically unaffected by 
the decomposing and purifying action of bacteria. Sanitary engineers, and students of sanitation generally, now agree that the cesspool is an unsanitary method of disposing of sewage. They are also agreed that one of the most feasible and sanitary methods of disposing of sewage in case of isolated residences

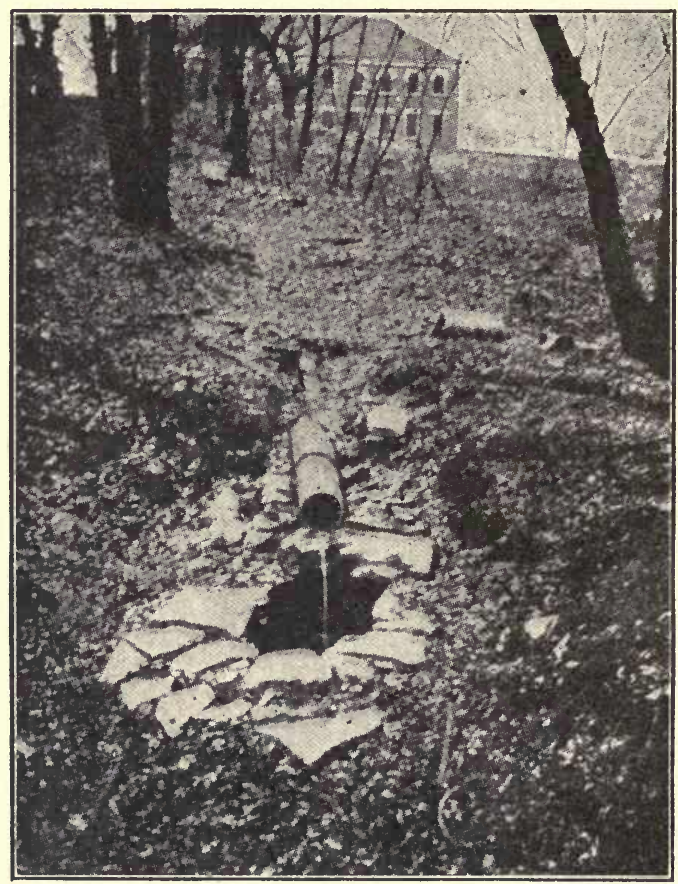

FIG. 315.-Pollution of ground water: sewage discharging into sink-holes.

is by using some type of SEPTIC TANK or DISPOSAL TANK and SUBSURFACE DRAINS.

602. The Septic Tank.-The modern sEPTIC TANK consists of two, and often three, compartments (Figs. 316 and 317). Each of these compartments is cemented so as to be absolutely water-tight. The sewage from the house enters compartment No. 1. In this compartment ANAEROBIC BACTERIA (Art. 465, 


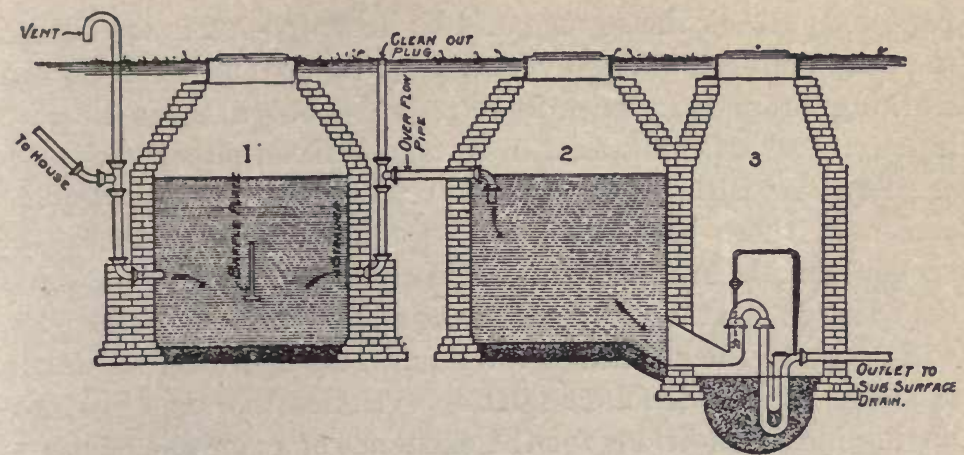

Fig. 316.-A septic tank. (From Practical Up-To-Date Plumbing, Clow.)
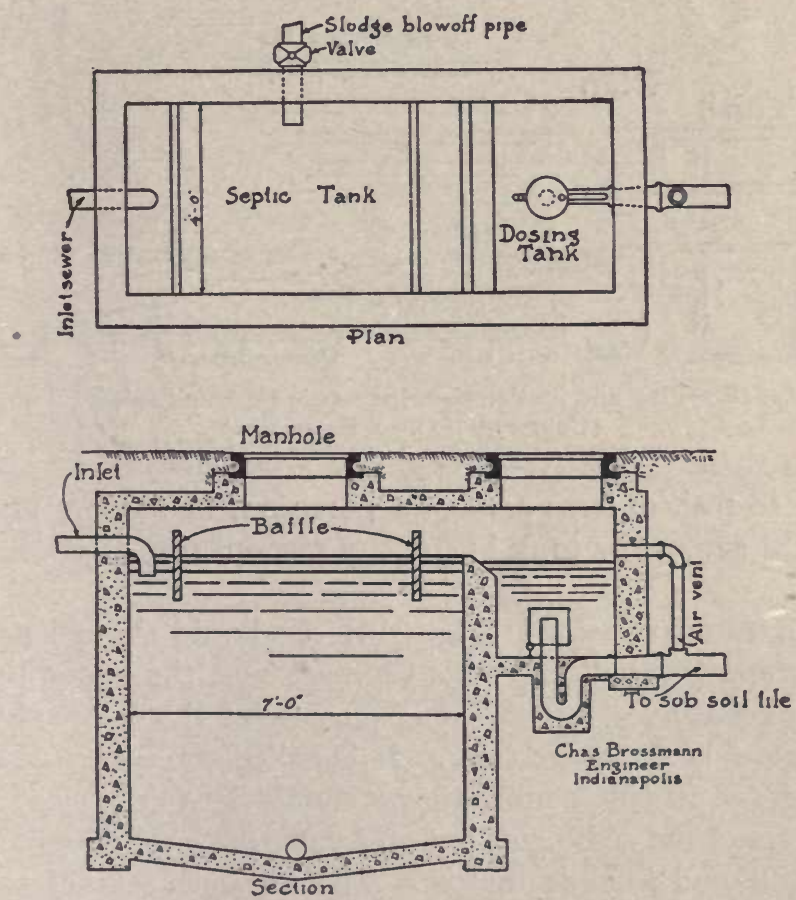

FIG. 317.-Plan and section of septic tank suitable for medium sized residences. (Courtesy of Chas. Brossman.) 
page 408) attack the sewage and by decomposing it soon cause the solid material to dissolve, or, as we say, to LIquefy. When working properly, this process requires but a short time to liquefy most solid material in sewage. Even paper and cloth are liquefied within a few weeks or months. The liquefying action of these bacteria sets free considerable quantities of carbon dioxide, ammonia, and other gases which escape around the cover of the tank; it also breaks all fats into small particles, which rise to the surface of the liquid and there form a tough, leathery scum which completely excludes the air, thus producing ideal conditions for the existence of anaerobic bacteria. To prevent the still undissolved solids from being stirred up
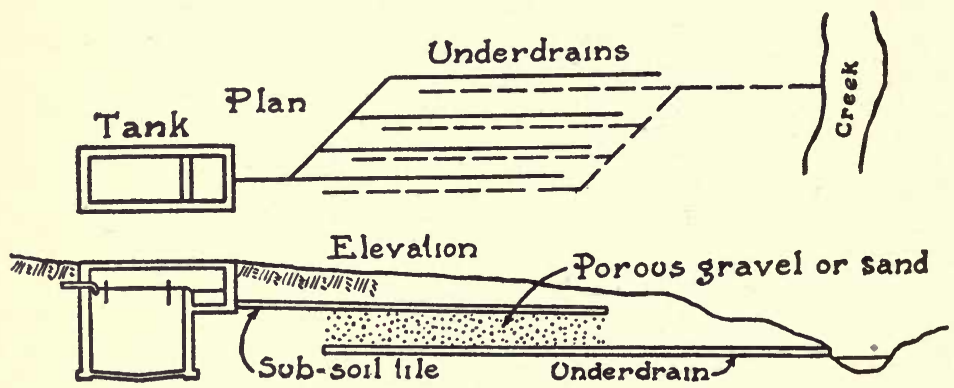

FIG. 318.-Plan and section showing septic tank and subsoil filter. (Courtesy of Chas. Brossman.)

by the in-rush of fresh sewage a partition, or BAFFLE PLATE, is placad across the tank in front of the opening of the house drain.

From compartment 1 (Fig. 316) the liquid sewage passes into compartment 2. In this compartment the bacterial action still continues, but the chief purpose of the compartment is to serve as a storage tank. It is called the Dosing TANK. The sewage in this compartment should be fairly clear and nearly free from sediment, but still contains large amounts of undecomposed organic matter. The sewage accumulates in this compartment till it is nearly full and is then drawn off through the INTERMITTENT SIPHON in compartment 3 into the 
SUBSURFACE DRAINS (Fig. 318). Compartment 3 is sometimes omitted and the siphon is placed in compartment 2, the dosing tank, where it is submerged by the liquid. It is more convenient, however, to set the siphon in a separate compartment, since it is necessary occasionally to examine the siphon to see that it is working properly.

603. The Imhoff Septic Tank.-A septic tank of somewhat more expensive construction is now generally used in disposing

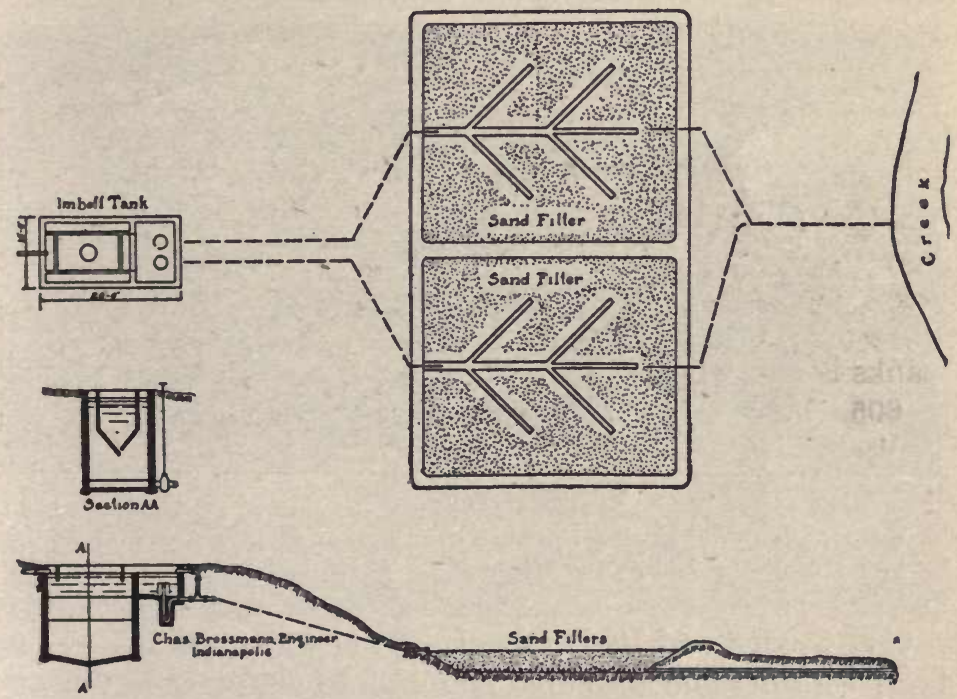

FIG. 319.-Imhoff type of tank and sand filter for small institutions. (Indianapolis Country Club.) (Courtesy of Chas. Brossman.)

of sewage from cities and institutions where considerable quantities must be taken care of. In the IMHOFF TYPE, the septic tank is really composed of two compartments, one suspended within the other (Figs. 319 and 320). The inner, suspended compartment is the SETTLING CHAMBER; the lower compartment is the SLUDGE CHAMBER. The two sides of the settling chamber do not quite meet at the bottom (Sec. $A A$, Fig. 319). As the sewage passes through this settling chamber, the 
solid matter settles through this opening into the sludge chamber below. It is chiefly in the sludge chamber that LIQUEFACTION Or DIGESTION takes place as a result of the action of the anaerobic bacteria. This type of septic tank is considered superior because the contents of the sludge chamber are but slightly disturbed by, or mixed with, the constant in-flow of fresh sewage. The bacterial action is, therefore, more certain and perfect.

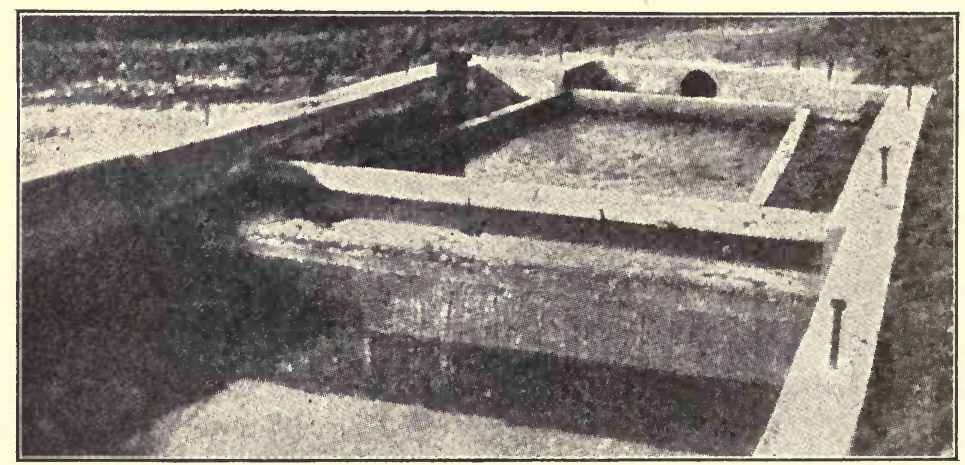

FIG. 320.--Imhoff tank showing sludge formation at sides. Settling chamber in center. Dosing chamber in foreground. Sewer inlet shown at far end. (Julietta, Ind.) (Courtesy of Chas. Brossman.)

604. Sludge and Its Disposal.-Even when operating at its best, considerable insoluble material accumulates in a septic tank. This accumulation is known as SLUDGE. Occasionally the sludge must be removed from a septic tank. It is claimed that the Imhoff type of septic tank produces a sludge more solid and more readily handled than that produced by tanks of the type shown in Figs. 316 and 317. Sludge from septic tanks is valuable as fertilizer.

605. The Complete Oxidation of the Sewage.-In the septic tank only partial oxidation of the organic matter in the sewage ever takes place. While the outflowing sewage from the septic tank should be fairly clear and free from sediment, it still contains large amounts of undecomposed organic matter 
in solution. The methods followed and apparatus used to accomplish this final and complete oxidation of the sewage depends upon surrounding conditions and the amount of sewage to be handled. If small amounts of sewage only are to be disposed of, and the character of the soil permits, the final oxidation may be accomplished by means of subsoil drains and underdrains only (Fig. 318). If large amounts of sewage are to be disposed of, or if the surrounding soil is not reasonably open, porous soil, CONTACT FILTER BEDS are generally provided (Figs. 319 and 321). In either case the same general principles

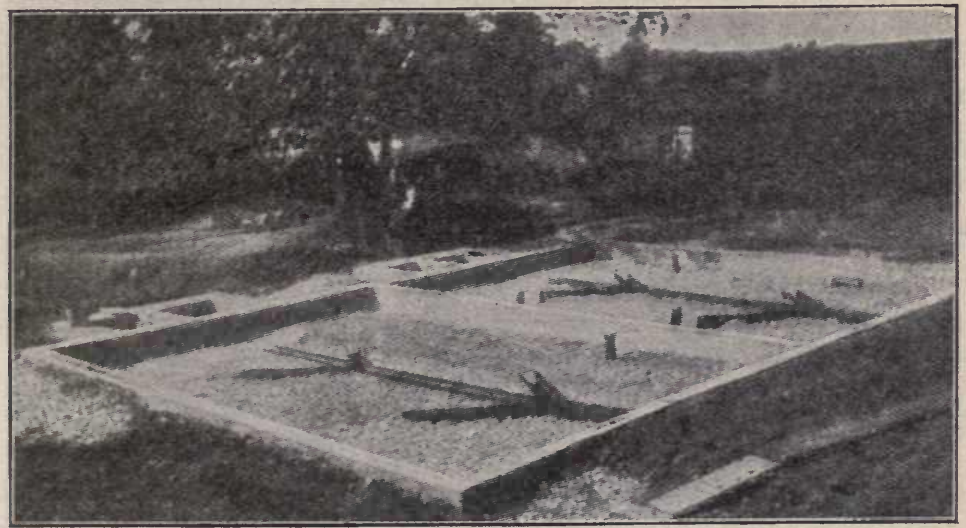

FIG. 321.-Contact filters of stone. (Julietta, Ind.) Sewage is discharged from tank, Fig. 320, to these beds. (Courtesy of Chas. Brossman.)

are applied; namely, suitable conditions are provided whereby aerobic bacteria may work upon the sewage, completing its oxidation to mineral matter.

606. The Subsurface Drain.-After passing through the siphon the sewage enters the SUBSURFACE DRAIN (see Fig. 318). This is merely a line of drain tile laid a few inches beneath the surface of the soil. The septic tank must evidently be constructed on higher land than the plot used for the drainage. All joints between the tile are left slightly open, from $1 / 4$ to $1 / 2$ in. To prevent dirt from entering through these open joints, 
a piece of a larger tile is laid over each joint. The liquid sewage readily passes out into the soil through these open joints. Here it is attacked by AEROBIC BACTERIA (Art. 465) and is completely decomposed, i.e., it is completely mineralized.

Since aerobic bacteria live and multiply only in the presence of an abundance of air, they are to be found in large numbers only near the surface of well-drained soil. It is because the aerobic bacteria can not survive without an abundant supply of air that the intermittent siphon is used to empty the septic tank. If the discharge from the tank were constant and steady, the ground surrounding the upper end of the drain would constantly be water-soaked, thus preventing air from entering the soil, and therefore preventing the sewage from being acted upon by aerobic bacteria. By using the siphon, the contents of the tank are completely discharged into the drain once in from 6 to 24 hours, and the volume discharged, at one time, is sufficient to fill the drain its entire length. The area covered by the drain is intended to be great enough to insure the complete oxidation and mineralization of the sewage of one discharge before the next discharge occurs.

607. The Contact Filter Bed.-When the amount of sewage to be handled is too great, or the character of the soil is such as not to permit of the successful use of the subsoil drain, contact beds are provided (Figs. 319 and 321). These beds are merely beds of gravel, broken stone, or coarse sand. The sewage is run out from the dosing tank upon the surface of these beds. As it soaks down through the sand or gravel, the organic matter adheres to, or is deposited upon, the surface of the rock particles, where it is attacked and destroyed by aerobic bacteria. The sewage is retained in the contact bed for a fixed period of time and then is drawn off, thus permitting air to enter all spaces between the rock particles, a necessary condition for the growth and multiplication of aerobic bacteria. The water drawn off from such a bed should be practically free from organic or other injurious matter. 
608. Summary.-The principal points to be remembered in regard to the use of the septic tank are the following:

1. The sewage must be disposed of while yet reasonably fresh and inoffensive.

2. To do so, it must be conveyed at once to the septic tank where the solids in it are liquefied by anaerobic bacteria. It must then be spread in a thin layer upon the surface of the soil, or allowed to pass into the upper layers of the soil, or into contact beds, in such a manner that aerobic bacteria will quickly act upon it, completely oxidizing and mineralizing it.

3. The mechanical appliances used are simply such as will most easily and certainly accomplish these results. 


\section{CHAPTER X}

\section{MACHINES, WORK, AND ENERGY}

\section{MACHINERY IN THE HOME AND ON THE FARM}

609. The Tools of the Early Colonist and Pioneer.-In early colonial days practically all work was done by hand. When machines were used they were of the simplest kind. This has always been the case with pioneers. When the colonist or pioneer wished to build a new home, he supplied himself with a rifle, a knife and an ax, a hatchet, and a saw and went forth into the woods. With his rifle and knife he supplied himself with food. With his ax he felled the trees and constructed his log house. He made all his own furniture-his chairs, his table and his bedstead. He fashioned out of wood such other conveniences as he needed.

610. Agricultural Tools of the Colonist and Pioneer.-When the pioneer had "cleared" a small space around his cabin, he naturally wished to raise some grain and garden truck. At first, the land was generally very fertile and free from weeds; little cultivation was necessary. In the spring the seed was scratched into the soil. In the fall the crop was harvested by using such tools as the pioneer could make. The corn was shelled and the wheat threshed by hand. The corn and wheat were ground into meal and flour between stones.

Later, as the pioneer's efforts at agriculture became more varied and he had oxen to help him, he secured a cast-iron plow. He also secured $a$ hand sickle and finally a cradle to aid him in harvesting his grain. He likewise made a flail for threshing it. As settlers became more numerous, grist mills were built upon the streams, and settlers from far and near carried their grain to these mills to be ground into meal and 
flour. Even then, their agricultural tools were so few and so poorly adapted to their needs that the farmer of today, were he obliged to use them, would feel helpless.

611. Household Tools of the Colonist and Pioneer.-The kitchen equipment and dishes of the pioneers were few indeed. A kettle or two, a few plates, and some knives and spoons constituted their cooking and serving equipment. But very early they found use for other household tools. It was impossible for them to buy clothing, therefore, they soon began to raise flax and wool in the northern colonies and cotton in the southern colonies and to make their own clothing. To do this they were obliged to make tools for carding, spinning, and weaving of "homespun" cloth. While these tools were crude and simple, they answered the purposes for which they were intended, and every member of the household became skilful in using them.

612. Pioneers were Skilful in the Use of Tools.-Although the colonists and pioneers had few tools to use, they were far more skilful in the use of such tools as they did have than are most of us today. There were no factories to manufacture the many articles they needed for their comfort, nor did they have money with which to buy them. We can, perhaps, appreciate the skill of the colonist in the use of tools when we realize that they, not only sheared the sheep, cleaned, washed, picked, carded, spun, dyed, and wove the wool into cloth and made the cloth into clothing, but that they were also obliged to make practically all the utensils used in these processes.

613. The Coming of the Factory.-About the beginning of the 19th century (1800) improved machinery, driven by water power, began to be used in the making of cloth. It was soon found to be more economical to buy cloth made in the factory than to make it in the home. During the 19th century, cotton and woolen mills with power-driven machinery were developed. At the present time no one thinks of manufacturing cloth in the home. Today much of the cloth is made up into garments ready to wear before leaving the factory. 
The 19th century was a period when there were few machines and labor-saving devices in the home. All this means that knowledge concerning machines and machinery largely disappeared from the home.

- 614. Knowledge of Machinery again Becoming Necessary in the Home.-While almost all the primitive industries have disappeared from the home, there have recently come into the home many new forms of machines and devices all of which make necessary some knowledge of applied science. Lighting systems of various kinds, heating devices, systems of water supply, plumbing, vacuum cleaners, sewing machines, and

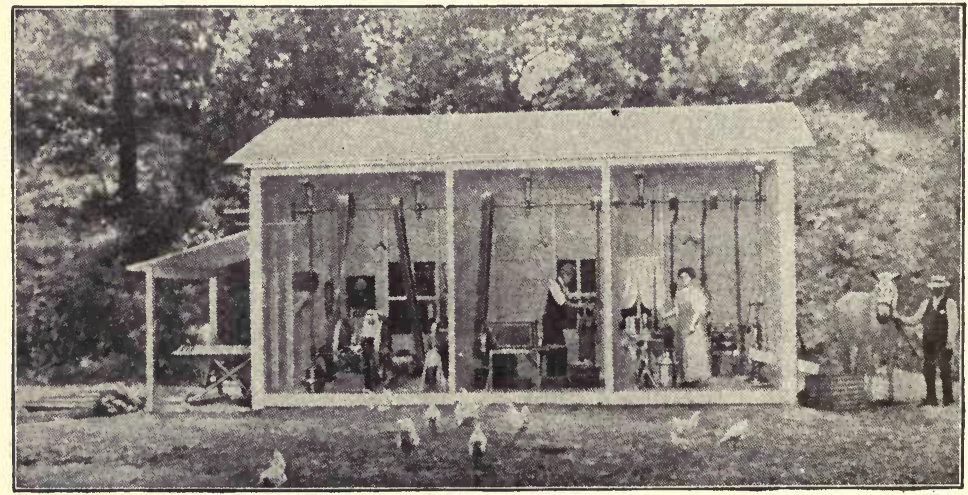

FIG. 322.-A farm power house.

motors for the operating of machinery of various kinds-all these conveniences require knowledge of applied science. The housewife with no knowledge of the laws of science can not expect to handle successfully the conveniences of the modern home.

615. Knowledge of Mechanics Necessary for the Farmer.Today the farmer requires a knowledge of mechanics at every turn. Most of the work on the farm is now done by means of machinery. The farmer with no knowledge of the laws of mechanics can not operate intelligently his plows, cultivators, mowing machines, binders, seeders, or numerous other tools 
found upon every farm. Moreover, many farms are now supplied with a power house in which a gasoline engine furnishes the power which runs the pump, cream separator, churn, corn sheller, feed grinder, and possibly a dynamo for generating the current for electric lighting, and a circular saw for sawing wood (Fig. 322). Many farmers now own automobiles, and these machines require a good knowledge of mechanics if they are to be handled with safety and economy. If all auto drivers were familiar with the laws of mechanics, many accidents would be avoided.

616. This, An Age of Machinery.-The farmer and the housewife need to learn a lesson from the factory and the wellorganized industrial plant. There, one man often operates a machine which does the work formerly requiring the labor of 10 , 100 , or possibly 1000 men. Rapidly the farmer is learning to avail himself of the advantages of using machinery. As yet, the housewife has made little use of machinery to aid her in her household duties. The cleaning of the house, washing and ironing, skimming of the milk and churning of the butter-these and many other processes are carried on by hand with little thought of using easily obtained labor-saving devices.

Make a list of the labor-saving machines for use on the farm and in the home.

\section{SOME COMMON MACHINES}

\section{The Sewing Machine}

617. Earliest Sewing Machines.-The first sewing machine of which there is authoritative record was invented by an Englishman, Thomas Saint, in 1790. It is not known that he made more than one machine. This machine, as well as others made during the following 50 years, was intended for embroidery and fancywork, not for practical purposes, such as the making of garments or other useful articles. All of the earlier machines were run by hand and were awkward, clumsy affairs constructed chiefly of wood and having many serious 
defects. The sewing machine did not seriously affect American life until after the middle of the 19th century. About 1850 really practical machines were invented. Even these

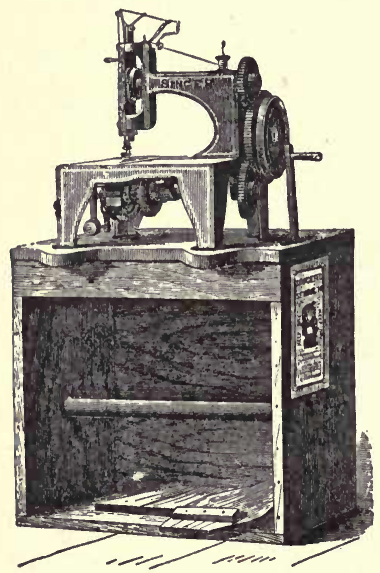

Frg. 323.--Sewing machine, 1850. The shipping box was used as a table for the machine. machines were crude compared with the machines of today (Fig. 323).

618. Classes of Sewing Machines.-Sewing machines may be classified according to the kind of stitch they make. Although a great variety of stitches have been used at different times-some 75 in number-practically only three kinds of stitches are today in use. They are the Lock sTITCH, the CHAIN STITCH, and the BUTTONHOLE sTITCH. The lock stitch is the most common and, for most purposes, the most satisfactory. Chain-stitch machines, however, have advantages for certain purposes:

1. Chain-stitch machines are simpler in construction and generally use but a single thread. 2. The thread, when sewed into a seam, is readily removed, i.e., the seam is quickly ripped out by the mere breaking of the thread. 3. The seam sewed by means of the chain stitch is elastic, while the lockstitch seam is not. 4. The chain-stitch machine can be operated satisfactorily at a higher speed than the lock-stitch machine. Figure 324 shows the manner in which the chainstitch machine forms the stitch.

Chain-stitch machines are frequently used in factories producing ready-made garments on account of their greater speed. Owing to the ease with which a chain-stitch seam may be ripped, and the liability of a stitch's being broken by accident, the chain-stitch seam is not regarded as satisfactory for many purposes. 
Exercise 100.-A Study of the Chain-stitch Seam and the Lock-stitch Seam

Secure samples of the chain-stitch seam and the lock-stitch seam, each sewed in loosely woven cloth cut on the bias. First, examine
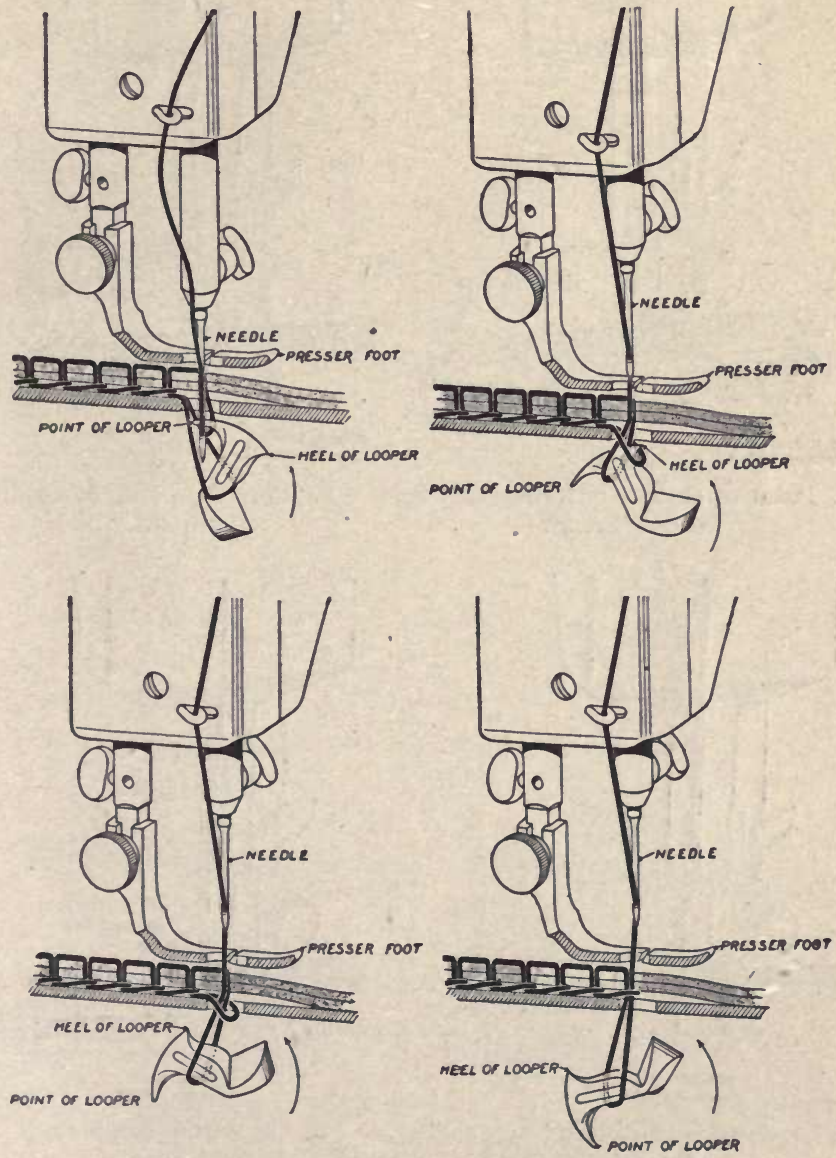

Frg. 324.-How a chain-stitch machine forms the knot.

each seam to see which is more elastic, and second, note the ease with which each seam may be ripped. Can you rip out the entire chain-stitch seam by merely breaking one stitch and pulling upon 
the broken thread? Can the lock stitch seam be ripped in this manner?

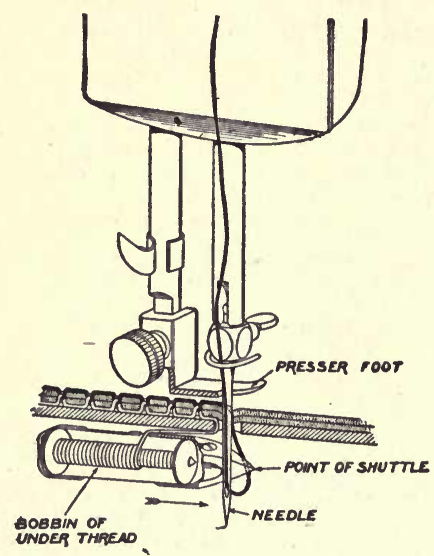

1. Point of shuttle entering loop of needle thread.

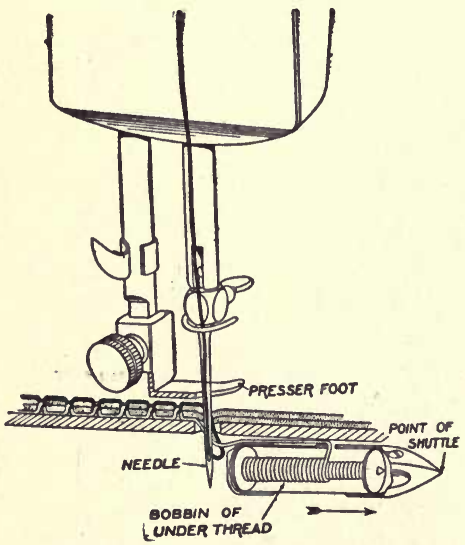

3. Shuttle thread enclosed by needle thread.

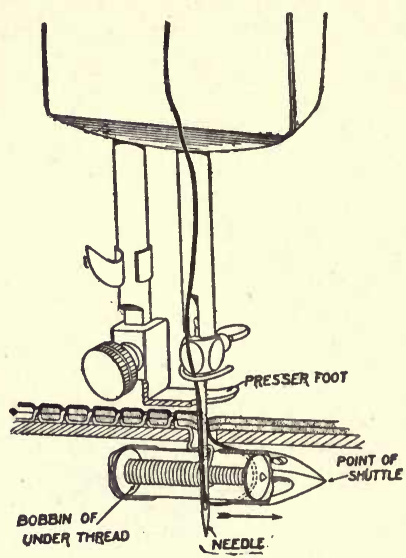

2. Shuttle in loop of needle thread.

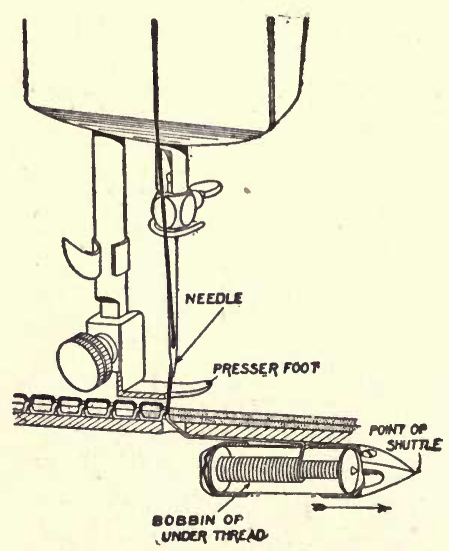

4. Stitch completed.

FIG. 325.-How a vibrating-shuttle machine forms the knot.

619. Classes of Lock-stitch Machines.-Lock-stitch machines are classified according to the way in which the stitch 
is formed. The common classes are ROTARY-HOOK, OSCILLATING-HOOK Or OSCILLATING-SHUTTLE machines, and VIBRATING-SHUTTLE machines.

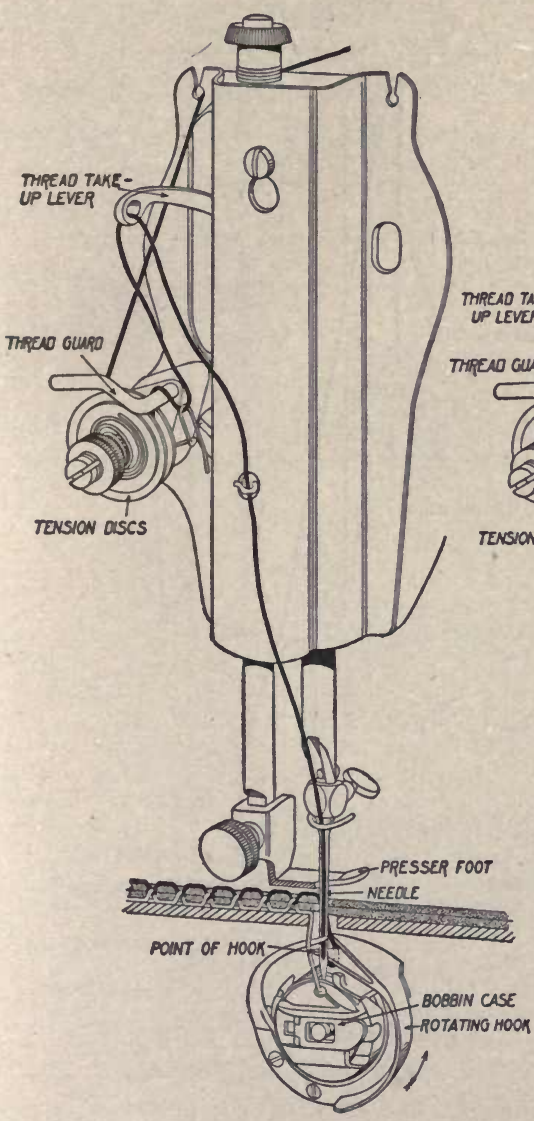

1. Hook entering the loop of the needle thread.

FIG. 326.-How a rotary hook makes the knot.

While the majority of all lock-stitch machines in use today are of the vibrating-shuttle type (Fig. 325), certain rotaryhook machines have been among the most successful from the 
first. In 1851, Mr. A. B. Wilson invented a rotary-hook machine, the first of that type, which was very successful.

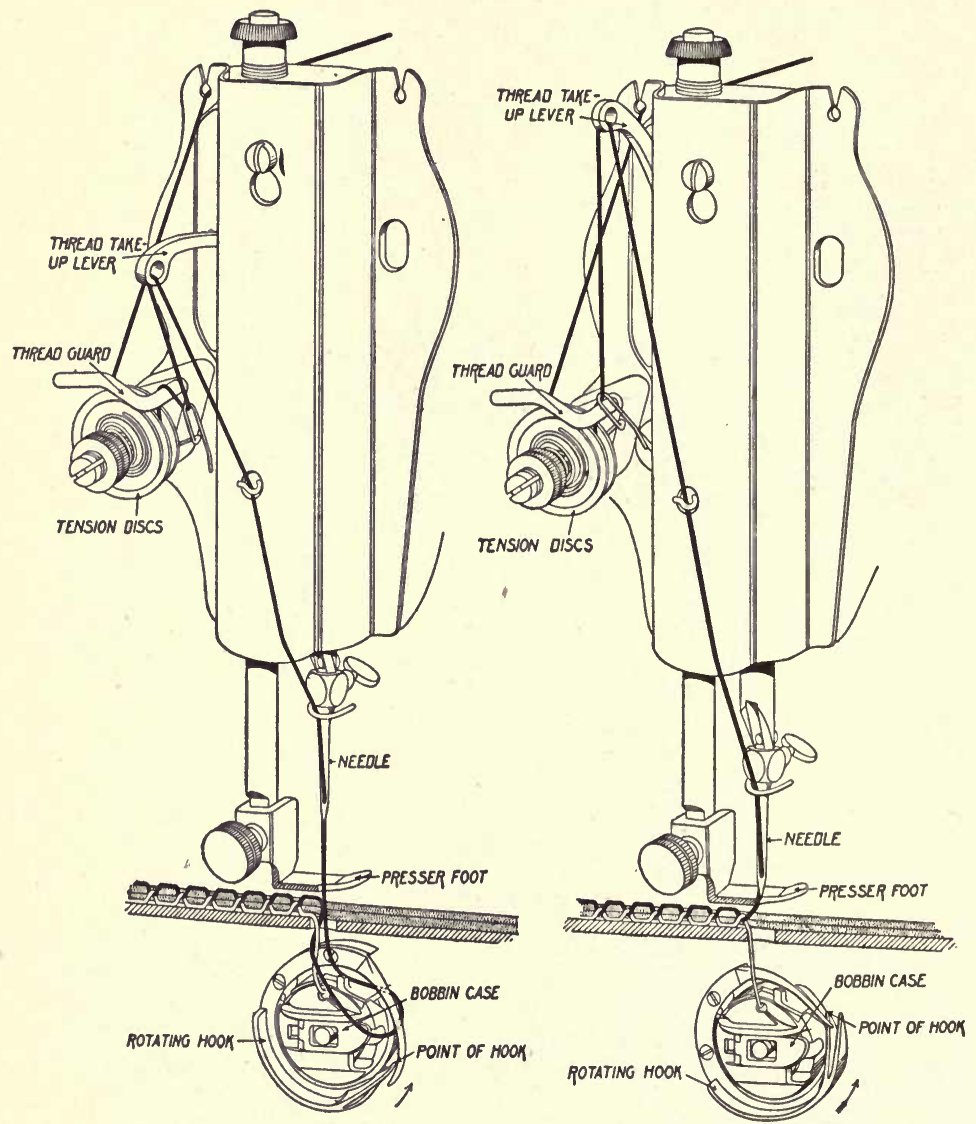

3. Under thread enclosed by needle thread.

4. Stitch completed. FIG. 327.-How a rotary hook makes the knot.

Figures 326 and 327 show the way in which the rotary-hook machine forms the stitch.

In the rotary-hook machines, the hook makes one complete rotation for each stitch. 
In the oscillating-hook or oscillating-shuttle machine, the hook or shuttle makes one-half of a rotation, i.e., turns onehalf way around on its axis, and then reverses and returns to its former position, for each stitch.

In the vibrating-shuttle machine the shuttle may move in a straight line or in the are of a circle. In either case, the shuttle makes one complete vibration, i.e., a motion forward and back, for each stitch.

\section{Exercise 101.-A Study of the Sewing Machine}

(This exercise may be studied at home if no machine is available at school.)

1. Note the name of the machine.

2. Note just how the motion of the treadle is transferred to the drive wheel by means of the pitman. One complete vibration of the treadle produces how many revolutions of the drive wheel?

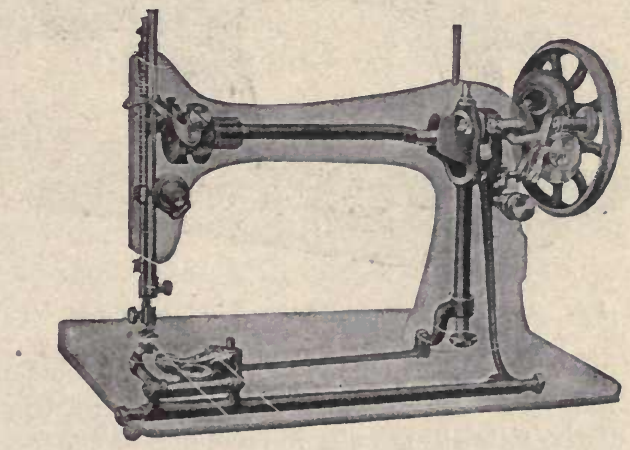

Fig. 328.-Head of a vibrating-shuttle machine.

3. Measure the diameter of the drive wheel. What, then, is its circumference? Measure the diameter of the pulley on the head of the machine over which the belt passes. What is its circumference?

4. Provided there is no slipping of the belt, how many revolutions of the pulley will be produced by one revolution of the drive wheel?

5. Turn the pulley carefully and see how many stitches are taken by the needle for each revolution of the pulley. How many stitches are taken, then, to each complete vibration of the treadle? Move the treadle through one complete vibration and count the number of stitches taken to check your calculation. 
6. Place a piece of cloth in position and stitch a seam for 10 seconds by the watch. Let one assistant watch the time while a second assistant counts the number of vibrations of the treadle. How many stitches, then, are taken per minute. (Some manufacturers claim that as many as 3000 stitches per minute have been taken with their machines.)

7. Remove the face plate, if removable, and discover exactly how the rotary motion of the pulley is changed to a vibratory motion of the NEEDLE and the TAKE-UP LEVER.

8. Note exactly how the presser-foot is raised from the cloth. What is its purpose?

9. Examine the feeding device and determine how it works. Just how is the length of the stitch regulated? Does the length of the

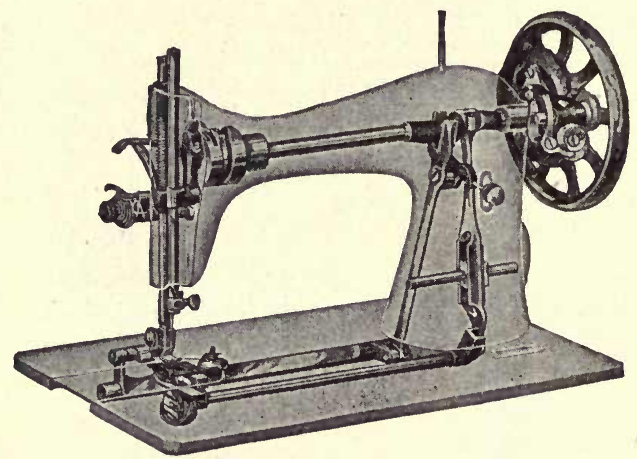

Fig. 329.-Head of a rotary-hook machine.

stitch depend upon the speed with which the needle acts or upon the motion of the feed? Be certain that you understand the regulation of the length of the stitch. Do the movements of the feeder tell the direction in which the balance wheel must be turned?

10. Is the machine studied a chain-stitch or a lock-stitch machine? Note exactly how the stitch is made.

11. If the machine is a lock-stitch machine, determine whether it is (a) a rotary-hook machine, (b) an oscillating-hook or oscillatingshuttle machine, (c) or a vibrating-shuttle machine.

12. Determine exactly how the knot is produced. Does the loop which forms the knot pass completely around the hook or shuttle? If so, describe exactly how it does so. Can the hook or shuttle, then, be rigidly attached to any fixed or moving part of the machine? Do not decide this point till you have made a careful study of the way in which the knot is produced. 


\section{The Cream Separator}

620. Importance of the Cream Separator.-The cream separator is found nowadays in almost every creamery, in every city milk-supply house, in many dairies, and on most farms where any considerable quantity of milk is produced. It is one of the most common and useful machines. As its name implies, it is a machine used to separate the cream from the other portions of whole milk.

621. Former Methods of Separating Cream.-Primitive man doubtless separated cream from the other portions of milk from the time he first began to use as food the milk from his herds of goats. Until recent times the separation was usually made by placing the milk in shallow crocks, jars, or pans. The cream, being lighter than the other portions of the milk, rose to the top and could then be removed, leaving the skim milk undisturbed. Frequently the skimming was not made until the milk had become sour, thus giving the cream as much time as possible to separate. This method is known as the SHALLOW SETTING METHOD.

Several years ago the DEEP SETTING METHOD largely displaced the shallow setting method in the better dairies. In the deep setting method, the milk is placed in deep cans which are usually placed in vats of cool water. By thus keeping the milk at a low temperature, souring is delayed and, consequently most of the cream has time to become separated while the milk is still sweet and of much value as food for man and his domesticated animals.

A third method of cream separation is sometimes employed. It is known as the WATER DILUTION METHOD. If fresh milk is diluted by the addition of cold water (about half and half) the cream separates much more rapidly. This method is not often used because the separation of cream is not generally so complete as in the case of the other methods, and because the skim milk is so diluted that it is less valuable.

622. Principle of the Cream Separation.-In each of the three methods of cream separation given, the difference in 
weight, or more correctly stated, the difference in density of the cream and the skim milk is utilized to cause the separation. It is much as if we were to fill a peck measure with a mixture of buck shot and peas and were then to shake the measure. The lead shot being heavier than the peas they would settle to the bottom of the measure and the peas would be forced to the top.

If, however, we were to fasten the measure securely to a rapidly rotating platform, the contents of the measure would fly out against the sides of the measure. The shot being heavier, or more dense, than the peas, they would be forced more strongly against the outside of the measure. The shot would therefore be found to gather against the outside of the measure while the peas would form a sort of lining on the inside of the shot. The force which holds the shot and peas away from the center of the measure is called CENTRIFUGAL

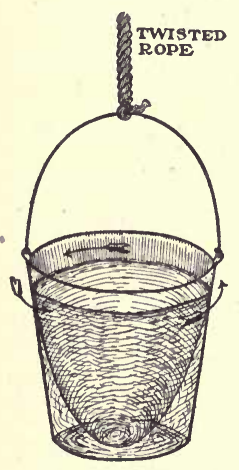

Frg. 330.-Xray view. Centrifugal force holds water against side of pail. FORCE (centri, center and fugal, to fly from).

The shallow setting, the deep setting, and the water dilution methods of separating cream all depend upon the force of gravity to cause the separation are therefore called GRAVITY METHODS. With the cream separator, however, centrifugal force is employed to cause the cream and skim milk to separate.

\section{Exercise 102.-To Illustrate and Study Centrifugal Force}

1. Suspend from the ceiling by means of a braided cord (such as a small window-sash cord) a 12-qt. pail or bucket. Place about 2 qt. of water in the pail. Seizing the bail of the pail, cause it to rotate rapidly (Fig. 330). Watch the effect upon the surface of the water. When the motion dies down, give it another whirl in the same direction. Continue thus to whirl the pail till the braided cord has acquired considerable twist. Now, by placing the hand in the water, bring it to rest, at the same time preventing the cord from untwisting till the water is quiet. Now, let the cord untwist; it will cause the pail to rotate rapidly. 
Watch the effect upon the water in the pail. The shape which the water assumes will be more evident if numerous small fragments of paper or some saw dust be placed in the water.

2. Place some water in a small pail and then swing the pail rapidly in a vertical circle over your head. Can you do so without allowing any of the water to fall out of the pail. Does this show that the centrifugal force may be greater than the force of gravity? Explain.

623. The Cream Separator.-In a cream separator (Fig. 331) the heavier portions of whole milk, which constitute the skim milk, are separated from the lighter portions, which constitute the cream, by centrifugal force. In the type here illustrated, the whole milk is fed slowly down through the top opening 1 (Fig. 332). This tubular shaft is closed at its lower end but it has vertical slots in its lateral wings, 2 and 2 . Through these vertical slots the milk passes in thin sheets between rapidly revolving disks, 4 and 4 , each of which is shaped somewhat like an inverted funnel. In the illustration the space between the upper disks is greatly exaggerated for the sake of clearness. These disks revolve at

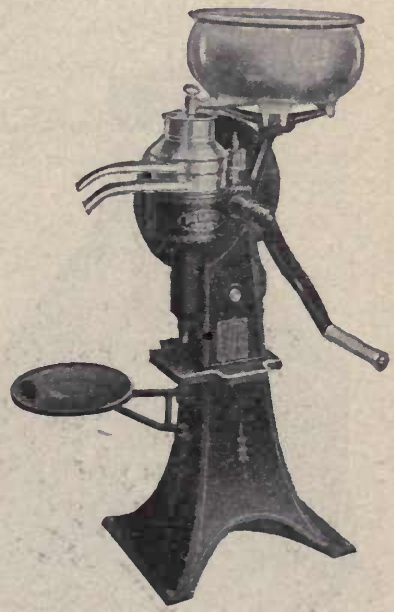

FIG. 331.- The cream separator. a rate of from 5000 to 15,000 r.p.m. (revolutions per minute). Figure 333 shows the gearing by means of which this high rate motion is obtained.

The resulting centrifugal force is very great. The heavier, i.e., denser, portion of the milk in each of the thin sheets is thrown outward or against the under side of the disk above, while the cream being lighter, i.e., less dense, remains against the upper side of the disk just below. Thus it is that the cream is separated from the skim milk. The cream accumulates at the center of the separator as shown by the lighter shading, 3, 3, in the illustration (Fig. 332), while the heavier 
skim milk is forced to the outside of the separator and finally past the lower rim of the disks as shown by the darker shadings in the illustration. It will be noted that the wings, 2 and 2, through which the whole milk passes, extend past the rising column of cream, thus avoiding any remixing of the cream with the milk. Since the fresh supply of whole milk is constantly flowing into the separator down the tubular shaft, it forces the separated cream upward and out at the cream outlet as shown by the dark arrows on the light background, and it

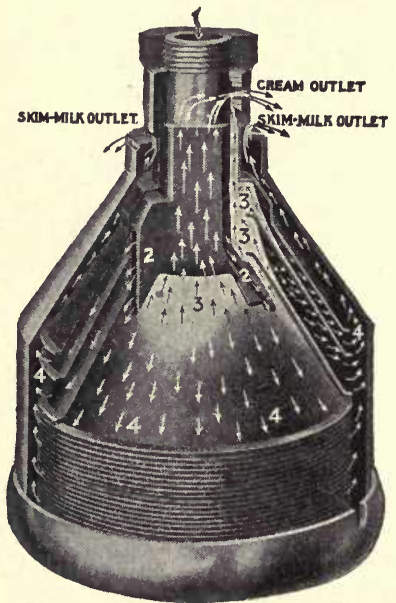

FIG. 332.- Showing the construction and operation of the cream separator.

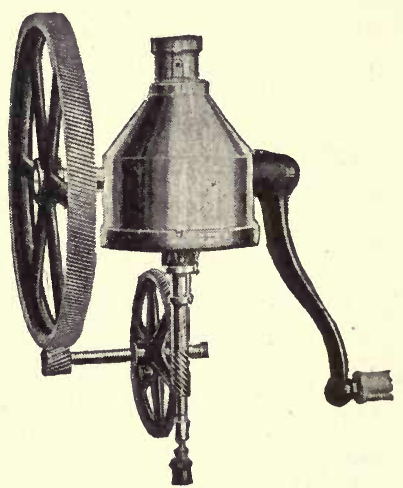

FIG. 333.-The gearing of the cream separator.

also forces the separated skim milk upward and out at the skim-milk outlet as shown by the light arrows on the dark background.

624. Advantages of the Cream Separator.-The advantages of using a cream separator are many: 1. The separation is more complete than by other methods. 2. The separation is best made while the milk is still warm, making it unnecessary to cool and store large quantities of milk. 3. The skim milk is more valuable for feeding purposes when thus obtained while 
still fresh. 4. The cream obtained can be "ripened" more evenly (see Arts. 402 and 446), thus producing butter of better quality and flavor. 5. In most states and cities whole milk offered for sale as food must contain a certain percentage of butter fat (Art. 401). Practically all of the butter fat is contained in the separated cream. It is common practice in many states for milk dealers to separate the cream from the skim milk in the milk they handle. By then mixing the cream and skim milk in certain definite proportions they can produce milk containing an unvarying amount of butter fat. ${ }^{1}$ 6. It is common practice for farmers to separate the cream from the skim milk, shipping the cream to the creamery where it is made into butter and feeding the skim milk on the farm, thus saving much cost for transportation.

\section{The Farm Power House}

625. Regulating the Speed of Machines.-In a farm power house, as well as in a factory, different machines must run at

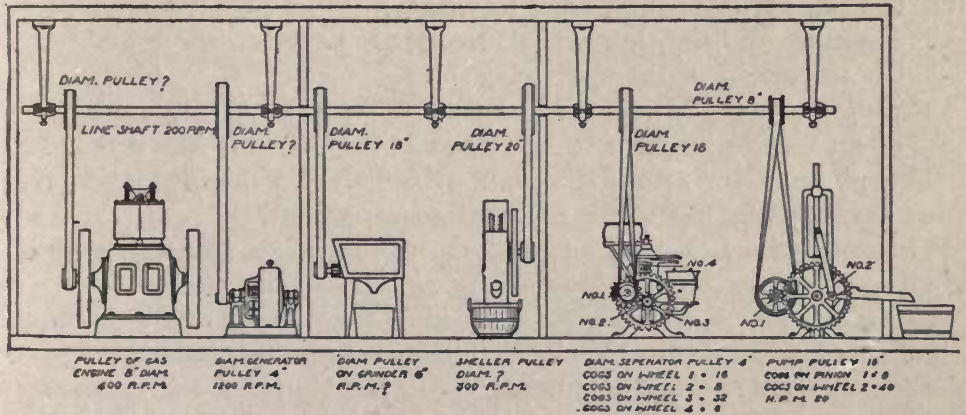

FIg. 334.-Regulation of the speed of machines in a farm power house.

different speeds. The proper speed for a dynamo is not the same as that for a cream separator or a pump. It is often desirable, however, to have a single engine and LINE SHAFT from which power is distributed to all the machines. By using pulleys of different diameters and suitable gearing upon the machines, it - $i$ This practice is prohibited by law in some states. 
is possible to run each machine at its proper speed. The usual method of distributing power from a single мотог (see Art. 651) and of regulating the speed of each machine is illustrated in Fig. 334 and the following set of problems:

\section{PROBLEMS}

1. The gasoline engine (Fig. 334), runs at the rate of 400 r.p.m. (revolutions per minute) and has a pulley 8 in. in diameter. The line shaft is to have 200 r.p.m. What must be the diameter of the shaft pulley?

2. If the dynamo has a 4 -in. pulley and is to run at 1200 r.p.m., what must be the diameter of the line-shaft pulley which drives it?

3. If the pulley of the feed grinder is $6 \mathrm{in}$. in diameter and the line-shaft pulley which drives it is 18 in., what is the speed of the grinder in r.p.m.?

4. If the corn sheller is to have 500 r.p.m. and the line-shaft pulley which drives it is $20 \mathrm{in}$. in diameter, what must be the diameter of the sheller pulley?

5. The diameter of the line-shaft pulley which drives the cream separator is $18 \mathrm{in}$. The pulley on the separator is $4 \mathrm{in}$. in diameter. What is the speed of the pulley in r.p.m.?

This pulley and the spur-wheel, No. 1, are keyed to the same shaft. What is the speed of the spur-wheel?

The spur-wheel, No. 1, has 16 cogs. These cogs mesh with the cogs of an 8-cog pinion, No. 2. What is the speed of the pinion?

The pinion, No. 2, and the spur-wheel, No. 3, are keyed to the same shaft. What is the speed of the spur-wheel?

The spur-wheel, No. 3, has 32 cogs which mesh with the cogs of the 6-cog pinion, No. 4. How many r.p.m. has the pinion?

If pinion, No. 4, has the same speed as the disks of the separator, what are the r.p.m. of the disks? This is how many times the r.p.m. of the line shaft? It is how many times the r.p.m. of the engine?

6. The line-shaft pulley for driving the pump is $8 \mathrm{in}$. in diameter. The pump pulley is 16 in. in diameter. How many r.p.m. has the pump pulley?

The pump pulley and pinion, No. 1, are keyed to a common shaft. The pinion, No. 1, has 8 cogs which mesh with the 40 -cog spur-wheel, No. 2. The pump rod is operated by a pitman attached to the spur-wheel. How many strokes per minute does the pump make?

Is the pump gearing used to increase, or to decrease, the speed, or r.p.m.? What is true of the gearing of the cream separator? 


\section{MASS, WEIGHT, FORCE, WORK, AND POWER}

626. Meaning of Terms. - In all study and use of machines we need to understand exactly the meaning of certain terms. No two people can talk intelligently about machinery and its operation unless both use the same terms to express exactly the same thought; moreover, we must gain much of our knowledge concerning machinery from reading and it is impossible for us to understand what we read unless we know the exact meaning of the terms used. The terms used in all text-books, in reliable magazines, in all government reports, and in most advertising circulars, are carefully chosen and have certain definite meanings. If we are to be intelligent people and are to speak accurately when referring to mechanical matters, we must know the exact meaning of the terms we use.

627. Mass.-By Mass we mean the quantity of matter in an object. We never mean its weight, its size, or its density. When we buy a certain quantity of flour, sugar, eggs, bananas, potatoes, or coal, we are paying for a certain mass of the article purchased. We may determine and speak of the mass purchased in several ways: We generally speak of buying a certain number of pounds of sugar, or of a certain number of eggs or bananas, or of a certain number of pecks or bushels of apples. In every case, however, what we endeavor to do is to determine the mass of the article purchased. It is becoming more and more common for all such commodities to be bought and sold by the POUND-MAss. A dozen bananas is an indefinite quantity; likewise, a dozen eggs does not indicate clearly the amount of mass because they vary so greatly in mass. Some cities, states, and national governments have passed laws obliging all dealers to buy and sell by the mass instead of the dozen, or the peck, or the bushel. Nearly all commodities are thus bought and sold when handled in large quantities. For example, while we speak of buying oats or corn at a certain price per bushel, we actually pay the price for $32 \mathrm{lb}$.-mass of oats or for 56 lb.-mass of corn. We shall see soon that we 
generally determine the mass by first-determining the weight, but we must never confuse the weight of an object with its mass.

628. The Units of Mass.-The common UNIT of Mass used in the United States is the Pound. Originally the old English pound-mass was the mass of 7680 grains of wheat. During the reign of Henry VIII (1509 to 1547) the standard pound was reduced somewhat till it represented the mass of 7000 grains of wheat, hence we say there are 7000 grains in $1 \mathrm{lb}$. The English government, many years ago, prepared a piece of platinum equaling this mass and declared that to be the STANDARD POUND. Since colonial days we have always accepted this mass as the mass of a STANDARD POUND.

Two other standard UNITS OF MASS are the GRAM and the KILOGRAM of the metric system. The metric system of weights and measures is now used by all civilized nations except Great Britain and the United States. The gram-mass is the mass in 1 c.c. of water at $4^{\circ} \mathrm{C}$. The kilogram equals 1000 grams. In 1893 the United States government defined the avoirdupois pound as equal to 453.6 grams. The kilogram, then, is approximately equal to $2.2 \mathrm{lb}$. Calculate this.

629. Weight, Gravitation and Gravity.-By the weIGHT of an object we mean the pull of the earth upon that object. We all know that any object which is free to fall does fall toward the earth. I'his is because both earth and object attract each other. Physicists and astronomers have proved that every body in the universe attracts every other body. In general, this attraction of bodies for other bodies is called the force of GRAvitation. When, however, we are speaking of the attraction between the earth and any object near its surface we speak of the force as the PULL OF GRAVITY.

Now, if we support a body so that it is not free to fall toward the earth, it then exerts a push or a pull upon the support. It is this push or pull which we call the WEIGHT of the object. The weight of an object, then, is merely the measure of the force of gravity upon it. We shall see later that weight is 
merely one form of FoRCE. It is now very evident that we do not go to the grocery to purchase a certain weight of sugar or to the meat market to buy a certain weight of meat. What we do wish to buy is a certain mass of sugar or mass of meat.

630. How Weights and Masses are Determined.-The easiest way to determine the mass of an object, however, is to determine its weight. A 1-lb. mass has just $1 \mathrm{lb}$. of weight. Knowing this, we see that determining the weight of an object tells us at once its mass. This is not at all new to us when we stop to think of it. We have been used all our lives to seeing masses determined by determining the weights of those objects. We want to purchase a certain mass of meat; the dealer determines the mass by determining the weight of the meat. While it is easily possible to determine the mass of an object without determining its weight at all, ordinary scales and balances simply tell us the weight of the object and it is because we accept the fact that a pound-mass weighs just $1 \mathrm{lb}$. that we are willing to accept this method of determining the mass of our purchases.

631. Beam Balances.The most common, as well as the most accurate, devices for determining the weights

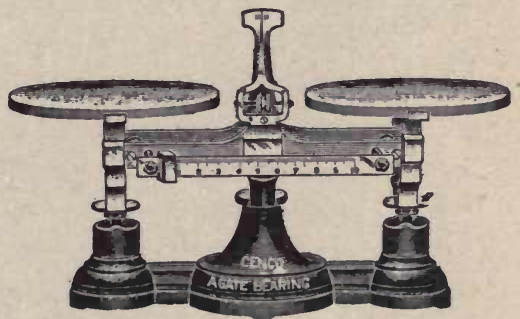

Fig. 335.-Beam balance. of objects are the various forms of BEAM BALANCES. A beam balance consists of a rigid beam mounted horizontally upon a sharp, hard support called a KNIFE-EDGE or FULCRUM (Fig. 335). Each end of this beam carries a pan which is also suspended from a "knife-edge." Great care is taken to eliminate friction. If the two arms of the balance are of exactly equal lengths, a 1-lb. mass upon one scale pan will exactly balance a 1-lb. mass upon the other pan. If the two arms of the beam balance be of unequal lengths, in order to balance each other, the two masses must be inversely proportional to the lengths of 
the arms. A common example of a beam balance with unequal arms is the old-fashioned steelyards (Fig. 336). If, in such a balance, the cbject whose weight is to be determined is 2 in. from the point of support while the known mass is $20 \mathrm{in}$. from the support, then the weight of the unknown object is exactly 10 times that of the known mass.

The weight of the known mass : the weight of the unknown mass :: $2: 20$.

The weights are inversely proportional to the lengths of the arms.

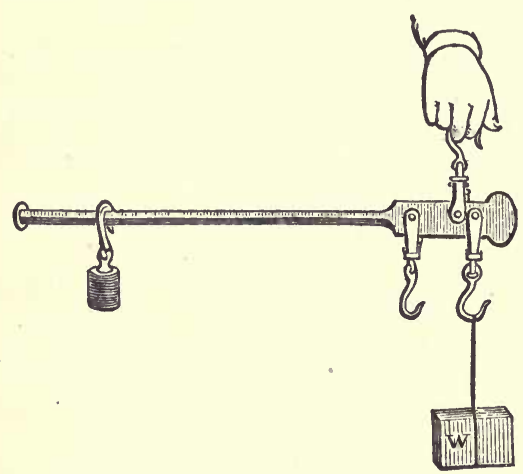

FIG. 336.-Common steelyards.

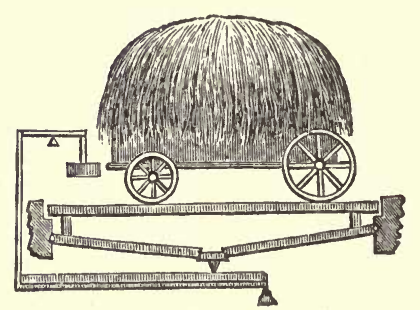

FIG. 337.-Wagon scales.

Generally, scales used in weighing heavy objects are constructed by using several such beams in combination. The common wagon scales are a familiar example of such a combination of unequal armed beam balances (Fig. 337). In such cases, it is common for the beams to be so combined that a 1-lb. mass will balance, perhaps, $1000 \mathrm{lb}$. or more.

632. Spring Balances.-The principle of the SPRING BALANCE is very different. A coiled steel spring is mounted within a metal case (Fig. 338). The upper end of this coiled spring is secured to the upper end of the case; the lower end of the spring is free but carries a small rod or wire which, in turn, carries the hook upon which the mass whose weight is to be determined is hung. A small pointer, or index, fastened to 
the lower end of the spring is so mounted that it hangs just in front of the face of the case, upon which is stamped the scale. When a mass is suspended on the hook, the coiled spring is stretched and the index indicates the weight.

Spring balances are very convenient and easy to handle but usually they are not very accurate. Even though a spring balance may be carefully made and fairly accurate when new, it is likely to wear with use and give false readings later.

633. Force.-By Force we mean a push or a pull. It is force which tends to produce motion in a body or to change the direction or speed of a moving body. All forces are pushes or pulls. Solids may be either pushed or pulled; liquids and gases, however, must be moved by being pushed. A railroad train may be either pushed or pulled; but water and air can be moved only by being pushed. Explain why this is so (see suction, Art. 374).

634. The Units of Force.-The names given to the units of force are the same as those given to the units of mass. We speak of a POUND OF FORCE and a POUND OF MASS; of a GRAM OF FORCE and a GRAM OF MASS; of a KILOGRAM OF FORCE and a KILOGRAM of MAss. This use of the same names for units of

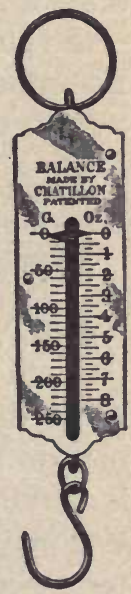

FIg. 338. - Spring balances. mass and units of force is unfortunate and confusing. Many people do not clearly see the difference between a pound of force and a pound of mass. We must never forget that a pound of mass is a certain quantity of matter while a pound of force is a certain amount of push or pull. We can eat a pound-mass of beefsteak but we exert a pound force of effort when we lift the steak against the pull of gravity.

635. Comparison of Force and Weight.-A pound of force is equal to the weight of a $1-\mathrm{lb}$. mass; the gram-force is equal to the weight of a 1-gram mass; the kilogram-force is equal to the weight of a $1-\mathrm{kg}$. mass. It must be remembered, however, that while weight always acts in a vertical line, i.e., 
toward the center of the earth, forces may act in any direction whatever. A team of horses pulling a plow exerts a force, but the direction of the force is in a nearly horizontal line. A locomotive usually exerts a pull, i.e., a force, which is almost exactly horizontal. A boy may throw a ball in any direction he chooses, but in doing so he exerts a force upon it. Weight, then, is a term which we apply to a force due to a certain cause - the pull of the earth-and is always acting in a vertical line. Before we go further in this study of machinery we should be certain that we clearly understand the difference between:

A pound-mass, a pound-weight, and a pound-force;

A gram-mass, a gram-weight, and a gram-force;

A kilogram-mass, a kilogram-weight, and a kilogram-force.

636. Work:-By Work we mean a push or a pull acting through distance. The table or desk which supports your books does no work. The columns which support the porch roof do no work. A man attempting to lift a piano which he is unable to lift, or a team of horses attempting to pull a loaded wagon which it is unable to move, does no work. As the term work is used in mechanics, no person or machine does work unless a force actually acts through space. A force exerted in an attempt to move an object which does not move is WASTED EFFORT-but no work is done.

This use of the term work is not peculiar to mechanics; it is really the common, everyday meaning of the term. When a man lets the contract for the building of a house, he agrees to pay for the work done, never for effort put forth. The contractor, in turn, pays his men for the work they actually do. Even though the employer pays his men by the day, he continues to employ only those who actually accomplish the required amount of work.

637. The Units of Work. - The common English unit of work is the FOOT-POUND. The FOOT-POUND is the amount of work done by a force of one pound acting through a distance of one foot. Since a 1-lb. mass weighs $1 \mathrm{lb}$., we do $1 \mathrm{ft}$.-lb. of work 
when we lift the $1-\mathrm{lb}$. mass $1 \mathrm{ft}$. against the pull of gravity; we also do $1 \mathrm{ft}$.-lb. of work when we support it so as to prevent it from falling while we lower it $1 \mathrm{ft}$. We do work when we climb a flight of stairs; we also do the same amount of work when we descend the same flight of stairs.

The most common metric unit of work is the KILOGRAMMETER. It is the amount of work done when a force of one kilogram acts through a distance of one meter.

\section{PROBLEMS}

1. How many foot-pounds of work does a 150-lb. man do in climbing a flight of stairs $10 \mathrm{ft}$. in height? How much does he do in descending the same flight?

2. If a horse exerts an average pull of $100 \mathrm{lb}$. while plowing, how much work does he do while plowing a furrow 1 mile in length? If he walks at the rate of 3 miles per hour, how many foot-pounds of work does he do per hour?

3. A boy carries a skuttle of coal weighing $10 \mathrm{Kg}$. up a flight of stairs 3 meters in height. How many kilogram-meters of work does he do?

638. Time is not a Factor in Work. - Time is not considered in determining amount of work. The amount of work done by a man in shoveling a ton of coal into a wagon is independent of the time required to do it. It requires neither more nor less work to plow an acre of land if the plowing be done in an hour or in a day. We all recognize this in everyday life. We are willing to pay no more for the shoveling of the coal or the plowing of the ground because the man who does the work requires a longer time in which to do it. In fact, we are often willing to pay a little extra if the work be done in the shorter time.

639. Power, Activity, or Rate of Work. - The unit in which POWER, ACTIVITY, Or RATE OF WORK is measured is the HORSEPOWER. A machine is said to be a ONE-HORSE-POWER MACHINE when it is capable of doing $33,000 \mathrm{ft}$. $-l b$. of work per minute, or $550 \mathrm{ft}$. $l b$. of work per second. This unit of power was chosen and named by James Watt (see Art. 680); he supposed that an average horse could work at about this rate. In 
order to work at this rate, however, a horse must exert an average pull of $125 \mathrm{lb}$. while walking at the rate of 3 miles per hour, or he must exert an average pull of $150 \mathrm{lb}$. while walking at the rate of $2 \frac{1}{2}$ miles per hour. (Calculate.) A strong horse weighing $1400 \mathrm{lb}$. can stand it to work at this rate, 10 hours each day (see Art. 657). An average man can stand it to work at the rate of about $1 / 7$ of a horse-power, eight hours each day.

\section{MACHINES}

640. Machines and Their Uses.-Any device is called a machine if it is used to transfer or transform energy, or if it is

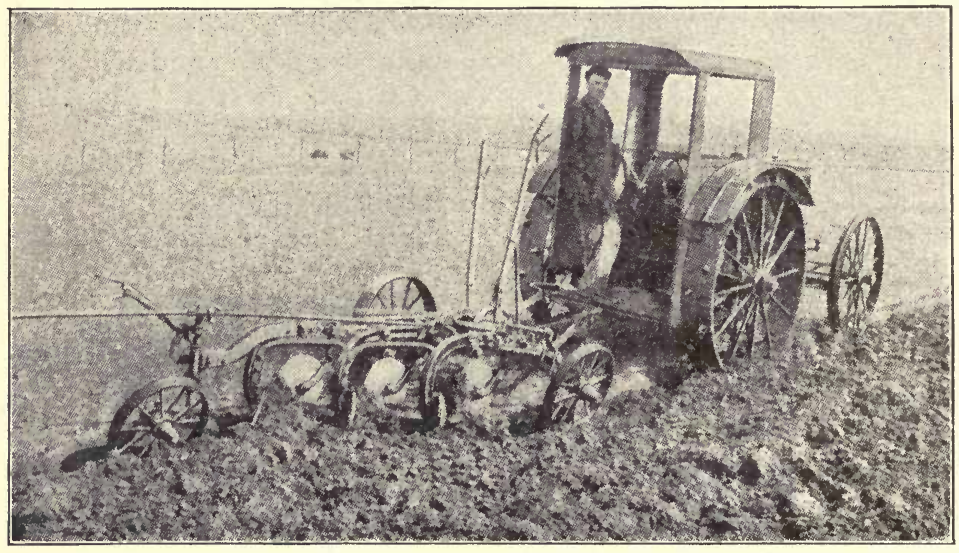

FIG. 339.-A farm gasoline tractor pulling a three-bottom plow and doing the work of 6 or 8 horses or of 50 men.

used to change the direction, or magnitude of a force doing work (see Art. 85, Definition of Energy).

Man uses machines for a great variety of purposes. A crowbar, a set of pulleys, or a jackscrew enables a man to move a body whose weight is so great that he would be unable to move it without the use of the machine. A fishing pole enables the boy to drop his hook quietly into the pool at a point he otherwise could not reach; it also enables him to jerk the hook more 
quickly. The sewing machine enables a woman to operate the needle by moving her foot while both hands are free to handle the work; moreover, the needle makes several stitches while her foot is making a single motion (Art.619, Ex. 101). The plow, the cultivator, the mowing machine, or the binder enables the farmer to utilize the efforts of horses. Steam engines, gas engines, electric dynamos and motors enable man to utilize the energy in fuel at a small fraction of the cost of hiring the same amount of work done by manual labor or even by horses (Fig. 339). Moreover, one man often operates such a machine while it does the work which would otherwise have to be done by hundreds of men. Waterwheels enable men to utilize the energy in running water-energy which would otherwise go to waste. When this energy has been transformed into electricity it can be transmitted on wires many miles and then be used to light our homes, run our trains and street cars, and do a large portion of the work which has been done by men in days past (see Arts. 668 and 673).

641. Mechanical Advantage of a Machine.-Man uses a machine only when he gains some advantage by so doing. This advantage gained by using a machine is called the MECHANICAL ADVANTAGE of the machine. Machines may offer mechanical advantage of several different kinds:

1. A machine has MECHANICAL ADVANTAGE OF FORCE when, by using it, a greater force is exerted than could otherwise be exerted. Examples: By using a pinchbar-a crowbar of a certain shape - a man is able to move a heavily loaded freight car which he could not move without it. By using a common claw hammer, a man can draw a nail which otherwise he could not pull. Give as many other examples as possible.

2. A machine has Mechanical AdVANTAGE OF SPEED when it is used to increase the speed with which the force acts. Examples: A fly swatter, a sewing machine, an egg beater, an old-fashioned spinning wheel. Name as many other examples as you can.

3. A machine may have Mechanical ADVANTAGe OF DIREC- 
TION OR OF POSITION. Examples: By using a single fixed pulley the direction of the force is changed and the operator may choose his own position. The handle of the common pump, the key of the typewriter, the wheel or handle of the washing machine, the common door knob-all these and many other devices are advantageous because they aid in changing the direction of the applied force or they enable the operator to choose his position, or both.

A machine may have mechanical advantage of two or more kinds at the same time. It is impossible, however, for a machine to have both mechanical advantage of force and mechanical advantage of speed at the same time. What advantages are afforded by the sewing machine over those of the hand needle?

642. Numerical Expression of Mechanical Advantage.Mechanical advantage of force and mechanical advantage of speed are each frequently expressed numerically, i.e.; in numbers. The ratio of the force delivered by a machine to the force applied to the machine is said to express the mechanical advantage of force of the machine.

Mechanical advantage of force $=$

Number of units of force delivered

Number of units of force applied

Example: A man by using a crowbar exerts a force of $1000 \mathrm{lb}$. upon a rock while exerting a force of $100 \mathrm{lb}$. upon the handle of the crowbar. In this case the mechanical advantage of force is $\frac{1000 \mathrm{lb} .}{100 \mathrm{lb} \text {. }}=10$.

The ratio of the speed with which the force acts to the speed of the applied force is said to express the mechanical advantage of speed of the machine.

Mechanical advantage of speed $=$

Number of units of speed of the force delivered.

Number of units of speed of force applied

Example: The knives of an egg beater pass 5 times around a 2 -in. circle while the handle on the drive wheel passes once 
around a circle of the same diameter. In this case the mechanical advantage of speed of the machine is

$$
\frac{5 \times 2 \times 3.1416 \text { in. }}{2 \times 3.1416 \text { in. }}=5 \text {. }
$$

It is evident that the mechanical advantage of direction or position can not thus be expressed in numbers.

643. Simple and Compound Machines.-Six simple MACHINES are generally recognized: The LEVER, the WHEEL and AXLE, the PULLEY, the INCLINED PLANE, the WEDGE, and the SCREW. Most machines are compound Machines, i.e., they are combinations of two or more of the simple machines. A sewing machine, a typewriter, a clock, a binder, a threshing machine, or an automobile is made up by combining large numbers of simple machines.

\section{Exercise 103.-Study of a Compound Machine}

Examine carefully a sewing machine, a typewriter, a clock, or any other complex machine, noting the simple machines involved and how they are combined.

644. Friction.-Friction is the resistance which opposes an effort to stide or roll one surface over another. Every surface is more or less rough. Even the hardest and best polished surfaces are found to be rough, to have uneven surfaces, when examined under a magnifying glass. When we attempt to slide one surface over another, the rough places on one surface catch upon the rough places upon the other. This roughness of the surfaces is the cause of friction.

The operation of any machine is affected by friction to some extent. (1) Oiling all moving parts which come into contact lessens friction. (2) In general, there is less friction between two surfaces of different material than between surfaces of the same material. For this reason bearings are usually made of different material from that of the axles which rest upon them. (3) Friction is less between two surfaces when one of them rolls upon the other than when one slides upon the cther. A ball bearing, therefore, has less friction than a 
common sliding bearing. Every boy or girl who rides a bicycle or uses roller skates knows that a ball-bearing wheel runs easier than one without ball bearings.

\section{Exercise 104.-A Study of Ball Bearings}

Examine the ball bearings in a bicycle or a roller skate to see exactly how they are constructed and how they work.

645. The Law of Machines.-The work (or energy, see Art. 85) put into a machine and also the work (or energy) taken out of a machine must, of course, be measured in work units, i.e., in such units as foot-pounds, or gram-centimeters, or kilogram-meters. The work put into a machine is equal to the product of the applied force and the distance through which that force acts; the work delivered by a machine equals the product of the force delivered and the distance through which it acts. If there were no friction, the work delivered by a machine would exactly equal the work put into it.

LAW OF MACHINEs. - The work or energy put into a machine would equal the work or energy delivered by the machineif all friction were eliminated.

646. Friction Generally Hinders but Sometimes Helps.In fact, however, the work delivered by a machine is never exactly equal to that put into it. In most cases the work delivered by a machine is less than that put into it because of friction in the machine. Occasionally, however, a machine is used in such a manner as to yield an output greater than the input. For example, if a set of pulleys, an inclined plane, or an elevator is used to lower a heavy object from the top floor of a building to the basement, the work put into the machine is less than that taken out of it. Friction, in this case, tends to keep the body from falling; it is working with the operator.

647. Efficiency of a Machine.-The EFFICIENCY OF A MACHINE is measured by the ratio of the work (or energy) delivered by a machine to the work (or energy) put into it. 
Efficiency of a machine $=$

$\frac{\text { Work or energy delivered, or output }}{\text { Work or energy put in, or input }}$

It is generally expressed in percentage. It is usually less than 100 per cent. but it may be greater than 100 per cent. Illustrations:

1. If a block and tackle, i.e., a set of pulleys, be used to raise a piano from the ground to the top floor of a building, we find that we are obliged to put considerably more work into the machine than we get out of it. If the piano weighs 1000 lb. and it is raised $50 \mathrm{ft}$., how much work is accomplished? In this case we are obliged, not only to do this amount of work, but we must also do work in overcoming friction. The efficiency of the machine in this case is not likely to be more than 50 to 75 per cent.

2. Supposing now that we wish to lower the same piano from the top floor of the building to the ground again. If we use the same block and tackle we shall find that we are not now obliged to put as much work into the machine as we get out of it. Exactly the same amount of work will be accomplished in lowering the piano as was accomplished in raising it but the friction of the machine tends to keep the piano from falling. Friction is now aiding us -it is working with us. The efficiency of the machine will now probably be from 133 to 200 per cent.

648. Friction is Often Useful.-We generally find it an advantage to reduce friction in a machine as much as possible; sometimes, however, we find friction of great service to us. When we wish to haul a heavy load $u p$ a hill we make every effort to reduce friction. When we start down hill, however, we set the brakes, or possibly chain one rear wheel, in order to increase friction. A locomotive owes its power to pull a train to the friction between its drive wheels and the rails. The largest locomotive ever built weighs 336 tons and can exert a pulling force of about 60 tons and can easily pull a train of 200 cars each weighing 50 tons (Fig. 340). If this 


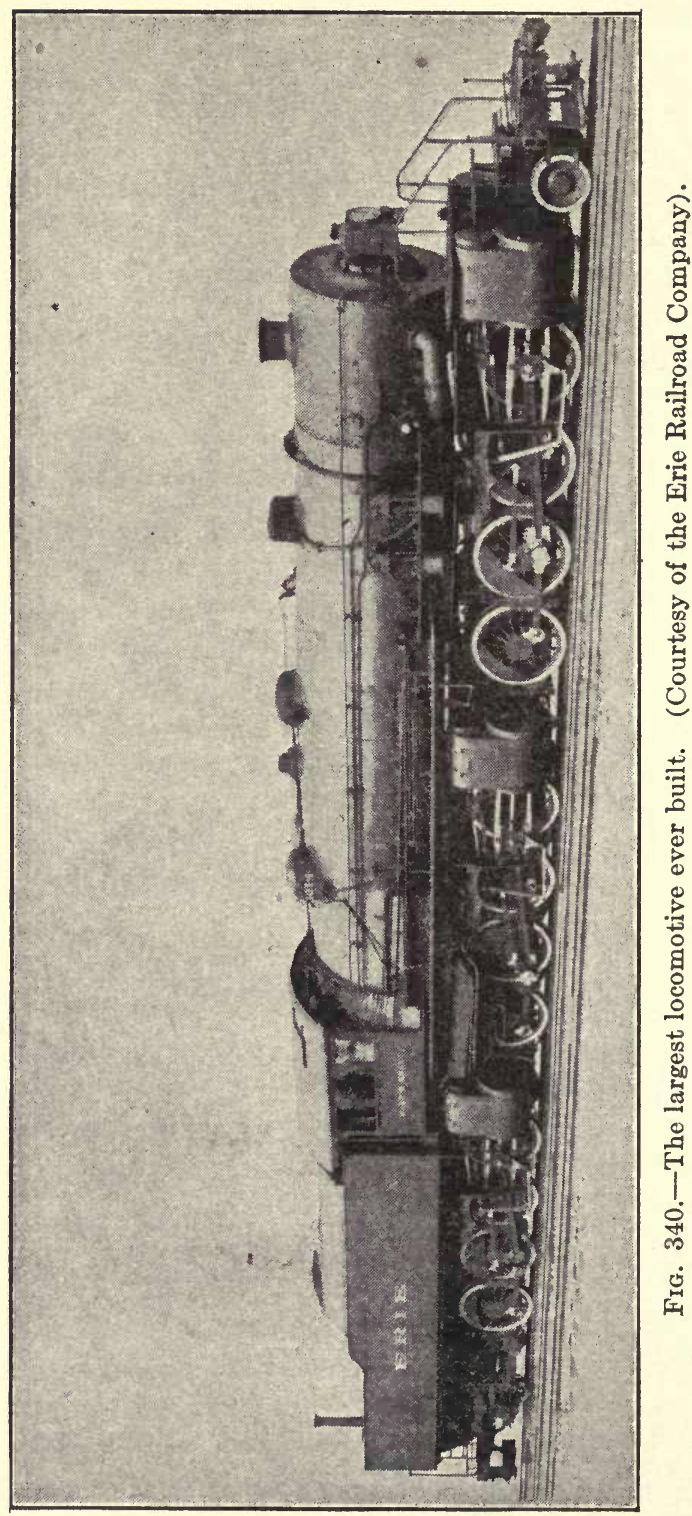


locomotive were attached to a train requiring a force of more than 60 tons to move it, the locomotive would be unable to start the train because its drive wheels would then slip on the rails. A bicycle or an automobile is likewise propelled by the friction between its wheels and the ground. Men working upon the ice wear ice creepers on their shoes to increase friction between their shoes and the ice. After an ice or sleet storm, horses are almost useless for hauling loads unless they are sharp shod. Why? Give as many cases as you can where friction is of service to us. How do the brakes of a railroad train bring the train to rest? How is friction involved in feeding the paper through a typewriter or printing press? Explain how a leather belt is used to drive a sewing machine or a threshing machine.

649. Friction Produces Heat.-All energy lost due to friction reappears in the form of heat. It is the friction of the head of the match upon a rough surface which produces sufficient heat to ignite the match. What evidence is there that a large amount of heat is produced by the brakes of a railroad train when it is brought to a sudden stop? What effect is produced upon one's hands when sliding down a rope too rapidly? If the bearings of a machine are not frequently oiled they are likely to become "heated" and possibly ruined. Explain why this is so.

\section{ENERGY AND ITS RELATION TO THE USE OF MACHINES}

650. What is Meant by Energy?-Anything which is capable of doing work possesses ENERGY. ENERGY is the capacity for doing work (Art. 85). Man, by putting forth effort, does work; therefore he possesses energy. A horse may do work; therefore, he possesses energy. A steam engine, as long as it is supplied with fuel and water and is properly controlled, can do work; therefore it possesses energy. The machine by itself, i.e., without fuel and water, can do no work. It is the fuel which gives it the ability to do work. The energy comes from 
the fuel, not from the mechanism of the engine. We have seen in Chap. VI that from which man or the horse gets his supply of energy. What is it?

651. Motors.-Any machine or animal used to transform energy into work is called a мотоR. A steam engine transforms the energy in coal into work; it is a COAL-STEAM MOTOR. A gasoline engine transforms the energy in gasoline into work; it is a GASOLINE мотоR. A machine which transforms the energy in an electric current into work is an ELECTRIC MOTOR. To the extent that any man or animal simply transforms the energy in the food eaten into mechanical work, he is a motor. Agriculturists speak of the work horse as an ANIMAL MOTOR.

A steam engine or gasoline engine is capable of doing work only as long as it is consuming fuel; as soon as it ceases to consume fuel it ceases to be able to do work. It is equally true that a man or a horse soon ceases to be able to do work unless supplied with food. It is the energy in the food eaten which enables man or animal to do work. Thus we see that man may differ little from a machine if he consumes food merely for the purpose of transforming the energy in the food into mechanical work.

652. One Difference between an Animal Motor and a Mechanical Motor.-While a mechanical motor, such as a steam engine or a gasoline engine, ceases to be able to do work almost at the instant that the fuel supply is exhausted, an animal motor can continue to do work for some time after its food supply is exhausted. This is because the fat and other tissue of the body can be converted into energy when necessary. Any animal, however, which is obliged to do hard labor without a sufficient supply of food will lose weight rapidly and will soon die.

653. Efficiency of Various Motors.-Many experiments performed show that the average efficiency of man as a motor is about 20 per cent. That is, it has been found that a man is able to convert about 20 per cent. of the energy in the food he eats into mechanical work. Similar experiments show 
that the horse can also convert about 20 per cent. of the energy in its food into work (see Art. 658). A steam engine will convert from 4 to 10 per cent. of the energy in coal into work; therefore it has from 4 to 10 per cent. efficiency. A few years ago in a series of tests made by the Northern Pacific Railroad it was found that the efficiency of its best freight locomotives was but 3.8 per cent. Good gas and gasoline engines have an efficiency of from 20 to 35 per cent. Electric motors frequently develop an efficiency of 75 to 90 per cent. From these figures one might conclude that the electric motor was the least expensive motor and that the steam engine was the most expensive motor for us to employ to do our work. Such a conclusion, however, is hasty and incorrect. The fact is that the steam engine is one of the least expensive motors to operate while the electric motor is rather expensive to operate. Can you suggest any reason why this should be so? Before we finish this chapter we shall see what the explanation really is.

654. The Work Equivalent of a Calorie of Heat.-Many experiments have been made to determine the amount of work which is equivalent to a calorie of heat. In 1840, an Englishman, Joule, made such a determination. He suspended masses of iron by means of cords in such a manner that they might slowly fall and in so doing revolve a set of paddles immersed in a vessel of water. The paddles, in stirring the water, produced friction which produced heat and therefore raised the temperature of the water. He noted the weight of the iron masses and the distance through which they fell. From these figures he determined the amount of work done. He also noted the weight of the water and the number of degrees of temperature through which it rose. From these figures, he determined the number of calories of heat produced. Other experimenters have used other methods of determining this relation. It is now known that 1 greater calorie ( 1 Cal.) (Art. 121) is equal to $3080 \mathrm{ft} .-1 \mathrm{~b}$. (Art. 637) of work. This means that, if all the energy in food or fuel could be converted 
into work without loss, we should be able to produce 3080 ft.-lb. of work for every calorie of heat energy in the food or fuel. We have seen that it is impossible to do this. The horse is able to convert but about 20 per cent. of the energy in his food into work. Therefore we can not hope to secure more than about $616 \mathrm{ft}$.-lb. of work for each calorie (1 Cal.) of energy in the food the horse eats.

655. Calories of Energy Needed to do 1 Horse-powerhour of Work.-We have seen that 1 horse-power is the ability of a motor to do 33,000 ft.-lb. of work per minute (Art. 639). A horse-power-hour of work, then, is $60 \times 33,000 \mathrm{ft} .-1 \mathrm{~b}$. or, $1,980,000 \mathrm{ft} .-\mathrm{lb}$. Since 1 greater calorie of heat equals 3080 ft.-lb., we see that 640 Cal. of energy are required to do 1 horse-power-hour of work. A motor having an efficiency of 100 per cent. would, then, consume 640 Cal. of food or fuel while doing 1 horse-power-hour of work.

640 greater calories of heat $=1$ horse-power-hour of work

656. Cost of 1 Horse-power-day of Work by the Steam Engine.-One lb. of coal when burned yields from 3000 to 3600 Cal. of heat (Art. 122). Since the average stationary steam engine has an efficiency of from 5 to 8 per cent., it utilizes only from 150 to 275 Cal. to the pound of coal. Even then it requires only from $2.5 \mathrm{lb}$. to $4.5 \mathrm{lb}$. of coal to do 1 horsepower-hour of work. In practice, a steam engine is considered as being in fair condition if it does 1 horse-power-hour of work on $4 \mathrm{lb}$. of coal. A steam engine, having the usual efficiency, will probably require from 25 to $35 \mathrm{lb}$. of coal per horse-powerday of 8 hours. The cost of this coal at $\$ 3.00$ per ton would be from $33 / 4$ cts. to $5 \frac{1}{4}$ cts. per horse-power-day.

(The student should verify these calculations in every case.)

657. How Much Work a Horse Can Do.-King, in his Physics of Agriculture, says that it is commonly agreed that for steady and continuous work 10 hours per day, walking at the rate of $2 \frac{1}{2}$ miles per hour, a horse should not be asked to pull (exert a force of) more than about $1 / 10$ or $1 / 8$ of its own 
weight. The work performed by horses of different weights would, then, be about as follows:

Work Performed per Day by Horses of Different Weights Walking at the Rate of 20 Miles per Day, OR $21 / 2$ Miles Per Hour

$\begin{array}{rrr}\begin{array}{c}\text { Weight of } \\ \text { horse }\end{array} & \text { Pull exerted } & \text { Rate of work at } 23 \text { miles per hour } \\ 800 \mathrm{lb} & 80 \text { to } 100 \mathrm{lb} . & 0.53 \text { to } 0.67 \text { horse-power. } \\ 1000 \mathrm{lb} & 100 \text { to } 125 \mathrm{lb} . & 0.67 \text { to } 0.83 \text { horse-power. } \\ 1200 \mathrm{lb} & 120 \text { to } 150 \mathrm{lb} . & 0.80 \text { to } 1.00 \text { horse-power. } \\ 1400 \mathrm{lb} & 140 \text { to } 175 \mathrm{lb} . & 0.93 \text { to } 1.17 \text { horse-power. } \\ 1600 \mathrm{lb} & 160 \text { to } 200 \mathrm{lb} \text {. } & 1.07 \text { to } 1.33 \text { horse-power. }\end{array}$

(The student should verify these figures.)

658. Why the Horse can not Compete with the Steam Engine as a Motor.-We have seen that a strong horse can not work steadily at a rate faster than 1 horse-power. We shall presume that 8 hours, working at full capacity, makes a full length day for a horse to labor. Now, although a horse can convert 20 per cent. of the energy in its food into effective work, it still is true that the food of the horse is so much more expensive than the fuel of the steam engine that the horse is quite unable to compete with the engine.

The principal food of the horse is corn or oats. Smith, in Profitable Stock Feeding, says that a horse weighing $1200 \mathrm{lb}$. at severe labor, needs $16 \mathrm{lb}$. of oats and $12 \mathrm{lb}$. of hay per day. Other authorities give the following rule for feeding a working horse: $1 \frac{1}{2} \mathrm{lb}$. of oats or corn and $1 \mathrm{lb}$. of hay per day for each $100 \mathrm{lb}$. of weight. The energy in a pound of oats is about 1500 Cal. (see Table XIV, Art. 391. Remember that the husk of the oat is removed in making oat meal; that the energy in a pound of corn is about $1650 \mathrm{Cal}$.).

1. We shall consider that a $1200-1 b$. horse is able to do 1 horsepower of work for eight hours per day. We shall consider his food as $18 \mathrm{lb}$. of oats per day, and omit any consideration of the hay or "roughage" consumed because the available energy in it is not great. What is the efficiency of this horse as a motor?

First: $18 \mathrm{lb}$. of oats contain $18 \times 1500$ Cal. of energy, or 27,000 
Cal. of energy. But these 27,000 Cal. $=83,160,000 \mathrm{ft}$.-lb. of work (Art. 654).

Second: 1 horse-power for eight hours $=8 \times 60 \times 33,000 \mathrm{ft}$. $-1 \mathrm{~b}$. or $15,840,000 \mathrm{ft}$.-lb. of work.

Hence: Efficiency of the horse $=\frac{15,840,000 \mathrm{ft} .-\mathrm{lb} .}{83,160,000 \mathrm{ft} .-\mathrm{lb} .}=0.19$ or 19 per cent.

What is the cost of feeding this horse? We shall suppose that oats are worth $40 \mathrm{cts}$. a bu. (32 lb.). The cost of $18 \mathrm{lb}$. will be $22 \frac{1}{2}$ cts. If we count the cost of the $12 \mathrm{lb}$. of hay at $\$ 15$ a ton, we must add 9 cts. more making the cost for feed $311 / 2$ ct. per day. Thus we see that, considering the cost of feed and coal only, the horse is some six or eight times as expensive as is the steam engine when used as a motor.

2. Work and Cost of Feed of an 1100-lb. Horse.-Henry, in Feed and Feeding, concludes that an 1100-lb. horse should be able to haul a load 20 miles in a day, exerting an average pull of $100 \mathrm{lb}$. and that the horse should walk at the rate of 2.9 miles an hour. How many hours does he expect the horse to work? At how many horse-power does he expect this horse to work? Ans. About 0.8 horse-power.

Henry gives as the proper ration for this horse the following: 10 lb. of meadow hay; $10 \mathrm{lb}$. of oats and $6.4 \mathrm{lb}$. of corn. If the hay costs $\$ 15$ a ton, oats 40 cts. a bu., and corn 60 cts. a bu., what is the cost of feeding this horse per day?

How many foot-pounds of work does this horse do a day? What is the cost of feeding this horse while he does 1 horse-powerday (of eight hours) of work?

Ans. About 33 cts.

If the coal to run a steam engine costs 4 cts. per horse-power-day (day $=$ eight hours), how does the cost for feed of this horse compare with the cost of coal to run the engine while the two motors are doing the same amount of work?

How do you think that the cost of care and shelter of such a horse would compare with the cost of care and shelter for a 1 horse-power steam engine? What is true about the cost of caring for a horse and such an engine when they are not at work? How would the money invested in the horse compare with that invested in a 1-horse-power steam engine? Do you see why all these things must be considered when comparing a horse with a steam engine as a motor?

659. A Man can not Compete with Either the Horse or the Steam Engine as a Motor.-It is generally agreed that a man of average strength can work at the rate of $1 / 8$ to $1 / 6$ of a horse-power for eight hours a day. This means that it re- 
quires six or eight men working one day to do a full horse-powerday of work. Now the cost of a man's daily food varies greatly, but it is probably true that the cost of food for a laboring man is generally somewhere from 30 to 60 cts. a day. The food for a man is not nearly so great in quantity as that consumed by a horse nor does it contain so many calories of heat, but it is of much finer quality, it should be much more varied, and it must be cooked and prepared so that its cost per pound is several times as great. It is probably true that the cost of food for the well-fed workingman is as great as that of the well-fed working horse. Since man can do but about one-seventh as much work as the horse, it is evident that man is an expensive motor when compared with either a horse or a steam engine.

When thus considering merely the cost of the food of the workingman, we are entirely neglecting the cost of comfortable shelter, of clothing, of reading matter, of traveling expenses, of amusements, and all the other elements of higher living which make life really worth while. Moreover, the laboring man is usually the head of a family and therefore must provide food, shelter, clothing, school books, and all the other necessities of life for the several members of his family. When we consider all these things, we see clearly that no working man can possibly compete with other forms of motors. He must labor at tasks which other motors are unable to perform.

Cost of 1 Horse-power-day of Work, Considering Fuel and FOOD ONLY

By steam engine..............

By gasoline engine...........

By horse.................

4 to 5 ets.

By man

10 to 15 cts.

30 to 40 cts.

$\$ 2.50$ to $\$ 5.00$

660. Why We often Use the Horse instead of the Steam Engine.-The horse, not only does useful work, but while doing it he is obliged to do a large amount of useless work. The horse in Art. 658, Prob. 2, not only hauled the load 20 miles per 
day, but while doing so he also transported his own body the same distance. The stationary engine does no useless work in moving its own mass through space. One of the reasons why the efficiency of the stationary engine is greater than that of the locomotive is that the locomotive does a large amount of useless work in transporting its own mass.

There are many kinds of work, however, which can be done at a lower cost by the horse than by the steam motor. In excavating for a house or in grading up around the house after it is built, for most hauling about the farm, for the delivery of grain to the local market, for the cultivating and the harvesting of crops on the ordinary farm, the horse is still often the most practical motor we have.

661. Why We often Employ the Labor of Man instead of the Horse or the Steam Motor.-Just as we still employ the horse instead of the steam engine to do many kinds of work, so in spite of the high cost of his labor we still find it profitable to employ man to do much of our work. In the construction of buildings there will probably always be a demand for laborers to handle the brick and mortar, and the wheelbarrow and spade, as well as to handle the hammers, the saws, the planes, and the trowels. In most lines of work there is some rough work which might possibly be done by machines but which can at present be more cheaply done by the cheapest of human labor. More and more, however, work of this nature is being done by other motors and man is finding that he must prepare himself for doing such work as requires thoughtful, intelligent action.

\section{SOME COMMON MECHANICAL MOTORS}

662. Common Mechanical Motors.-In the last section we saw that, while man and the horse were both more efficient motors than the steam engine, it still is true that the steam engine is a much less expensive motor to operate-that the most efficient motor is not necessarily the least expensive to 
employ. In this section we shall study briefly the principles of some of the more common mechanical motors; in the following section we shall see where the losses of energy occur in using them and note the approximate relative cost of operating them.

Nearly all power used today to run the machinery in factories and mills and about mines, to pump the water for city water systems, and to light city streets and homes by electricity, to propel ships at sea, and railroad and interurban trains on land, to run street cars and automobiles-in fact, to operate machinery for any purpose-is derived from a few different kinds of mechanical motors. These motors are (1) water motors, (2) steam motors, (3) gas motors, including gasoline or crude oil motors, and (4) electric motors.

\section{WATER Motors}

663. Kinds of Waterwheels.--Running and falling water has been used since the beginning of civilization to produce

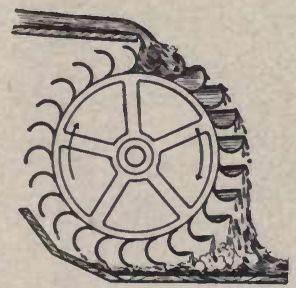

FIG. 341.-The overshot water wheel.

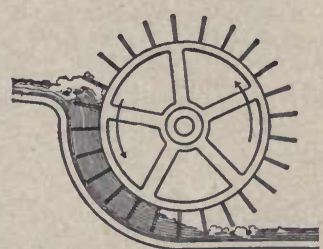

FIG. 342.-The breast wheel.

power and do work for man. Waterwheels of different kinds have been used. OvERSHOT, BREAST, AND UNDERSHOT WHEELS are the older types, while the IMPULSE AND TURBINE WHEELS are of recent origin.

664. Overshot Wheels.-Overshot wheELs have generally been used when a small stream having a considerable fall is available (Fig. 341). Why? Such wheels are sometimes 50 or $60 \mathrm{ft}$. in diameter and may develop an efficiency of 80 or 90 per cent. How is the power produced by such a wheel? 
665. Breast Wheels.-BreAst WHEELs are generally used when a larger flow of water is available but less fall can be secured (Fig. 342). How does this wheel differ from the overshot wheel? The efficiency of the breast wheel is usually less than that of the overshot wheel. Can you see why this should be so?

666. Undershot Wheels.-UNDERshot WHEELS are used when only a slight fall of water is obtainable (Fig. 343). While the weight of the falling water is the principal source of power in the overshot and breast wheels, in the case of the undershot wheel, the force of the impact of the water against the blades or paddles is the chief source of power. Undershot wheels frequently have low efficiency. Why is this so?

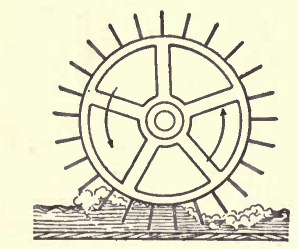

FIG. 343.-The undershot wheel.

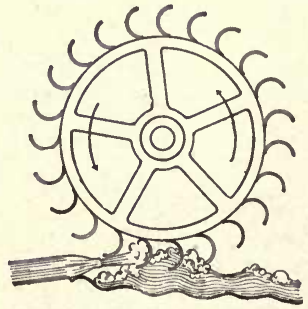

Fig. 344.-The Pelton wheel or impulse wheel.

667. Impulse Wheels.-IMpulse WHEELs are used when there is a small supply of water but available under a great "head" (Art. 574) or pressure. Frequently small streams or lakes located high up in a mountain may be utilized for power purposes. In such cases the water is often conveyed down the mountain side in strong iron pipes. At the foot of the mountain, the water under high pressure is permitted to escape through a nozzle at high velocity. This stream is directed against cup-shaped buckets on the rim of the wheel (Fig. 344). After striking the buckets, the water falls to the ground robbed of its energy.

These wheels have some advantages over other kinds of 
waterwheels: They can easily be changed in location. They are small compared with other wheels for the amount of power

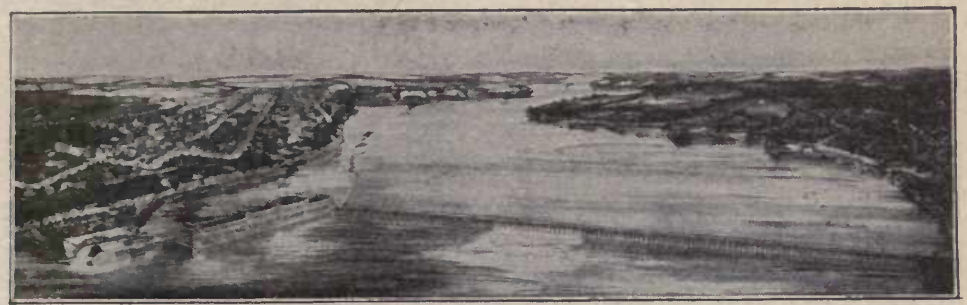

FIG. 345.-General view of the Mississippi River, the locks, the power house and the dam at Keokuk. The power plant is capable of producing 300,000 horse-power. It cost $\$ 25,000,000$.

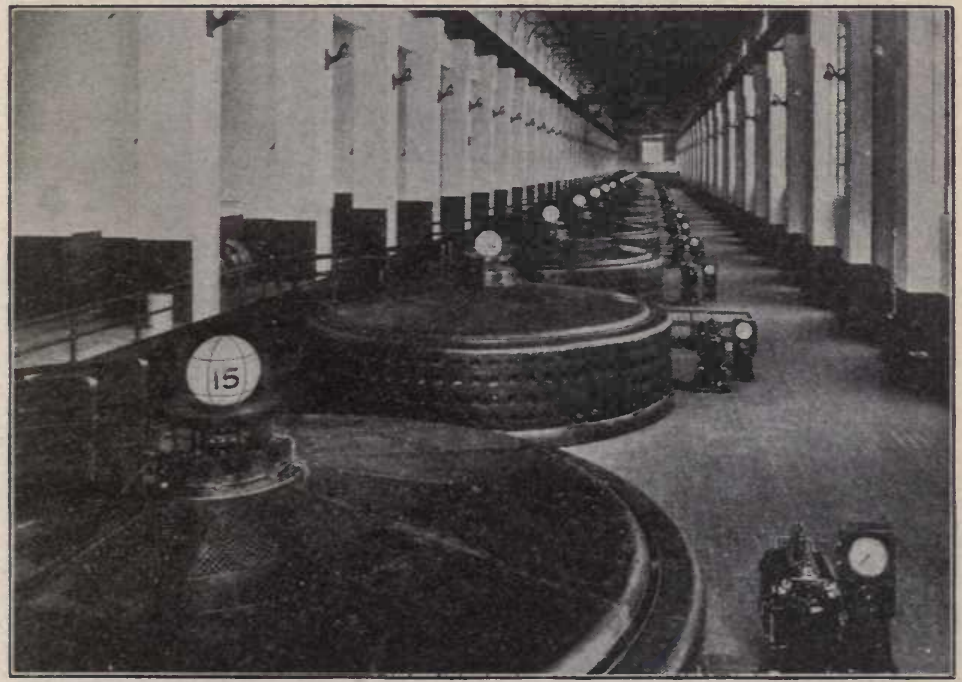

Fig. 346.-Interior view of the power house at Keokuk showing the 15 generators now installed, each of which produces 10,000 horse-power of electrical energy.

they are able to produce. One such wheel constructed several years ago was but $3 \mathrm{ft}$. in diameter and received its supply of water from a stream $2100 \mathrm{ft}$. above the wheel. The diameter 
of the nozzle was but $1 / 2$ in. and yet the wheel did 100 horsepower of work. The efficiency of impulse wheels is frequently 80 or 90 per cent.

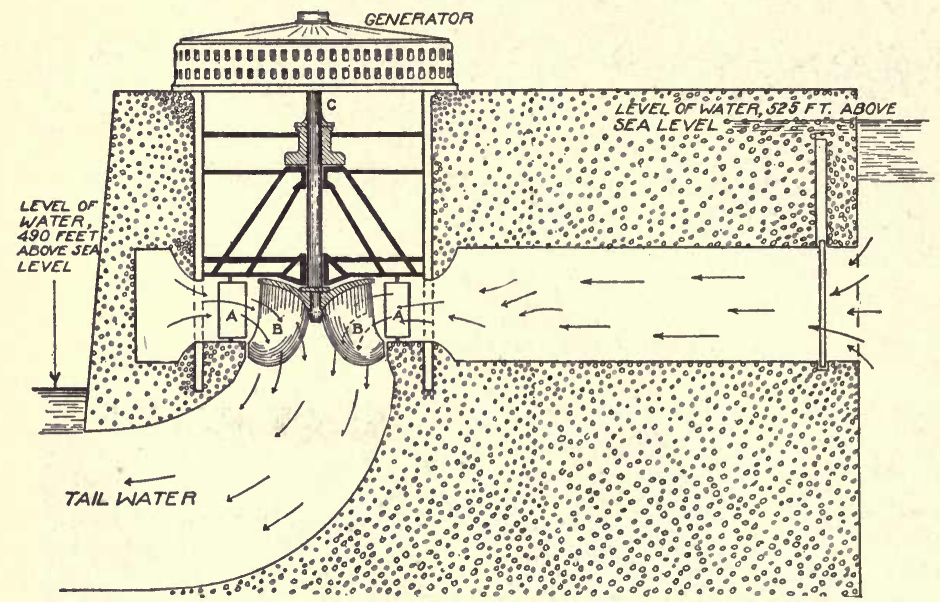

FIG. 347.-Vertical cross section of the turbine pit

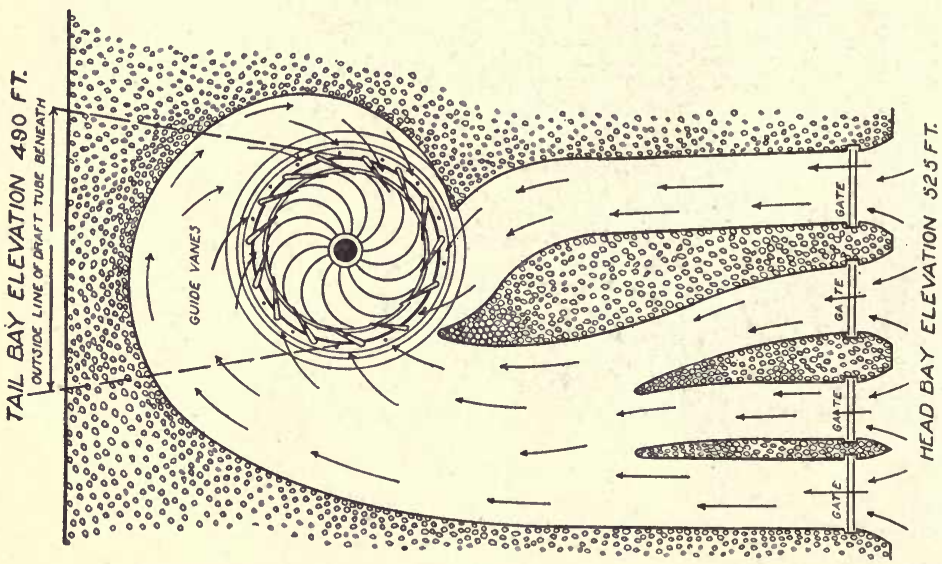

FIG. 348.-Horizontal cross section of the turbine pit.

668. Turbine Wheels.-TURBINE WHEELs are now generally taking the place of the older types of wheels. The water 
power at Niagara Falls as well as that of the Mississippi River at Keokuk, Iowa, (Fig. 345) is developed by means of turbine wheels. At Niagara they operate under a "head" of about $170 \mathrm{ft}$. and at Keokuk with a "head" of about 30 ft. At the present time 500,000 horse-power is developed at Niagara Falls and 150,000 horse-power at Keokuk (Fig. 346).

The turbine wheel is placed at the bottom of a cylindrical well or pit. The water at the bottom of the well is under

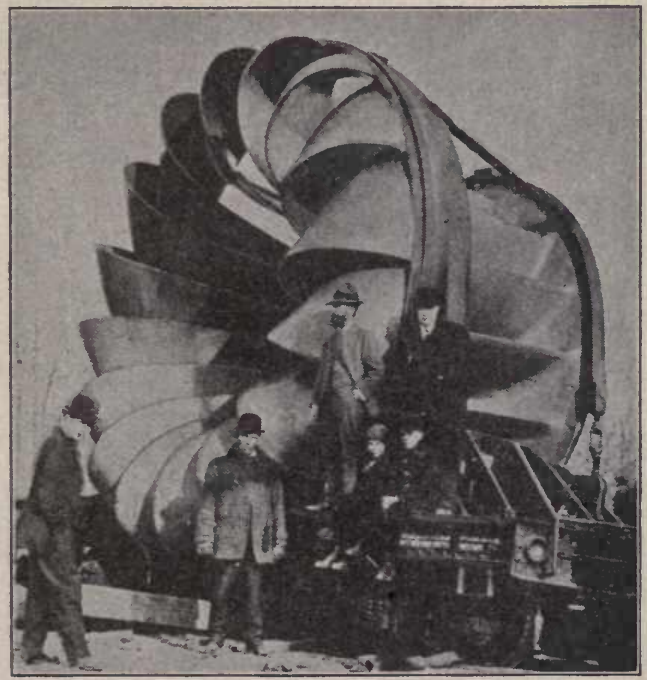

FIG. 349.-One of the turbine wheels in the Keokuk power plant. It hangs on the bottom of a steel shaft over two feet in diameter and turns one of the $10,000 \cdot h . p$. generators shown in Fig. 346 .

high pressure and is forced horizontally through spaces between fixed or stationary vanes set at a certain angle (Figs. 347 and 348). The water strikes against the vanes or blades of the movable wheel causing it to rotate (Fig. 349). After its energy is expended upon the vanes of the movable wheel, the water drops into the outlet, or TAILRACE. A shaft which revolves with the wheel extends upward above the surface of the water where it runs a dynamo or other machinery. 
Turbine wheels are generally used where a large flow of water under a moderate "head" is available. They often give an efficiency of 80 or 90 per cent.

\section{Source of All Energy}

669. The Sun is the Source of All Energy.-The original source of the energy in water power is the sun (see Art. 205). We have seen that water is constantly evaporating when exposed to the air. Evaporation is constantly taking place from every body of water, from every moist surface, and from the leaves of plant life (Arts. 21 and 241). We have also seen that evaporation always means the absorption of heat and the production of cold (Art. 244). It would seem, therefore, that this constant evaporation ought to result in the lowering of the temperature of the earth's surface. Moreover, the heat of the earth's crust is constantly radiating through the atmosphere into space. Why, then, does not the earth's surface become so chilled that all of the water upon it is frozen and all life disappears? See Chap. IV, Arts. 244 and 252, for your answer. Review the cause of precipitation, i.e., of rain and snow. The source of energy in running and falling water is the elevation of water by evaporation and the distribution of the water vapor over the earth's surface by winds, both of which are due to energy from the sun.

We have seen that the energy in all plant and animal life is also originally obtained from the sun (Chap. VII, Art. 380). Coal is known to be the product of the remains of plant life long ago buried in the earth's crust. Geologists tell us that petroleum also is the result of decomposed plant and animal matter which'was buried ages ago. The sun is the original source of all stored-up energy which man may use to produce power.

670. Water Power, the Cheapest of All Power.-Water power is today the least expensive of all available power. 
So long as the sun continues to pour its energy down upon the earth, so long will evaporation continue to take place, the rain will continue to fall, and running water will be available to do work for mankind. The largest expense connected with obtaining power from running water is the cost of constructing the necessary dams and installing the machinery of the plant. This often requires a large outlay of capital. The cost of producing the power after the plant is once installed is small. When man wishes to obtain power from coal or petroleum, he must first raise them to the earth's surface, and this requires much labor and expense.

\section{Available Water Power of the United States}

671. Amount of Water Power Available.-The government has estimated that there is sufficient available water power in the United States, if it were utilized, to run every machine in all our factories and mills, to propel all our railroad trains, street cars, and automobiles, to light all our streets and homes - in fact to operate every machine in the United States. Only about one-fifth of this power is, however, now being utilized, the rest is running to waste. About $30,000,000$ horse-power is now required in the United States for power purposes. About 6,000,000 horse-power of water power has thus far been developed. The use of water power is, however, growing rapidly.

672. Distribution of Water Power.-One of the principal reasons why so small a portion of our available water power-has been developed is the fact that generally water power can be developed only in mountainous, or at least, in hilly regions. Why? Most of the water power thus far developed is located in New England, New York, and Pennsylvania; along the Appalachian Mountains from Georgia northward; in Michigan, Wisconsin, and Minnesota; and along the Rocky and Sierra Nevada Mountains in the west (Fig. 350). The largest power plants in the United States are those at Niagara Falls and on the Mississippi River at Keokuk, Iowa. Much of the 
available water power is located some distance from the great manufacturing centers where it would be most useful.

673. Transmission of Power.-Recently it has been found possible to transmit energy in the form of electric current a distance of 200 miles with profit. On the map (Fig. 350), a circle with a 200 mile radius has been drawn about the

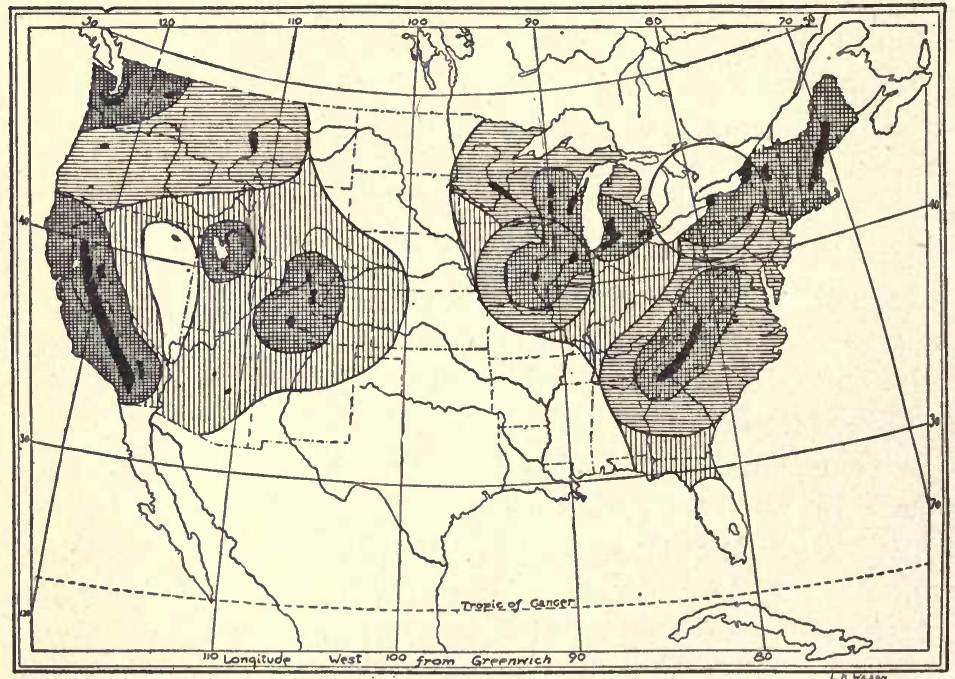

FIG. 350.-Distribution of water power of United States. The heavily shaded portions show the regions where water power is easily available; the horizontally shaded portions, where hydro-electric power is easily available; the vertical shading, where hydro-electric power is possibly available.

power plants at Niagara Falls and at Keokuk, Iowa. Any point lying within these circles may easily be supplied with power from these plants. St. Louis, Missouri, 137 miles distant is now consuming the iarger portion of the power generated at Keokuk (Fig. 351). Much of the power generated at Niagara Falls is sold in the cities of western New York. Many of the cities on the coast of California receive practically all their power from HYDRO-ELECTRIC PLANTS located many miles distant in the Sierra Nevada Mountains (see Art. 570, Chap. IX). 


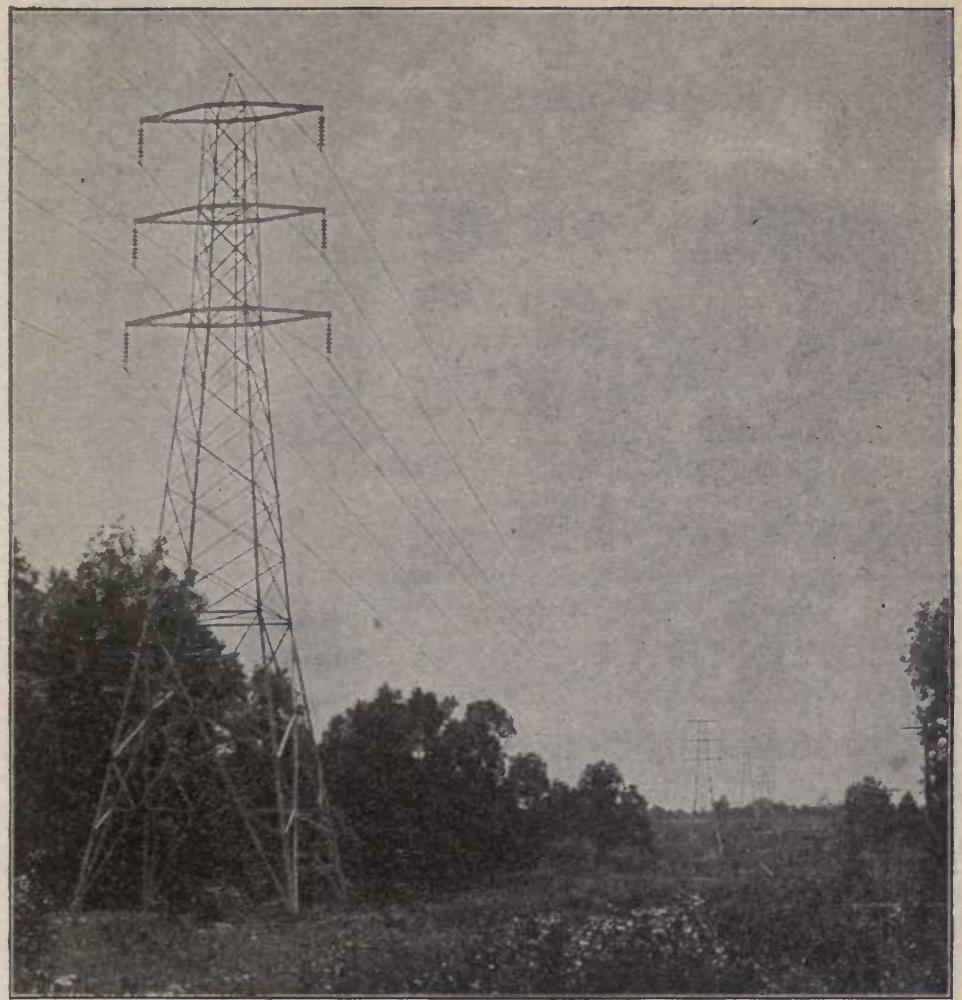

FIG. 351.-Line for transmission of electric power from Keokuk to St. Louis.

\section{The Steam Engine}

674. Importance of the Steam Engine.-No other device or machine invented by man has had as great an influence upon the material advancement of civilization as has the steam engine. It is estimated that the steam engines of the world are today doing from 150 to 200 million horse-power of work. This is many times the amount of work the entire population of the civilized world could do were every adult human being working daily at hard manual labor. The steam engine 
during the last century has largely freed civilized man from hard labor. It has made possible the mine, the mill, the factory, the steam ship, and the railroad. It has made man almost the complete master of the physical forces of the world.

675. Use of the Earliest Steam Engines.-It was just at the beginning of the 18th century (1700) that the steam engine first began to be recognized as a useful machine. During the 18th century, however, practically the only use to which it was put was the pumping of water from the mines of England. Before the invention of the steam engine, many of the coal mines were frequently flooded and some were actually abandoned.

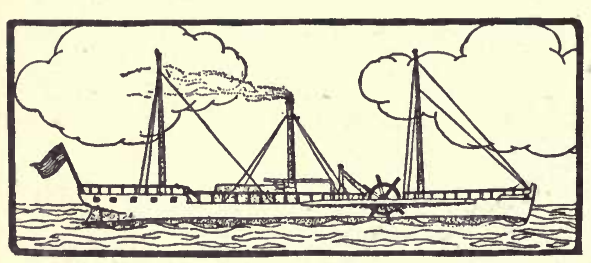

FIg. 352.-Fulton's steamboat, Clermont. (From Stories of Useful Inventions. Courtesy of the Century Company.)

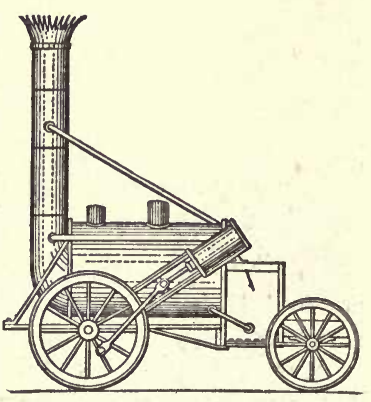

FIG. 353.-The Rocket. (From Hoadley's Essentials of Physics. Courtesy of American Book Co.)

It was not until the closing years of that century that people really began to believe that the steam engine could be used successfully for other purposes. It was about 1785 that the first experimental steamboats were made and not until 1807 that Fulton made the Clermont (Fig. 352), the first really successful steamboat. It was not until 1825 that Stevenson constructed the Rocket (Fig. 353), the first successful locomotive. Today the steam engine is probably doing threefourths of the work done in the civilized world.

676. Source of Power in the Steam Engine.-When water is changed into steam it expands about 1600 times in volume; a cubic inch of water becomes nearly a cubic foot of steam. If the boiling water and steam are confined in a closed vessel, 
a boiler, the steam soon develops great pressure and it is this pressure which is utilized in the steam engine.

677. The Newcomen Air-steam Engine.-Although several devices using steam had earlier been invented, the first really useful engine was invented by an Englishman named Newcomen in 1705. The Newcomen ENGINE, however, was an air-steam engine; in fact, it was not steam pressure but air pressure which actually did the work. For about threequarters of a century, or until about 1874, this air-steam engine was the only type known and used.

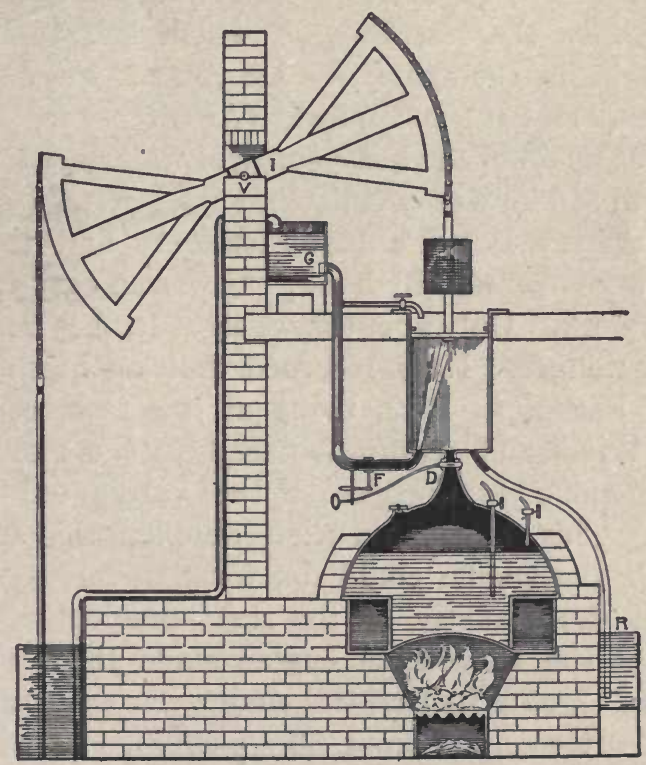

FIG. 354. - The Newcomen air-steam engine, 1705.

678. Principle of the Newcomen Engine.-The principle of this engine is shown in Fig. 354. The only use to which this engine was put was pumping water. The pump-rod and piston were balanced at the two ends of a beam, I, which was free to rotate on its axis, $V$. The piston moved up 
and down in the cylinder. When the valve, $D$, was opened, steam rushed into the cylinder as the piston moved up and the pump-rod descended. The valve, $D$, was now closed and the valve, $F$, opened. This permitted a spray of cold water from the tank, $G$, to enter the cylinder. This spray of cold water condensed the steam in the cylinder, producing a vacuum in the cylinder beneath the piston. The air pressure upon the upper surface of the piston then forced the piston down to the bottom of the cylinder. This raised the pump-rod and plunger. This was the working stroke. The water spray was then cut off and the water and condensed steam drained off into the reservoir, $R$, which had to be placed about $30 \mathrm{ft}$. below the cylinder. Do you see why? (Review air pressure (Art. 210) and pumps (Art., 559 to 561).) The valve, $D$, was again opened, the spray of water again admitted and a second stroke was completed.

679. Humphrey Potter's Invention.-At first the valves, $D$, and $F$, were operated by hand. It was an easy task and a boy did the work. Only about six or eight strokes were usually made each minute. It is recorded that an ingenious boy, Humphrey Potter, in 1713, tiring of this task, contrived a system of levers and strings fastened to the moving beam in such a manner as to operate the valves automatically (Fig. 355). This boy's invention doubled the amount of work which the engine could do, for the valves were now opened and shut exactly at the right moment. With this improvement the Newcomen engine made 15 or 16 strokes each minute. But at its best this engine was extremely wasteful of fuel. It required from 35 to $50 \mathrm{lb}$. of coal to do a horse-power-hour of work, some eight to ten times as much as is required by steam engines today (see Art. 656).

680. Watt's Improvement.-It remained for James Watt, a Scotchman, to perfect the steam engine. About 1774, Watt so perfected the steam engine that it became practically the engine of today. He discovered the chief source of energy loss in Newcomen's engine and overcame it. He saw that 


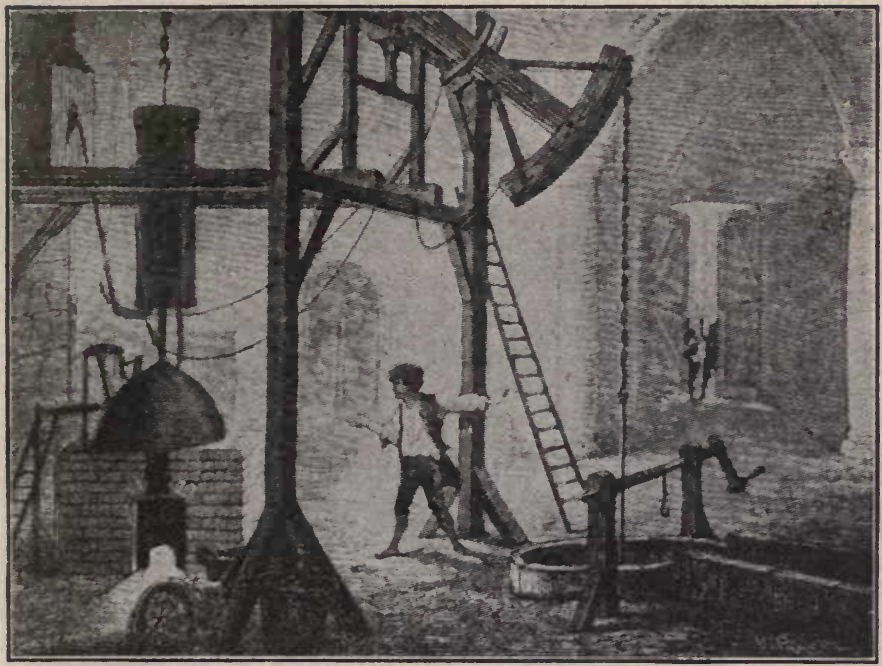

FIG. 355.-Humphrey Potter's latches and strings. (From Stories of Useful Inventions. Courtesy of the Century Company.)

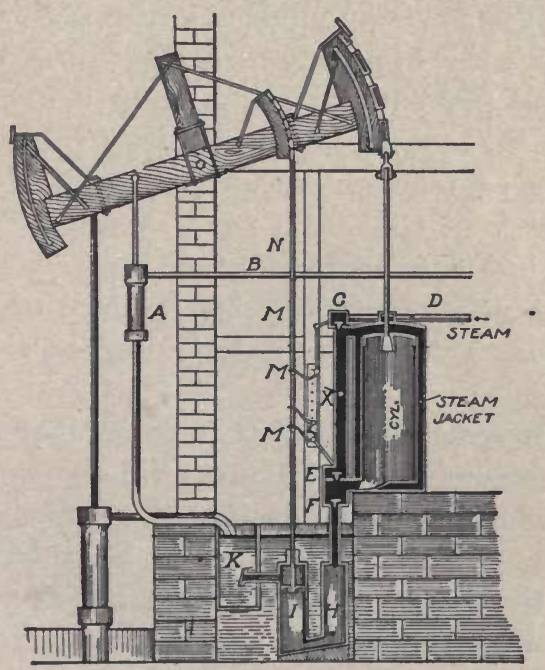

FIg. 356.-Watt's engine. 
the chief difficulty with Newcomen's engine was the loss of heat energy about the cylinder. He was determined to reduce this loss; to do so he made three important improvements:

First, Watt saw that the spray of cold water forced into the cylinder at each stroke so cooled the cylinder and piston that a large amount of the energy in the steam admitted at the next stroke was consumed in reheating the cylinder. $\mathrm{He}$ therefore provided for the condensation of the exhaust steam in another vessel ( $H$, Fig. 356) which was constantly surrounded by cold water. He also surrounded the cylinder with a jacket of steam.

Second, Watt made his an all-steam-engine whereas Newcomen's was an air-steam engine. His purpose in doing so was to keep the cylinder hot. The upper end of the cylinder of Newcomen's engine was open to the air and air pressure was used to force the piston down. The piston and cylinder were, therefore, constantly losing heat to the air. Watt closed both ends of the cylinder of his engine and made the piston rod work through a sTUFFING BOx, a small opening packed steam-tight, just as steam engines are constructed today.

Third, Watt's third improvement was to use oil to lubricate the piston and prevent the steam from passing it. It was impossible in those days for mechanics to make the pistons and cylinders as true and close fitting as they are made today. To prevent the steam from escaping past the piston as well as to lubricate it, Newcomen kept a stream of water running constantly upon the upper surface of the piston of his engine (Fig. 354). This water absorbed a large amount of the heat from the steam.

These improvements by Watt greatly increased the efficiency of the steam engine. It now did the same amount of work while using but about one-fourth as much coal as Newcomen's engine used. We must remember that Watt's motto was: "Keep the cylinder and piston as hot as possible all the time," a rule which is followed in all steam-engine construction today. 
681. How Watt's Engine Worked.-In Watt's engine the steam entered through the pipe ( $D$, Fig. 356$)$. Just as the piston reached the top of the cylinder the valves, $C$ and $F$, were opened and the valve, $E$, closed. The opening of the valve, $C$, permitted the steam to flow into the cylinder above the piston forcing it downward. The opening of the valve, $F$, permitted the steam in the cylinder below the piston to escape into the vessel, $H$, where it was condensed by the surrounding cold water. The condensation of this steam tended to produce a vacuum in the lower portion of the cylinder. The steam also entered the jacket surrounding the cylinder; thus the cylinder was always kept hot. Just as the piston reached the bottom of the cylinder the valves, $C$ and $F$, closed and the valve, $E$, opened. The steam could then no longer enter from the pipe, $D$, but it could flow through the pipe, $X$, from the upper portion of the cylinder into the lower portion. The pressure was now the same on both sides of the piston and the weight of the pump-rod pulled that end of the beam down and so raised the piston again to the top of the cylinder. The valves were operated by the pins, $M, M, M$, on the $\operatorname{rod} N$. The water formed by the condensation of steam was forced by the pump, $I$, into the hot well, $K$. The pump, $A$, raised this warm water from the hot well and forced it into the boiler again through the pipe, $B$.

682. Watt's Double Acting Engine.-While the engine just described was by far the most economical and effective engine which had ever been made, still, Watt was not satisfied. Live steam, i.e., steam under full pressure, entered only one end of the cylinder and actually did work only while forcing the piston downward. About 10 years later, 1784, Watt invented a DOUBLE ACTING ENGINE, i.e., one in which the steam under full pressure entered first one end of the cylinder and then the other. In this way the piston was forced first to one end of the cylinder and then the other end by the live steam. 
683. The Modern Steam Engine.-The construction and operation of the modern steam engine is shown in Fig. 357. The governor controls the speed of the engine by controlling the rate at which the steam enters the cylinder. The governor belt running from the shaft of the flywheel causes the governor to revolve. As the speed increases, the heavy balls, owing to centrifugal force (Art. 622), tend to swing farther out, i.e., revolve in a larger circle. As they do so they force the cut-off valves down, thus reducing the flow of steam.

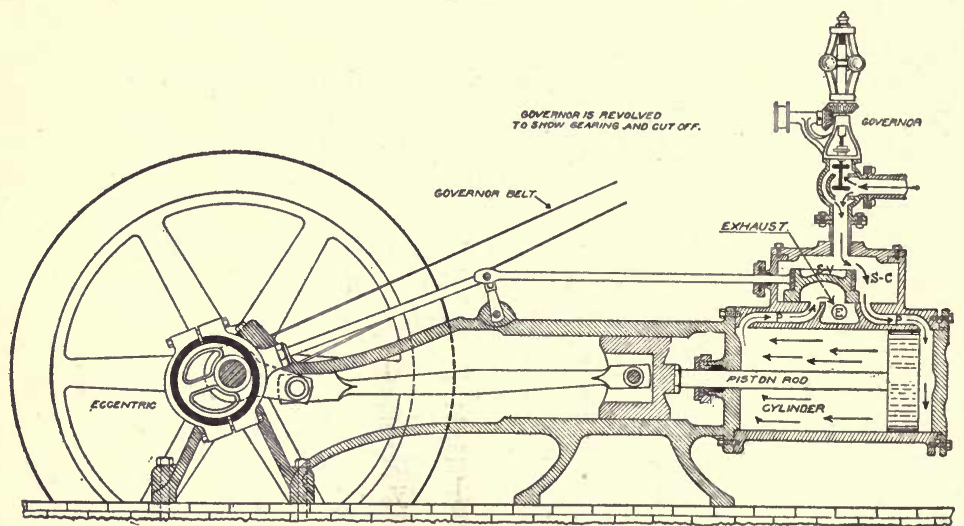

FIG. 357.-The modern steam engine.

As the flow of steam decreases, the force with which the piston is driven becomes less and the speed of the flywheel is lessened. As the speed of the flywheel becomes less, the cut-off valves again rise admitting more steam. Thus the speed of the engine is automatically controlled.

After passing the governor cut-off valves, the steam enters the steam chest, $S-C$. From the steam chest it passes through the port, $P$, into the right-hand end of the cylinder. The steam pressure then forces the piston to the left. The steam in the left end of the cylinder escapes through the other port, $P$, to the exhaust, $E$, whence it escapes to the air or the condenser. 
An ingenious device called the ECCENTRIC on the shaft of the flywheel operates the slide valve, $S-V$. Just as the piston

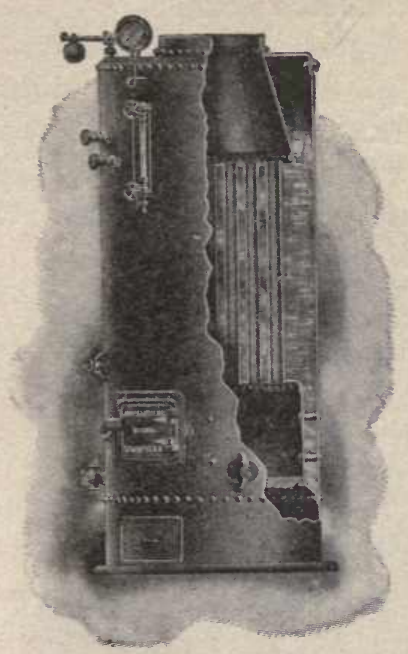

Fig. 358.-An upright boiler with casing cut away, showing the tubes.

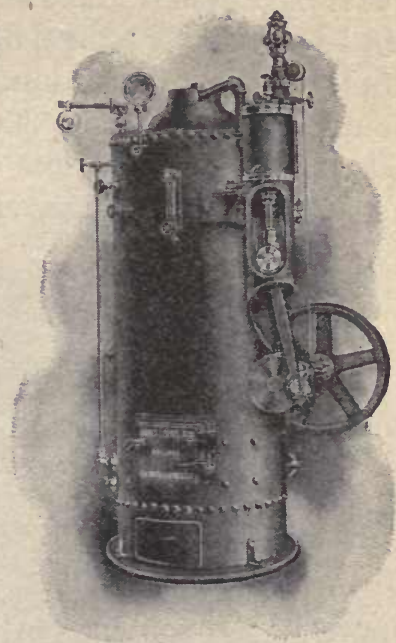

FIG. 359.-An upright boiler with the engine attached to the side of the boiler.

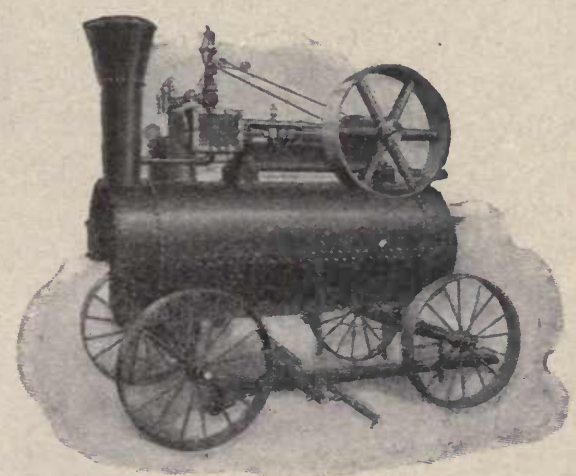

Fig. 360.-A horizontal tubular boiler with the engine mounted on top.

reaches the left end of the cylinder, the slide valve is moved far enough to the right to admit the steam to the left end of 
the cylinder and allow the steam in the right end of the cylinder to escape through the exhaust.

684. The Boiler.-The boiler in which the steam is generated may be any one of several different types. The more common types are the tubular upright (Figs. 358 and 359) and the tubular horizontal (Fig. 360) boilers. But with any form of boiler three safety devices must be supplied: A water gauge, a steam pressure gauge, and a safety valve. Review Arts. 158,159 , and 160.

\section{The Gas Engine}

685. The Internal Combustion Engine.-We have seen that in the case of the steam engine the fuel is burned beneath the boiler, producing steam which is then conveyed to the engine. It is evident that the boiler may be located some distance from the engine. In gas engines, however, the fuel is burned within the cylinder of the engine. Such engines are, therefore, called INTERNAL COMBUSTION ENGINES.

686. The Fuel of Internal Combustion Engines.-Such engines may burn almost any kind of combustible gases. Everybody is somewhat familiar with such engines burning gasoline and used in automobiles or on farms. But internal combustion engines, or gas engines as they are commonly called, may also use as fuel natural gas, coal gas, water gas, producer gas, kerosene, crude petroleum, alcohol; or even finely powdered coal.

687. The Earliest Gas Engines.-The first really successful internal combustion engines burned gasoline. They were made in France and Germany in 1861 and 1862. The first successful gas engines made in the United States were made in 1873.

688. Importance of the Gas Engine.-For many years these engines were not of great importance. They were then used only where small amounts of power were needed occasionally and in places where other power was not easily obtainable. In recent years, however, engines burning 
gasoline, crude petroleum, and gas produced from coal, either as producer gas (Art. 119) or as a waste product from blast furnaces, have become of great importance.

689. The Gasoline Engine and the Automobile.-Many attempts have been made during the past two centuries to produce self-propelled vehicles adapted to use on public streets and country roads (Fig. 361). Until the gasoline engine was perfected but little progress was made in this

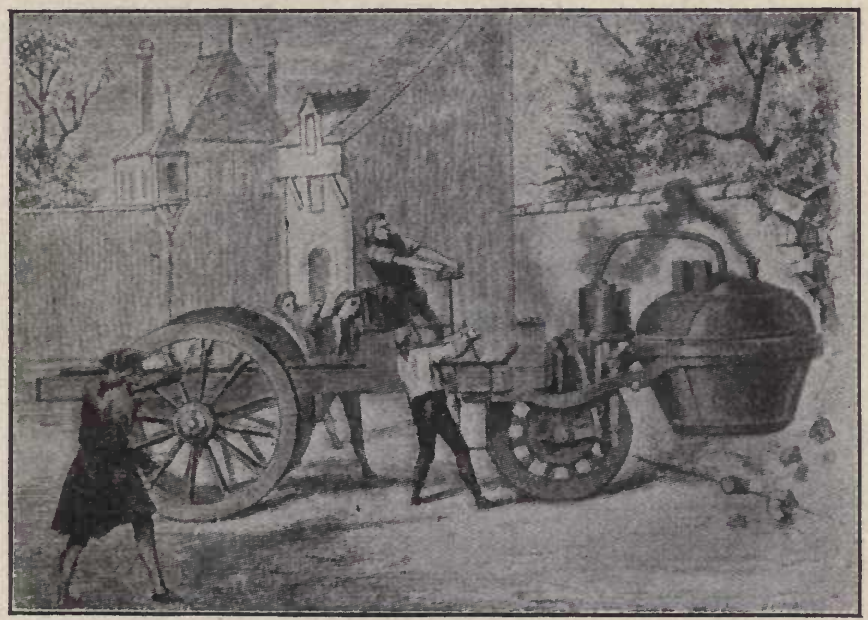

Fig. 361.-Cugnot's steam carriage, 1769. (From Stories of Useful Inventions. By Courtesy of the Century Company.)

direction. The ordinary steam engine was found to be too heavy and cumbersome to be easily adapted to this use. The modern gasoline engine for use in automobiles weighs but about 10 or $15 \mathrm{lb}$. to the horse-power; moreover, it is ready for use at all times and can be started at a moment's notice. The chief advantages, then, of the gasoline engine for this purpose are its comparative lightness and the fact that no time need be lost in heating it ready for service.

690. Gasoline Motors and Aeroplanes.-For many centuries men have looked forward to the day when they should be 
able to navigate the air, to fly as the birds do. Experimentors realized the necessity of producing a motor of great power with as little weight as possible. Before the end of the last century, in 1896, Prof. Langley at Washington, D. C., constructed a steam-driven flying machine which flew without - a passenger several times, once more than a half mile over the Potomac River before its fuel supply was exhausted and it fell of its own weight into the water. ${ }^{1}$ All attempts to produce a successful "heavier-than-air" flying machine failed until the gasoline engine was highly perfected. Every other

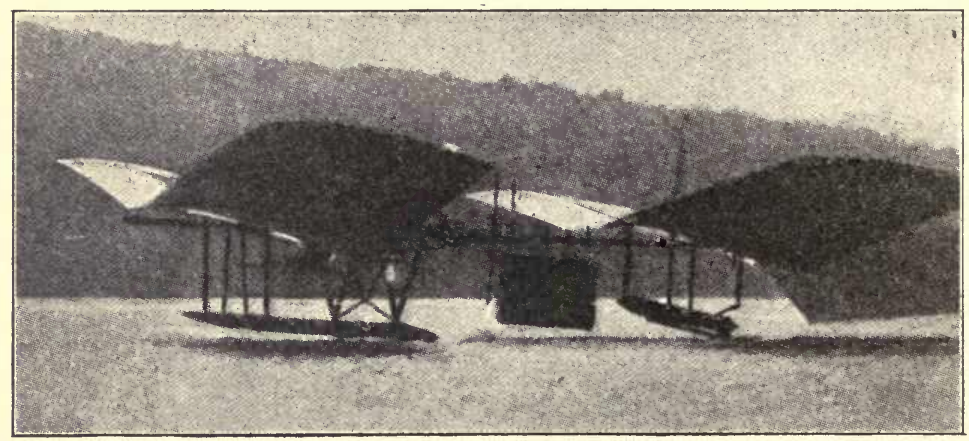

Fig. 362.-The Langley aeroplane flying, May 28, 1914.

type of motor has proved too heavy for the power it could produce. Gasoline motors now used on aeroplanes are marvels of lightness and power. Such engines usually weigh but from 3 to $5 \mathrm{lb}$. per horse-power.

\section{Importance of the Gas Engine in Large Power Plants.} -During recent years it has been shown that gas engines are much more economical of fuel than are steam engines in

${ }^{1}$ It is an interesting fact that two attempts were made in 1904 to prove that Langley's aeroplane could fly while carrying a pilot. Upon both occasions, however, the machine plunged into the river as quickly as it was launched. It is now known that the trouble lay partly in the inexperience of the pilot. On May 28, 1914, Glenn Curtis, an experienced flyer, made a successful flight with the Langley aeroplane which had rested for years in the archives of the Smithsonian Institute and had been styled "Langley's Folly" (Fig. 362). 
large power plants. During the World's Columbian Exposition at St. Louis in 1903 and for a few years following, the United States Government maintained at St. Louis a fuel-testing plant. The purpose was to determine the relative values of fuels and the most economical use of fuel for power production. As a result of a long series of experiments, it was shown that the best modern steam engines require about two and one-half times as much coal as do gas engines producing the same amount of power in large power plants. Of course the coal is first converted into producer gas and this gas is used as fuel in the engine. Many recent power plants are equipped with producer gas producers and gas engines (see Figs. 82 and 295 and review Art. 119).

692. How the Gas Engine Works.-Like Newcomen's airsteam engine, the gas engine cylinder is closed only at one end. The mixture of gas and air is admitted into the closed end of the cylinder and then ignited. Rapid combustion takes place, producing very high temperature thus expanding the gases greatly. The pressure produced drives the piston to the opposite end of the cylinder.

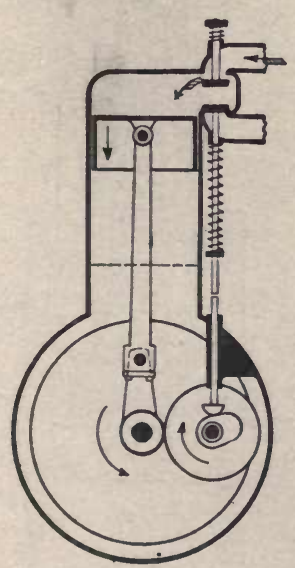

FI G. 363 . - First cycle, diagram. Suction stroke.
693. The Fourcycle Engine.-Most gas engines are of the type known as FourSTROKE Or FOURCYCLE engines. By this is meant that the piston moves the length of the cylinder four times and the flywheel makes two revolutions for each explosion of gas. The operation of the engine is as follows:

First Stroke: The

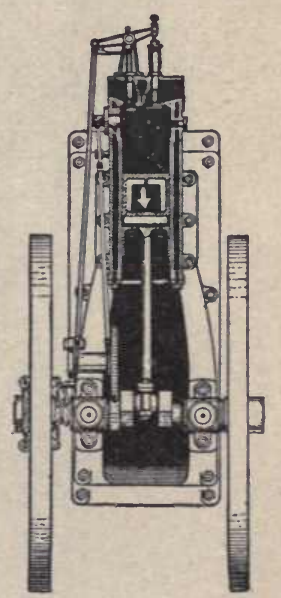

FIG. 364. - First cycle, engine. Suction stroke. 


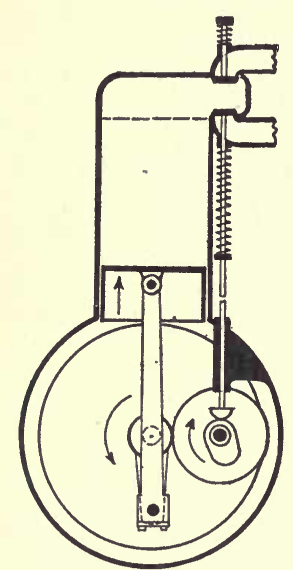

FIG. 365.-Second cycle, diagram. Compression stroke.

piston moves from the closed end of the cylinder to the open end. This produces a partial vacuum, and suction causes air charged with a spray of the liquid fuel or a mixture of air and gas to rush in through the intake valve (Figs. 363 and 364).

Second Stroke: The piston moves from the open end of the piston to the closed end. This compresses the charge of fuel and air to from

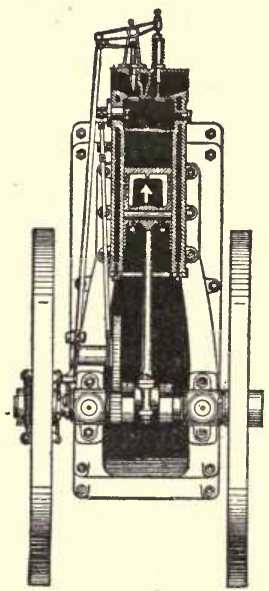

Fig. 366,-Second cycle, engine. Compression stroke.

one-fourth to one-fifteenth of its original volume, depending upon the kind of fuel used (Figs. 365 and 366).

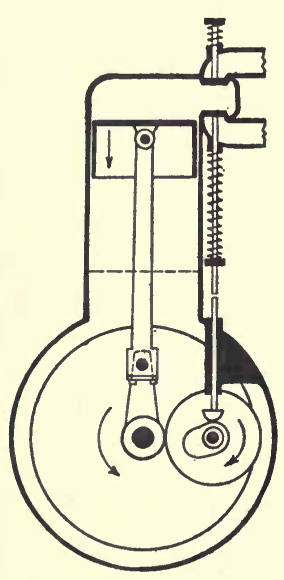

FI . 367 . - Third cycle, diagram. Working stroke.

Ignition: Just at the end of the second stroke the charge is ignited, usually by an electric spark.

Third Stroke: This is the expansion or WORKING STROKE. The burning gases produce great pressure upon the piston and drive it toward the open end of the cylinder (Figs. 367 and 368 ).

Fourth Stroke: The exhaust valve is

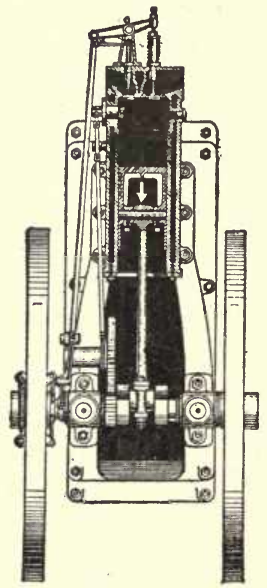

FI G. 368 . - Third cycle, engine. Working cycle,
stroke. 


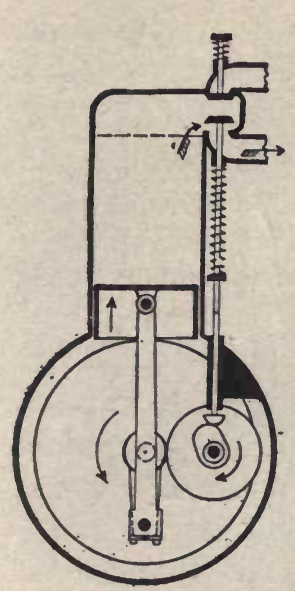

FIG. 369.-Fourth cycle, diagram. Exhaust stroke. opened and as the piston returns to the closed end of the cylinder it forces the products of combustion out through the exhaust port (Figs. 369 and 370 ).

The four strokes are (1) suction stroke, (2) compression stroke, (3) working stroke, (4) exhaust stroke. These four strokes constitute one complete cycle or round of action.

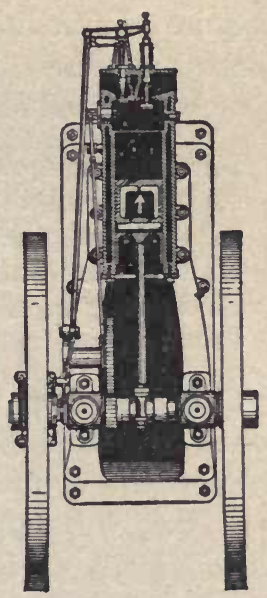

FIG. 370.-Fourth cycle, engine. Exhaust stroke.

694. Purpose of Compression.-The purpose of compressing the gas before igniting it is to secure the most rapid combustion possible. The gas in the cylinder is much like brush in a brush heap. It we wish the brush to burn rapidly we must tramp it down into a compact mass. The more compact the brush, the more rapidly it burns and the hotter the fire. In like manner the compression of the gas in the cylinder produces more rapid combustion, and hence a higher temperature. Greater pressure on the piston results.

695. Compression must not be too Great.-Whenever a gas is compressed heat is produced. The pump becomes hot when we "pump up" a bicycle or automobile tire. In compressing the gas in the cylinder of a gas engine, care must be taken that the temperature of the gas is not raised to the kindling temperature (see Art. 95) before the end of the compression stroke. What would be the result if the gas were ignited during the second stroke? How would this affect the power of the engine?

696. Compression for Different Gases.-Different fuels 
require different amounts of compression to produce the largest amount of power. In practice, the different gases are compressed about as follows:

Kerosene, compressed to about $1 / 4$ to $1 / 5$ of its original volume, Gasoline, compressed to about $1 / 5$ to $1 / 6$ of its original volume, Alcohol, compressed to about $1 / 10$ to $1 / 15$ of its original volume, Natural gas, compressed to about $1 / 7$ to $1 / 10$ of its original volume, Coal gas, compressed to about $1 / 6$ to $1 / 10$ of its original volume, Producer gas, compressed to about $1 / 10$ to $1 / 15$ of its original volume

697. Keeping the Cylinder Cool.-We saw that Watt, when developing the steam engine, adopted the motto, "Keep the cylinder as hot as possible." With gas engines, however, the danger is that the cylinder will get too hothot enough to ignite the gas too soon. The cylinders of small gas engines are sometimes cooled by air, a fan forcing the air past the cylinder. Such engines are called AIR-COOLED ENGINES. All large gas engines are WATER-COOLED ENGINES. The cylinders of water-cooled engines are surrounded by jackets similar to the jackets Watt used on his steam engines. But in this case the jacket contains flowing water to keep the cylinder cool instead of steam to keep the cylinder hot.

698. Need of the Heavy Flywheel.-We have seen that in the four-cycle engine, force is being exerted upon the piston but one-fourth of the time, i.e., during the third stroke. But the engine must continue to do work all the time. We should therefore expect the engine to run with an unsteady motion. It would do so were it not for the heavy flywheels. The heavy flywheels absorb a large amount of energy during the working stroke and give it up again during the other three strokes. Being massive they have great capacity for holding energy and therefore vary but little in speed during the cycle.

699. Many-cylindered Engines on Automobiles.-It is undesirable to load an automobile with heavy flywheels, although a steady motion is very desirable. For this reason nearly all gasoline engines used on cars are constructed with 
several cylinders. The pistons of the four-cylinder engine are connected with the drive shaft in such a manner that, while one piston is performing the first stroke, another is performing the second stroke, the third piston the third stroke, and the fourth the fourth stroke. Thus we see that some one of the pistons is at work every instant. This produces a steady motion. In the six-cylinder, eight-cylinder, and twelve-cylinder engines the power is still more nearly constant (Fig. 371).

\section{ENERGY LOSSES AND COST OF FUEL FOR DIFFERENT MOTORS}

In actual practice the efficiency of power plants of the same general type varies so greatly and the cost of fuel

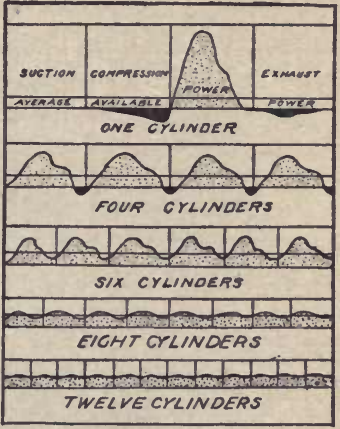

Fig. 371.-How several cylinders produce a constant, steady power. varies so much in different parts of the country that only average efficiencies and relative cost can be given. Nevertheless, as a closing section in the study of motors it is interesting to note, as far as we can do so, the average efficiency

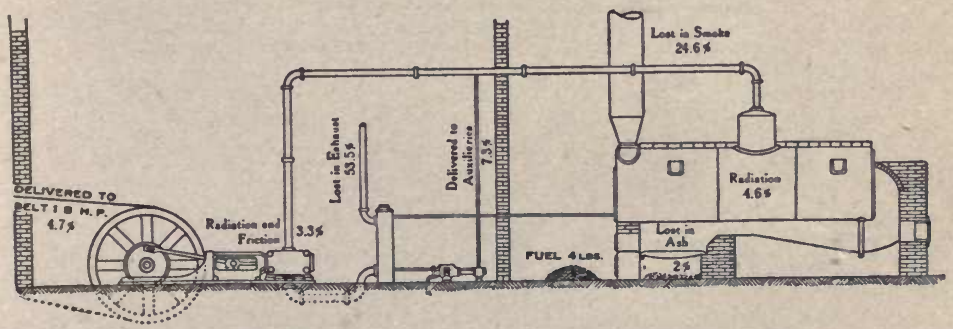

Fig. 372.-Losses of energy in a steam power plant.

and relative cost of fuel for the different kinds of motors in common use.

700. Sources of Energy Loss.-The sources of loss usually occurring in the different power plants are shown in the 


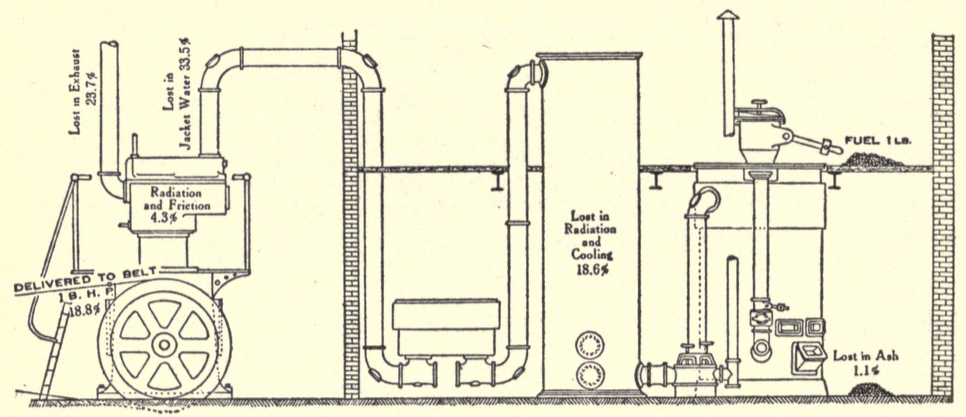

FIG. 373.-Losses of energy in a producer gas and gas engine plant.

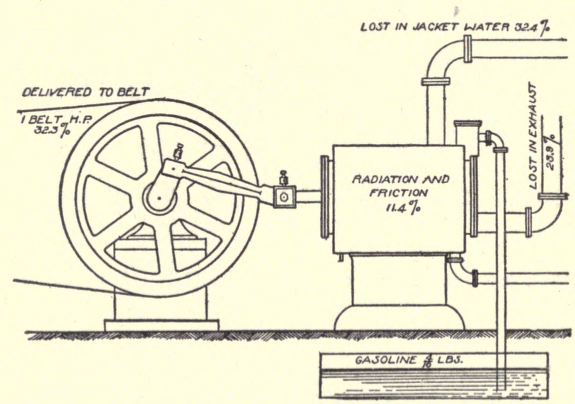

FIG. 374.-Gasoline engine.

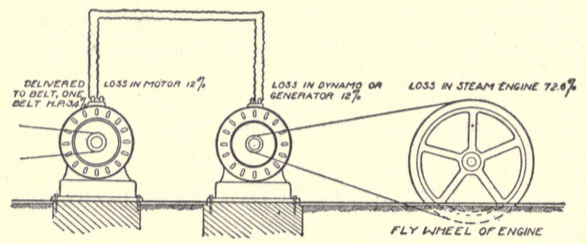

Fig. 375.-Losses of energy in steam-electric power plants. 
illustrations (Figs. 372, 373, 374, and 375). These losses are also indicated in tabulated form as follows:

Energy Losses in Steam Plants, Producer Gas Plants and Gas Engines, Gasoline Engines, and in Steam Electric Power Plants

$\begin{array}{cccc}\text { Energy lost before reaching } & \begin{array}{c}\text { Steam } \\ \text { plant, and gas } \\ \text { the engine }\end{array} & \begin{array}{c}\text { Gasoline } \\ \text { pengine, }\end{array} & \begin{array}{c}\text { Steam- } \\ \text { electric } \\ \text { plant, }\end{array} \\ \text { per cent. } & \text { per cent. } & \text { per cent. } & \text { per cent }\end{array}$

$\begin{array}{lllllll}\text { In ashes . . . } \ldots \ldots \ldots \ldots \ldots \ldots & 2.0 & 1.1 & \ldots \ldots \ldots & 1.4\end{array}$

$\begin{array}{lllll}\text { In radiation and cooling........ } & 4.6 & 18.6 & \ldots \ldots \ldots & 3.4\end{array}$

In smoke............... $24.6 \quad \ldots \ldots \ldots \ldots \ldots .619 .0$

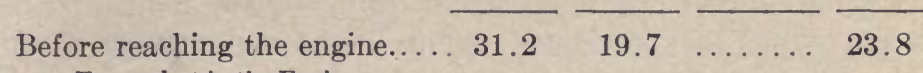

Energy lost in the Engine

$\begin{array}{llllll}\text { Radiation and friction......... } & 3.3 & 4.3 & 11.4 & 2.3\end{array}$

$\begin{array}{llllll}\text { Exhaust................... } & 53.5 & 23.7 & 23.9 & 41.0\end{array}$

$\begin{array}{lllll}\text { Water jackets............... } & 0.0 & 33.5 & 32.4 & 0.0\end{array}$

$\begin{array}{llllll}\text { Auxiliaries................. } & 7.3 & 0.0 & 0.0 & 5.5\end{array}$

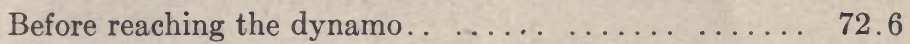

In the dynamo or generator... $\ldots \ldots \ldots \ldots \ldots \ldots \ldots$

In the motor........................... 12.0

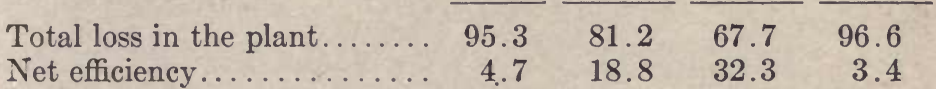

\section{PROBLEMS}

In solving the following problems we shall suppose that the energy in coal is 3100 Cal. per $1 \mathrm{~b}$. and that bituminous coal costs $\$ 2$ per ton; that the energy in gasoline is $4785 \mathrm{Cal}$. per $\mathrm{lb}$. and it costs 15 cts. per gal. We know that 1 horse-power-hour of work equals 640 Cal. of heat (Art. 655).

1. How many pounds of coal will the steam engine (Fig. 372), require to do 1 horse-power-hour of work? What would be cost of fuel for 1 horse-power per day of eight hours?

Solution: The engine delivers only 4.7 per cent. of the energy in the form of useful work. One lb. of coal contains $3100 \mathrm{Cal}$. of energy. Therefore, 4.7 per cent. of $3100 \mathrm{Cal}$. or $145.7 \mathrm{Cal}$. is the amount of energy delivered as work. But 1 horse-power of work equals 640 Cal. of heat. It will therefore require $640 \div 145.7$ or about $4.4 \mathrm{lb}$. of coal per horse-power-hour.

Such a plant could be operated on bituminous coal costing $\$ 2$ 
per ton or $1 / 10$ et. per lb. The cost of $4.4 \mathrm{lb}$. of coal would, therefore, be $44 / 100$ ct. To operate this engine eight hours the cost would be $8 \times 0.44$ ct. or 3.52 cts. per $\mathrm{H}$. P.

2. How many pounds of coal will the gas producer and gas engine (Fig. 373), require to do 1 horse-power-hour of work? Ans. $1.1 \mathrm{lb}$.

What would be the cost of coal per horse-power-day of eight hours, if bituminous coal costing $\$ 2$ per ton were used? If anthracite coal costing $\$ 6$ per ton were used?

Ans. 1.1 cts. for bituminous coal.

$3.3 \mathrm{cts}$. for anthracite coal.

3. How many pounds of gasoline would be required by the gasoline engine (Fig. 374), while doing 1 horse-power-hour of work?

Ans. About $4 / 10 \mathrm{lb}$.

What would be the cost for gasoline per horse-power-day of e ght hours if it cost 15 cts. per gal. and each gallon weighs $6 \mathrm{lb}$.?

Ans. About $8.5 \mathrm{cts}$.

(Note.-If the engine were large it would probably burn crude petroleum costing not more than one-fourth as much as the gasoline.)

4. How many pounds of coal per horse-power-hour would be required to produce power by means of the electric plant (Fig. 375).

Ans. Nearly $6.1 \mathrm{lb}$.

What would be the cost of running this plant per horse-power-day. of eight hours if the steam engine burned soft coal costing $\$ 2$ per ton?

Ans. About 4.8 cts.

Summary jf the Four Power Plants

\begin{tabular}{|c|c|c|}
\hline $\begin{array}{l}\text { Steam } \\
\text { plant, }\end{array}$ & $\begin{array}{c}\text { Producer gas } \\
\text { and gas } \\
\text { engine, } \\
\text { per cent. }\end{array}$ & $\begin{array}{c}\text { Gasoline engine, } \\
\text { per cent. }\end{array}$ \\
\hline
\end{tabular}

$\begin{array}{llll}\text { Efficiency of the plant... } 4.7 & 18.8 & 32.3 & 3.4\end{array}$

Cost for fuel per horse-

1.1 cts. on 8.5 cts. on soft coal gasoline

power-day of 8 hours. $3.2 \mathrm{cts}$. $3.3 \mathrm{cts}$. on 3 or $4 \mathrm{cts}$. on $4.8 \mathrm{cts}$ hard coal crude petroleum

While these figures are only approximations, they show clearly that we should never confuse the efficiency of a motor with the cost of doing work by means of the motor. 


\section{APPENDIX \\ WEIGHTS AND MEASURES}

ENGLISH SYSTEM

LINEAR MEASURE OR MEASURES OF LENGTH

$\begin{aligned} 12 \text { inches (in). } & =1 \text { foot (ft.) } \\ 3 \text { feet } & =1 \text { yard (yd.) } \\ 51 / 2 \text { yards } & =1 \text { rod (rd.) } \\ 161 / 2 \text { feet } & =1 \text { rod } \\ 320 \text { rods } & =1 \text { mile (mi.) } \\ 1760 \text { yards } & =1 \text { mile } \\ 5280 \text { feet } & =1 \text { mile }\end{aligned}$

SQUARE MEASURE OR SURFACE MEASURE
144 square inches (sq. in.) $\quad=1$ square foot (sq. $\mathrm{ft}$.)
9 square feet $\quad=1$ square yard (sq. yd.)
$301 / 4$ square yards $\quad=1$ square rod (sq. rd.)
160 square rods $\quad=1$ acre (A.)
1 square mile $\quad=1$ section
36 square miles, or 36 sections $=1$ township

\section{CUBIC MEASURE OR MEASURE OF VOLUME}

1728 cubic inches (cu. in.) $=1$ cubic foot (cu. ft.)

27 cubic feet (cu. ft.) = 1 cubic yard (cu. yd.)

\section{AVOIRDUPOIS WEIGHT}

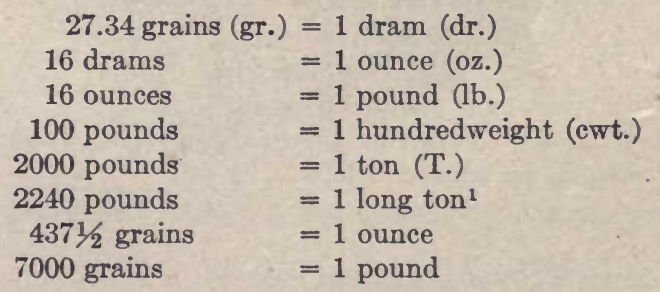

1 The long ton is used at the United States custom houses and often in wholesale transactions in coal and iron, as well as being in general use in Great Britain. 


\section{MEASURES OF TIME}

$\begin{aligned} 60 \text { seconds (sec.) } & =1 \text { minute }(\min .) \\ 60 \text { minutes } & =1 \text { hour }(\mathrm{hr} .) \\ 24 \text { hours } & =1 \text { day }(\text { da.) } \\ 7 \text { days } & =1 \text { week }(\mathrm{wk} .) \\ 3651 / 4 \text { days, or } 12 \text { months } & =1 \text { year }(\mathrm{yr} .) \\ 10 \text { years } & =1 \text { decade } \\ 10 \text { decades, or } 100 \text { years } & =1 \text { century }\end{aligned}$

UNITED STATES LIQUID MEASURE

4 gills (gi.) $=1$ pint (pt.)

2 pints $=1$ quart (qt.)

4 quarts $=1$ gallon (gal.)
231 cubic inches $=1$ gallon

$31 \frac{1}{2}$ gallons $=1$ barrel (bbl.)

57.75 cubic inches $=1$ liquid quart

\section{UNITED STATES DRY MEASURE}

2 pints (pt.) $=1$ quart (qt.)

8 quarts $\quad=1$ peck (pk.)

4 pecks $\quad=1$ bushel (bu.)
32 quarts $\quad=1$ bushel
67.2 cubic inches $=1$ quart
2150.4 cubic inches $=1$ bushel

\section{HOUSEHOLD MEASURES (APPROXIMATE VALUES)}

$\begin{array}{llc}1 \text { drop } & = & 1 / 10 \text { cubic centimeter } \\ 1 \text { teaspoonful } & = & 5 \text { cubic centimeters } \\ 1 \text { tablespoonful } & = & 3 \text { teaspoonfuls } \\ 16 \text { tablespoonfuls } & = & 1 \text { cup } \\ 2 \text { cups } & = & 1 \text { pint, liquid } \\ 1 \text { pint, liquid } & = & 473.1 \text { cubic centimeters } \\ 1 \text { pint, dry } & = & 550.5 \text { cubic centimeters }\end{array}$

\section{MISCELLANEOUS}

1 United States gallon of water weighs 8.33 pounds

1 cubic foot of water weighs 62.3 pounds

1 cubic foot of dry air at sea level weighs 1.23 ounces

1 gallon of gasoline weighs about 6 pounds

The average air pressure at sea level $=1033$ grams per square centimeter, or 14.7 pounds per square inch

1 horse power $=550$ foot-pounds per second or 33,000 foot-pounds per minute

1 greater calorie $=3080$ foot-pounds

1 horse power-hour $=1,980,000$ foot-pounds

1 horse power-hour $=640$ greater calories

1 pound of coal yields from 3000 to 3200 greater calories of heat 


\section{METRIC SYSTEM}

\section{LINEAR MEASURE OR MEASURES OF LENGTH}

$\begin{aligned} 10 \text { millimeters }(\mathrm{mm} .) & =1 \text { centimeter }(\mathrm{cm} .) \\ 100 \text { centimeters } & =1 \text { meter }(\mathrm{m} .) \\ 1000 \text { meters } & =1 \text { kilometer }(\mathrm{km} .)\end{aligned}$

\section{SQUARE MEASURE OR MEASURES OF SURFACE}

100 square millimeters (sq. mm.) $=1$ square centimeter (sq. cm.)

10,000 square centimeters $\quad=1$ square meter (sq. m.) $1,000,000$ square meters $=1$ square kilometer (sq. $\mathrm{km}$.)

\section{MEASURES OF VOLUME OR CAPACITY}

1,000 cubic millimeters (cu. mm.) = 1 cubic centimeter (cu. $\mathrm{cm}$.) $1,000,000$ cubic centimeters $\quad=1$ cubic meter (cu. m.)

1,000 cubic centimeters $\quad=1$ liter $(1$.

MEASURES OF WEIGHT OR MASS
$\begin{aligned} 1000 \text { milligrams (mg.) } & =1 \text { gram (g. or gm.) } \\ 100 \text { centigrams (cg.) } & =1 \text { gram } \\ 1000 \text { grams } & =1 \text { kilogram }(\mathrm{kg} .) \\ 1000 \text { kilograms } & =1 \text { metric ton }\end{aligned}$

\section{MISCELLANEOUS}

1 cubic centimeter of water at $4^{\circ} \mathrm{C}$. or $39.2^{\circ} \mathrm{F}$. weighs 1 gram

1 liter of water at $4^{\circ} \mathrm{C}$. or $39.2^{\circ} \mathrm{F}$. weighs 1 kilogram

1 cubic centimeter of dry air at the sea level weighs 0.001293 grams

1 liter of dry air at the sea level weighs 1.293 grams

The average air pressure at sea level $=1033$ grams per square centimeter

Inches and $1 / 32$ of an inch

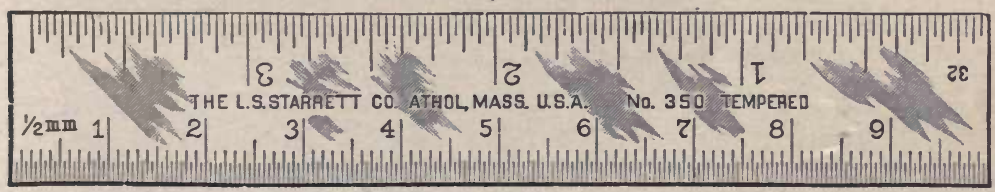

Centimeters and $1 / 2$ of a millimeter

\section{METRIC AND ENGLISH EQUIVALENTS}

$\begin{array}{lll}1 \text { inch } & =2.54 & \text { centimeters } \\ 1 \text { foot } & =30.48 \text { centimeters } \\ 1 \text { quart (U. S. liquid) } & =0.9464 \text { liter } \\ 1 \text { quart (U. S. dry) } & =1.101 \text { liters } \\ 1 \text { ounce (avoirdupois) } & =28.35 \text { grams }\end{array}$


1 pound (avoirdupois) $=0.4536$ kilogram

1 centimeter

$=0.3937 \mathrm{inch}$

1 meter

$=39.37$ inches

1 liter

$=1.051$ quarts (U. S. liquid)

1 liter

$=0.9081$ quart (U. S. dry)

1 kilogram

$=2.205$ pounds (avoirdupois)

MENSURATION RULES

Circumference of a circle

Area of a circle

Surface of a sphere

Volume of a sphere

Lateral surface of a cylinder $=$ circumference of base $\times$ altitude
$=$ diameter $\times 3.1416$, or $\pi$

$=\left\{\begin{array}{l}1 / 2 \text { circumference } \times \text { radius } \\ \text { diameter squared } \times 0.7854 \\ \text { radius squared } \times 3.1416\end{array}\right.$

$=\left\{\begin{array}{l}\text { diameter } \times \text { circumference } \\ 4 \times 3.1416 \times \text { square of radius }\end{array}\right.$

$=\{$ diameter cubed $\times 0.5236$

$4 / 3$ of radius cubed $\times 3.1416$

$=$ area of base $\times$ altitude 


\section{GLOSSARY}

\section{TERMS DEFINED AS USED IN THIS TEXT}

absolute humidity. - Weight of water vapor, grains per $\mathrm{cu} . \mathrm{ft}$. acclimatize, ă-clīma-tĩz.-Adaption of plants and animals to a climate. acetone, ăg $c^{\prime} \bar{e}-t o ̄ n .-A n$ inflammable liquid which readily dissolves acetylene.

acetylene, ă-çêt' y-lēn.-An illuminating gas; a hydrocarbon. aeration, $\bar{a}^{\prime \prime} \bar{e} r-\bar{a}^{\prime}$ shøn.-To supply or charge with air. aerobic, $\bar{a}^{\prime \prime}$ ër- $\bar{o}^{\prime}$ blc.- - Applied to organisms which live in free oxygen. aeroplane, $\bar{a}^{\prime}$ ër-o-plān.-A heavier-than-air flying machine.

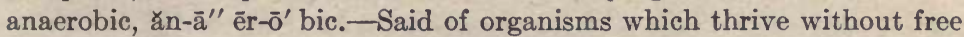
oxygen.

anthracite, ăn' thrä-sìt.-Coal containing but little volatile matter. antiseptic, ăn" tİ-š̌p' tic.-That which prevents the growth of organisms. antitoxine, $\mathrm{an}^{\prime \prime}$ ti-tððx' In.-A substance which neutralizes toxines. Appalachian, ăp"a-lăch' i-ăn.-Mountain range in eastern United States apparatus, ap"a-rā' tŭs.-Appliances and materials used in performing experiments.

aqua ammonia, a $\bar{a}^{\prime}$ kwà ă-mō' ni-a.-Ammonia dissolved in water. aqueduct, $\mathrm{ak}^{\prime}$ wlı-dŭkt.-A conduit for conveying water. Archimedes, är" ki-mē' dēz.-Greek mathematician, 287-212 B.C. artesian, är-tē'zhan.-Deep well, usually flowing. First found in Ärtois, France.

artificial, är" ti-fYsh' al.-Produced by art, not by nature. assimilate, $\breve{a}$-sı̌m'i-lāt.-To transform food into protoplasm. atmosphere, ăt' mos-fēr.-All the gases surrounding the solid earth. attenuate, ăt-těn' yụ-ät. - To weaken, especially in virulence. automatic, a! tō-măt' ic.-Self-moving, self-regulating. automobile, a tō-mō' brl. - Self-propelling vehicle. axle, $а \mathrm{ks}^{\prime}$ l. - A support upon which a wheel turns. bacillus, ba-çı' ŭs (pl. bacilli).- - A rod-shaped bacterium. baguios, bä'-ḡi-ōs (sing. baguio).-Philippine hurricanes. barograph, băr o-gräf.-Instrument which writes continuous record of atmospheric pressure.

barometer, ba-rom' e-tēr.-An instrument for measuring the atmospheric pressure. 
Baume', bō" $\bar{m}^{\prime \prime}$ '- -Antoine (ăn-tŏin') Baume, a French chemist, 17281804.

bituminous, bi-tū' mi-nŭs.-Coal with much volatile matter. Soft coal. Boyle, bðyl.-Robert Boyle, English physicist and chemist, 1627-1691. bromine, brō' min.-A reddish-brown, liquid element with suffocating odor.

buoyancy, boi' an-si.-Power or tendency to keep afloat (noun).

bouyant, boi' ant.-Tendency to float (adjective).

calcium carbide, eăl' çi-ŭm eär' br̆d.-A rock-like chemical compound. calorie, kăl' o-re.-A heat unit.

calorific, kăl" o-rıf' $\mathrm{lk}$.- - Heat producing. calorimeter, kăl" o-rı̆m' e-tẽr.-An apparatus for measuring heat. calorimetry, kăl" o-rım' e-try.-Process of measuring heat. camphor, eăm' for.-A fragrant, gum-like compound.

capillarity, căp" il-lăr' i-ty.-Force or process by which water rises through soil.

capita, eăp' i-ta.-Per capita (Latin) meaning per head or for each person.

carbohydrate, kär" bo-hy' drāt.-A compound composed of carbon, hydrogen and oxygen.

carbureter, kär" bu-rět' ẽr.-1. A device for introducing hydrocarbons into water gas. 2. That part of a gasoline lamp or gasoline engine where gasoline gas and air are mixed. carniverous, kär-nǏv' o-rŭs.-Applied to flesh eating animals. cellulose, sèl' yư-lōs.-A material composing the cell-walls of plant structure.

Celsius, sěl' si-ŭs.-A Swedish astronomer, 1701-1744.

centigrade, çěn' ti-grād.-A thermometer scale (centum, Latin, meaning hundred).

centrifugal, çen-trıf' yü-ğal.-Tendency to fly from the center.

Chambord, shän" bör'.-A village in France.

chlorine, klō' rřn.-A greenish-yellow, gaseous, poisonous element.

cirrus, çı̆r' ŭs.-A high cloud composed of hair-like fibers.

clinometer, elī-nom' e-tẽr.-An instrument for determining altitude.

cloud.-Water vapor condensed into visible particles floating in the air. coagulate, eō-ăğ' yụ-lāt.-To change a substance like blood to solid form. coccus, eŏ $e^{\prime}$ ŭs (pl. cocci, $\epsilon^{\prime} e^{\prime}$ çi).- - A sperical bacterium.

conduit, cŏn' dıt.-A tube or pipe for electric wires or conducting water. conserving, cŏn-sẽrv' ing.-Preventing the waste of, as of moisture from the soil.

consomme, kôn" sō-mā'.-A clear meat soup.

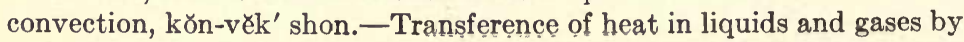
means of currents. 
corrode, eð-rōd'.-To eat away gradually, to rust. counter-clockwise.-Turning in the direction opposite that of a clock's hands.

Croton, erō' ton.-A river northeast of New York City. culture, eŭl' tūr, or eŭl' chụr.-1. A growth of microörganisms. 2. A culture medium.

culture medium.-Material in which microörganisms wili grow. cumulus, $e \bar{u}^{\prime} m \bar{u}-l u$ s. - A cloud of heap-like form with rounded top. cutaneous, $e \bar{u}-\overline{t a}^{\prime}$ nē-ŭs.-Pertaining to the skin.

cyclone, çy' elōn.-1. A system of winds several hundred miles in diameter, circling around a center. 2. A violent storm occurring over the Indian Ocean.

decay, dē-eā.'-Rotting, spoiling, putrefying, disintegrating.

denitrifying, dē-nī' tri-fy-ing.-Removing nitrogen from compounds. dew.-Water vapor condensed on cool objects as grass or the ground. dew-point.- The temperature at or below which dew or frost would form. dextrin, dekss' try̌n.- One of the carbohydrates.

dextrose, děks' trōs.-Grape sugar, as found in honey.

diagnosis, dī" $a \bar{g}-n \bar{o}^{\prime}$ sis. - The identification of a disease.

diaphragm, dī' a-frăm.-A dividing partition or membrane.

diffused, dY-fūșd'.-Widely scattered, as a vapor in the air.

diffusers, dY-füs' ẽrs.-Tanks in which the sugar is extracted from beets. diffusion, dY-f $\bar{u}^{\prime}$-zhon.-The act or process of scattering.

digestion, di-g̈es' chon.-The process of changing food to a soluble and diffusible form.

diphtheria, dłf-thē' ri-a.-An acute infectious disease of the throat. disinfectant, d's" In-f 'c $^{\prime}$ tant.-A substance which will kill bacteria. distillation, d' $\mathrm{Is}^{\prime \prime}$ tY-lă' shun.-Operation of separating the more volatile from the less volatile portion of a liquid, as petroleum, or of a solid, as wood or coal.

divining rod, di-vin' ing.-A forked stick by means of which one pretends to be able to locate underground veins of water. A rod supposed to possess supernatural powers.

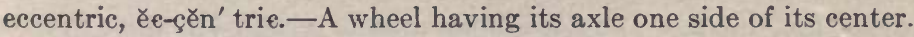
efficiency, è-fish' en-çy.-Ratio of the useful work to the energy expended. enzyme, ěn' zym.-A substance that induces the process of digestion. equatorial calms, $\bar{e}^{\prime \prime} \mathrm{kwa}-\mathrm{to}^{\prime}$ ri-al eäms. - The belt of calms near the equator.

equivalent, $\overline{\mathrm{e}}-\mathrm{kw} \mathbf{v}^{\prime}$ a-lènt.-Equal in value. eureka, ū-rē' ka.- "I have found it."

evaporate, ē-văp' o-rāt. - To change a liquid to a vapor at a temperature below boiling. exhalation, ěks" ha-lä' shon.-Breathing out. 
Fahrenheit, fä' rĕn-hït.-A German physicist, 1686-1736.

fallacy, făl' a-çy.-False or unsound reasoning.

fallowing, făl' o-ing.- To cultivate land without attempting to raise a crop.

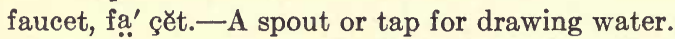

fermentation, fër" mĕn-tā'shon.-Chemical changes induced by the enzymes of organisms.

filament, frl' a-ment.-A thread-like body, as the filament of an electric light bulb.

flagella, fla-ǧ̀l' a (sing. flagellum).-The swimming organs of microörganisms.

Flügge, flüg' ge.-A German scientist now living.

fluorine, flōō' or-ľn.-A pale, greenish, gaseous, exceedingly active chemical element.

franchise, frân' chīs.-A special privilege granted by the government.

frost.-Frozen dew; formation of dew at temperatures below freezing.

fulcrum, fŭl' erŭm.-A support against which a lever rests or upon which it turns.

fungus, fŭn' ğ ğs (pl. fungi).-A plant of simple structure; without green color.

fusion, $\mathrm{fu}^{\prime}$ zhon.-Melting.-Act or process of changing a solid, as ice, to a liquid.

galleries, ğăl' ẽr-iez.-Underground passageways.

gaseous, ğăs' e-ŭs.-Pertaining to a gas or of the nature of a gas.

gasoline, ğăs' o-lın.-A colorless, volatile, inflammable distillate from petroleum.

gauge, ḡāg.--An instrument for measuring pressure, as of illuminating gas, water or steam.

gauze, gạz.-A woven wire fabric. Wire cloth-like, fabric used to distribute heat evenly.

glacial, $\bar{g} l \bar{a}^{\prime}$ shăl.-Pertaining to or caused by masses of ice.

gluten, ğlōō' tern.-The sticky portion of wheat flour.

gluttenous, glŭt' n-ŭs.-The act or habit of eating to excess.

gradient, ğrā' di-ěnt.-The slope of barometric pressure, as from Dakota to Missouri, Art. 276.

gravity, ğrăv' i-ty.-The pull of the earth upon all objects near it.

green plant.-A plant which has the green pigment chlorophyll in its

leaves and other organs.

hail, hāl.-Frozen precipitation, usually composed of alternate layers of snow and ice.

heredity, he-rěd' i-ty.-The process by which qualities are transmitted to offspring.

horizon, ho-rī' zon.-The line between the sky and the earth or sea 
host, hōst.-The organism upon which a parasite lives.

humidifier, hū-m\'d' i-fĩ-ẽr.-A device for increasing the moisture of indoor air.

humidity, hū-mId' i-ty.-Moisture or dampness. Condition of air as regards moisture.

humus, hū' mŭs.-The organic matter of the soil, usually giving it a dark color.

hurricane, hŭr' i-eān.-A violent storm of the cyclone type occurring in the West Indies.

hydrant, $h \bar{y}^{\prime}$ drănt.-A discharge pipe connected with a city water main for fire fighting.

hydraulic, hȳ-drạ' lle.-Pertaining to water under pressure, as hydraulic pressure.

hydrocarbon, hy" $\bar{y}^{\prime \prime}$ drō-kär' bon.-A compound composed of hydrogen and carbon.

hydrochloric acid, hy $\bar{y}^{\prime \prime}$ drō-klō' rı̌e ăs' Id.-A compound of hydrogen and chlorine.

hydrometer, hȳ-drŏm' e-tēr.-An instrument for determining the density of liquids.

hydrophyte, hy $\bar{y}^{\prime}$ drō-fït.-A plant which lives in water or water soaked ground.

hypha, hy $\bar{y}^{\prime}$ fa (pl. hyphæ).-The thread-like parts of a fungus.

hypocaust, hy̆p' o-east.-Basement chambers and flues used for heating Roman buildings.

Imhoff, $\mathrm{Im}^{\prime}$ hof.-Inventor of a certain form of septic tank.

immunity, I-mū' ni-ty.-Freedom from liability of a disease. incandescent, In" kăn-děs' ent.-White or glowing from heat.

inclemency, In-elěm' en-çy.-Harsh, severe, rigorous, applied to weather or climate.

infection, In-f̌e $e^{\prime}$ shon.-To be inoculated with disease organisms. infiltration, $\mathrm{In}^{\prime \prime}$ f fl-trā' shon.-Passing of liquids through small openings. inhalation, In" hā-lā' shon.-Breathing in.

inocculate, In-ð $e^{\prime}$ yụ-lāt.-To put disease organisms into the body of an animal or plant.

inorganic, In" orr-ğăn'ie.-Not organic. Not formed by or pertaining to an organism.

insulation, In" sū-lā' shon.-Surrounding a body with non-conductors, as of heat or electricity.

interurban, In" tẽr-âr' băn.-Between cities, applied to electric railroads. iodine, $\overline{\mathbf{i}}^{\prime} \mathrm{o}$-din-A bluish-black, crystalline element, used externally as a medicine.

irrigate, ${ }^{\prime} r^{\prime}$ i-ḡāt. - To water land by artificial means.

isolated, 's' o-lāt" ed.-Separated from others. In a detached place. 
Joule, joul.-James Prescott Joule, an English physicist, 1818-1889.

Keokuk, $\vec{e}^{\prime}$ o-kŭk. - A city in Iowa on the Mississippi River.

kerosene, kẽr' o-sēn.-Common illuminating oil. A product of petroleum.

kilowatt, kr1' o-wat.-A unit of electrical energy equal to 1000 watts. Kuwoshiwo, kụ" ro-shï' wo. (Formerly Kuwo-Siwo).-Japanese Current in the Pacific Ocean.

lactose, lăk' tōs.-The sugar found in milk.

Langley, lăng' ly.--Samuel Pierpont Langley, American scientist, 18341906.

leaching, lēch' ing.-1. Dissolving mineral salts out of the soil. 2. Soaking of sewage into the soil.

lever, le $\bar{e}^{\prime}$ verr or lěv' ẽr.-One of the simple machines. A stiff, rigid bar. levulose, lěv' u-lōs. - The sugar found in fruits.

life process.-A process necessary to life.

lightning, lit' ning.-The flash of an electric discharge to or from a cloud.

liquefy, lik' we-fy.-To convert into or to become a liquid.

loom, lōōm.-A flexible insulating tube used as a conduit for electric wires.

Los Angeles, lðs ăn' gēe-lēz.-A city in southern California.

Loup River, lu. - A river in central Nebraska.

luminous, lū' mi-nŭs.-Giving off light.

luxurious, lŭğ-zhū' ri-ŭs.-Pertaining to indulgence in pleasures of the senses which are unnecessary for health and comfort.

macedoine, mä" çe $\underline{e}^{\prime \prime} d w a n '$.-A dish of mixed vegetables, used as stock for soup.

maltose, môl' tōs or mạlt' ōs.-A hard, white, crystalline sugar formed by the action of malt on starch.

manometer, mā-nŏm' e-tẽr.-An instrument for measuring pressure.

maximum, măx'i-mum.-Highest. The maximum thermometer indicates the highest temperature.

mean, mēn.-Average. The mean temperature is the average temperature.

mechanical advantage.-Advantage obtained by using a mechanical device.

mesophyte, měs' o-fït.-A plant which requires a medium amount of moisture.

metabolism, mē-tăb' o-lYzm or mē-tăb'o-lism.-Total process of obtaining nourishment from food.

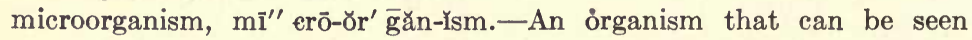
only by use of the microscope. microscopic, $\mathrm{mï}^{\prime \prime}$ erō-seðp' ie.-Seen only by the aid of a microscope. 
minimuin, mın' i-mŭm.-Least, lowest. The minimum thermometer indicates the lowest temperature.

molecule, mol' e-eūl.-The smallest particle of matter that can exist as such.

monsoons, mðn-sōōns'.-Winds along the coast, blowing toward the land in summer and toward the sea in winter.

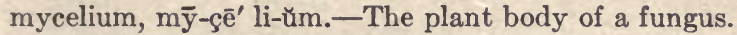
naphtha, năf' tha.-A volatile distillate from petroleum. neutralize, nū' tral-iz. - To destroy the power of, as acids neutralize alkalies.

Newcomen, nū-€ð̆m' en.-Thomas Newcomen, an English inventor, 1663-1729.

non-green plants.-Plants which lack chlorophyll and therefore are not green.

non-luminous, nðn-lū' mi-nŭs.-Not giving off light.

nutation, $n \bar{u}-t \bar{a}^{\prime}$ shon.-A revolving motion, giving rise to a nodding motion.

nutrition, nū-tr'sh' $\not n$.- The process by which growth is promoted and waste repaired in living organisms.

oleomargarine, $\bar{o}^{\prime \prime}$ lè-ō-mär' gă-rinn. (not mar' jēr-ēn). -A substitute for butter.

olla, $\gamma^{\prime}$ yà or öl' à (Spanish).-A porous, earthen water jar or container. organic, ôr-ḡăn' iє.-1. Formed by or pertaining to an organism. 2. A chemical compound having carbon for its chief constituent. organism, ôr' ğan-ism.-A living being having different organs performing special functions.

oscillating, $\mathrm{\gamma s}^{\prime} \mathrm{i}-\mathrm{la} \mathrm{t}^{\prime \prime}$ ing. - Swinging back and forth on its axis.

Ostwald, ðst' vạlt.-Wilhelm Ostwald, a noted German chemist, now living.

paraffin, păr'a-finn.-A translucent, waxy, solid substance derived from petroleum.

parasite, păr' a-sit.-An organism that lives upon or within the body of another.

Pasteur, päs" târ'.-Louis Pasteur, a celebrated French chemist and bacteriologist, 1822-1895.

pasteurization, päs" târ-i-zā' shon.-Killing active organisms by heat. pathogenic, păth" o-gen' ic.-Disease causing.

percolation, pēr" $€ \bar{o}-1 \bar{a} '$ shon.-Passing slowly through small openings. perforated, pēr' fo-rāt" ed.-Pierced with small holes. pinion, pln' yŏn.-A small toothed wheel driving or driven by a larger cog-wheel.

pitman, plt'man.-A rod connecting a moving lever with a rotating wheel. 
platinum, plăt' i-nŭm.-A valuable, steel-gray, heavy, malleable metallic element.

plenum, plē' nŭm.-Applied to space full of matter, as plenum system of ventilation.

pneumatic, nū-măt' ic.-Pertaining to or containing compressed air.

Ponce de Leon, pōn' the de le $\underline{e}^{\prime}$ onn.-Juan Ponce de Leon, a Spanish explorer, 1460-1521.

porcelain, pôrç'lin, pōr $\mathbf{r}^{\prime}$ çe-lān.-A translucent earthenware, usually glazed.

precipitation, prē-çly" to or toward the earth.

propulsion, prō-pŭl' shon.-Pushing; operation of propelling. protein, prō' të-ln. - One of the three food principles.

protractor, prō-tră $\epsilon^{\prime}$ tor.-An instrument for measuring angles. radiation, $\mathrm{r} \overline{\mathrm{a}}^{\prime \prime}$ di-a $\overline{\mathrm{a}}^{\prime}$ shon.-The giving off of heat to or through space. range, rāng. - 1. A stove with one side as a front. 2. Difference between the highest and the lowest, as the range of temperature. relative humidity.-The humidity expressed in per cent. of saturation. reservoir, rěz' ẽr-vwor or rẹș' ẽr-vwor.-A huge tank or receptacle for storing water.

residue, resș i-du.-The portion remaining after part is removed. revolution, rěv" o-lü' shon.-Complete circuit made by a body around a center.

Roquefort, rōk" fōr' or rōk' fört.-A commune in France famed for its goats and cheese.

rotary, rō' tā-ry.-Turning around completely on its axis. sanitary, săn' i-tā-ry.-Relating to the preservation of health. saturation, săch" u-rä' shon.--State of being filled with (water) vapor. sedentary, sěd" en-tā-ry.--Pertaining to inactivity, as a sedentary life. semi-transparent, sĕm" i-trăns-păr' ent.-Partly admitting of the passage of light.

septic, sěp' tre.-Productive of putrefaction, rotting or decay. serum, sê' rŭm.-Blood with the corpuscles removed. A part of the blood.

sewage, sū' àg.-Waste matter carried off in sewers. shallot, shă lot't.-An onion-like vegetable used as food. shower, shðw' ẽr.-A brief fall of rain, sometimes of hail or snow. Sierra Nevada, si-ěr' a ne-vä' da.-A mountain range in eastern California.

silicon, sn' i-kon.-One of the chemical elements, found in sand. siphon, $\mathrm{si}^{\prime}$ fon.-A bent tube through which liquid flows. sleet, slēt.-Frozen or partly frozen rain. sludge, slŭdg.- Soft, muddy, pasty, refuse which form in the bottom of a septic tank. 
souffle, sōō" flä'.-A light, spongy, frothy, baked food. snow.-Falling water vapor condensed at a temperature below freezing. solstice, soll' stiç.-Date upon which the sun seems to turn back north in the winter, December 22, or back south in the summer, June 21. specific heat, spē-sıf' $\mathrm{Yk}$-Heat required to raise 1 gram of a substance $1^{\circ} \mathrm{C}$.

spore, spōr.-A reproductive cell in higher fungi. A resting cell in bacteria.

squall cloud, skwal.-A low, ragged, tumbling cloud often seen with the wind gust in front of a thunderstorm.

sterile, ster $\mathbf{r}^{\prime}$ 11.-Free from microörganisms. sterilization, sterr" $11-\bar{i}-z \bar{a}^{\prime}$ shon.-Act of making sterile. stratus, strä' tŭs.-A flat layer cloud of rather uniform thickness. strata, strā' ta (sing. stratum).-Layers, as of rock in the earth's crust. substratum, sŭb-strā'turm.-Material through which the hyphæ of a fungus grow.

sucrose, sū' krōs.-One of the sugars, as cane sugar, beet sugar, maple sugar.

susceptible, sŭs-cěp' ti-ble.-Opposite of immune; liability to disease. thermograph, ther' mō-g̈räf.-An instrument for writing a continuous record of temperature.

thermostat, thēr' mō-stăt. - A device for automatically regulating temperature.

threshing, thrěsh' ing.- Separating grain or seed from straw or stalks. thunderstorm, thŭn' dēr-stôrm.-A shower accompanied by thunder and lightning.

tornado, tðr $\mathrm{r}-\mathrm{n} \overline{\mathrm{a}}^{\prime}$ dō. $-\mathrm{A}$ violent, whirling, twisting wind a few hundred yards or less in diameter, usually with a hanging funnel cloud at its core.

toxine, troks' In.-A poison, often of bacterial origin.

treadle, trĕd' 1.-A lever operated by the foot to run a machine, as a sewing machine.

tungsten, tŭng' stěn.-A steel-gray, heavy, metallic metal, used for lamp filaments.

turbine, tấ $\mathbf{r}^{\prime}$ b̆n or târ' bin. - One form of water wheel.

typhoon, tȳ-fōōn'.-A violent cyclonic storm occurring over the China seas.

raccinate, vă $\epsilon^{\prime}$ çi-nāt.-To treat with a vaccine. vaccine, vă $e^{\prime}$ çin. - A substance which induces immunity in an organism. vacuum, văe yụ-ŭm.- Space without matter, especially space devoid of air.

vaporize, va $\bar{a}^{\prime} \mathrm{p} \not r-i \bar{z} .-$ To change into gaseous form. vernier, vēr' ni-ër.-A sliding scale on a barometer for measuring to very small divisions. 
vibrating, vī' brāt-ing.-Moving back and forth in a straight line or the arc of a circle.

virulence, vir' u-lěnç.-The disease producing property of an organism. virus, $\mathrm{vi}^{\prime}$ rŭs. - The substance used in vaccination.

vitality, vī-tăl' i-ty.-Life; power; surplus energy.

vitiated, vissh' i-āt" ed.-Polluted; impure.

volatile, vð̌l' à-třl.-Easily evaporated.

waterspout.-A tornado occurring over water.

Welsbach, wěls' băc.-Carl Auer Freiherr Welsbach, an Austrian scientist, 1858-

westerlies.- The belt or zone of winds blowing from the west in both temperate zones.

xerophyte, $z \bar{e}^{\prime}$ rō-fïte.-A plant which thrives in dry soil and dry air. yucca, yŭe' a.-Lilly-like plant, a native of southwestern United States and Mexico. 


\section{INDEX}

All references are to pages.

Absolute humidity, 158, 219; Table of, 220.

Acetylene, 47 ; generators, 47 ; cost of, 48; illuminant for vehicles, 49 ; danger from, 50 ; use for heating, 103.

Aeration of the soil, 465 .

Air, constituents of, 80,311 ; -duct, 124 ; within refrigerator, 160 ; pure, 311 ; effect of breathing, 312 ; vitiated, 312,327 ; ideal indoor, 319, 307 ; effect of vitiated, 327 ; weight of, 179; weighing, exp., 180; pressure of, 181; moisture in, 212-235; soil, 460465.

Air blast, 97.

Alcohol, how produced, 392 ; distillation of, 20, 391; boiling point of, 19 .

Ammonia, 165; properties of, 163; from proteins, 404,350 ; test of proteins, 350; boiling point and pressure of, 165.

Animal life, dependent upon climate, 290.

Antenaria, 387.

Anthrax, 423 ; symptoms, 424 ; prevention and cure, 425 ; vaccine, 427.

Antiseptic, 415.

Antitoxine, 433.

Arc lamp, 52.

Archimedes' principle, 116, 117.

Aspergillus, 386.

Atmospheric pressure, measurement of, 183; variation with altitude, 190.

Attenuated, 426.

Atwater, Dr., 351, 352.

Automatic cut-off, 508.

Babcock test, for fat, 360 .

Bacilli, 400; anthrax, 424; diph- Bone char, 374. theria, 431; typhoid, 439; influenza, 440; tuberculosis, 442.

Bacteria, 383, 396 ; forms of, 399 ; where found, 400; soil, 401; and nitrogen in the soil, 403; nitrifying, 404; nitrogen fixing, 405 ; nodule, 405; denitrifying, 408; aerobic, 408; anaerobic, 408; and soil leaching, 410; and soil acidity, 411; and decay, 412; food of, 413 ; and moisture, 413 ; and temperature, 414 ; and light, 415 ; relation to canning, 417; relation to disease, 421-446.

Bacteriology, 397, 425.

Baguios, 277.

Balances, beam, 537; spring, 538.

Barograph, 193.

Barometer, siphon, 186; Fortin's pattern, 186; correcting the reading of, 187; correcting for temperature, Table, 188; correcting for altitude, Table, 191; effect of passing storm upon, 257; and wind indications, 261 .

Baumé's hydrometer, 27; test for oil, 28.

Blood pressure, 182.

Blower, of gasoline gas machine, 37 ; of the plenum system, 333.

Boiler, the, $\mathbf{5 7 4}$; of hot water heating system, 127; of steam heating system, 131; of kitchen range, 479, 490; of Central Square water works, $486 ; 18$ th Century hot water supply, 500; circulation through range, 501.

Boiling, 15; temperature of water, 15 ; temperature of alcohol, 19; of mixture of alcohol and water, 20 ; point, meaning of, 17; point of water, 134; at varying pressures, 135. 
Boyle's law, 463.

Bran, 370.

Breast water wheel, 558 .

Brick oven, 72, 146.

Brine, use in refrigeration, 168; how temperature is regulated, 168.

Built-in refrigerators, 161 .

Buoyancy, 115.

Burner, of kerosene lamp, 6; center draft, 8; gas, 46.

Burning point, 4, 29.

Butter, 362 ; renovated, 362; test of real, 365 ; water in, 362 .

Butterine, 363; tax on, 365 ; test of 365.

Calorie, greater, 107; lesser, 107; equivalent in foot-pounds, 551 ; equivalent in horsepower-hours, 552.

Calorimeter, 107.

Calorimetry, 107.

Candle, early, 2; modern, 2 ; how it burns, 3; fresh air, need of, 5 ; sale of in U. S., 3.

Canning, 416; domestic, 417; factory, 418.

Capillarity, 467.

Carbohydrates, 348; test for, 349.

Carbon cycle, 347, 402.

Carbureter, of gasoline stove, 151; of gasoline gas machine, 37 .

Casein, 365.

Cell division, 382 .

Cellulose, 349 .

Centigrade scale, 14 ; to change to Fahrenheit, 17.

Centrifugal force, 530, 484.

Centrifugal pump, 484.

Centrifuge of Babcock machine, 361.

Charcoal, 90, 91.

Charles' law, 114.

Cheese, 365 ; filled, 366 ; full cream, 365 ; composition of, 366 .

Chemical, elements, 76; energy, 78; change, 78,79 ; compounds, 79 .

Chemistry of combustion, 76-89; summary of, 88.

Chimney, kerosene lamp, use of, 8; invention of, 113; draft in, 118; construction of, 119.

Circular lows, winds about, 259.
Climate, 288, 281; relation to health, 288; relation to plant life, 289; relation to animal life, 290 ; relation to man, 290 ; factors determining, 291; effect of wind upon, 298; the ideal, 302; areas of, 303; indoor, 306, 307; why change of may be beneficial, 307 .

Climometer, construction and use of, 281.

Clouds, 225-234 ; classes and characteristics, 231; formation, 232 ; cumulus, 232 ; cumulus that may rain, 238; how they change in the passing of a low, 263; indications by, 263 .

Coal, burning of, 93; bituminous, 93; anthracite, 93,109 ; composition of, 93; -gas, 101; production of, 109; fields of, 111; our apparent supply, 109.

Cocci, 400; pneumococci, 438.

Coke, 93.

Colds, 441, 329.

Cold storage, 171 ; effect on modern life, 171 ; plant, 172 ; temperature required, 172; control of temperature in, 172 .

Combustion, chemistry of, $\mathbf{8 8}$; complete of soft coal, $96 ; v s$. slow oxidation, 345 .

Compression of gases, 579 .

Convection currents, 113 ; cause of, $115-120$; in the refrigerator, 156 ; in stove heated room, 120,332 ; in chimney, 118; caused by furnace, 124 ; in. hot water heating system, 127; in water front, 500 .

Cookers, fireless, 153.

Cooking temperature, 152.

Corn, conditions for growth of, 197, 287; flakes, 371 ; grits, 372 ; starch, 372; syrup, 373.

Cotton seed oil, 368.

Cream separator, 529; advantages of, 532; efficiency of-problem. 362.

Culture, or culture medium, 391, 425; hay, 398.

Cumulus clouds, 226, 228, 229, 230, 231 ; formation of, 232 ; size of, 233 ; showers from, 236 ; path of, 237.

Cycles of gas engine, 577 
Cyclones, 260, 276; vs. tornad es, 247.

Cylinder, 580; purpose of several on automobiles, 580 ; heated on Watt's engine, 570.

Day, length of, 284, 286.

Decay, 399, 412 ; prevention of by canning, 416; prevention of by refrigeration, 154 .

Denitrifying bacteria, 408 .

Dew, 224; formation of, 224 ; false, 224 ; and ground-air, 462 .

Dew-point, 159; and fall of temperature at night, 221; Table of, 222 ; curve of $v s$. temperature, 223.

Dextrin, 373, 349.

Dextrose, $373,349$.

Digestion by molds, 385 .

Diphtheria, 431; toxine of, 433; antitoxine of, 433 ; prevention of, 436.

Direct radiation, 330 .

Direct-indirect radiation, 331 .

Diseases, theories of, ancient, 422; semi-scientific, 422.

Disinfectant, 415 .

Distillation, 21; of alcohol, 21, 391 ; of petroleum, 23 ; of wood, 90 ; of soft coal, 94 .

Drainage through the soil, 458 ; purpose of soil drainage, 461 .

Drains, 504; venting of, 505; the trap of, 506; subsurface, 515 .

Dry air, in refrigerator, 160; effect of on foods, 160; evil effect on health, 323 ; requires high temperature, 323.

Duct, cold air, 124.

Dust, dangers of, 336 ; live and dead, 337; house dust, 337; how disposed of, 339 .

Earth's breathing, inhalation, 462 ; exhalation, 462 ; causes of, 463 ; effect on soil moisture, 463 .

Efficiency of machines, 546; how measured, 546.

Efficiency of motors, 550 .

Electric current, heating effect of, 50.

Electric lighting, 50; incandescent lamp, 51; arc lamp, 52; cost of, 69.

Electric wiring, 53.

Elements, chemical, 76; food, 345 .

Elliptical lows, 260.

Energy, 77, 546, 549; chemical, 78; kinetic, 77 ; potential, 77; electrical, 77; conservation of, 78; meaning of, 549; source of all, 562 ; losses of in motors, 581.

Engine, steam, 565-574; gas, 574; gasoline, 575; many cylindered, 580; Newcomen's, 567; Watt's, 568 ; modern steam, 572 .

Enzyme, 385, 392.

Evaporation, 9, 15, 212; effect of extent of surface, 10; effect of temperature, 10; effect of air currents, 10; of different liquids, 10; laws of, 11; defined, 15 ; how controlled, 214, 465; effect on personal comfort, 215; effect on industries and materials, 216; average rate of, $456 ;$ map, mean annual, 213; measurement of, 214.

Evaporator, sugar, 375.

Explosive mixtures, of hydrogen, 87; of gasoline gas, 103; of acetylene, 50 .

Factory, the coming of, 519; ice, 163.

Fahrenheit scale, 14; to change to centigrade, 17.

Fallowing, 405.

Fats, 348; vaporization of, 4 ; flashing point of, 4 ; burning point of, 4.

Fermentation, 393; and bread making, 395; alcoholic, 393; butyric, 393; lactic, 393; protein, 394 ; and the refrigerator, 154.

Ferments, 393.

Ferrel's law, 274; application to a low, 275; application to general circulation, 273.

Filter bed, 516 .

Filtering city water, 484 .

Fire, discovery of, 1 ; importance of, $71 ; 100$ years ago, 71 .

Fire hydrant, 492; drip of, 494 . 
Fireless cooker, 153.

Fireplace, 112, 72; old fashioned, 72; 18th Century, 112; low efficiency of, 142 ; modern ventilating, 143; cooking by, 145 .

Flame, 91 ; blowing out of, 91 ; luminous and non-luminous, 92; conditions for, 92.

Flashing point, 4, 29.

Floating bodies and buoyancy, 115 .

Flour, 369 ; baker's, 369; graham, 369 ; patent, 369 ; whole wheat, 370.

Flushing tank, siphon, 507.

Flywheel, purpose of, 580 .

Food, 347 ; classes of, 348; composition of, Table, 353; cost of, 378; elements, 345; how much? 352 , 355; manufacture of, 358-378; principles, 348; heat value of, 355.

Foods, contest for by microorganisms, 380; energy of, 380; origin of, 380 ; cereal, 369 ; dairy, 359 ; meat, 366 .

Foot-pound, 540; equivalent in calories, 551.

Force, 539; units of, 539; compared with weight, 539; centrifugal, 484, 530.

Force pump, 477.

Fortin's barometer, 186.

Freezing, of ice cream, 169; mixtures, 171.

Freezing point, 15; of water, 166.

Friction, 545 ; effect on water pressure, 492; sometimes helpful, 546; produces heat, 549 .

Frost, definition, 224; and radiation, 207; fighting of, 208; and air drainage, 210; and wind, 212; and dew, 224.

Fuel, 76; elements, 76; composition of solid, Table, 94; liquid, 100 ; gaseous, 101 ; composition of gaseous, Table, 105; heat value of, Table, 109.

Fulcrum, 537.

Furnace, 123; air blast of, 97; side feed, 98; setting of, 123; air supply for, 123; a successful, 126 .

Gas, natural, 23; coal, 101; water, 102; gasoline, 37, 103; acetylene,
103; producer, 104; engine, 574; pressure on illuminating, 45; meter, 44; cost of illuminating, 68 ; compression of, 580 .

Gas meter, 43; construction and operation, 44; reading of, 45 .

Gasoline, 25 ; grades of, 26 ; properties of, 26; danger from, 31 ; lamps, 34; gas machines, 37; importance of, 39 ; manufacture from natural gas, 40; gas, 37, 103; stove, 149; motor, 550; engine, 575 .

Gasoline engine, in automobiles, 575 ; in aeroplanes, 575 ; in farm power house, 520,534 .

Gauge, pressure, 136; vacuum, 136; water, 138,574 ; water pressure, 495.

Glacial drift, 456 .

Glucose, 373.

Gluten, 370.

Grape sugar, 373, 391.

Grate, modern ventilating, 143; cooking before, 145 .

Gravitation, 536.

Gravity, 536; system of ventilation, 329-333; separation of cream, 529; effect on ground water, 453-460.

Ground air, 460-465; and ground moisture, 465.

Ground water, 450; relation to river water, 459 ; relation to wells, 469; movement through the soil, 458; relation to plant life, 466 .

Hair hygrometer, 219; use in schoolroom, 325 .

Hay culture, 398.

Health, and climate, 288; and sunshine, 300; seeking in change of climate, 302; effect of indoor climate upon, 307; change of climate beneficial, 307; and living in the open air, 308; effect of pure air upon, 312; effect of humidity upon, 322; effect of dust upon, 337; duty regarding public, 448 .

Heat, quantity, defined, 106 ; units of, 107; how measured, 107; effect upon volume of air, 114; 
radiant, 121; factors of heat quantity, 129; sensible, 129, 167; of vaporization, 129; of condensation, 167; sun's, how it varies, 282 ; effect of sun's upon atmosphere, 205; produced by friction, 549; work equivalent of, 551 ; value of solid fuels, 109; value of gaseous fuels, 105; value of foods, 353 ; and temperature, 129; of fusion of ice, 161.

Heating, by stove, 120, 122; by furnace, 123 ; by hot water, 127 ; by steam, 131; hot water and steam systems contrasted, 132; vacuum system; 140; effect of the sun, 281-286; of one-room school, 331; of several-room school, 333; plenum system of, 333.

Henry's law, 480.

Highs, described, 264; paths of, 268 ; unusual paths of, 272 ; of the entire earth, July, 278 ; of the entire earth, January, 279.

Horse, work by, 552 ; cost of feeding, 554; efficiency as a motor, 554 .

Horsepower, 541.

Horsepower-day, cost by steam engine, 552; cost by horse motor, 553 ; cost by human labor, 555 .

Horsepower-hour, equivalent in calories, 552 .

Hot blast, on stoves and furnaces, 97.

Hot water for use in country homes, 479; in city residences, 490 ; in the 18th Century, 500; in modern residence, 479, 490, 501.

Hot water heating, 127; essential features, 128; advantages of, 128 , contrasted with steam, 132; and ventilation, 330

Human body, temperature of, 317; temperature of and metabolism, 318 ; composition of, 344 ; its needs, 344 .

Humidity, absolute, 158; relative, 158; seasonal changes in relative, 293; maps of, relative, 294,295 , 296 ; relation to ventilation, 316 ; importance of, 321 ; how regulated, 325 ; of schoolrooms, 327; relative, Table, 218; absolute, Table, 220.

Humphrey Potter's invention, 568. Hydrocarbons, 87.

Hydrogen, preparation of, 85 ; properties of, 85; explosive mixture of, 87.

Hydrometer, Baum6's, 27; use in testing oils, 28 .

Hydrophobia, 446.

Hydrophytes, 466 .

Hygrometer, 216; hair, 219; use in schoolroom, 325 .

Hyphæ, 385.

Hypocaust, Roman, 112.

Ice, manufacture of, 163 ; plant, or factory, 163; melting point of, 15 ; heat of fusion of, 161; cream, freezing of, 170.

Ignition, 578 .

Illuminating gas, 43 ; measurement of, 43 ; cost of, 68 ; composition of, 105; used as fuel, 101.

Illuminating oil, 6, 25, 26; inspection of, 28.

Immunity, 427; natural, 427; acquired, 427.

Impulse water wheel, 558.

Incandescent lamp, 51; gas mantle, 62,68 .

Indirect radiation, 330 .

Infantile paralysis, 448 .

Infiltration galleries, 460 .

Influenza, 440 .

Jenner, Edward, 429.

Kerosene, 6, 25, 26; vapor of, 8 ; danger of cheap, 31.

Kerosene lamp, 5, 33; parts of, 6; chimney and burner, use of, 6 .

Kilogram, 536, 539.

Kindling temperature, 85.

Koch, Robert, 398.

Lactose, 349.

Lakes and rivers, origin of, 457 .

Lamp, primitive, 2; Greek and Roman, 2; kerosene, 5; gasoline, 34,36 . 
Lard, 368; compound, 368; substitutes, 368.

Leaching, cesspool, 509; of soil, 410.

Length of day, 284-286; effect of, 287.

Levulose, 349.

Lift pump, 477.

Light, 54; direct and diffused, 55; diffused natural, 56 ; diffused artificial, 61; indirect, 63 ; proper amount, 65 ; distribution of, 66 ; cost of, 68 .

Lightning, 241; heat lightning, 242.

Lows, 251, 253, 255-264; movement of a low, 255; winds about a low, 258; elliptical, 260; changes caused by, 264; the paths of, 267 ; unusual paths of, 268-272; relation to general circulation, 272.

Lubricating oil, 26; effect on friction, 545; use in Watt's engine, 570.

Machines, 542; of the early colonists, 518; knowledge of, 520; this, an age of, 521; sewing, 521; horsepower of, 541; mechanical advantage of, 543 ; simple and compound, 454; law of, 546; efficiency of, 546 .

Malaria, 445.

Maltos, 349, 373.

Mantle, for gasoline lamp, 35; for gas lamp, 68; diffused light from, 62 .

Manufactured ice, 164; purity of, 169 ; cost of, 169.

Mass, 535; units of, 536; how determined, 537; pound of, 539; kilogram of, 539.

Measles, 447.

Measuring, of rain, 194, 220; of snow, 195; of temperature, 12, 196,197 ; of moisture, 219 ; of efficiency of machines, 546; of gas, 44; of water, 497.

Meat foods, 366; deterioration of, 366 ; preserving of, 367 ; inspection of, 368.

Mechanical advantage, 543; kinds of, 543; numerical expression of, 544.

Mechanical stokers, 99.
Mesophytes, 466.

Metabolism, 317 ; effect of external temperature upon, 318.

Meter, water, 495; gas, 43; construction of water meter, 496; reading of water meter, 497 .

Microörganisms, 380-449; effect on foods, 154, 380; effect on sewage, 510-517.

Mildew, 388.

Milk, 359; determination of fat in, 360.

Mixer, of gasoline lamp, 34; of gasoline gas machine, 39 .

Molds, 384-389; effect on foods, 388 ; foods of, 385 ; kinds of, 387 ; spores of, 386 .

Monsoons, 278.

Motor spirit, or motor oil, 40.

Motors, 550; mechanical, 556; animal, 550; horse and steam contrasted, 553; cost of operating different, 555; water, 557; steam, 565; gas, 574; energy losses in, 581 .

Mucor, 386.

Mumps, 447.

Mycelium, 385.

Naphtha, 25.

Natural gas, 23; manufacture, into gasoline, 40.

Neutral, 364.

Neutralizer, 374.

Newcomen's air-steam engine, 567.

Nitrifying bacteria, 404 .

Nitrogen, of the soil, 403; fixing bacteria, 405; effect of cropping on, 407.

Nodule bacteria, 405 .

Oil, kerosene, 5 ; whale, 5; illuminating, 26; inspection of, 28 ; cotton seed, 368; lubricating, effect on friction, 545; flashing and burning points of, 4, 29 .

Oleo oil, 364.

Oleomargarine, 363 ; $\operatorname{tax}$ on, 365 ; test of, 365 .

Open-air living and sleeping, 308.

Oscillating hook sewing machine, 525.

Oscillating shuttle sewing machine, 525. 
Oven, brick, 72, 146.

Overshot water wheel, 557 .

Oxidation, slow, 345 ; and temperature, 84; and concentration, 84 .

Oxygen, 81; preparation and properties, 81 ; concentration of, 84 .

Paraffin, 26; flashing point of, 4; burning point of, 4 .

Parasites, 381, 421.

Pasteur, Louis, 398.

Pasteurization, 419.

Pathogenic, 424.

Penicillium, 387.

Petroleum, 22, products of, 23-24; distillation of, 23; our supply of, 41 ; production and fields of, 42 .

Plant life, determined by climate, 289; determined by moisture, 465.

Plant relationships, 382 .

Plants, how they absorb moisture, 466.

Plenum system, 333.

Plumbing, 498; development of, 498 ; importance of, 502 ; sanitary fixtures, 592.

Pneumatic tank, 478.

Pneumonia, 438.

Pound, standard, 536; of mass, 539 ; of force, 539; foot-pound, 540.

Power, 541; house on farm, 520, 534 ; transmission of, 564 ; source of in a machine, 550 .

Power house, on farm, 520, 534; Keokuk water, 559.

Precipitation, rainfall map, 289; rain, 234; measurement of, 194, $195,220$.

Pressure, of the blood, 182; relation to temperature of water, 135; gauge, 136, 495; reduction of in steam heating, 140; how maintained on water system, 489 ; and head of water, 491 ; in steam boiler, 566; of air, 181, 185; area of and wind direction, 252 ; areas control weather, 267 ; a cause of earth's breathing, 463 .

Producer gas, 104 ; composition of, 195.

Proteins, 349; how much required, 351 ; tests for, 350 ; weighing, 351 .
Psychrometer, 216.

Public health, 448.

Pump, suction, 476 ; lift, 477 ; force, 477; centrifugal, 484.

Pure air, amount required, 311, 313.

Putrefaction, 394.

Pyroligneous acid, 90.

Rabies, 446.

Radiant heat, 121.

Radiation, 121; laws of, 121; indirect system of, 330 ; direct system of, 330; direct-indirect system of, 331; and night cooling, 207; and frost, 207.

Rain, measurement of, 194; drops, size of, 234; and the passing low, 264.

Rainfall, map, 289 ; annual amount, 456; calculation from moisture in the air, 220.

Range, coal, 140; gas, 151.

Rear-icing refrigerator, 161.

Reflector, 146, 147; for controlling and distributing light, 66.

Refrigeration, and its uses, 154; and transportation, 174 .

Refrigerator, 154; uses of, 154; styles of, 155, 162; mechanical, 162.

Registers and risers, placing of 124.

Relative humidity, 158; seasonal changes in, 293; daily changes in, 295; determination of, 216 , 325; Table of, 218.

Rennet, 365.

Roman, lamps, 2; hypocaust, 112; plumbing, 498.

Rotary hook sewing machine, 525 . Rotting, 412.

Run-off, annual, 457.

Safety valve, 136; ball and lever, 137 ; pop, 137.

Saprophytes, 381, 382.

Saturated solution, 168.

Saturation, 158.

Scales, thermometer, 18; beam balances, 537; spring balances, 538.

Scarlet fever, 447.

Screenings, 370. 
Seasons, the cause of, 281-288; lag of, 207.

Separator, cream, 529-531; advantages of, 532 .

Septic tank, 510; Imhoff, 513; sludge from, 514 .

Settling tank, 484.

Sewage, 508; disposal of, 509; oxidation of, 514; liquefaction of, 512; summary concerning, 517.

Sewing machine, earliest, 521; classes of, 522 ; classes of lock stitch, 524; exercise upon, 527.

Shorts, 370.

Showers, local, 235; to foresee them, 236; how they grow, 238; thunder showers, 240.

Shuttle, oscillating, 525; vibrating, 525.

Side-icing refrigerator, 155.

Side-feed furnace, 98.

Siphon, the, 506; barometer, 186; flushing tank, 507.

Siphoning of traps, 506.

Slow oxidation, 345.

Sludge, its disposal, 514.

Small pox, 428; and vaccination, 430.

Smudge pots, 208.

Snow, 234; measurement of, 195; of a passing low, 264 .

Soil, nature of, 402 ; -water, 452; drainage through, 458;-air, 460; -temperature, 462; thermometer, 462; conserving moisture of, 465 ; increasing moisture capacity of, 467; humus in, 409; acidity of, 411 ; bacteria, 401.

Soil-air, 460; movements of, 461; causes of movements, 462-465.

Solstice, summer, 286; winter, 287.

Spirilla, 400.

Spirits of hartshorn, 165.

Sporangium, 386.

Spore production, 386.

Starch, 349.

Steam engine, earliest, 566 ; compared with horse as a motor, 553 ; importance of, 565; source of power of, 566; Newcomen airsteam, 567; Watt's, 568; the modern, 572 .

Steam heating, principles of, 131; equipment for, 132; contrasted with hot water, 132; vacuum system, 140.

Sterilization, 419.

Stokers, mechanical, 99.

Storms, local, 235; hail, 242; general, 248,255 , effect on barometer, 257.

Stove, Franklin's, 75; early cooking, 147; range, 149; gasoline, 149; gas, 151; jacketed, 331.

Substratum, 386.

Sucrose, 349.

Suction, defined, 341; pump, 476; system of ventilation, 336 ; stroke of the gasoline engine, 577 .

Sugar, 375; from beets, 376; from cane, 376 ; refining of, 377 .

Sulphite, sodium, 367.

Sulphur and copper, union of, 79.

Sun, migration of, 277; altitude and heating effect, 281; heating effects, 284-286; source of all energy, 562 .

Sunshine, and health, 300; effect on disease germs, 415, 300; average amount, 301.

Syrup, corn, 373; refiner's, 373.

Tank, septic, 510; flushing, 507.

Temperature, 12; fixed points in nature, 13; of steam arising from water, 17 ; vs. pressure, 138 ; of steam in a vacuum system, 142 ; of steam in a pressure boiler, 138; cooking, 152; control of budily, 317 ; effect of upon metabolism, 381 ; ideal of indoor air, 319 ; thermostat control of, 335 ; measurement of, 196; obtaining records of, 199 ; facts about, 205207; as affected by wind, 252; how it changes during a low, 262; soil, 462; and bacteria, 414.

Tempering coil, 334 .

Thermograph, 199.

Thermometer, 12; principle of, 13; Fahrenheit, 14; centigrade, 14; "freezing point," 15; "boiling point," 15; ordinary, 197; maximum and minimum, 197; recording, 199 need of ; testing, 200; need of sheltering, 201 ; soil, 462.

Thermostat, 335 . 
Thunderstorm, 240.

Top-icing refrigerator, 155 .

Tornado, 244; effects of, 246; and cyclone contrasted, 247.

Torricelli's experiment, 182.

Toxine, 433.

Trap, the, 506.

Tuberculosis, 441 ; bacillus of, 442 ; and occupation, 443; curable, 444.

Turbine, water wheel, 560 .

Typhoid, fever, 439; carrier, 440.

Underfeed furnace, 99.

Undershot water wheel, 558.

Vaccination, 426, 428.

Vaccine, 427.

Vacuum, gauge, 136; system of heating, 140 ; valve, 140 ; system, advantage of, 142 ; cleaning, 338 .

Valve, vacuum, 140; safety, 136, 574; float, or automatic cut off, 508.

Van Leeuwenhoek, 397.

Vapor, of candle, 4; kerosene, 8; paraffin, 5 ; water, 16,212 ; condensation of, 224, 225.

Vaporizing, 15, 131 .

Ventilation, 311 ; need of, 311 ; theories regarding, 312 ; amount of air required for, 316 ; relation of humidity to, 316; effect of air movements upon, 320 ; ideal indoor air, 319; in colonial days, 328 ; of modern dwellings, 329 ; of the one-room school, 331; plenum system of, 333 .

Vernier, 186.

Vibrating shuttle, 525 .

Vitiated air, 312, 327.

Water, -gas, 102; man's dependence upon, 450; ground, 453; table or plane, 454 ; vein of, 470 ; "witching" for, 471; artesian, 472; city systems of, 482 ; amount of used, 483; front, or back, 500 ; pressure gauge, 495 ; meter, 495; wheels, 557.

Water meter, 495; construction of, 496 ; reading of, 497 .

Water power, source of, 562 ; amount available 563; distribution of, 563 .
Water systems, 482; publicly and privately owned, 482 ; source of supply for, 484; development of, 485; of New York City, 486; of Los Angeles, 488; deep-well supply, 488; under pressure, 489 ; head of, 491 ; for country residence, 478; for hot water, 499.

Water wheels, kinds of, 557 ; overshot, 557; breast, 558; undershot, 558; impulse, 558; turbine, 560 .

Watt, the, 69 ; -hour, 69.

Watt's engine, 568 ; how it worked, 571 ; double acting, 571 .

Weather, 176-288; defined, 176, 288; cause of, 177; instruments, 179; making the map of, 250 ; causes of unusual, 267; resulting from lows and highs, 268; relation to sun's migration, 277.

Weight, 536; how determined, 537; compared with force, 539.

Wells, and the water table, 454; and a vein of water, 470 ; deep and shallow, 472; artesian, 472; shallow wells often dangerous, 481 ; protecting shallow wells, 482.

Westerlies, 277.

Wheat, 369; flour, 369; shredded, 370 ; spring, and winter, 369 .

Whey, 365.

Whooping cough, 447.

Wind, 298; map of velocities, 299; caused by unequal pressure, 251 ; velocity of, 252 ; effect on temperature, 252; how it shifts with a low, 258; law of, 259; about an elliptical low, 260; -barometer indications, 261; path of, 265 ; deflection of, 275 ; land and sea, 278 .

Wood, burning of, 89.

Work, 540; units of, 540; equivalent in calories of heat, 551 .

Working stroke of gasoline engine, 578 .

Xerophytes, 466.

Yeasts, 383-389; fermentation by, 391 ; and bread, 394 ; and liquors, 394 ; wild and cultivated, 395. 






\section{UNIVERSITY OF CALIFORNIA LIBRARY}

This book is DUE on the last date stamped below.

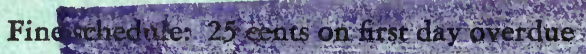

Wh 50 etents ot fourth day overdue

\section{One dollar on seventh day overdue.}


YB 5682!

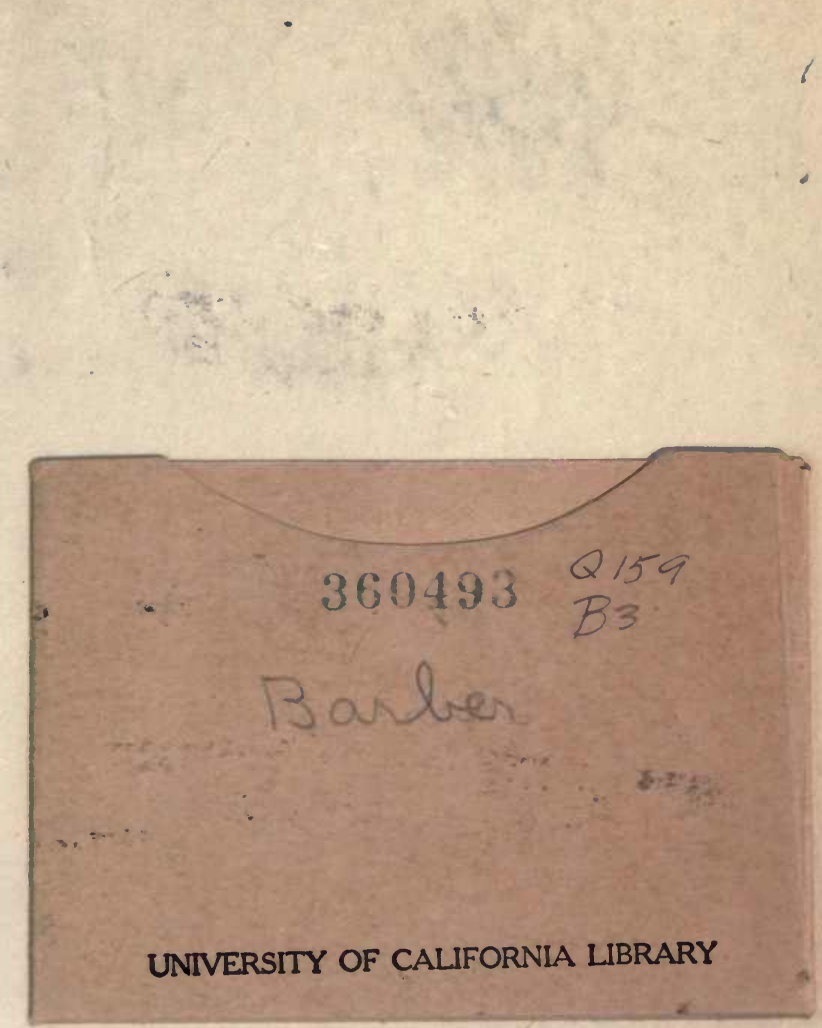




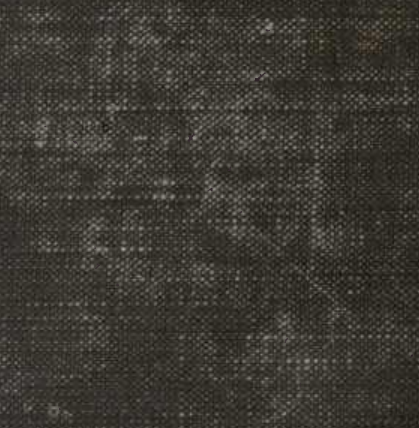

